\title{
WestVirginiaUniversity
}

THE RESEARCH REPOSITORY @ WVU

Graduate Theses, Dissertations, and Problem Reports

2004

\section{Theoretical and experimental analysis of FRP bridge decks under thermal loads}

Krit Laosiriphong

West Virginia University

Follow this and additional works at: https://researchrepository.wvu.edu/etd

\section{Recommended Citation}

Laosiriphong, Krit, "Theoretical and experimental analysis of FRP bridge decks under thermal loads" (2004). Graduate Theses, Dissertations, and Problem Reports. 2620.

https://researchrepository.wvu.edu/etd/2620

This Dissertation is protected by copyright and/or related rights. It has been brought to you by the The Research Repository @ WVU with permission from the rights-holder(s). You are free to use this Dissertation in any way that is permitted by the copyright and related rights legislation that applies to your use. For other uses you must obtain permission from the rights-holder(s) directly, unless additional rights are indicated by a Creative Commons license in the record and/ or on the work itself. This Dissertation has been accepted for inclusion in WVU Graduate Theses, Dissertations, and Problem Reports collection by an authorized administrator of The Research Repository @ WVU.

For more information, please contact researchrepository@mail.wvu.edu. 


\title{
Theoretical and Experimental Analysis of FRP Bridge Decks under Thermal Loads
}

\author{
By \\ Krit Laosiriphong \\ Dissertation submitted to the \\ College of Engineering and Mineral Resources \\ at West Virginia University \\ in partial fulfillment of the requirements \\ for the degree of \\ Doctor of Philosophy \\ in \\ Civil and Environmental Engineering
}

Hota GangaRao, Ph.D., Chair

Udaya Halabe, Ph.D.

H.L. (Roger) Chen, Ph.D.

Rakesh Gupta, Ph.D.

Ruifeng Liang, Ph.D.

Vimala Shekar

Department of Civil and Environmental Engineering

Morgantown, West Virginia

2004

Keywords : FRP Bridge Deck, Thermal Load, Composite

Copyright 2004 Krit Laosiriphong 


\section{ABSTRACT \\ Theoretical and Experimental Analysis of FRP Bridge Decks under Thermal Loads}

\section{Krit Laosiriphong}

The temperature difference between the top and bottom of a fiber reinforced polymer (FRP) composite deck $\left(120^{\circ} \mathrm{F}\right)$ is nearly three times that of conventional concrete decks $\left(40^{\circ} \mathrm{F}\right)$. The large temperature difference is attributed to low thermal conductivity of FRP material and low thermal mass due to hollow core. Thermal response studies have been conducted for FRP bridge decks under thermal fluctuations and temperature difference across the deck depth.

In this study, thermal tests were conducted on two FRP bridge deck modules ( 4" and 8 " deep decks) in the laboratory by heating or cooling at the top surface of FRP deck (i.e., room temperature at bottom surface). The FRP deck boundaries were either four free boundaries (FFFF) or two opposites boundaries being free while the remaining two were simply supported (SSFF). Deflections and strains were recorded at different location under thermal loads. Closed form solutions with first term approximation were derived using the plate bending theory using Macro Approach and Navier-Levy method for SSFF boundary conditions. Theoretical results (using Macro Approach, Navier-Levy, and FEM) were compared with experimental results. In addition, thermal responses of two FRP deck bridges (i.e., Market Street Bridge and Wickwire Run Bridge) under thermal difference between the deck top and bottom were evaluated after establishing coefficients of thermal expansion (CTE) of both FRP decks. The laboratory test data indicated that the FRP deck exhibits a hogging effect (upward convexity) when it was subjected to positive temperature difference (i.e., $T_{\text {top }}>T_{\text {bottom }}$, heating test) and a sagging effect when it was subjected to negative temperature difference (i.e., $T_{\text {top }}<T_{\text {bottom }}$, cooling test). Deflections increased with increasing magnitude of temperature difference. The positive strain (expansion) and compressive stress were induced in the FRP deck when temperature of FRP decks was increased by direct exposure to Sun light. Partial deck restraint, provided by steel stringer, resulted in partially induced stresses. The transient thermal stresses could be as high as $45 \%$ of the allowable stress of FRP decks and the transient thermal strain could be as high as $86 \%$ of allowable strain of the FRP bridge deck modules. 


\section{Acknowledgements}

First I wish to thank God for allowing me the opportunity to study. My deep appreciation is extended to my family for their love, encouragement, and faithful support. I would like to express my sincere appreciation to my advisor, Dr. Hota Gangarao, for invaluable guidance throughout this research. I would also like to thank Vimala Shekar for her participation in the implementation of this study. Her enthusiastic support and constant review of the manuscript have been invaluable to the progress and completion of this work. I would also like to thank my committee members for reviewing the dissertation and providing constructive comments.

Special thanks are also due to Chandra Sekhar Jinka and Srinavas Aluri for their assistance in testing and instrumentation in the field. The assistance provided by Dana Humberson and William J. Comstock with the experimental work is likewise greatly appreciated.

I would also like to thank the Federal Highway Administration, West Virginia Division of Highways (WVDOH) for providing the financial support for this project. Many thank are extended to Bedford Reinforced Plastic Inc. for supplying FRP bridge deck test modules. 


\section{Table of Contents}

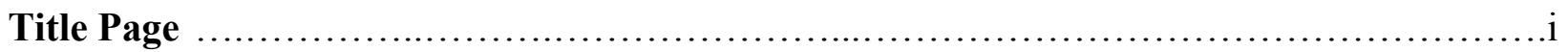

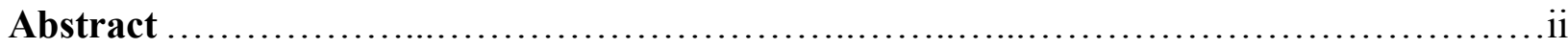

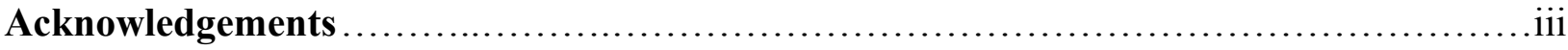

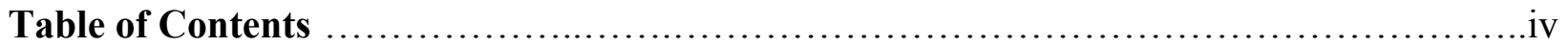

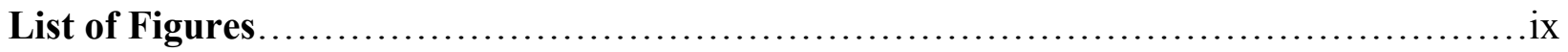

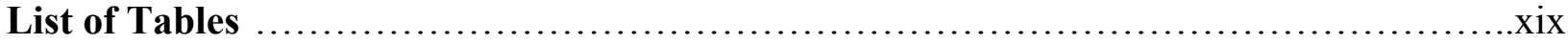

Chapter 1 : Introduction

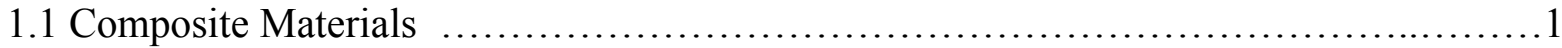

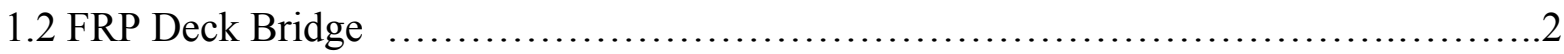

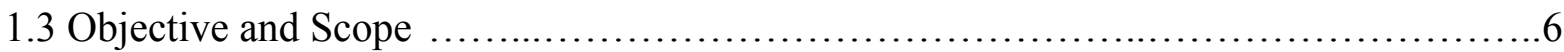

Chapter 2 : Literature Reviews

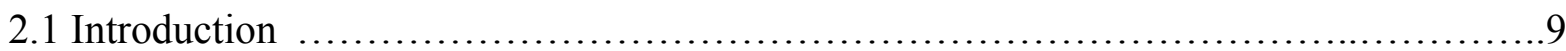

2.2 Temperature difference and Basic Concepts of Thermal Effect ...................... 9

2.3 Thermal Analysis of Composite Beams and Plates .............................. 14

\section{Chapter 3 : Coefficient of Thermal Expansion (CTE) Measurements in Laboratory}

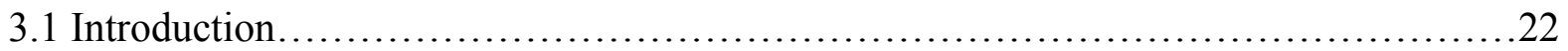

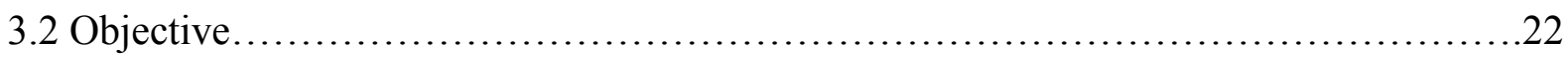

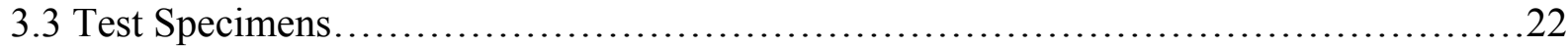

3.3.1 Component Level Specimens..........................................23

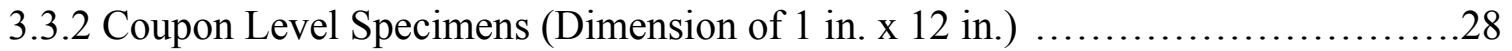

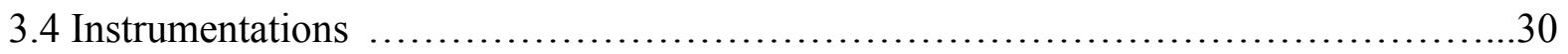

3.4.1 Strain Measurement ................................................. 30 


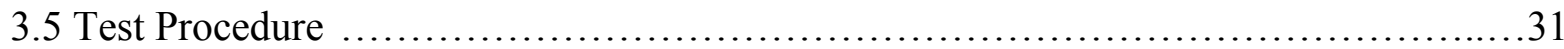

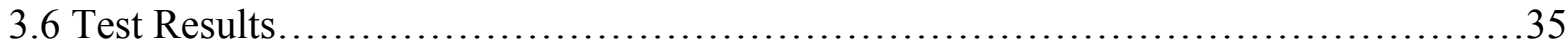

3.7 Calculation of CTE (using a micromechanics approach) ........................42

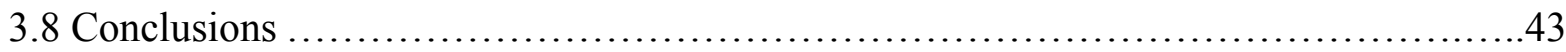

\section{Chapter 4 : Thermal Testing of FRP Bridge Deck under a Gradient Temperature in}

\section{Laboratory}

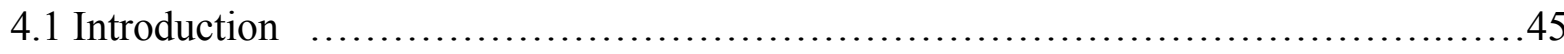

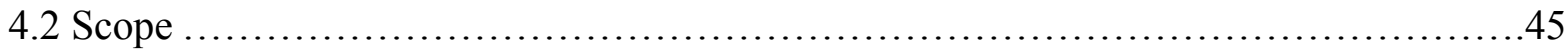

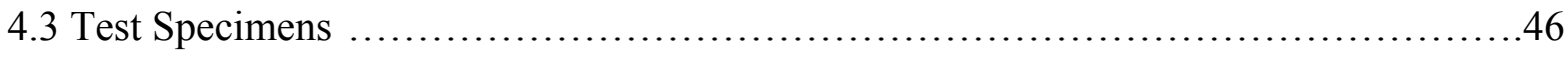

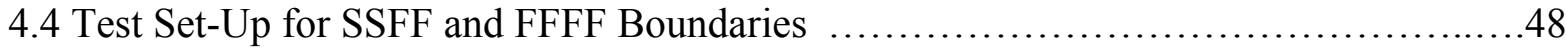

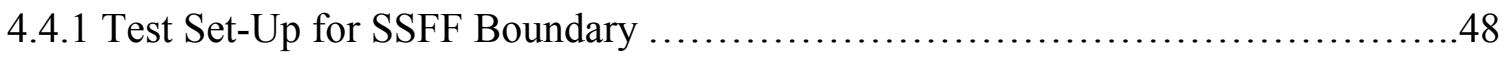

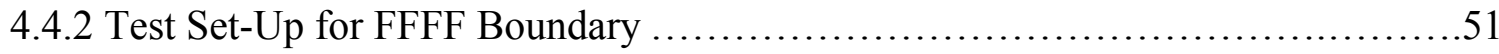

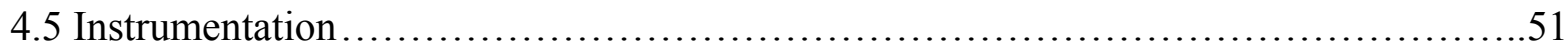

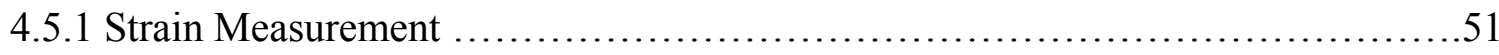

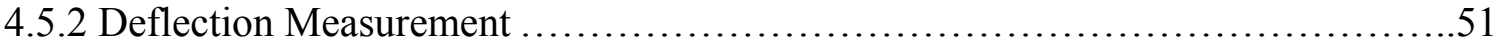

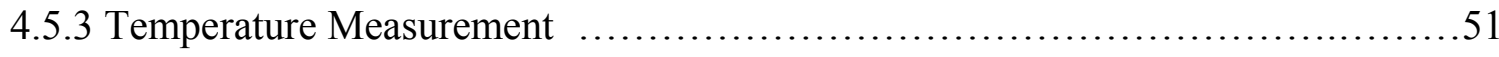

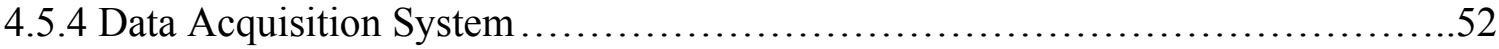

4.5.5 Locations of Strain Gages, LVDT and Temperature Sensor .................52

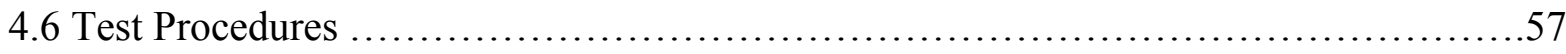

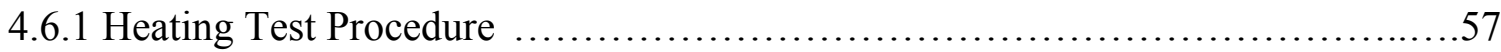

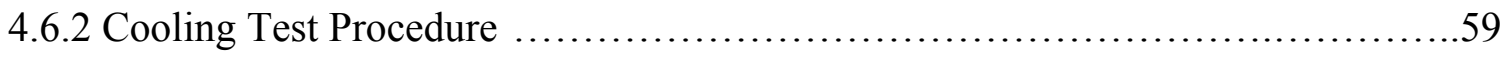

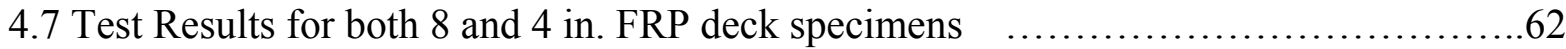


4.7.1 Test Results for 8 in. FRP deck specimen .62

4.7.1.1 Test Results for Test Case 8HS (Heating Test + SSFF Boundary) ...........62

4.7.1.2 Test Results for Test Case 8HF (Heating Test + FFFF Boundary) .........66

4.7.1.3 Test Results for Test Case 8CS (Cooling Test + SSFF Boundary) .......67

4.7.1.4 Test Results for Test Case 8CF (Cooling Test + FFFF Boundary) ...........68

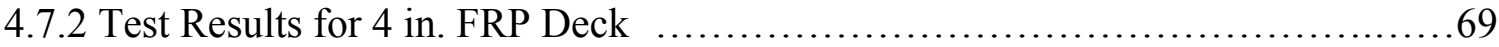

4.7.2.1 Test Results for Test Case 4HS (Heating Test + SSFF Boundary) ...........69

4.7.2.2 Test Results for Test Case 4HF (Heating Test + FFFF Boundary) ...........70

4.7.2.3 Test Results for Test Case 4CS (Cooling Test + SSFF Boundary) ...........71

4.7.2.4 Test Results for Test Case 4CF (Cooling Test + FFFF Boundary) ...........72

\section{Chapter 5 : Correlation of Laboratory Thermal Data with Theory}

5.1 Thermal Analysis based on Navier-Levy's Method …............................ 80

5.2 Thermal Analysis based on Macro Approach $\quad$ …................................... 85

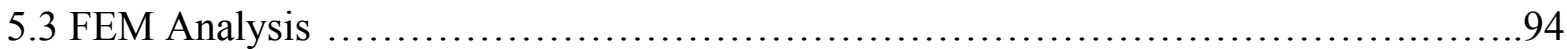

5.4 Comparison between experimental and theoretical results $\quad \ldots \ldots \ldots \ldots \ldots \ldots \ldots \ldots \ldots . \ldots 9 . \ldots \ldots$

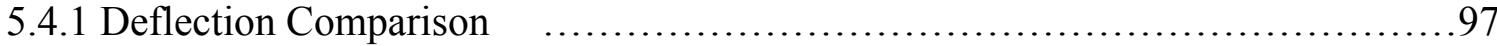

5.4.2 Strain Comparison ........................................................... 100

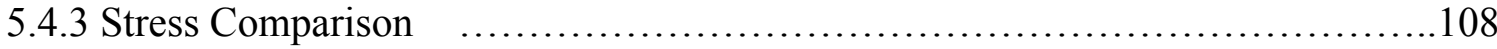

5.5 Discussion and Conclusions ..................................................... 113

\section{Chapter 6 : Field Evaluations of FRP Bridges}

6.1 General Details of Market Street and Wickwire Run Bridges …..................117

6.2 Field Test Results of Market Street and Wickwire Run Bridges ...................120

6.3 Evaluation of Thermal Stresses in Market Street Bridge .............................121 
6.3.1 Evaluation of thermal stress based on field test results (strain data)

6.3.2 Evaluation of thermal stress using FEM analysis (Market Street Bridge)

6.4 Evaluation of Theoretical Deflection (Macro Approach) Versus Field Deflection in

Wickwire Run Bridge

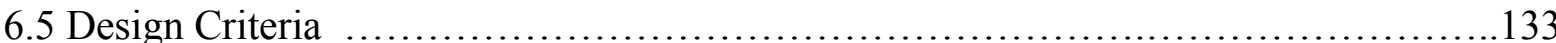

6.6 Design Examples ...........................................................

6.7 Conclusions

\section{Chapter 7 : Conclusions and Recommendations}

7.1 Conclusion 140

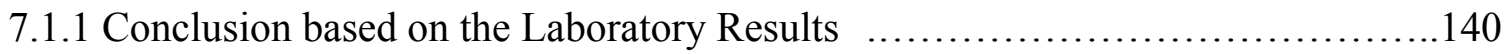

7.1.2 Conclusion based on the Field Results ...................................142

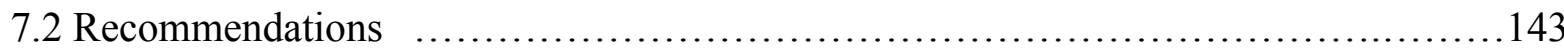

\section{Appendix A : Basic Thermal Analysis of Isotropic Beam and Orthotropic Plate}

A.1 Basic thermal analysis for 1-D isotropic beam 144

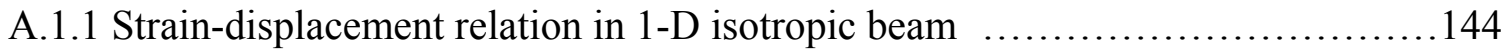

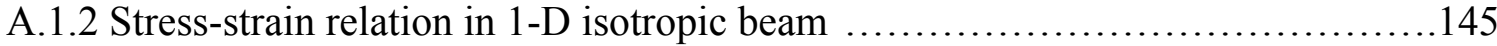

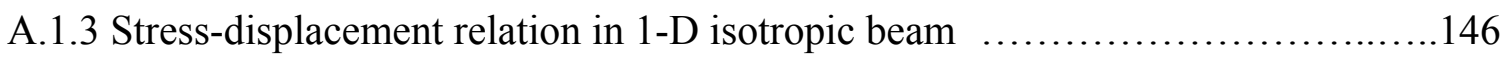

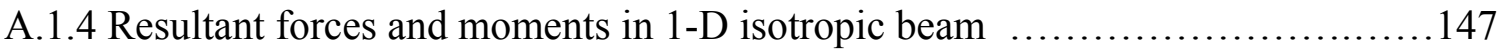

A.1.5 Design Example for a beam under a linear gradient temperature ................150

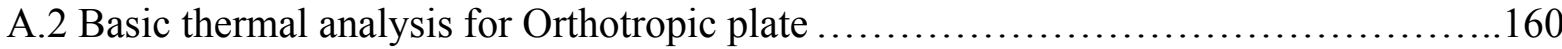

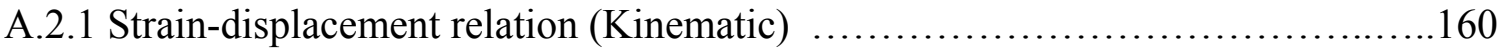

A.2.2 Stress-strain relation in orthotropic plate (Constitutive Equation) $\ldots . \ldots \ldots \ldots . . .163$

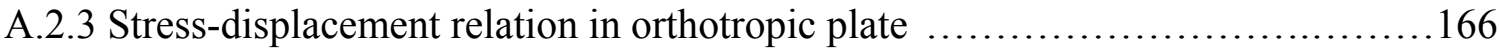


A.2.4 Resultant forces and moments in orthotropic plate 167

A.2.5 Temperature Increment $(\Delta T(z))$ along the depth

Appendix B : Derivation of Coefficients $M_{n}^{T_{x x}}(x)$ and $M_{n}^{T_{y y}}$ for thermal load moment $\ldots . .175$

Appendix C : Laboratory Test Results for 8 in. FRP Bridge Deck .....................177

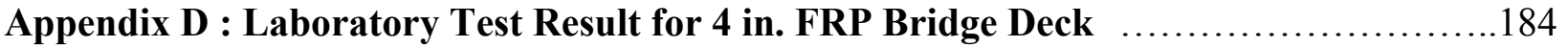

Appendix E : Theoretical Results from Navier-Levy and Macro Approach

E.1 Deflection Plot based on Navier-Levy Method

E.2 Matlab Program Code for Computation based on Navier-Levy Method

E.3 Deflection Plot based on Macro Approach ......................................210

E.4 Matlab Program Code for Computation based on Macro Approach ...................212

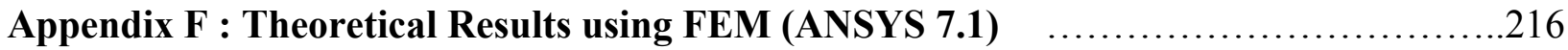

Appendix G : Thermal Analysis of FRP Bridge Deck as Orthotropic Panels

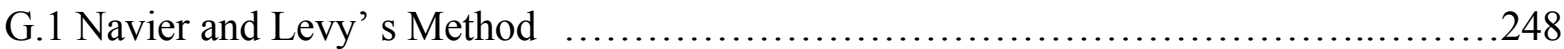

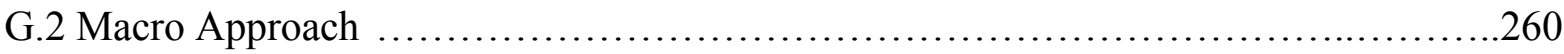




\section{List of Figures}

Figure 1.1: Installing FRP Deck on steel stringer. . ........................................

Figure 1.2: Using Nylon Strap to Lift FRP Deck. ..........................................

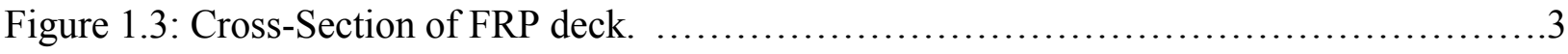

Figure 1.4: Applying Pliogrip Adhesive to a FRP Deck Module. .............................

Figure 1.5: Market Street Bridge - Open to Traffic. .....................................

Figure 2.1: Linear-Uniform Vertical Temperature Distribution; $\Delta T=$ Temperature

Differential (John B. Kennedy, 1987). .....................................12

Figure 2.2: Sandwich Panel Subjected to Thermal Gradient (R. Hussein, 1992). ................13

Figure 2.3: Depth-Deflection Relationships for a Thick Plate $(\mathrm{a} / \mathrm{h}=4)$ for Various Theories...19

Figure 3.1(a): Specimen \#1 ( A Module of 4 in. FRP Deck with 29 inches in Length). ..........24

Figure 3.1(b): Specimen \#1 : Locations and Number of Strain Gages. .......................24

Figure 3.2(a): Specimen \#2 (A Module of 8 in. FRP Deck with 24 inches in Length)...........25

Figure 3.2(b): Specimen \#2: Locations and Number of Strain Gages. .........................25

Figure 3.3(a): Specimen \#3 (Four Modules of 4 in. FRP Deck with $3 \mathrm{ft}$. in Length). .............26

Figure 3.3(b): Specimen \#3: Locations and Number of Strain Gages. $\quad$......................26

Figure 3.4(a): Specimen \# 4 (Three Modules of 8 in. FRP Deck with $3 \mathrm{ft}$. in Length). . ..........27

Figure 3.4(b): Specimen \#4: Location and Number of Strain Gages. $\quad$.......................27

Figure 3.5: Specimen \# 5: Locations and Number of Strain Gages. . .........................28

Figure 3.6: Specimen \# 6: Locations and Number of Strain Gages. .........................28

Figure 3.7: Specimens \#7 and \#8 : Locations and Number of Strain Gages. ...................29

Figure 3.8: Specimens $\# 9$ and \#10: Locations and Number of Strain Gages. ...................30

Figure 3.9: Reference Material ( ULE Titanium Silicate Code 7971 ) with Strain Gage. . ........32 
Figure 4.1: Cross Section of 4 inch and 8 inch Deep FRP Deck for a Module.

Figure 4.2: A 4 inch Deep FRP Deck Specimen. .47

Figure 4.3: A 8 inch Deep FRP Deck Specimen. .....................................48

Figure 4.4: Test Set-Up for SSFF Boundary Condition. ..............................49

Figure 4.5: Simply Supported Boundary Edges. .....................................49

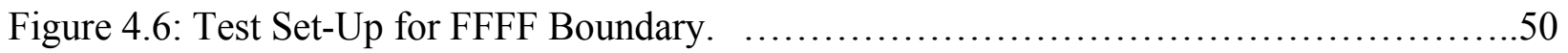

Figure 4.7: Steel Roller at the Corner of the FRP Deck. ..............................51

Figure 4.8: Locations of all Sensors on Top Surface of 8 inch. FRP Deck. ..................53

Figure 4.9: Location of all Sensors on Bottom Surface of 8 inch FRP Deck. .................54

Figure 4.10: Locations of all Sensors on Top Surface of 4 inch FRP Deck. ..................55

Figure 4.11: Locations of all Sensors on Bottom Surface of 4 inch FRP Deck. ...............56

Figure 4.12: The Aluminum Cover Box. ...........................................58

Figure 4.13 The Adjusted Opening Window. ........................................59

Figure 4.14: Plastic Sheet Covered the Entire Top Surface. ..............................60

Figure 4.15: Applying Dry Ice on the Top Surface of FRP Deck. ........................61

Figure 4.16: Covering the Dry Ice with Plastic Sheet. ................................61

Figure 4.17: Insulation Sheets Covered on the Top of Dry Ice..........................62

Figure 4.18: Deck Temperature Versus Testing Time. ..................................63

Figure 4.19: Temperature Difference Between Top and Bottom Deck Surface. ...............64

Figure 4.20: Deflection VS Testing Time at Center and Edge of FRP Deck. .................65

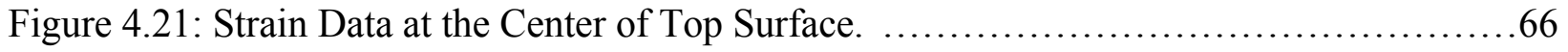

Figure 4.22: Deck Temperature VS Testing Time (Test Case 8HF). .......................66

Figure 4.23: Temperature Difference between Top and Bottom Deck Surface(Test Case 8HF)..66 
Figure 4.24: Deflection VS Testing Time at Center and Edge of FRP Deck (Test Case 8HF)...66

Figure 4.25: Strain Data at the Center of Top Surface (Test Case 8HF)....................66

Figure 4.26: Deck Temperature VS Testing Time (Test Case 8CS)......................67

Figure 4.27: Temperature Difference between Top and Bottom Deck Surface(Test Case 8CS)..67

Figure 4.28: Deflection VS Testing Time at Center and Edge of FRP Deck (Test Case 8CS)...67

Figure 4.29: Strain Data at the Center of Top Surface (Test Case 8CS).....................67

Figure 4.30: Deck Temperature Versus Testing Time (Test Case 8CF)....................68

Figure 4.31: Temperature Difference between Top and Bottom Deck Surface(Test Case 8CF)..68

Figure 4.32: Deflection VS Testing Time at Center and Edge of FRP Deck (Test Case 8CF)...68

Figure 4.33: Strain Data at the Center of Top Surface (Test Case 8CF) .....................68

Figure 4.34: Deck Temperatures VS Testing Time (Test Case 4HS). .....................69

Figure 4.35: Temperature Difference between Top and Bottom Deck Surface(Test Case 4HS)..69

Figure 4.36: Deflection VS Testing Time at Center and Edge of FRP Deck (Test Case 4HS)...69

Figure 4.37: Strain Data at the Center of Top Surface (Test Case 4HS). ...................69

Figure 4.38: Deck Temperatures VS Testing Time (Test Case 4HF). .......................70

Figure 4.39: Temperature Difference between Top and Bottom Deck Surface(Test Case 4HF)..70

Figure 4.40: Deflection VS Testing Time at Center and Edge of FRP Deck (Test Case 4HF)...70

Figure 4.41: Strain Data at the Center of Top Surface (Test Case 4HF). ....................70

Figure 4.42: Deck Temperatures VS Testing Time (Test Case 4CS). ..................... 71

Figure 4.43: Temperature Difference between Top and Bottom Deck Surface(Test Case 4CS)..71

Figure 4.44: Deflection VS Testing Time at Center and Edge of FRP Deck (Test Case 4CS)....71

Figure 4.45: Strain Data at the Center of Top Surface (Test Case 4CS)....................71

Figure 4.46: Deck Temperatures VS Testing Time (Test Case 4CF). ......................72 
Figure 4.47: Temperature Difference between Top and Bottom Deck Surface(Test Case 4CF)..72 Figure 4.48: Deflection VS Testing Time at Center and Edge of FRP Deck (Test Case 4CF)...72

Figure 4.49: Strain Data at the Center of Top Surface (Test Case 4CF) .....................72

Figure 5.1: Deflection of FRP deck at the center for Test Case 8HS (Navier-Levy's Method, $\mathrm{n}=1,3,5, \ldots, 15)$. .84

Figure 5.2: Deflection Contour for Test Case 8HS (Navier-Levy's Method, $n=1)$. ............84

Figure 5.3: Deflection Contour for Test Case 8HS (Using Macro Approach)..................88

Figure 5.4: Temperature Change Profile for Test Case 8 HS............................. 89

Figure 5.5: Diameters of holes were larger than that of threaded rods.......................91

Figure 5.6: Quarter Model of a 8 in. FRP Deck Specimen. .............................95

Figure 5.7: Quarter Model of a 4 inch FRP Deck Specimen...............................96

Figure 5.8: Deflection Bar Chart for all of Test Cases...................................99

Figure 5.9: Strain Bar Chart for Test Case 8 HS. ..................................... 103

Figure 5.10: Strain Bar Chart for Test Case 8CS..................................... 104

Figure 5.11: Strain Bar Chart for Test Case 8HF..................................... 104

Figure 5.12: Strain Bar Chart for Test Case 8 CF...................................... 105

Figure 5.13: Strain Bar Chart for Test Case 4HS................................... 105

Figure 5.14: Strain Bar Chart for Test Case 4CS.................................... 106

Figure 5.15: Strain Bar Chart for Test Case 4HF.................................... 106

Figure 5.16: Strain Bar Chart for Test Case 4CF..................................... 107

Figure 6.1: Cross Section of FRP Deck Placed on Bridge Stringers......................118

Figure 6.2: Cross Section at Center of Market Street Bridge.............................118

Figure 6.3: View Before Applying Polymer Concrete (Market Street bridge). ...............119 
Figure 6.4: View After Applying Polymer Concrete (Market Street Bridge) 119

Figure 6.5: Cross Section at Center of Wickwire Run Bridge................................ 120

Figure 6.6: Change in Temperature Profile for Market Street Bridge..........................122

Figure 6.7: Market Street Bridge FEM Model.......................................... 127

Figure 6.8: Plan View for Center Spacing of Wickwire Run Bridge..........................131

Figure 6.9: Temperature Plot for Wickwire Run Bridge................................. 139

Figure A.1: $\mathrm{x}$ and $\mathrm{z}$ Directions of a Beam. ............................................

Figure A.2: Beam Geometry and Coordinate System................................... 147

Figure A.3: Temperature Change Profile along the Depth................................. 148

Figure A.4: Undeformed and Deformed Geometries of a Plate (Reddy 1999)..................161

Figure A.5: Positive Directions of $\mathrm{x}, \mathrm{y}$ and $\mathrm{z}$ Axis (Ref. Reddy, 1999)........................170

Figure A.6: Axial Forces and Moment Resultants on Plate (Ref. Reddy, 1999)................170

Figure C.1: Temperature on Top/Bottom Surface for Test Case 8HS........................177

Figure C.2: Temperature Difference $\left(\Delta T=T_{\text {top }}-T_{\text {bottom }}\right)$ for Test Case 8HS ...................177

Figure C.3: Center/Edge Deflections for Test Case 8HS ..................................177

Figure C.4: Strain in $y$ direction @ Top Surface for Test Case 8HS ............................177

Figure C.5: Strain in $y$ direction @ Bottom Surface for Test Case 8HS .........................177

Figure C.6: Temperature on Top/Bottom Surface for Test Case 8HF........................178

Figure C.7: Temperature Difference $\left(\Delta T=T_{\text {top }}-T_{\text {bottom }}\right)$ for Test Case 8HF …..............178

Figure C.8: Center/Edge Deflections for Test Case 8HF ................................ 178

Figure C.9: Strain in $y$ Direction @ Top Surface for Test Case 8HF.............................178

Figure C.10: Strain in $x$ Direction @ Top Surface for Test Case 8HF...........................179

Figure C.11: Strain in $y$ Direction @ Bottom Surface for Test Case 8HF .......................179 
Figure C.12: Strain in $x$ Direction @ Bottom Surface for Test Case 8HF 179

Figure C.13: Temperature on Top/Bottom Surface for Test Case 8CS .180

Figure C.14: Temperature Difference ( $\left.\Delta T=T_{\text {top }}-T_{\text {bottom }}\right)$ for Test Case 8CS. 180

Figure C.15: Center/Edge Deflections for Test Case 8CS 180

Figure C.16: Strain in $y$ Direction @ Top Surface for Test Case 8CS 180

Figure C.17: Strain in $x$ Direction @ Top Surface for Test Case 8CS

Figure C.18: Strain in $y$ Direction @ Bottom Surface for Test Case 8CS .181

Figure C.19: Strain in $x$ Direction @ Bottom Surface for Test Case 8CS

Figure C.20: Temperature on Top/Bottom Surface for Test Case 8CF 182

Figure C.21: Temperature Difference ( $\left.\Delta T=T_{\text {top }}-T_{\text {bottom }}\right)$ for Test Case 8CF

Figure C.22: Center/Edge Deflections for Test Case 8CF ….............................. 182

Figure C.23: Strain in $y$ Direction @ Top Surface for Test Case 8CF ...........................182

Figure C.24: Strain in $x$ Direction @ Top Surface for Test Case 8CF ..........................183

Figure C.25: Strain in $y$ Direction @ Bottom Surface for Test Case 8CF .......................183

Figure C.26: Strain in $x$ Direction @ Bottom Surface for Test Case 8CF .......................183

Figure D.1: Temperature on Top/Bottom Surface for Test Case 4HS ........................184

Figure D.2: Temperature Difference $\left(\Delta T=T_{\text {top }}-T_{\text {bottom }}\right)$ for Test Case 4HS $\ldots \ldots \ldots \ldots \ldots \ldots \ldots 184$

Figure D.3: Center/Edge Deflections for Test Case 4HS ................................. 184

Figure D.4: Strain in $y$ direction @ Top Surface for Test Case 4HS ............................184

Figure D.5: Strain in $x$ direction @ Top Surface for Test Case 4HS ...........................185

Figure D.6: Strain in $y$ direction @ Bottom Surface for Test Case 4HS .......................185

Figure D.7: Strain in $x$ direction @ Bottom Surface for Test Case 4HS .........................185

Figure D.8: Temperature on Top/Bottom Surface for Test Case 4HF …....................186 
Figure D.9: Temperature Difference ( $\left.\Delta T=T_{\text {top }}-T_{\text {bottom }}\right)$ for Test Case 4HF 186

Figure D.10: Center/Edge Deflections for Test Case 4HF ................................186

Figure D.11: Strain in $y$ direction @ Top Surface for Test Case 4HF ...........................186

Figure D.12: Strain in $x$ direction @ Top Surface for Test Case 4HF $\quad \ldots \ldots \ldots \ldots \ldots \ldots \ldots \ldots . . . . . . . .186$

Figure D.13: Strain in $y$ direction @ Bottom Surface for Test Case 4HF ........................186

Figure D.14: Strain in $x$ direction @ Bottom Surface for Test Case 4HF .......................186

Figure D.15: Temperature on Top/Bottom Surface for Test Case 4CS …...................188

Figure D.16: Temperature Difference $\left(\Delta T=T_{\text {top }}-T_{\text {bottom }}\right)$ for Test Case 4CS ................ 188

Figure D.17: Center/Edge Deflections for Test Case 4CS .................................188

Figure D.18: Strain in $y$ direction @ Top Surface for Test Case 4CS ...........................188

Figure D.19: Strain in $x$ direction @ Top Surface for Test Case 4CS ..........................189

Figure D.20: Strain in $y$ direction @ Bottom Surface for Test Case 4CS ........................189

Figure D.21: Strain in $x$ direction @ Bottom Surface for Test Case 4CS........................189

Figure D.22: Temperature on Top/Bottom Surface for Test Case 4CF …...................190

Figure D.23: Temperature Difference $\left(\Delta T=T_{\text {top }}-T_{\text {botom }}\right)$ for Test Case 4CF ................. 190

Figure D.24: Center/Edge Deflections for Test Case 4CF ..................................190

Figure D.25: Strain in $y$ direction @ Top Surface for Test Case 4CF ...........................190

Figure D.26: Strain in $x$ direction @ Top Surface for Test Case 4CF ..........................191

Figure D.27: Strain in $y$ direction @ Bottom Surface for Test Case 4CF ........................191

Figure D.28: Strain in $x$ direction @ Bottom Surface for Test Case 4CF ….................191

Figure E.1: Deflection Mesh for Test Case 8HS (Navier-Levy)........................... 192

Figure E.2: Center Deflection and Deflection Difference for Test Case 8HS (Navier-Levy)....193

Figure E.3: Edge Deflection and Deflection Difference for Test Case 8HS (Navier-Levy)......193 
Figure E.4: Deflection Mesh for Test Case 8CS (Navier-Levy). ............................ 194

Figure E.5: Center Deflection and Deflection Difference for Test Case 8CS (Navier-Levy)....194

Figure E.6: Edge Deflection and Deflection Difference for Test Case 8CS (Navier-Levy)......195

Figure E.7: Deflection Mesh for Test Case 4HS (Navier-Levy). ...........................195

Figure E.8: Center Deflection and Deflection Difference for Test Case 4HS (Navier-Levy)....196

Figure E.9: Edge Deflection and Deflection Difference for Test Case 4HS (Navier-Levy)......196

Figure E.10: Deflection Mesh for Test Case 4CS (Navier-Levy). ..............................197

Figure E.11: Center Deflection and Deflection Difference for Test Case 4CS (Navier-Levy)...197

Figure E.12: Edge Deflection and Deflection Difference for Test Case 4CS (Navier-Levy)....198

Figure E.13: Deflection Mesh for Test Case 8HS (Macro Approach). ........................210

Figure E.14: Deflection Mesh for Test Case 8CS (Macro Approach)........................2210

Figure E.15: Deflection Mesh for Test Case 4HS (Macro Approach).........................211

Figure E.16: Deflection Mesh for Test Case 4CS (Macro Approach)..........................211

Figure F.1: A Quarter Model of 8 in. FRP Deck Specimens...............................217

Figure F.2: Displacement Contour Plot in Z Direction (Test Case 8HS) ......................217

Figure F.3: Strain Contour Plot in X Direction (Test Case 8HS)...........................218

Figure F.4: Strain Contour Plot in Y Direction (Test Case 8HS) ...........................218

Figure F.5: Stress Contour Plot in X Direction (Test Case 8HS)............................219

Figure F.6: Stress Contour Plot in Y Direction (Test Case 8HS).............................219

Figure F.7: Displacement Contour Plot in Z Direction (Test Case 8HF)....................220

Figure F.8: Strain Contour Plot in X Direction (Test Case 8HF). ..........................220

Figure F.9: Strain Contour Plot in Y Direction (Test Case 8HF)..............................221

Figure F.10: Stress Contour Plot in X Direction (Test Case 8HF).........................221 
Figure F.11: Stress Contour Plot in Y Direction (Test Case 8HF) .........................222

Figure F.12: Displacement Contour Plot in Z Direction (Test Case 8CS)...................222

Figure F.13: Strain Contour Plot in X Direction (Test Case 8CS)..........................223

Figure F.14: Strain Contour Plot in Y Direction (Test Case 8CS), ..........................223

Figure F.15: Stress Contour Plot in X Direction (Test Case 8CS)..........................224

Figure F.16: Stress Contour Plot in Y Direction (Test Case 8CS) . .........................224

Figure F.17: Displacement Contour Plot in Z Direction (Test Case 8CF). ...................225

Figure F.18: Strain Contour Plot in X Direction (Test Case 8CF)..........................225

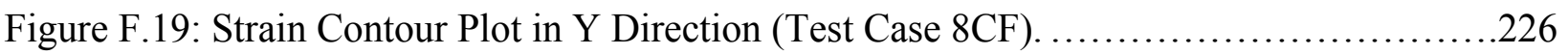

Figure F.20: Stress Contour Plot in X Direction (Test Case 8CF). .........................226

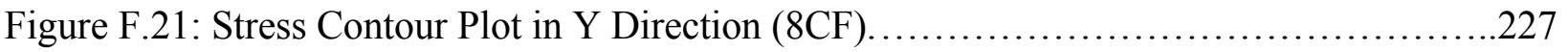

Figure F.22: A Quarter Model of 4 in. FRP Deck Specimens..............................227

Figure F.23: Displacement Contour Plot in Z Direction (Test Case 4HS)....................228

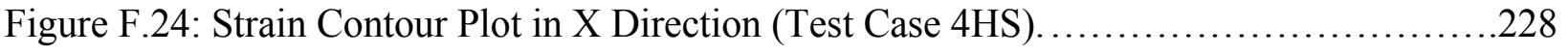

Figure F.25: Strain Contour Plot in Y Direction (Test Case 4HS).........................222

Figure F.26: Stress Contour Plot in X Direction (Test Case 4HS)..........................229

Figure F.27: Stress Contour Plot in Y Direction (Test Case 4HS) .........................230

Figure F.28: Displacement Contour Plot in Z Direction (Test Case 4HF) ....................230

Figure F.29: Strain Contour Plot in X Direction (Test Case 4HF)............................231

Figure F.30: Strain Contour Plot in Y Direction (Test Case 4HF)..........................231

Figure F.31: Stress Contour Plot in X Direction (Test Case 4HF), ........................2232

Figure F.32: Stress Contour Plot in Y Direction (Test Case 4HF) .........................2232

Figure F.33: Displacement Contour Plot in Z Direction (Test Case 4CS) ...................233 
Figure F.34: Strain Contour Plot in X Direction (Test Case 4CS).......................233

Figure F.35: Strain Contour Plot in Y Direction (Test Case 4CS)..........................234

Figure F.36: Stress Contour Plot in X Direction (Test Case 4CS). .......................234

Figure F.37: Stress Contour Plot in Y Direction (Test Case 4CS)........................235

Figure F.38: Displacement Contour Plot in Z Direction (Test Case 4CF)...................235

Figure F.39: Strain Contour Plot in X Direction (Test Case 4CF).......................236

Figure F.40: Strain Contour Plot in Y Direction (Test Case 4CF) .......................236

Figure F.41: Stress Contour Plot in X Direction (Test Case 4CF).........................237

Figure F.42: Stress Contour Plot in Y Direction (Test Case 4CF) .......................237

Figure G.1: Plate with FFSS Boundary Condition....................................248

Figure G.2: Plate with Elastic Beams..............................................260 


\section{List of Tables}

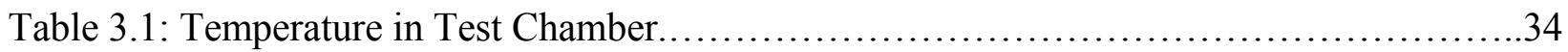

Table 3.2: Raw Strain data $\left(\varepsilon_{\text {specimen }}\right)$ for Specimens \#1 and \#2 and Strain Data $\left(\varepsilon_{\text {reference material }}\right)$

for Reference Material.........................................................

Table 3.3: Raw Strain Data $\left(\varepsilon_{\text {specimen }}\right)$ for Specimens \#3 and \#4 and Strain Data $\left(\varepsilon_{\text {reference material }}\right)$ for Reference Material............................................................. 36

Table 3.4 Raw Strain Data $\left(\varepsilon_{\text {specimen }}\right)$ for Specimens \#5 to \#10 and Strain Data $\left(\varepsilon_{\text {reference material }}\right)$

for Reference Material.......................................................... 37

Table 3.5: True Strain Data $(\varepsilon)$ for Specimens \# 1 and \# 2 .................................. 38

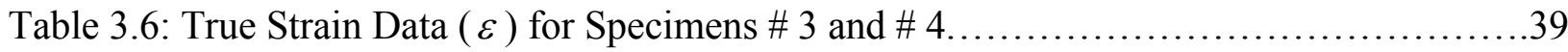

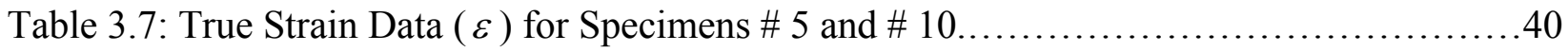

Table 3.8: CTE of 4 in. FRP Deck...........................................................

Table 3.9: CTE of 8 in. FRP Deck.........................................................

Table 3.10: Average CTE of 4 inch and 8 inch FRP Deck at Top/Bottom Surfaces..............43

Table 3.11: Average CTE of 4 inch and 8 inch FRP Deck at Web ............................43

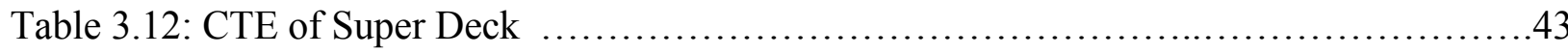

Table 4.1: Experimental Data of 8 inch FRP Deck Specimen..................................73

Table 4.2: Experimental Data of 4 inch FRP Deck Specimen.................................74

Table 5.1: Structural Properties of 8 in. and 4 in. FRP Bridge Deck Component.................77

Table 5.2: Experimental Data for Heating and Cooling Tests of 8 in. FRP Deck................78

Table 5.3: Experimental Thermal Data for Heating and Cooling Tests of 4 in. FRP Deck. ........79

Table 5.4: Deflection Results based on Navier-Levy Method. .................................85 
Table 5.5: Deflection, Strain and Stress at Center for Test Case 8HS (Based on Macro Approach)

Table 5.6: Deflection, Strain and Stress at Center for Test Case 8HS and 8CS (Based on

Macro Approach).

Table 5.7: Deflection, Strain and Stress at Center for Test Case 4HS and 4CS (Based on

Macro Approach).

Table 5.8: Results at Center for all of Test Cases (FEM Analysis)....

Table 5.9: Deflection Results (Experiment, FEM, Navier-Levy, and Macro Approach)

for all of Test Cases.

Table 5.10: Percent Deflection Difference (Theory V.S. Experiment).

Table 5.11: Strain Results for 8 inch FRP Deck........................................ 101

Table 5.12: Strain Results for 4 inch FRP Deck...................................... 102

Table 5.13: Average of Percent Strain Difference for all of Test Cases

(for 4 inch and 8 inch FRP decks.) 108

Table 5.14: Experimental Stress Results..........................................110

Table 5.15: Stress Results (Experiment, FEM and Macro approach) for 8 inch FRP Deck.....111

Table 5.16: Stress Results (Experiment, FEM and Macro approach) for 4 inch FRP Deck. ....112

Table 5.17: Average Deflection Difference in Percentage................................113

Table 5.18: Average Strain Difference in Percentage.....................................114

Table 6.1: Thermal Strain Data for Market Street Bridge................................ 120

Table 6.2: Deflection Data for Wickwire Run Bridge................................. 121

Table 6.3: Induced Thermal Stresses based of Field Results for Market Street Bridge. .........126

Table 6.4: Induced Thermal Stresses based FEM Results for Market Street Bridge 
with $\Delta T_{\text {top }}=36^{\circ} \mathrm{F}, \Delta T_{\text {bottom }}=10^{\circ} \mathrm{F}$.

Table 6.5: FEM Results for $\Delta T_{\text {top }}=100^{\circ} \mathrm{F}$ and $\Delta T_{\text {bottom }}=30^{\circ} \mathrm{F}$ .129

Table 6.6: Properties of Super Deck. 132

Table 6.7: Theoretical and Field Deflections for Wickwire Run Bridge.

Table 6.8: Total Stress on FRP Deck. 133

Table 6.9: Total Strain on FRP Deck. 133

Table 6.10: Induced Thermal Strain (Field Data) and Stress of Market Street Bridge 134

Table A.1 Basic Mechanical Law with Temperature Effect. 144

Table A.2: Comparison Results of Beam Theory and FEM for Case 1 .153

Table A.3: Comparison Results of Beam Theory and FEM for Case 2........................157

Table A.4: Comparison Results of Beam Theory and FEM for Case 3. 


\section{Chapter 1}

\section{Introduction}

\subsection{Composite Materials}

A composite material consists of two or more constituent materials such as fibers and resins. The fiber-reinforced polymer (FRP) composite materials, consisting of glass and/or carbon fibers, polymeric resins, additives, pigments, and other constituents, have been used in many applications. For example, FRPs are used to build aircraft, space structures, helicopters, space, automobiles, sporting goods, bridge decks, and others because of their superior thermo-mechanical properties over conventional materials. FRP composites possess high stiffness and strength to weight, high specific energy absorption and excellent fatigue performance and corrosion resistance (Mallick, 1946). Depending on the matrix (cured resin) used, composite materials are classified as polymer matrix composites (PMCs), metal matrix composites (MMCs), or ceramic matrix composites (CMCs). The majority of the commercial composites are manufactured of polymer matrices (Mallick, 1997). The fiber materials play an important role in composites. Many researchers have investigated the effects of fiber forms, fiber type, fiber volume fraction, and orientation of fiber. In general, the higher the fiber volume fraction results in a higher modulus and a higher strength. In structural applications, the fiber volume fraction ranges from $30 \%-70 \%$. The most common types of fibers used in advanced composites for structural applications are glass, aramid and carbon fibers (or roving and fabrics). The glass fiber is the least expensive fiber while carbon has been named the most expensive. Glass fibers are divided into three classes, which are: Eglass, S-glass, and C-glass. The E-glass fiber is the most common type of the three types of glass fibers which are used in civil applications. The glass fiber is treated as an isotropic 
material and has a lower thermal expansion coefficient than steel. The aramid fibers have excellent fatigue and creep resistance. The two most common types of aramid fibers that are used in structural applications are Kevlar 29 and Kevlar 49. The aramid fiber is regarded as an anisotropic material. Carbon fibers generally have the higher modulus than aramid or glass fibers. Carbon fibers have lower thermal expansion coefficients than aramid and glass fibers. Also, carbon fibers have a very high fatigue and creep resistance. Carbon fibers are divided into three types, such as high strength, high modulus, and ultra-high modulus fibers. The density, Young's modulus and tensile strength of all three types of fibers can be obtained from Mallick (1997).

The matrix materials (or resin) that are combined with fibers can be made of polymers, metals, or ceramics. The most common resins used in load bearing (structure) composites are polyester, epoxies, and vinyl esters.

\subsection{Fiber Reinforced Polymer (FRP) Bridge Deck}

As described in the section above, composites can be made of different combinations of fibers and matrix materials and are used in many different applications. One of the applications in civil structures is the FRP bridge deck. Market Street Bridge (GangaRao and Laosiriphong 2001) is one of FRP deck bridges in West Virginia with steel stringers, as shown in Figure 1.1. In Figure 1.1, portions of the deck were installed on steel stringer using nylon straps to lift (Figure 1.2). The cross section of FRP deck, manufactured by Creative Pultrusion Inc., is shown in Figure 1.3. The FRP modules are inter-connected by an adhesive bonding (Pliogrip) (Figure 1.4). The predrilled FRP deck modules were connected to steel stringers using threaded Nelson studs and non-shrink cement grout. The threaded Nelson 
studs ( 0.5 inch diameter) were welded to steel stringers in the field. After FRP deck modules were completely installed, a 1/8 inch thick of polymer concrete wearing surface was applied over top surface of the FRP deck.. Market Street Bridge after completion is shown in Figure 1.5.

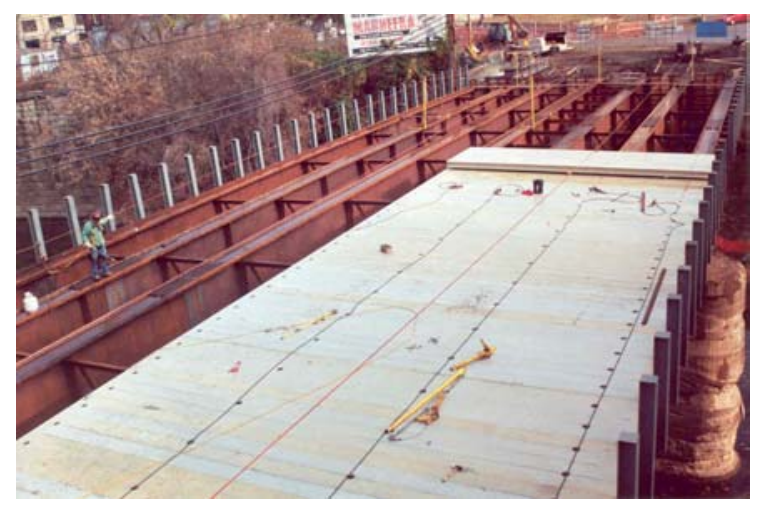

Figure 1.1: Installing FRP Deck on steel stringer.

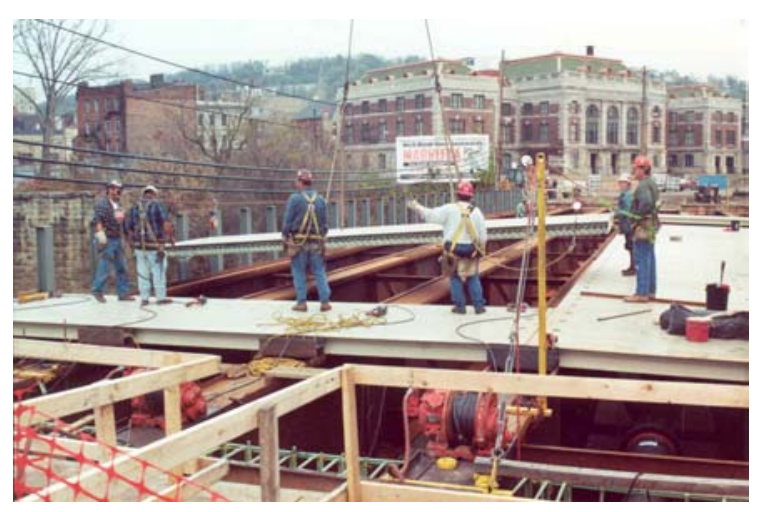

Figure 1.2: Using Nylon Strap to Lift FRP Deck.

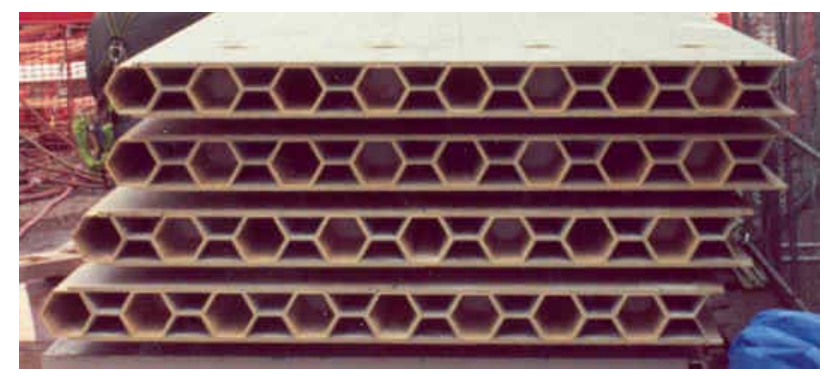


Figure 1.3: Cross-Section of FRP deck.

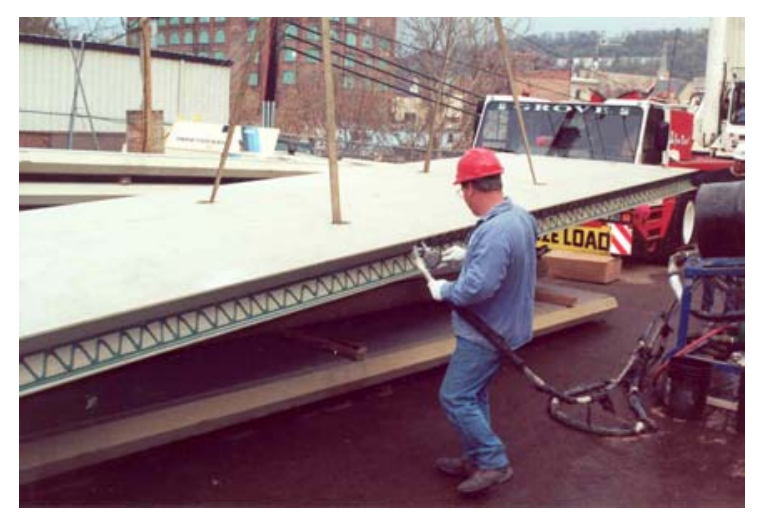

Figure 1.4: Applying Pliogrip Adhesive to a FRP Deck Module.

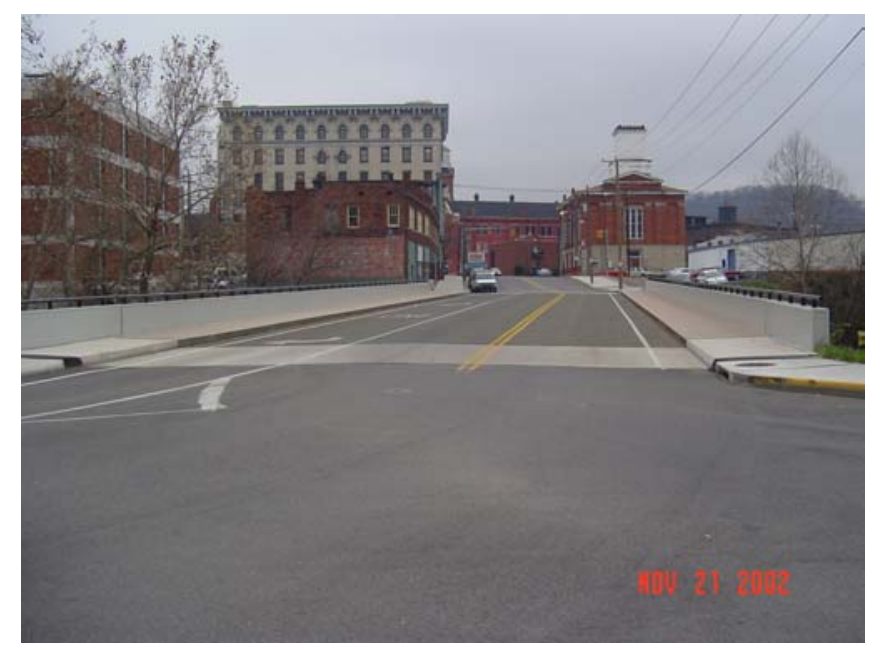

Figure 1.5: Market Street Bridge - Open to Traffic.

The use of the fiber reinforced polymer (FRP) deck has become an alternative method for improving the life of a bridge deck in relation to using concrete decks. The stiffness and strength of a conventionally reinforced concrete bridge deck reduces because of various environmental effects and the various chemicals used for deicing snow in the winter. The deicing salts used in winter (only considered in some states) increase the corrosion rate of steel reinforced concrete bridge decks, which results in the bridge deck replacement ranging 
on an average from 15 to 25 years, depending on location, traffic intensity, and construction quality. Since FRP bridge decks have excellent corrosion resistance, they can lengthen the deck service life compared to conventional concrete decks. Also, FRP decks are much lighter than conventional concrete bridge decks (about 70-80\% lighter), reducing the self weight and increasing the live load capacity without significantly altering the in-service substructure. Installation of FRP decks is rapid because of their modular construction approach and use of lighter erection equipment. One of the recent concerns with FRP decks is the wearing surface delamination after a short in service duration. The wearing surface problem can be solved by following the proper installation procedures and using the proper materials (Shekar, Petro, and GangaRao 2002). Several technical and quality control issues may be the cause of the wearing surface problems. The wearing surface could be installed while the FRP deck is subjected to high gradient temperature through the depth. Such a gradient temperature can create residual stress in the wearing surface during cooling of the deck in the night hours. Another potential delamination problem can occur when the FRP deck surface is not properly cleaned before installing the wearing surface. Also, field joints in each panel of the FRP deck should be reinforced by layers of composite fabric, as well as sanded for a clean surface (without FRP gel coat) (Shekar, Petro, and GangaRao, 2002) before installing wearing surface.

The gradient temperature (the temperature difference between the deck top and bottom) of the FRP bridge deck is high compared to conventional concrete deck because of the hollow section and relatively low thermal conductivity (Thermal conductivity of concrete is around 0.8 to $1.2 \mathrm{~W} / \mathrm{m}^{\circ} \mathrm{K}$ while that of FRP deck is about $0.375 \mathrm{~W} / \mathrm{m}^{\circ} \mathrm{K}$ ). Typically, the maximum temperature gradient of a FRP bridge deck is $80^{\circ}$ to $90^{\circ} \mathrm{F}$ during hot sunny day 
while that of a conventional concrete deck is around $20^{\circ}$ to $40{ }^{\circ} \mathrm{F}$. During winter, the temperature gradient is not as high as in summer. When the temperature of the top surface is higher than that of the bottom surface, the deck will have a tendency to heave in the upward direction.

Thermal responses in fiber reinforced polymer (FRP) decks due to temperature fluctuation have become a very critical issue (based on field observations) and several bridge decks have been monitored in the field and simulated in a laboratory setting.

\subsection{Objective and Scope}

The objectives of this study are to determine thermal strain and deflection of a FRP deck subjected to temperature difference in the laboratory and the field and to develop theoretical and design procedures for FRP decks under thermal loads. A detailed procedure to accomplish the above objectives is given below:

Chapter 2: Review the existing literature in terms of thermal effects in the composites.

Chapter 3: Determine the coefficients of thermal expansion of FRP deck specimens supplied by Bedford Reinforce Plastic Inc.

Chapter 4: Present the laboratory test data (i.e. heating test and cooling test) for FRP deck specimens under temperature gradient. Simply supported boundary and free boundary conditions are simulated in the laboratory tests.

Chapter 5: Correlate laboratory thermal data with theory.

Chapter 6: Obtain the data from field and compare filed data to theoretical results.

Chapter 7: Conclusions and Recommendations.

Appendix A: Basic thermal analysis of isotropic beam and orthotropic plate 
Appendix B: Derivation of Coefficients $M_{n}^{T_{x x}}(x)$ and $M_{n}^{T_{y y}}(x)$ for thermal load moment Appendix C: Laboratory test results for 8 in. FRP bridge deck Appendix D: Laboratory test results for 4 in. FRP bridge deck Appendix E: Theoretical results from Navier-Levy and Macro Approach Appendix F: Theoretical results using FEM (ANSYS Version 7.1)

Appendix G: Develop analytical solutions for FRP decks under temperature changes using Navier-Levy method and Macro Approach. 


\section{References}

- Alampalli, Sreenivas and Kunin, Jonathan, "Load Testing of An FRP Bridge Deck on a Truss Bridge", Special Report FHWA/NY/SR-01/137, NYDOT.

- GangaRao, Hota and Laosiriphong, Krit, "Design and Construction of Market Street Bridge", Society For The Advancement of Material and Process Engineering, $46^{\text {th }}$ International SAMPE Symposium and Exhibition, Long Beach, California, 2001, pp 1321-1330.

- Mallick, P. K., Fiber-reinforced composites : materials, manufacturing, and design, Edition \#2, Marcel Dekker, 1993.

- Shekar, Vimala, Petro, Samer H., and GangaRao, Hota V.S., "Construction of FiberReinforced Plastic Modulars Decks for Highway Bridges", Transportation Research Record No. 1813, pp 203-209, 2002.

- Tang, Benjamin, "Fiber Reinforced Polymer Composites Applications in USA DOTFederal Highway Administration", 1997 


\section{Chapter 2}

\section{Literature Reviews}

\subsection{Introduction}

All practical structures are subjected to varying structural responses under thermal changes as in cases of mechanical loads. Therefore it is necessary to understand and include the thermal effects in the structural design (Vinson, 1999). Bridge structures are subjected to high temperature difference on deck slab. Generally, temperature difference along the depth of FRP deck bridge is higher than that of traditional concrete deck bridge by about 2 or 3 times since hollow cross-section of FRR deck reduces the amount of heat dissipating from the top surface to bottom surface of a deck slab. Typically, FRP deck bridges experience higher temperature difference than traditional concrete deck bridges. In this chapter, temperature differences in the field and thermal analysis of beams and FRP plates are presented based on available literatures.

\subsection{Temperature difference and Basic Concepts of Thermal Effect}

Emanuel and Taylor (1985) studied the effects of different span length as a function of thermal stresses in bridges. They concluded that thermal stress was independent of span length for prismatic (constant) sections. Also, they concluded that thermal stresses were not directly dependent on the size of cross section, but may be indirectly dependent on the cross section. However, thermal stresses were dependent on the temperature difference, which in turn was dependent on the cross-sectional properties. They also explained some of the concepts of thermal stresses by dividing non-uniform temperature to three different components such as; uniform, linear and nonlinear component. The uniform component 
(uniform temperature change) produces axial displacement without stress if the movement was unrestrained. Total restraint of axial movements would induce stress without strain, and partial restraint would produce some combination of stress and strain. The gradient temperature change (Figure 2.1) was a curvature-inducing strain which produces vertical deflections without stress if the vertical movement was unrestrained. Total restraint of vertical movement would induce stress without strain, and partial restraint would produce some combination of stress and strain. The nonlinear component was a stress-inducing strain with stresses resulting from continuity of cross section and the assumption that plane sections remain plane. Thermal stresses induced from a nonlinear component were produced by the nonlinear strain component. It was noted that an important factor affecting thermal stresses in a composite section (concrete deck and steel beam) was the difference in coefficient of thermal expansion of the component members (such as the deck and beam) and temperature distribution along the depth of a bridge deck and stiffening beams. Thermal strain induces movement without stress for unstained boundaries, while stress without strain is induced if movements were to be fully restrained. Similarly, a combination of stress and strain was induced under thermal gradients along the depth, if movements were partially restrained. Magnitude of temperature difference on a deck slab is an important factor in thermal analysis. For example, for higher temperature difference along the depth of deck slabs, applied forces or moments due to temperature can be increased. McClure (1984) investigated temperature distribution in a bridge structure and found that there was no significant longitudinal temperature variation. McClure concluded that thermal analysis can be reduced from a three-dimensional problem to a one-dimensional problem comprising of a vertical temperature variation through the section depth of composite bridges. Naruoka (1957) carried 
out thermal tests on the Shigita Bridge in Japan. It was observed that the temperature distribution was almost constant in a steel girder and fairly linear in the concrete deck slab. The maximum temperature difference between top and bottom of a concrete deck slab was around $40{ }^{\circ} \mathrm{F}$ and thermal stresses were found to be comparable to dead load and live load stresses in composite bridges.

Zuk (1965) investigated six simply-supported composite bridges (concrete deck slab supported by steel beams). The temperature difference between top and bottom of concrete deck slab can be as high as $40^{\circ} \mathrm{F}\left(22^{\circ} \mathrm{C}\right)$ during summer seasons and as low as $-10^{\circ} \mathrm{F}$ $\left(-6^{\circ} \mathrm{C}\right)$ in winter season. He also obtained field data on the vertical temperature distribution in a concrete deck-steel stringer bridge over the Hardware River near Charlottesville, North Carolina. The results revealed that the temperature difference of concrete deck slab ranged from $20^{\circ} \mathrm{F}$ to $35^{\circ} \mathrm{F}\left(11^{\circ} \mathrm{C}\right.$ to $\left.19^{\circ} \mathrm{C}\right)$ during the day and $-3^{\circ} \mathrm{F}$ to $-7^{\circ} \mathrm{F}\left(-2^{\circ} \mathrm{C}\right.$ to $\left.-4^{\circ} \mathrm{C}\right)$ during the night. Emanuel (1978) used a finite element model to predict the vertical temperature distribution in concrete deck bridges from a computerized reduction of 20 years of weather data recorded by National Weather Service at a station in Columbia, Missouri. It showed that the maximum temperature difference between top and bottom of concrete deck slab occurs at approximately 2.00 p.m. in July which was about $39^{\circ} \mathrm{F}\left(22^{\circ} \mathrm{C}\right)$ while the minimum temperature difference occurred at 4.00 a.m. which was about $-3^{\circ} \mathrm{F}\left(-2^{\circ} \mathrm{C}\right)$. Kennedy and Soliman (1987) proposed a realistic and simple vertical temperature distribution through the depth of a concrete deck slab and steel beams as shown in Figure 2.1. Steel beams had a very small temperature variation through the depth, which can be considered as a constant. Based on field data in Middle Atlantic States and Southern Ontario, the maximum temperature differentials (positive gradient) occurred when the concrete deck 
slab was exposed to the Sun's radiation during summer or winter seasons. The minimum temperature difference (negative gradient) occurred when the concrete deck slab was suddenly drenched with cold rain or snow. They also recommended that the maximum and minimum temperature differences in summer season were about $40^{\circ} \mathrm{F}$ and $-7.5^{\circ} \mathrm{F}$, respectively and about $20^{\circ} \mathrm{F}$ and $-7.5^{\circ} \mathrm{F}$ in winter season. It was noted the positive temperature difference represented higher temperature on top surface than bottom surface while negative temperature difference represented lower temperature on top surface than bottom surface. The temperature distribution from Kennedy and Soliman (1987) appeared to be the most realistic and simple to accept. This was confirmed by field test measurements. Furthermore, the calculation of thermal stresses based on a linear-uniform variation became much simpler for a bridge structure.
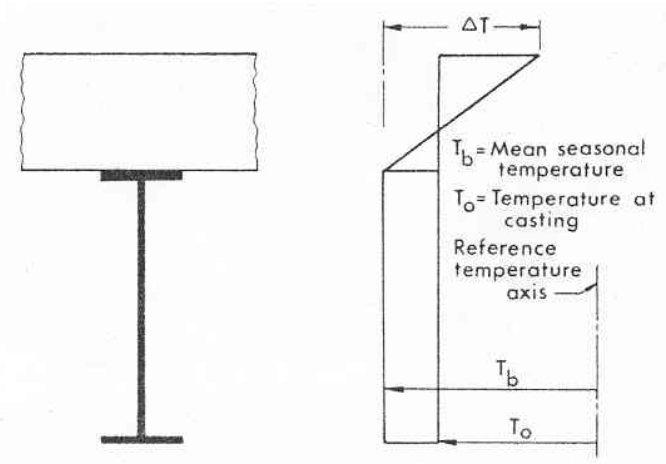

Figure 2.1: Linear-Uniform Vertical Temperature Distribution; $\Delta T=$ Temperature Differential (John B. Kennedy, 1987).

Hussein, Fazio, and Ha (1992) studied the effects of bonding stiffness in sandwich panels subjected to temperature changes. Sandwich panels made of thin skins and a lightweight core, which have different coefficient of thermal expansion. Sandwich panels are considered as a three-layer sandwich (top skin, core skin, and bottom skin). The temperature 
change in a sandwich panel was divided into uniform temperature change and gradient temperature change, as shown in Figure 2.2. Airy's stress function was used to solve for solutions. Numerical results were compared to experimental values from a sandwich panel made of an aluminum skin and a wood core. Experimental results are in good agreement with theory. It was found that thermal stresses are a function of material properties of sandwich skin and core, and also the rigidity between skin and core. A sandwich panel with a flexible core may not produce significant thermal stresses. If the core had some rigidity then temperature change will induce thermal stresses. Also difference in coefficient of thermal expansion (CTE) of skin and core play an important role in thermal stresses.

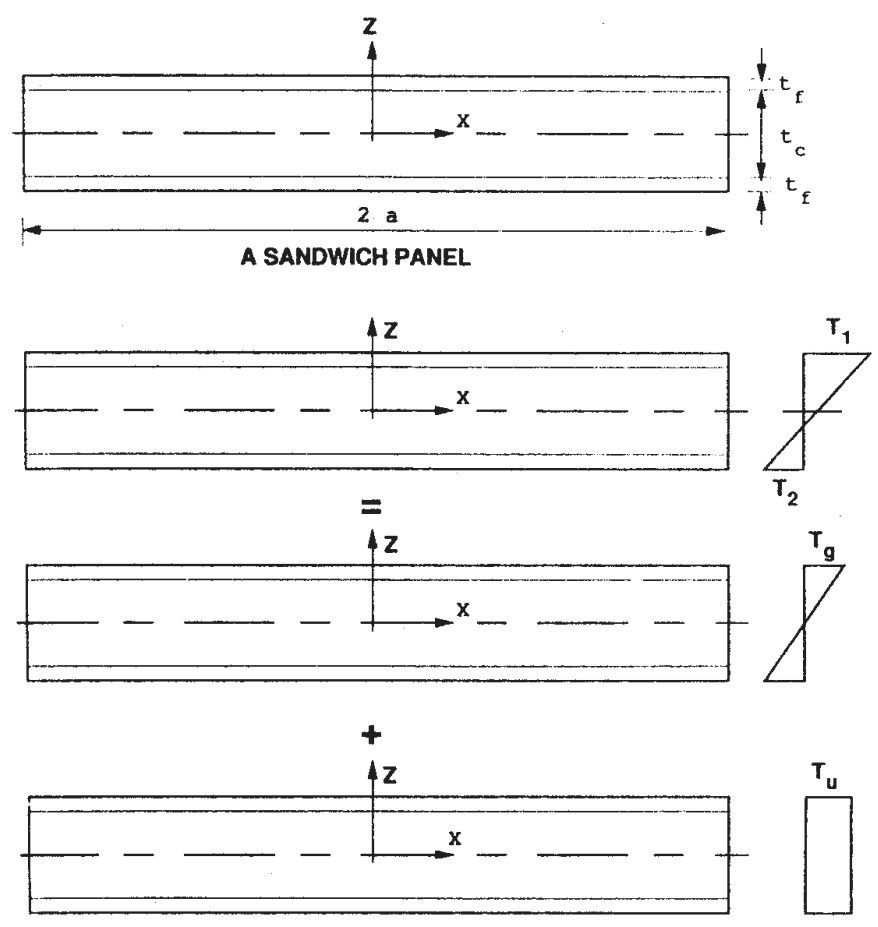

Figure 2.2: Sandwich Panel Subjected to Thermal Gradient (R. Hussein, 1992).

It can be concluded that the maximum and minimum of temperature differences on concrete deck slab are $40^{\circ} \mathrm{F}$ and $-7.5^{\circ} \mathrm{F}$ (Note : Positive temperature difference $=$ top temperature higher than bottom temperature, Negative temperature difference $=$ top 
temperature lower than bottom temperature). The Federal Highway Administration recommended the designer to consider a temperature difference that can be as high as $100{ }^{\circ} \mathrm{F}$ in fiber reinforced polymer (FRP) deck slabs.

Dutta, Kwon and Lopez-Anido (2003) evaluated the fatigue performance of FRP bridge decks under high and low temperatures. FRP bridge decks was subjected to four million simulated wheel load cycles at low temperature, $-30^{\circ} \mathrm{C}\left(-22^{\circ} \mathrm{F}\right)$, and another four million cycles at high temperature, $50^{\circ} \mathrm{C}\left(122^{\circ} \mathrm{F}\right)$. It was concluded that progressive degradation in stiffness with load cycling was observed under two extreme temperatures, $-30^{\circ} \mathrm{C}\left(-22^{\circ} \mathrm{F}\right)$ and $50^{\circ} \mathrm{C}\left(122^{\circ} \mathrm{F}\right)$ and the stiffness of FRP bridge decks under simulated wheel loads was more susceptible to two extreme temperature changes than to ten million cumulative load cycles.

Dutta (2004) performed outdoor tests with Sun exposure on FRP bridge decks to monitor temperature rise and fall of FRP bridge decks on both top and bottom surfaces during the summer months of New Hampshire. It was concluded that the temperature on top and bottom surfaces can be as high as $150^{\circ} \mathrm{F}$ and $77^{\circ} \mathrm{F}$, respectively which resulted in the temperature difference of $73^{\circ} \mathrm{F}$.

\subsection{Thermal Analysis of Composite Beams and Plates}

Timoshenko and Krieger (1959) studied thermal stress in isotropic plates with clamped edges. The variation of temperature was assumed to be linear along the thickness and did not vary in planes parallel to surfaces of plate. Bending, due to temperature difference, did not produce any stress if the edges were free. The maximum thermal stress was found for the case that the middle plane of the plate was free to expand, but edges of the 
plate were clamped so that they cannot rotate. The maximum thermal stress was equal to the formula $\frac{\alpha t E}{2(1-v)}$. Stress was proportional to coefficient of thermal expansion $(\alpha)$, to temperature difference $(t)$ between top and bottom surface, and to modulus of elasticity $(E)$. Since the temperature difference increases in proportion to the thickness of plate, it can be concluded that greater thermal stresses were to be expected in thick plates than in thin plates. Also, if temperature of the upper surface of a plate was higher than that of bottom surface, the plates bended convexly upward.

Wu and Tauchert (1980) analyzed deformations and stress resultants for symmetric orthotropic laminates subjected to a temperature variation, which varies along the thickness but not in horizontal plan of the laminates. The Levy method and the Classical Plate theory were used in their analysis. Two cases of boundary conditions were analyzed, such as four simply supported edges, and two parallel edges being simply supported while the other two were clamped. The following are the governing equations for symmetric laminates in this analysis (Stavsky, 1963)

$$
\begin{gathered}
A_{11} u_{, x x}+A_{66} u_{, y y}+\left(A_{12}+A_{66}\right) v_{, x y}-N_{x, x}^{T}=0 \\
\left(A_{12}+A_{66}\right) u_{, x y}+A_{66} v_{, x x}+A_{22} v_{, y y}-N_{y, y}^{T}=0 \\
D_{11} w_{, x x x x}+2\left(D_{12}+2 D_{66}\right) w_{, x x y y}+D_{22} w_{, y y y y}+M_{x, x x}^{T}+M_{y, y y}^{T}=q
\end{gathered}
$$

As a consequence of the assumed symmetry in boundaries, the governing equations of vertical deformation $(w)$ and in-plane deformations ( $u$ and $v$ ) are assumed to be independently. Generally, force and moment resultants in laminates can be written as 
$\left\{\frac{N}{M}\right\}=\left[\frac{A \mid B}{B \mid D}\right]\left\{\frac{\varepsilon^{0}}{k}\right\}-\left\{\frac{N^{T}}{M^{T}}\right\}$, where $[A],[B]$ and $[D]$ were extensional, coupling and bending stiffness coefficients, respectively. $\left\{N^{T}\right\}$ and $\left\{M^{T}\right\}$ were thermal forces and moments, respectively. Since laminates in this case study were symmetric, the coupling stiffness coefficient, $[B]$, becomes zero. Therefore, force and moment resultants for symmetric laminates can be reduced as $\{N\}=[A]\left\{\varepsilon^{0}\right\}-\left\{N^{T}\right\}$ and $\{M\}=[D]\{k\}-\left\{M^{T}\right\}$.

The thermal forces, thermal moments, transverse load, and deflection were expressed in the form of the Fourier Series. Deformations $(u, v$ and $w)$ were also expanded in the Fourier Series, which satisfy boundary conditions and governing equations. An illustrative example of unidirectionally reinforced polymer composite plates subjected to a linear temperature difference was computed. The results from this example were compared to the results obtained from finite-element and the Rayleigh-Ritz techniques wherein the agreement was very satisfactory. $\mathrm{Wu}$ and Tauchert (1980) also analyzed the deformations and stress resultants for antisymmetric cross-ply and angle-ply orthotropic laminates. In the case of antisymmetric laminates, the coupling coefficient, $[B]$, was not zero. The analysis was the same as symmetric laminates but the coupling coefficient, $[B]$, was included in governing equations, thermal forces, and thermal moments make the problem more complicated than symmetric laminates cases. The following are governing equations for antisymmetric laminates;

$$
\begin{gathered}
A_{11} u_{, x x}+2 A_{16} u_{, x y}+A_{66} u_{, y y}+A_{16} v_{, x x}+\left(A_{12}+A_{66}\right) v_{, x y}+A_{26} v_{, y y}-B_{11} w_{, x x x}-3 B_{16} w_{, x x y} \\
-\left(B_{12}+2 B_{26}\right) w_{, x y y}-B_{26} w_{, y y y}-N_{x, x}^{T}-N_{x y, y}^{T}=0 \\
A_{16} u_{, x x}+\left(A_{12}+A_{66}\right) u_{, x y}+A_{26} u_{, y y}+A_{66} v_{, x x}+2 A_{26} v_{, x y}+A_{22} v_{, y y}-B_{16} w_{, x x x}-\left(B_{12}+2 B_{26}\right) w_{, x x y} \\
-3 B_{26} w_{, x y y}-B_{22} w_{, y y y}-N_{y, y}^{T}-N_{x y, x}^{T}=0
\end{gathered}
$$




$$
\begin{aligned}
& D_{11} w_{, x x x x}+4 D_{16} w_{, x x x y}+2\left(D_{12}+2 D_{26}\right) w_{, x x y y}+4 D_{26} w_{, x y y y}+D_{22} w_{, y y y y}-B_{11} u_{, x x x}-3 B_{16} u_{, x x y}-\left(B_{12}+2 B_{66}\right) u_{, x y y} \\
& -B_{26} u_{, y y y}-B_{16} v_{, x x x}-\left(B_{12}+2 B_{66}\right) v_{, x x y}-3 B_{26} v_{, x y y}-B_{22} v_{y y y}+M_{x, x x}^{T}+2 M_{x y, x y}^{T}+M_{y, y y}^{T}=q
\end{aligned}
$$

Thermal forces and moments can be expressed as $\left\{\frac{N}{M}\right\}=\left[\frac{A \mid B}{B \mid D}\right]\left\{\frac{\varepsilon^{0}}{k}\right\}-\left\{\frac{N^{T}}{M^{T}}\right\}$. It was found that the coupling stiffness coefficients, $[B]$, have a significant effect upon the thermal deformations of the two-ply laminate. The coupling is relatively unimportant for plates having a large number of plies ( $\mathrm{N} \geq 8$ layers).

Classical (Kirchhoff) lamination theory (CLT) has been used for a number of years and was still valid for thin plates. Mindlin (1951) proposed a first-order shear-deformation theory that includes the effects of transverse shear deformation but required the use of shear correction factors. Shear deformation assumes a greater significance for fiber-reinforced laminates, as compared to homogenous plates, due to a large ratio of longitudinal elastic modulus to the transverse shear modulus. In order to eliminate the use of shear correction factors, Jonnalagadda (1993) proposed higher order of displacement functions to cubic functions called the Cubic Theory. The plate theory can simply be developed by assuming displacement functions correctly. If displacement functions were assumed differently then the innovative plate theories can be used. The following were six different displacement functions which lead to six different plate theories.

$$
\begin{aligned}
& u(x, y, z)=u^{o}(x, y)+z \psi_{x}(x, y)+C_{1} z^{2} \xi_{x}(x, y)+C_{2} z^{3} \phi_{x}(x, y) \\
& v(x, y, z)=v^{o}(x, y)+z \psi_{y}(x, y)+C_{3} z^{2} \xi_{y}(x, y)+C_{4} z^{3} \phi_{y}(x, y)
\end{aligned}
$$




$$
w(x, y, z)=w^{o}(x, y)+C_{5} z \psi_{z}(x, y)+C_{6} z^{2} \xi_{z}(x, y)+C_{7} z^{3} \phi_{z}(x, y)
$$

Cubic Plate Theory : No constants was equal to 0

Quadratic Plate Theory : $\mathrm{C}_{7}=0$, the remaining constants $=1$

Linear Plate Theory : $\mathrm{C}_{6}=\mathrm{C}_{7}=0$, the remaining constants $=1$

Reddy Plate Theory : $\mathrm{C}_{5}=\mathrm{C}_{6}=\mathrm{C}_{7}=0$, the remaining constants $=1$

Chang Plate Theory: $\mathrm{C}_{1}=\mathrm{C}_{3}=\mathrm{C}_{5}=\mathrm{C}_{7}=0$

Mindlin-Reissner Plate Theory : All constants were equal to 0

According to the displacement functions above, Jonnalagadda (1993) used the cubic displacement function (Cubic theory) to study the effect of the inclusion of "thickening" or the transverse normal strain on the thermal deflection of plates and compared the results to the Kirchoff (Classical Plate Theory), Reddy and Chang theories. The principle of virtual displacement as shown below was used to obtain equilibrium equations for plate.

$$
\int_{-h / 2}^{h / 2} \int_{A}\left(\sigma_{x} \delta \varepsilon_{x}+\sigma_{y} \delta \varepsilon_{y}+\sigma_{z} \delta \varepsilon_{z}+\sigma_{x y} \delta \gamma_{x y}+\sigma_{y z} \delta \gamma_{y z}+\sigma_{x z} \delta \gamma_{x z}\right) d A d z=0
$$

It was noted that different displacement functions resulted in different theories (for example, the Plate Theory, Quadratic Plate Theory, Linear Plate Theory, Reddy Plate Theory, Chang Plate Theory, and Mindlin-Reissner Plate Theory). After the relations of force/moment resultants and stress and the relations of strain and displacement were established, stress and strain in principle of virtual displacement were substituted by these relations and integrated by parts. For the Cubic Theory, eight equations of equilibrium were obtained after integrating by parts. The displacement function can be solved by satisfying the equations of equilibrium and boundary conditions. The forces, stresses, and strains of a plate can be calculated based on displacement functions, which were obtained after satisfying 
equations of equilibrium and boundary conditions. Jonnalagadda (1993) obtained numerical results (for the Cubic Theory) for center deflection of a symmetric eight-layer graphite/epoxy square laminate plate subjected to a linear temperature along the depth and compared with various theories based on different displacement functions. It was concluded that Reddy's theory neglected the transverse normal strain effects, and Chang's theory was only accurate when the composite plate was subjected to an antisymmetric thermal load. It was shown in Figure 2.3 that a quadratic deflection variation in the thickness direction yielded results equal to those obtained using a cubic variation when the in-plane displacements were assumed to vary cubically with the thickness coordinate in both formulations. It was recommended that FRP composite plates subjected to a through-thickness temperature field of order higher than linear may require the use of a cubic function through-thickness displacement representation.

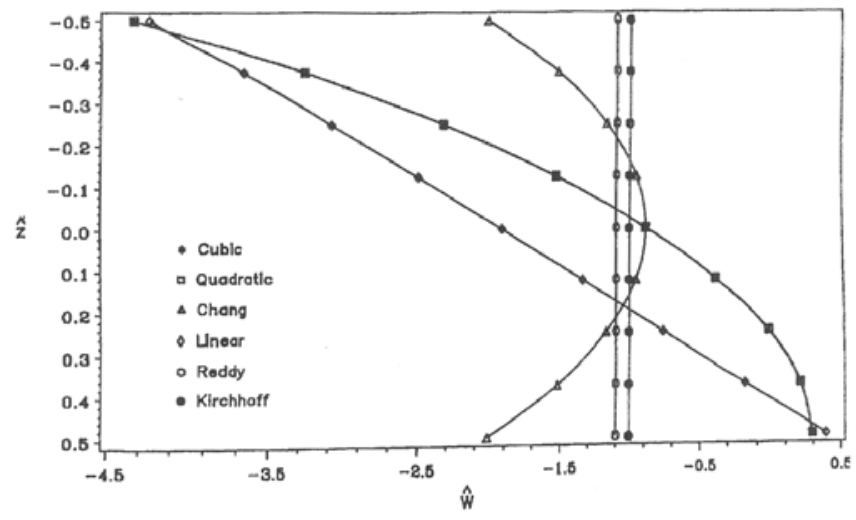

Figure 2.3: Depth-Deflection Relationships for a Thick Plate $(\mathrm{a} / \mathrm{h}=4)$ for Various Theories. 


\section{References}

- Dutta, Piyush K., Kwon, Soon-Chul and Lopez-Anido, Roberto (2003), "Fatigue Performance Evaluation of FRP Composite Bridge Deck Prototypes under High and Low Temperatures", Transportation Research Board, $82^{\text {nd }}$ Annual Meeting, Washington, D.C.

- Emanuel, Jack H. and Taylor, Charles M. (1985), "Length-Thermal Stress Relations for Composite Bridges", Journal of Structural Engineering, Vol. 111, No. 4, April, 1985.

- Emanuel, Jack H. and Hulsey, J.L. (1978), “Temperature Distributions in Composite Bridges”, Journal of the Structural Division, ASCE. 104(1), 65-78.

- Hussein, R., Fazio, P. and Ha, K. (1992), " Effects of Bonding Stiffness on Thermal Stresses in Sandwich Panels.", Journal of Aerospace Engineering, Vol. 5, No. 4, October 1992.

- Jonnalagadda, Krishna D., Tauchert, Theodore R., and Blandford, George E. , "HighOrder Thermalelastic Composite Plate Theories : An Analytic Comparison", J. Thermal Stresses, Vol 16, P265-284, 1993.

- Kennedy, John B. and Soliman, Mohamed H. (1987), "Temperature Distribution in Composite Bridges”, Journal of Structural Engineering, Vol. 113 No. 3, March, 1987.

- McClure, R.M., West, H. H. and Hoffman, P.C. (1984), "Observations from Tests on a Segmental Bridge." $2^{\text {nd }}$ Bridge Engineering Conference, Transportion Research Record, 950. 2, National Research Council, Minneapolis, Minn.

- Mindlin, R.D., "Influence of Rotary and Shear on Flexural Motions of Isotropic, Plates", ASME J. Appl. Mech., vol.18, pp 31-39, 1951.

- Naruoka, M. H. and Yamaguti, T. (1957). "The Measurement of the Temperature of the Interior of the Reinforce Concrete Slab of the Shigita Bridge and Presumption of Thermal Stress." Proceedings. Symposium on the Stress Measurements for Bridge and Structure, Japanese Society for Promotion of Science, Tokyo, Japan, 109-115.

- Stavsky, Y., “Thermoelasticity of Heterogeneous Aeolotropic Plates.”, J. Eng. Mech. Div., Proc. ASCE, vol. 89, pp. 89-109, 1963.

- Timoshenko, Stephen P. and Woinowsky-Krieger, S. (1959), Theory of Plates and Shells., Edition \#2, McGrawHill, 1959.

- Vinson, Jack R. (1999), “ Behavior of Sanwich Structures.” Publisher : CRC Press, March, 1999. 
- Wu, C. H. and Tauchert, T. R. , "Thermoelastic Analysis of Laminated Plates. 1: Symmetric Specially Orthotropic Lamenates,”, J. Thermal Stresses, Vol. 3, P247-259, 1980.

- Wu, C. H. and Tauchert, T. R., "Thermoelastic Analysis of Laminated Plates. 2: Antisymmetric Cross-Ply and Angle-Ply Laminates", J.Thermal Stresses, Vol. 3, P365$378,1980$.

- Zuk, W. (1965), "Simplified Design Check of Thermal Stresses in Composite Highway Bridges." Highway Research Record. 103. 


\section{Chapter 3}

\section{Coefficient of Thermal Expansion (CTE) Measurements in Laboratory}

\subsection{Introduction}

The coefficient of thermal expansion (CTE) is a basic physical property which can be an important factor to design a structure under thermal fluctuations. The coefficients of thermal expansion (CTE) were defined as the strain increment per degree temperature variation in the material. The higher CTE implies a larger expansion or contraction. In Appendix $G$, the first term approximation for rectangular plates was derived. The required elastic properties in the analysis were $\mathrm{E}_{1}, \mathrm{E}_{2}, \mathrm{G}_{12}, v_{12}, v_{21}, \alpha_{1}$ and $\alpha_{2}$. The definitions of each notation can be found in Appendix G. All elastic properties except CTE (i.e. $\alpha_{1}$ and $\alpha_{2}$ ) of both 4 inch and 8 inch deep fiber reinforced polymer (FRP) decks (see Figure 3.1(a) and 3.2(a) for cross section) can be found in the reports written by Punyamurthula (2004) and Howard (2002), respectively. Therefore, the CTE $\left(\alpha_{1}\right.$ and $\left.\alpha_{2}\right)$ of both FRP decks were determined in this chapter experimentally.

\subsection{Objective}

The objective of this chapter is to measure the CTE of two types of FRP decks (4 inches and 8 inches in depth ).

\subsection{Test Specimens}

The 4 inch and 8 inch FRP deck specimens were shown in Figure 3.1(a) and 3.2(a), respectively. The specimens were manufactured by Bedford Reinforced Plastic Inc.. The size 
of test specimens were divided into two categories such as component and coupon levels which were described in section 3.3.1 and 3.3.2.

\subsubsection{Component Level Specimens}

Specimen \#1 : A module of 4 in. FRP deck with 29 inches in length (i.e. Dimension of 29 in. $x 29$ in. $x$ 4in. depth, See Figures 3.1(a) and (b))

Specimen \#2 : A module of 8 in. FRP deck with 24 inches in length (i.e. Dimension of 24 in. $x 24$ in. $x 8$ in. depth, See Figures 3.2 (a) and (b))

Specimen \#3 : Four modules of 4 in. FRP deck (Dimension of $6.83 \mathrm{ft} . \mathrm{x} 3 \mathrm{ft} . \mathrm{x} 4 \mathrm{in}$. depth, See Figures 3.3 (a) and (b))

Specimen \#4 : Three modules of 8 in. FRP deck (Dimension of $4.5 \mathrm{ft} . \times 3 \mathrm{ft} . \mathrm{x} 8$ in. depth, See Figures 3.4 (a) and (b))

Specimen \#5 : A module of 4 in. FRP deck with 1 inches in length (i.e. Dimension of 1 in. $x 29$ in. $x 4$ in. depth, See Figure 3.5)

Specimen \#6 : A module of 8 in. FRP deck with 1 inches in length (i.e. Dimension of 1 in. $x 24$ in. $x 8$ in. depth, See Figure 3.6) 


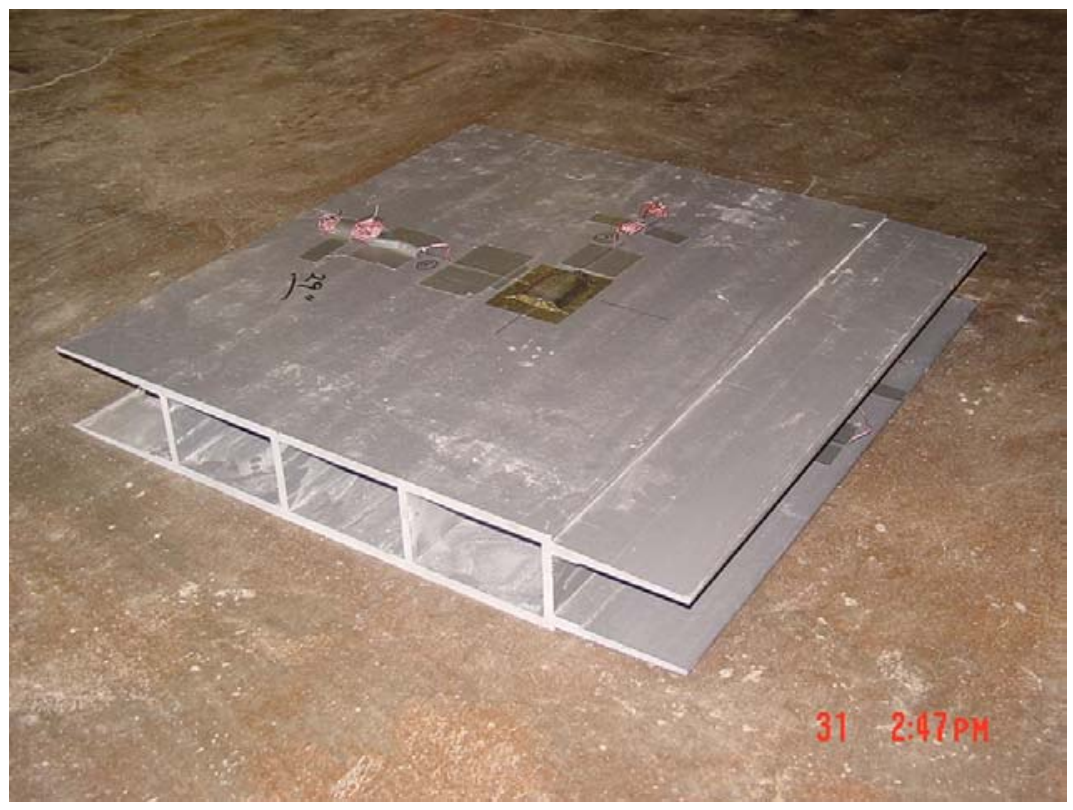

Figure 3.1(a): Specimen \#1 ( A Module of 4 in. FRP Deck with 29 inches in Length).

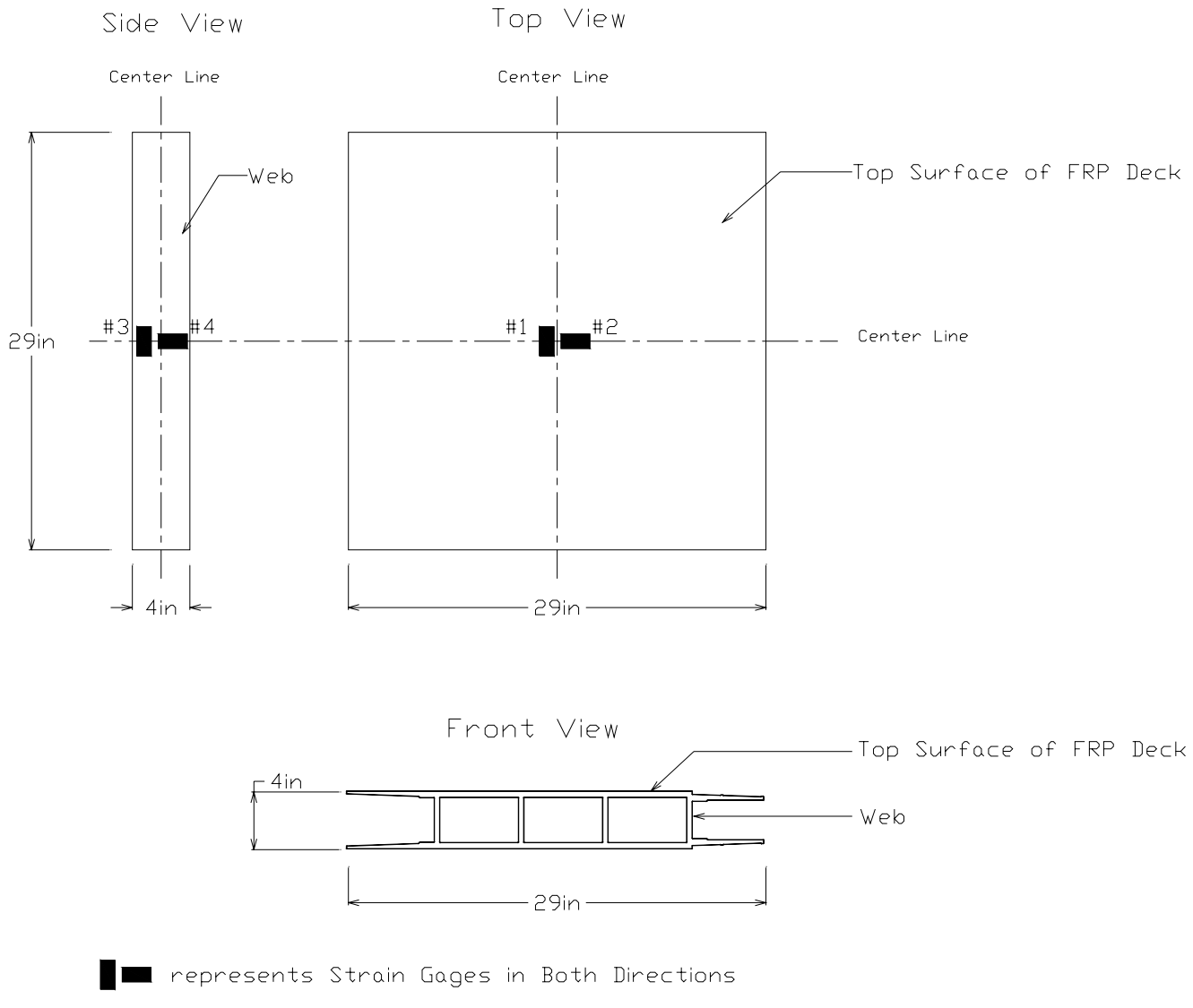

Figure 3.1(b): Specimen \#1 : Locations and Number of Strain Gages. 


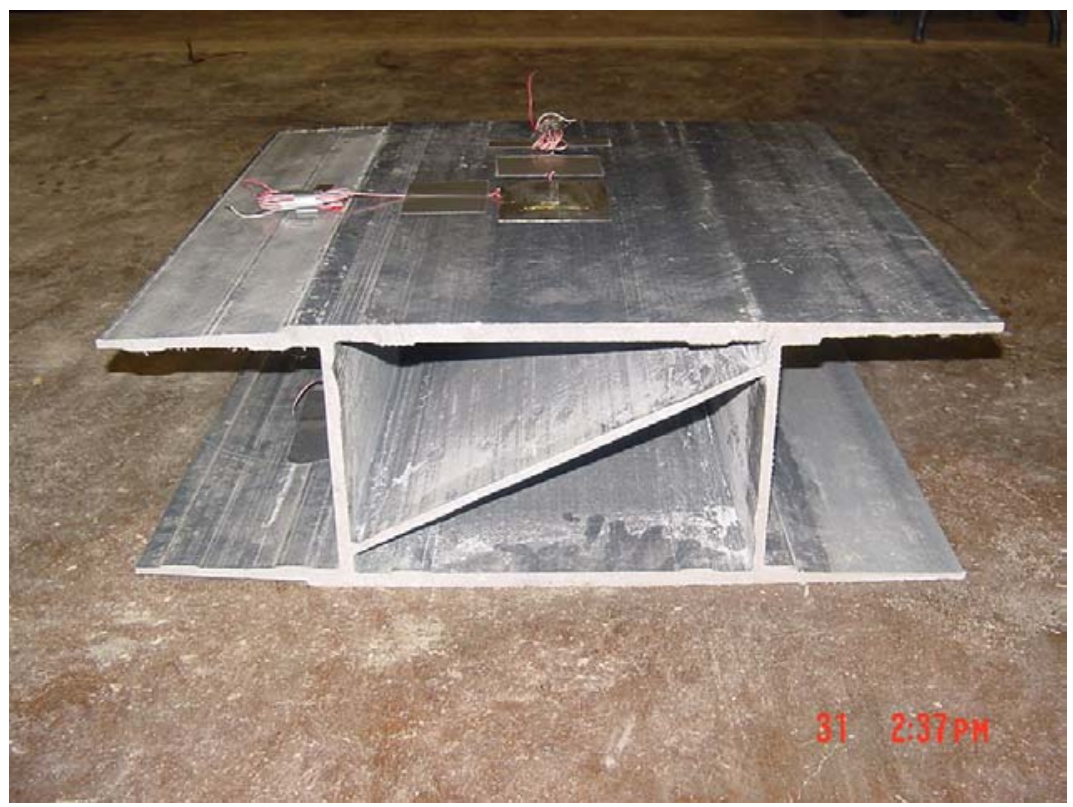

Figure 3.2(a): Specimen \#2 (A Module of 8 in. FRP Deck with 24 inches in Length).

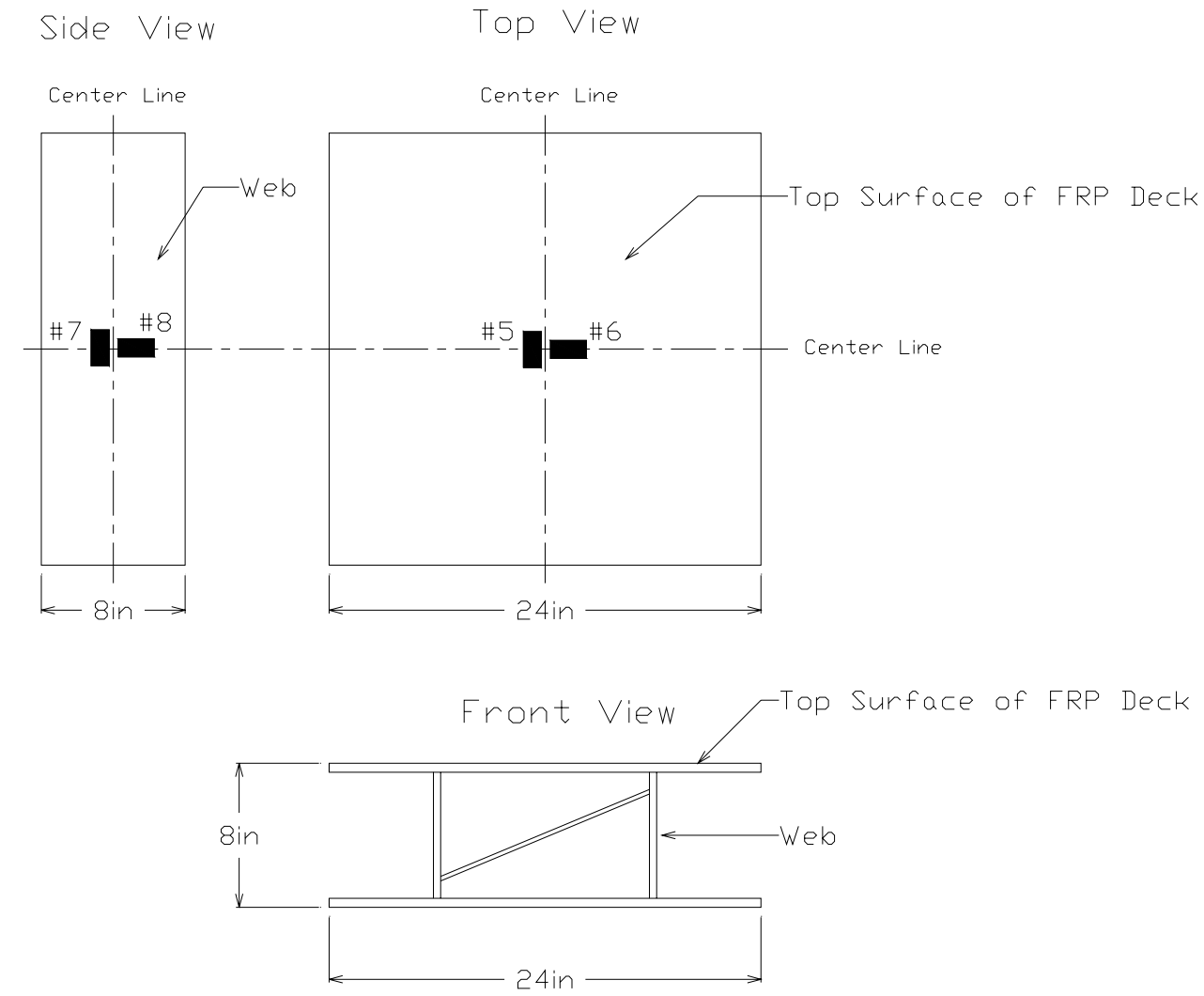

$\mathbf{m}$

Figure 3.2(b): Specimen \#2: Locations and Number of Strain Gages. 


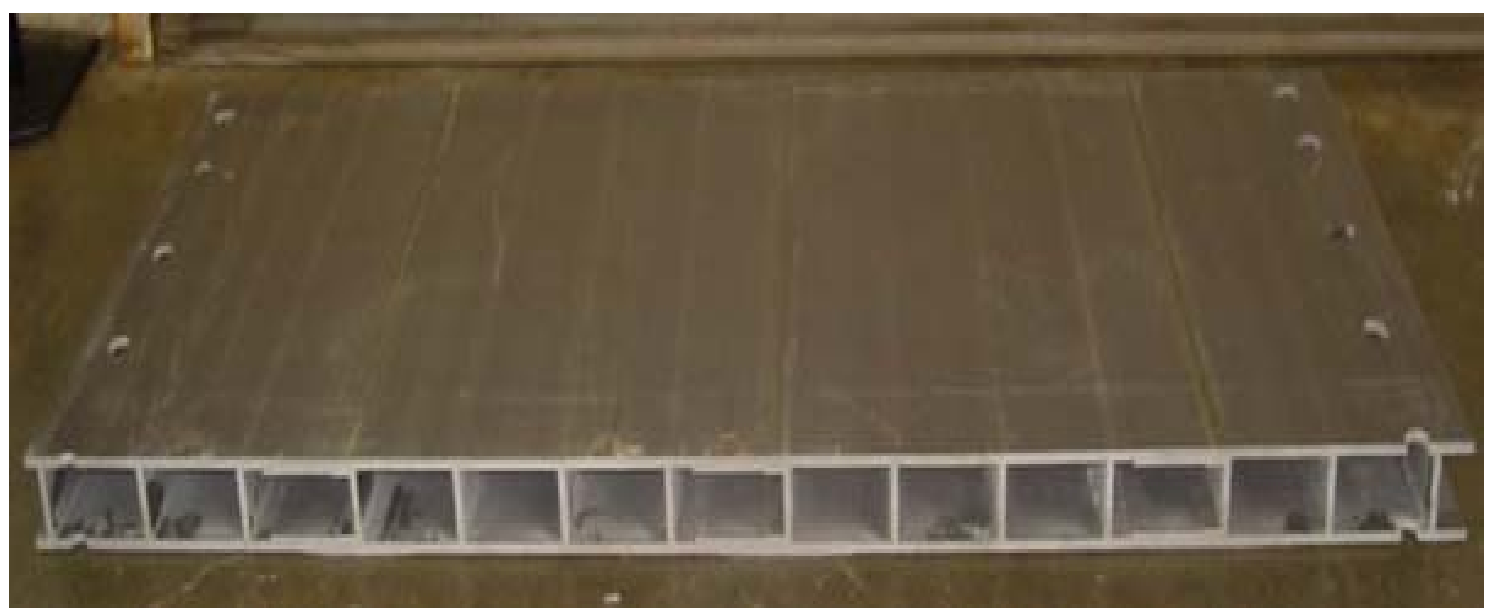

Figure 3.3(a): Specimen \#3 (Four Modules of 4 in. FRP Deck with $3 \mathrm{ft}$. in Length).

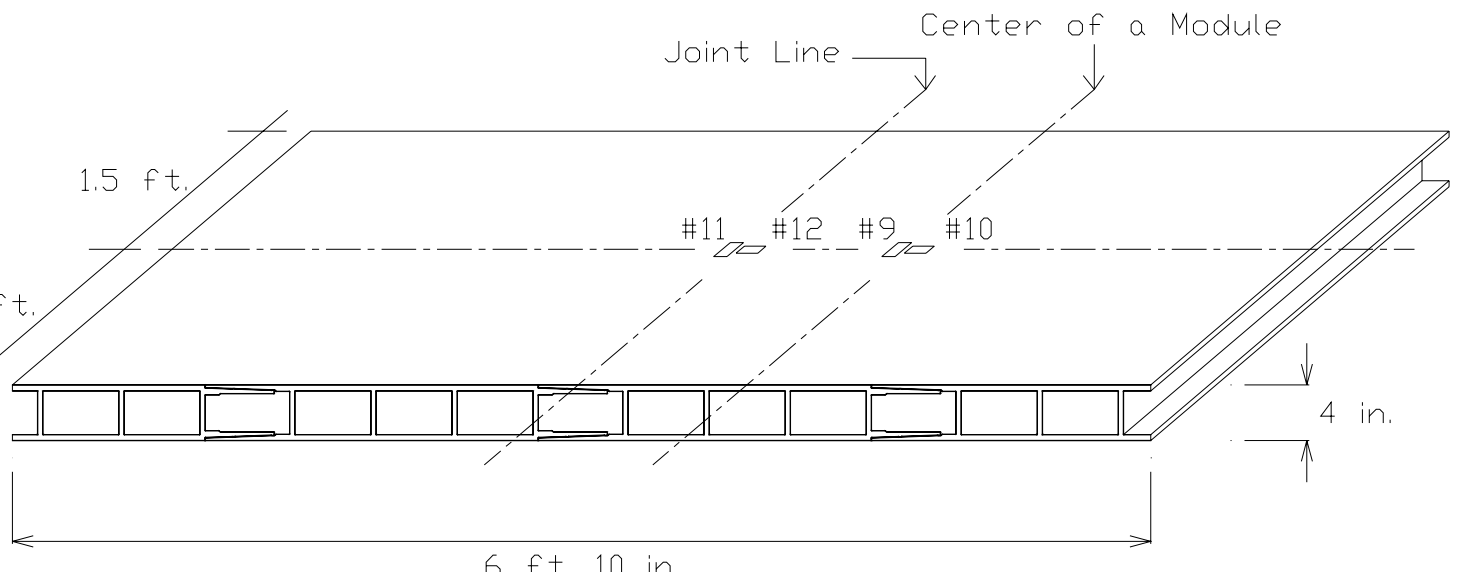

Figure 3.3(b): Specimen \#3: Locations and Number of Strain Gages. 


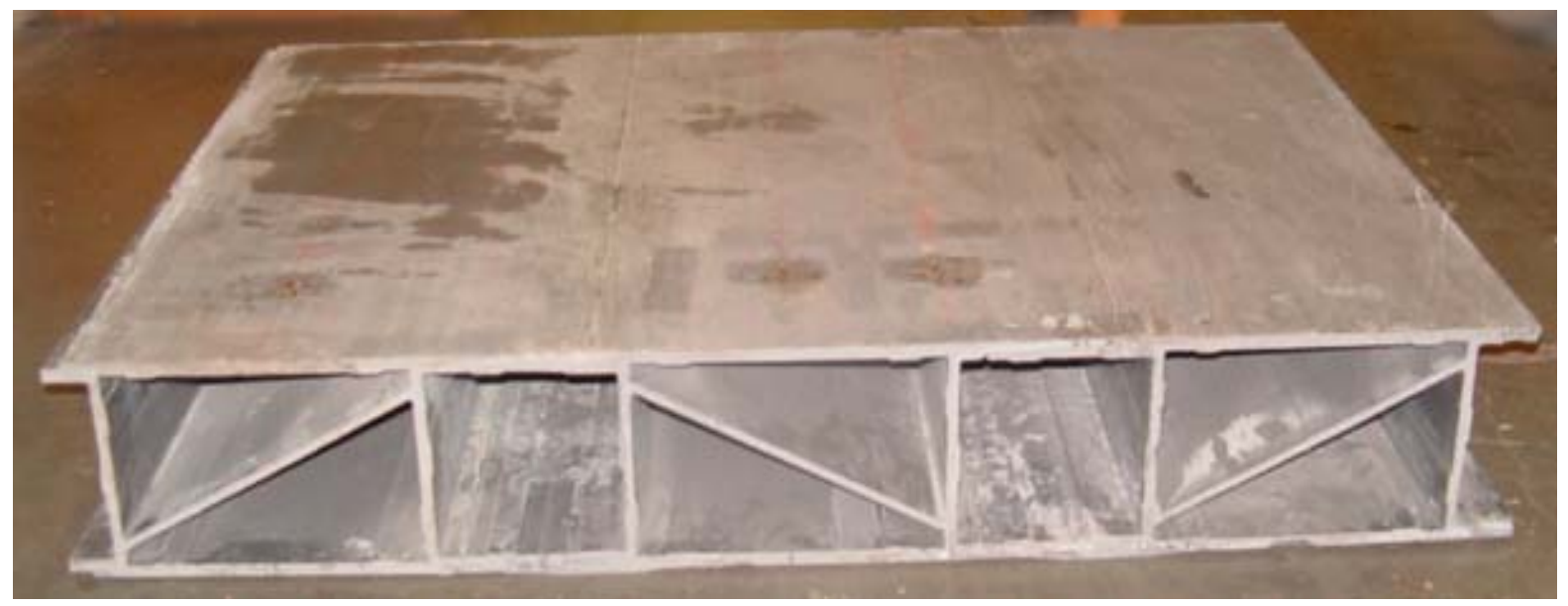

Figure 3.4(a): Specimen \# 4 (Three Modules of 8 in. FRP Deck with $3 \mathrm{ft}$. in Length).

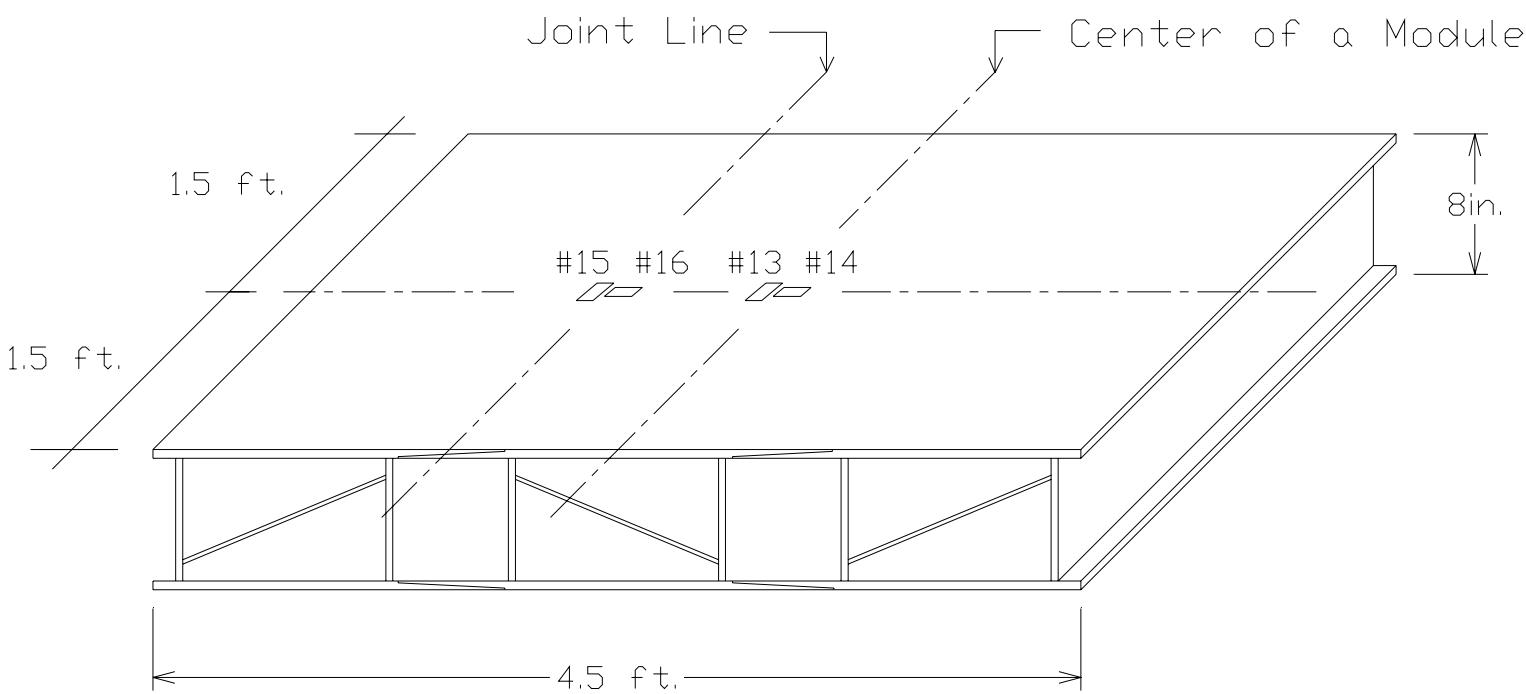

Figure 3.4(b): Specimen \#4: Location and Number of Strain Gages. 


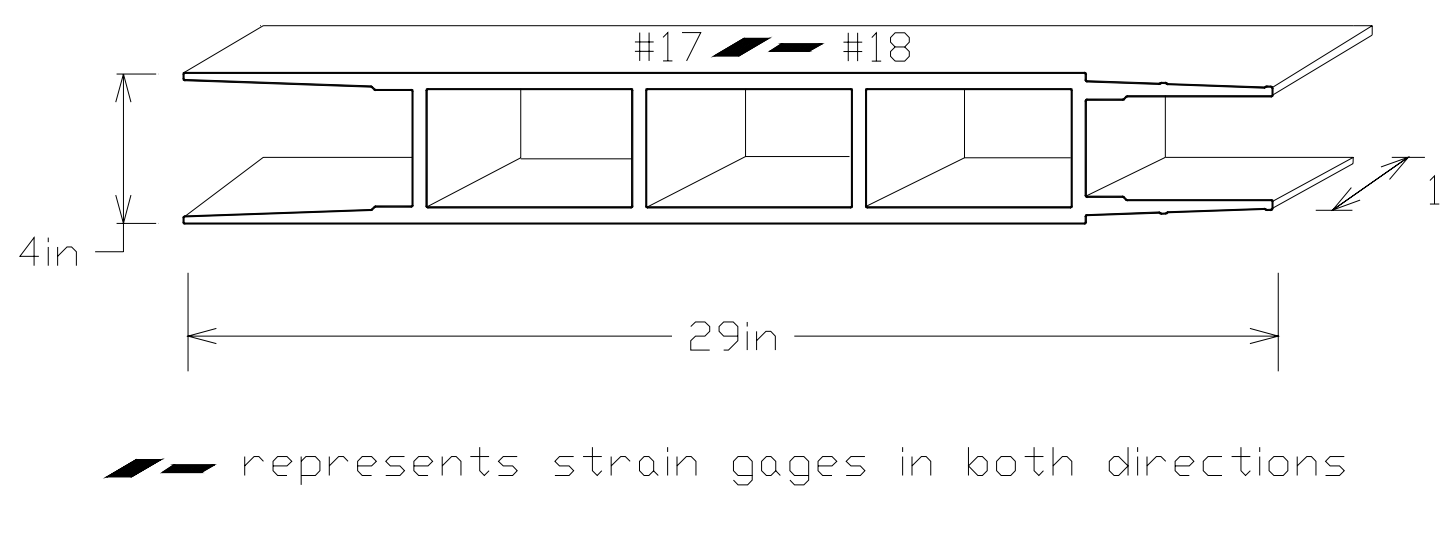

Figure 3.5: Specimen \# 5: Locations and Number of Strain Gages.

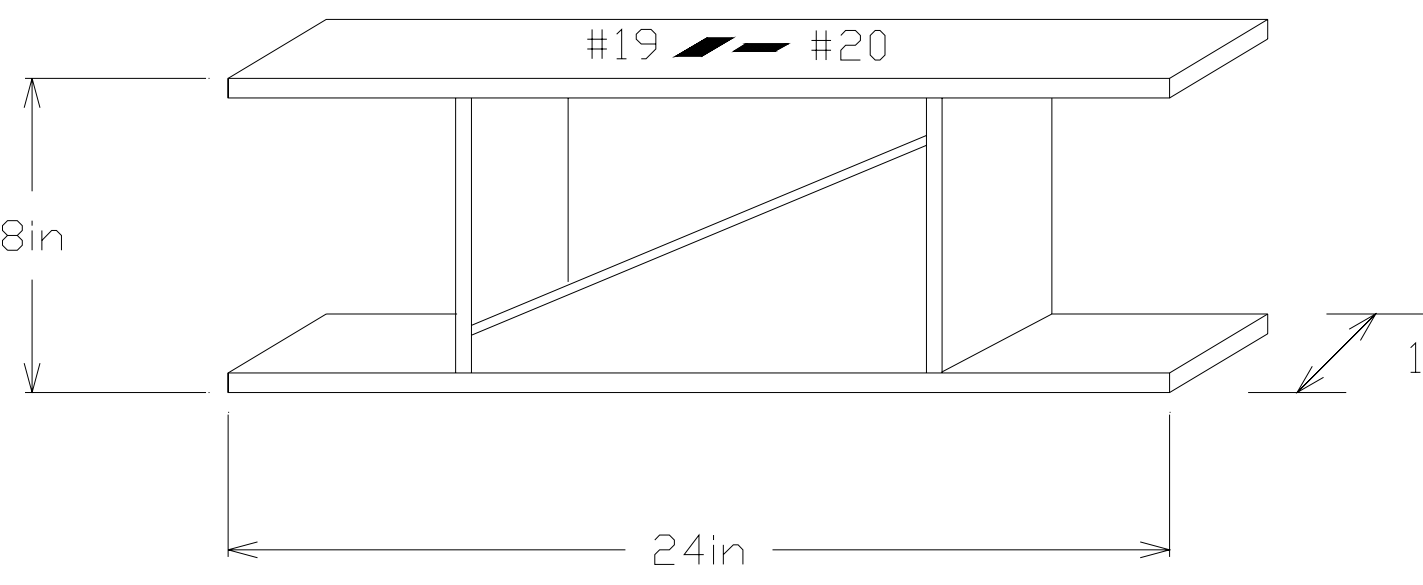

Figure 3.6: Specimen \# 6: Locations and Number of Strain Gages.

\subsubsection{Coupon Level Specimens (Dimension of 1 in. $x 12$ in.)}

Four coupon level specimens were cut from top surface of 4 inch and 8 inch FRP deck in both strong and weak directions of the FRP deck. Strong direction of the FRP deck is the cell direction while the weak direction is perpendicular to the strong direction. Dimension of a coupon level specimen was 1 inch $\times 12$ inch. Strain gages were attached to the coupon specimens at the center in both direction (Strong and Weak Directions) as shown in Figures 
4.7 and 4.8. The following were four coupon specimens for both the 4 inch and 8 inch FRP deck :

Specimens \#7 and \#8: Cut in Strong and Weak directions of 4 in. FRP deck, respectively, as shown in Figure 3.7.

Specimens \#9 and \#10 : Cut in Strong and Weak directions of 8 in. FRP deck, respectively, as shown in Figure 3.8.
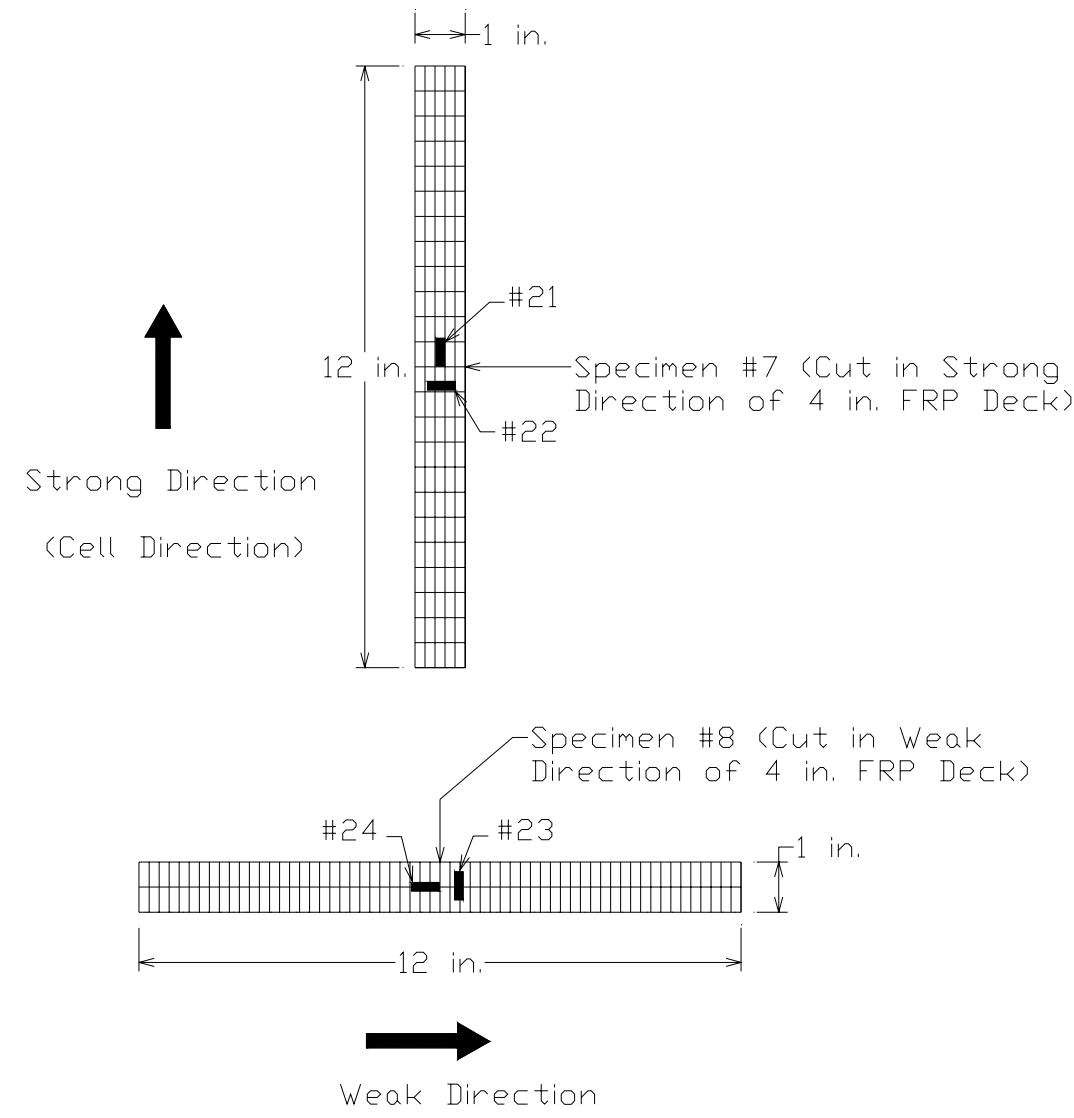

$\underline{1}$

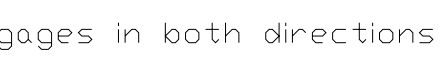

Figure 3.7: Specimens \#7 and \#8 : Locations and Number of Strain Gages. 


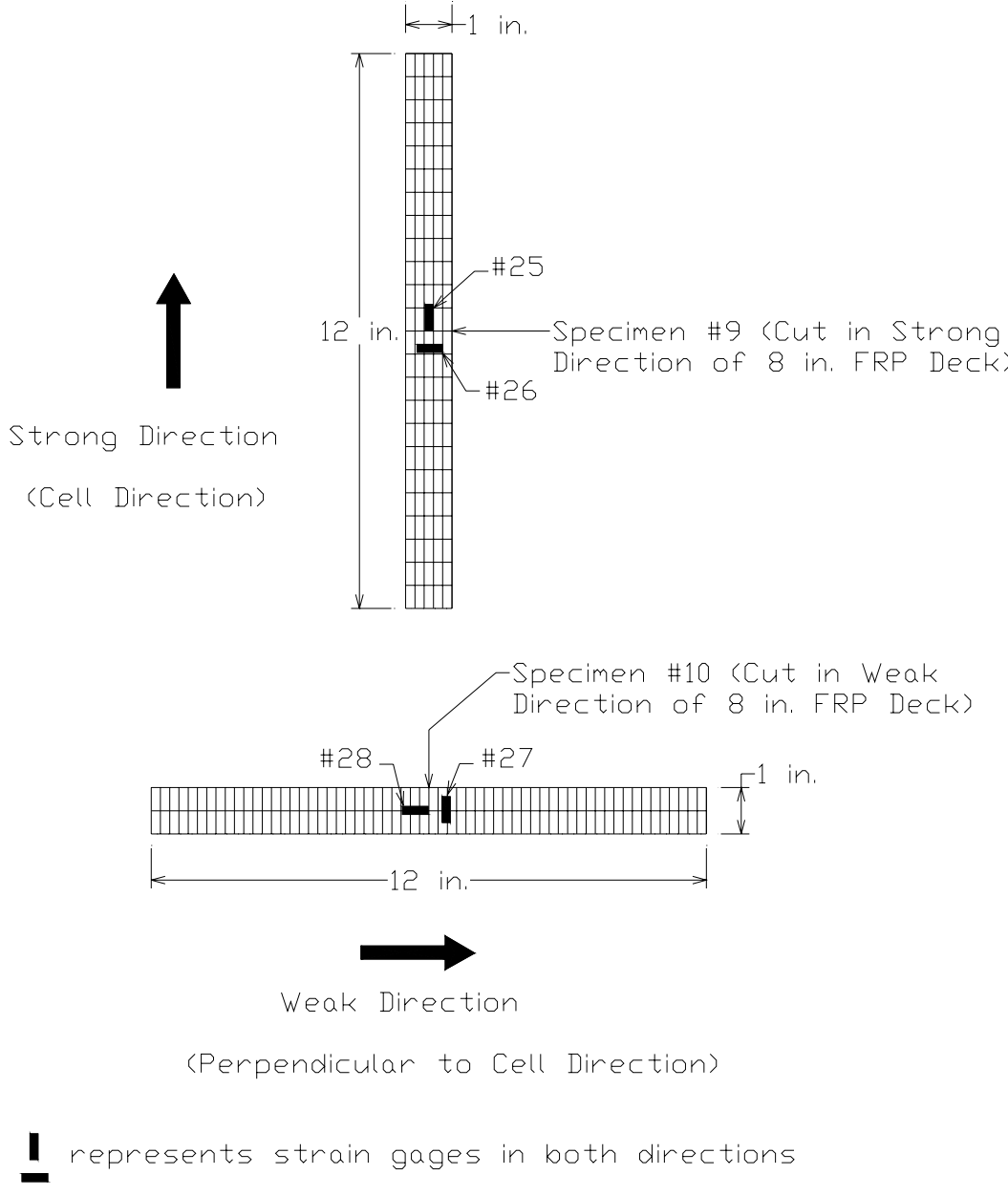

Figure 3.8: Specimens \#9 and \#10 : Locations and Number of Strain Gages.

\subsection{Instrumentations}

\subsubsection{Strain Measurement}

The type of strain gage for the test was CEA-06-250-UW-350. Refer to Vishay Measurements Group for more details.

\subsubsection{Reference Materials ( ULE Tilnium Silicate Code 7971), See Figure 3.9}




\subsection{Test Procedure}

The strain gage was used to determine either the expansion or contraction of materials under temperature change. Generally, the strain gage also expands or contracts when temperature is changed. Therefore, compensation for this effect was required to obtain true expansion or contraction of materials alone. Micro-Measurement Inc., a strain gage supplier, recommended a technique to compensate for this effect. The technique for measuring a thermal expansion coefficient was based on the technical note, tn513 from MicroMeasurement Inc. The technique used two well-matched strain gages, with one bonded to a reference material, and the second to a specimen. In principle, the reference material could be any substance for which the expansion properties were accurately known over the temperature range of interest. In practice, it is often advantageous to select a material with expansion properties as close to zero as possible. This provided an output signal that closely corresponds to the "absolute" expansion coefficient of the test material, and permitted a more straightforward testing procedure (Technical Note 513). An excellent reference material to use was ULE Tilanium Silicate Code 7971, as shown in Figure 3.9. This special glass has an extremely low thermal expansion coefficient, particularly over the temperature range from about $-50^{\circ} \mathrm{F}$ to $+350^{\circ} \mathrm{F}\left(-45^{\circ} \mathrm{C}\right.$ to $\left.+175^{\circ} \mathrm{C}\right)$. When a strain gage was installed on a stressfree specimen of any testing material, and the temperature of the materials were changed, the output of the gage changed correspondingly. This effect was defined as thermal output (strain reading from reference material) and was caused by two factors. One of the factors was that the resistivity of the grid alloy changed with temperature. The other factor was that the resistance changed because of a difference of thermal expansion of gages and test materials. The CTE of specimens was the ratio of strain increment to temperature increment (i.e. 
$\left.\alpha=\frac{\varepsilon}{\Delta T}\right)$. As described previously, temperature change has an effect on strain gages. Therefore, the raw strain reading needed to be compensated in order to obtain the true strain (true expansion or contraction of specimens) by the following formula.

$$
\varepsilon=\varepsilon_{\text {specimen }}-\varepsilon_{\text {reference material }}
$$

where $\varepsilon$ is true strain increment of specimens under temperature change.

$\varepsilon_{\text {specimen }}$ is strain reading on strain gage installed to a specimen.

$\varepsilon_{\text {reference material }}$ is strain reading on strain gage installed to a reference material.

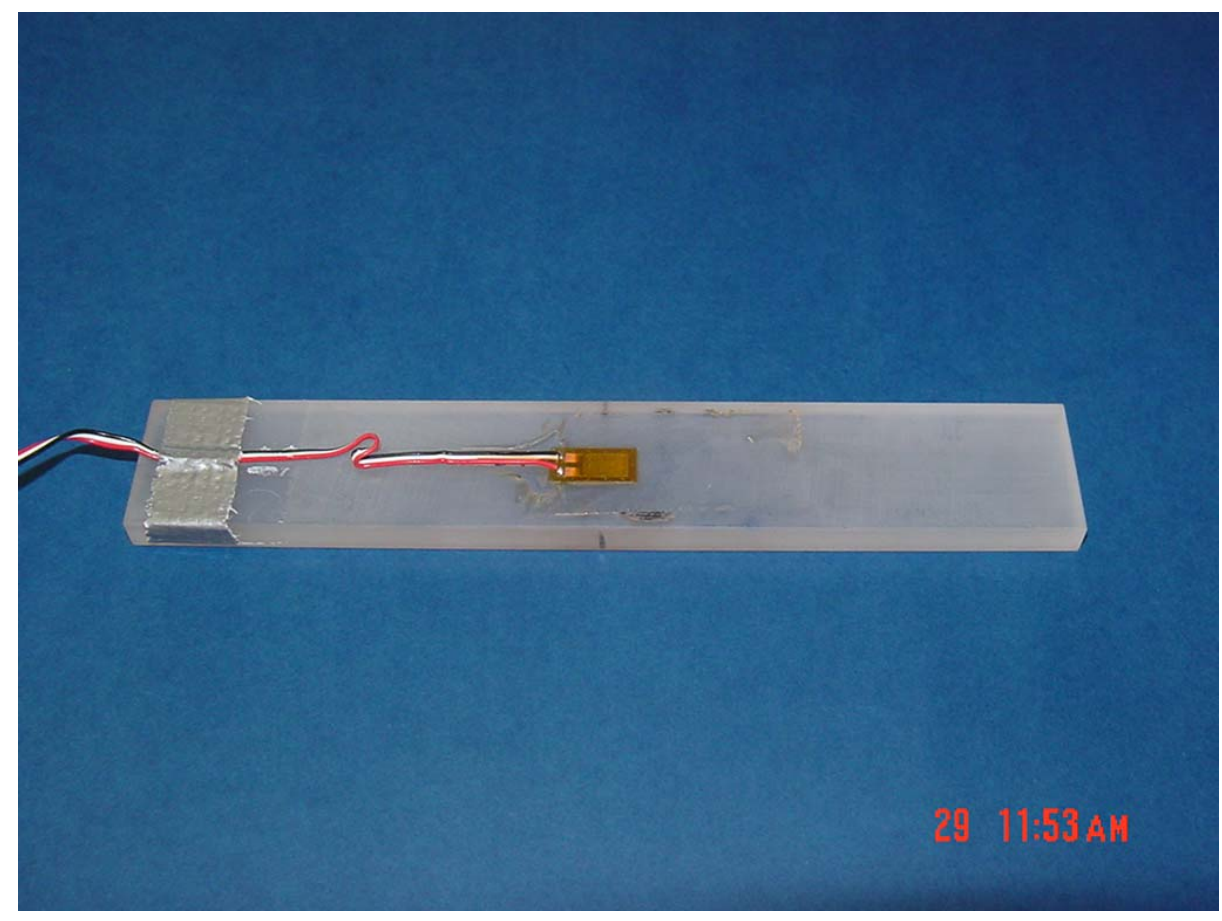

Figure 3.9: Reference Material ( ULE Tilanium Silicate Code 7971 ) with Strain Gage. 
The following is the test procedure:

1. Installing strain gages on test specimens and on a reference material (Refer to section 3.3 for locations of strain gages).

2. For specimens \#1 and \#2 : Suspending specimens \#1 and \#2 at an end of a test specimen with rope in order to allow the specimens expand or contract freely. The direction of strong axis (cell direction ) of a test specimen is aligned into the gravity direction. This helps in reducing the expansion and bending moment effect from self-weight of specimen compared to weak direction aligned into the gravity direction.

Specimens \#3 to \#10 were placed on a roller at the ends with free expansion.

3. Keeping specimens in a Thermotron walk-in environmental test chamber. Temperature in Thermotron walk-in environmental chamber was programmed as shown in Table 3.1 .

4. Recording strain reading for several repeated cycles until strain reading was consistent. 


\begin{tabular}{|c|c|c|}
\hline Interval & $\begin{array}{c}\text { Interval Time } \\
\text { (hrs.) }\end{array}$ & $\begin{array}{c}\text { Temperature } \\
\left({ }^{\circ} \mathrm{F}\right)\end{array}$ \\
\hline \hline 1 & 1 & 72 to 110 \\
\hline 2 & 23 & 110 \\
\hline 3 & 1 & 110 to 121 \\
\hline 4 & 23 & 121 \\
\hline 5 & 1 & 121 to 72 \\
\hline 6 & 23 & 72 \\
\hline 7 & 8 & 72 to -20 \\
\hline 8 & 8 & -20 \\
\hline 9 & 8 & -20 to 110 \\
\hline 10 & 24 & 110 \\
\hline 11 & 7 & 110 \\
\hline 12 & 2 & 110 to 72 \\
\hline
\end{tabular}

Table 3.1: Temperature in Test Chamber. 


\subsection{Test Results}

Test results were shown in table 3.2

\begin{tabular}{|c|c|c|c|c|c|c|c|c|c|c|}
\hline \multirow{5}{*}{$\frac{0}{0}$} & \multirow{5}{*}{ 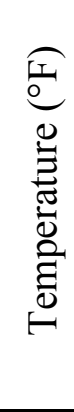 } & \multicolumn{4}{|c|}{$\begin{array}{c}\text { Specimen \#1 } \\
(4 \text { in. FRP Deck, 29" x } 29 \text { ") }\end{array}$} & \multicolumn{4}{|c|}{$\begin{array}{c}\text { Specimen \#2 } \\
\text { (8 in. FRP Deck, 24" x 24") }\end{array}$} & $\begin{array}{l}\text { Reference } \\
\text { Material }\end{array}$ \\
\hline & & \multicolumn{8}{|c|}{$\varepsilon_{\text {specimen }}(\mu \varepsilon)($ Refer to Eq. 3.1) } & \multirow{4}{*}{$\begin{array}{c}\mathcal{E}_{\text {reference material }} \text {. } \\
(\mu \varepsilon)\end{array}$} \\
\hline & & \multicolumn{2}{|c|}{ Top Surface } & \multicolumn{2}{|c|}{ Web } & \multicolumn{2}{|c|}{ Top Surface } & \multicolumn{2}{|c|}{ Web } & \\
\hline & & Strong & Weak & Strong & Weak & Strong & Weak & Strong & Weak & \\
\hline & & $\# 1$ & $\# 2$ & $\# 3$ & $\# 4$ & $\# 5$ & $\# 6$ & $\# 7$ & $\# 8$ & \\
\hline \multirow{4}{*}{1} & 72 & 0 & 0 & 0 & 0 & 0 & 0 & 0 & 0 & 0 \\
\hline & 110 & -10 & 89 & 10 & 281 & -59 & 299 & -38 & 229 & -244 \\
\hline & 121 & -46 & 152 & -9 & 320 & -82 & 375 & -64 & 276 & -322 \\
\hline & -20 & -114 & -427 & -207 & -687 & -54 & -698 & -129 & -593 & 401 \\
\hline \multirow{4}{*}{2} & 72 & 0 & 0 & 0 & 0 & 0 & 0 & 0 & 0 & 0 \\
\hline & 110 & -25 & 118 & 4 & 260 & -61 & 290 & -42 & 221 & -246 \\
\hline & 121 & -52 & 148 & -9 & 308 & -83 & 374 & -66 & 275 & -323 \\
\hline & -20 & -113 & -378 & -207 & -687 & -56 & -695 & -132 & -593 & 400 \\
\hline \multirow{4}{*}{3} & 72 & 0 & 0 & 0 & 0 & 0 & 0 & 0 & 0 & 0 \\
\hline & 110 & -27 & 128 & 5 & 254 & -58 & 288 & -41 & 222 & -245 \\
\hline & 121 & -44 & 151 & -7 & 321 & -83 & 375 & -65 & 275 & -322 \\
\hline & -20 & -112 & -360 & -209 & -684 & -59 & -696 & -133 & -589 & 402 \\
\hline \multirow{4}{*}{4} & 72 & 0 & 0 & 0 & 0 & 0 & 0 & 0 & 0 & 0 \\
\hline & 110 & -27 & 130 & 1 & 253 & -63 & 285 & -44 & 220 & -244 \\
\hline & 121 & -48 & 148 & -14 & 318 & -90 & 372 & -70 & 269 & -321 \\
\hline & -20 & -113 & -361 & -206 & -688 & -60 & -694 & -133 & -588 & 402 \\
\hline
\end{tabular}

Note : Strain on Reference Material in the last column represents $\varepsilon_{\text {reference material }}$ in Eq. 3.1

Table 3.2: Raw Strain data $\left(\varepsilon_{\text {specimen }}\right)$ for Specimens \#1 and \#2 and Strain Data $\left(\varepsilon_{\text {reference material }}\right)$ for Reference Material. 


\begin{tabular}{|c|c|c|c|c|c|c|c|c|c|c|c|}
\hline \multirow{5}{*}{$\frac{0}{0}$} & \multirow{4}{*}{\multicolumn{2}{|c|}{ Temperature }} & (4 in. FR & $\begin{array}{l}\text { Specime } \\
\text { P Decl }\end{array}$ & $\begin{array}{l}\text { en \# } 3 \\
\mathrm{k}, \text { Full Sc }\end{array}$ & ale) & $(8$ in. $\mathrm{F}$ & $\begin{array}{l}\text { Specim } \\
\text { RP Dec }\end{array}$ & $\begin{array}{l}\text { en \# } 4 \\
\mathrm{k}, \text { Full S }\end{array}$ & cale) & $\begin{array}{c}\text { Reference } \\
\text { Material }\end{array}$ \\
\hline & & & \multicolumn{8}{|c|}{$\varepsilon_{\text {specimen }}(\mu \varepsilon)($ Refer to Eq. 3.1) } & \multirow{4}{*}{$\begin{array}{c}\varepsilon_{\text {reference materials }} \\
(\mu \varepsilon)\end{array}$} \\
\hline & & & \multicolumn{2}{|c|}{ Center of a Module } & \multicolumn{2}{|c|}{ Connection Joint } & \multicolumn{2}{|c|}{ Center of a Module } & \multicolumn{2}{|c|}{ Connection Joint } & \\
\hline & & & $\# 9$ & $\# 10$ & $\# 11$ & $\# 12$ & $\# 13$ & $\# 14$ & $\# 15$ & $\# 16$ & \\
\hline & $\mathrm{C}$ & $\mathrm{F}$ & Strong & Weak & Strong & Weak & Strong & Weak & Strong & Weak & \\
\hline \multirow{4}{*}{1} & 22 & 71.60 & 0 & 0 & 0 & 0 & 0 & 0 & 0 & 0 & 0 \\
\hline & 43 & 109.40 & 27 & 134 & -8 & 137 & -26 & 258 & -31 & 298 & -238 \\
\hline & 49 & 120.20 & 28 & 163 & -10 & 162 & -47 & 331 & -41 & 354 & -314 \\
\hline & -29 & -20.20 & -284 & -465 & -236 & -507 & -173 & -720 & -201 & -792 & 322 \\
\hline \multirow{4}{*}{2} & 22 & 71.60 & 0 & 0 & 0 & 0 & 0 & 0 & 0 & 0 & 0 \\
\hline & 43 & 109.40 & 28 & 122 & -1 & 122 & -25 & 248 & -31 & 284 & -238 \\
\hline & 49 & 120.20 & 29 & 161 & -11 & 154 & -49 & 327 & -41 & 354 & -315 \\
\hline & -29 & -20.20 & -284 & -466 & -234 & -494 & -177 & -722 & -203 & -793 & 322 \\
\hline \multirow{4}{*}{3} & 22 & 71.60 & 0 & 0 & 0 & 0 & 0 & 0 & 0 & 0 & 0 \\
\hline & 43 & 109.40 & 27 & 121 & -9 & 119 & -30 & 251 & -33 & 281 & -238 \\
\hline & 49 & 120.20 & 28 & 161 & -10 & 153 & -49 & 327 & -41 & 353 & -315 \\
\hline & -29 & -20.20 & -285 & -467 & -234 & -494 & -176 & -721 & -203 & -792 & 321 \\
\hline
\end{tabular}

Note : Strain on Reference Material in the last column represents $\varepsilon_{\text {reference material }}$ in Eq. 3.1

Table 3.3: Raw Strain Data ( $\left.\varepsilon_{\text {specimen }}\right)$ for Specimens \#3 and \#4 and Strain Data $\left(\varepsilon_{\text {reference material }}\right)$ for Reference Material. 


\begin{tabular}{|c|c|c|c|c|c|c|c|c|c|c|c|c|c|c|c|c|c|}
\hline \multirow{6}{*}{$\frac{0}{0}$} & \multirow{6}{*}{ 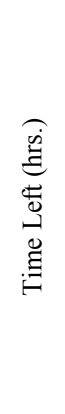 } & \multirow{6}{*}{ 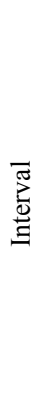 } & \multirow{5}{*}{\multicolumn{2}{|c|}{ 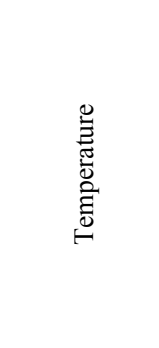 }} & \multicolumn{6}{|c|}{4 in FRP Deck } & \multicolumn{6}{|c|}{8 in. FRP Deck } & \multirow{6}{*}{ 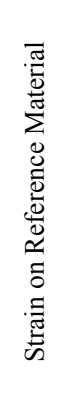 } \\
\hline & & & & & \multicolumn{12}{|c|}{$\varepsilon_{\text {specimen }}(\mu \varepsilon)($ Refer to Eq. 3.1) } & \\
\hline & & & & & \multicolumn{2}{|c|}{ Specimen \#5 } & \multicolumn{2}{|c|}{ Specimen \#7 } & \multicolumn{2}{|c|}{ Specimen \#8 } & \multicolumn{2}{|c|}{ Specimen \#6 } & \multicolumn{2}{|c|}{ Specimen \#9 } & \multicolumn{2}{|c|}{ Specimen \#10 } & \\
\hline & & & & & \multicolumn{2}{|c|}{$\begin{array}{l}\text { Cross Section } \\
\text { ( } 1 " \text { in length) }\end{array}$} & \multicolumn{2}{|c|}{$\begin{array}{c}\text { Coupon } \\
\text { (Cut in Strong } \\
\text { Direction) }\end{array}$} & \multicolumn{2}{|c|}{$\begin{array}{c}\text { Coupon } \\
\text { (Cut in Weak } \\
\text { Direction) } \\
\end{array}$} & \multicolumn{2}{|c|}{$\begin{array}{l}\text { Cross Section } \\
(1 " \text { in length) }\end{array}$} & \multicolumn{2}{|c|}{$\begin{array}{c}\text { Coupon } \\
\text { (Cut in Strong } \\
\text { Direction) } \\
\end{array}$} & \multicolumn{2}{|c|}{$\begin{array}{c}\text { Coupon } \\
\text { (Cut in Weak } \\
\text { Direction) } \\
\end{array}$} & \\
\hline & & & & & Strong & Weak & Strong & Weak & Strong & Weak & Strong & Weak & Strong & Weak & Strong & Weak & \\
\hline & & & ${ }^{\circ} \mathrm{C}$ & ${ }^{\circ} \mathrm{F}$ & \#17 & $\# 18$ & $\# 21$ & $\# 22$ & $\# 23$ & $\# 24$ & \#19 & $\# 20$ & \#25 & \#26 & \#27 & \#28 & \\
\hline \multirow{4}{*}{1} & 7.08 & 6 & 22 & 71.60 & 0 & 0 & 0 & 0 & 0 & 0 & 0 & 0 & 0 & 0 & 0 & 0 & 0 \\
\hline & 6.55 & 10 & 43 & 109.40 & -43 & 91 & -44 & 99 & -52 & 70 & -55 & 360 & -73 & 313 & -53 & 392 & -236 \\
\hline & 5.11 & 4 & 49 & 120.20 & -75 & 122 & -63 & 138 & -85 & 103 & -91 & 467 & -107 & 386 & -86 & 485 & -313 \\
\hline & 0.46 & 8 & -29 & -20.20 & -99 & -369 & -107 & -352 & -96 & -329 & -152 & -904 & -130 & -837 & -157 & -972 & 324 \\
\hline \multirow{4}{*}{2} & 8.57 & 6 & 22 & 71.60 & 0 & 0 & 0 & 0 & 0 & 0 & 0 & 0 & 0 & 0 & 0 & 0 & 0 \\
\hline & 1.01 & 2 & 43 & 109.40 & -48 & 95 & -42 & 99 & -58 & 67 & -56 & 375 & -74 & 322 & -52 & 400 & -238 \\
\hline & 0.17 & 4 & 49 & 120.20 & -74 & 107 & -63 & 120 & -74 & 79 & -88 & 469 & -108 & 394 & -91 & 495 & -315 \\
\hline & 2.34 & 8 & -29 & -20.20 & -98 & -369 & -102 & -342 & -93 & -329 & -148 & -901 & -131 & -834 & -155 & -970 & 320 \\
\hline \multirow{4}{*}{3} & 0.45 & 6 & 22 & 71.60 & 0 & 0 & 0 & 0 & 0 & 0 & 0 & 0 & 0 & 0 & 0 & 0 & 0 \\
\hline & 0.3 & 10 & 43 & 109.40 & -48 & 87 & -51 & 85 & -52 & 56 & -54 & 370 & -75 & 317 & -54 & 399 & -238 \\
\hline & 9.55 & 4 & 49 & 120.20 & -64 & 102 & -67 & 117 & -78 & 65 & -88 & 476 & -108 & 398 & -83 & 498 & -316 \\
\hline & 2.28 & 8 & -29 & -20.20 & -105 & -373 & -107 & -351 & -88 & -331 & -151 & -897 & -130 & -831 & -157 & -964 & 321 \\
\hline
\end{tabular}

Note : Strain on Reference Material in the last column represents $\varepsilon_{\text {reference material }}$ in Eq. 3.1

Table 3.4 Raw Strain Data ( $\left.\varepsilon_{\text {specimen }}\right)$ for Specimens \#5 to \#10 and Strain Data $\left(\varepsilon_{\text {reference material }}\right)$ for Reference Material.

The test data was recorded up to three or four cycles until consistent results were noted. One cycle represented twelve intervals (refer to Table 4.1). Based on the test data in Tables 3.2 to 3.4, strain data of all strain gages were consistent for all cycles. This leaded the author to discontinue the test. 
The raw strain data from tables 3.2 to 3.4 were calculated based on Eq. (3.1) to obtain the true strain as shown in Tables 3.5 to 3.7, respectively.

\begin{tabular}{|c|c|c|c|c|c|c|c|c|c|}
\hline \multirow{5}{*}{ 䍘 } & \multirow{5}{*}{ 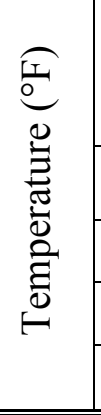 } & \multicolumn{4}{|c|}{$\begin{array}{c}\text { Specimen \#1 } \\
\text { (4 in. FRP Deck, 29" x } 29 \text { ") }\end{array}$} & \multicolumn{4}{|c|}{$\begin{array}{c}\text { Specimen \#2 } \\
\text { (8 in. FRP Deck, 24" x 24") }\end{array}$} \\
\hline & & \multicolumn{8}{|c|}{$\varepsilon=\varepsilon_{\text {specimen }}-\varepsilon_{\text {reference material }}(\mu \varepsilon)$} \\
\hline & & \multicolumn{2}{|c|}{ Top Surface } & \multicolumn{2}{|c|}{ Web } & \multicolumn{2}{|c|}{ Top Surface } & \multicolumn{2}{|c|}{ Web } \\
\hline & & Strong & Weak & Strong & Weak & Strong & Weak & Strong & Weak \\
\hline & & $\# 1$ & $\# 2$ & $\# 3$ & $\# 4$ & $\# 5$ & $\# 6$ & $\# 7$ & $\# 8$ \\
\hline \multirow{4}{*}{1} & 72 & 0 & 0 & 0 & 0 & 0 & 0 & 0 & 0 \\
\hline & 110 & 234 & 333 & 254 & 525 & 185 & 543 & 206 & 473 \\
\hline & 121 & 276 & 474 & 313 & 642 & 240 & 697 & 258 & 598 \\
\hline & -20 & -515 & -828 & -608 & -1088 & -455 & -1099 & -530 & -994 \\
\hline \multirow{4}{*}{2} & 72 & 0 & 0 & 0 & 0 & 0 & 0 & 0 & 0 \\
\hline & 110 & 221 & 364 & 250 & 506 & 185 & 536 & 204 & 467 \\
\hline & 121 & 271 & 471 & 314 & 631 & 240 & 697 & 257 & 598 \\
\hline & -20 & -513 & -778 & -607 & -1087 & -456 & -1095 & -532 & -993 \\
\hline \multirow{4}{*}{3} & 72 & 0 & 0 & 0 & 0 & 0 & 0 & 0 & 0 \\
\hline & 110 & 218 & 373 & 250 & 499 & 187 & 533 & 204 & 467 \\
\hline & 121 & 278 & 473 & 315 & 643 & 239 & 697 & 257 & 597 \\
\hline & -20 & -514 & -762 & -611 & -1086 & -461 & -1098 & -535 & -991 \\
\hline \multirow{4}{*}{2} & 72 & 0 & 0 & 0 & 0 & 0 & 0 & 0 & 0 \\
\hline & 110 & 217 & 374 & 245 & 497 & 181 & 529 & 200 & 464 \\
\hline & 121 & 273 & 469 & 307 & 639 & 231 & 693 & 251 & 590 \\
\hline & -20 & -515 & -763 & -608 & -1090 & -462 & -1096 & -535 & -990 \\
\hline
\end{tabular}

Note : $\varepsilon=\varepsilon_{\text {specimen }}-\varepsilon_{\text {reference material }}\left(\varepsilon_{\text {specimen }}\right.$ and $\varepsilon_{\text {reference material }}$ are obtained from Table 3.2)

Table 3.5: True Strain Data $(\varepsilon)$ for Specimens \# 1 and \# 2. 


\begin{tabular}{|c|c|c|c|c|c|c|c|c|c|c|}
\hline \multirow{5}{*}{ 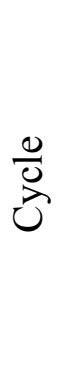 } & \multirow{4}{*}{\multicolumn{2}{|c|}{ Temperature }} & $(4$ in. $\mathrm{F}$ & $\begin{array}{l}\text { Specim } \\
\text { RP Dec }\end{array}$ & $\begin{array}{l}\text { hen \# } 3 \\
\text { ck, Full S }\end{array}$ & & \multicolumn{4}{|c|}{$\begin{array}{c}\text { Specimen \# } 4 \\
\text { (8 in. FRP Deck, Full Scale) }\end{array}$} \\
\hline & & & \multicolumn{8}{|c|}{$\varepsilon=\varepsilon_{\text {specimen }}-\varepsilon_{\text {reference material }}(\mu \varepsilon)$} \\
\hline & & & \multicolumn{2}{|c|}{ Center of a Module } & \multicolumn{2}{|c|}{ Connection Joint } & \multicolumn{2}{|c|}{ Center of a Module } & \multicolumn{2}{|c|}{ Connection Joint } \\
\hline & & & $\# 9$ & $\# 10$ & $\# 11$ & $\# 12$ & $\# 13$ & $\# 14$ & $\# 15$ & $\# 16$ \\
\hline & $\mathrm{C}$ & $\mathrm{F}$ & Strong & Weak & Strong & Weak & Strong & Weak & Strong & Weak \\
\hline \multirow{4}{*}{1} & 22 & 1.60 & 0 & 0 & 0 & 0 & 0 & 0 & 0 & \\
\hline & 43 & 109.40 & 265 & 372 & 230 & 375 & 212 & 496 & 207 & 36 \\
\hline & 49 & 120.20 & 342 & 477 & 304 & 476 & 267 & 64 & 273 & 668 \\
\hline & -29 & -20.20 & -606 & -787 & -558 & -829 & -495 & -1042 & -523 & -1114 \\
\hline \multirow{4}{*}{2} & 22 & & 0 & 0 & 0 & 0 & 0 & 0 & 0 & 0 \\
\hline & 43 & 109.40 & 266 & 360 & 237 & 360 & 213 & 486 & 207 & 522 \\
\hline & 49 & 120.20 & 344 & 476 & 304 & 469 & 266 & 642 & 274 & 669 \\
\hline & -29 & -20.20 & 06 & -788 & 556 & -816 & -499 & -1044 & -525 & -1115 \\
\hline \multirow{4}{*}{3} & 22 & & 0 & 0 & 0 & 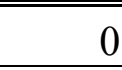 & 0 & 0 & 0 & 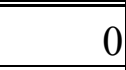 \\
\hline & 43 & 109.40 & 265 & 359 & 229 & 357 & 208 & 489 & 205 & 519 \\
\hline & 49 & 120.20 & 343 & 476 & 305 & 468 & 266 & 642 & 274 & 668 \\
\hline & -29 & -20.20 & -606 & -788 & -555 & -815 & -497 & -1042 & -524 & -1113 \\
\hline
\end{tabular}

Note : $\varepsilon=\varepsilon_{\text {specimen }}-\varepsilon_{\text {reference material }}\left(\varepsilon_{\text {specimen }}\right.$ and $\varepsilon_{\text {reference material }}$ are obtained from Table 3.3)

Table 3.6: True Strain Data $(\varepsilon)$ for Specimens \# 3 and \# 4. 


\begin{tabular}{|c|c|c|c|c|c|c|c|c|c|c|c|c|c|c|c|c|}
\hline \multirow{6}{*}{ 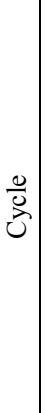 } & \multirow{6}{*}{ 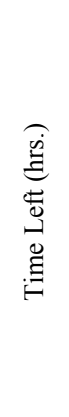 } & \multirow{6}{*}{ 焉 } & \multirow{5}{*}{\multicolumn{2}{|c|}{ 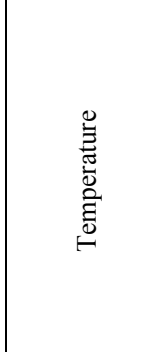 }} & \multicolumn{6}{|c|}{4 in FRP Deck } & \multicolumn{6}{|c|}{8 in. FRP Deck } \\
\hline & & & & & \multicolumn{12}{|c|}{$\varepsilon=\varepsilon_{\text {specimen }}-\varepsilon_{\text {reference material }}(\mu \varepsilon)$} \\
\hline & & & & & \multicolumn{2}{|c|}{ Specimen \#5 } & \multicolumn{2}{|c|}{ Specimen \#7 } & \multicolumn{2}{|c|}{ Specimen \#8 } & \multicolumn{2}{|c|}{ Specimen \#6 } & \multicolumn{2}{|c|}{ Specimen \#9 } & \multicolumn{2}{|c|}{ Specimen \#10 } \\
\hline & & & & & \multicolumn{2}{|c|}{$\begin{array}{l}\text { Cross Section } \\
\text { (1" in length) }\end{array}$} & \multicolumn{2}{|c|}{$\begin{array}{c}\text { Coupon } \\
\text { (Cut in Strong } \\
\text { Dir.) }\end{array}$} & \multicolumn{2}{|c|}{$\begin{array}{c}\text { Coupon } \\
\text { (Cut in Weak } \\
\text { Dir.) }\end{array}$} & \multicolumn{2}{|c|}{$\begin{array}{l}\text { Cross Section } \\
(1 " \text { in length) }\end{array}$} & \multicolumn{2}{|c|}{$\begin{array}{c}\text { Coupon } \\
\text { (Cut in Strong } \\
\text { Dir.) }\end{array}$} & \multicolumn{2}{|c|}{$\begin{array}{c}\text { Coupon } \\
\text { (Cut in Weak } \\
\text { Dir.) }\end{array}$} \\
\hline & & & & & Strong & Weak & Strong & Weak & Strong & Weak & Strong & Weak & Strong & Weak & Strong & Weak \\
\hline & & & $\mathrm{C}$ & $\mathrm{F}$ & $\# 17$ & \#18 & $\# 21$ & $\# 22$ & $\# 23$ & $\# 24$ & $\# 19$ & $\# 20$ & $\# 25$ & $\# 26$ & $\# 27$ & $\# 28$ \\
\hline \multirow{4}{*}{1} & 7.08 & 6 & 22 & 71.60 & 0 & 0 & 0 & 0 & 0 & 0 & 0 & 0 & 0 & 0 & 0 & 0 \\
\hline & 6.55 & 10 & 43 & 109.40 & 193 & 327 & 192 & 335 & 184 & 306 & 181 & 596 & 163 & 549 & 183 & 628 \\
\hline & 5.11 & 4 & 49 & 120.20 & 238 & 435 & 250 & 451 & 228 & 416 & 222 & 780 & 206 & 699 & 227 & 798 \\
\hline & 0.46 & 8 & -29 & -20.20 & -423 & -693 & -431 & -676 & -420 & -653 & -476 & -1228 & -454 & -1161 & -481 & -1296 \\
\hline \multirow{4}{*}{2} & 8.57 & 6 & 22 & 71.60 & 0 & 0 & 0 & 0 & 0 & 0 & 0 & 0 & 0 & 0 & 0 & 0 \\
\hline & 1.01 & 2 & 43 & 109.40 & 190 & 333 & 196 & 337 & 180 & 305 & 182 & 613 & 164 & 560 & 186 & 638 \\
\hline & 0.17 & 4 & 49 & 120.20 & 241 & 422 & 252 & 435 & 241 & 394 & 227 & 784 & 207 & 709 & 224 & 810 \\
\hline & 2.34 & 8 & -29 & -20.20 & -418 & -689 & -422 & -662 & -413 & -649 & -468 & -1221 & -451 & -1154 & -475 & -1290 \\
\hline \multirow{4}{*}{3} & 0.45 & 6 & 22 & 71.60 & 0 & 0 & 0 & 0 & 0 & 0 & 0 & 0 & 0 & 0 & 0 & 0 \\
\hline & 0.3 & 10 & 43 & 109.40 & 190 & 325 & 187 & 323 & 186 & 294 & 184 & 608 & 163 & 555 & 184 & 637 \\
\hline & 9.55 & 4 & 49 & 120.20 & 252 & 418 & 249 & 433 & 238 & 381 & 228 & 792 & 208 & 714 & 233 & 814 \\
\hline & 2.28 & 8 & -29 & -20.20 & -426 & -694 & -428 & -672 & -409 & -652 & -472 & -1218 & -451 & -1152 & -478 & -1285 \\
\hline
\end{tabular}

Note : $\varepsilon=\varepsilon_{\text {specimen }}-\varepsilon_{\text {reference material }}\left(\varepsilon_{\text {specimen }}\right.$ and $\varepsilon_{\text {reference material }}$ are obtained from Table 3.4)

Table 3.7: True Strain Data $(\varepsilon)$ for Specimens \# 5 and \# 10.

The true strain data from Tables 3.5 to 3.7 was averaged and calculated for the CTE.

The CTE was calculated by the following formula, $\alpha=\frac{\varepsilon}{\Delta T}$ with two ranges of temperature, such as $-20^{\circ}$ to $72^{\circ} \mathrm{F}$ and $72^{\circ}$ to $121^{\circ} \mathrm{F}$ with the reference base temperature being equal to the room temperature $\left(72^{\circ} \mathrm{F}\right)$. The CTE for all of the specimens are shown in Tables 3.8 and 3.9 for 4 inch and 8 inch FRP deck. 


\begin{tabular}{|c|c|c|c|c|c|}
\hline \multicolumn{6}{|c|}{ CTE of 4 in. FRP Deck $\left(\mu \varepsilon /{ }^{\circ} F\right)$} \\
\hline \multirow{3}{*}{$\begin{array}{l}\text { Specimen \# } \\
\text { (Dimension) }\end{array}$} & \multirow{3}{*}{ Descriptions } & \multicolumn{4}{|c|}{ Temperature Range $\left({ }^{\circ} \mathrm{F}\right)$} \\
\hline & & \multicolumn{2}{|c|}{$72<\mathrm{T}<120$} & \multicolumn{2}{|c|}{$-20<\mathrm{T}<72$} \\
\hline & & $\alpha_{1}$ & $\alpha_{2}$ & $\alpha_{1}$ & $\alpha_{2}$ \\
\hline \multirow{2}{*}{ \#1 (29"x29") } & Flange (Suspended Specimen) & 5.73 & 9.56 & $\mid 5.59$ & 8.51 \\
\hline & Web (Suspended Specimen) & 6.47 & 13.19 & 6.61 & 11.82 \\
\hline \multirow{2}{*}{$\# 3\left(6.83^{\prime} \times 3^{\prime}\right)$} & Full Scale@ Center of a module & 7.04 & 9.71 & 6.60 & 8.58 \\
\hline & Full Scale@Connection Joint & 6.20 & 9.66 & 6.06 & 8.93 \\
\hline \#5 (1"x12") & Cross Section with 1 " in length & 5.03 & 8.72 & 4.60 & 7.54 \\
\hline \#7 (1"x12") & Coupon (Cut in Strong Direction) & 5.11 & 8.91 & 4.65 & 7.30 \\
\hline \#8 (1"x12") & Coupon (Cut in Weak Direction) & 4.85 & 8.07 & 4.51 & 7.10 \\
\hline
\end{tabular}

Note : $\alpha_{1}$ and $\alpha_{2}$ represent CTE in the strong and weak direction of FRP deck, respectively

Table 3.8: CTE of 4 in. FRP Deck.

\begin{tabular}{|c|c|c|c|c|c|}
\hline \multicolumn{6}{|c|}{ CTE of 8 in. FRP Deck $\left(\mu \varepsilon /{ }^{\circ} F\right)$} \\
\hline \multirow{3}{*}{$\begin{array}{c}\text { Specimen \# } \\
\text { (Dimension) }\end{array}$} & \multirow{3}{*}{ Descriptions } & \multicolumn{4}{|c|}{ Temperature Range $\left({ }^{\circ} \mathrm{F}\right)$} \\
\hline & & \multicolumn{2}{|c|}{$72<\mathrm{T}<120$} & \multicolumn{2}{|c|}{$-20<\mathrm{T}<72$} \\
\hline & & $\alpha_{1}$ & $\alpha_{2}$ & $\alpha_{1}$ & $\alpha_{2}$ \\
\hline \multirow{2}{*}{ \#2 (24"x24") } & Flange (Suspended Specimen) & 4.85 & 14.14 & 4.98 & 11.92 \\
\hline & Web (Suspended Specimen) & 5.29 & 12.23 & 5.79 & 10.78 \\
\hline \multirow{2}{*}{ \#4 (4.5'x3') } & Full Scale @ Center of a module & 5.53 & 13.10 & 5.41 & 11.36 \\
\hline & Full Scale@ Connection Joint & 5.54 & 13.83 & 5.71 & 12.14 \\
\hline \#6 (1"x12") & Cross Section with 1 " in length & 4.73 & 16.09 & 5.14 & 13.32 \\
\hline \#9 (1"x12") & Coupon (Cut in Strong Direction) & 4.29 & 14.61 & 4.92 & 12.59 \\
\hline \#10 (1"x12") & Coupon (Cut in Weak Direction) & 4.78 & 16.70 & 5.21 & 14.06 \\
\hline
\end{tabular}

Note : $\alpha_{1}$ and $\alpha_{2}$ represent CTE in the strong and weak direction of FRP deck, respectively

Table 3.9: CTE of 8 in. FRP Deck. 


\subsection{Calculation of CTE (using a micromechanics approach)}

The CTE of composite material can be determined using a micro mechanics approach. The following equations were used to calculate the CTE.

$$
\begin{gathered}
\alpha_{1}=\frac{E_{f} \alpha_{f} V_{f}+E_{m} \alpha_{m} V_{m}}{E_{f} V_{f}+E_{m} V_{m}} \\
\alpha_{2}=\left(1+v_{m}\right) \alpha_{m} V_{m}+\left(1+v_{f}\right) \alpha_{f} V_{f}-\alpha_{1} v_{12}
\end{gathered}
$$

where $E_{f}$ and $E_{m}$ are modulus of fiber and matrix, respectively.

$\alpha_{f}$ and $\alpha_{m}$ are CTE of fiber and matrix, respectively.

$V_{f}$ and $V_{m}$ are fiber volume fraction and matrix volume fraction, respectively.

$v_{f}$ and $v_{m}$ are Poisson's ratio of fiber and matrix, respectively.

$v_{12}$ is the major Poisson's ratio.

Substituting the fiber (E-glass) and matrix (Vinyl ester) properties for 4" and 8" FRP decks into Eqs. (3.2) and (3.3) we obtain

$$
\begin{aligned}
\alpha_{1} & =\frac{E_{f} \alpha_{f} V_{f}+E_{m} \alpha_{m} V_{m}}{E_{f} V_{f}+E_{m} V_{m}} \\
& =\frac{\left(1.2 \times 10^{7}\right)\left(3 \times 10^{-6}\right)(0.52)+\left(7.5 \times 10^{5}\right)\left(17 \times 10^{-6}\right)(0.42)}{\left(1.2 \times 10^{7}\right)(0.52)+\left(7.5 \times 10^{5}\right)(0.42)} \\
& =3.76 \times 10^{-6} \mu \varepsilon /^{\circ} \mathrm{F} \\
\alpha_{2} & =\left(1+v_{m}\right) \alpha_{m} V_{m}+\left(1+v_{f}\right) \alpha_{f} V_{f}-\alpha_{1} v_{12} \\
& =(1+0.55)\left(17 \times 10^{-6}\right)(0.48)+(1+0.26)\left(3 \times 10^{-6}\right)(0.52)-\left(3.76 \times 10^{-6}\right)(0.25) \\
& =13.67 \mu \varepsilon /{ }^{\circ} \mathrm{F}
\end{aligned}
$$




\subsection{Conclusions}

The coefficient of thermal expansion (CTE) in the weak direction of the FRP deck was higher than that in the strong direction. The average CTE of 4 inch and 8 inch FRP decks at the top deck surface, bottom deck surface and deck web are shown in Tables 3.10 and 3.11, respectively. In addition, the CTE of Super Deck was added in this section and shown in Table 3.12 .

\begin{tabular}{|c|c|c|c|c|}
\hline \multicolumn{4}{|c|}{ CTE at Top/Bottom Surface of FRP Deck (4” and 8" decks) } \\
\hline \multirow{2}{*}{$\begin{array}{c}\text { Temperature Range } \\
\left({ }^{\circ} F\right)\end{array}$} & 4 in. FRP Deck & \multicolumn{2}{|c|}{8 in. FRP Deck } \\
\cline { 2 - 5 } & $\alpha_{1}\left(\mu \varepsilon /{ }^{\circ} F\right)$ & $\alpha_{2}\left(\mu \varepsilon /{ }^{\circ} F\right)$ & $\alpha_{1}\left(\mu \varepsilon /{ }^{\circ} F\right)$ & $\alpha_{2}\left(\mu \varepsilon /{ }^{\circ} F\right)$ \\
\hline $72<\mathrm{T}<120$ & 5.18 & 8.82 & 4.66 & 15.39 \\
\hline$-20<\mathrm{T}<72$ & 4.84 & 7.61 & 5.06 & 12.97 \\
\hline
\end{tabular}

Notes: The average CTE of 4 in. deck was based on specimens \#1, 5, 7, and 8

The average CTE of 8 in. deck was based on specimens \#2, 6, 9, and 10

Table 3.10: Average CTE of 4 inch and 8 inch FRP Deck at Top/Bottom Surfaces.

\begin{tabular}{|c|c|c|c|c|}
\hline \multicolumn{4}{|c|}{ CTE at Web of FRP Deck (4" and 8" decks) } \\
\hline \multirow{2}{*}{$\begin{array}{c}\text { Temperature Range } \\
\left({ }^{\circ} F\right)\end{array}$} & 4 in. FRP Deck & \multicolumn{2}{|c|}{8 in. FRP Deck } \\
\cline { 2 - 5 } & $\alpha_{1}\left(\mu \varepsilon /{ }^{\circ} F\right)$ & $\alpha_{2}\left(\mu \varepsilon /{ }^{\circ} F\right)$ & $\alpha_{1}\left(\mu \varepsilon /{ }^{\circ} F\right)$ & $\alpha_{2}\left(\mu \varepsilon /{ }^{\circ} F\right)$ \\
\hline $72<\mathrm{T}<120$ & 6.47 & 13.19 & 5.29 & 12.23 \\
\hline$-20<\mathrm{T}<72$ & 6.61 & 11.82 & 5.79 & 10.78 \\
\hline
\end{tabular}

Table 3.11: Average CTE of 4 inch and 8 inch FRP Deck at Web.

\begin{tabular}{|c|c|c|}
\hline \multicolumn{2}{|c|}{ CTE at Top/Bottom Surface of FRP Deck (Super Deck) } \\
\hline $\begin{array}{c}\text { Temperature Range } \\
\left({ }^{\circ} \mathrm{F}\right)\end{array}$ & $\alpha_{1}\left(\mu \varepsilon /{ }^{\circ} \mathrm{F}\right)$ & $\alpha_{2}\left(\mu \varepsilon /{ }^{\circ} \mathrm{F}\right)$ \\
\hline $72<\mathrm{T}<120$ & 6.07 & 9.75 \\
\hline$-20<\mathrm{T}<72$ & 5.86 & 8.98 \\
\hline
\end{tabular}

Table 3.12 CTE of Super Deck 


\section{References}

- Howard, Isaac (2002), "Development of Lightweight FRP Bridge Deck Designs and Evaluations", Thesis (WVU).

- Punyamurthula, Deepthi (2004), "Structure Performance of Low Profile FRP Deck", Thesis (WVU).

- Technical Note (TN 513 ) from Micro-Measurements Inc. (http://www.vishay.com/brands/measurements_group/guide/tn/tn513/513t.htm.) 


\section{Chapter 4}

\section{Thermal Testing of FRP Bridge Deck}

\section{under Temperature Differences in Laboratory}

\subsection{Introduction}

To understand the behaviors of fiber reinforced polymer (FRP) decks under temperature differences, 4 inch and 8 inch FRP deck specimens were tested in a laboratory. FRP deck specimens were subjected to positive and negative temperature difference.

\subsection{Scope}

The thermal testing of 8 inch and 4 inch deep FRP bridge decks under a temperature difference was studied and presented in this chapter. The thermal tests of FRP bridge deck specimens were divided into four different test cases based on different boundaries and thermal loads applied to the test specimens. It can be shown in the following organization chart:

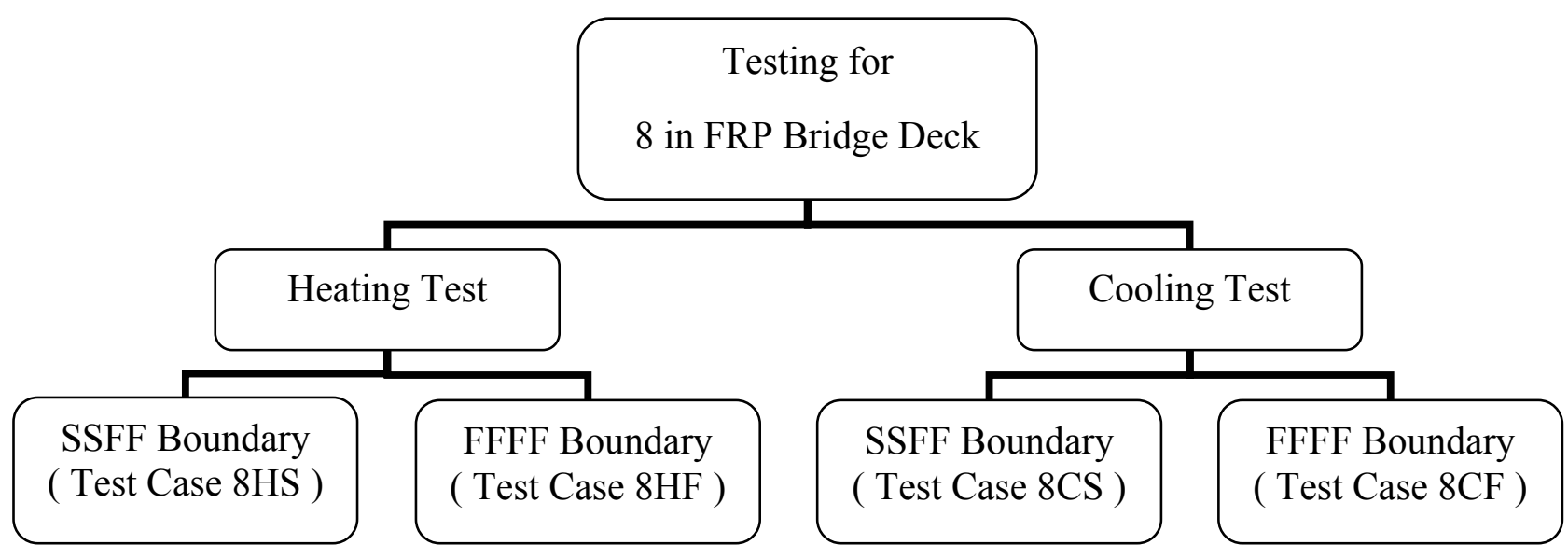

Notations of the above chart for each test case :

8HS represented 8 in. FRP deck + Heating Test + SSFF Boundary. 
8 HF represented 8 in. FRP deck + Heating Test + FFFF Boundary.

8CS represented 8 in. FRP deck + Cooling Test + SSFF Boundary.

8CF represented 8 in. FRP deck + Cooling Test + FFFF Boundary.

SSFF Boundary represented two simply supported edges and two free edges.

FFFF Boundary represented four free edges.

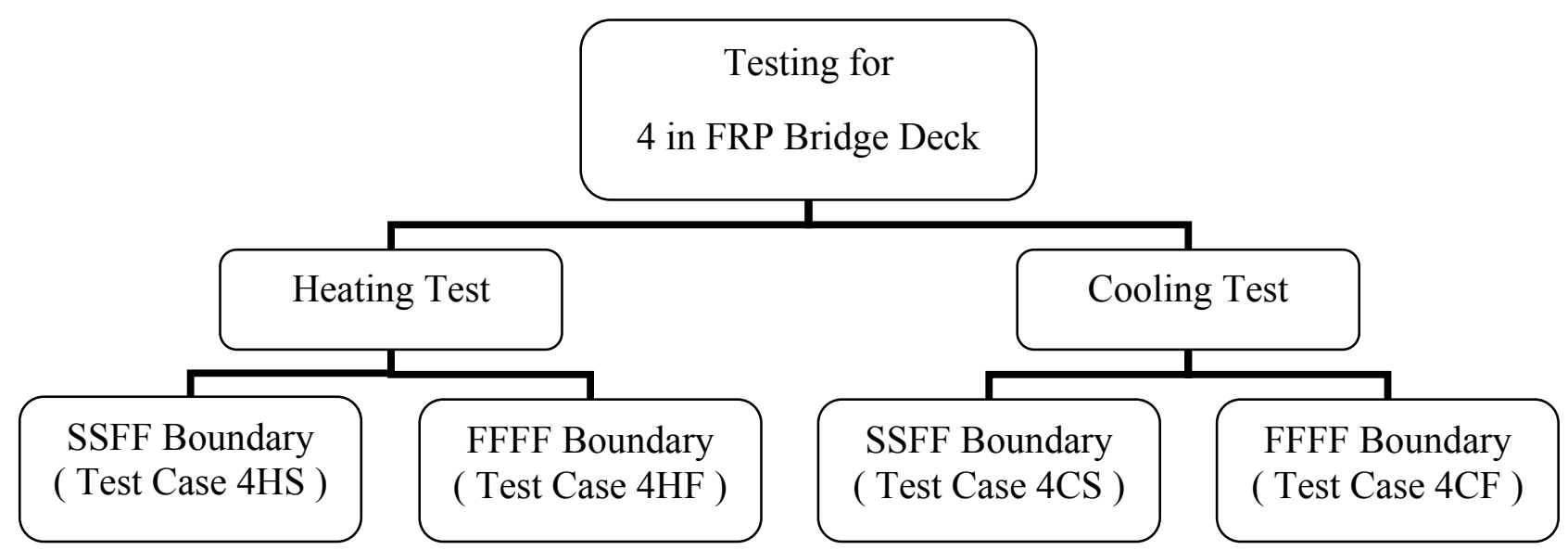

In the above chart, the brief notation for each test case :

4HS represented 4 in. FRP deck + Heating Test + SSFF Boundary.

4HF represented 4 in. FRP deck + Heating Test + FFFF Boundary.

4CS represented 4 in. FRP deck + Cooling Test + SSFF Boundary.

4CF represented 4 in. FRP deck + Cooling Test + FFFF Boundary.

SSFF Boundary represented two simply supported edges and two free edges.

FFFF Boundary represented four free edges.

\subsection{Test Specimens}

The cross section of 4 and 8 in FRP bridge deck for a deck module were shown in Figure 4.1 (a) and (b). 


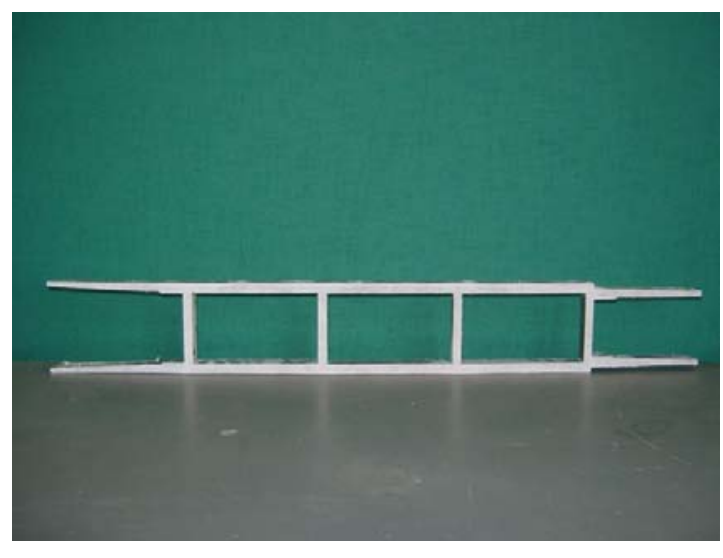

a) 4 inch Deep FRP Deck.

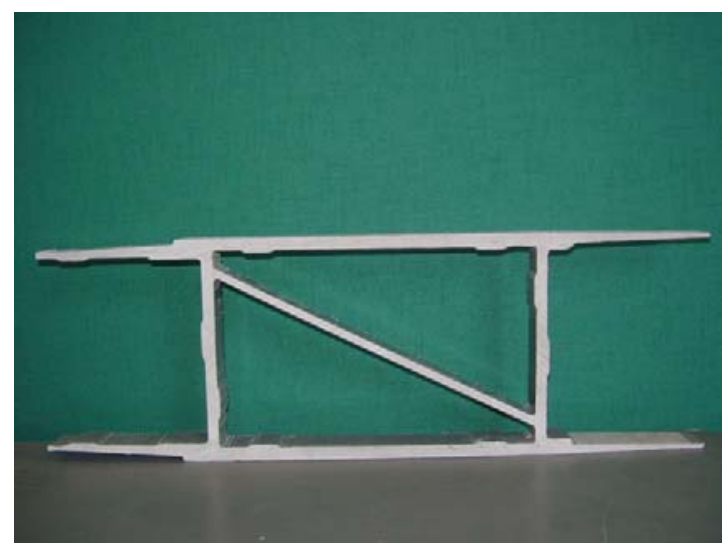

b) 8 inch Deep FRP Deck

Figure 4.1: Cross Section of 4 inch and 8 inch Deep FRP Deck for a Module.

Two test specimens (4 inch and 8 inch FRP deck) were assembled by BRP Inc. Each specimen consisted of four FRP deck modules. The dimensions of 4 inch and 8 inch FRP deck specimens (shown in Figure 4.2 and 4.3) were $72 \times 81 \times 8$ inch deep and $72 \times 82 \times 8$ inch, respectively.

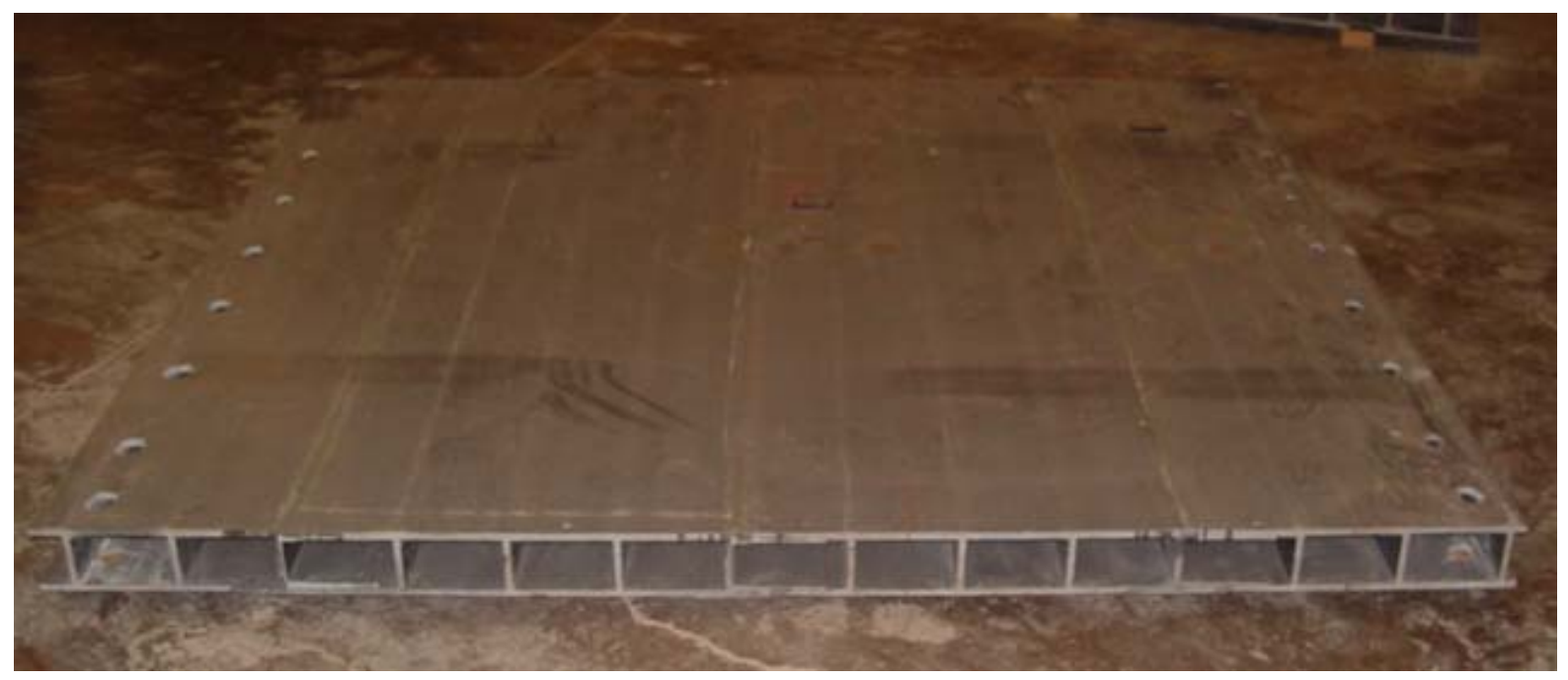

Figure 4.2: A 4 inch Deep FRP Deck Specimen. 


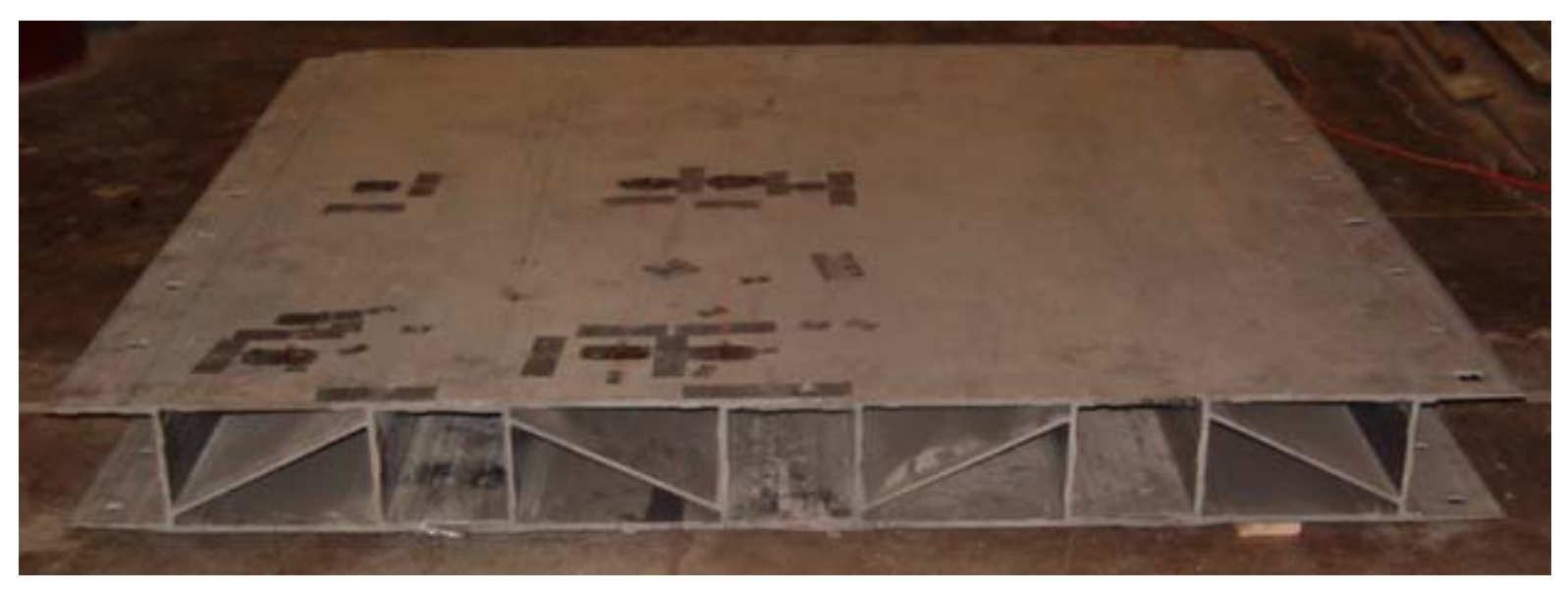

Figure 4.3: A 8 inch Deep FRP Deck Specimen.

\subsection{Test Set-Up for SSFF and FFFF Boundaries}

\subsubsection{Test Set-Up for SSFF Boundary ( Two Simply Supported Edges + Two Free} Edges)

The Test Set-Up of SSFF Boundary was shown in Figure 4.4. The stud bolts were embedded into concrete supports with 8 inch spacing. The FRP bridge deck specimen was placed on concrete supports with a bearing width of 6 inches. The $3 / 8$ inch threaded rods were connected to the stud bolts through the FRP specimen, and a steel $\mathrm{C}$ channel (6 inch deep) was placed along the edge of specimen in order to distribute the forces from threaded rod equally along the edge supports, as shown in Figure 4.5. 


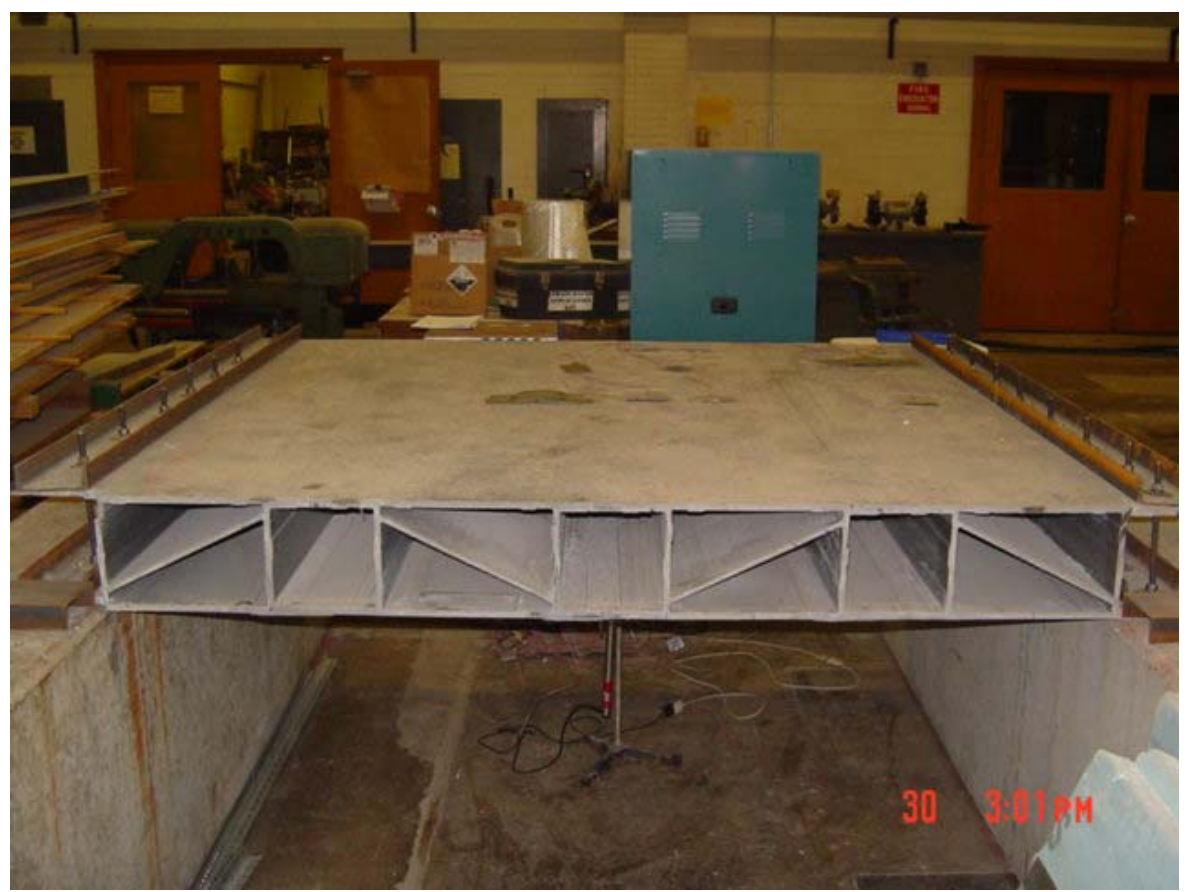

Figure 4.4: Test Set-Up for SSFF Boundary Condition.

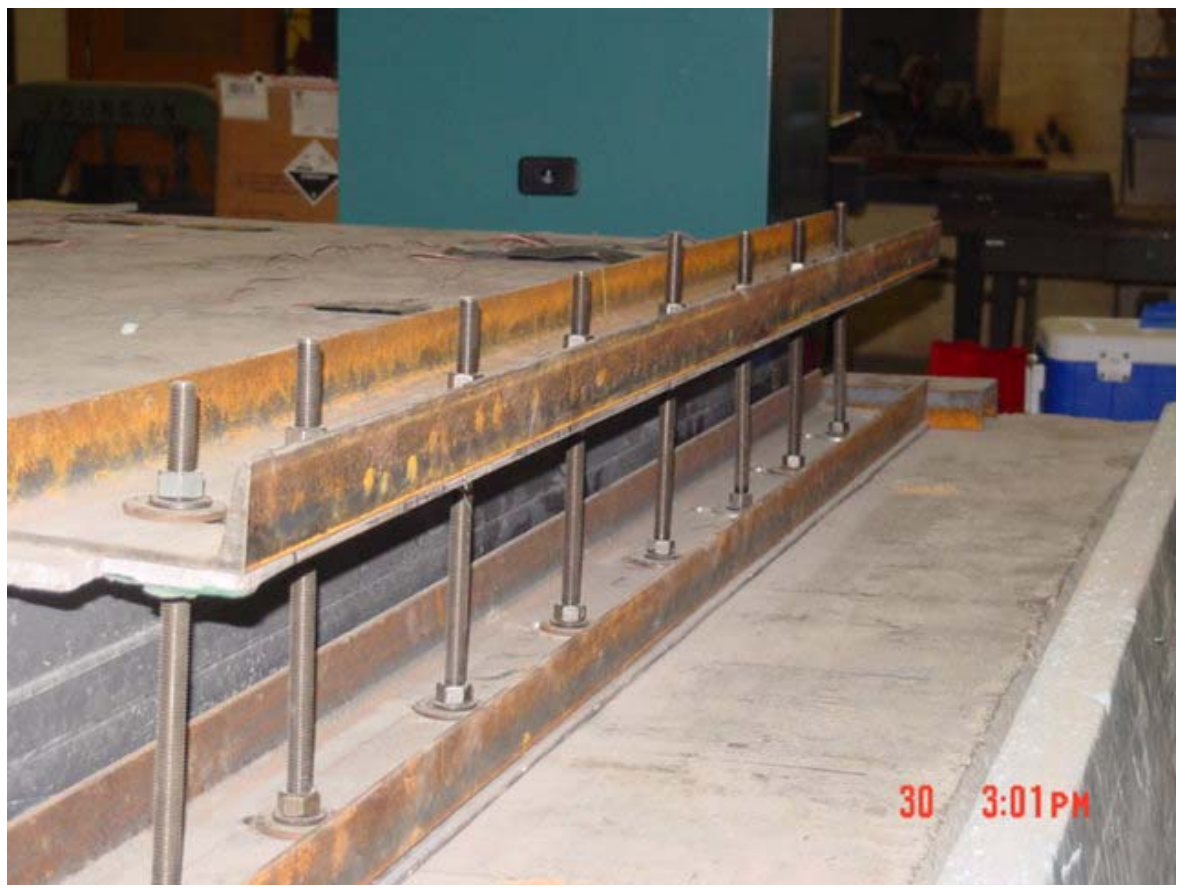

Figure 4.5: Simply Supported Boundary Edges. 


\subsubsection{Test Set-Up for FFFF Boundary (All Four Sides are Free Edges.)}

The test set-up of FFFF Boundary did not require any mechanism to hold the FRP deck specimen. The steel rollers, 6 inches long, were inserted between the FRP Deck and the concrete beam support at four corners of the FRP deck in order to allow the FRP deck specimen to expand freely, as shown in Figure 4.6 and 4.7.

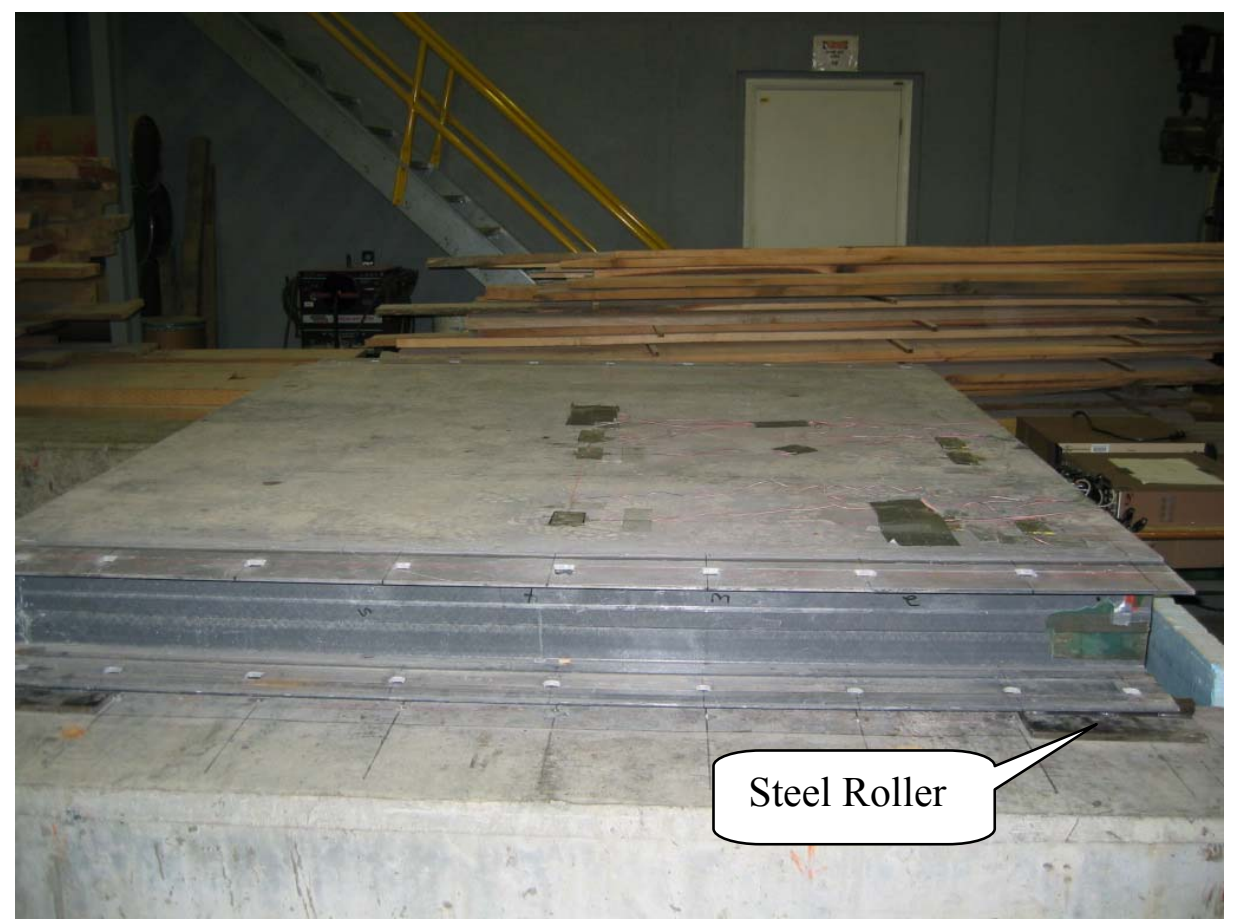

Figure 4.6: Test Set-Up for FFFF Boundary. 


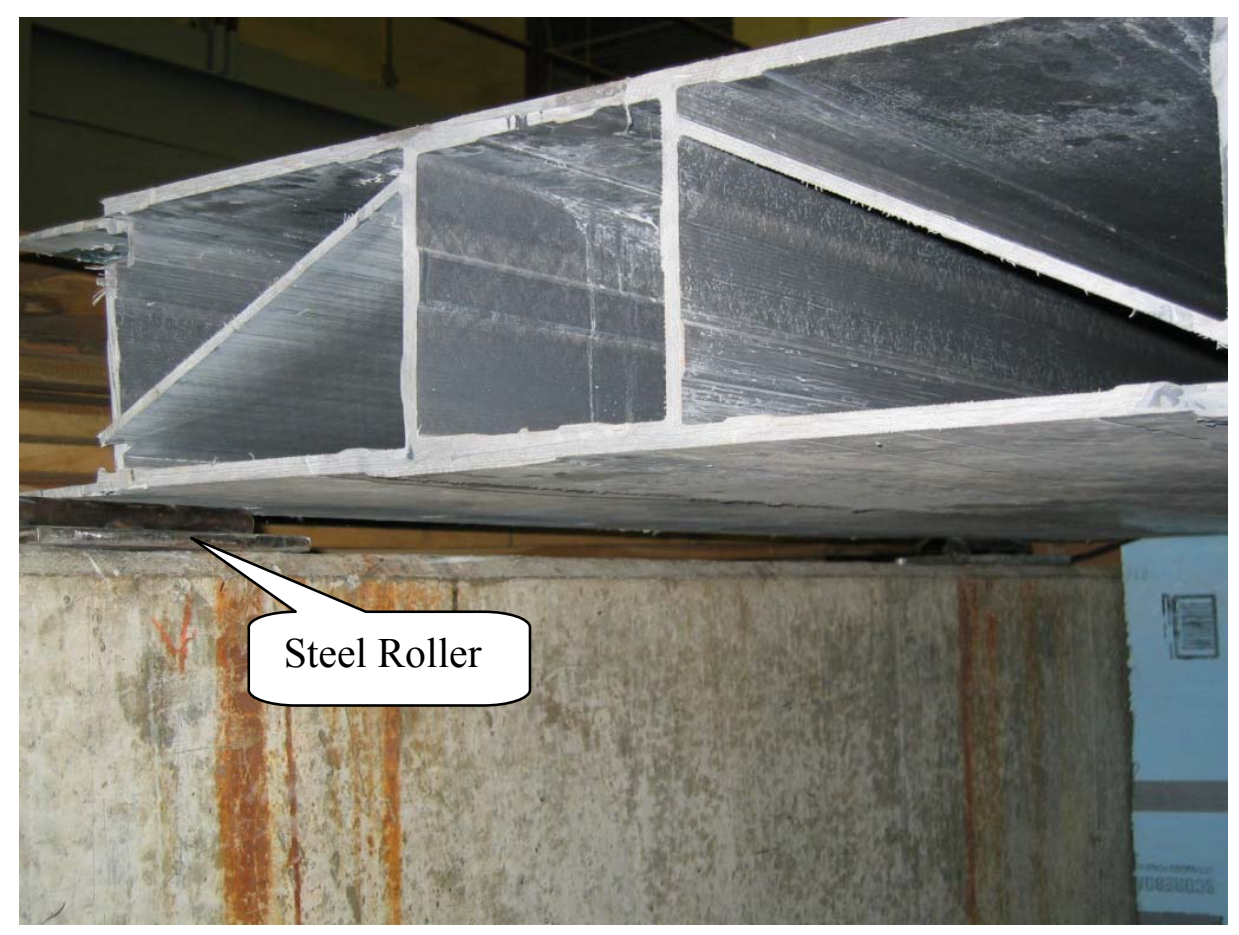

Figure 4.7: Steel Roller at the Corner of the FRP Deck.

\subsection{Instrumentation}

\subsubsection{Strain Measurement}

The type of strain gage for the test was CEA-06-250-UW-350. Refer to Vishay Measurements Group for more details.

\subsubsection{Deflection Measurement}

Deflection Data was recorded by using LVDT (Linear Variable Deflection Transducer ).

\subsubsection{Temperature Measurement}

TG sensor and LST Matching Networks were used to measure the temperature of FRP Deck Surface. Type of TG sensor and LST Matching Networks were WTG-50B and LST-100F-350D respectively. Refer to Vishay Measurements Group Inc. for more details. 


\subsubsection{Data Acquisition System}

Data acquisition system 5000 and strain smart software were used to acquire the data.

Data were recorded at low range rate of 1 sample per second. Refer to Vishay Meausurements Group Inc. for more details.

\subsubsection{Locations of Strain Gages, LVDT and Temperature Sensor}

The locations of strain gages, TG sensors and LVDT were shown in Figure 4.8 through 4.11 for both 4 and 8 in. FRP deck specimens. 


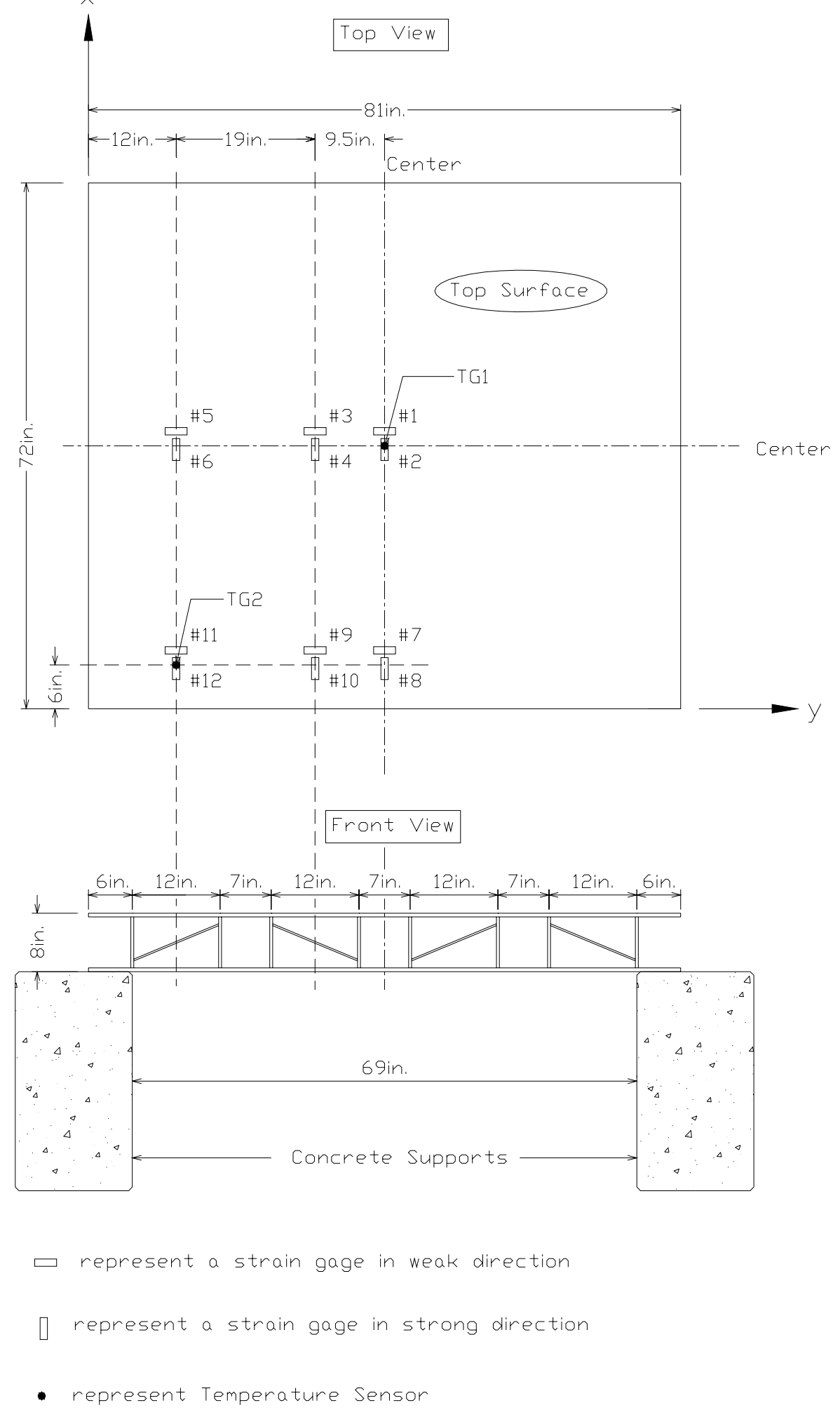

Figure 4.8: Locations of all Sensors on Top Surface of 8 inch. FRP Deck. 


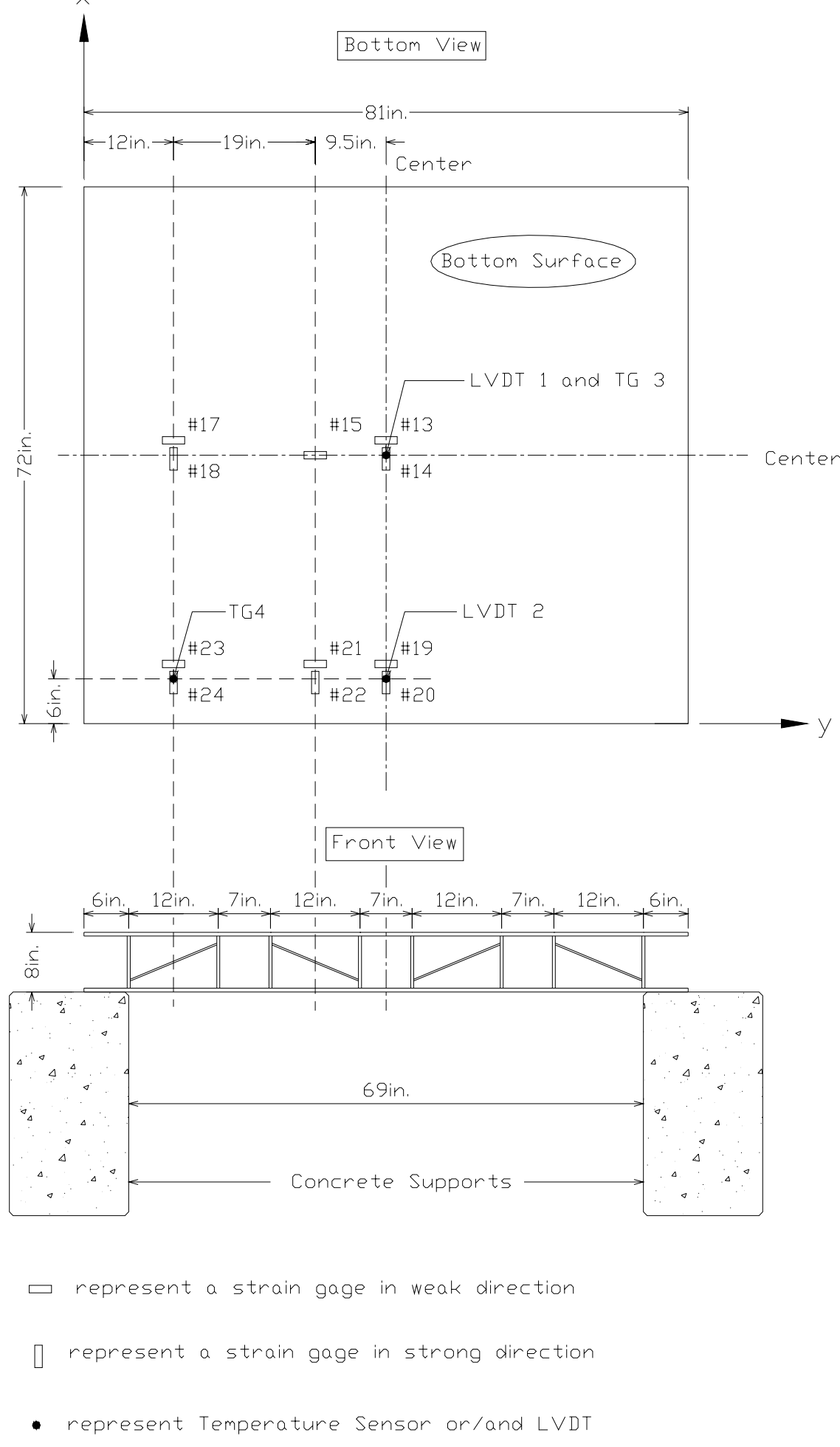

Figure 4.9: Location of all Sensors on Bottom Surface of 8 inch FRP Deck. 


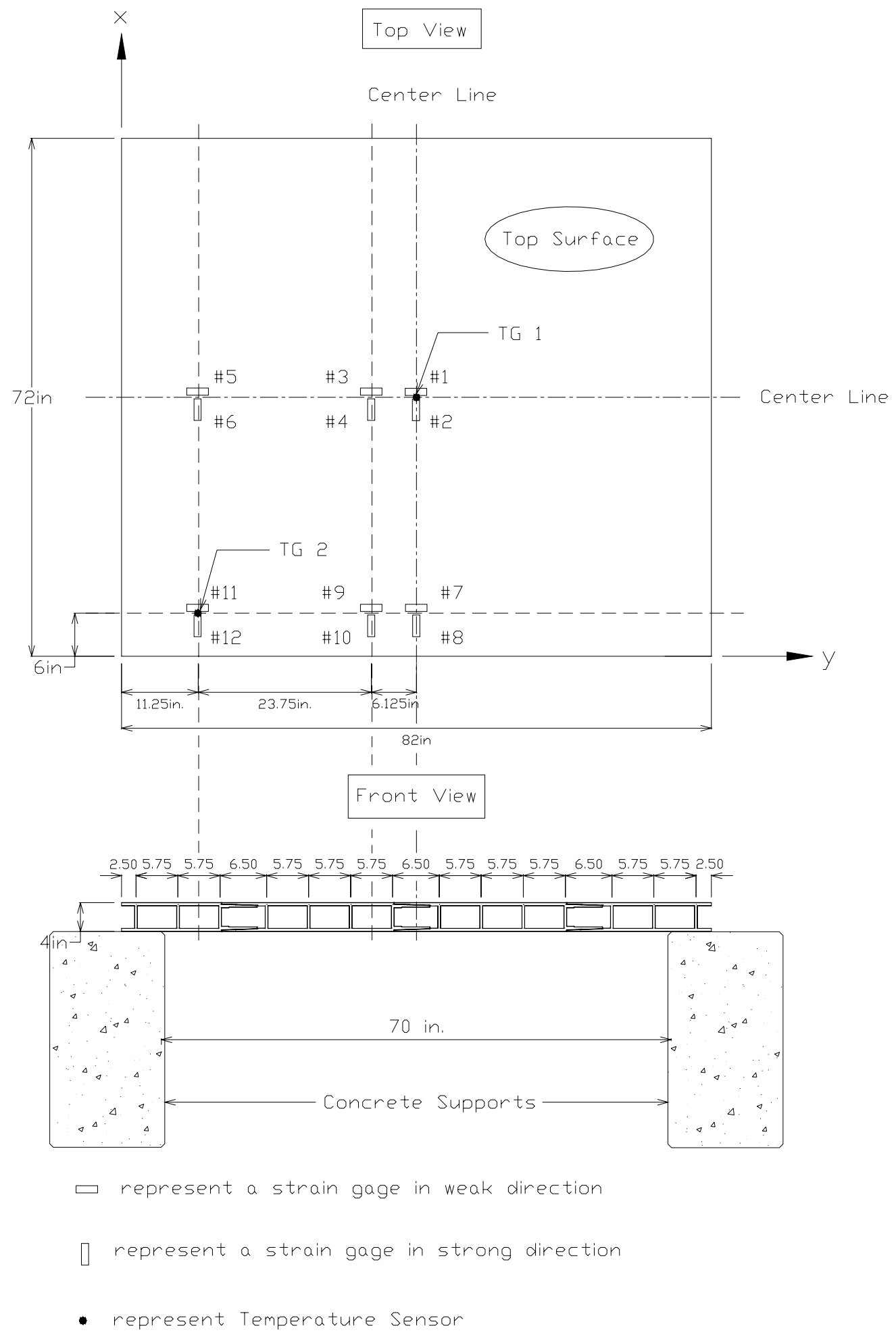

Figure 4.10: Locations of all Sensors on Top Surface of 4 inch FRP Deck. 


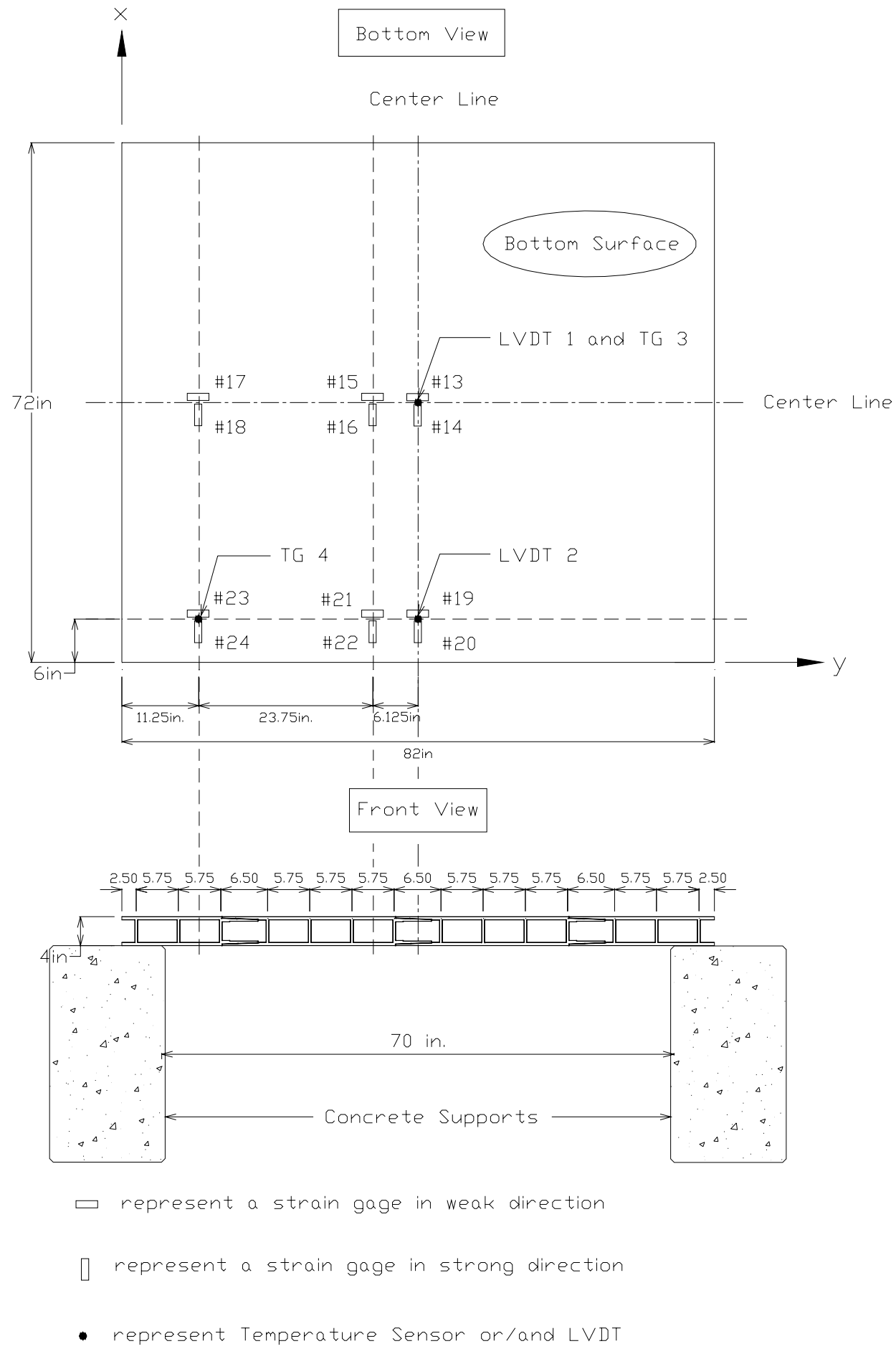

Figure 4.11: Locations of all Sensors on Bottom Surface of 4 inch FRP Deck. 


\subsection{Test Procedures}

The test procedures for heating tests were different from that of the cooling tests. In the case of heating test, the top surface of the FRP bridge deck was heated from a propane heater while the bottom surface of FRP deck was left at room temperature. The temperature of the top surface of FRP deck in the heating test was maintained around $150^{\circ}$ to $155^{\circ} \mathrm{F}$, which was the typical temperature found in the field on a hot sunny day. In the case of a cooling test, the top surface of the FRP bridge deck was subjected to cooling with dry ice while the bottom surface of FRP bridge deck was left at room temperature. In general, temperature of dry ice was around $-110^{\circ} \mathrm{F}$. This can be used in the cooling test to cool temperature of the top surface of FRP deck down to temperature as low as -20 to $-40{ }^{\circ} \mathrm{F}$ depending on the amount of dry ice. The heating and cooling test procedure was presented in section 4.5.1 and 4.5.2.

\subsubsection{Heating Test Procedure}

The top surface of FRP deck was heated by the propane heater until the temperature reached $150^{\circ}-155^{\circ} \mathrm{F}$ while the bottom surface was left at a room environment. This created a positive temperature difference, the difference of top and bottom deck temperature. The stepby-step heating test procedure is described below:

1. Setting up deck boundary for SSFF or FFFF Boundary (Refer to 4.3.1 or 4.3.2 for test setup).

2. Placing the propane heater at the center on the top surface of the FRP deck. Heat from heater can be adjusted manually. 
3. Covering the entire top surface of the deck with aluminum box as shown in Figure 4.12. The aluminum box had an adjusted opening as shown in Figure 4.13 to allow heat out if temperature was too high.

4. Air conditioning or fan can be used to maintain the temperature of the bottom deck closed to room temperature.

5. Connecting all sensors to data acquisition system and start recording the data.

6. Turning on the heater and adjusting the heater until the temperature of top surface reaches $150^{\circ} \mathrm{F}$ and keeping this temperature for 2 hours.

7. Turning off the heater and allow the FRP deck to cool down to room temperature and stop recording the data after temperature of FRP deck drop down to room temperature.

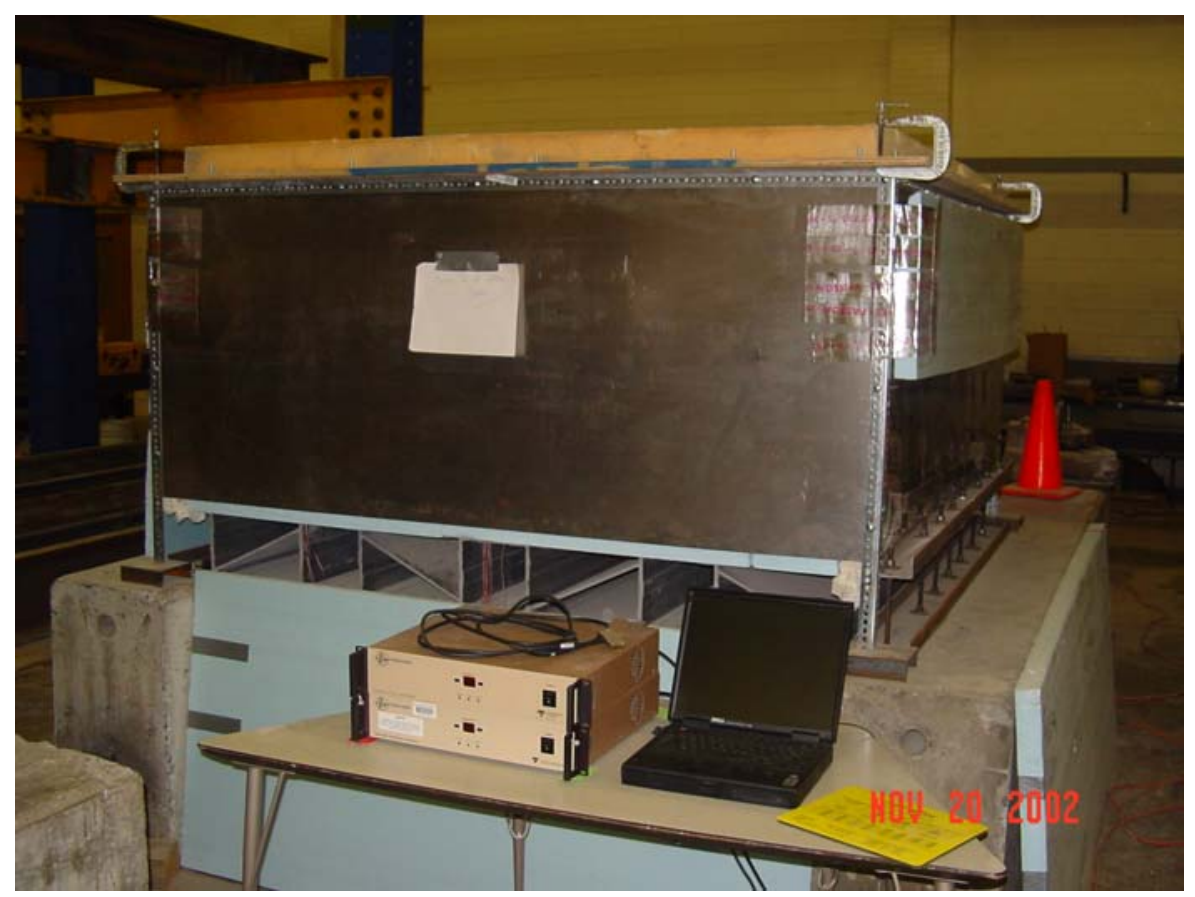

Figure 4.12: The Aluminum Cover Box. 


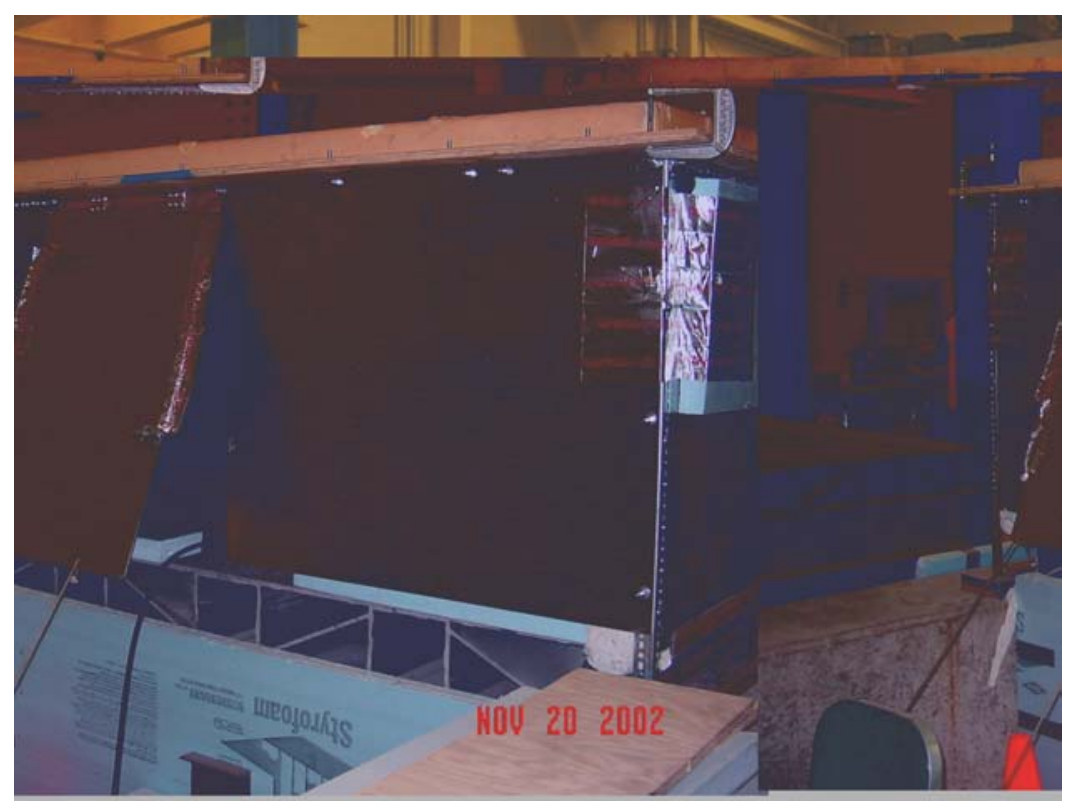

Figure 4.13 The Adjusted Opening Window.

\subsubsection{Cooling Test Procedure}

The top surface of deck was cooled to around $-30{ }^{\circ} \mathrm{F}$ to $-40{ }^{\circ} \mathrm{F}$ while the bottom surface was left at room temperature. This created negative temperature difference. The step by step heating test procedure was described through following:

1. Setting up deck boundary for SSFF or FFFF Boundary (Refer to 4.3.1 or 4.3.2 for test setup).

2. Covering the entire top surface of FRP deck with the plastic sheet ( Figure 4.14) in order to protect sensors and remove dry ice after testing.

3. Connecting all sensors to data acquisition and start recording the data. At this stage, there is no thermal load applied to FRP deck.

4. Covering entire top surface of FRP deck with $120 \mathrm{lbs}$ of pebble dry ice (Figure 4.15).

5. Covering dry ice with plastic sheet and insulation sheet as shown in Figure 4.16 and 4.17. 
6. Keep recording data for at least 2 hrs after FRP deck reaching its lowest temperature (around $-30{ }^{\circ} \mathrm{F}$ to $-40{ }^{\circ} \mathrm{F}$ ).

7. Removing insulation sheet and dry ice from the FRP deck.

8. Stop recording the data after the deck temperature rises to room temperature.

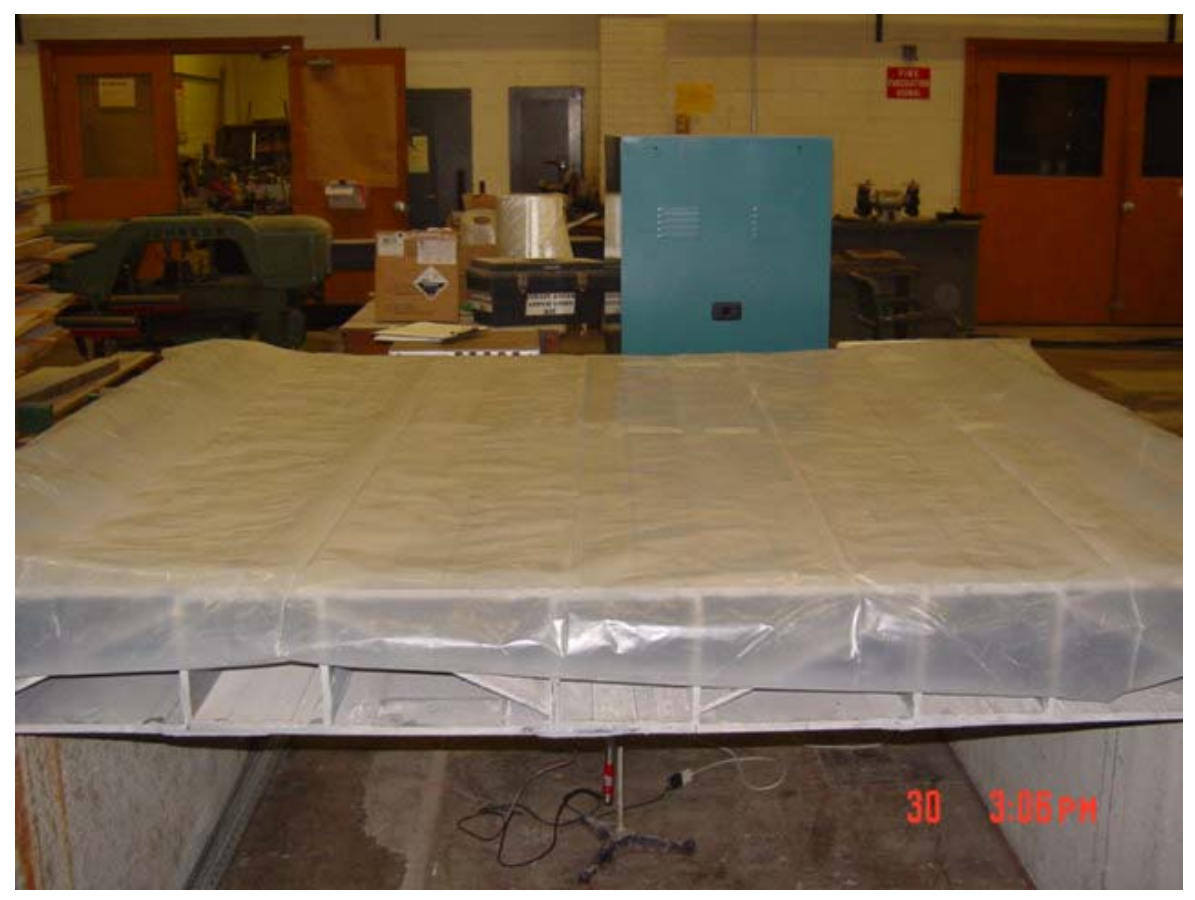

Figure 4.14: Plastic Sheet Covered the Entire Top Surface. 


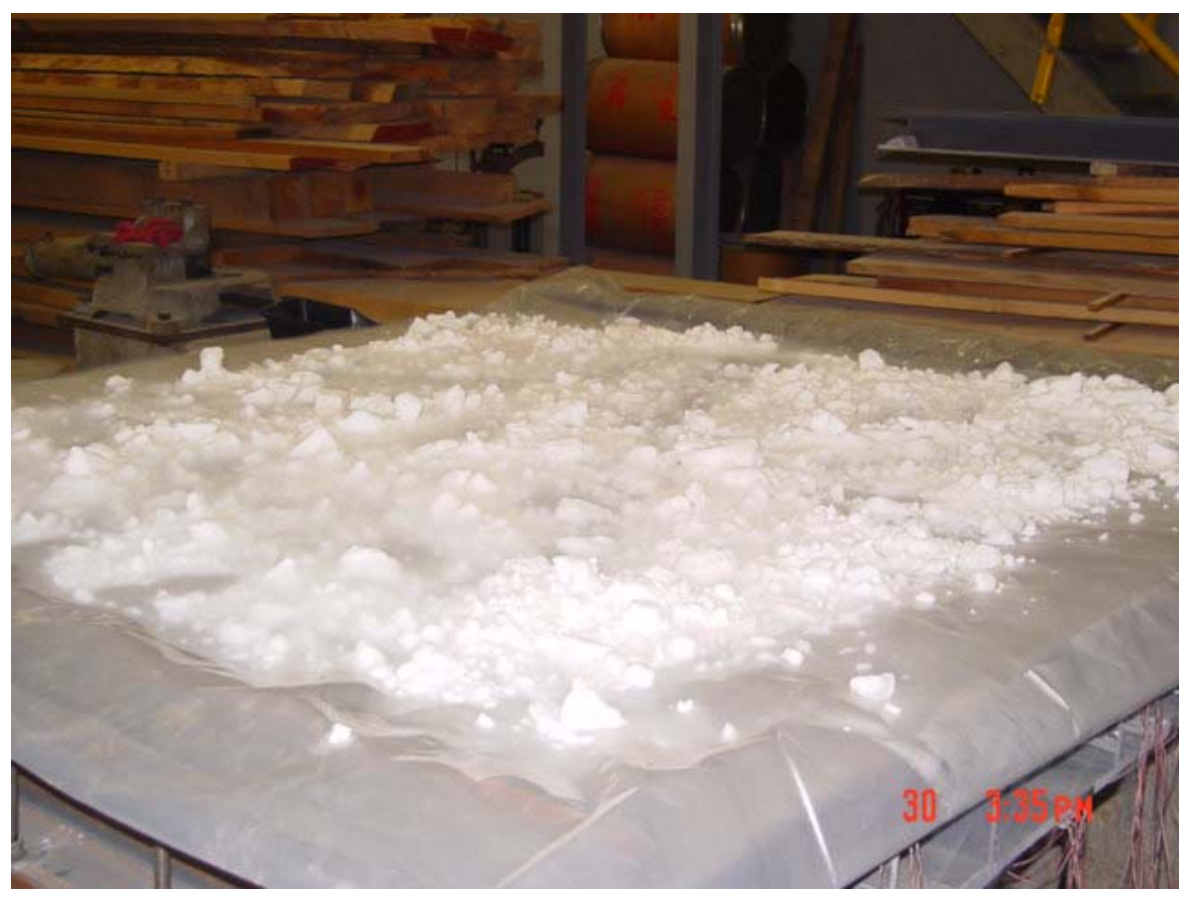

Figure 4.15: Applying Dry Ice on the Top Surface of FRP Deck.

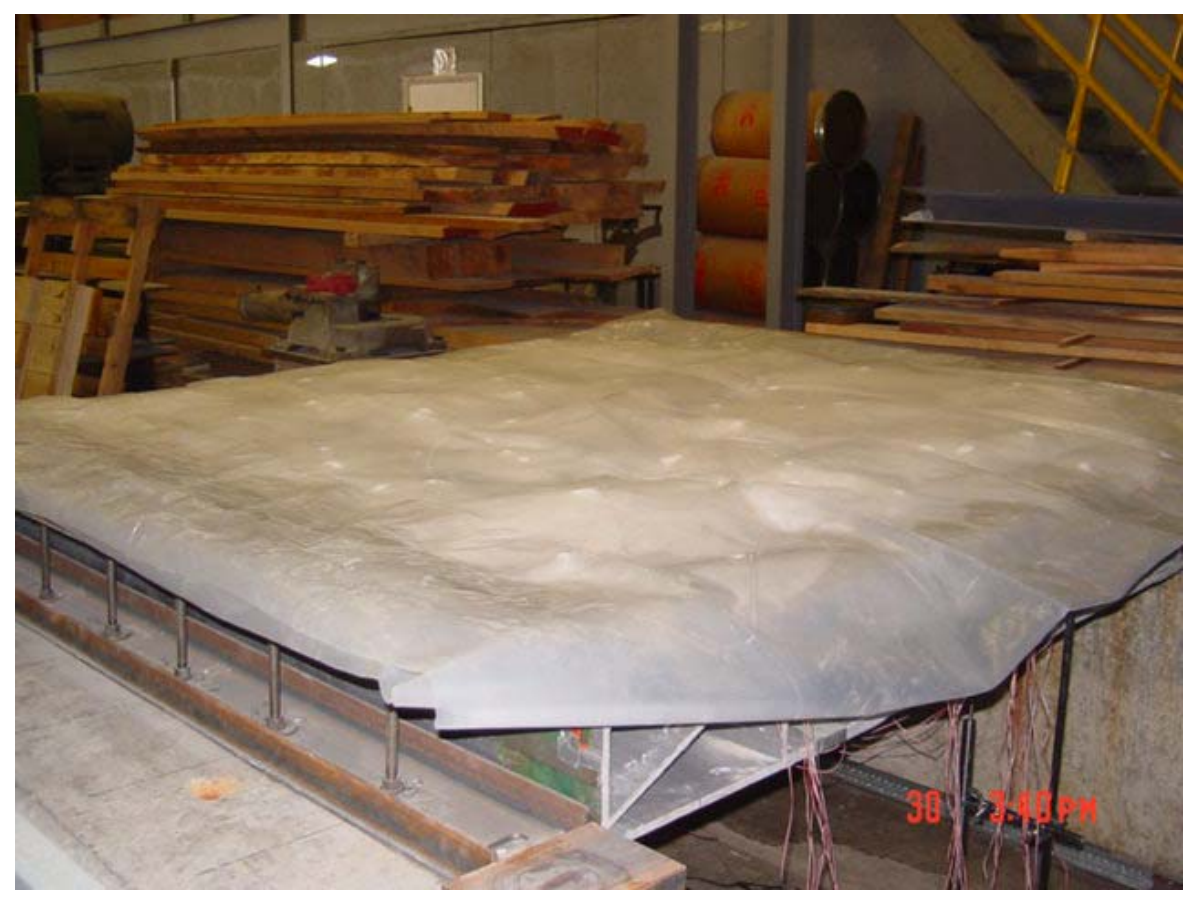

Figure 4.16: Covering the Dry Ice with Plastic Sheet. 


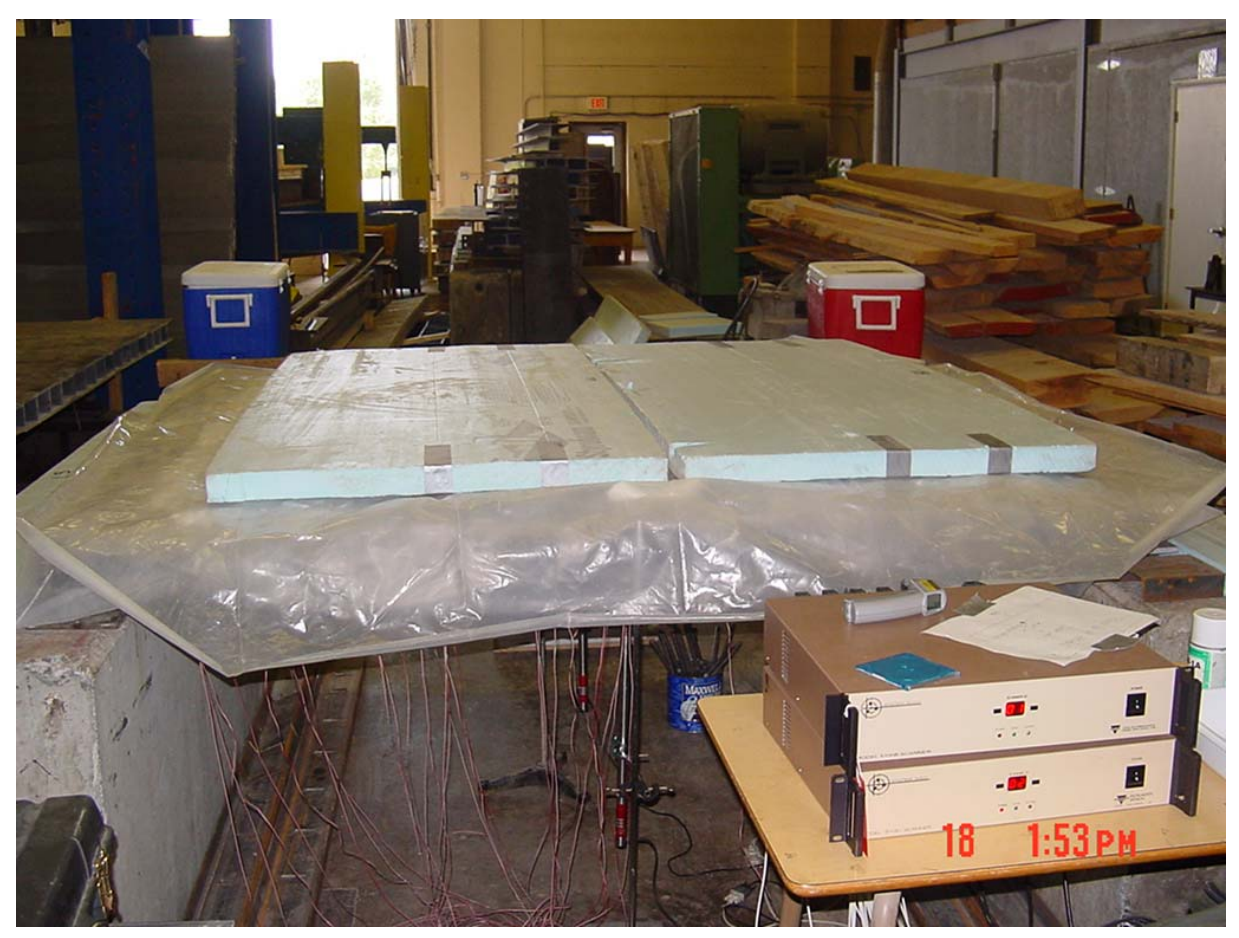

Figure 4.17: Insulation Sheets Covered on the Top of Dry Ice.

\subsection{Test Results for both 8 inch and 4 inch FRP Deck Specimens}

Some of the test results were presented in this section. All of the test data can be found in Appendix C and D for 4 inch and 8 inch FRP deck specimens.

\subsubsection{Test Results for 8 in. FRP deck specimen}

\subsubsection{Test Results for Test Case 8HS (Heating Test + SSFF Boundary)}

\section{Temperature Data at the center on the top and bottom surface}

The temperature data of top and bottom surface were represented by temperature sensor TG \#1 and TG \#3, respectively (Refer to Figure 4.8 and 4.9). The results are shown in Figure 4.18. The two letters at the right top corner of Figure 4.18 represented the notation of the test case. For example, $8 \mathrm{HS}$ represented 8 inch FRP deck + Heating Test + SSFF Boundary. 


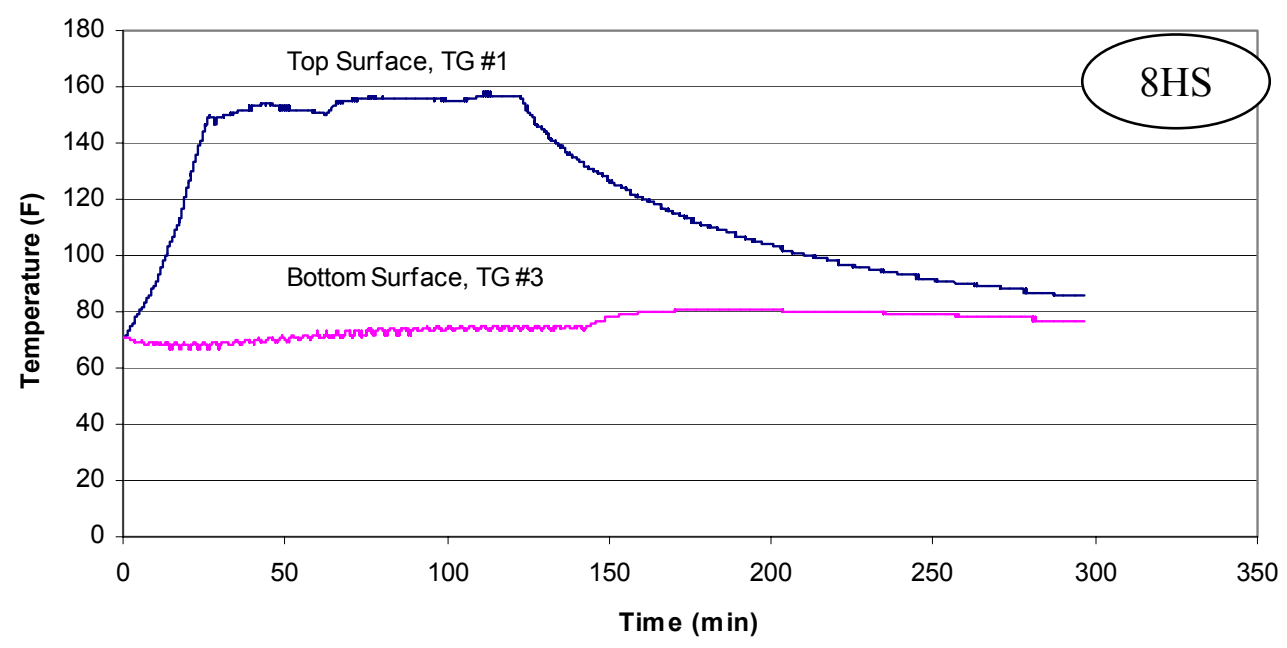

Figure 4.18: Deck Temperature Versus Testing Time.

\section{Temperature Difference Between Top and Bottom Surface of FRP Deck}

Temperature difference, $\Delta \mathrm{T}$, was calculated using the following equation.

$$
\Delta \mathrm{T}=\mathrm{T}_{\text {top }}-\mathrm{T}_{\text {bottom }}
$$

where

$$
\begin{aligned}
& \Delta \mathrm{T}=\text { Temperature Difference } \\
& \mathrm{T}_{\text {top }}=\text { Temperature of Top Deck Surface ( Data from TG \#1@ center ) } \\
& \mathrm{T}_{\text {bottom }}=\text { Temperature of Bottom Deck Surface ( Data from TG\#3@ center ) }
\end{aligned}
$$

The temperature data from Figure 4.18 were substituted into the above equation and are shown in Figure 4.19. 


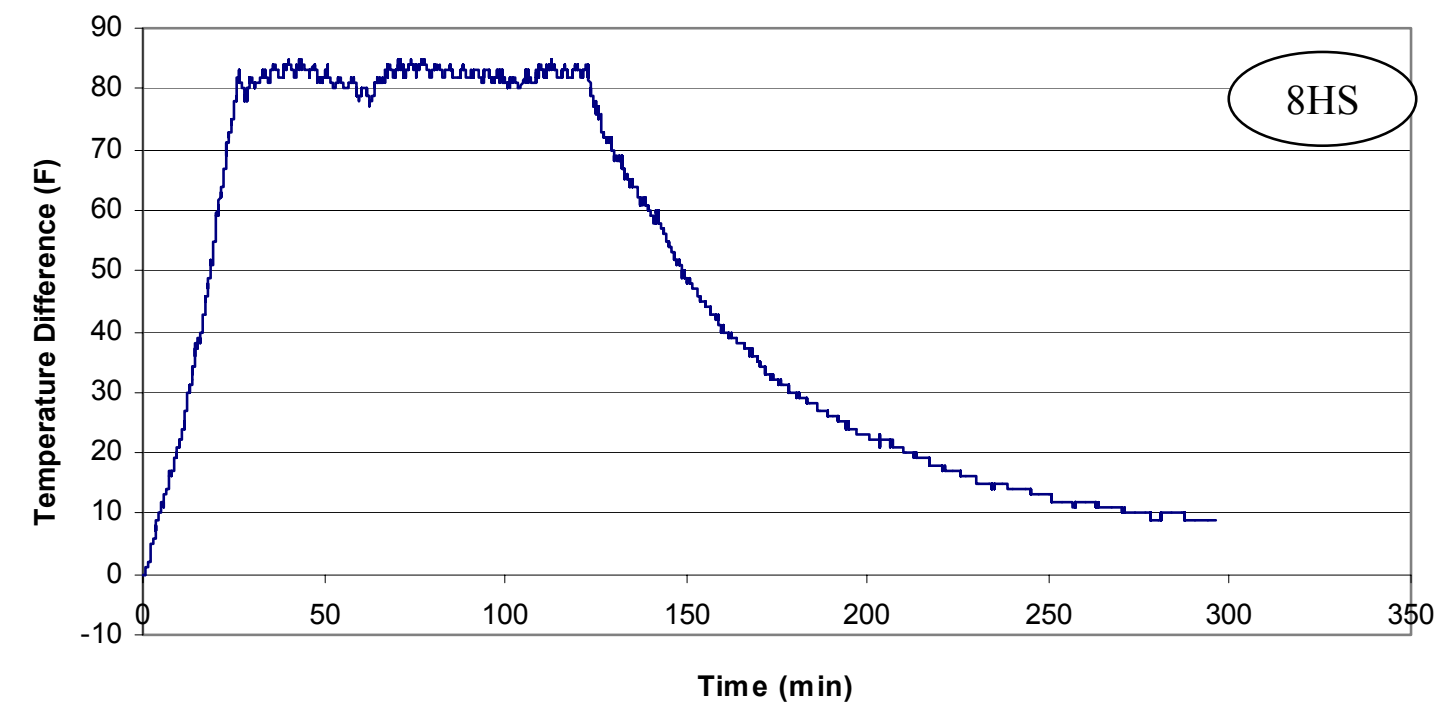

Figure 4.19: Temperature Difference Between Top and Bottom Deck Surface.

\section{Deflection Data at the center and edge}

The deflection locations at the center and edge of FRP deck were represented by LVDT \#1 and \#2 ( Refer to Figure 4.8 for detail ). The deflection data versus testing time was plotted as shown in the following Figure (Figure 4.20). 


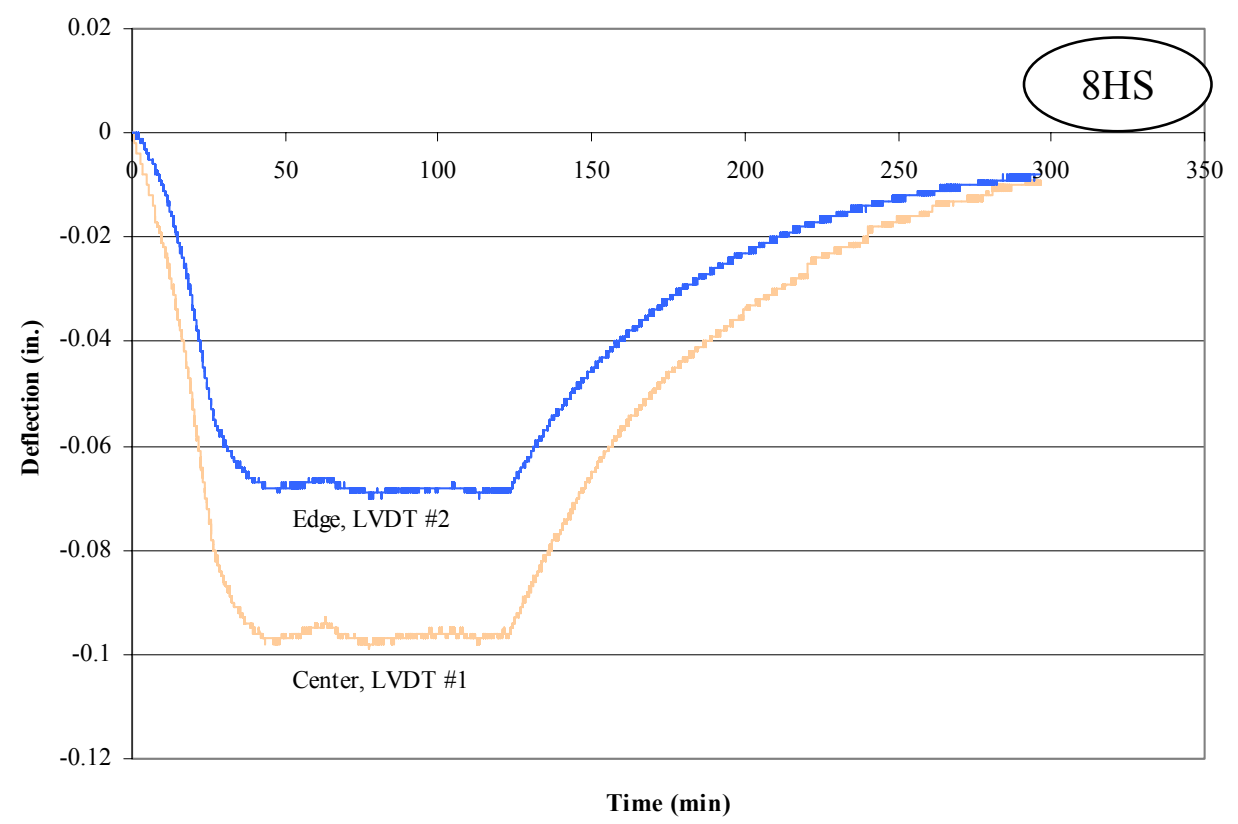

Figure 4.20: Deflection VS Testing Time at Center and Edge of FRP Deck.

\section{Strain data at the center of top surface}

Strain gage \#1 was located at the center of top surface (Refer to Figure 4.8). Strain data of gage \#1 are shown in Figure 4.21:

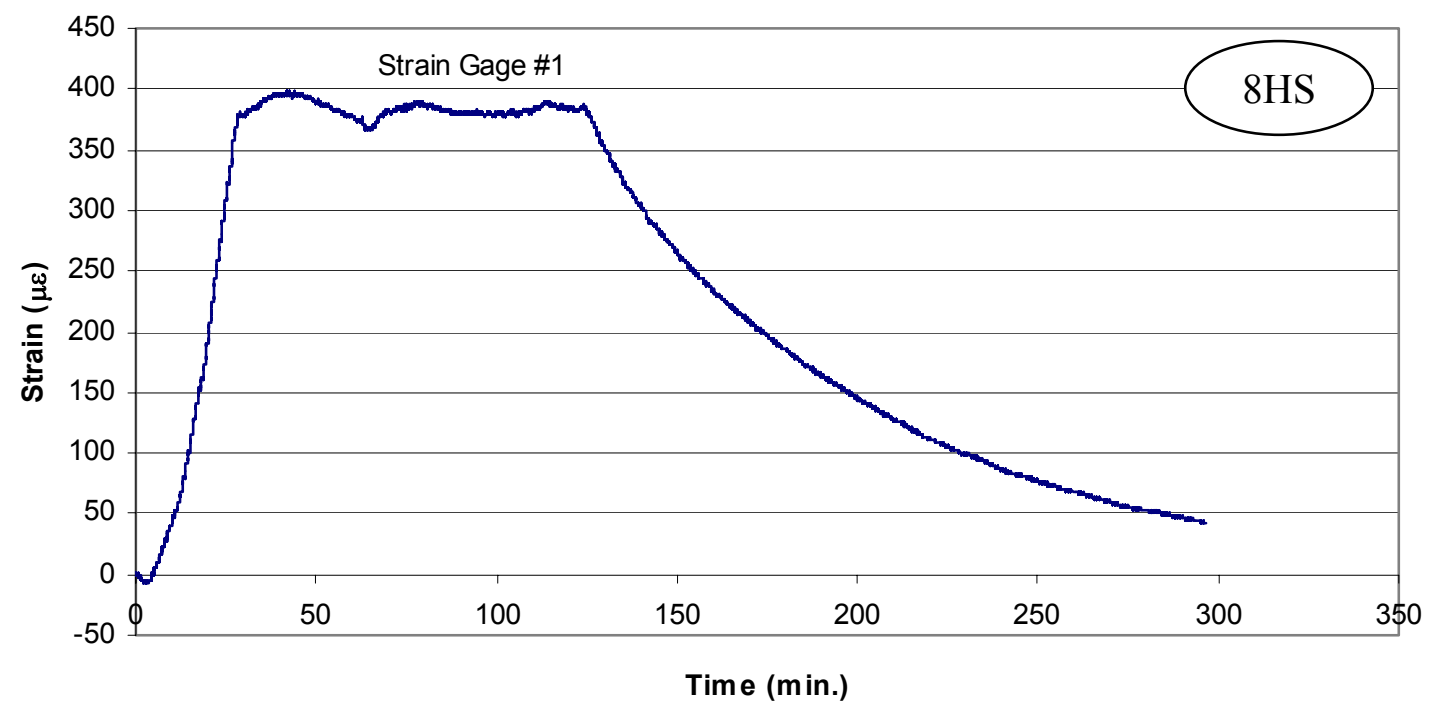

Figure 4.21: Strain Data at the Center of Top Surface. 


\subsubsection{Test Results for Test Case 8HF (Heating Test + FFFF Boundary)}

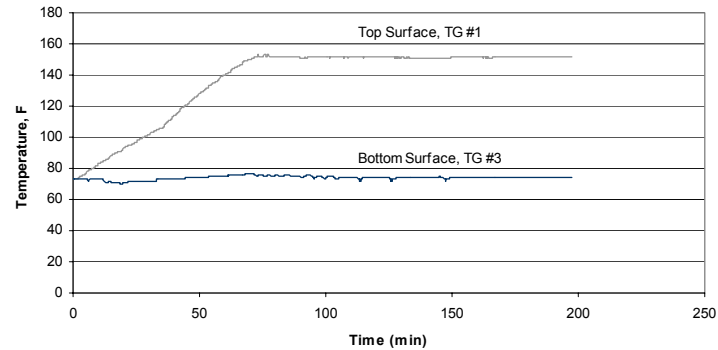

Figure 4.22

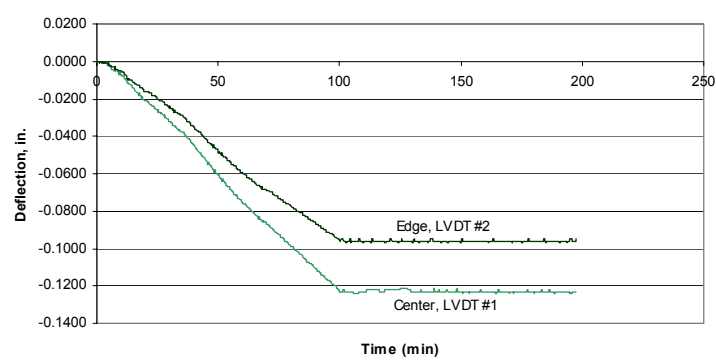

Figure 4.24

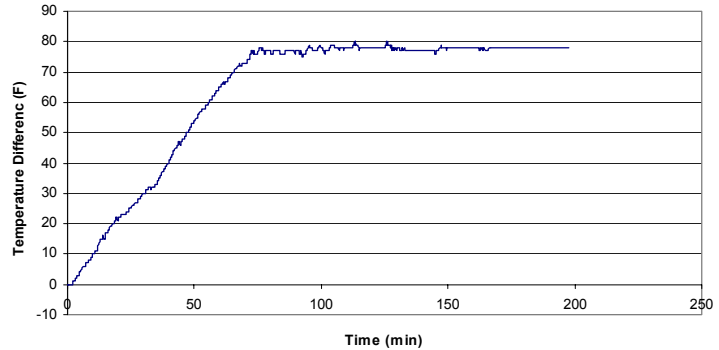

Figure 4.23

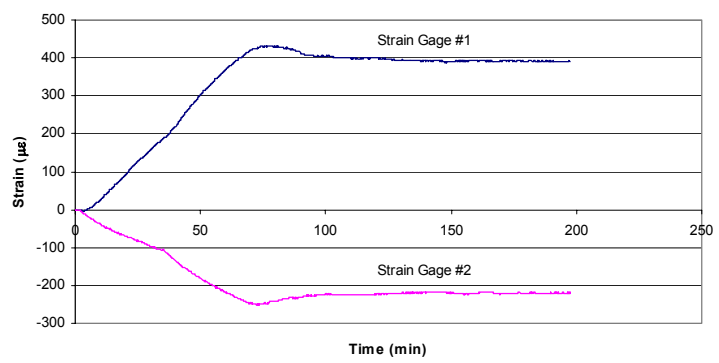

Figure 4.25

The following were titles of above Figures :

Figure 4.22: Deck Temperature VS Testing Time (Test Case 8HF).

Figure 4.23: Temperature Difference between Top and Bottom Deck Surface(Test Case 8HF)

Figure 4.24: Deflection VS Testing Time at Center and Edge of FRP Deck (Test Case 8HF).

Figure 4.25: Strain Data at the Center of Top Surface (Test Case 8HF). 


\subsubsection{Test Results for Test Case 8CS (Cooling Test + SSFF Boundary)}

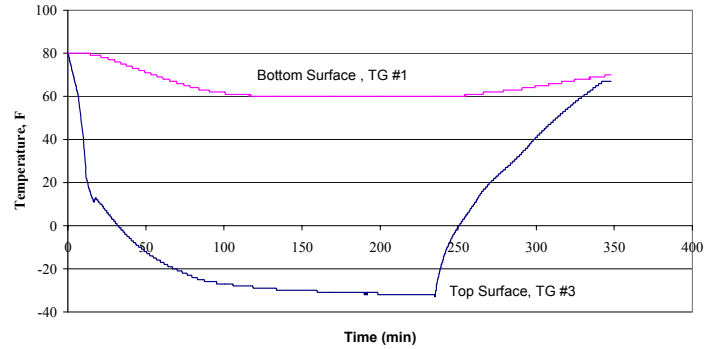

Figure 4.26

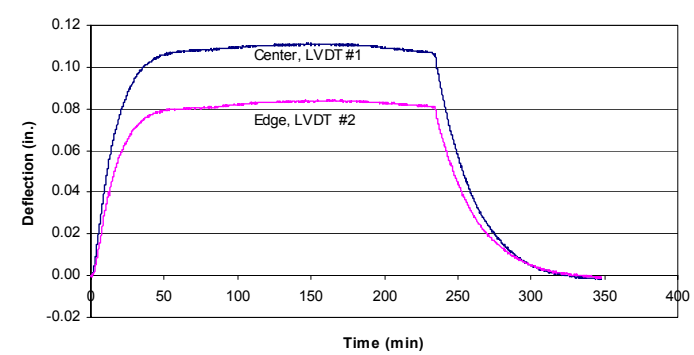

Figure 4.28

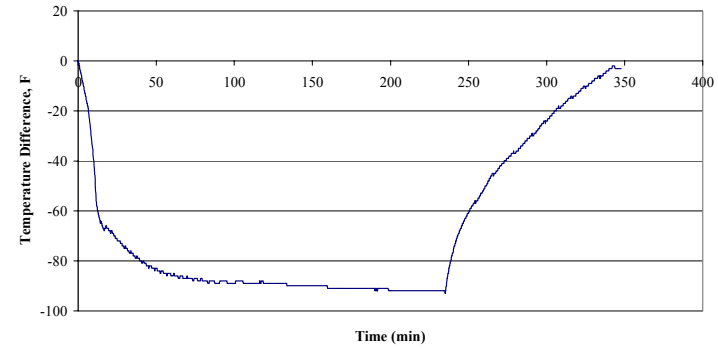

Figure 4.27

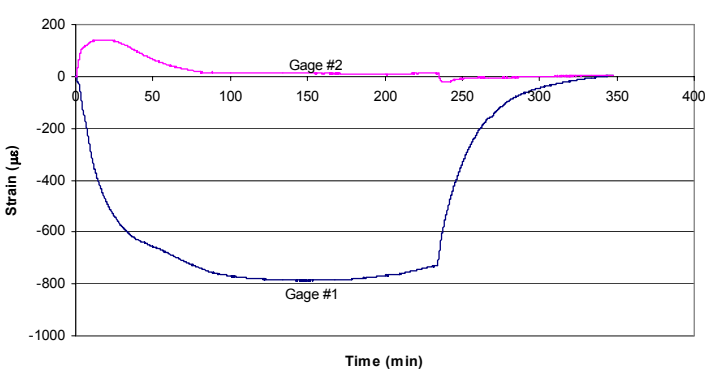

Figure 4.29

The following were titles of above Figures :

Figure 4.26: Deck Temperature VS Testing Time (Test Case 8CS).

Figure 4.27: Temperature Difference between Top and Bottom Deck Surface(Test Case 8CS)

Figure 4.28: Deflection VS Testing Time at Center and Edge of FRP Deck (Test Case 8CS).

Figure 4.29: Strain Data at the Center of Top Surface (Test Case 8CS). 


\subsubsection{Test Results for Test Case 8CF (Cooling Test + FFFF Boundary)}

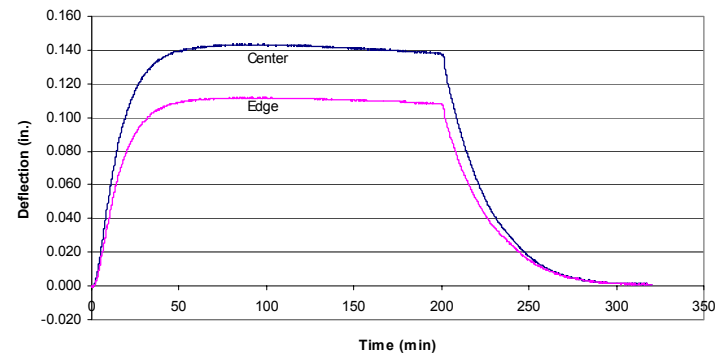

Figure 4.30

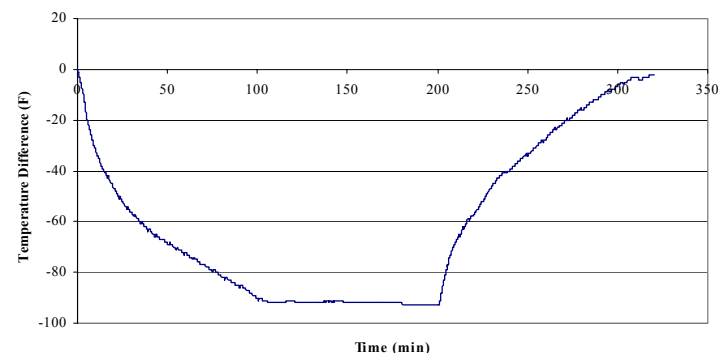

Figure 4.32

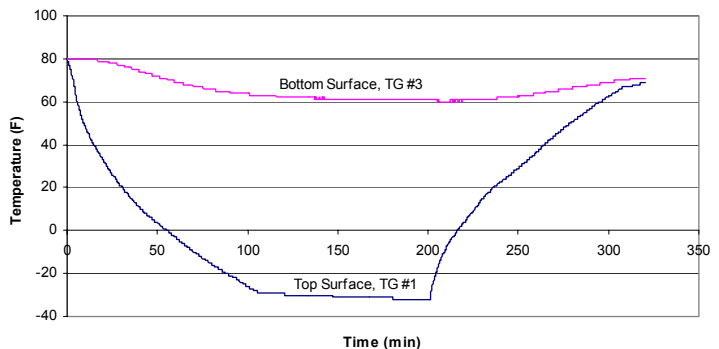

Figure 4.31

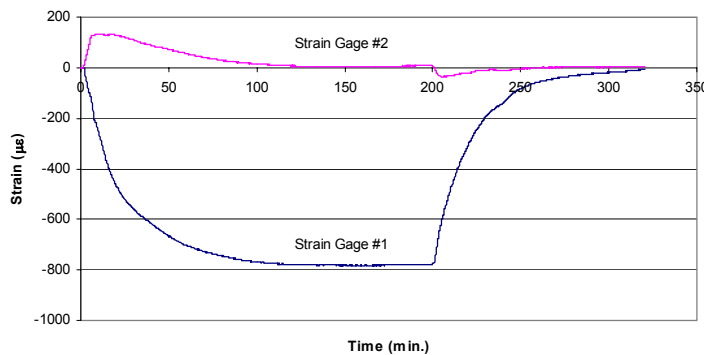

Figure 4.33

The following were titles of above Figures :

Figure 4.30: Deck Temperature Versus Testing Time (Test Case 8CF).

Figure 4.31: Temperature Difference between Top and Bottom Deck Surface(Test Case 8CF) Figure 4.32: Deflection VS Testing Time at Center and Edge of FRP Deck (Test Case 8CF). Figure 4.33: Strain Data at the Center of Top Surface (Test Case 8CF). 


\subsubsection{Test Results for 4 in. FRP Deck}

\subsubsection{Test Results for Test Case 4HS (Heating Test + SSFF Boundary)}

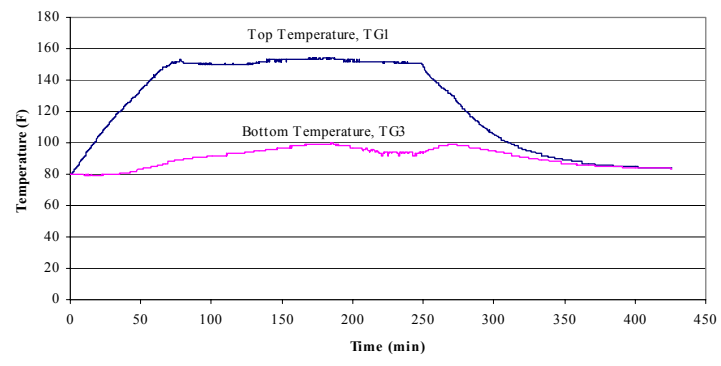

Figure 4.34

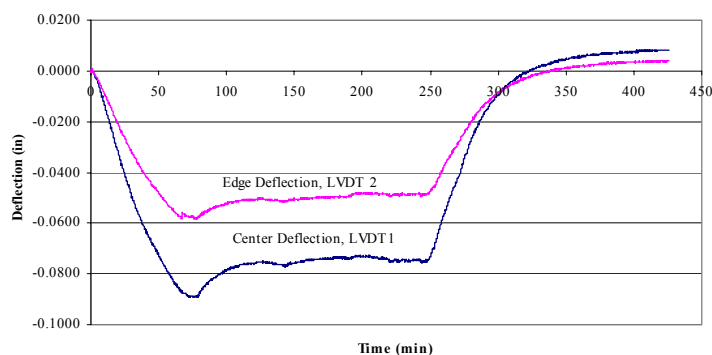

Figure 4.36

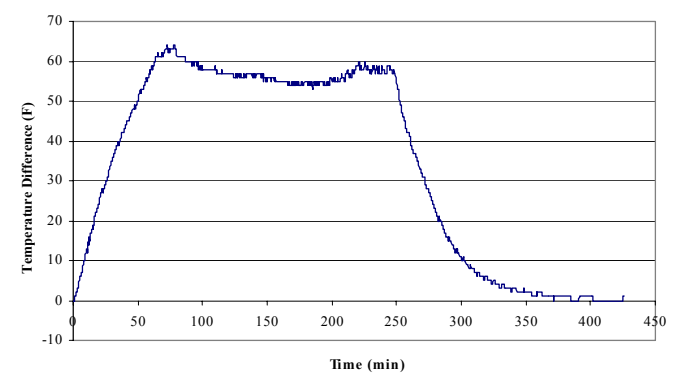

Figure 4.35

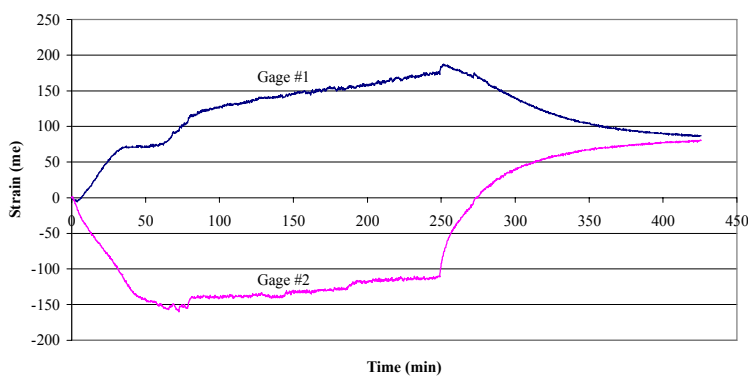

Figure 4.37

The following were titles of above Figures :

Figure 4.34: Deck Temperatures VS Testing Time (Test Case 4HS).

Figure 4.35: Temperature Difference between Top and Bottom Deck Surface(Test Case 4HS)

Figure 4.36: Deflection VS Testing Time at Center and Edge of FRP Deck (Test Case 4HS).

Figure 4.37: Strain Data at the Center of Top Surface (Test Case 4HS). 


\subsubsection{Test Results for Test Case 4HF (Heating Test + FFFF Boundary)}

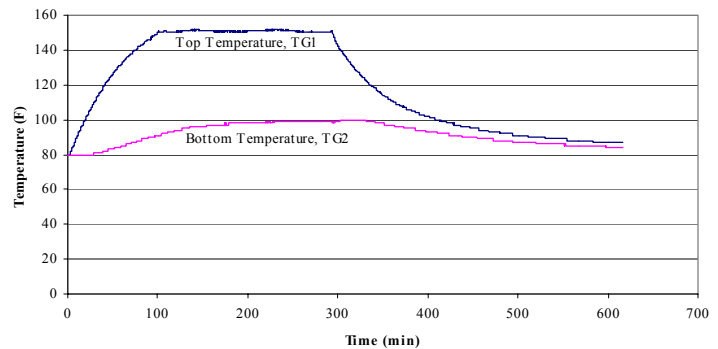

Figure 4.38

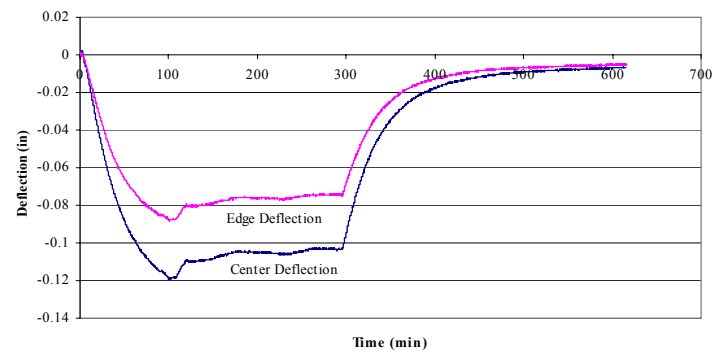

Figure 4.40

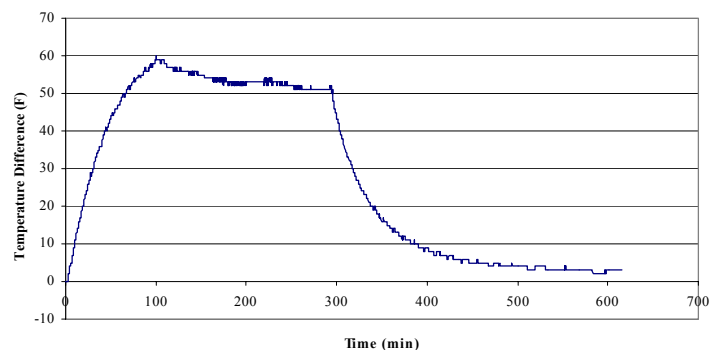

Figure 4.39

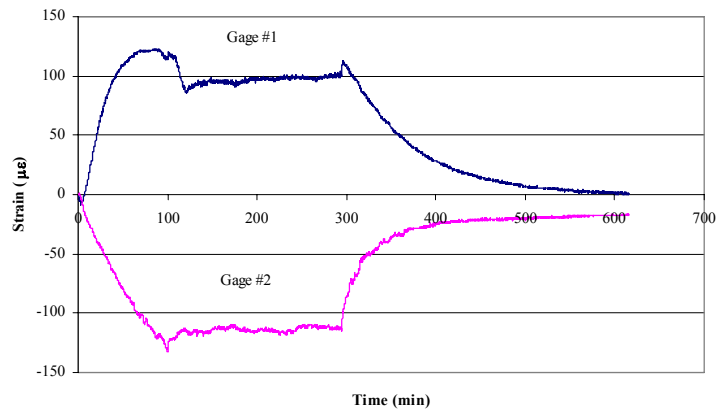

Figure 4.41

The following were titles of above Figures :

Figure 4.38: Deck Temperatures VS Testing Time (Test Case 4HF).

Figure 4.39: Temperature Difference between Top and Bottom Deck Surface(Test Case 4HF)

Figure 4.40: Deflection VS Testing Time at Center and Edge of FRP Deck (Test Case 4HF).

Figure 4.41: Strain Data at the Center of Top Surface (Test Case 4HF). 


\subsubsection{Test Results for Test Case 4CS (Cooling Test + SSFF Boundary)}

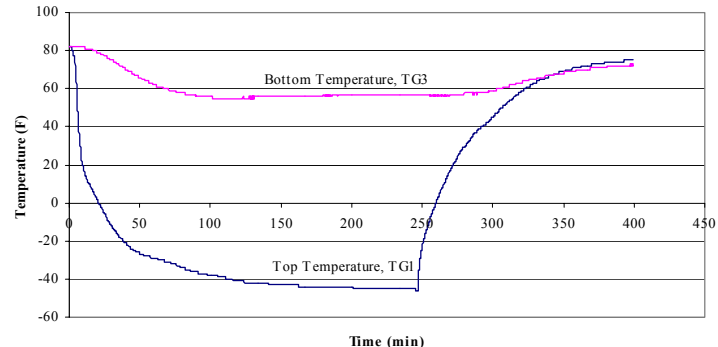

Figure 4.42

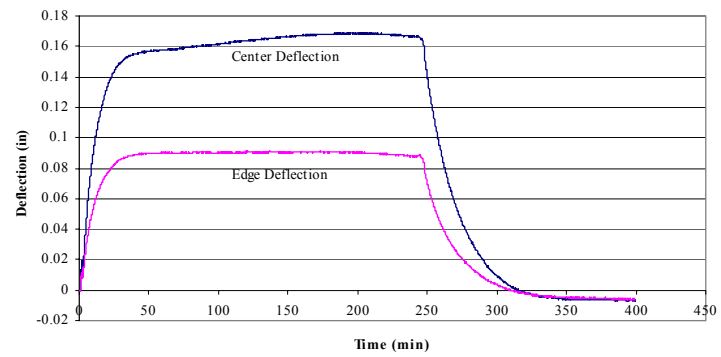

Figure 4.44

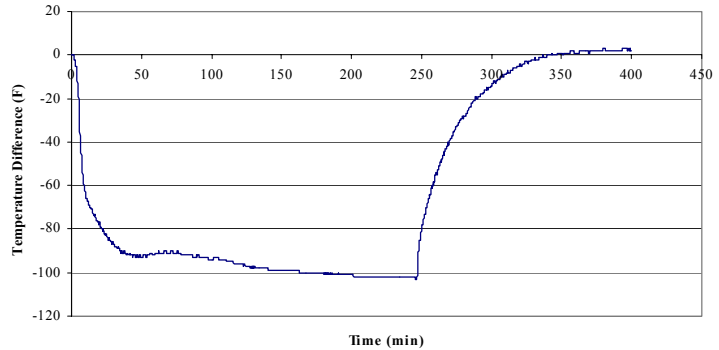

Figure 4.43

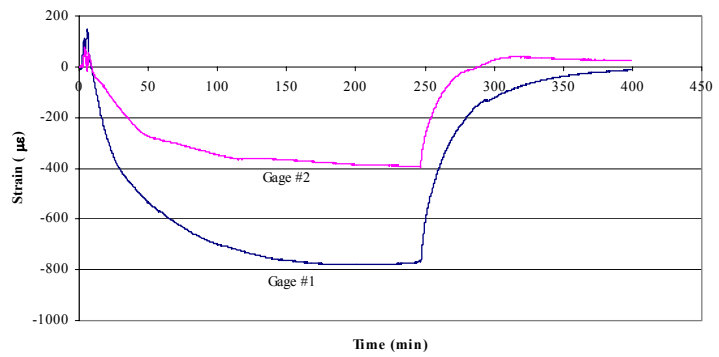

Figure 4.45

The following were titles of above Figures :

Figure 4.42: Deck Temperatures VS Testing Time (Test Case 4CS).

Figure 4.43: Temperature Difference between Top and Bottom Deck Surface(Test Case 4CS)

Figure 4.44: Deflection VS Testing Time at Center and Edge of FRP Deck (Test Case 4CS).

Figure 4.45: Strain Data at the Center of Top Surface (Test Case 4CS). 


\subsubsection{Test Results for Test Case CF (Cooling Test + FFFF Boundary)}

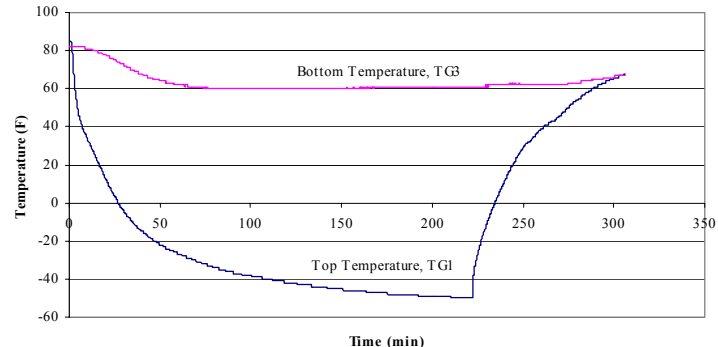

Figure 4.46

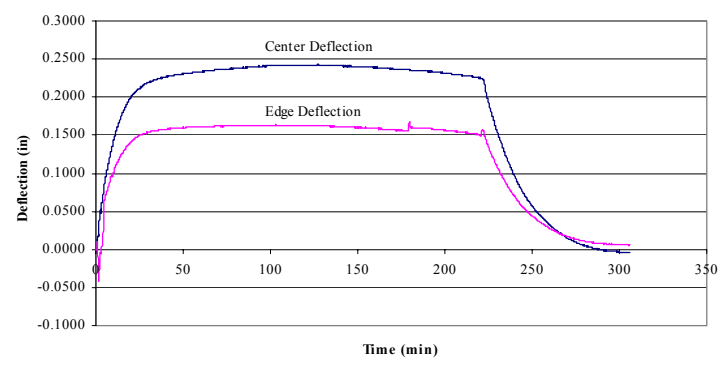

Figure 4.48

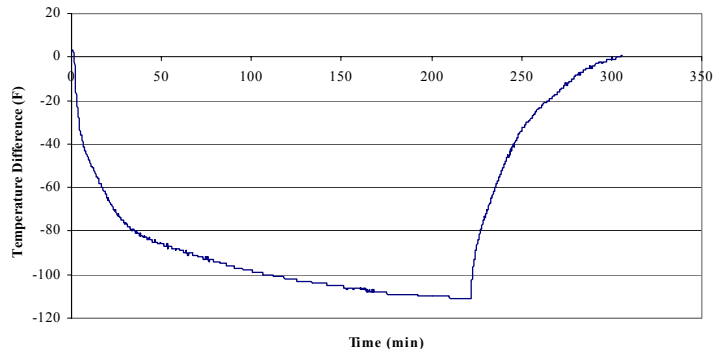

Figure 4.47

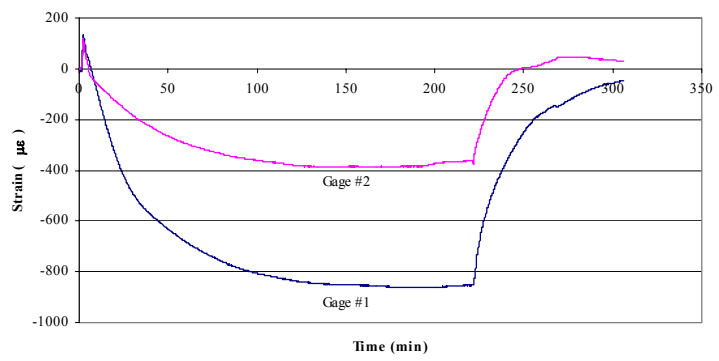

Figure 4.49

The following were titles of above Figures :

Figure 4.46: Deck Temperatures VS Testing Time (Test Case 4CF).

Figure 4.47: Temperature Difference between Top and Bottom Deck Surface(Test Case 4CF)

Figure 4.48: Deflection VS Testing Time at Center and Edge of FRP Deck (Test Case 4CF).

Figure 4.49: Strain Data at the Center of Top Surface (Test Case 4CF). 
According to the results from figures 4.18 to 4.49 , the experimental data for all test cases were tabulated in Tables 4.1 and 4.2 for 8 inch and 4 inch FRP deck specimens. The test data was chosen at the testing time (between 100 and 200 minutes) after establishing constant temperature load.

\begin{tabular}{|c|c|c|c|c|}
\hline \multicolumn{5}{|c|}{ Experimental Data for 8 in. FRP Deck } \\
\hline \multirow{2}{*}{$\begin{array}{l}\text { Test Conditions } \\
\text { Boundary Conditions }\end{array}$} & \multicolumn{2}{|c|}{ Heating Test } & \multicolumn{2}{|c|}{ Cooling Test } \\
\hline & SSFF & FFFF & SSFF & FFFF \\
\hline Notations of Test Case & $8 \mathrm{HS}$ & $8 \mathrm{HF}$ & $8 \mathrm{CS}$ & $8 \mathrm{CF}$ \\
\hline Results at Testing Time (min.) & 100 & 150 & 150 & 150 \\
\hline Top Surface Temperature, $T_{t o p},\left({ }^{\circ} \mathrm{F}\right)$ & 155 & 152 & -30 & -31 \\
\hline Bottom Surface Temperature, $T_{\text {bottom }},\left({ }^{\circ} \mathrm{F}\right)$ & 74 & 74 & 60 & 61 \\
\hline Reference Temperature, $T_{r e f},\left({ }^{\circ} \mathrm{F}\right)$ & 71 & 73 & 80 & 80 \\
\hline$\Delta T_{\text {top }}=T_{t o p}-T_{r e f},\left({ }^{\circ} \mathrm{F}\right)$ & 84 & 79 & -110 & -111 \\
\hline$\Delta T_{\text {bottom }}=T_{\text {bottom }}-T_{\text {ref }},\left({ }^{\circ} \mathrm{F}\right)$ & 3 & 1 & -20 & -19 \\
\hline$\Delta T_{\max }=\Delta T_{\text {top }}-\Delta T_{\text {bottom }},\left({ }^{\circ} \mathrm{F}\right)$ & 81 & 78 & -90 & -92 \\
\hline Deflection at Center (in.), LVDT \#1 & -0.096 & -0.123 & $0.103^{\mathrm{i}}$ & $0.133^{\mathrm{i}}$ \\
\hline Deflection at Edge (in.), LVDT \#2 & -0.068 & -0.097 & $0.078^{\mathrm{i}}$ & $0.104^{\mathrm{i}}$ \\
\hline Raw Strain \#1 $(\mu \varepsilon)^{\text {ii }}$ & 381 & 391 & -787 & -782 \\
\hline Raw Strain \#2 $(\mu \varepsilon)$ ii & - & -221 & 13 & 4 \\
\hline Raw Strain \#13 $(\mu \varepsilon)^{\text {ii }}$ & -17 & -30 & -14 & -39 \\
\hline Raw Strain \#14 $(\mu \varepsilon)^{\text {ii }}$ & - & -2 & 35 & 86 \\
\hline Thermal Output of Top Surface $(\mu \varepsilon)^{\mathrm{iii}}$ & -554 & -521 & 480 & 484 \\
\hline Thermal Output of Bottom Surface $(\mu \varepsilon)^{\mathrm{iii}}$ & -20 & -7 & -87 & 83 \\
\hline True Strain $\# 1(\mu \varepsilon)$ iv & 935 & 912 & -1267 & -1266 \\
\hline True Strain \#2 $(\mu \varepsilon){ }^{\text {iv }}$ & - & 300 & -467 & -480 \\
\hline True Strain $\# 13(\mu \varepsilon)^{\text {iv }}$ & 3 & -23 & -101 & -122 \\
\hline True Strain \#14 $(\mu \varepsilon)^{\text {iv }}$ & - & 5 & -52 & 3 \\
\hline
\end{tabular}

Table 4.1: Experimental Data of 8 inch FRP Deck Specimen. 


\begin{tabular}{|c|c|c|c|c|}
\hline \multicolumn{5}{|c|}{ Experimental Data for 4 in. FRP Deck } \\
\hline \multirow{2}{*}{$\begin{array}{l}\text { Test Conditions } \\
\text { Boundary Conditions }\end{array}$} & \multicolumn{2}{|c|}{ Heating Test } & \multicolumn{2}{|c|}{ Cooling Test } \\
\hline & SSFF & FFFF & SSFF & FFFF \\
\hline Test Case & $4 \mathrm{HS}$ & $4 \mathrm{HF}$ & $4 \mathrm{CS}$ & $4 \mathrm{CF}$ \\
\hline Results at Testing Time (min) & 150 & 200 & 150 & 150 \\
\hline Top Surface Temperature, $T_{t o p},\left({ }^{\circ} \mathrm{F}\right)$ & 153 & 151 & -43 & -45 \\
\hline Bottom Surface Temperature, $T_{\text {bottom }},\left({ }^{\circ} \mathrm{F}\right)$ & 97 & 98 & 56 & 60 \\
\hline Reference Temperature, $T_{\text {ref }},\left({ }^{\circ} \mathrm{F}\right)$ & 80 & 80 & 82 & 84 \\
\hline$\Delta T_{\text {top }}=T_{\text {top }}-T_{\text {ref }},\left({ }^{\circ} \mathrm{F}\right)$ & 73 & 71 & -125 & -129 \\
\hline$\Delta T_{\text {bottom }}=T_{\text {bottom }}-T_{\text {ref }},\left({ }^{\circ} \mathrm{F}\right)$ & 17 & 18 & -26 & -24 \\
\hline$\Delta T_{\max }=\Delta T_{\text {top }}-\Delta T_{\text {bottom }},\left({ }^{\circ} \mathrm{F}\right)$ & 56 & 53 & -99 & -105 \\
\hline Deflection at Center (in.), LVDT \#1 & -0.094 & -0.105 & $0.159^{\mathrm{i}}$ & $0.232^{\mathrm{i}}$ \\
\hline Deflection at Edge (in.), LVDT \#2 & -0.051 & -0.076 & $0.085^{\mathrm{i}}$ & $0.154^{\mathrm{i}}$ \\
\hline Raw Strain \#1 $(\mu \varepsilon)^{\mathrm{ii}}$ & 146 & 96 & -762 & -852 \\
\hline Raw Strain \#2 $(\mu \varepsilon){ }^{\text {ii }}$ & -131 & -116 & -367 & -386 \\
\hline Raw Strain \#13 $(\mu \varepsilon)^{\text {ii }}$ & 59 & 10 & -92 & -170 \\
\hline Raw Strain $\# 14(\mu \varepsilon)^{\text {ii }}$ & -20 & -32 & 3 & 24 \\
\hline Thermal Output of Top Surface $(\mu \varepsilon)^{\mathrm{iii}}$ & -481 & -468 & 545 & 562 \\
\hline Thermal Output of Bottom Surface $(\mu \varepsilon)^{\mathrm{iii}}$ & -112 & -119 & 113 & 104 \\
\hline True Strain $\# 1(\mu \varepsilon)^{\text {iv }}$ & 627 & 564 & -1307 & -1414 \\
\hline True Strain $\# 2(\mu \varepsilon)^{\text {iv }}$ & 350 & 352 & -912 & -948 \\
\hline True Strain $\# 13(\mu \varepsilon)^{\text {iv }}$ & 171 & 129 & -205 & -275 \\
\hline True Strain \#14 $(\mu \varepsilon)^{\text {iv }}$ & 92 & 87 & -110 & -81 \\
\hline
\end{tabular}

Table 4.2: Experimental Data of 4 inch FRP Deck Specimen. 


\section{Note :}

$\mathrm{i}=$ The center and edge deflection data were already subtracted from 0.008 and 0.006 in., respectively, due to weight of $100-120$ lbs dry ice.

ii $=$ The raw strain was the strain value obtained from data acquisition while temperature was fluctuating. The raw strain needs to be compensated for thermal effect on strain gages to obtain true strain.

iii $=$ Thermal output was calculated by using linear interpolation from the experimental data in Tables 3.3 and 3.4 of chapter 3 . In table 3.2, strain on the reference material $\left(\varepsilon_{\text {reference material }}\right)$ in cycle 2 was $-323 \mu \varepsilon$ when the temperature changed from 72 to $121^{\circ} \mathrm{F}$ ( $\Delta T=49^{\circ} \mathrm{F}$, temperature increment). In Table 3.2, strain on the reference material $\left(\varepsilon_{\text {reference material }}\right)$ in cycle 1 was $401 \mu \varepsilon$ when the temperature changed from 72 to $-29^{\circ} \mathrm{F}$ $\left(\Delta T=92^{\circ} \mathrm{F}\right.$, temperature decrement).

In the heating test, Thermal Output per ${ }^{\circ} \mathrm{F}=\frac{-323}{49}=-6.59 \mu \varepsilon /{ }^{\circ} \mathrm{F}$.

In the cooling test, Thermal Output per ${ }^{\circ} \mathrm{F}=\frac{401}{-92}=-4.36 \mu \varepsilon /{ }^{\circ} \mathrm{F}$.

Thermal outputs from table 4.1 and 4.2 were calculated base on the following equation. Thermal Output of Top Surface $=\left(\Delta T_{\text {top }}\right) \times\left(\right.$ Thermal Output per $\left.{ }^{\circ} \mathrm{F}\right)$

Thermal Output of Bottom Surface $=\left(\Delta T_{\text {bottom }}\right) \times\left(\right.$ Thermal Output per $\left.{ }^{\circ} \mathrm{F}\right)$

iv $=$ True strain was the strain value after subtracting temperature effect on strain gage from raw strain. This can be computed by the following formula True strain (iv) = Raw Strain (ii) - Thermal Output (iii) Note : Discussions and analysis are presented in the next chapter (Chapter 5). 


\section{Chapter 5}

\section{Correlation of Laboratory Thermal Data with Theory}

This chapter focuses on the theoretical analysis (stresses, strains, and deflections) for FRP bridge deck components ( 8 inch and 4 inch deep) under thermal loads. The analysis was based on Navier-Levy, Macro approach, and Finite Element Method (FEM). The procedure for force and deformation computations using Navier-Levy and Macro approaches are presented in sections 5.1 and 5.2. Navier-Levy and Macro approaches can be found in sections G.3 and G.4, of Appendix G. Further, the Matlab program was used for computing numerical results and graphical plots for Navier-Levy and Macro approaches. The matlab code for Navier-Levy and Macro approaches are shown in Appendix E.

In section 5.3, FEM analysis and results are provided for all test cases (details for test cases can be found in section 4.2 of chapter 4). FEM contour plots and text commands for ANSYS for all test cases are presented in Appendix F. Theoretical results for all test cases (Based on Navier-Levy, macro and Finite Element approaches) are presented in section 5.4 and compared with laboratory test results. Discussions and conclusions are presented in section 5.5.

The structural properties for 8 inch and 4 inch deep FRP deck components that were used in the theoretical analysis are shown in Table 5.1 (Howard, 2002 and Punyamurthula, 2004). 


\begin{tabular}{|c|c|c|c|}
\hline Notation & Descriptions & $\begin{array}{l}8 \text { in. deep FRP Deck } \\
\text { (by Howard, 2002) }\end{array}$ & $\begin{array}{l}4 \text { in. deep FRP Deck } \\
\text { (by Punyamurthula, 2004) }\end{array}$ \\
\hline $\mathrm{E}_{1}$ & $\begin{array}{l}\text { Young's Moduli } \\
\text { in strong direction }\end{array}$ & $4 \times 10^{6}$ psi. & $3.8 \times 10^{6}$ psi. \\
\hline $\mathrm{E}_{2}$ & $\begin{array}{l}\text { Young's Moduli } \\
\text { in weak direction }\end{array}$ & $1.1 \times 10^{6}$ psi. & $1.0 \times 10^{6} \mathrm{psi}$. \\
\hline $\mathrm{G}_{12}$ & $\begin{array}{l}\text { Shear Moduli } \\
\text { in the } 1-2 \text { plane }\end{array}$ & $0.54 \times 10^{6}$ psi. & $0.54 \times 10^{6}$ psi. \\
\hline $\mathrm{D}_{11}$ & $\begin{array}{l}\text { Flexural Rigidity } \\
\text { in Strong Direction }\end{array}$ & $7 \times 10^{7}$ lbs.-in. & $11 \times 10^{6}$ lbs.-in. \\
\hline $\mathrm{D}_{22}$ & $\begin{array}{l}\text { Flexural Rigidity } \\
\text { in Weak Direction }\end{array}$ & $1.81 \times 10^{7}$ lbs. - in. & $2.75 \times 10^{6}$ lbs.-in. \\
\hline $\mathrm{D}_{12}$ & --------------------------- & $0.41 \times 10^{7}$ lbs. - in. & $0.69 \times 10^{6}$ lbs.-in. \\
\hline $\mathrm{D}_{66}$ & Torsional Rigidity & $9.32 \times 10^{6}$ lbs. - in. & $1.5 \times 10^{6}$ lbs.-in. \\
\hline$v_{12}$ & $\begin{array}{l}\text { Poison Ratio } \\
\text { when stressed in } 1 \text { direction }\end{array}$ & 0.23 & 0.25 \\
\hline$v_{21}$ & $\begin{array}{l}\text { Poison Ration } \\
\text { when stressed in } 2 \text { direction }\end{array}$ & 0.062 & 0.0658 \\
\hline$\alpha_{1}$ & $\begin{array}{l}\text { Thermal Coefficient } \\
\text { in strong direction }\end{array}$ & $\begin{array}{l}4.85 \mu \varepsilon /{ }^{\circ} \mathrm{F}\left(70 \text { to } 121^{\circ} \mathrm{F}\right) \\
4.98 \mu \varepsilon /{ }^{\circ} \mathrm{F}\left(-20 \text { to } 70^{\circ} \mathrm{F}\right)\end{array}$ & $\begin{array}{l}5.73 \mu \varepsilon /{ }^{\circ} \mathrm{F}\left(70 \text { to } 121^{\circ} \mathrm{F}\right) \\
5.59 \mu \varepsilon /{ }^{\circ} \mathrm{F}\left(-20 \text { to } 70{ }^{\circ} \mathrm{F}\right)\end{array}$ \\
\hline$\alpha_{2}$ & $\begin{array}{l}\text { Thermal Coefficient } \\
\text { in weak direction }\end{array}$ & $\begin{array}{l}14.14 \mu \varepsilon /{ }^{\circ} \mathrm{F}\left(70 \text { to } 121^{\circ} \mathrm{F}\right) \\
11.92 \mu \varepsilon /{ }^{\circ} \mathrm{F}\left(-20 \text { to } 70{ }^{\circ} \mathrm{F}\right)\end{array}$ & $\begin{array}{l}9.56 \mu \varepsilon /{ }^{\circ} \mathrm{F}\left(70 \text { to } 121^{\circ} \mathrm{F}\right) \\
8.51 \mu \varepsilon /{ }^{\circ} \mathrm{F}\left(-20 \text { to } 70^{\circ} \mathrm{F}\right)\end{array}$ \\
\hline
\end{tabular}

Table 5.1: Structural Properties of 8 in. and 4 in. FRP Bridge Deck Component.

( Ref. Howard, 2002 and Punyamurthula, 2004) 


\section{Experimental Data under Thermal Loads.}

The experimental data (deflection and strain) at geometric center (mid-span) of 8 inch and 4 inch deep FRP deck components are tabulated in Tables 5.2 and 5.3, respectively (Refer Table $4.1 \& 4.2$ of Chapter 4 ).

\begin{tabular}{|c|c|c|c|c|}
\hline \multicolumn{5}{|c|}{ Experimental Thermal Data for 8 in. FRP Deck } \\
\hline Test Case & $8 \mathrm{HS}$ & $8 \mathrm{HF}$ & $8 \mathrm{CS}$ & $8 \mathrm{CF}$ \\
\hline Boundary Condition & SSFF & FFFF & SSFF & FFFF \\
\hline$T_{\text {top }},\left({ }^{\circ} \mathrm{F}\right)$ & 155 & 152 & -30 & -31 \\
\hline$T_{\text {bottom }},\left({ }^{\circ} \mathrm{F}\right)$ & 74 & 74 & 60 & 61 \\
\hline$T_{r e f},\left({ }^{\circ} \mathrm{F}\right)$ & 71 & 73 & 80 & 80 \\
\hline$\Delta T_{\text {top }}=T_{\text {top }}-T_{\text {ref }},\left({ }^{\circ} \mathrm{F}\right)$ & 84 & 79 & -110 & -111 \\
\hline$\Delta T_{\text {bottom }}=T_{\text {bottom }}-T_{\text {ref }},\left({ }^{\circ} \mathrm{F}\right)$ & 3 & 1 & -20 & -19 \\
\hline$\Delta T_{\max }=\Delta T_{\text {top }}-\Delta T_{\text {bottom }},\left({ }^{\circ} \mathrm{F}\right)$ & 81 & 78 & -90 & -92 \\
\hline$w_{\text {center }}\left(\frac{a}{2}, \frac{b}{2}\right)$, LVDT 1, (in.) & -0.096 & -0.123 & 0.103 & 0.133 \\
\hline$w_{\text {edge }}\left(6, \frac{b}{2}\right)$, LVDT 2, (in.) & -0.068 & -0.097 & 0.078 & 0.104 \\
\hline$\varepsilon_{y y_{-} \text {top surface }} @$ Center, Gage \#1 $(\mu \varepsilon)$ & 935 & 912 & -1267 & -1266 \\
\hline 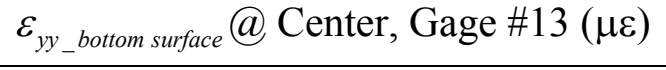 & 3 & -23 & -101 & -122 \\
\hline$\varepsilon_{x x_{-} \text {top surface }} @$ Center, Gage \#2 $(\mu \varepsilon)$ & - & 300 & -467 & -480 \\
\hline 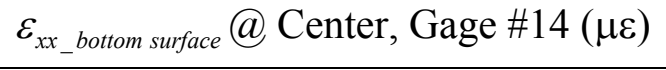 & - & 5 & -52 & 3 \\
\hline
\end{tabular}

Note : " $\mathrm{xx}$ " subscripts represent strong direction (Cell direction) of FRP deck specimen. " yy " subscript represents weak direction of FRP deck specimen. $w_{\text {center }}$ and $w_{\text {edge }}$ are deflections from LVDT 1 and 2 (Refer to Figure 4.9 of Chapter 4 for locations), respectively. Locations of strain gages $\# 1,2,13$ and 14 can be found in Figures 4.8 and 4.9 .

Table 5.2: Experimental Data for Heating and Cooling Tests of 8 in. FRP Deck. (Refer to section 4.2 of chapter 4 for details of test cases) 


\begin{tabular}{|c|c|c|c|c|}
\hline \multicolumn{5}{|c|}{ Experimental Thermal Data for 4 in. FRP Deck } \\
\hline Test Case & 4HS & $4 \mathrm{HF}$ & $4 \mathrm{CS}$ & $4 \mathrm{CF}$ \\
\hline Boundary Condition & SSFF & FFFF & SSFF & FFFF \\
\hline$T_{\text {top }},\left({ }^{\circ} \mathrm{F}\right)$ & 153 & 151 & -43 & -45 \\
\hline$T_{\text {bottom }},\left({ }^{\circ} \mathrm{F}\right)$ & 97 & 98 & 56 & 60 \\
\hline$T_{\text {ref }},\left({ }^{\circ} \mathrm{F}\right)$ & 80 & 80 & 82 & 84 \\
\hline$\Delta T_{\text {top }}=T_{\text {top }}-T_{\text {ref }},\left({ }^{\circ} \mathrm{F}\right)$ & 73 & 71 & -125 & -129 \\
\hline$\Delta T_{\text {bottom }}=T_{\text {bottom }}-T_{\text {ref }},\left({ }^{\circ} \mathrm{F}\right)$ & 17 & 18 & -26 & -24 \\
\hline$\Delta T_{\max }=\Delta T_{\text {top }}-\Delta T_{\text {bottom }},\left({ }^{\circ} \mathrm{F}\right)$ & 56 & 53 & -99 & -105 \\
\hline$w_{\text {center }}\left(\frac{a}{2}, \frac{b}{2}\right)$, LVDT 1 , (in.) & -0.094 & -0.105 & 0.159 & 0.232 \\
\hline$w_{\text {edge }}\left(6, \frac{b}{2}\right)$, LVDT 2, (in.) & -0.051 & -0.076 & 0.085 & 0.154 \\
\hline 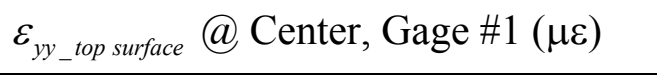 & 627 & 564 & -1307 & -1414 \\
\hline 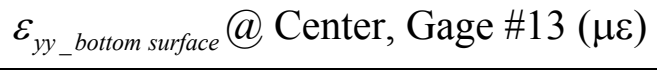 & 171 & 129 & -205 & -275 \\
\hline$\varepsilon_{x x_{-} \text {to surface }} @$ Center, Gage \#2 $(\mu \varepsilon)$ & 350 & 352 & -912 & -948 \\
\hline$\varepsilon_{x x_{-} \text {bottom sufface }} @$ Center, Gage \#14 ( $\left.\mu \varepsilon\right)$ & 92 & 87 & -110 & -81 \\
\hline
\end{tabular}

Note : “ xx " subscript represents strong direction (Cell direction) of FRP deck specimen. " yy " subscript represents weak direction of FRP deck specimen. $w_{\text {center }}$ and $w_{\text {edge }}$ are deflections from LVDT 1 and 2 (Refer to Figure 4.11 of Chapter 4 for locations), respectively. Locations of strain gages \#1, 2, 13 and 14 can be found in Figures 4.10 and 4.11 .

Table 5.3: Experimental Thermal Data for Heating and Cooling Tests of 4 in. FRP Deck. (Refer to section 4.2 of chapter 4 for details of test cases) 


\subsection{Thermal Analysis based on Navier-Levy Method (Refer to Section G.1 in Appendix G)}

The procedure for deflection computations based on the Navier-Levy method for test case $8 \mathrm{HS}$ (the term $8 \mathrm{HS}$ means a heating test with simply supported boundary condition for 8 inch deep FRP deck) are presented in this section. The deflection plot and Matlab code for computation are shown in Appendix E. All equations in the following computations are obtained from section G.1 in Appendix G.

\section{$\underline{\text { Deflection Computation for Test Case 8HS with } \mathbf{n}=1}$}

All structural properties and temperature details for the 8" deep FRP bridge deck components are obtained from Tables 5.1 and 5.2, respectively. Structural properties for 8” deep FRP deck component were shown as following:

$\mathrm{E}_{\mathrm{xx}}=4 \times 10^{6}$ psi., $\mathrm{E}_{\mathrm{yy}}=1.1 \times 10^{6}$ psi.

$\mathrm{G}_{\mathrm{xy}}=0.54 \times 10^{6} \mathrm{psi}$

$\mathrm{D}_{\mathrm{xx}}=7.0 \times 10^{7}$ lbs.-in., $\mathrm{D}_{\mathrm{yy}}=1.81 \times 10^{7}$ lbs.-in., $\mathrm{D}_{\mathrm{xy}}=0.41 \times 10^{7}$ lbs.-in., $\mathrm{D}_{\mathrm{ss}}=9.32 \times 10^{6}$ lbs.-in.

$v_{x y}=0.23, v_{y x}=0.062$

$\propto_{\mathrm{xx}}=4.85 \mu \varepsilon /{ }^{\circ} \mathrm{F}, \propto_{\mathrm{yy}}=14.14 \mu \varepsilon /{ }^{\circ} \mathrm{F}$

$a=72$ in., $b=69$ in., $h=8$ in (Refer Figure G.1).

Determination of thermal load $M_{0}^{T_{x x}}$ and $M_{0}^{T_{y y}}$

$$
\Delta T_{\max }=\Delta T_{\text {top }}-\Delta T_{\text {bottom }}=155-74=81
$$

From Eq. (G.17) and (G.18)

$$
M_{0}^{T_{x x}}=-\left(D_{x x} \alpha_{x x}+D_{x y} \alpha_{y y}\right)\left(\frac{\Delta T_{\max }}{h}\right)=-4.0259 \times 10^{3} \text { lbs.-in./in. }
$$


$M_{0}^{T_{y y}}=-\left(D_{x y} \alpha_{x x}+D_{y y} \alpha_{y y}\right)\left(\frac{\Delta T_{\max }}{h}\right)=-2.7932 \times 10^{3}$ lbs.-in./in.

$\hat{D}_{x y}=D_{x y}+2 D_{s s}=2.2710 \times 10^{7}$ and $\hat{D}_{x y}^{2}=5.1574 \times 10^{14}$ lbs.-in.

$D_{x x} D_{y y}=1.2670 \times 10^{15} \mathrm{lbs}^{2}{ }^{2}$ in. ${ }^{2}$

Since $\hat{D}_{x y}^{2}<D_{x x} D_{y y}($ Case 3 as in Appendix G),

$\lambda_{1}$ and $\lambda_{2}$ are determined from Eqs. (G.30) and (G.31). The first term approximation is used in this computation (i.e. $\mathrm{n}=1$ ).

Based on the first term approximation with $\mathrm{n}=1\left(\beta_{n}=\frac{n \pi}{b}, \therefore \beta_{1}=\frac{\pi}{b}\right)$

From Eq. (G.30), $\lambda_{1}^{2}=\frac{\beta_{n}^{2}}{2 D_{x x}}\left(\sqrt{D_{x x} D_{y y}}+\hat{D}_{x y}\right), \quad \lambda_{1}=0.0294$

From Eq. (G.31), $\lambda_{2}^{2}=\frac{\beta_{n}^{2}}{2 D_{x x}}\left(\sqrt{D_{x x} D_{y y}}-\hat{D}_{x y}\right), \quad \lambda_{2}=0.0138$

The following coefficients are calculated based on Eqs. (G.42) to (G.65)

From Eq. (G.54), $a_{1}=\cosh \left(a \lambda_{1}\right) \cos \left(a \lambda_{2}\right)=2.2926$

From Eq. (G.55), $a_{2}=\sinh \left(a \lambda_{1}\right) \sin \left(a \lambda_{2}\right)=3.4267$

From Eq. (G.56), $a_{3}=\cosh \left(a \lambda_{1}\right) \sin \left(a \lambda_{2}\right)=3.5278$

From Eq. (G.57), $\quad a_{4}=\sinh \left(a \lambda_{1}\right) \cos \left(a \lambda_{2}\right)=2.2269$

From Eq. (G.58), $\quad b_{1}=\lambda_{2}^{2}-\lambda_{1}^{2}=-6.7254 \times 10^{-4}$

From Eq. (G.59), $\quad b_{2}=\lambda_{1} \lambda_{2}=4.0585 \times 10^{-4}$

From Eq. (G.45), $\quad k_{1}=\frac{-4 D_{x y} \beta_{n}^{2} b^{2} M_{0}^{T_{y y}}-4 n^{2} \pi^{2} D_{y y} M_{0}^{T_{x x}}}{n^{3} \pi^{3} D_{y y}}=5.9334 \times 10^{3}$

From Eq. (G.46), $\quad k_{2}=\left(a_{1} b_{1}+2 a_{2} b_{2}\right) D_{x x}+\beta_{n}^{2} a_{1} D_{x y}=1.0631 \times 10^{5}$ 
From Eq. (G.47), $k_{3}=\left(a_{3} b_{1}-2 a_{4} b_{2}\right) D_{x x}+\beta_{n}^{2} a_{3} D_{x y}=-2.6256 \times 10^{5}$

From Eq. (G.48), $\quad k_{4}=\left(2 a_{3} b_{2}+a_{4} b_{1}\right) D_{x x}+\beta_{n}^{2} a_{4} D_{x y}=1.1458 \times 10^{5}$

From Eq. (G.49), $\quad k_{5}=\left(-2 a_{1} b_{2}+a_{2} b_{1}\right) D_{x x}+\beta_{n}^{2} a_{2} D_{x y}=-2.6239 \times 10^{5}$

From Eq. (G.50), $\quad k_{6}=\left(-a_{3} \lambda_{2}^{3}+3 a_{4} b_{2} \lambda_{2}+3 a_{3} b_{2} \lambda_{1}-a_{4} \lambda_{1}^{3}\right) D_{x x}+\beta_{n}^{2}\left(a_{4} \lambda_{1}-a_{3} \lambda_{2}\right) \bar{D}_{x y}$

$$
=8.2815 \times 10^{3}
$$

From Eq. (G.51),

$k_{7}=\left(a_{1} \lambda_{2}^{3}+3 a_{2} b_{2} \lambda_{2}-3 a_{1} b_{2} \lambda_{1}-a_{2} \lambda_{1}^{3}\right) D_{x x}+\beta_{n}^{2}\left(a_{1} \lambda_{2}-a_{2} \lambda_{1}\right) \bar{D}_{x y}=3.9651 \times 10^{3}$

From Eq. (G.52),

$k_{8}=\left(-a_{2} \lambda_{2}^{3}+3 a_{1} b_{2} \lambda_{2}+3 a_{2} b_{2} \lambda_{1}-a_{1} \lambda_{1}^{3}\right) D_{x x}+\beta_{n}^{2}\left(a_{1} \lambda_{1}-a_{2} \lambda_{2}\right) \bar{D}_{x y}=8.2926 \times 10^{3}$

From Eq. (G.53),

$k_{9}=\left(a_{4} \lambda_{2}^{3}+3 a_{3} b_{2} \lambda_{2}-3 a_{4} b_{2} \lambda_{1}-a_{3} \lambda_{1}^{3}\right) D_{x x}+\beta_{n}^{2}\left(a_{3} \lambda_{1}+a_{4} \lambda_{2}\right) \bar{D}_{x y}=4.2337 \times 10^{3}$

From Eq. (G.60), $c_{1}=\frac{2 b_{2} D_{x x}}{b_{1} D_{x x}+\beta_{n}^{2} D_{x y}}=-1.4736$

From Eq. (G.61), $c_{2}=\frac{4\left(\beta_{n}^{2} b^{2} D_{x y} M_{0}^{T_{y y}}+n^{2} \pi^{2} D_{x x} M_{0}^{T_{x x}}\right)}{n^{3} \pi^{3} D_{y y}\left(b_{1} D_{x x}+\beta_{n}^{2} D_{x y}\right)}=0.1539$

From Eq. (G.62), $c_{3}=-\frac{\lambda_{1} \beta_{n}^{2} \bar{D}_{x y}+\left(3 \lambda_{1} \lambda_{2}^{2}-\lambda_{1}^{3}\right) D_{x x}}{\lambda_{2} \beta_{n}^{2} \bar{D}_{x y}+\left(\lambda_{2}^{3}-3 \lambda_{1}^{2} \lambda_{2}\right) D_{x x}}=1.6868$

From Eq. (G.63), $c_{4}=-\frac{k_{2} c_{1}+k_{5}}{k_{3} c_{3}+k_{4}}=-1.2764$

From Eq. (G.64), $c_{5}=-\frac{k_{2} c_{2}+k_{1}}{k_{3} c_{3}+k_{4}}=0.0679$

From Eq. (G.41), $A_{n}=c_{1} D_{n}+c_{2}=0.0292$

From Eq. (G.42), $B_{n}=c_{3} C_{n}=-0.0676$

From Eq. (G.43), $C_{n}=c_{4} D_{n}+c_{5}=-0.0401$ 
From Eq. (G.44), $D_{n}=-\frac{k_{6} c_{2}+k_{7} c_{3} c_{5}+k_{8} c_{5}}{k_{6} c_{1}+k_{7} c_{3} c_{4}+k_{8} c_{4}+k_{9}}=0.0846$

Maximum deflection, $w(x, y)$, occurs at the geometric center of the deck plate. Substituting $x=\frac{a}{2}$ and $y=\frac{b}{2}$ into Eq. (G.35), we obtain:

$w(x, y)=\sum_{n=1}^{\infty}\left(\frac{4 b^{2}}{n^{3} \pi^{3} D_{y y}} M_{0}^{T_{y y}}+A_{n} \cosh \lambda_{1} x+B_{n} \sinh \lambda_{1} x+C_{n} \cosh \lambda_{2} x+D_{n} \sinh \lambda_{2} x\right) \sin \beta_{n} y$

$\therefore w_{\text {center }}\left(\frac{a}{2}, \frac{b}{2}\right)=-0.0988$ in. and $\therefore w_{\text {edge }}\left(6, \frac{b}{2}\right)=-0.0680$ in. for $\mathrm{n}=1$

Note : Negative sign represents upward direction.

\section{Deflection Computation for Test Case 8HS with $n=3,5,7 \ldots$}

In this section, deflection computation for $8 \mathrm{HS}$ test case is computed for higher order term approximations with $\mathrm{n}=3,5,7 \ldots$ so as to compare the results with first term approximation. It should be noted that for $n=2,4,6 \ldots$ the thermal load moment is zero due to symmetry of the deflected shape function.

The deflection solution for $\mathrm{n}=1$ to 15 was obtained using MATLAB program. The deflection solutions for different $\mathrm{n}$ values are plotted in Figure 5.1. We can observe that as number of approximation terms (n) increases; the deflection converges or is nearly constant. It can be concluded that the more $\mathrm{n}$ terms are incorporated in computations, the more accuracy we obtain.

Based on Figure 5.1, the central deflection is nearly constant for $n>7$. The difference in deck deflections when $n=1$ versus when $n=15$ is only $3 \%$, implying that the first term approximation can be used to predict deflection with a high degree of accuracy. The 
deflection contour over FRP deck is shown in Figure 5.2 based on the first term approximation, $\mathrm{n}=1$.
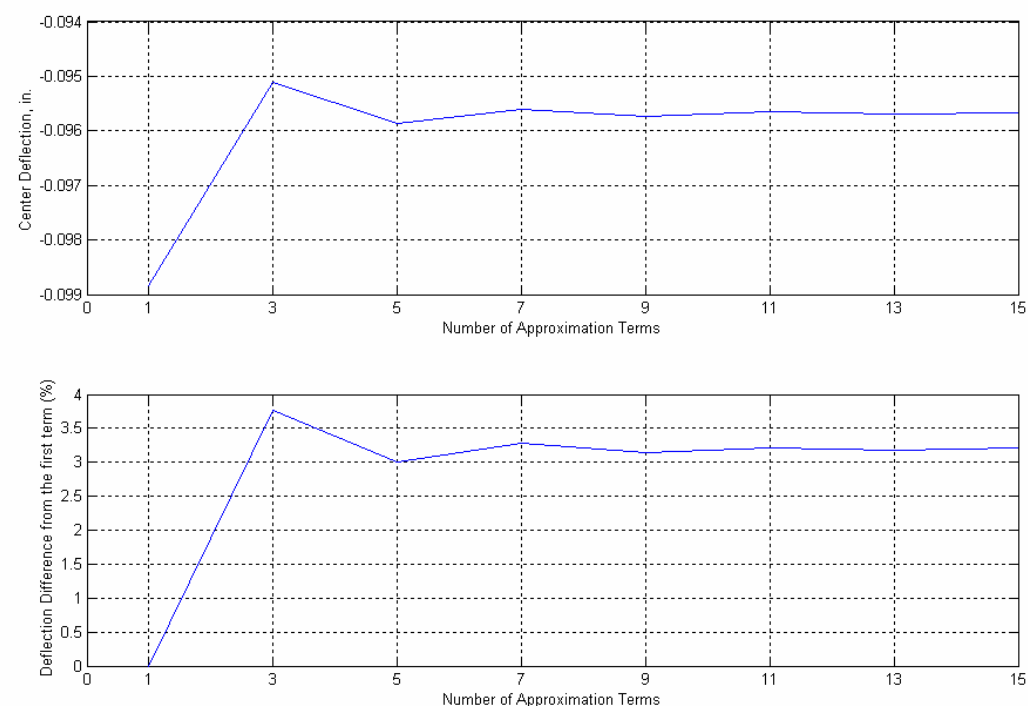

Figure 5.1: Deflection of FRP deck at the center for Test Case 8HS. (Navier-Levy's Method, $\mathrm{n}=1,3,5, \ldots, 15$ ).

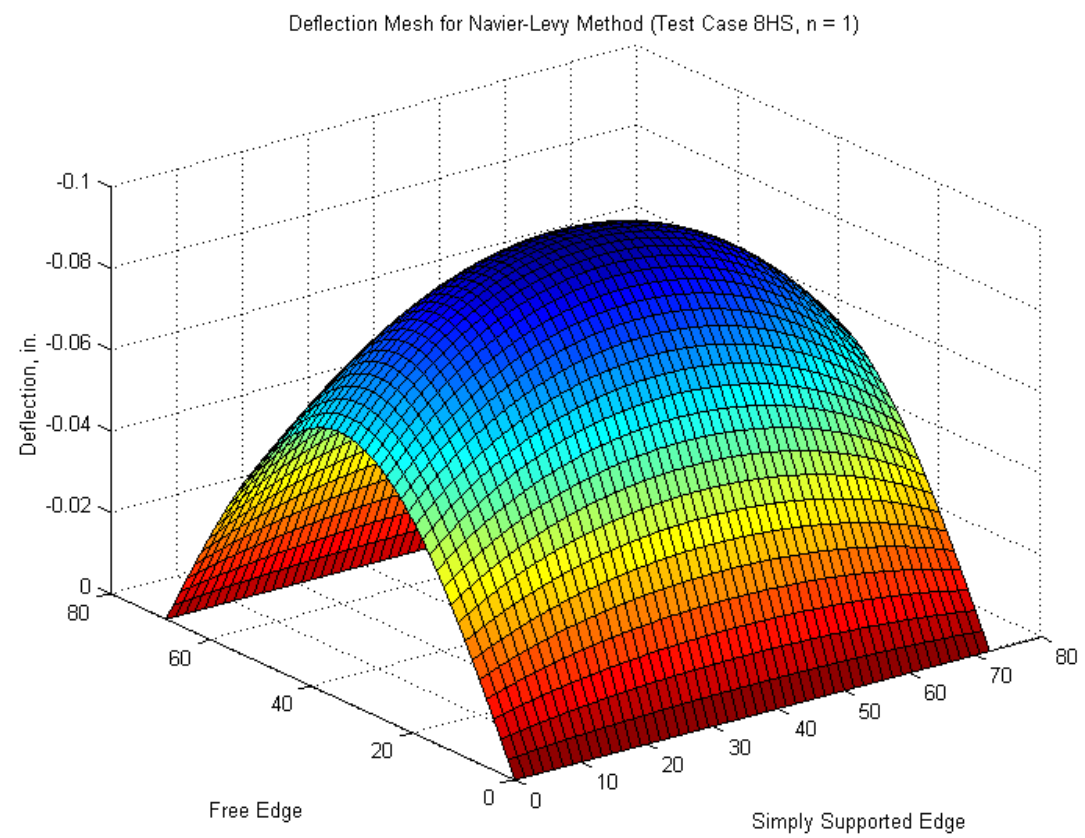

Figure 5.2: Deflection Contour for Test Case 8HS (Navier-Levy’s Method, n=1). 
Deflections for other test cases are determined by using the above procedure and tabulated in Table 5.4. Deflection contour plot and Matlab code for computation of all test cases can be found in Appendix E.

\begin{tabular}{|c|c|c|}
\hline \multirow{2}{*}{ Deflections based on Navier-Levy Method ( $\mathrm{n}=1)$} \\
\hline \multirow{2}{*}{ Test Case } & \multicolumn{2}{|c|}{ Deflection (in.) } \\
\cline { 2 - 3 } & @Center & @Edge \\
\hline $8 \mathrm{HS}$ & -0.0988 & -0.0767 \\
\hline $8 \mathrm{CS}$ & 0.0946 & 0.0705 \\
\hline $4 \mathrm{HS}$ & -0.1021 & -0.0692 \\
\hline $4 \mathrm{CS}$ & 0.1631 & 0.1073 \\
\hline
\end{tabular}

Notes: Strain and stress computations are not presented in Navier-Levy approach (out of scope).

Table 5.4: Deflection Results based on Navier-Levy Method.

\subsection{Thermal Analysis based on the Macro Approach (Refer to Section G.2 in Appendix G)}

Theoretical analysis based on the Macro approach for test case 8HS is presented in this section. The deflection plot and matlab code for computation are shown in Appendix E. All equations in the following computations are obtained from section G.2 in Appendix G.

\section{Deflection Computation for Test Case 8HS (Using Macro Approach)}

All structural properties and temperature details for the 8" deep FRP bridge deck components are obtained from Tables 5.1 and 5.2, respectively. Structural properties for 8" deep FRP deck component are shown as following: 
$\mathrm{E}_{\mathrm{xx}}=4 \mathrm{x} 10^{6}$ psi., $\mathrm{E}_{\mathrm{yy}}=1.1 \times 10^{6} \mathrm{psi}$.

$\mathrm{G}_{\mathrm{xy}}=0.54 \times 10^{6} \mathrm{psi}$.

$D_{x x}=7.0 x 10^{7}$ lbs.-in., $D_{y y}=1.81 \times 10^{7}$ lbs.-in., $D_{x y}=0.41 \times 10^{7}$ lbs.-in., $D_{s s}=9.32 \times 10^{6}$ lbs.-in.

$v_{x y}=0.23, v_{y x}=0.062$

$\propto_{\mathrm{xx}}=4.85 \mu \varepsilon /{ }^{\circ} \mathrm{F}, \propto_{\mathrm{yy}}=14.14 \mu \varepsilon /{ }^{\circ} \mathrm{F}$

$\mathrm{a}=72$ in., $\mathrm{b}=69$ in., $\mathrm{h}=8$ in (Refer Figure G.1)

Note: In section G.2 of Appendix G, Macro approach is derived for a plate with two opposite edges ( which are simple supports @ y=0 and b) and the other two opposite edges (which are elastic beams @ $\mathrm{x}=0, \mathrm{a}$ ). This analysis can be used for two simply supports (@ $\mathrm{y}=0$ and $\mathrm{b}$ ) and free boundaries (@ $\mathrm{x}=0$, a) by substituting $E I=0$ (i.e. Flexural rigidity of elastic beams $\left(E I\right.$ or $\left.B_{e}\right)$ is zero because elastic beam supports do not exist in heating and cooling tests, only free boundary.) in the following computations.

Determine thermal load, $M_{0}^{T_{x x}}$ and $M_{0}^{T_{y y}}$

$$
\Delta T_{\max }=\Delta T_{\text {top }}-\Delta T_{\text {bottom }}=155-74=81
$$

From Eq. (G.17) and (G.18)

$M_{0}^{T_{x x}}=-\left(D_{x x} \alpha_{x x}+D_{x y} \alpha_{y y}\right)\left(\frac{\Delta T_{\max }}{h}\right)=-4.0259 \times 10^{3}$ lbs.-in./in.

$M_{0}^{T_{y y}}=-\left(D_{x y} \alpha_{x x}+D_{y y} \alpha_{y y}\right)\left(\frac{\Delta T_{\max }}{h}\right)=-2.7932 \times 10^{3}$ lbs.-in./in.

From Eq. (G.96), $k_{1}=\frac{2\left(b^{4} D_{x x}^{2}+a^{2} b^{2} D_{x x} D_{x y}+4 a^{2} b^{2} D_{x x} D_{s s}\right)}{\pi a^{3}\left(2 B_{e} D_{x x}+a D_{x y}^{2}+4 a D_{x y} D_{s s}\right)}=25.1111$

From Eq. (G.97), $k_{2}=\frac{-32 b^{4} D_{x x}}{\pi^{5} a\left(2 B_{e} D_{x x}+a D_{x y}^{2}+4 a D_{x y} D_{s s}\right)}=-1.8587 \times 10^{-4}$

From Eq. (G.98), $k_{3}=\left(4 \pi^{3} a^{6} D_{x y} D_{y y}+8 \pi^{3} a^{4} b^{2} \hat{D}_{x y} D_{x y}-4 \pi^{3} a^{4} b^{2} D_{x x} D_{y y}\right) k_{2}+16 a^{2} b^{6} D_{x x}$

$$
=3.5626 \times 10^{24}
$$


From Eq. (G.99), $k_{4}=16 a^{4} b^{4} D_{x x}=5.0043 \times 10^{30}$

From Eq. (G.100)

$$
\begin{aligned}
k_{5} & =\pi^{3}\left(4 a^{4} b^{2} D_{x x} D_{y y}-4 a^{6} D_{x y} D_{y y}-8 a^{4} b^{2} \hat{D}_{x y} D_{x y}\right) k_{1}+\pi^{4}\left(a^{4} b^{2} D_{x x} D_{y y}+2 a^{2} b^{4} \hat{D}_{x y} D_{x x}+b^{6} D_{x x}^{2}\right) \\
& =5.0043 \times 10^{29}
\end{aligned}
$$

From Eq. (G.93), $W_{11}=\frac{k_{3} M_{0}^{T_{x x}}+k_{4} M_{0}^{T_{y y}}}{k_{5}}=-0.0325$

From Eq. (G.95), $c_{2}=k_{1}+\frac{k_{2} M_{0}^{T_{x x}}}{W_{11}}=2.0617$

From Eq. (G.94), $c_{1}=\frac{\pi^{2} D_{x y}}{2 b^{2} D_{x x}} c_{2}=1.2708 \times 10^{-4}$

The maximum deflection, $w(x, y)$, occurs at the center of the deck plate. Substituting $x=\frac{a}{2}$

and $y=\frac{b}{2}$ into Eq. (G.92), we obtain

$$
\begin{aligned}
& w(x, y)=W_{11} \sin \left(\frac{\pi y}{b}\right)\left[\sin \left(\frac{\pi x}{a}\right)+c_{1} x(x-a)+c_{2}\right] \\
& \therefore w_{\text {center }}\left(\frac{a}{2}, \frac{b}{2}\right)=-0.0942 \text { in. } \quad \therefore w_{\text {edge }}\left(6, \frac{b}{2}\right)=-0.0767 \text { in. }
\end{aligned}
$$

The deflection contour over FRP deck is shown in Figure 5.3 (Note the deflection results are based on the first term approximation, $\mathrm{n}=1$ ). 


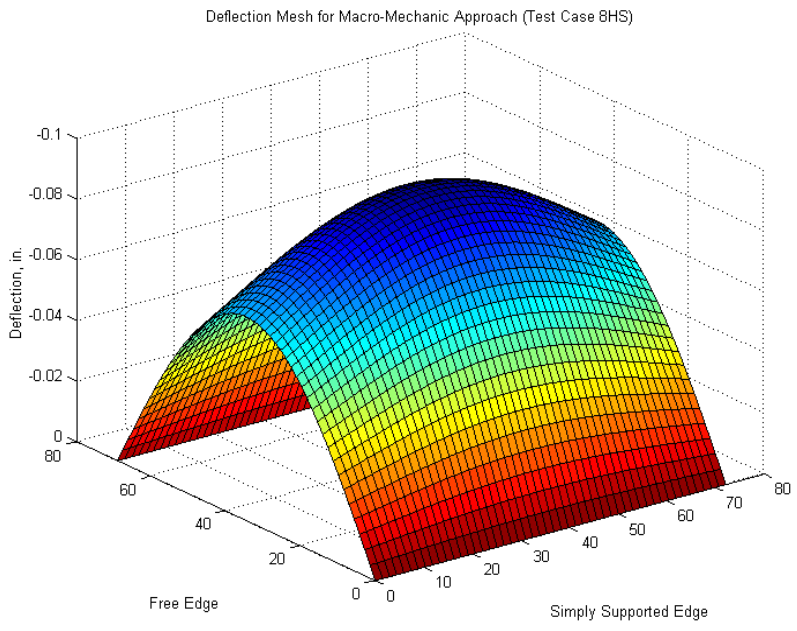

Figure 5.3: Deflection Contour for Test Case 8HS (Using Macro Approach).

88 


\section{Strain Computation for Test Case 8HS (Using Macro Approach)}

According to Table 5.2, temperature changes on the top and bottom surfaces of the FRP deck specimen for Test Case $8 \mathrm{HS}$ are $84^{\circ} \mathrm{F}$ and $3{ }^{\circ} \mathrm{F}$, respectively. The temperature change is assumed to vary linearly along the depth. The temperature change profile is plotted, as shown in Figure 5.4.

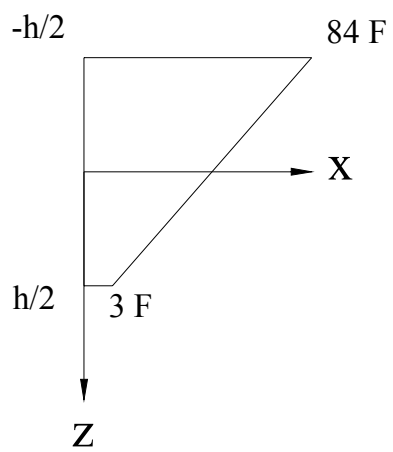

Temperature Increment

$$
\begin{aligned}
& \Delta T(z)=T(z)-T_{\text {ref }} \\
& \Delta T_{\text {top }}=\Delta T(-4)=155-71=84^{\circ} \mathrm{F} \\
& \Delta T_{\text {bottom }}=\Delta T(4)=74-71=3^{\circ} \mathrm{F}
\end{aligned}
$$

$43.5 \mathrm{~F}$

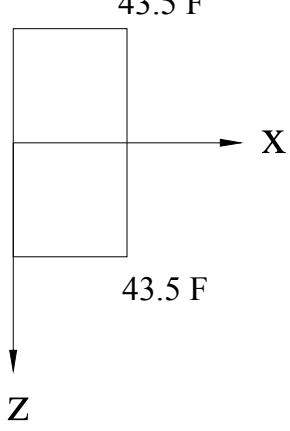

Axial Effect

$$
T^{0}=\frac{\Delta T_{\text {top }}+\Delta T_{\text {bottom }}}{2}
$$$$
=\frac{84+3}{2}
$$$$
=43.5^{\circ} \mathrm{F}
$$

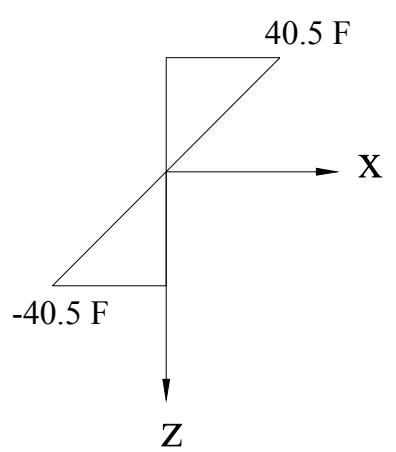

Bending Effect

$$
\begin{aligned}
T^{1} z & =-\frac{\Delta T_{\max }}{h} z \\
& =-\frac{81}{8} z \\
& =-10.125 z
\end{aligned}
$$

Figure 5.4: Temperature Change Profile for Test Case 8HS.

Note : In figure 5.4, we have $T^{0}=43.5$ and $T^{1}=-10.125$

For bending effects, the strain can be calculated using following formula (Refer to Eq.

$$
\begin{aligned}
& \varepsilon_{x x_{-} \text {bending }}=\varepsilon_{x x}^{1} z=-W_{11} \sin \left(\frac{\pi y}{b}\right)\left[-\frac{\pi^{2}}{a^{2}} \sin \left(\frac{\pi x}{a}\right)+2 c_{1}\right] z \\
& \varepsilon_{y y_{\_} \text {bending }}=\varepsilon_{y y}^{1} z=\frac{\pi^{2}}{b^{2}} W_{11} \sin \left(\frac{\pi y}{b}\right)\left(\sin \left(\frac{\pi x}{a}\right)+c_{1} x(x-a)+c_{2}\right) z
\end{aligned}
$$


Using the above equations, strain @ the center of top surface $\left(x=\frac{a}{2}, y=\frac{b}{2}\right.$ and $\left.z=-\frac{h}{2}=-4\right)$ and bottom surface $\left(x=\frac{a}{2}, y=\frac{b}{2}\right.$ and $\left.z=\frac{h}{2}=4\right)$ are as follows:

$\left.\begin{array}{l}\therefore \varepsilon_{x x_{-} \text {bending }}=214 \mu \varepsilon \\ \therefore \varepsilon_{y y_{-} \text {bending }}=781 \mu \varepsilon\end{array}\right\} \quad$ Top surface $\left.\quad \begin{array}{l}\therefore \varepsilon_{x x_{-} \text {bending }}=-214 \mu \varepsilon \\ \therefore \varepsilon_{y y_{-} \text {bending }}=-781 \mu \varepsilon\end{array}\right\} \quad$ Bottom Surface

\section{$\underline{\text { Stress Computation for Test Case 8HS (Using Macro Approach) }}$}

For a bending effect, the stress component of the FRP deck plate can be calculated by the following formula (Refer to Eq. G.108):

$$
\left\{\begin{array}{l}
\sigma_{x x} \\
\sigma_{y y}
\end{array}\right\}=\left[\begin{array}{ll}
Q_{11} & Q_{12} \\
Q_{12} & Q_{22}
\end{array}\right]\left\{\begin{array}{c}
-W_{11} \sin \left(\frac{\pi y}{b}\right)\left[-\frac{\pi^{2}}{a^{2}} \sin \left(\frac{\pi x}{a}\right)+2 c_{1}\right] z-\alpha_{x x} T^{1} z \\
\frac{\pi^{2}}{b^{2}} W_{11} \sin \left(\frac{\pi y}{b}\right)\left(\sin \left(\frac{\pi x}{a}\right)+c_{1} x(x-a)+c_{2}\right) z-\alpha_{y y} T^{1} z
\end{array}\right\}
$$

Using the above equations, stress @ the center of top surface $\left(x=\frac{a}{2}, y=\frac{b}{2}, z=-\frac{h}{2}=-4\right)$ and bottom surface $\left(x=\frac{a}{2}, y=\frac{b}{2}, z=-\frac{h}{2}=4\right)$ are as follows:

$\left.\begin{array}{l}\therefore \sigma_{x x_{-} \text {bending }}=122.70 \text { psi. } \\ \therefore \sigma_{y y_{-} \text {bending }}=216.70 \text { psi. }\end{array}\right\}$ Top Surface

$\left.\begin{array}{l}\therefore \sigma_{x x_{-} \text {bending }}=-122.70 \text { psi. } \\ \therefore \sigma_{y y_{-} \text {bending }}=-216.70 \text { psi. }\end{array}\right\}$ Bottom Surface

The experimental strains at the center of FRP deck $\left(\varepsilon_{x x}, \varepsilon_{y y}\right)$ are shown in Table 5.2.

It can be seen in Table 5.2 that experimental strain results in SSFF (two opposite edges are simply supported edges and the other two opposite edges are free) and FFFF (all four edges free) boundaries are close for all test cases because in the laboratory, true simply supported 
edge conditions (zero in-plane expansion) were difficult to attain. The main reason for this was that in the simply supported edge conditions, the deck was able to move partially along the horizontal plane. This is attributed to the fact that the diameters of threaded rods were smaller than the hole diameter on edges of the FRP decks, which allowed the FRP deck to expand or contract in the horizontal plane (see Figure 5.5), with partial (not full) horizontal restraint.

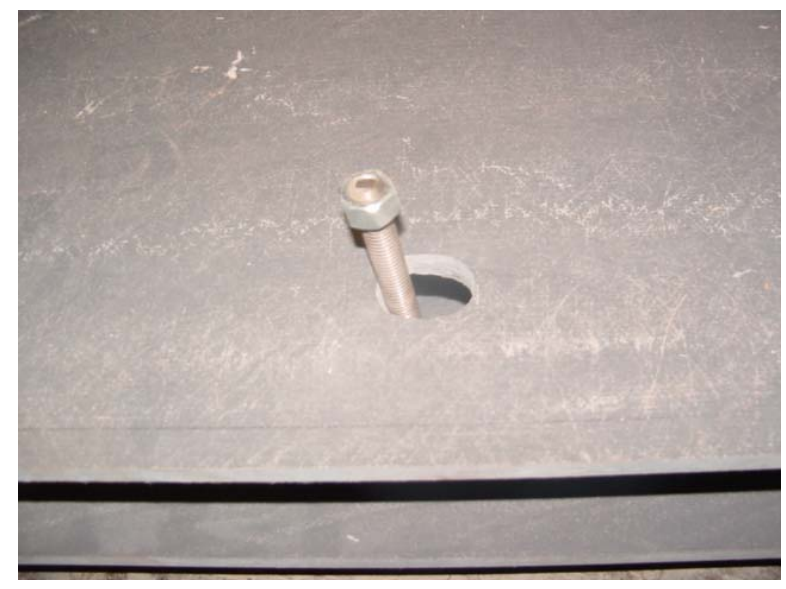

Figure 5.5: Diameters of holes were larger than that of threaded rods.

In order to account for an axial effect (movement in horizontal plane) for the 8HS test case, we assume that the deck plate expands or contracts freely in the horizontal plane for a SSFF condition. Therefore, the total strain on the FRP deck is equal to a combination of strain from bending, as well as axial effects, which is assumed to be free to expand under laboratory conditions. The combination of bending and axial effects can be expressed as:

$$
\begin{gathered}
\varepsilon_{\text {total }}=\varepsilon_{\text {bending }}+\varepsilon_{\text {axial }} \\
\sigma_{\text {total }}=\sigma_{\text {bending }}+\sigma_{\text {axial }}
\end{gathered}
$$


Thermally induced axial strain $\left(\varepsilon_{\text {axial }}\right)$ in the cell and traffic directions: $\varepsilon_{x x_{-} a x i a l}=\alpha_{x x} T^{0}$ and $\varepsilon_{y y_{\_} a x i a l}=\alpha_{y y} T^{0}$ (since the FRP deck was found to freely expand or contract in horizontal plane for SSFF boundary condition).

Thermally induced axial stress $\left(\sigma_{\text {axial }}\right)$ in the cell and traffic directions: $\sigma_{x x \_a x i a l}=0$ and $\sigma_{y y_{-} \text {axial }}=0$. The thermally induced axial stress are assumed to be zero because the FRP deck was found to freely expand or contract in the horizontal plane for SSFF boundary condition in the laboratory.

Combining the thermal bending and axial effect together, deflection, strain and stress are shown in Table 5.5

\begin{tabular}{|l|c|c|c|}
\hline \multicolumn{4}{|c|}{$\begin{array}{c}\text { Deflection, Strain and Stress for Test Case 8HS } \\
\text { (Based on Macro Approach) }\end{array}$} \\
\hline$w_{\text {center }}\left(\frac{a}{2}, \frac{b}{2}\right)$, in. & -0.0942 \\
\hline$w_{\text {edge }}\left(6, \frac{b}{2}\right)$, in. & -0.0671 \\
\hline & Bending Effect & Axial Effect & Bending + Axial \\
\hline$\varepsilon_{x_{-} \text {Top Surface }}(\mu \varepsilon)$ & 214 & 211 & 425 \\
\hline$\varepsilon_{x x_{-} \text {Bottom Surface }}(\mu \varepsilon)$ & -214 & 211 & -3 \\
\hline$\varepsilon_{y y_{-} \text {Top Surface }}(\mu \varepsilon)$ & 781 & 615 & 1396 \\
\hline$\varepsilon_{y y_{-} \text {Bottom Surface }}(\mu \varepsilon)$ & -781 & 615 & -166 \\
\hline$\sigma_{x x_{-} \text {Top Surface }}(\mathrm{psi})$ & 126 & 0 & 126 \\
\hline$\sigma_{x x_{-} \text {Bottom Surface }}(\mathrm{psi})$. & -126 & 0 & -126 \\
\hline$\sigma_{y y_{-} \text {Top Surface }}(\mathrm{psi})$ & 237 & 0 & -237 \\
\hline$\sigma_{y y_{-} \text {Bottom Surface }}(\mathrm{psi})$. & -237 & 0 & \\
\hline
\end{tabular}

Table 5.5: Deflection, Strain and Stress at Center for Test Case 8HS. (Based on Macro Approach) 
Stress and strains for other test cases are determined by using the above procedure and tabulated in Tables 5.6 and 5.7. The deflection contour plot and the Matlab code for computation of all test cases can be found in section E. 3 and E.4 of Appendix E.

\begin{tabular}{|c|c|c|}
\hline \multicolumn{3}{|c|}{$\begin{array}{c}\text { Deflection, Strain and Stress for Test Case 8HS and 8CS } \\
\text { (Based on Macro Approach) }\end{array}$} \\
\hline Test Case & $8 \mathrm{HS}$ & $8 \mathrm{CS}$ \\
\hline$w_{\text {center }}\left(\frac{a}{2}, \frac{b}{2}\right)$, in. & -0.0942 & 0.0900 \\
\hline$w_{\text {edge }}\left(6, \frac{b}{2}\right)$, in. & -0.0739 & 0.0670 \\
\hline (a) center & Bending + Axial $=$ Total & Bending + Axial $=$ Total \\
\hline$\varepsilon_{x x_{-} \text {Top Surface }}(\mu \varepsilon)$ & $214+211=425$ & $-241+-324=-565$ \\
\hline$\varepsilon_{x x_{-} \text {Bottom Surface }}(\mu \varepsilon)$ & $-214+211=-3$ & $241+-324=-83$ \\
\hline$\varepsilon_{y y_{-} \text {Top Surface }}(\mu \varepsilon)$ & $781+615=1396$ & $-747+-775=-1522$ \\
\hline$\varepsilon_{y y_{-} \text {Bottom Surface }}(\mu \varepsilon)$ & $-781+615=-166$ & $747+-775=-28$ \\
\hline$\sigma_{x x_{-} \text {Top Sufface }}$ (psi.) & $126+0=126$ & $0=-123$ \\
\hline$\sigma_{x x_{-} \text {Bottom Surface }}(\mathrm{psi})$. & $-126+0=-126$ & $0=123$ \\
\hline$\sigma_{y y_{-} \text {Top Surface }}(\mathrm{psi})$. & $237+0=$ & $0=-239$ \\
\hline$\sigma_{y y_{-} \text {Bottom Surface }}$ (psi.) & $-237+0=-237$ & $0=239$ \\
\hline
\end{tabular}

Table 5.6: Deflection, Strain and Stress at Center for Test Case 8HS and 8CS. (Based on Macro Approach) 


\begin{tabular}{|c|c|c|c|c|c|c|}
\hline \multicolumn{7}{|c|}{$\begin{array}{l}\text { Deflection, Strain and Stress for Test Case 4HS and 4CS } \\
\text { (Based on Macro Approach) }\end{array}$} \\
\hline Test Case & \multicolumn{3}{|c|}{$4 \mathrm{HS}$} & \multicolumn{3}{|c|}{$4 \mathrm{CS}$} \\
\hline$w_{\text {center }}\left(\frac{a}{2}, \frac{b}{2}\right)$, in. & \multicolumn{3}{|c|}{-0.0968} & \multicolumn{3}{|c|}{0.1546} \\
\hline$w_{\text {edge }}\left(6, \frac{b}{2}\right)$, in & \multicolumn{3}{|c|}{-0.0642} & \multicolumn{3}{|c|}{0.0985} \\
\hline (a) center & Bending & + Axial $=$ & $=$ Total & Bending & + Axial & $=$ Total \\
\hline$\varepsilon_{x x_{-} T o p \text { Surface }}(\mu \varepsilon)$ & 170 & $+258=$ & $=428$ & -291 & +-422 & $=-713$ \\
\hline$\varepsilon_{x x_{-} \text {Bottom Surface }}(\mu \varepsilon)$ & -170 & $+258=$ & $=$ & 291 & +-422 & $=-131$ \\
\hline$\varepsilon_{y y_{-} T o p \text { Surface }}(\mu \varepsilon)$ & 390 & $+430=$ & $=820$ & -623 & +-642 & $=-1265$ \\
\hline$\varepsilon_{y y_{-} \text {Bottom Surface }}(\mu \varepsilon)$ & -390 & $+430=$ & 40 & 623 & +-642 & -19 \\
\hline$\sigma_{x x_{-} T o p \text { Surface }}($ psi. $)$ & 67 & $+0=$ & 67 & -108 & + & $=-108$ \\
\hline$\sigma_{x x_{-} \text {Bottom Surface }}$ (psi.) & -67 & +0 & -67 & 108 & + & 108 \\
\hline$\sigma_{y y_{-} T o p \text { Surface }}$ (psi.) & 127 & +0 & -127 & -209 & + & $=-209$ \\
\hline$\sigma_{y y_{3} \text { Bottom Surface }}$ (psi.) & -127 & +0 & 127 & 209 & + & $=209$ \\
\hline
\end{tabular}

Table 5.7: Deflection, Strain and Stress at Center for Test Case 4HS and 4CS.

(Based on Macro Approach)

\subsection{FEM Analysis}

A FEM analysis was carried out to evaluate thermal stresses, strains and deflections in 8 inch and 4 inch deep FRP bridge decks. The shell 93 element from ANSYS V7.1 was used for thermal analysis of the FRP deck. The element had six degrees of freedom at each node (translations in the nodal $\mathrm{x}, \mathrm{y}$, and $\mathrm{z}$ directions and rotations about the nodal $\mathrm{x}, \mathrm{y}$ and $\mathrm{z}$ axes). The deck web, deck top surface, and deck bottom surface were modeled as shell elements. The structural properties of 8 inch and 4 inch deep FRP decks can be found in Table 5.1. 
The FRP deck was only modeled one quarter of the entire dimension since the structure has symmetric geometry and boundary. The "dsym" text command was conducted in this model for symmetric geometry and boundary. The temperature of the FRP deck was applied to nodes by using body load option (BF command). The temperature change on the top and bottom surfaces was uniform while the temperature on the deck web varied along depth linearly. In-plane nodal geometry at intersections between web and flange was identical. The element size of 4 inch and 8 inch FRP deck model are about 0.9 inches x 0.9 inches. The total number of nodes and elements for 8 inch FRP deck models are 20,172 nodes and 6,720 elements for a quarter model. The total nodes and elements for 4 in. FRP deck model are 12,608 nodes and 4240 elements for a quarter model. The FEM nodal geometries for 8 inch and 4 inch FRP decks are shown in Figure 5.6 and 5.7. Top surface was at $Z=0$.

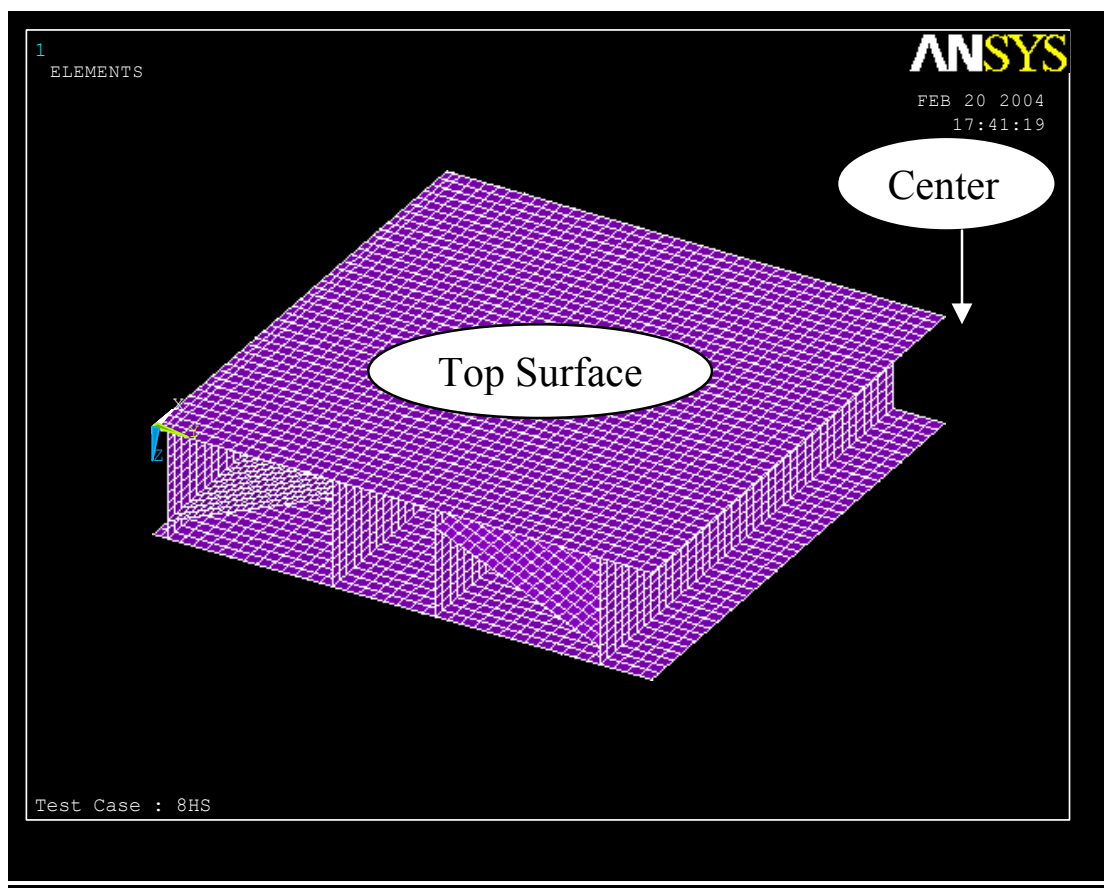

Figure 5.6: Quarter Model of a 8 inch FRP Deck Specimen. 


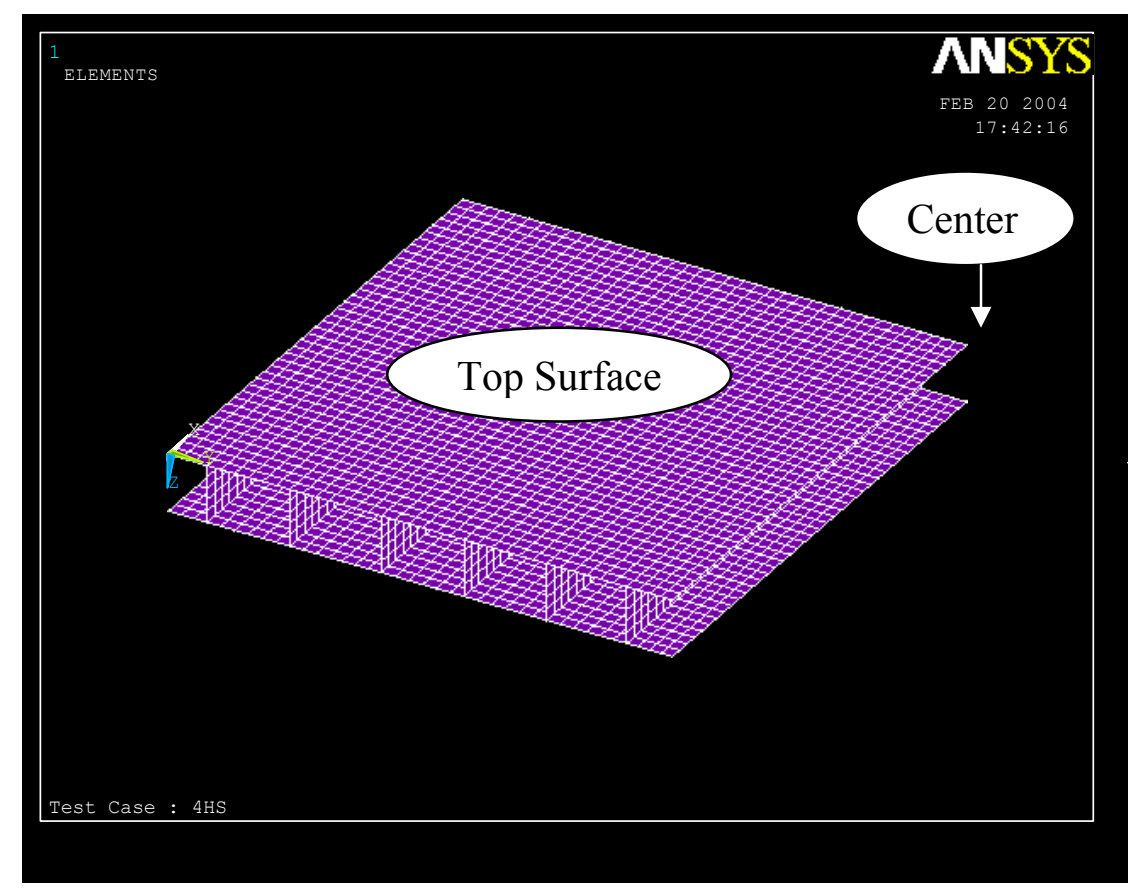

Figure 5.7: Quarter Model of a 4 inch FRP Deck Specimen.

Note : $X, Y, Z$ coordinates of FEM model in Figures 5.6 and 5.7 are similar to those of Navier-Levy and Macro approaches in Figures G.1 and G.2.

The FEM contour plots and FEM text command for all test cases are presented in

Appendix F. The FEM results at the center of FRP deck are shown in Table 5.8.

The notations used in the Table 5.8 are as follows :

$w_{\text {center }}\left(\frac{a}{2}, \frac{b}{2}\right)$ and $w_{\text {edge }}\left(6, \frac{b}{2}\right)=$ Deflection @ center and edge of the FRP deck, respectively.

$\varepsilon_{x x_{-} \text {TopSurface }}$ and $\varepsilon_{x x_{-} \text {Bottom Surface }}=$ Strain in $x$ direction on top/bottom surface, respectively.

$\varepsilon_{y y_{-} \text {Top Surface }}$ and $\varepsilon_{y y_{-} \text {Bottom Surface }}=$ Strain in $y$ direction on top/bottom surface, respectively.

$\sigma_{x x_{-} \text {Top Surface }}$ and $\sigma_{x x_{-} \text {Bottom Surface }}=$ Stress in $x$ direction on top/bottom surface, respectively.

$\sigma_{y y_{-} \text {Top Surface }}$ and $\sigma_{y y_{-} \text {Bottom Surface }}=$ Stress in $y$ direction on top/bottom surface, respectively.

Refer to Figures 4.8 through 4.11 in chapter 4 for $x, y$ direction. 


\begin{tabular}{|c|c|c|c|c|c|c|c|c|}
\hline \multicolumn{9}{|c|}{ FEM Results at Center of FRP Specimen } \\
\hline$\underline{\text { Test Case }}$ & $8 \mathrm{HS}$ & $8 \mathrm{CS}$ & $8 \mathrm{HF}$ & $8 \mathrm{CF}$ & 4HS & $4 \mathrm{CS}$ & $4 \mathrm{HF}$ & $4 \mathrm{CF}$ \\
\hline Boundary Condition & SSFF & FFFF & SSFF & FFFF & SSFF & FFFF & SSFF & FFFF \\
\hline$T_{t o p},\left({ }^{\circ} \mathrm{F}\right)$ & 155 & 152 & -30 & -31 & 153 & 151 & -43 & -45 \\
\hline$T_{\text {bottom }},\left({ }^{\circ} \mathrm{F}\right)$ & 74 & 74 & 60 & 61 & 97 & 98 & 56 & 60 \\
\hline$T_{r e f},\left({ }^{\circ} \mathrm{F}\right)$ & 71 & 73 & 80 & 80 & 80 & 80 & 82 & 84 \\
\hline$\Delta T_{t o p}=T_{t o p}-T_{r e f},\left({ }^{\circ} \mathrm{F}\right)$ & 84 & 79 & -110 & -111 & 73 & 71 & -125 & -129 \\
\hline$\Delta T_{\text {bottom }}=T_{\text {bottom }}-T_{\text {ref }}$ & 3 & 1 & -20 & -19 & 17 & 18 & -26 & -24 \\
\hline$\Delta T_{\max }=\Delta T_{\text {top }}-\Delta T_{\text {bottom }}$ & 81 & 78 & -90 & -92 & 56 & 53 & -99 & -105 \\
\hline$w_{\text {center }}\left(\frac{a}{2}, \frac{b}{2}\right)$, in. & -0.1089 & 0.1051 & -0.1243 & 0.1307 & -0.0998 & 0.1598 & -0.1275 & 0.2330 \\
\hline$w_{\text {edge }}\left(6, \frac{b}{2}\right)$, in. & -0.0855 & 0.0784 & -0.1014 & 0.1029 & -0.0633 & 0.0968 & -0.0930 & 0.1665 \\
\hline$\varepsilon_{x x_{-} T o p \text { Surface }}(\mu \varepsilon)$ & 421 & -564 & 395 & -567 & 436 & -729 & 423 & -752 \\
\hline$\varepsilon_{x x_{-} \text {Bottom Surface }}(\mu \varepsilon)$ & 3 & -86 & -8 & -80 & 80 & -115 & 87 & -104 \\
\hline$\varepsilon_{y y_{-} \text {Top Surface }}(\mu \varepsilon)$ & 1211 & -1330 & 1153 & -1359 & 719 & -1095 & 705 & -1144 \\
\hline$\varepsilon_{y y_{-} \text {Bottom Surface }}(\mu \varepsilon)$ & 19 & -219 & -22 & -190 & 142 & -190 & 146 & -158 \\
\hline$\sigma_{x x_{-} T o p \text { Surface }}($ psi.) & 62 & -69 & 59 & -70 & 73 & -125 & 67 & -129 \\
\hline$\sigma_{x x_{-} \text {Bottom Surface }}($ psi.) & -53 & 59 & -59 & 70 & -73 & 125 & -67 & 129 \\
\hline$\sigma_{y y_{-} T o p \text { Surface }}$ (psi.) & 30 & -25 & 42 & -43 & 26 & -39 & 31 & -54 \\
\hline$\sigma_{y y_{-} \text {Bottom Surface }}$ (psi.) & -29 & 25 & -44 & 44 & -26 & 39 & -31 & 54 \\
\hline
\end{tabular}

Table 5.8: Results at Center for all of Test Cases (FEM Analysis).

\subsection{Comparison between experimental and theoretical results}

\subsubsection{Deflection Comparison (Experiment, FEM, Navier-Levy and Macro Approach)}

According to the results from sections 5.1, 5.2 and 5.3, deflection results for all test cases are tabulated in Tables 5.9 and 5.10. 


\begin{tabular}{|c|c|c|c|c|c|}
\hline Test Case & Deflection (in.) & Experiment & FEM & Navier-Levy & Macro Approach \\
\hline \multirow{2}{*}{$8 \mathrm{HS}$} & $w_{\text {center }}(a / 2, b / 2)$ & -0.0960 & -0.1089 & -0.0988 & -0.0942 \\
\hline & $w_{\text {edge }}(6, b / 2)$ & -0.0680 & -0.0855 & -0.0767 & -0.0739 \\
\hline \multirow{2}{*}{$8 \mathrm{CS}$} & $w_{\text {center }}(a / 2, b / 2)$ & 0.1030 & 0.1051 & 0.0946 & 0.0900 \\
\hline & $w_{\text {edge }}(6, b / 2)$ & 0.0780 & 0.0784 & 0.0705 & 0.0670 \\
\hline \multirow{2}{*}{$8 \mathrm{HF}$} & $w_{\text {center }}(a / 2, b / 2)$ & -0.1230 & -0.1243 & - & - \\
\hline & $w_{\text {edge }}(6, b / 2)$ & -0.0970 & -0.1014 & - & - \\
\hline \multirow{2}{*}{$8 \mathrm{CF}$} & $w_{\text {center }}(a / 2, b / 2)$ & 0.1330 & 0.1282 & - & - \\
\hline & $w_{\text {edge }}(6, b / 2)$ & 0.1040 & 0.0946 & - & - \\
\hline \multirow{2}{*}{$4 \mathrm{HS}$} & $w_{\text {center }}(a / 2, b / 2)$ & -0.0940 & -0.0998 & -0.1021 & -0.0968 \\
\hline & $w_{\text {edge }}(6, b / 2)$ & -0.0509 & -0.0633 & -0.0692 & -0.0642 \\
\hline \multirow{2}{*}{$4 \mathrm{CS}$} & $w_{\text {center }}(a / 2, b / 2)$ & 0.1590 & 0.1598 & 0.1631 & 0.1546 \\
\hline & $w_{\text {edge }}(6, b / 2)$ & 0.0850 & 0.0968 & 0.1073 & 0.0985 \\
\hline \multirow{2}{*}{$4 \mathrm{HF}$} & $w_{\text {center }}(a / 2, b / 2)$ & -0.1050 & -0.1275 & - & - \\
\hline & $w_{\text {edge }}(6, b / 2)$ & -0.0760 & -0.0930 & - & - \\
\hline \multirow{2}{*}{$4 \mathrm{CF}$} & $w_{\text {center }}(a / 2, b / 2)$ & 0.2320 & 0.2330 & - & - \\
\hline & $w_{\text {edge }}(6, b / 2)$ & 0.1540 & 0.1665 & - & - \\
\hline
\end{tabular}

Note : Temperature data for all test cases are shown below

\begin{tabular}{|l|c|c|c|c|c|c|c|c|}
\hline Test Case & $8 \mathrm{HS}$ & $8 \mathrm{CS}$ & $8 \mathrm{HF}$ & $8 \mathrm{CF}$ & $4 \mathrm{HS}$ & $4 \mathrm{CS}$ & $4 \mathrm{HF}$ & $4 \mathrm{CF}$ \\
\hline Boundary Condition & SSFF & FFFF & SSFF & FFFF & SSFF & FFFF & SSFF & FFFF \\
\hline$T_{\text {top }},\left({ }^{\circ} \mathrm{F}\right)$ & 155 & 152 & -30 & -31 & 153 & 151 & -43 & -45 \\
\hline$\left.T_{\text {bottom }},{ }^{\circ} \mathrm{F}\right)$ & 74 & 74 & 60 & 61 & 97 & 98 & 56 & 60 \\
\hline$T_{\text {ref }},\left({ }^{\circ} \mathrm{F}\right)$ & 71 & 73 & 80 & 80 & 80 & 80 & 82 & 84 \\
\hline$\Delta T_{\text {top }}=T_{\text {top }}-T_{\text {ref }},\left({ }^{\circ} \mathrm{F}\right)$ & 84 & 79 & -110 & -111 & 73 & 71 & -125 & -129 \\
\hline$\Delta T_{\text {bottom }}=T_{\text {bottom }}-T_{\text {ref }},\left({ }^{\circ} \mathrm{F}\right)$ & 3 & 1 & -20 & -19 & 17 & 18 & -26 & -24 \\
\hline$\Delta T_{\max }=\Delta T_{\text {top }}-\Delta T_{\text {bottom }},\left({ }^{\circ} \mathrm{F}\right)$ & 81 & 78 & -90 & -92 & 56 & 53 & -99 & -105 \\
\hline
\end{tabular}

Table 5.9: Deflection Results (Experiment, FEM, Navier-Levy, and Macro Approach) for all of Test Cases. 
Results from the above table are plotted in the form of a bar chart, which are shown in Figure 5.8.

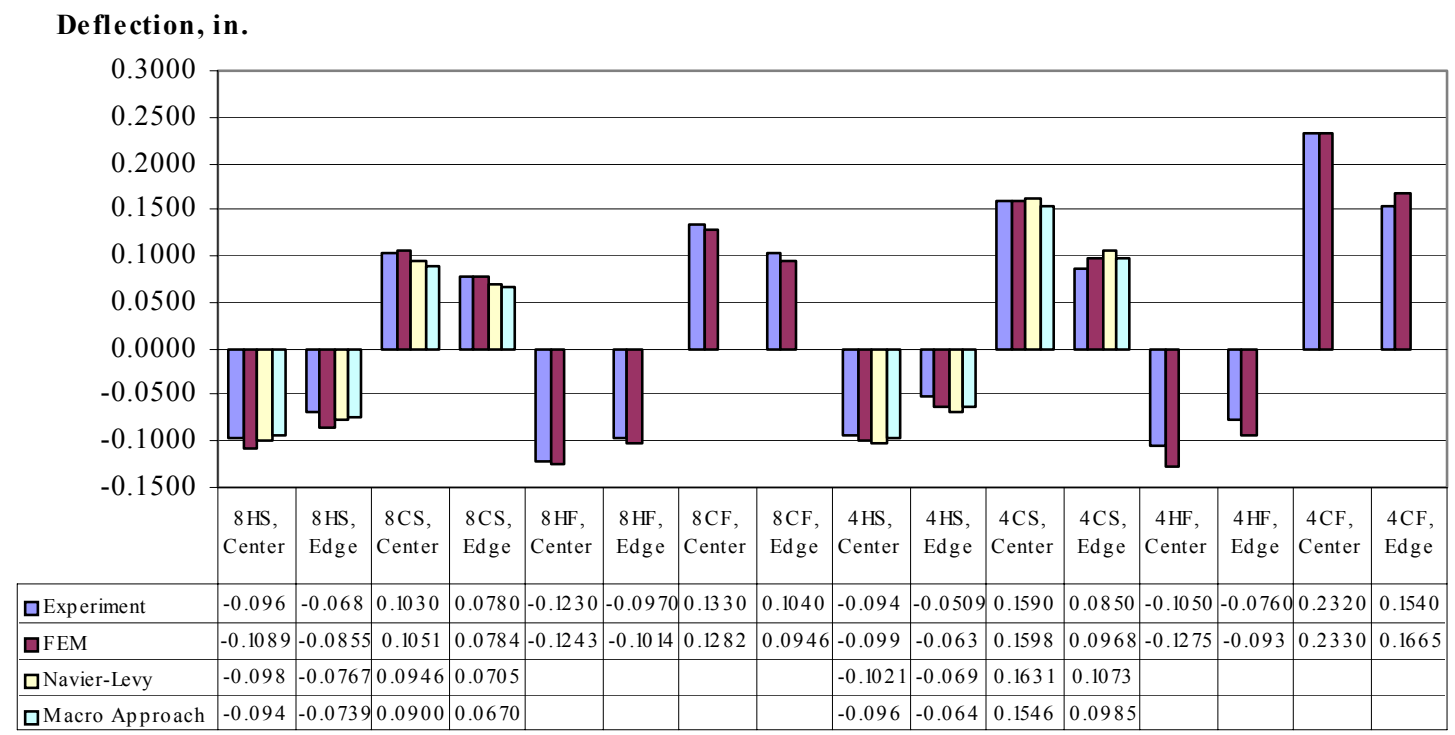

Test Cases

Figure 5.8: Deflection Bar Chart for all of Test Cases. 


\begin{tabular}{|c|c|c|c|}
\hline \multicolumn{4}{|c|}{ Percent Deflection Difference, \% (Theory V.S. Experiment) } \\
\hline Test Cases & $\begin{array}{c}\text { FEM V.S. } \\
\text { Experiment }\end{array}$ & $\begin{array}{c}\text { Navier-Levy V.S. } \\
\text { Experiment }\end{array}$ & $\begin{array}{c}\text { Macro-Mechanics V.S. } \\
\text { Experiment }\end{array}$ \\
\hline $8 \mathrm{HS} @$ Center & $13 \%$ & $3 \%$ & $2 \%$ \\
\hline $8 \mathrm{HS} @$ Edge & $26 \%$ & $13 \%$ & $9 \%$ \\
\hline $8 \mathrm{CS} @$ Center & $2 \%$ & $8 \%$ & $13 \%$ \\
\hline $8 \mathrm{CS} @$ Edge & $1 \%$ & $10 \%$ & $14 \%$ \\
\hline $8 \mathrm{HF} @$ Center & $1 \%$ & - & - \\
\hline $8 \mathrm{HF} @$ Edge & $5 \%$ & - & - \\
\hline $8 \mathrm{CF} @$ Center & $4 \%$ & - & - \\
\hline $8 \mathrm{CF} @$ Edge & $9 \%$ & - & $3 \%$ \\
\hline $4 \mathrm{HS} @$ Center & $6 \%$ & $9 \%$ & $26 \%$ \\
\hline $4 \mathrm{HS} @$ Edge & $24 \%$ & $36 \%$ & $3 \%$ \\
\hline $4 \mathrm{CS} @$ Center & $1 \%$ & $3 \%$ & $16 \%$ \\
\hline $4 \mathrm{CS} @$ Edge & $14 \%$ & $26 \%$ & - \\
\hline $4 \mathrm{HF} @$ Center & $21 \%$ & - & - \\
\hline $4 \mathrm{HF} @$ Edge & $22 \%$ & - & - \\
\hline $4 \mathrm{CF} @$ Center & $0.4 \%$ & - & $11 \%$ \\
\hline $4 \mathrm{CF} @$ Edge & $8 \%$ & - & \\
\hline \hline Average & $10 \%$ & $13 \%$ & - \\
\hline
\end{tabular}

Table 5.10: Percent Deflection Difference (Theory V.S. Experiment).

\subsubsection{Strain Comparison (Experiment, FEM and Macro Approach)}

According to the results from section 5.1, 5.2 and 5.3, strain results for all test cases are tabulated as Tables 5.11 and 5.12. 


\begin{tabular}{|c|c|c|c|c|}
\hline \multicolumn{5}{|c|}{ Strain Results at the Center of FRP Deck $(\mu \varepsilon)$} \\
\hline Test Cases & Top / Bottom Surface & Experiment & FEM & Macro Approach \\
\hline \multirow{4}{*}{$8 \mathrm{HS}$} & $\varepsilon_{y y_{-} \text {Top Surface }},($ Gage \#1) & 935 & 1211 & 1396 \\
\hline & $\varepsilon_{x x_{-} \text {Top Surface }},($ Gage \#2) & - & 421 & 425 \\
\hline & $\varepsilon_{y y_{-} \text {Bottom Surface }},($ Gage \#13) & 3 & 19 & -166 \\
\hline & $\varepsilon_{x x_{-} \text {Bottom Surface }},($ Gage \#14) & - & 3 & -3 \\
\hline \multirow{4}{*}{$8 \mathrm{CS}$} & $\varepsilon_{y y_{-} T o p \text { Surface }}$ & -1267 & -1330 & -1522 \\
\hline & $\mathcal{E}_{x x_{-} T o p \text { Surface }}$ & -467 & -564 & -565 \\
\hline & $\varepsilon_{y y_{-} \text {Bottom Surface }}$ & -101 & -219 & -28 \\
\hline & $\varepsilon_{x x_{-} \text {Bottom Surface }}$ & -52 & -86 & -83 \\
\hline \multirow{4}{*}{$8 \mathrm{HF}$} & $\varepsilon_{y y_{-} T o p \text { Surface }}$ & 912 & 1153 & - \\
\hline & $\varepsilon_{x x_{-} T o p \text { Surface }}$ & 300 & 395 & - \\
\hline & $\varepsilon_{y y_{-} \text {Bottom Surface }}$ & -23 & -22 & - \\
\hline & $\varepsilon_{x x_{-} \text {Bottom Surface }}$ & 5 & -8 & - \\
\hline \multirow{4}{*}{$8 \mathrm{CF}$} & $\varepsilon_{y y_{-} \text {Top Surface }}$ & -1266 & -1359 & - \\
\hline & $\varepsilon_{x x_{-} T o p \text { Surface }}$ & -480 & -567 & - \\
\hline & $\varepsilon_{y y_{-} \text {Bottom Surface }}$ & -122 & -190 & - \\
\hline & $\varepsilon_{x x_{-} \text {Bottom Surface }}$ & 3 & -80 & - \\
\hline
\end{tabular}

Note: Refer to Figure 4.8 and 4.9 in Chapter 4 for $x, y$ directions. Temperature data for all test cases are shown below.

\begin{tabular}{|l|c|c|c|c|c|c|c|c|}
\hline$\underline{\text { Test Case }}$ & $8 \mathrm{HS}$ & $8 \mathrm{CS}$ & $8 \mathrm{HF}$ & $8 \mathrm{CF}$ & $4 \mathrm{HS}$ & $4 \mathrm{CS}$ & $4 \mathrm{HF}$ & $4 \mathrm{CF}$ \\
\hline$\left.T_{\text {top }},{ }^{\circ} \mathrm{F}\right)$ & 155 & 152 & -30 & -31 & 153 & 151 & -43 & -45 \\
\hline$\left.T_{\text {bottom }},{ }^{\circ} \mathrm{F}\right)$ & 74 & 74 & 60 & 61 & 97 & 98 & 56 & 60 \\
\hline$T_{\text {ref }},\left({ }^{\circ} \mathrm{F}\right)$ & 71 & 73 & 80 & 80 & 80 & 80 & 82 & 84 \\
\hline$\Delta T_{\text {top }}=T_{\text {top }}-T_{\text {ref }},\left({ }^{\circ} \mathrm{F}\right)$ & 84 & 79 & -110 & -111 & 73 & 71 & -125 & -129 \\
\hline$\Delta T_{\text {bottom }}=T_{\text {bottom }}-T_{\text {ref }},\left({ }^{\circ} \mathrm{F}\right)$ & 3 & 1 & -20 & -19 & 17 & 18 & -26 & -24 \\
\hline$\Delta T_{\max }=\Delta T_{\text {top }}-\Delta T_{\text {bottom }},\left({ }^{\circ} \mathrm{F}\right)$ & 81 & 78 & -90 & -92 & 56 & 53 & -99 & -105 \\
\hline
\end{tabular}

Table 5.11: Strain Results for 8 inch FRP Deck. 


\begin{tabular}{|c|c|c|c|c|}
\hline \multicolumn{5}{|c|}{ Strain Results at the Center of FRP Deck $(\mu \varepsilon)$} \\
\hline Test Cases & Top / Bottom Surface & Experiment & FEM & Macro-Mechanics \\
\hline \multirow{4}{*}{ 4HS } & $\varepsilon_{y y_{-} \text {Top Surface }},($ Gage \#1) & 627 & 719 & 820 \\
\hline & $\varepsilon_{x x_{-} \text {Top Surface }},($ Gage \#2) & 350 & 436 & 428 \\
\hline & $\varepsilon_{y y_{\text {B Bottom Surface }}},($ Gage \#13) & 171 & 142 & 40 \\
\hline & $\varepsilon_{x x_{-} \text {Bottom Surface }},($ Gage \#14) & 92 & 80 & 88 \\
\hline \multirow{4}{*}{$4 \mathrm{CS}$} & $\varepsilon_{y y_{-} T o p \text { Surface }}$ & -1307 & -1095 & -1265 \\
\hline & $\varepsilon_{x x_{-} T o p \text { Surface }}$ & -912 & -729 & -713 \\
\hline & $\varepsilon_{y y_{-} \text {Bottom Surface }}$ & -205 & -190 & -19 \\
\hline & $\mathcal{E}_{x x_{-} \text {Bottom Surface }}$ & -110 & -115 & -131 \\
\hline \multirow{4}{*}{$4 \mathrm{HF}$} & $\varepsilon_{y y_{-} \text {Top Surface }}$ & 564 & 705 & - \\
\hline & $\varepsilon_{x x_{-} T o p \text { Surface }}$ & 352 & 423 & - \\
\hline & $\varepsilon_{y y_{-} \text {Bottom Surface }}$ & 129 & 146 & - \\
\hline & $\varepsilon_{x x_{-} \text {Bottom Surface }}$ & 87 & 87 & - \\
\hline \multirow{4}{*}{$4 \mathrm{CF}$} & $\varepsilon_{y y_{-} T o p \text { Surface }}$ & -1414 & -1144 & - \\
\hline & $\varepsilon_{x x_{-} \text {Top Surface }}$ & -948 & -752 & - \\
\hline & $\varepsilon_{y y_{-} \text {Bottom Surface }}$ & -275 & -158 & - \\
\hline & $\varepsilon_{x x_{-} \text {Bottom Surface }}$ & -81 & -104 & - \\
\hline
\end{tabular}

Note: Refer to Figure 4.10 and 4.11 in Chapter 4 for $x, y$ directions. Temperature data for all test cases are shown below.

\begin{tabular}{|l|c|c|c|c|c|c|c|c|}
\hline$\underline{\text { Test Case }}$ & $8 \mathrm{HS}$ & $8 \mathrm{CS}$ & $8 \mathrm{HF}$ & $8 \mathrm{CF}$ & $4 \mathrm{HS}$ & $4 \mathrm{CS}$ & $4 \mathrm{HF}$ & $4 \mathrm{CF}$ \\
\hline$T_{\text {top }},\left({ }^{\circ} \mathrm{F}\right)$ & 155 & 152 & -30 & -31 & 153 & 151 & -43 & -45 \\
\hline$T_{\text {bottom }},\left({ }^{\circ} \mathrm{F}\right)$ & 74 & 74 & 60 & 61 & 97 & 98 & 56 & 60 \\
\hline$T_{\text {ref }},\left({ }^{\circ} \mathrm{F}\right)$ & 71 & 73 & 80 & 80 & 80 & 80 & 82 & 84 \\
\hline$\Delta T_{\text {top }}=T_{\text {top }}-T_{\text {ref }},\left({ }^{\circ} \mathrm{F}\right)$ & 84 & 79 & -110 & -111 & 73 & 71 & -125 & -129 \\
\hline$\Delta T_{\text {bottom }}=T_{\text {bottom }}-T_{\text {ref }},\left({ }^{\circ} \mathrm{F}\right)$ & 3 & 1 & -20 & -19 & 17 & 18 & -26 & -24 \\
\hline$\Delta T_{\max }=\Delta T_{\text {top }}-\Delta T_{\text {bottom }},\left({ }^{\circ} \mathrm{F}\right)$ & 81 & 78 & -90 & -92 & 56 & 53 & -99 & -105 \\
\hline
\end{tabular}

Table 5.12: Strain Results for 4 inch FRP Deck. 
According to strain results in the above table (Tables 5.11 and 5.12), the strain bar charts for each test case are shown Figure 5.9 through Figure 5.16.

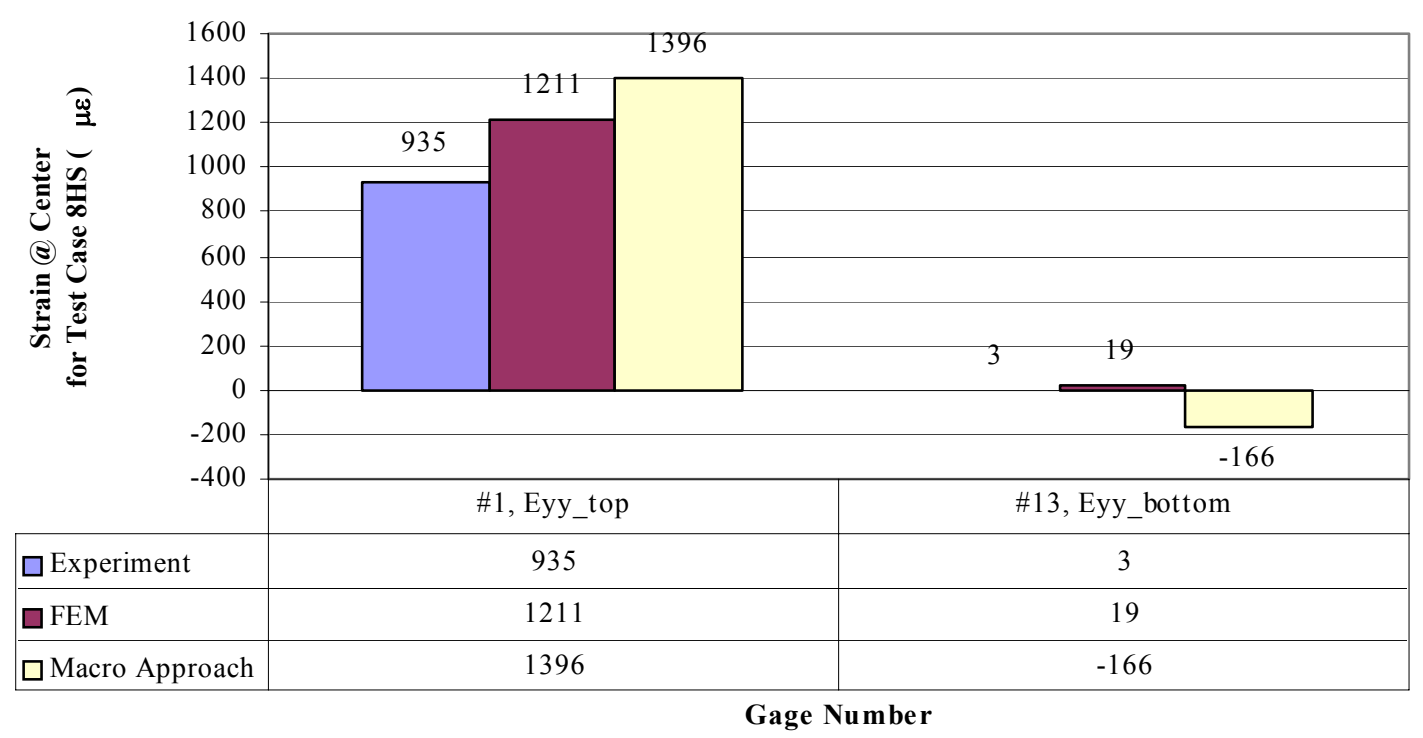

Figure 5.9: Strain Bar Chart for Test Case 8HS. 


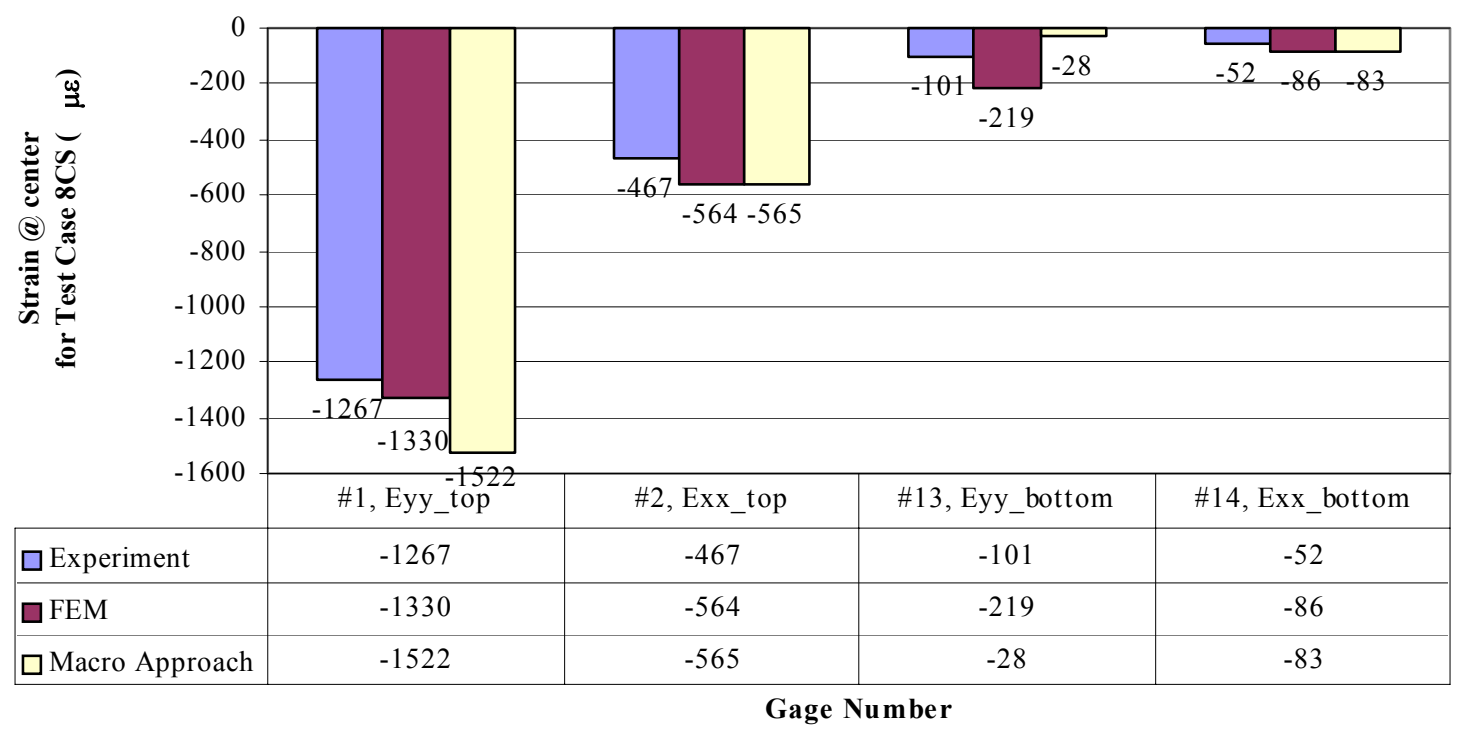

Figure 5.10: Strain Bar Chart for Test Case 8CS.

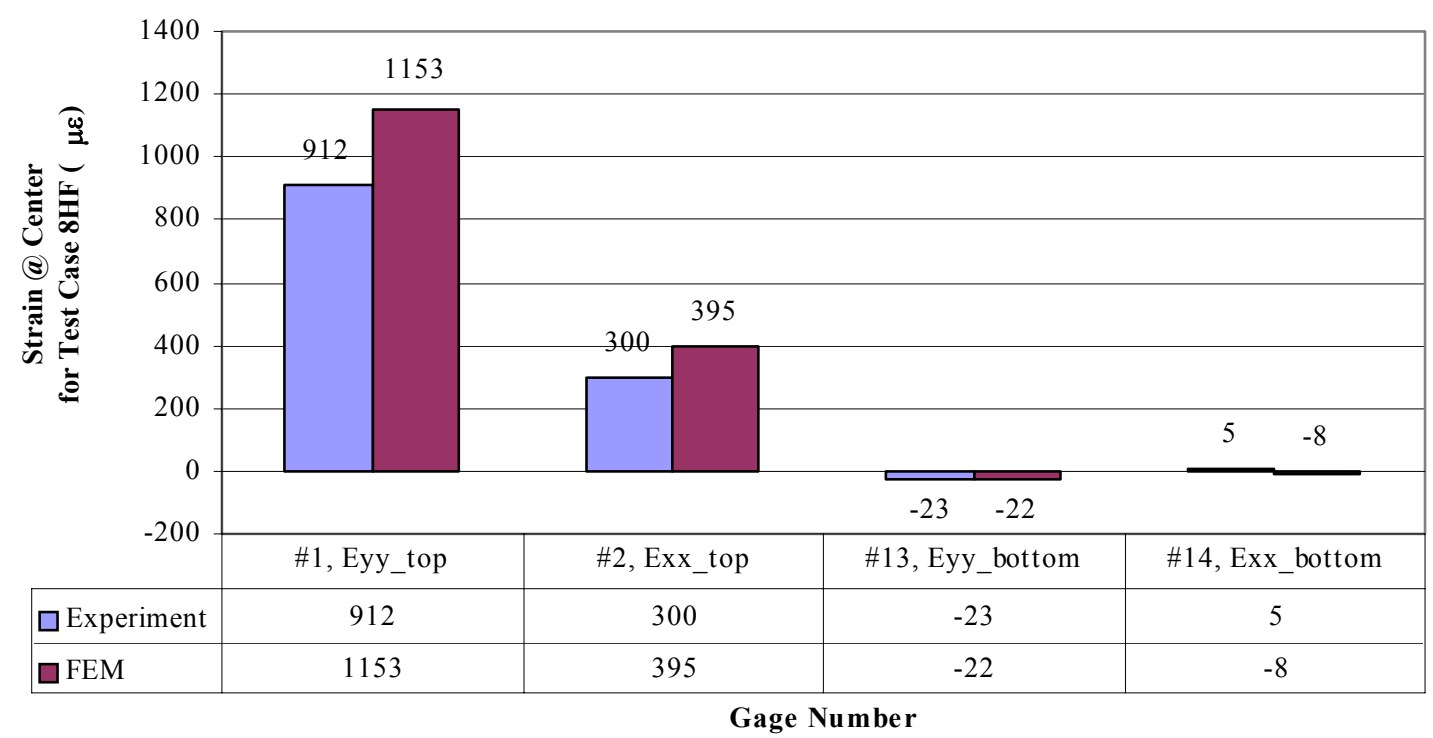

Figure 5.11: Strain Bar Chart for Test Case 8HF. 


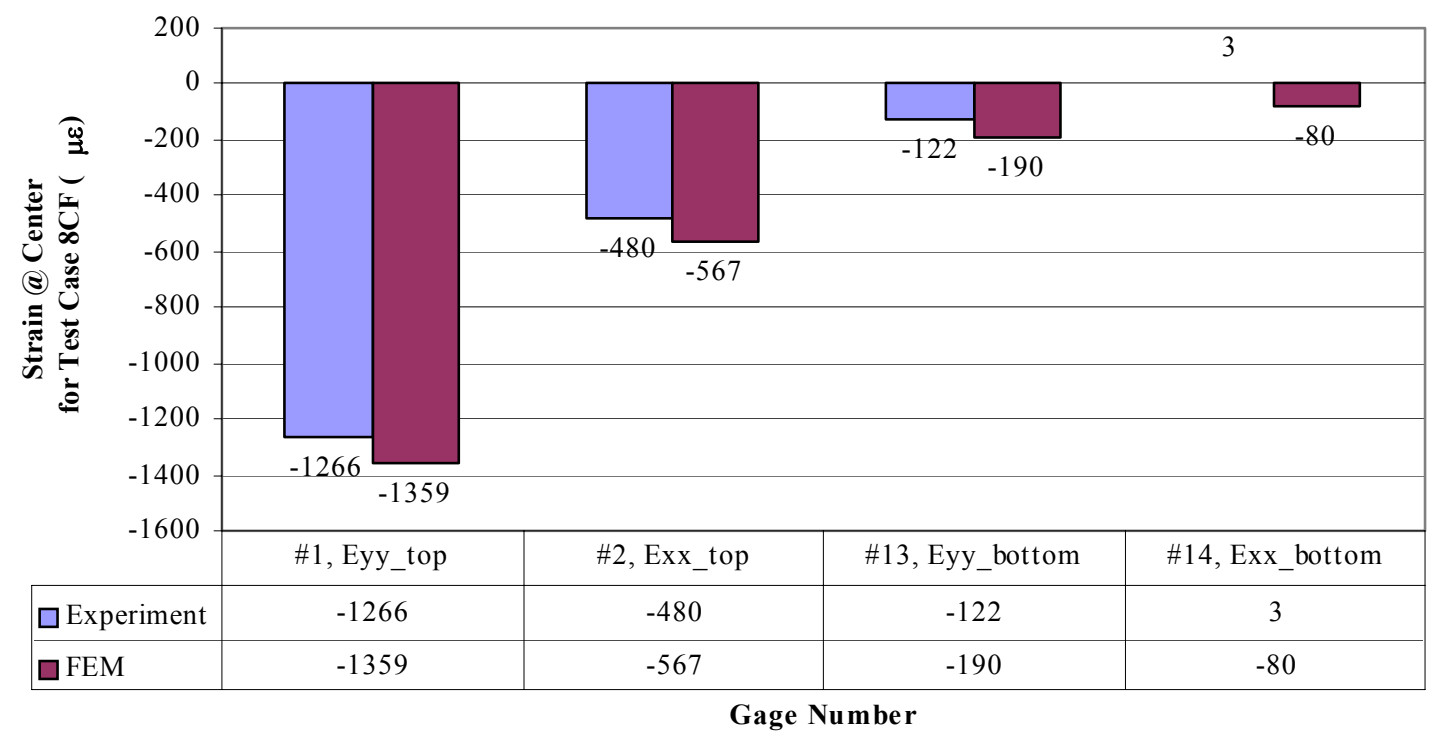

Figure 5.12: Strain Bar Chart for Test Case 8CF.

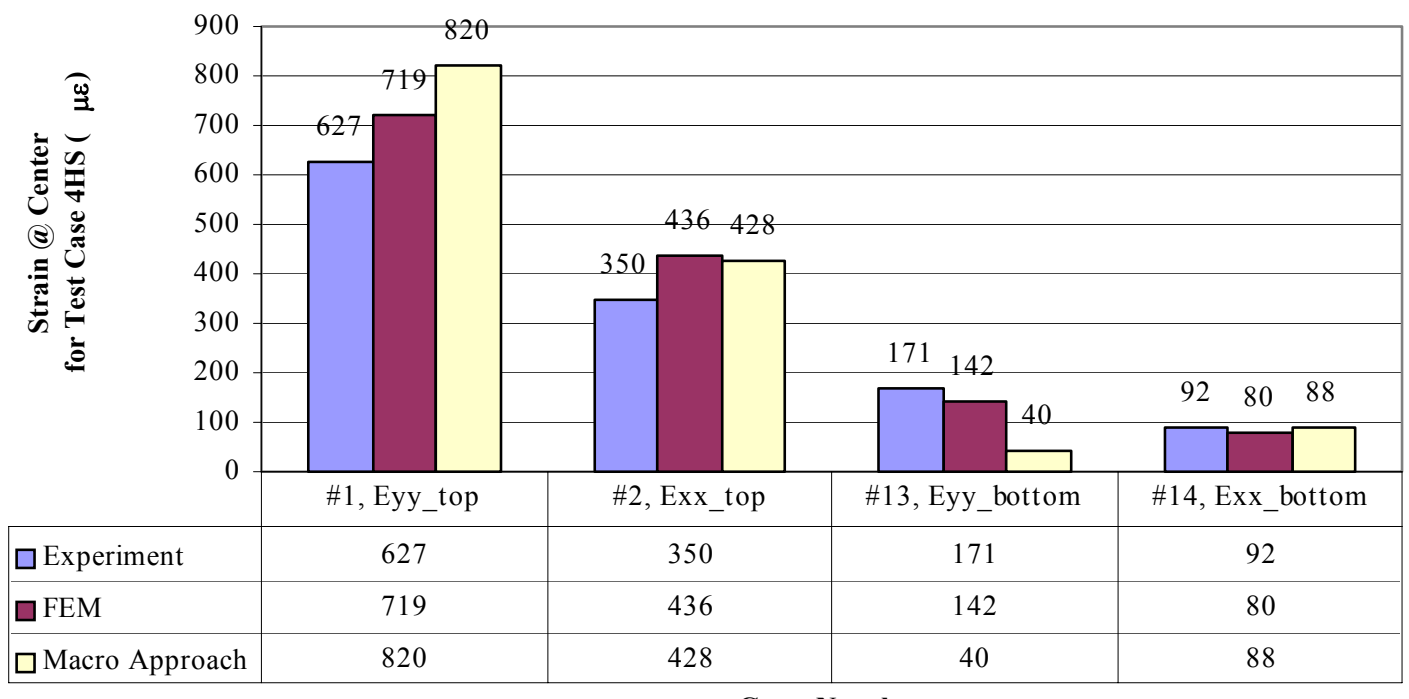

Gage Number

Figure 5.13: Strain Bar Chart for Test Case 4HS. 
$-19$

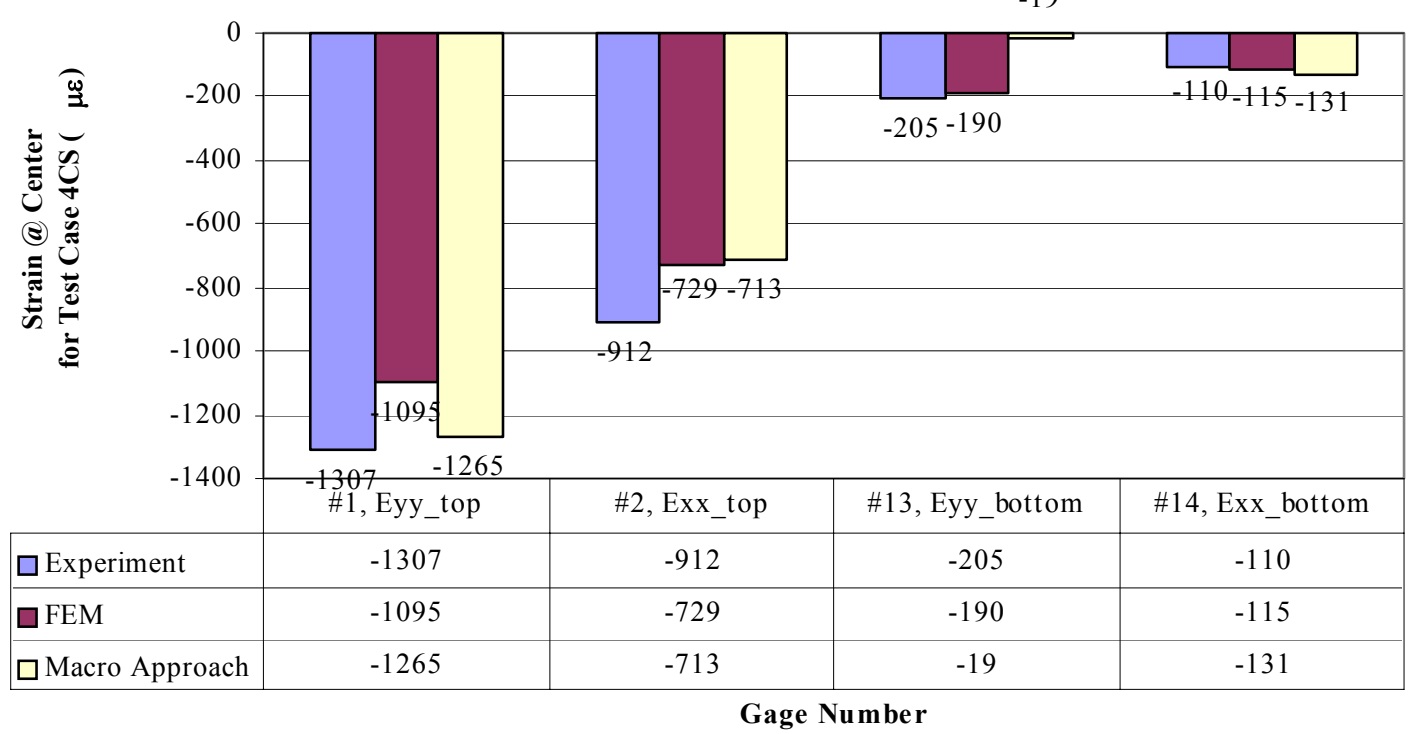

Figure 5.14: Strain Bar Chart for Test Case 4CS.

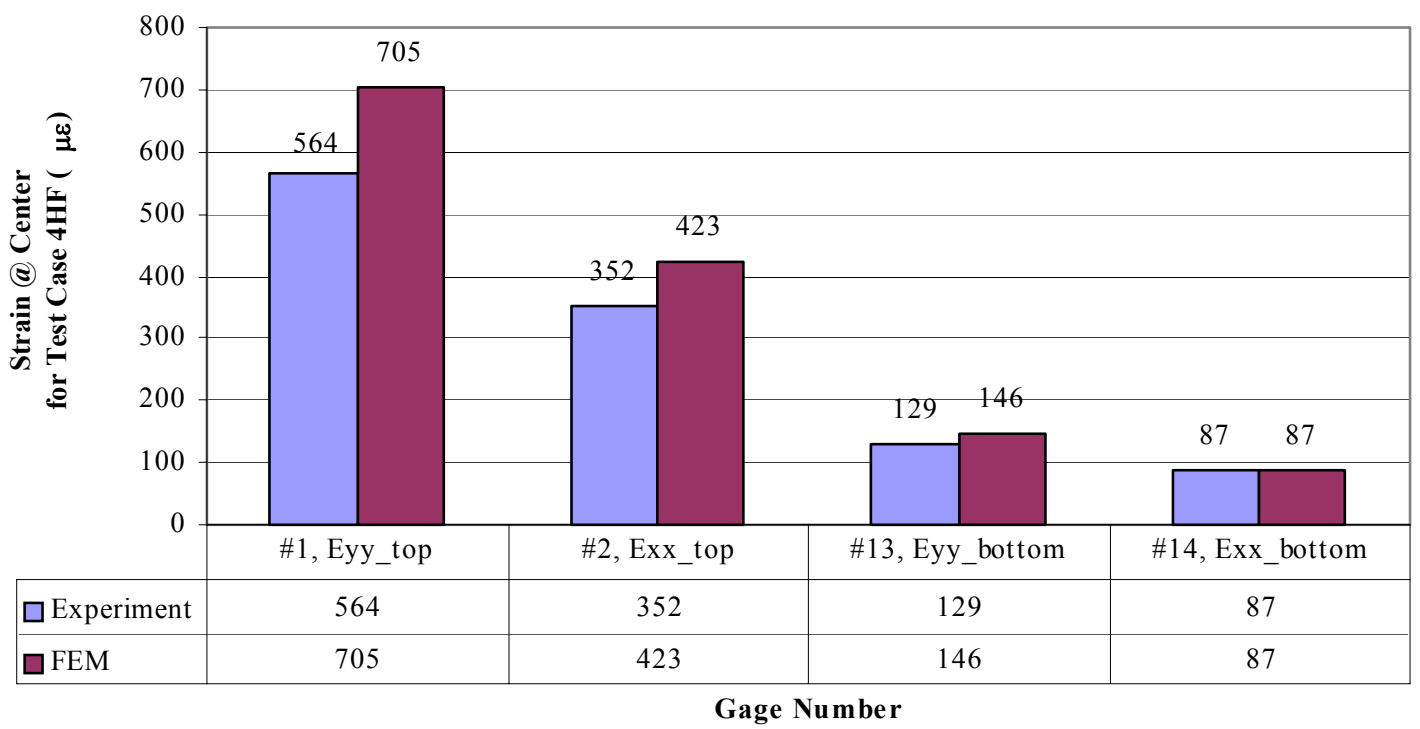

Figure 5.15: Strain Bar Chart for Test Case 4HF. 


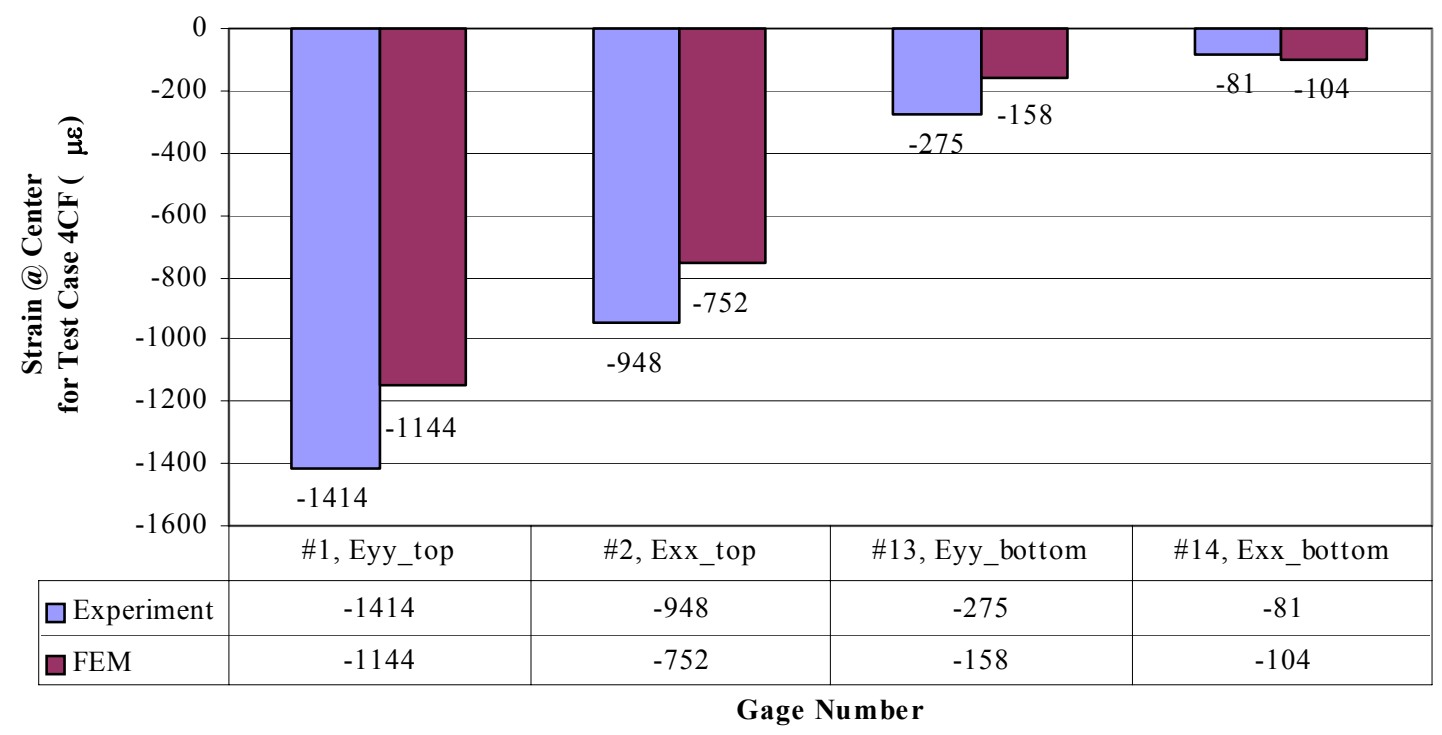

Figure 5.16: Strain Bar Chart for Test Case 4CF.

According to strain bar charts as in Figure 5.9 through 5.16, strain results on bottom surface are small compared to those on top surface because of low temperature change. Percent strain difference (or Percent strain error) was calculated based on the following formula:

$\%$ Strain Difference $=\left|\frac{\text { Exp. }- \text { FEM }}{\text { Exp. }}\right| \times 100$ or $\left|\frac{\text { Exp. }- \text { Macro. }}{\text { Exp. }}\right| \times 100$

The average percent strain difference for both 4 inch and 8 inch FRP deck (for all test cases) are tabulated in Table 5.13. 


\begin{tabular}{|l|c|c|}
\hline \multicolumn{3}{|c|}{ Average of $\%$ strain difference for all of test cases ( for 4 and 8 in. FRP decks.) } \\
\hline \multicolumn{1}{|c|}{ Location } & Experiment V.S. FEM & Experiment V.S. Macro Approach \\
\hline Both Top/Bottom Surface & $21 \%^{*}$ & $25 \% * *$ \\
\hline Only Top Surface & $20 \%$ & $22 \%$ \\
\hline
\end{tabular}

Note : $\quad *=$ Calculation is based on 26 out of 29 data samples.

$* *=$ Calculation is based on 10 out of 13 data samples.

Table 5.13: Average of Percent Strain Difference for all of Test Cases

(for 4 inch and 8 inch FRP decks.)

\subsubsection{Stress Comparison (Experiment, FEM and Macro Approach)}

Experimental stress can be calculated from experimental strain results. The stressstrain relation for orthotropic material under thermoelastic effect is (Refer to Eq. (A.39) in Appendix A)

$$
\left\{\begin{array}{c}
\sigma_{x x} \\
\sigma_{y y}
\end{array}\right\}=\left[\begin{array}{l}
Q_{x x} Q_{x y} \\
Q_{x y} Q_{y y}
\end{array}\right]\left\{\begin{array}{l}
\varepsilon_{x x}-\alpha_{x x} \Delta T \\
\varepsilon_{y y}-\alpha_{y y} \Delta T
\end{array}\right\}
$$

where $Q_{x x}=\frac{E_{x}}{1-v_{x y} v_{y x}}, Q_{x y}=\frac{v_{x y} E_{y}}{1-v_{x y} v_{y x}}$, and $Q_{y y}=\frac{E_{y}}{1-v_{x y} v_{y x}}$

\section{Computation of Experimental Stresses on Top Surface for Test Case 4HS}

Elastic properties of $E_{x}, E_{y}, v_{x y}, v_{y x}, \alpha_{x x}$, and $\alpha_{y y}$ can be found in Table 5.1. Strain data $\left(\alpha_{x x}, \alpha_{y y}\right)$, top temperature $\left(T_{t o p}\right)$ and reference temperature $\left(T_{r e f}\right)$ for test case 4HS are obtained from Table 5.3.

$$
\begin{aligned}
& Q_{x x}=\frac{E_{x}}{1-v_{x y} v_{y x}}=\frac{3.8 \times 10^{6}}{1-(0.25)(0.0658)}=3.86 \times 10^{6} \mathrm{psi} . \\
& Q_{x y}=\frac{v_{x y} E_{y}}{1-v_{x y} v_{y x}}=\frac{0.25\left(1 \times 10^{6}\right)}{1-(0.25)(0.0658)}=2.54 \times 10^{6} \mathrm{psi} .
\end{aligned}
$$


$Q_{y y}=\frac{E_{y}}{1-v_{x y} v_{y x}}=\frac{1 \times 10^{6}}{1-(0.25)(0.0658)}=1.02 \times 10^{6} \mathrm{psi}$.

$\Delta T_{\text {top }}=T_{\text {top }}-T_{\text {ref. }}=153-83=73{ }^{\circ} \mathrm{F}$

$\varepsilon_{x x}=350 \mu \varepsilon, \varepsilon_{y y}=627 \mu \varepsilon$ ( Refer to Table 5.3 for test case $4 \mathrm{HS}$ )

Substituting $Q_{x x}, Q_{x y}, Q_{y y}, \Delta T, \varepsilon_{x x}$ and $\varepsilon_{y y}$ into the above equation we obtain stress

components on top surface as

$\therefore \sigma_{x x}=Q_{x x}\left(\varepsilon_{x x}-\alpha_{x x} \Delta T\right)+Q_{x y}\left(\varepsilon_{y y}-\alpha_{y y} \Delta T\right)=-282 \mathrm{psi}$.

$\therefore \sigma_{y y}=Q_{x y}\left(\varepsilon_{x x}-\alpha_{x x} \Delta T\right)+Q_{y y}\left(\varepsilon_{y y}-\alpha_{y y} \Delta T\right)=-89$ psi. $\}$ Top Surface

Following the above computation for other test cases, the experimental stress results are tabulated in Table 5.14. 


\begin{tabular}{|c|c|c|c|c|c|c|c|c|}
\hline \multicolumn{7}{|c|}{ Experimental Stress Results @ the Center of FRP Deck (psi.) } \\
\hline Test Cases & $8 \mathrm{HS}$ & $8 \mathrm{CS}$ & $8 \mathrm{HF}$ & $8 \mathrm{CF}$ & $4 \mathrm{HS}$ & $4 \mathrm{CS}$ & $4 \mathrm{HF}$ & $4 \mathrm{CF}$ \\
\hline$\sigma_{y y_{\text {_top Surface }}}$ & - & 70 & -250 & 82 & -89 & -302 & -131 & -379 \\
\hline$\sigma_{x x_{-} \text {Top Surface }}$ & - & 339 & -390 & 310 & -282 & -886 & -241 & -957 \\
\hline$\sigma_{y y_{-} \text {Bottom Surface }}$ & - & 166 & -41 & 141 & 7 & 26 & -48 & -58 \\
\hline$\sigma_{x x_{-} \text {Bottom Surface }}$ & - & 228 & -9 & 423 & -19 & 141 & -73 & 187 \\
\hline
\end{tabular}

Note: Refer to Figure 4.8 and 4.10 of Chapter 4 for Directions of $\sigma_{x x}$ and $\sigma_{y y}$. Experimental stress results in Test Case 8HS are not available since experimental strain $\left(\varepsilon_{x x}\right)$ in $x$ direction are not available. Temperature data for all test cases are shown below

\begin{tabular}{|l|c|c|c|c|c|c|c|c|}
\hline Test Case & $8 \mathrm{HS}$ & $8 \mathrm{CS}$ & $8 \mathrm{HF}$ & $8 \mathrm{CF}$ & $4 \mathrm{HS}$ & $4 \mathrm{CS}$ & $4 \mathrm{HF}$ & $4 \mathrm{CF}$ \\
\hline Boundary Condition & SSFF & FFFF & SSFF & FFFF & SSFF & FFFF & SSFF & FFFF \\
\hline$T_{\text {top }},\left({ }^{\circ} \mathrm{F}\right)$ & 155 & 152 & -30 & -31 & 153 & 151 & -43 & -45 \\
\hline$\left.T_{\text {bottom }},{ }^{\circ} \mathrm{F}\right)$ & 74 & 74 & 60 & 61 & 97 & 98 & 56 & 60 \\
\hline$T_{\text {ref }},\left({ }^{\circ} \mathrm{F}\right)$ & 71 & 73 & 80 & 80 & 80 & 80 & 82 & 84 \\
\hline$\Delta T_{\text {top }}=T_{\text {top }}-T_{\text {ref }},\left({ }^{\circ} \mathrm{F}\right)$ & 84 & 79 & -110 & -111 & 73 & 71 & -125 & -129 \\
\hline$\Delta T_{\text {bottom }}=T_{\text {bottom }}-T_{\text {ref }},\left({ }^{\circ} \mathrm{F}\right)$ & 3 & 1 & -20 & -19 & 17 & 18 & -26 & -24 \\
\hline$\Delta T_{\max }=\Delta T_{\text {top }}-\Delta T_{\text {bottom }},\left({ }^{\circ} \mathrm{F}\right)$ & 81 & 78 & -90 & -92 & 56 & 53 & -99 & -105 \\
\hline
\end{tabular}

Table 5.14: Experimental Stress Results. 
Theoretical and experimental stress results are tabulated in Tables 5.15 and 5.16. Theoretical stress results from Macro Approach and FEM are obtained from sections 5.2 and 5.3 .

\begin{tabular}{|c|c|c|c|c|}
\hline \multicolumn{5}{|c|}{ Stress Results at the Center of 8 in. FRP Deck (psi.) } \\
\hline Test Cases & Top / Bottom Surface & Experiment & FEM & Macro Approach \\
\hline \multirow{4}{*}{$\begin{array}{c}8 \mathrm{HS} \\
(\mathrm{SSFF})\end{array}$} & $\sigma_{y y_{-} \text {Top Surface }}$ & - & 30 & 237 \\
\hline & $\sigma_{x x_{-} \text {Top Surface }}$ & - & 62 & 126 \\
\hline & $\sigma_{y y_{-} \text {Bottom Surface }}$ & - & -29 & -237 \\
\hline & $\sigma_{x x_{-} \text {Bottom Surface }}$ & - & -53 & -126 \\
\hline \multirow{4}{*}{$\begin{array}{c}8 \mathrm{CS} \\
(\mathrm{SSFF})\end{array}$} & $\sigma_{y y_{-} T o p \text { Surface }}$ & 70 & -25 & -239 \\
\hline & $\sigma_{x x \_ \text {Top Surface }}$ & 339 & -69 & -123 \\
\hline & $\sigma_{y y_{-} \text {Bottom Surface }}$ & 166 & 25 & 239 \\
\hline & $\sigma_{x x_{-} \text {Bottom Surface }}$ & 228 & 59 & 123 \\
\hline \multirow{4}{*}{$\begin{array}{c}8 \mathrm{HF} \\
(\mathrm{FFFF})\end{array}$} & $\sigma_{y y_{\text {_T}} \text { Top Surface }}$ & -250 & 43 & - \\
\hline & $\sigma_{x x \_ \text {Top Surface }}$ & -390 & 59 & - \\
\hline & $\sigma_{y y_{2} \text { Bottom Surface }}$ & -41 & -44 & - \\
\hline & $\sigma_{x x_{-} \text {Bottom Surface }}$ & -9 & -59 & - \\
\hline \multirow{4}{*}{$\begin{array}{c}8 \mathrm{CF} \\
(\mathrm{FFFF})\end{array}$} & $\sigma_{y y_{-} \text {Top Surface }}$ & 82 & -43 & - \\
\hline & $\sigma_{x x_{-} \text {Top Surface }}$ & 310 & -70 & - \\
\hline & $\sigma_{y y_{-} \text {Bottom Surface }}$ & 142 & 44 & - \\
\hline & $\sigma_{x x_{-} \text {Bottom Surface }}$ & 423 & 70 & - \\
\hline
\end{tabular}

Table 5.15: Stress Results (Experiment, FEM and Macro Approach) for 8 inch FRP Deck.

Notes: Thermal stress of orthotropic materials $\left(\left\{\begin{array}{c}\sigma_{x x} \\ \sigma_{y y}\end{array}\right\}=\left[\begin{array}{c}Q_{x x} Q_{x y} \\ Q_{x y} Q_{y y}\end{array}\right]\left\{\begin{array}{c}\varepsilon_{x x}-\alpha_{x x} \Delta T \\ \varepsilon_{y y}-\alpha_{y y} \Delta T\end{array}\right\}\right)$ are calculated based on a combination of strain in two principle directions (i.e. $\varepsilon_{x x}, \varepsilon_{y y}$ ). A small strain error in one principle direction can lead to large stress error after combining strains in both directions with temperature effect ( $\alpha \Delta T)$ for stress calculation, leading to high difference of stress in Tables 5.15 and 5.16. 


\begin{tabular}{|c|c|c|c|c|}
\hline \multicolumn{5}{|c|}{ Stress Results at the Center of 4 in. FRP Deck (psi.) } \\
\hline Test Cases & Top / Bottom Surface & Experiment & FEM & Macro Approach \\
\hline \multirow{4}{*}{$\begin{array}{c}\text { 4HS } \\
\text { (SSFF) }\end{array}$} & $\sigma_{y y \_ \text {Top Surface }}$ & -89 & 26 & 127 \\
\hline & $\sigma_{x x_{-} \text {Top Surface }}$ & -282 & 73 & 67 \\
\hline & $\sigma_{y y_{-} \text {Bottom Surface }}$ & 7 & -26 & -127 \\
\hline & $\sigma_{x x_{-} \text {Bottom Surface }}$ & -19 & -73 & -67 \\
\hline \multirow{4}{*}{$\begin{array}{c}4 \mathrm{CS} \\
(\mathrm{SSFF})\end{array}$} & $\sigma_{y y_{-} \text {Top Surface }}$ & -302 & -40 & -209 \\
\hline & $\sigma_{x x_{-} \text {Top Surface }}$ & -886 & -125 & -108 \\
\hline & $\sigma_{y y_{-} \text {Bottom Surface }}$ & 26 & 40 & 209 \\
\hline & $\sigma_{x x_{\text {BBottom Surface }}}$ & 141 & 125 & 108 \\
\hline \multirow{4}{*}{$\begin{array}{c}\text { 4HF } \\
\text { (FFFF) }\end{array}$} & $\sigma_{y y_{-} \text {Top Surface }}$ & -131 & 31 & - \\
\hline & $\sigma_{x x_{-} \text {Top Surface }}$ & -241 & 67 & - \\
\hline & $\sigma_{y y_{-} \text {Bottom Surface }}$ & -48 & -31 & - \\
\hline & $\sigma_{x x_{-} \text {Bottom Surface }}$ & -73 & -67 & - \\
\hline \multirow{4}{*}{$\begin{array}{c}4 \mathrm{CF} \\
(\mathrm{FFFF})\end{array}$} & 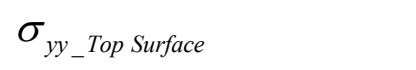 & -379 & -55 & - \\
\hline & $\sigma_{x x_{\text {_T}}}{ }_{\text {P Surface }}$ & -957 & -129 & - \\
\hline & $\sigma_{y y_{-} \text {Bottom Surface }}$ & -58 & 55 & - \\
\hline & $\sigma_{x x_{-} \text {Bottom Surface }}$ & 187 & 129 & - \\
\hline
\end{tabular}

Table 5.16: Stress Results (Experiment, FEM and Macro Approach) for 4 inch FRP Deck.

Notes: Thermal stress of orthotropic materials $\left(\left\{\begin{array}{l}\sigma_{x x} \\ \sigma_{y y}\end{array}\right\}=\left[\begin{array}{l}Q_{x x} Q_{x y} \\ Q_{x y} Q_{y y}\end{array}\right]\left\{\begin{array}{l}\varepsilon_{x x}-\alpha_{x x} \Delta T \\ \varepsilon_{y y}-\alpha_{y y} \Delta T\end{array}\right\}\right)$ are calculated based on a combination of strain in two principle directions (i.e. $\varepsilon_{x x}, \varepsilon_{y y}$ ). A small strain error in one principle direction can lead to large stress error after combining strains in both directions with temperature effect $(\alpha \Delta T)$ for stress calculation, leading to high difference of stress in Tables 5.15 and 5.16 . 


\subsection{Discussions and Conclusions}

\section{$\underline{\text { Deflection }}$}

- From Table 5.9 it is observed that for all the heating test cases, the deflections in FRP deck have negative sign, which means that the deck exhibits a hogging effect (upward convexity). This is because in the heating tests, the temperature of top surface is higher than that of bottom surface. Similarly for all the cooling tests, it can be seen that deflection in the FRP deck has a positive sign, which means the deck exhibits sagging effect. This is because in the cooling tests, the temperature of top surface is lower than that of bottom surface.

- The theoretical deflection based on Macro Approach and Navier-Levy Method was nearly constant when number of Fourier series terms was higher than $7(n>7)$. The deflection difference in percent between one term approximation $(n=1)$ and fifteen term approximation $(n=15)$ was about $3 \%$.

- The average deflection difference in percent between Experiment versus Navier-Levy, Macro, and FEM analysis are within 15\%, which indicates that the theory is in good correlation with experimental test results (Refer Table 5.17).

\begin{tabular}{|l|c|}
\hline \multicolumn{2}{|c|}{ Average Deflection Difference in Percent Between Experiment and Theory } \\
\hline Experiment V.S. Navier-Levy $\left(1^{\text {st }}\right.$ term approximation $)$ & $13 \%$ \\
\hline Experiment V.S. Macro Approach $\left(1^{\text {st }}\right.$ term approximation $)$ & $11 \%$ \\
\hline Experiment V.S. FEM & $10 \%$ \\
\hline
\end{tabular}

Table 5.17: Average Deflection Difference in Percentage (Refer to Table 5.10).

- Based on theoretical analysis (FEM, Navier-Levy, and Macro Approach), center deflection can be predicted more accurately than the edge deflection. The average 
difference in deflections between theory and experiment at center and edge is $6 \%$ and $10.7 \%$, respectively.

- The FRP deck deflection did not depend primarily on temperature of top or bottom surface individually, but the deflection did depend primarily on the temperature difference between the top and bottom deck surfaces. Deflections increased with increasing magnitude of temperature difference.

- Deflection is predicted more accurately than strain and stress because boundary restraint mechanism in a laboratory can control the vertical movement ( $\left.\begin{array}{lll}w & \text { or } & u_{z}\end{array}\right)$, which agrees more closely with theoretical boundary conditions.

\section{Thermal Strain}

- The average strain difference in percentage between Experiment versus Macro Approach, and FEM analyses are about 20\% and are shown in Table 5.18.

\begin{tabular}{|l|c|}
\hline \multicolumn{2}{|c|}{ Average Strain Difference in Percent Between } \\
\hline Experiment V.S. Macro Approach (1 ${ }^{\text {st }}$ term approximation $)$ & $25 \%$ \\
\hline Experiment V.S. FEM & $21 \%$ \\
\hline
\end{tabular}

Note: Average strain difference in percent between Experiment V.S. Macro Approach is based on 10 out of 13 data samples. Average strain difference in percent between Experiment V.S. FEM is based on 26 out of 29 data samples.

Table 5.18: Average Strain Difference in Percentage.

- It can be seen from Table 5.2 that experimental strain results in SSFF (two simply support edges and two free edges) and FFFF (all four edges free) boundaries are close for all test cases. This is because a boundary restraint for simply supported edges in 
the laboratory tests was not one hundred percent effective to resist expansion or contraction in the horizontal plane, but resistance in vertical displacement along the simply supported edge was excellent.

- During the cooling tests on 4 inch and 8 inch deep FRP decks, it was observed that there was no significant residual strain after the deck was brought to ambient temperature levels (after 200 minutes from the time the unloading was initiated) at the end of each thermal cycle. However, during the heating tests on 4 inch and 8 inch deep FRP decks, a significant amount of residual strain $(\approx 25$ to $100 \mu \varepsilon$; refer to heating test results in Appendix C and D), was left in the system at the end of each thermal cycle after 200 minutes from the start of unloading the decks. In the field, FRP decks undergo several thermal cycles, which will lead to high residual strain in deck and also to distress in wearing surfaces.

\section{Thermal Stress}

- Thermal strains in both the $x$ and $y$ directions have to be considered together for orthotropic materials while evaluating thermal stresses. In our study, a good correlation of thermal stresses between the theory and experimental test results was not possible because small error in strain measurements or strain changes can lead to large error in thermal stresses (Refer to Tables 5.15 and 5.16). Thermal stress depends on the effectiveness of boundary restraints in the laboratory. If boundaries are fully restrained, thermal stress will be fully developed while thermal strain will not be significant. According to Tables 5.15 and 5.16, it was found that theoretical stress (Macro approach and FEM) was not in a good agreement with experimental stress 
because the theoretical stress (Macro approach and FEM) was assumed to be zero for axial effect (free expansion in horizontal plane), which was not true under lab condition. Partial axial stress was induced during lab testing because of partial fixity in the horizontal plane of FRP decks. The inaccuracy in predicting thermal stress is attributed to in-plane partial fixity of the FRP deck (it was between free and fully fixity.).

- Thermal stress results between Macro and FEM approaches have the same trend (same sign convention in stress) for stress on the top and bottom surface because free movement in horizontal plane (but fix in vertical direction) is assumed in both Macro Approach and FEM.

- Rapid convergence of strains using the conventional plate theory is not guaranteed; hence a larger error with the first term approximation is noted than in deflection. 


\section{Chapter 6}

\section{Field Evaluations of FRP Bridges}

The thermal response of two FRP deck bridges (i.e. Market Street and Wickwire Run bridges) under temperature difference has been theoretically evaluated and compared with field data. In the Market Street Bridge, strains on the FRP deck under thermal fluctuations were recorded. Induced thermal stress in Market Street Bridge are evaluated based on field strain data (using stress-strain relation with temperature effect). Also FEM analysis is conducted on Market Street Bridge for discussion. In Wickwire Run Bridge, deflection on FRP deck under thermal fluctuation was recorded. Theoretical deflection (based on macro approach) is evaluated and compared with field deflection.

\subsection{General Details of Market Street and Wickwire Run Bridges $>$ Market Street Bridge}

The Market Street Bridge in Wheeling, WV was a replacement structure, designed by Alpha Associates, Morgantown, WV in collaboration with CFC-WVU. Initially, the bridge had a concrete filled steel grid deck supported on steel girders with sidewalks. In the year 2000, the deck was replaced with FRP composite deck supported on seven steel plate girders

(Web 3/4" x 78" and Flange $15 / 8$ " x 24"), which were spaced at 8.5 feet. The total span of the bridge is 179.5 feet and its width is 58 feet Figures 6.1 and 6.2 show the cross section of FRP bridge decks and elevation of Market Street Bridge respectively. In the Market Street Bridge, the FRP bridge deck is held to the steel plate girder using steel studs and cement grout. Installed superstructure views are shown in Figures 6.3 and 6.4. 


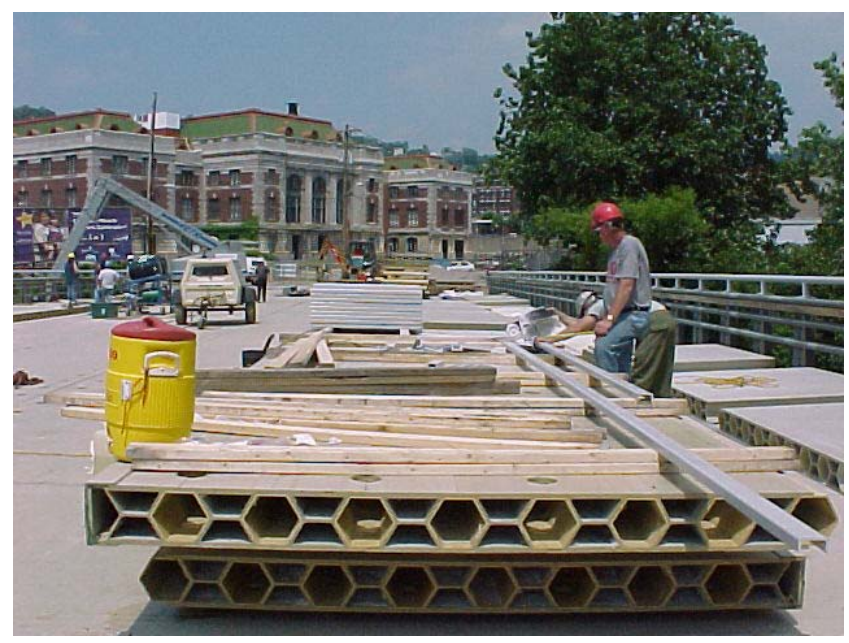

Figure 6.1: Cross Section of FRP Deck Placed on Bridge Stringers.

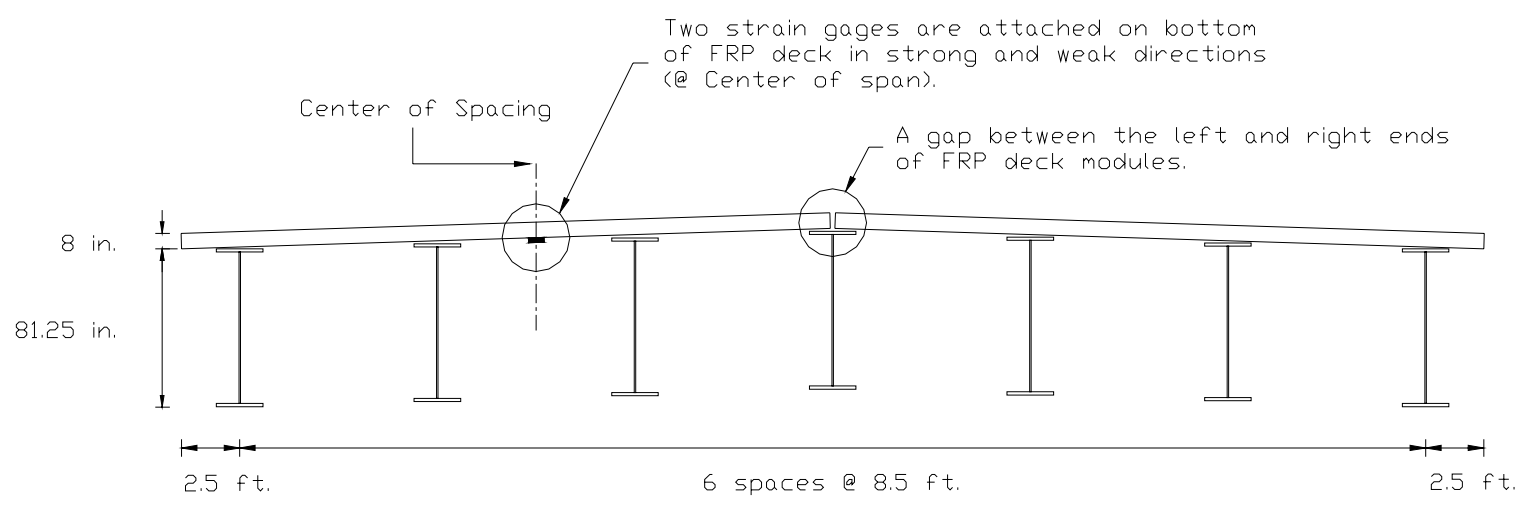

Figure 6.2: Cross Section at Center of Market Street Bridge. 


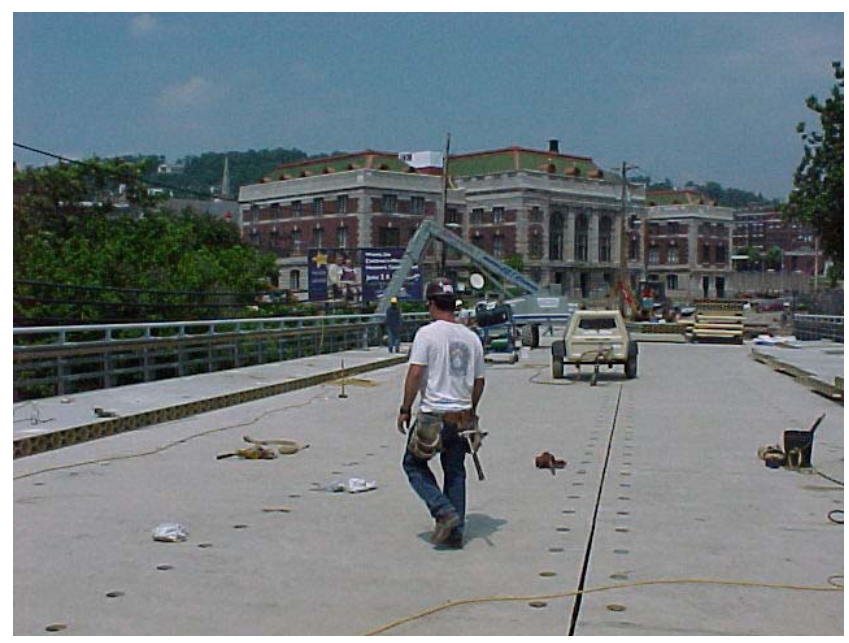

Figure 6.3: View Before Applying Polymer Concrete (Market Street bridge).

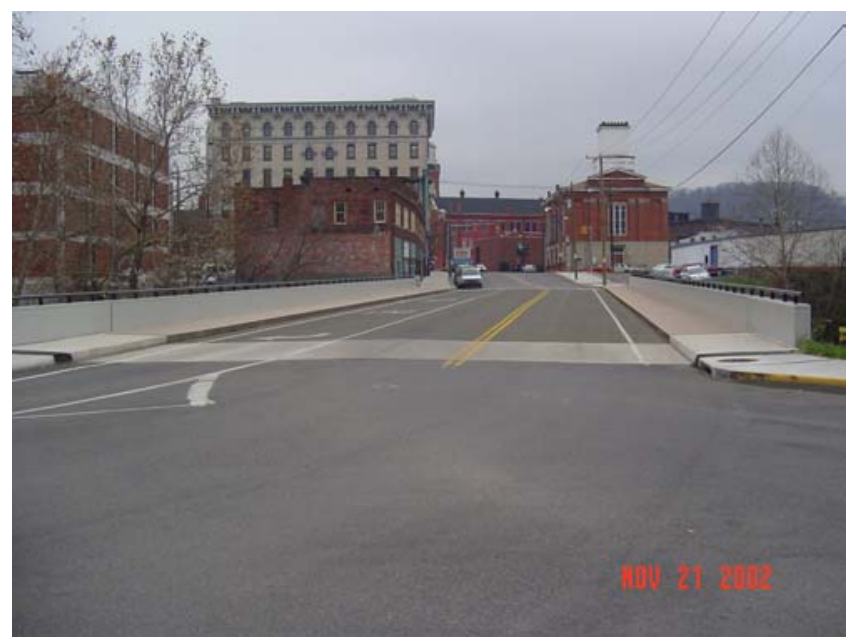

Figure 6.4: View After Applying Polymer Concrete (Market Street Bridge).

\section{Wickwire Run Bridge}

The Wickwire Run Bridge has FRP composite decks supported on four steel stringers spaced at 6 feet. The total span of the bridge is 30 feet by 21 feet 8 inches in width (Figure 6.5). The cross-section of FRP deck is same as in Market Street Bridge (Figure 6.1). 


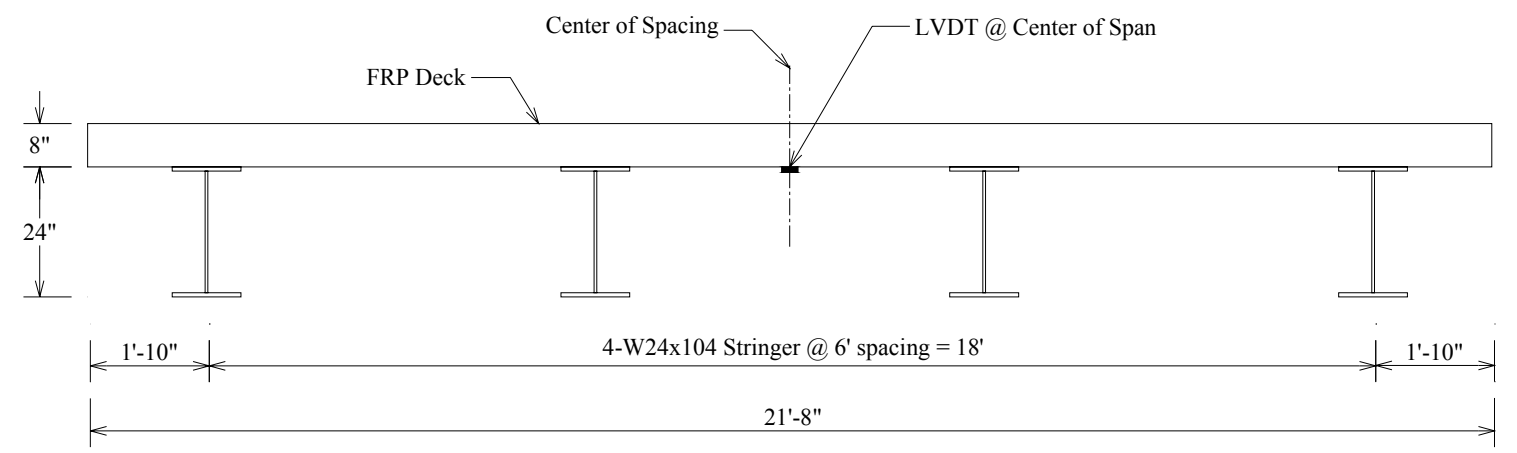

Figure 6.5: Cross Section at Center of Wickwire Run Bridge.

\subsection{Field Test Results of Market Street and Wickwire Run Bridges}

During the field monitoring of the Market Street Bridge and Wickwire Run Bridge, strain and deflections under temperature differences were measured using strain gages and LVDTs, respectively. The data was collected through a data acquisition system. The temperature difference through the depth (top and bottom) of deck was recorded using a noncontact infrared thermal device. Field test results (thermal strain) for the Market Street Bridge are shown in Tables 6.1. For the Wickwire Run Bridge, the field results (deflection) are shown in Table 6.2.

\begin{tabular}{|c|c|c|c|c|c|}
\hline \multirow{2}{*}{$\begin{array}{l}\text { Testing } \\
\text { Date }\end{array}$} & \multirow[t]{2}{*}{ Time } & \multicolumn{2}{|c|}{$\begin{array}{l}\text { Temperature }\left({ }^{\circ} \mathrm{F}\right) \\
\text { on FRP Deck at }\end{array}$} & \multicolumn{2}{|c|}{$\begin{array}{l}\text { Strain }(\mu \varepsilon) \\
\text { at Bottom of FRP Deck }\end{array}$} \\
\hline & & $\begin{array}{l}\text { Bottom } \\
\text { Surface }\end{array}$ & $\begin{array}{c}\text { Top } \\
\text { Surface }\end{array}$ & $\varepsilon_{11}$ & $\varepsilon_{22}$ \\
\hline \multirow[t]{2}{*}{$5 / 15 / 03$} & Initial Reading (11.34 am.) & 62 & 72 & 0 & 0 \\
\hline & Final Reading (1.10 pm.) & 72 & 108 & 41 & 5 \\
\hline \multirow{2}{*}{$2 / 26 / 04$} & Initial Reading (11.36 am.) & 20 & 47 & 0 & 0 \\
\hline & Final Reading (1.17 pm.) & 26 & 59 & 22 & 4 \\
\hline
\end{tabular}

Note : $\varepsilon_{11}$ and $\varepsilon_{22}$ are strains in the strong (or cell) and weak direction of FRP deck, respectively Table 6.1: Thermal Strain Data for Market Street Bridge.

(Refer to Figure 6.2 for Gage Locations) 


\begin{tabular}{|c|c|c|c|}
\hline \multirow{2}{*}{$\begin{array}{c}\text { Date } \\
6 / 26 / 03\end{array}$} & \multicolumn{2}{|c|}{ Temperature $\left({ }^{\circ} \mathrm{F}\right)$ on FRP Deck at } & \multirow{2}{*}{$\begin{array}{c}\text { Deflection } \\
\text { (in.) }\end{array}$} \\
\cline { 2 - 3 } & Bottom Surface & Top Surface & 0 \\
\hline Initial Reading $(8.11 \mathrm{am})$. & 61 & 61 & $\begin{array}{c}-0.0494 \\
\text { (upward) }\end{array}$ \\
\hline Final Reading $(2.30 \mathrm{pm})$. & 67 & 111 & \\
\hline
\end{tabular}

Table 6.2: Deflection Data for Wickwire Run Bridge.

(Refer to Figure 6.5 for LVDT Locations)

\subsection{Evaluation of Thermal Stresses in Market Street Bridge}

Thermal stresses in Market Street bridge are determined using field strain and temperature data (See Section 6.3.1). Theoretical analysis based on Finite Element Model (FEM) for thermal stresses and strains on Market Street is conducted which is shown in section 6.3.2. For simplicity, the deck slab is modeled using the finite element package (ANSYS) as a solid slab of 8 inch thick, which is identical to the thickness of the FRP deck. It should be noted that theoretical results based on 8 inch thick solid deck was as close to the field data that has 8 inch thick hollow deck.

\subsubsection{Evaluation of thermal stress based on field test results (strain data)}

According to data in Table 6.1, changes in temperature, on the top and bottom surface of FRP deck on $5 / 15 / 03$ are $36{ }^{\circ} \mathrm{F}$ and $10{ }^{\circ} \mathrm{F}$, respectively (i.e. $\Delta T_{\text {top }}=108-72=36$, $\Delta T_{\text {bottom }}=72-62=10$ ). The profile of changes in temperature through the thickness of the deck are shown in Figure 6.6 (a), where it was assumed that the change in temperature varies linearly through the thickness of the deck. 


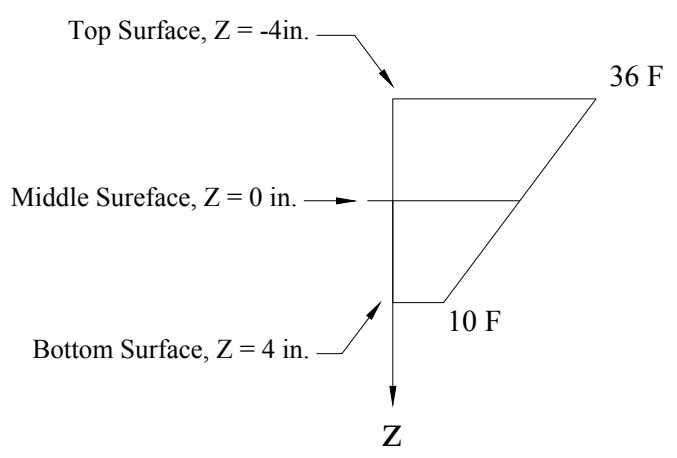

(a)

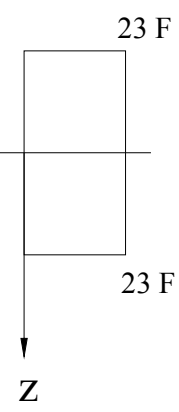

(b)

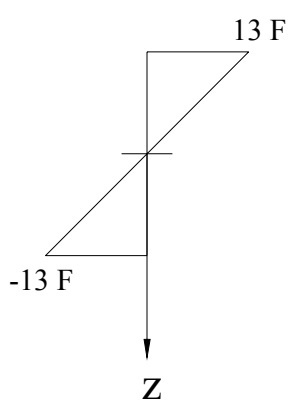

(c)

Figure 6.6: Change in Temperature Profile for Market Street Bridge.

An idealized temperature variation along the deck depth is a linear function of $\mathrm{z}$ (direction of FRP depth). Therefore, the change in temperature through the thickness of the deck is :

$$
\Delta T=T^{0}+T^{1} z=23-3.25 z
$$

where $T^{0}=\frac{\Delta T_{\text {top }}+\Delta T_{\text {bottom }}}{2}=\frac{36+10}{2}=23$ and $T^{1}=\frac{\Delta T_{\text {bottom }}-\Delta T_{\text {top }}}{h}=\frac{10-36}{8}=-3.25$

Before determining the thermal stress in FRP decks, we have to evaluate the strain increment (i.e. $\alpha \Delta T$ ) due to change in temperature under free boundary conditions, and obtain strain data under temperature change for actual field boundary conditions. Strain difference between the free and field boundary conditions will then be used to evaluate the induced thermal stress, using constitutive equations (relationships between stress and strain). The following section shows step-by-step procedure to find induced thermal stresses based on field data (as shown in Table 6.1). 


\section{Step 1: Determine induced strain for free condition}

Change in temperature profile as shown in Figure 6.6 (a) is divided in two parts that are uniform temperate change (Figure $6.6(\mathrm{~b})$ ) and gradient temperature change (Figure 6.6 (c)). Uniform temperature change $\left(T^{0}=23^{\circ} \mathrm{F}\right)$ causes FRP deck to expand uniformly through the depth in horizontal plane. Gradient temperature change $\left(T^{1} z=13 /-13^{\circ} \mathrm{F}\right.$ on top/bottom surface) causes bottom surface of FRP deck to contract and top surface of FRP deck to expand with the same amount of strain.

The induced strain due to uniform temperature change $\left(T^{0}\right)$ as in Figure $6.6(\mathrm{~b})$ - are:

$$
\left.\begin{array}{l}
\varepsilon_{11 \_ \text {uniform }}=\alpha_{11} T^{0}=\left(6.07 \times 10^{-6}\right)(23)=139.61 \mu \varepsilon \\
\varepsilon_{22 \_ \text {uniform }}=\alpha_{22} T^{0}=\left(9.75 \times 10^{-6}\right)(23)=224.25 \mu \varepsilon
\end{array}\right\} \text { @ Top and Bottom Surface }
$$

Note : Subscript 11 and 22 represent strong and weak direction of FRP deck. Coefficients of thermal expansion (CTE) of FRP deck are $\alpha_{11}=6.07 \mu \varepsilon /{ }^{\circ} \mathrm{F}$ and $\alpha_{22}=9.75 \mu \varepsilon /^{\circ} \mathrm{F}$.

The induced strain due to gradient temperature change $\left(T^{1} z\right)$ as in Figure $6.6(\mathrm{c})$ - are:

$$
\left.\begin{array}{l}
\varepsilon_{11 \_ \text {gradient }}=\alpha_{11} T^{1} z=\left(6.07 \times 10^{-6}\right)(-3.25)(-4)=78.91 \mu \varepsilon \\
\varepsilon_{22 \_ \text {gradient }}=\alpha_{22} T^{1} z=\left(9.75 \times 10^{-6}\right)(-3.25)(-4)=126.75 \mu \varepsilon
\end{array}\right\} \text { a Top Surface }
$$

Combining strains due to uniform and gradient temperature changes, we obtain induced strain for free boundary condition as:

$$
\begin{aligned}
& \varepsilon_{11_{-} \text {free }}=\varepsilon_{11 \_ \text {uniform }}+\varepsilon_{11 \_ \text {gradient }}=139.61+78.91=218.52 \mu \varepsilon \\
& \varepsilon_{22_{\text {free }}}=\varepsilon_{22 \_ \text {uniform }}+\varepsilon_{22 \text { gradient }}=224.25+126.75=351 \mu \varepsilon \\
& \text { (a) Top Surface } \\
& \varepsilon_{11 \_ \text {free }}=\varepsilon_{11 \_ \text {uniform }}+\varepsilon_{11 \_ \text {gradient }}=139.61-78.91=60.7 \mu \varepsilon \\
& \varepsilon_{22_{\text {frree }}}=\varepsilon_{22_{\text {_uniform }}}+\varepsilon_{22_{\text {gradient }}}=224.25-126.75=97.5 \mu \varepsilon
\end{aligned}
$$




\section{Step 2 : Field Strain}

Field strain on bottom surface of FRP deck (on 5/15/03, in Table 6.1) is:

$$
\left.\begin{array}{l}
\varepsilon_{11_{-} \text {field }}=43 \mu \varepsilon \\
\varepsilon_{22_{-} \text {field }}=5 \mu \varepsilon
\end{array}\right\} @ \text { Bottom Surface }
$$

Step 3 : Calculate induced thermal stress

Induced thermal stresses are calculated using stress-strain relation as given in Eq.(6.1).

$$
\left\{\begin{array}{l}
\sigma_{11} \\
\sigma_{22}
\end{array}\right\}=\left[\begin{array}{ll}
Q_{11} & Q_{12} \\
Q_{12} & Q_{22}
\end{array}\right]\left\{\begin{array}{l}
\varepsilon_{11_{-} \text {field }}-\varepsilon_{11_{-} \text {free }} \\
\varepsilon_{22_{-} \text {field }}-\varepsilon_{22_{-} \text {free }}
\end{array}\right\}
$$

where $Q_{11}=\frac{E_{1}}{1-v_{12} v_{21}}, Q_{12}=\frac{v_{12} E_{2}}{1-v_{12} v_{21}}, Q_{22}=\frac{E_{2}}{1-v_{12} v_{21}}$

Properties of FRP deck (Refer Table 6.6):

$$
E_{1}=3.05 \times 10^{6} \text { psi., } E_{2}=0.92 \times 10^{6} \text { psi., } v_{12}=0.25 \text { and } v_{21}=0.075
$$

Therefore,

$$
\begin{aligned}
& Q_{11}=\frac{E_{1}}{1-v_{12} v_{21}}=\frac{3.05 \times 10^{6}}{1-(0.25)(0.075)}=3.11 \times 10^{6} \mathrm{psi} . \\
& Q_{12}=\frac{v_{12} E_{2}}{1-v_{12} v_{21}}=\frac{(0.25)\left(0.92 \times 10^{6}\right)}{1-(0.25)(0.075)}=2.34 \times 10^{5} \mathrm{psi} \\
& Q_{22}=\frac{E_{2}}{1-v_{12} v_{21}}=\frac{0.92 \times 10^{6}}{1-(0.25)(0.075)}=9.38 \times 10^{5} \mathrm{psi} .
\end{aligned}
$$

Substituting $Q_{11,} Q_{12}$ and $Q_{22}$ into Eq. (6.1)

$$
\left\{\begin{array}{l}
\sigma_{11} \\
\sigma_{22}
\end{array}\right\}=\left[\begin{array}{ll}
Q_{11} & Q_{12} \\
Q_{12} & Q_{22}
\end{array}\right]\left\{\begin{array}{l}
\varepsilon_{11_{-} \text {field }}-\varepsilon_{11_{\text {ffree }}} \\
\varepsilon_{22_{\text {ffield }}}-\varepsilon_{22_{-} \text {free }}
\end{array}\right\}=\left(10^{6}\right)\left[\begin{array}{cc}
3.11 & 0.23 \\
0.23 & 0.94
\end{array}\right]\left\{\begin{array}{c}
(43-60.7)\left(10^{-6}\right) \\
(5-97.5)\left(10^{-6}\right)
\end{array}\right\}=\left\{\begin{array}{l}
-76.70 \text { psi. } \\
-90.88 \text { psi. }
\end{array}\right\}
$$

Note: Negative sign represents compressive stress. 
A thermal stress in the bottom of FRP deck is compressive in both, cell (-76.70 psi.) and weak directions (-90.88 psi.).

The other alternative method to calculate induced thermal stress will be as per Eq. (A.41) of Appendix A i.e.,

$$
\left\{\begin{array}{l}
\sigma_{11} \\
\sigma_{22}
\end{array}\right\}=\left[\begin{array}{ll}
Q_{11} & Q_{12} \\
Q_{12} & Q_{22}
\end{array}\right]\left\{\begin{array}{l}
\varepsilon_{11}-\alpha_{11} \Delta T \\
\varepsilon_{22}-\alpha_{22} \Delta T
\end{array}\right\} \text { (Ref. Reddy 1999) }
$$

where, $\varepsilon_{11}$ and $\varepsilon_{22}$ are measured strains in the field.

$\alpha_{11}$ and $\alpha_{22}$ are the coefficient of thermal expansion of FRP deck.

$\Delta T$ is temperature change at point of interest.

Substituting $Q_{11}, Q_{22}, Q_{12}, \varepsilon_{11}, \varepsilon_{22}, \alpha_{11}, \alpha_{22}$ and $\Delta T$ into Eq. (6.2), we obtain thermal stress at the bottom surface of FRP deck.

$$
\left\{\begin{array}{l}
\sigma_{11} \\
\sigma_{22}
\end{array}\right\}=\left[\begin{array}{ll}
Q_{11} & Q_{12} \\
Q_{12} & Q_{22}
\end{array}\right]\left\{\begin{array}{l}
\varepsilon_{11}-\alpha_{11} \Delta T \\
\varepsilon_{22}-\alpha_{22} \Delta T
\end{array}\right\}=\left(10^{6}\right)\left[\begin{array}{cc}
3.11 & 0.23 \\
0.23 & 0.94
\end{array}\right]\left\{\begin{array}{l}
43 \times 10^{-6}-\left(6.07 \times 10^{-6}\right)(10) \\
5 \times 10^{-6}-\left(9.75 \times 10^{-6}\right)(10)
\end{array}\right\}=\left\{\begin{array}{l}
-76.70 \text { psi. } \\
-90.88 \text { psi. }
\end{array}\right\}
$$

Note that $\Delta T$ in the above equation is temperature change at the bottom surface ( $\left.\Delta T_{\text {bottom }}\right)$ of FRP deck, which is equal to 0 (i.e. $\Delta T_{\text {bottom }}=72-62=10$ ). And $\varepsilon_{11}=43 \mu \varepsilon$ and $\varepsilon_{22}=5 \mu \varepsilon$ (Refer to field data in Table 6.1).

Using the above method, thermal stress for the field data as of 2/26/04 in Table 6.1 is calculated as following

$$
\left\{\begin{array}{l}
\sigma_{11} \\
\sigma_{22}
\end{array}\right\}=\left[\begin{array}{ll}
Q_{11} & Q_{12} \\
Q_{12} & Q_{22}
\end{array}\right]\left\{\begin{array}{l}
\varepsilon_{11}-\alpha_{11} \Delta T \\
\varepsilon_{22}-\alpha_{22} \Delta T
\end{array}\right\}=\left(10^{6}\right)\left[\begin{array}{ll}
3.11 & 0.23 \\
0.23 & 0.94
\end{array}\right]\left\{\begin{array}{l}
22 \times 10^{-6}-\left(6.07 \times 10^{-6}\right)(6) \\
4 \times 10^{-6}-\left(9.75 \times 10^{-6}\right)(6)
\end{array}\right\}=\left\{\begin{array}{c}
-57.60 \text { psi. } \\
-54.48 \text { psi. }
\end{array}\right\}
$$

Note : $\Delta T=26-20=6^{\circ} \mathrm{F}($ Refer to field data in Table 6.1) 
Induced thermal stress in Market Street Bridge from field data are given in Table 6.3.

\begin{tabular}{|c|c|c|c|c|c|c|c|}
\hline \multirow{2}{*}{ Date } & \multirow{2}{*}{$\begin{array}{c}\Delta T_{\text {bottom }} \\
\left({ }^{\circ} \mathrm{F}\right)\end{array}$} & \multirow{2}{*}{$\begin{array}{r}\Delta T_{t o p} \\
\left({ }^{\circ} \mathrm{F}\right)\end{array}$} & \multirow{2}{*}{$\begin{array}{c}\Delta T=\Delta T_{\text {top }}-\Delta T_{\text {bottom }} \\
\quad\left({ }^{\circ} \mathrm{F}\right)\end{array}$} & \multicolumn{4}{|c|}{ Bottom of FRP Deck (Field Data) } \\
\hline & & & & $\varepsilon_{11}(\mu \varepsilon)$ & $\varepsilon_{22}(\mu \varepsilon)$ & $\sigma_{11}($ psi.) & $\sigma_{22}($ psi.) \\
\hline $5 / 15 / 03$ & 10 & 36 & 26 & 43 & 5 & -77 & -91 \\
\hline $2 / 26 / 04$ & 6 & 10 & 4 & 22 & 4 & -58 & -54 \\
\hline
\end{tabular}

Note: Subscript 11 and 22 represent strong and weak direction of FRP deck

Table 6.3: Induced Thermal Stresses based on Field Results for Market Street Bridge.

\subsubsection{Evaluation of thermal stresses using FEM analysis (Market Street Bridge)}

Thermal stress analysis was conducted for the Market Street Bridge using the Finite Element Model (FEM). The FEM model was modeled for half-width of the bridge since a deck joint was provided along the bridge length at the geometric center of the bridge width (see Figure 6.2). In the FEM model, the deck slab was modeled as a solid slab of 8 inch thick, which is identical to the thickness of the FRP deck. This was carried out for simplification purposes only. The FEM model is shown in Figure 6.7 where the deck slab, top and bottom flanges of plate girders are modeled as "Solid 45" elements, while web of plate girders are modeled as a "Shell 93" element using ANSYS 7.1. All nodes at the junction of the top flange of the plate girder and bottom of deck are interconnected with the same nodes. The FEM model was developed for a quarter scale of full size and "dsym" command was used for symmetric case of deck geometry. The deck slab was modeled with four element layers each of 2 inch thickness so as to input the temperature through the depth of the deck. 
Thermal stresses and strain results at center span of the bridge (at location of strain gage in the Figure 6.2) based on FEM are shown in Table 6.4. The FE analysis was performed for two cases:

Case 1: Change in temperature increasing linearly from bottom to top of deck (i.e. $\Delta T=36,29.5,23,16.5$ and $10{ }^{\circ} \mathrm{F}$ ). Case 1 (represented as " $L$ " notation in Table 6.4) was performed as per the AASHTO's specification and is more conservative.

Case 2: Change in temperature increasing non-linearly from bottom to top of deck (i.e. $\Delta T=36,16,16,13$ and $10^{\circ} \mathrm{F}$ ). Case 2 (represented as " $N L$ " notation in Table 6.4) was performed to simulate the real field conditions where the change in temperature in hollow section of FRP deck slabs in not linear. Temperature change for both cases (i.e. case 1 and 2) is applied to nodes of deck slab as body load.

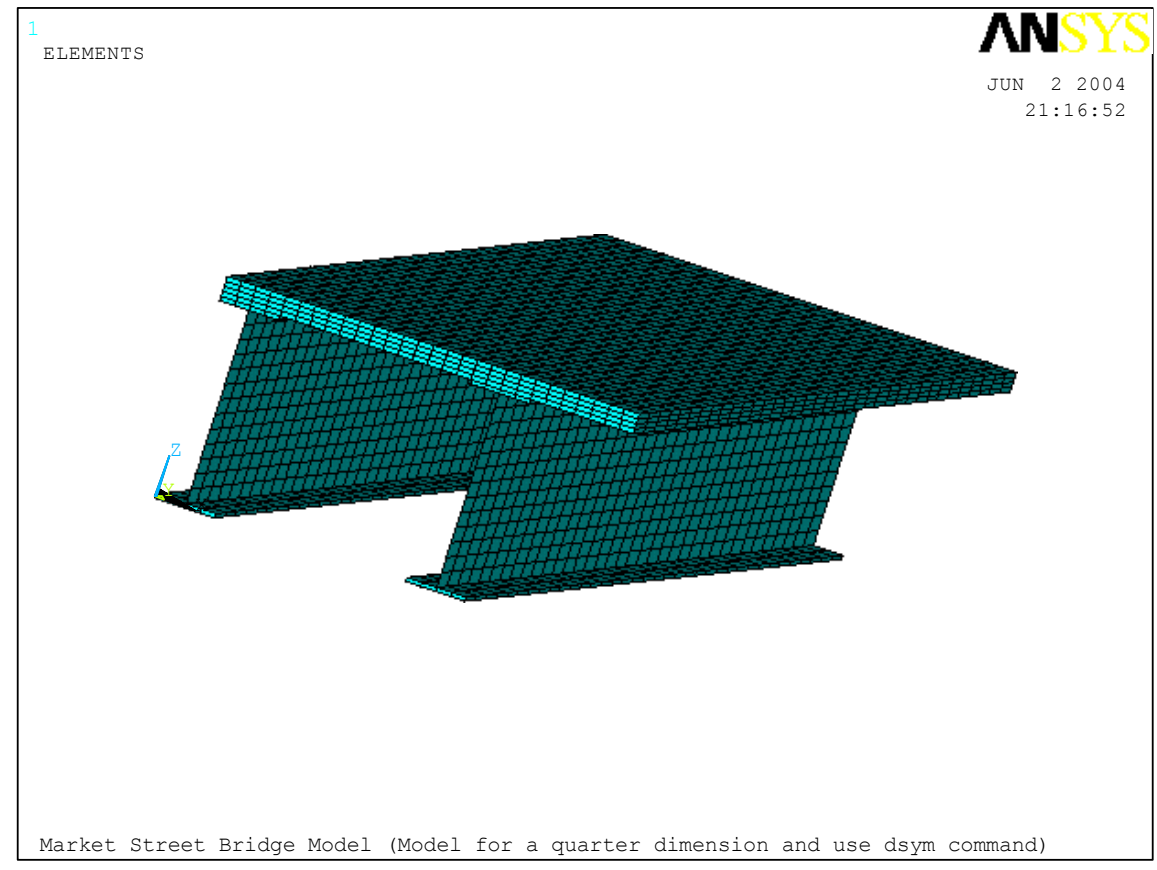

Figure 6.7: Market Street Bridge FEM Model. 


\begin{tabular}{|c|c|c|c|c|c|c|c|c|c|c|c|}
\hline \multirow[t]{2}{*}{ Location } & \multirow{2}{*}{$\begin{array}{l}\Delta T \\
\left({ }^{\circ} \mathrm{F}\right)\end{array}$} & \multirow{2}{*}{$\begin{array}{l}\alpha_{11} \Delta T \\
(\mu \varepsilon)\end{array}$} & \multirow{2}{*}{$\begin{array}{l}\alpha_{22} \Delta T \\
(\mu \varepsilon)\end{array}$} & \multicolumn{2}{|c|}{$\begin{array}{c}\varepsilon_{11} \\
(\mu \varepsilon)\end{array}$} & \multicolumn{2}{|c|}{$\begin{array}{c}\varepsilon_{22} \\
(\mu \varepsilon)\end{array}$} & \multicolumn{2}{|c|}{$\begin{array}{l}\sigma_{11} \\
\text { (psi.) }\end{array}$} & \multicolumn{2}{|c|}{$\begin{array}{l}\sigma_{22} \\
\text { (psi.) }\end{array}$} \\
\hline & & & & L & NL & $\mathrm{L}$ & $N L$ & $L$ & $N L$ & $L$ & $N L$ \\
\hline Top & 36 & 219 & 351 & 216 & 158 & 6.2 & 4.5 & -87 & -268 & -324 & -339 \\
\hline Bottom & 10 & 60.7 & 97.5 & 95 & 72 & 3 & 2.4 & 83 & 12 & -80 & -86 \\
\hline
\end{tabular}

Note : Subscripts "11" represents deck cell direction (x direction in FEM model). Subscript "22" represents direction perpendicular to deck cell direction or stringer direction (y direction in FEM model).

Table 6.4: Induced Thermal Stresses based on FEM Results for Market Street Bridge with $\Delta T_{\text {top }}=36^{\circ} \mathrm{F}, \Delta T_{\text {bottom }}=10^{\circ} \mathrm{F}$.

From Tables 6.3 and 6.4, it is observed that the induced strain (i.e. $\varepsilon_{11}$ and $\varepsilon_{22}$ ) on the deck's top and bottom are positive, which means that the FRP deck slab expands on top and bottom surfaces. It is also observed that the deck strain in the traffic direction $\left(\varepsilon_{22}\right)$ is less than the deck strain in the cell direction. This is attributed to the fact that flexural rigidity of system (deck/stringer) in the traffic direction is always higher than the flexural rigidity in the direction perpendicular to traffic.

With respect to stress based on field data calculation (Table 6.3) and FEM analysis (Table 6.4), it is observed that compressive stress exist on top and bottom surfaces of the deck except $\sigma_{11}$ on bottom surface in Table 6.4 was tensile stress as per FEM analysis. Since tensile strain ( $\varepsilon_{11}$, expansion) of deck slab was higher than the magnitude of $\alpha_{11} \Delta T$, theory resulted in a positive sign in stress (Refer to Eq. (6.2)).

The applied temperature change, $\Delta T_{\text {top }}=36^{\circ} \mathrm{F}$ and $\Delta T_{\text {bottom }}=10^{\circ} \mathrm{F}$, is not a critical scenario in the field. However, the critical temperature change may be as high as $100{ }^{\circ} \mathrm{F}$ at top and $30{ }^{\circ} \mathrm{F}$ at bottom of the deck. Therefore, the FEM model was conducted with higher 
applied temperature change of $100{ }^{\circ} \mathrm{F}$ on top surface and $30^{\circ} \mathrm{F}$ on bottom surface $\left(\Delta T_{\text {top }}=\right.$ $100^{\circ} \mathrm{F}$ and $\Delta T_{\text {bottom }}=30^{\circ} \mathrm{F}$ ). The FEM results for $\Delta T_{\text {top }}=100^{\circ} \mathrm{F}$ and $\Delta T_{\text {bottom }}=30^{\circ} \mathrm{F}$ are shown in Table 6.5 .

\begin{tabular}{|c|c|c|c|c|c|c|c||c|c||c|c|}
\hline \multirow{2}{*}{ Location } & \multirow{2}{*}{$\begin{array}{l}\Delta T \\
\left({ }^{\circ} \mathrm{F}\right)\end{array}$} & \multirow{2}{*}{$\begin{array}{l}\alpha_{11} \Delta T \\
(\mu \varepsilon)\end{array}$} & $\begin{array}{l}\alpha_{22} \Delta T \\
(\mu \varepsilon)\end{array}$ & \multicolumn{2}{|c|}{$\begin{array}{c}\varepsilon_{11} \\
(\mu \varepsilon)\end{array}$} & \multicolumn{2}{|c||}{$\begin{array}{c}\varepsilon_{22} \\
(\mu \varepsilon)\end{array}$} & \multicolumn{2}{|c||}{$\begin{array}{l}\sigma_{11} \\
(\mathrm{psi})\end{array}$} & \multicolumn{2}{|c|}{$\begin{array}{l}\sigma_{22} \\
(\mathrm{psi})\end{array}$} \\
\cline { 5 - 13 } & & & & $L$ & $N L$ & $L$ & $N L$ & $L$ & $N L$ & $L$ & $N L$ \\
\hline Top & 100 & 607 & 975 & 603 & 408 & 17 & 12 & -236 & -843 & -899 & -950 \\
\hline Bottom & 30 & 182 & 292 & 276 & 166 & 9 & 6 & 225 & -115 & -244 & -272 \\
\hline
\end{tabular}

Note: Subscripts "11" represents deck cell direction. Subscript "22" represents direction perpendicular to deck cell direction or stringer direction.

Table 6.5: FEM Results for $\Delta T_{\text {top }}=100^{\circ} \mathrm{F}$ and $\Delta T_{\text {bottom }}=30^{\circ} \mathrm{F}$.

It is observed from Table 6.5 that for the critical case of $\Delta T_{\text {top }}=100^{\circ} \mathrm{F}$ and $\Delta T_{\text {bottom }}=$ $30{ }^{\circ} \mathrm{F}$, induced compressive stress is as high as 950 psi., and induced tensile strain (expansion) is as high as $603 \mu \varepsilon$. This indicates that in case of orthotropic material, the induced stress cannot be higher than the stress that is obtained from the following equation:

$$
\left\{\begin{array}{l}
\sigma_{11} \\
\sigma_{22}
\end{array}\right\}=\left[\begin{array}{ll}
Q_{11} & Q_{12} \\
Q_{12} & Q_{22}
\end{array}\right]\left\{\begin{array}{l}
-\alpha_{11} \Delta T \\
-\alpha_{22} \Delta T
\end{array}\right\} \text { for both directions }
$$

and induced strain cannot be higher than strain obtained from the following equation,

$$
\left\{\begin{array}{l}
\varepsilon_{11} \\
\varepsilon_{22}
\end{array}\right\}=\left\{\begin{array}{l}
\alpha_{11} \Delta T \\
\alpha_{22} \Delta T
\end{array}\right\} \text { for both directions }
$$

It should also be noted that compressive (induced) stress cannot be higher than $E \alpha \Delta T$ and tensile strain (expansion) cannot be higher than $\alpha \Delta T$ for isotropic material. 


\subsection{Evaluation of theoretical deflection (Macro Approach) versus field deflection in Wickwire Run Bridge}

In Appendix G, the closed form solution (Macro Approach) is presented for a plate supported on simple supports on two opposite edges while the other two are elastic beams (Refer to Figure G.2). The Macro approach (refer to section G.2 of Appendix G) is used to calculate deflection at center spacing under the following assumptions. Two steel stringers (WF 24x104) are treated as simple supports and diaphragms (C15x33.9) at the ends of the stringers are treated as elastic beams, as shown in Figure 6.8. The stiffeners at the end of stringer are attached to FRP deck. Deflections are calculated using macro approach (Refer to section 5.2 in chapter 5).

Following the same procedures as in section 5.2 and substituting structural properties for FRP deck as in Table 6.6 and temperature data as in Table 6.2, we obtain theoretical deflections (based on Macro Approach).

It should be noted that $B_{e}=E I=\left(29 \times 10^{6}\right)(315)=9.135 \times 10^{9}$ lbs/in. ${ }^{6}$ (Diaphram

$\mathrm{C} 15 \times 33.9$ ) and $\Delta T_{\max }=T_{\text {top }}-T_{\text {bottom }}=111-67=44{ }^{\circ} \mathrm{F}$ (or $\Delta T_{\max }=\Delta T_{\text {top }}-\Delta T_{\text {bottom }}=54-6=44$ $\left.{ }^{\circ} \mathrm{F}\right)$. 


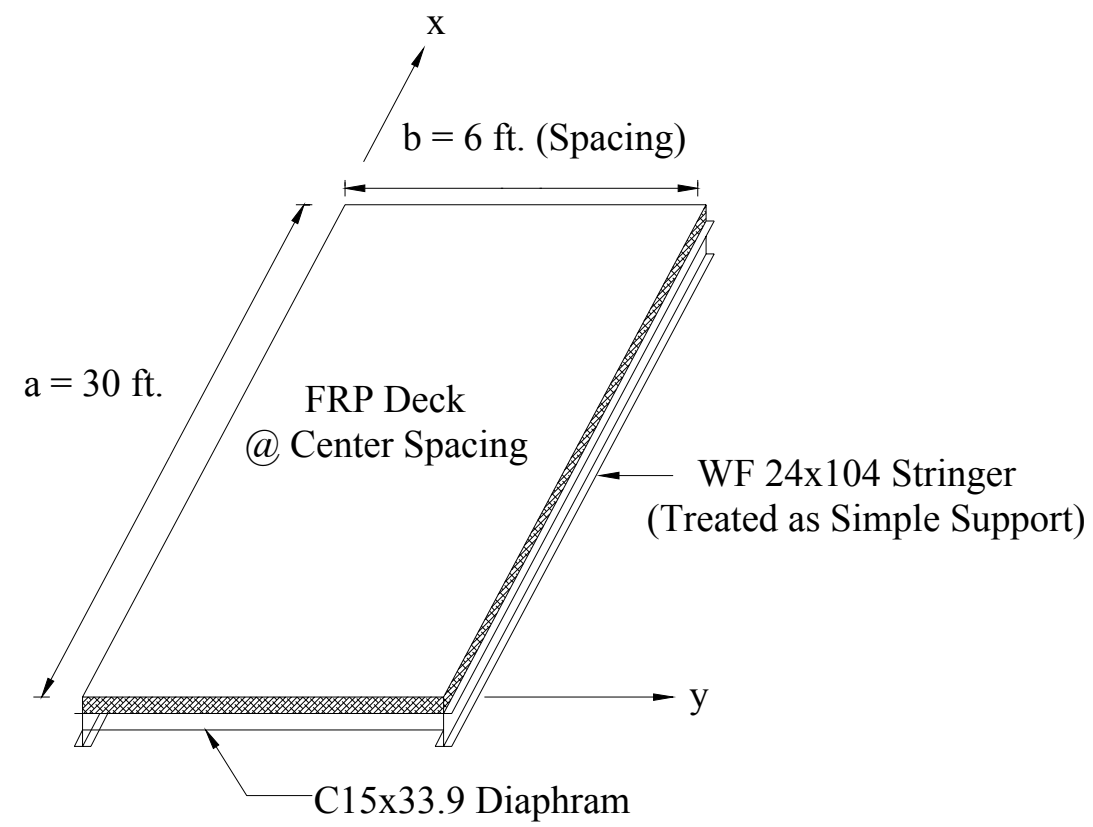

Figure 6.8: Plan View for Center Spacing of Wickwire Run Bridge.

The theoretical and field deflections are shown in Table 6.7. 


\begin{tabular}{|c|c|c|}
\hline \multicolumn{3}{|c|}{ Properties for Super Deck } \\
\hline $\mathrm{E}_{1}$ & Young's Moduli in strong direction & $3.05 \times 10^{6}$ psi. \\
\hline $\mathrm{E}_{2}$ & Young's Moduli in weak direction & $0.92 \times 10^{6} \mathrm{psi}$ \\
\hline $\mathrm{G}_{12}$ & Shear Moduli in the 1-2 plane & $0.44 \times 10^{6} \mathrm{psi}$ \\
\hline $\mathrm{D}_{11}$ & Flexural Rigidity in Strong Direction & $6.76 \times 10^{7}$ lbs.-in. \\
\hline $\mathrm{D}_{22}$ & Flexural Rigidity in Weak Direction & $1.82 \times 10^{7}$ lbs.-in. \\
\hline $\mathrm{D}_{12}$ & ------------------------------------- & $0.51 \times 10^{7}$ lbs.-in.] \\
\hline $\mathrm{D}_{66}$ & Torsional Rigidity & $4.3 \times 10^{5} \mathrm{lbs} .-\mathrm{in}$ \\
\hline$v_{12}$ & Poison Ratio when stressed in 1 direction & 0.25 \\
\hline$v_{21}$ & Poison Ration when stressed in 2 direction & 0.075 \\
\hline$\alpha_{1}$ & Thermal Coefficient in strong direction & $\begin{array}{l}6.07 \mu \varepsilon /{ }^{\circ} \mathrm{F}\left(70 \text { to } 121^{\circ} \mathrm{F}\right) \\
5.86 \mu \varepsilon /{ }^{\circ} \mathrm{F}\left(-20 \text { to } 70{ }^{\circ} \mathrm{F}\right)\end{array}$ \\
\hline$\alpha_{2}$ & Thermal Coefficient in weak direction & $\begin{array}{l}9.75 \mu \varepsilon /{ }^{\circ} \mathrm{F}\left(70 \text { to } 121^{\circ} \mathrm{F}\right) \\
8.98 \mu \varepsilon /{ }^{\circ} \mathrm{F}\left(-20 \text { to } 70{ }^{\circ} \mathrm{F}\right)\end{array}$ \\
\hline
\end{tabular}

Table 6.6: Properties of Super Deck.

\begin{tabular}{|c|c|c|c|c|c|}
\hline \multicolumn{6}{|c|}{ Wickwire Run Bridge } \\
\hline \multirow{2}{*}{$\begin{array}{l}\text { Date } \\
6 / 26 / 03\end{array}$} & \multicolumn{2}{|c|}{ Temperature $\left({ }^{\circ} \mathrm{F}\right)$ at } & \multirow{2}{*}{$\begin{array}{l}\Delta T \\
\left({ }^{\circ} \mathrm{F}\right)\end{array}$} & \multicolumn{2}{|c|}{ Deflection (in.) } \\
\hline & $\begin{array}{l}\text { Bottom } \\
\text { Surface }\end{array}$ & $\begin{array}{c}\text { Top } \\
\text { Surface }\end{array}$ & & Field Data & Macro Approach \\
\hline $\begin{array}{c}\text { Initial Reading } \\
(8.11 \mathrm{am} .)\end{array}$ & 61 & 61 & 0 & 0 & 0 \\
\hline $\begin{array}{c}\text { Final Reading } \\
(2.30 \mathrm{pm} .)\end{array}$ & 67 & 111 & 44 & -0.0494 & -0.0479 \\
\hline
\end{tabular}

Table 6.7: Theoretical and Field Deflections for Wickwire Run Bridge.

From Table 6.7, we can see that the theoretical deflection correlates well with field data. 


\subsection{Design Criteria}

The existing stress design criteria in conventional bridge decks are mainly based on the service loads, but in the FRP composite bridges the temperature related stresses should be considered in spite of service loads. Hence, during the design of FRP composite bridges, stresses and strains due to thermal loads should be combined with stresses and strains due to service loads, such as HS-25 truck type loading. A combination of thermal stress and stress under service load is shown in Table 6.8. A combination of thermal strain and strain due to service load is shown in Table 6.9.

\begin{tabular}{|l|c|c|c|}
\hline Location & $\begin{array}{c}\text { Max. Thermal Stress } \\
\text { (psi.) }\end{array}$ & $\begin{array}{c}\text { Max. Field Stress (psi.) } \\
\text { (Based on HS 25 Truck Load) }\end{array}$ & Total Stress (psi.) \\
\hline Deck Top & -900 & -260 & -1160 \\
\hline Deck Bottom & -270 & 400 & 130 \\
\hline
\end{tabular}

Table 6.8: Total Stress on FRP Deck.

\begin{tabular}{|l|c|c|c|}
\hline \multicolumn{1}{|c|}{ Location } & $\begin{array}{c}\text { Max. Thermal Strain } \\
(\mu \varepsilon)\end{array}$ & $\begin{array}{c}\text { Max. Field Strain }(\mu \varepsilon) \\
\text { (Based on HS 25 Truck Load) }\end{array}$ & Total Strain $(\mu \varepsilon)$ \\
\hline Deck Top & 603 & -65 & 538 \\
\hline Deck Bottom & 276 & 100 & 376 \\
\hline
\end{tabular}

Table 6.9: Total Strain on FRP Deck.

During the field monitoring of the Market Street Bridge, the strain due to service loads was found to be about $-65 \mu \varepsilon$ for deck top and $100 \mu \varepsilon$ for deck bottom, which translates to a stress of -260 psi. for the deck top and 400 psi for the deck bottom (Tables 6.8 and 6.9). The thermal stress due to temperature difference of $100{ }^{\circ} \mathrm{F}$ at top of deck and $30{ }^{\circ} \mathrm{F}$ at bottom of deck was about -900 psi. which is compressive (Table 6.8). Typically, the total stresses (maximum) in FRP bridge decks (thermal + service loads) is about -1160 psi., 
compressive (as shown in Table 6.8) out of which the thermal stresses is about $15 \%$ of allowable stresses of 6000 psi (i.e., $20 \%$ of ultimate stress which is 30,000 psi.) which is insignificant. Similarly the thermal strain is about $38 \%$ of allowable strain of $1600 \mu \varepsilon$ (i.e., $20 \%$ of ultimate strain which is $8000 \mu \varepsilon$ ).

However, in some decks (e.g., SuperDeck) the allowable stresses may be only 2000 psi (i.e., $20 \%$ of ultimate stress which is 10,000 psi), where the thermal stresses will be about $45 \%$ of allowable stresses, which is a significant amount of stresses in the decks. With respect to strain, the thermal strain will be about $86 \%$ of allowable strain of $700 \mu \varepsilon$ (i.e., $20 \%$ of ultimate strain which is $3500 \mu \varepsilon$.)

Hence a designer should be properly accounting for thermally induced stress and strain because of percent of thermal stress and strain in relation to traffic induced stresses and strains in FRP bridge decks.

\subsection{Design Examples}

The induced thermal strain (field data) and stress (calculated from thermal strain) of Market Street Bridge are shown in Table 6.10 (Refer to Tables 6.1 and 6.3).

\begin{tabular}{|l|c|c|c|c|c|c|c|}
\hline Location & $\begin{array}{l}\Delta T \\
\left({ }^{\circ} \mathrm{F}\right)\end{array}$ & $\begin{array}{l}\alpha_{11} \Delta T \\
(\mu \varepsilon)\end{array}$ & $\begin{array}{l}\alpha_{22} \Delta T \\
(\mu \varepsilon)\end{array}$ & $\begin{array}{c}\varepsilon_{11} \\
(\mu \varepsilon)\end{array}$ & $\begin{array}{c}\varepsilon_{22} \\
(\mu \varepsilon)\end{array}$ & $\begin{array}{l}\sigma_{11} \\
(\mathrm{psi})\end{array}$ & $\begin{array}{c}\sigma_{22} \\
(\mathrm{psi} .)\end{array}$ \\
\hline Top & 36 & 219 & 351 & $N / A$ & $N / A$ & $N / A$ & $N / A$ \\
\hline Bottom & 10 & 60.7 & 97.5 & 43 & 5 & -77 & -91 \\
\hline
\end{tabular}

Note: Subscript 11 and 22 represent strong and weak direction of FRP deck

Table 6.10 Induced Thermal Strain (Field Data) and Stress of Market Street Bridge. 
According to our field results in Table 6.10, it is observed that the induced thermal strain on the bottom surface of FRP deck was about $70 \%$ (i.e. $43 \mu \varepsilon / 60.7 \mu \varepsilon$ ) of $\alpha_{11} \Delta T$ in the cell (bridge width) direction and 5\% (i.e. $5 \mu \varepsilon / 97.5 \mu \varepsilon$ ) of $\alpha_{22} \Delta T$ in the traffic (span) direction. Therefore, induced thermal in strain Market Street bridge can be calculated from Eq. (6.3) as :

$$
\left\{\begin{array}{l}
\varepsilon_{11} \\
\varepsilon_{22}
\end{array}\right\}=\left\{\begin{array}{l}
70 \% \text { of } \alpha_{11} \Delta T \\
5 \% \text { of } \alpha_{22} \Delta T
\end{array}\right\}=\left\{\begin{array}{l}
0.70 \alpha_{11} \Delta T \\
0.05 \alpha_{22} \Delta T
\end{array}\right\}
$$

Notes : Positive sign represents expansion. Subscript "11" represents deck cell direction. Subscript "22" represents direction perpendicular to deck cell direction or stringer direction.

And the induced thermal stress for Market Street Bridge can be calculated from Eq. (6.4).

$$
\left\{\begin{array}{l}
\sigma_{11} \\
\sigma_{22}
\end{array}\right\}=\left[\begin{array}{ll}
Q_{11} & Q_{12} \\
Q_{12} & Q_{22}
\end{array}\right]\left\{\begin{array}{l}
30 \% \text { of }\left(-\alpha_{11} \Delta T\right) \\
95 \% \text { of }\left(-\alpha_{22} \Delta T\right)
\end{array}\right\}=\left[\begin{array}{ll}
Q_{11} Q_{12} \\
Q_{12} Q_{22}
\end{array}\right]\left\{\begin{array}{l}
-0.30 \alpha_{11} \Delta T \\
-0.95 \alpha_{22} \Delta T
\end{array}\right\}
$$

Notes : Negative sign represents compressive stress. Subscripts "11" represents deck cell direction. Subscript "22" represents direction perpendicular to deck cell direction or stringer direction.

The percentage of strain and stress distribution in Eqs. (6.3) and (6.4) can be used to calculate induced thermal strain and stress of Market Street Bridge for a critical temperature case $\left(\Delta T_{\text {top }}=100^{\circ} \mathrm{F}\right.$ and $\left.\Delta T_{\text {bottom }}=30^{\circ} \mathrm{F}\right)$. The following is the design example for Market Street Bridge under a critical temperature case of $\Delta T_{\text {top }}=100^{\circ} \mathrm{F}$ and $\Delta T_{\text {bottom }}=30^{\circ} \mathrm{F}$. It should be noted that the following design example is particularly suited for Market Street Bridge since the percentage of strain and stress distribution can be different in a different FRP bridge. 


\section{Design Example of Market Street Bridge}

Step 1 : Determined the Elastic Coefficient ( $\left.Q_{i j}\right)$ of FRP deck.

Properties of FRP Decks :

$$
E_{1}=3.05 \times 10^{6} \text { psi., } E_{2}=0.92 \times 10^{6} \text { psi., } v_{12}=0.25 \text { and } v_{21}=0.075
$$

$>$ The Elastic Coefficient $\left(Q_{i j}\right)$ of FRP deck.

$$
\begin{aligned}
& Q_{11}=\frac{E_{1}}{1-v_{12} v_{21}}=\frac{3.05 \times 10^{6}}{1-(0.25)(0.075)}=3.11 \times 10^{6} \mathrm{psi} \\
& Q_{12}=\frac{v_{12} E_{2}}{1-v_{12} v_{21}}=\frac{(0.25)\left(0.92 \times 10^{6}\right)}{1-(0.25)(0.075)}=2.34 \times 10^{5} \mathrm{psi} \\
& Q_{22}=\frac{E_{2}}{1-v_{12} v_{21}}=\frac{0.92 \times 10^{6}}{1-(0.25)(0.075)}=9.38 \times 10^{5} \mathrm{psi}
\end{aligned}
$$

\section{Step 2 : Calculated Induced thermal Strain.}

$>$ Coefficient of Thermal Expansion $(\alpha)$ of FRP Decks :

$\alpha_{11}=6.07 \mu \varepsilon /{ }^{\circ} \mathrm{F}$ (Strong Direction of FRP Decks)

$\alpha_{22}=9.75 \mu \varepsilon /^{\circ} \mathrm{F}$ (Weak Direction of FRP Decks)

$>$ Calculate Induced Thermal Strain using Eq. (6.3) :

Induced Thermal Strain on the Top Surface of FRP Deck : (Note : $\Delta T=100^{\circ} \mathrm{F}$ )

$$
\left\{\begin{array}{l}
\varepsilon_{11} \\
\varepsilon_{22}
\end{array}\right\}=\left\{\begin{array}{l}
0.70 \alpha_{11} \Delta T \\
0.05 \alpha_{22} \Delta T
\end{array}\right\}=\left\{\begin{array}{l}
0.70\left(6.07 \times 10^{-6}\right)(100) \\
0.05\left(9.75 \times 10^{-6}\right)(100)
\end{array}\right\}=\left\{\begin{array}{l}
425 \mu \varepsilon \\
49 \mu \varepsilon
\end{array}\right\}
$$

Induced Thermal Strain on the Bottom Surface of FRP Deck : (Note : $\Delta T=30^{\circ} \mathrm{F}$ )

$$
\left\{\begin{array}{l}
\varepsilon_{11} \\
\varepsilon_{22}
\end{array}\right\}=\left\{\begin{array}{l}
0.70 \alpha_{11} \Delta T \\
0.05 \alpha_{22} \Delta T
\end{array}\right\}=\left\{\begin{array}{l}
0.70\left(6.07 \times 10^{-6}\right)(30) \\
0.05\left(9.75 \times 10^{-6}\right)(30)
\end{array}\right\}=\left\{\begin{array}{l}
127 \mu \varepsilon \\
15 \mu \varepsilon
\end{array}\right\}
$$




\section{Step 3 : Calculated Induced Thermal Stress using Eq. (6.4)}

Substituting $Q_{i j}, \alpha_{11}, \alpha_{22}$, and $\Delta T$ into Eq. (6.4), we obtained :

Induced Thermal Stress on the Top Surface of FRP Deck : (Note : $\left.\Delta T=100^{\circ} \mathrm{F}\right)$

$$
\left\{\begin{array}{l}
\sigma_{11} \\
\sigma_{22}
\end{array}\right\}=\left[\begin{array}{ll}
Q_{11} Q_{12} \\
Q_{12} Q_{22}
\end{array}\right]\left\{\begin{array}{l}
-0.30 \alpha_{11} \Delta T \\
-0.95 \alpha_{22} \Delta T
\end{array}\right\}=\left[\begin{array}{ll}
3.11 & 0.23 \\
0.23 & 0.94
\end{array}\right]\left\{\begin{array}{l}
-0.30 \times 6.07 \times 100 \\
-0.70 \times 9.75 \times 100
\end{array}\right\}=\left\{\begin{array}{l}
-783 \text { psi. } \\
-911 \text { psi. }
\end{array}\right\}
$$

$>$ Induced Thermal Stress on the Bottom Surface of FRP Deck : (Note : $\Delta T=30^{\circ} \mathrm{F}$ )

$$
\left\{\begin{array}{l}
\sigma_{11} \\
\sigma_{22}
\end{array}\right\}=\left[\begin{array}{ll}
Q_{11} & Q_{12} \\
Q_{12} & Q_{22}
\end{array}\right]\left\{\begin{array}{l}
-0.30 \alpha_{11} \Delta T \\
-0.95 \alpha_{22} \Delta T
\end{array}\right\}=\left[\begin{array}{ll}
3.11 & 0.23 \\
0.23 & 0.94
\end{array}\right]\left\{\begin{array}{l}
-0.30 \times 6.07 \times 30 \\
-0.70 \times 9.75 \times 30
\end{array}\right\}=\left\{\begin{array}{l}
-236 \text { psi. } \\
-273 \text { psi. }
\end{array}\right\}
$$

It was noted that the above $\sigma_{11}$ and $\sigma_{22}$ correlated well with FEM results in Table 6.5 (for "NL" column).

\subsection{Conclusions}

- For a positive temperature difference $\left(\Delta T_{\max }\right)$ of $26^{\circ} \mathrm{F}$ (i.e. $\Delta T_{\text {top }}-\Delta T_{\text {bottom }}=36-10=$ $26^{\circ} \mathrm{F}$ ), induced thermal stress in the Market Street bridge on the bottom side is compressive with a magnitude of -77 psi. and -91 psi. (refer to Table 6.3) in the strong and weak directions, respectively. For positive temperature difference, $\left(\Delta T_{\max }\right)$ of $4^{\circ} \mathrm{F}$ (i.e. $\Delta T_{\text {top }}-\Delta T_{\text {bottom }}=10-6=4^{\circ} \mathrm{F}$ ), induced thermal stress on the bottom side is also compressive with a magnitude of -58 psi. and -54 psi. (refer to Table 6.3 ) in the strong and weak directions, respectively.

- Compressive stress (Table 6.3) is induced in the deck when the deck is subjected to a positive temperature difference and compressive stress increases with increase in temperature difference (i.e. $\Delta T_{\max }=\Delta T_{\text {top }}-\Delta T_{\text {bottom }}$ ). 
- Deck strains on the top and bottom surfaces are found to be positive (Table 6.3) which means that the FRP deck expands on both sides when subjected to positive temperature difference.

- Typically, the induced maximum thermal stress in FRP composite decks for a critical temperature change of $100{ }^{\circ} \mathrm{F}$ at top and $30{ }^{\circ} \mathrm{F}$ at bottom of the deck is found to be about 900 psi. of compressive stress (Refer to Table 6.6). The allowable stress in these FRP decks due to service load is about 6,000 psi. (GangaRao et.al., 2000) (= $20 \%$ of ultimate stress which is 30,000 psi.). This indicates that we have good margin of safety (1/6), as the thermal stresses is only about $15 \%$ of allowable stress. However, there is a possibility where thermal stresses could be as high as $45 \%$ of allowable stress (as in the Super Deck), where the allowable stress of the deck is 2,000 psi. ( $=20 \%$ of ultimate stress which is 10,000 psi.). In this scenario, a designer should be cautious in designing the deck due to significant amount of thermal stresses induced in the deck.

- Boundary conditions play an important role in thermal stresses and strains. Thermal stress is more significant than thermal strain when the boundaries are fully restrained and thermal strain is more significant than thermal stress when the boundaries are free to translate.

- Typically, the temperature difference of FRP bridges (around $80^{\circ} \mathrm{F}$ to $100^{\circ} \mathrm{F}$ ) is higher than that of traditional concrete bridge (around $20^{\circ} \mathrm{F}$ to $40^{\circ} \mathrm{F}$ ). This is because the hollow section of FRP deck is not able to dissipate heat from the top surface to the bottom surface as effectively as a solid cross section of a traditional concrete bridge, and also it has relatively low thermal conductivity (thermal conductivity of FRP deck 
is about $0.375 \mathrm{~W} / \mathrm{m}^{\circ} \mathrm{K}$ while that of concrete is around 0.8 to $1.2 \mathrm{~W} / \mathrm{m}^{\circ} \mathrm{K}$ ). In order to have a general idea of a temperature difference on FRP bridges, a temperature plot for the Wickwire Run Bridge is shown in Figure 6.9.

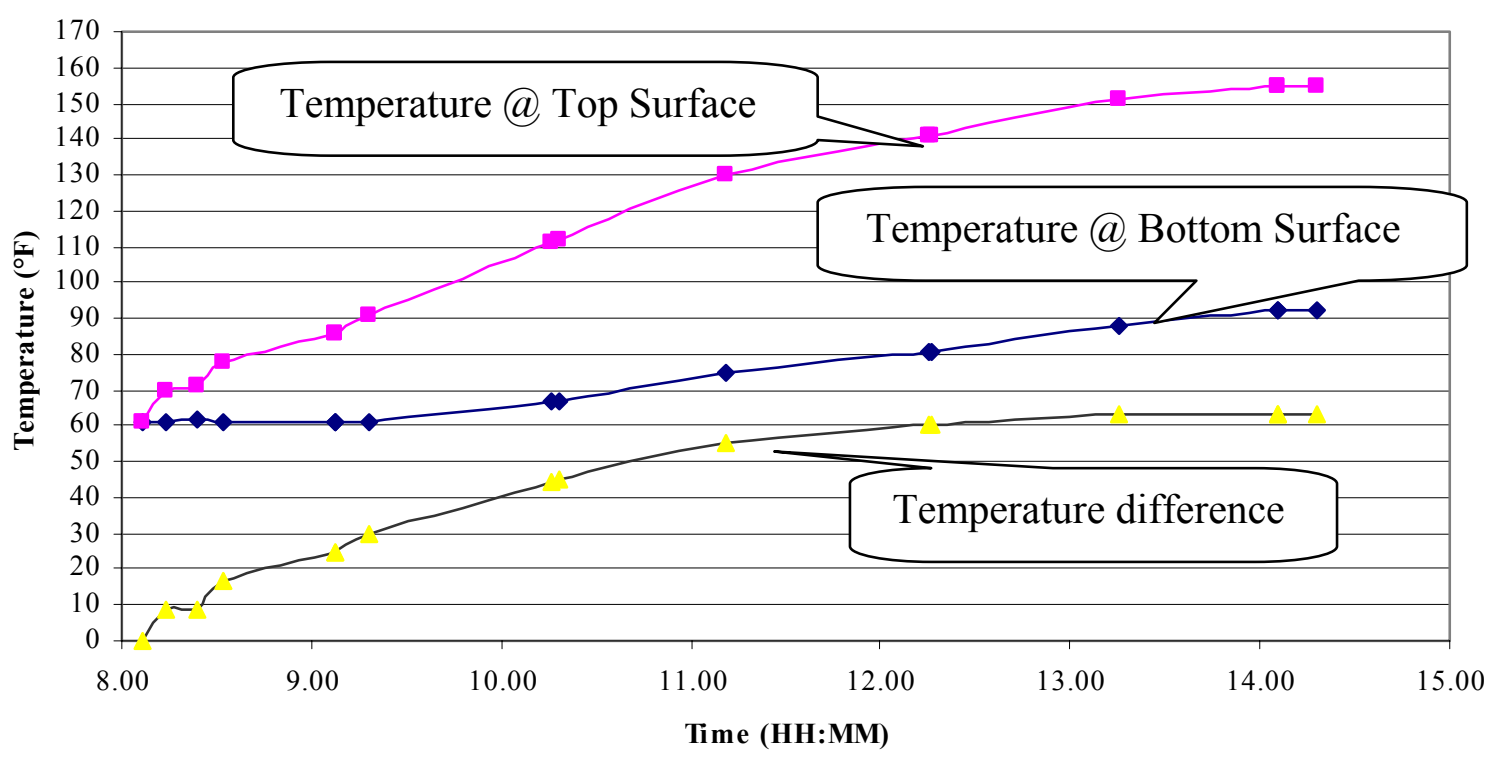

Figure 6.9: Temperature Plot for Wickwire Run Bridge. 


\section{Chapter 7}

\section{Conclusions and Recommendations}

This chapter focuses on conclusions based on the laboratory test data and field results. A few salient data are shown in section 7.1.1 and 7.1.2. The recommendations for future study are provided in section 7.2.

\subsection{Conclusions}

\subsubsection{Conclusions based on the Laboratory Results}

- The coefficient of thermal expansion (CTE) in the weak direction of the FRP deck was higher than that in the strong direction.

- The CTE of BRP's 4 in. a FRP deck is $5.66 \mu \varepsilon /{ }^{\circ} \mathrm{F}$ in the strong direction and $9.11 \mu \varepsilon /{ }^{\circ} \mathrm{F}$ in the weak direction.

- The CTE of BRP's 8 in. a FRP deck is $4.96 \mu \varepsilon /{ }^{\circ} \mathrm{F}$ in the strong direction and $14.75 \mu \varepsilon /{ }^{\circ} \mathrm{F}$ in the weak direction.

- The CTE of Super Deck is $6.07 \mu \varepsilon /{ }^{\circ} \mathrm{F}$ in the strong direction and $9.75 \mu \varepsilon /{ }^{\circ} \mathrm{F}$ in the weak direction.

- The FRP deck exhibits a hogging effect (upward convexity) when the temperature of top surface is higher than that of bottom surface.

- The FRP deck exhibits sagging effect (downward concavity) when the temperature of top surface is lower than that of bottom surface.

- Deflections increased with increasing magnitude of temperature difference. The FRP deck deflection does not depend on the absolute temperature of top or bottom surface, 
but depends primarily on the temperature difference between the top and bottom deck surfaces.

- For SSFF boundary condition, the maximum deflections of the FRP deck subjected to a linear gradient temperature can be well predicted using the $1^{\text {st }}$ term approximation of Macro approach.

- The distribution of thermal effects between the induced thermal strain and stress depends on the effectiveness of boundary restraints in horizontal plane and vertical plane. If boundaries are fully restrained, thermal stress is fully developed while thermal strain is not significant. On the other hand, if boundaries are free, thermal strain is fully developed while thermal stress is not significant.

- The FEM results (deflections and strains) of FRP deck are in good agreement with experimental data, where the deck was modeled as the individual "shel193" element (ANSYS) for top, bottom and web.

- Boundary restraint in the plane of FRP deck for simply supported edges in the laboratory tests was not one hundred percent effective. However, resistance in the vertical direction along the simply supported boundary was excellent.

- A good correlation of thermal stresses between the theory and experimental test results is difficult to obtain because a small strain error in one principle direction can lead to large stress error after combining strains in two different directions of a horizontal plane of a deck with temperature effect $(\alpha \Delta T)$.

$$
\text { Stress Calculation: }\left\{\begin{array}{l}
\sigma_{x x} \\
\sigma_{y y}
\end{array}\right\}=\left[\begin{array}{c}
Q_{x x} Q_{x y} \\
Q_{x y} Q_{y y}
\end{array}\right]\left\{\begin{array}{c}
\varepsilon_{x x}-\alpha_{x x} \Delta T \\
\varepsilon_{y y}-\alpha_{y y} \Delta T
\end{array}\right\}
$$




\subsubsection{Conclusions based on the Field Results}

- Compressive stress was induced in the FRP deck when the deck was subjected to a positive temperature difference and compressive stress increased with an increase in the magnitude of temperature difference (i.e., $\Delta T_{\max }=\Delta T_{\text {top }}-\Delta T_{\text {bottom }}$ ).

- Induced thermal strains on the top and bottom surfaces of deck were found to be positive which means that the FRP deck expands on both sides when the FRP bridge decks were subjected to positive temperature difference, but results in compressive stress.

- Deck strain in the traffic direction was less than the deck strain in the cell direction because flexural rigidity of the system (deck-stringer) in traffic direction was higher than flexural rigidity in direction perpendicular to traffic.

- For a critical temperature change of $100^{\circ} \mathrm{F}$ at deck top and $30^{\circ} \mathrm{F}$ at deck bottom, the induced thermal stress in FRP composite decks can be as high as 45\% of allowable stress in the weak direction and the induced thermal strain in FRP decks can be as high as $85 \%$ of allowable strain in the strong direction. 


\subsection{Recommendations}

- FRP decks are difficult to be restrained in the plane of a deck.

- The analysis (based on Macro approach and FEM) can be expanded by including temperature dependent properties of FRP deck and a non-linear temperature change along the depth of decks.

- The wearing surface has to be included in the FRP bridge deck finite element model to predict the effect of combining two different materials (i.e., wearing surface and FRP decks).

- In order to reduce the temperature difference between top and bottom of FRP decks, the core of FRP decks may be filled with some types of light foam materials, which can transfer heat from the top surface of a deck to the bottom surface. The brighter color of wearing surface may reduce the temperature on the top surface of the FRP deck under the exposure of Sun.

- Thermal field data (induced strain due to temperature change) for different types of deck-stringer connections and bridge structures are required in order to obtain the percentage distribution between thermal strain and stress for the design, which is a function of the in-plane restraint quality.

- The cumulative strains due to repeated thermal cycles might be a reason of the wearing surface cracking in the field joints, which requires further study. 


\section{Appendix A}

\section{Basic Thermal Analysis of Isotropic Beam and Orthotropic Plate}

Basic thermal analysis are presented in Appendix A. The objective of this appendix is to illustrate the basic mechanical law with temperature effect for beam and orthotropic plate which are required in thermal analysis of FRP deck in Appendix G. Appendix A is divided into two parts of basic thermal analysis (i.e. Isotropic beam and orthotropic plate). Table A.1 are shown the relation or basic mechanical law which presented in this appendix.

\begin{tabular}{|l|l|}
\hline \multirow{4}{*}{ A.1) For 1-D Isotropic Beam } & A.1.1) Strain-Displacement relation \\
\cline { 2 - 3 } & A.1.2) Stress-Strain relation \\
\cline { 2 - 3 } & A.1.3) Stress-Displacement relation \\
\hline & A.1.4) Resultant forces and moments \\
\hline & A.1.5) Design Example for a beam \\
\hline \multirow{4}{*}{ A.2) For Orthotropic Plate } & A.2.1) Strain-Displacement relation \\
\hline & A.2.2) Stress-Strain relation \\
\hline & A.2.3) Stress-Displacement relation \\
\hline & A.2.4) Resultant forces and moments \\
\hline & A.2.5) Temperature increment along the plate depth \\
\hline
\end{tabular}

Table A.1 Basic Mechanical Law with Temperature Effect.

\section{A.1 Basic thermal analysis for 1-D isotropic beam}

\section{A.1.1 Strain-displacement relation in 1-D isotropic beam}

The strain of isotropic beam is divided into two parts (i.e. membrane and bending strain) as following (see Figure A.1) 


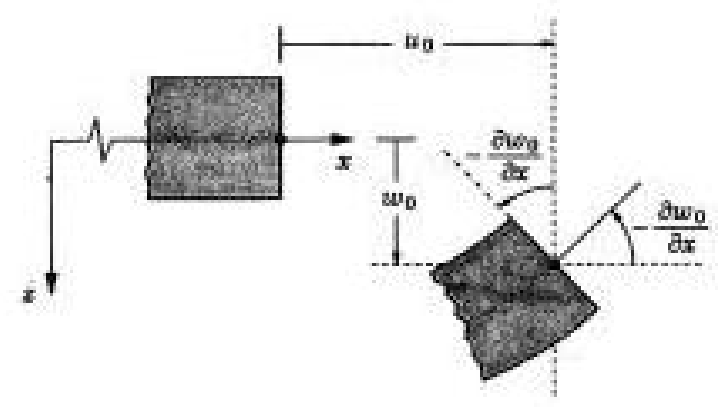

Figure A.1: $\mathrm{x}$ and $\mathrm{z}$ Directions of a Beam.

$$
\varepsilon_{x x}=\varepsilon_{x x}^{0}+z \varepsilon_{x x}^{1}
$$

where $\varepsilon_{x x}^{0}$ are the membrane strains, and $\varepsilon_{x x}^{1}$ are bending strains (or curvatures). Both membrane and bending strains are defined as $\varepsilon_{x x}^{0}=\frac{d u_{0}}{d x}$ and $\varepsilon_{x x}^{1}=-\frac{d^{2} w_{0}}{d x^{2}}$. Eq. (A.1) can be written in alternative forms as

$$
\varepsilon_{x x}=\frac{d u_{0}}{d x}-z \frac{d^{2} w_{0}}{d x^{2}} \quad \text { (Ref. Reddy 1999) }
$$

\section{A.1.2 Stress-strain relation in 1-D isotropic beam}

For a classical problem of combined bending and axial effects, the strain field can be structured as shown below

$$
\varepsilon_{\text {measured }}=\varepsilon_{\text {mech }}+\varepsilon_{\text {th }}
$$

where $: \varepsilon_{\text {measured }}$ is the strain measured on material. $\varepsilon_{\text {mech }}$ is mechanical strain due to an applied load or boundary conditions (i.e. $\varepsilon_{\text {mech }}=\frac{\sigma_{\text {mech }}}{E}$ ), $\varepsilon_{t h}$ is thermal strain from temperature change (i.e. $\varepsilon_{t h}=\alpha \Delta T, \alpha$ is the coefficient of thermal expansion and $\Delta T$ is the 
temperature increment from a reference temperature, $\Delta T=T-T_{\text {ref }}$ ). Equation (A.3) can be rewritten as :

$$
\varepsilon_{\text {measured }}=\frac{\sigma_{\text {mech }}}{E}+\alpha \Delta T
$$

Therefore the stress-strain relation can be expressed as

$$
\sigma_{\text {mech }}=E\left(\varepsilon_{\text {measured }}-\alpha \Delta T\right)
$$

For a beam, the above equation can be defined in alternative form as

$$
\sigma_{x x}=E_{x x}\left(\varepsilon_{x x}-\alpha_{x x} \Delta T\right)
$$

\section{A.1.3 Stress-displacement relation in 1-D isotropic beam}

Substituting Eq. (A.1) into Eq. (A.6), we obtain

$$
\sigma_{x x}=E\left(\varepsilon_{x x}^{0}+z \varepsilon_{x x}^{1}-\alpha_{x x} \Delta T\right)
$$

Substituting Eq. (A.2) into Eq.(A.6), we obtain

$$
\sigma_{x x}=E_{x}\left(\frac{d u_{0}}{d x}-z \frac{d^{2} w_{0}}{d x^{2}}-\alpha_{x x} \Delta T\right)
$$

According to section A.1.2 and A.1.3, stress resultants can be calculated from either the stress-strain relation in Eq. (A.6) or the stress-displacement relation in Eq. (A.8). It's important to understand that the strain $\left(\varepsilon_{x x}\right)$ in Eq. (A.6) is the strain which is measured from structures. If the measured strain $\left(\varepsilon_{x x}\right)$ and temperature change $(\Delta T)$ are known, we can calculate the stress resultants based on Eq. (A.6). To understand the concept clearly, examples of a rod with free and fully fixed ends, subjected to uniform temperature increment, will be discussed below. 
First we consider a rod with free ends (free expansion) subjected to a uniform temperature increment $\left(\Delta T=T^{0}\right)$. Since the rod can expand freely, the measured strain $\left(\varepsilon_{\text {measured }}\right)$ due to temperature increase, is equal to $\alpha T^{0}$ (i.e. $\varepsilon_{\text {measured }}$ or $\varepsilon_{x x}=\alpha T^{0}$ ). Substituting $\varepsilon_{\text {measured }}$ or $\varepsilon_{x x}=\alpha T^{0}$ into Eq. (A.6), we obtain $\sigma=E\left(\alpha T^{0}-\alpha T^{0}\right)=0$. Therefore, it can be concluded that when a rod with free ends is subjected to a uniform temperature increment, the stress resultant is zero but the measured strain is not zero (i.e. $\sigma_{x x}=0, \varepsilon_{x x} \neq 0$ but $\left.=\alpha T^{0}\right)$.

Secondly we consider a rod with fully fixed end (no expansion) subjected to uniform temperature increment $\left(\Delta T=T^{0}\right)$. Since the rod is fully fixed and cannot expand, the measured strain $\left(\varepsilon_{\text {measured }}\right)$ is zero. Substituting $\varepsilon_{\text {measured }}=0$ into Eq. (A.6), we obtain $\sigma_{x x}=E\left(0-\alpha T^{0}\right)=-E \alpha T^{0}$. Therefore, it can be concluded that when a rod with fully fixed ends is subjected to temperature increase, the measured strain is zero but the stress resultant is not zero (i.e. $\sigma_{x x} \neq 0=-E \alpha T^{0}$, compressive stress in rod but $\varepsilon_{x x}=0$ )

\section{A.1.4 Resultant forces and moments in 1-D isotropic beam}

Beam geometry and a linear temperature profile are shown in Figures A.2 and A.3, respectively. Assume a temperature change is a linear function along the depth $(z)$.

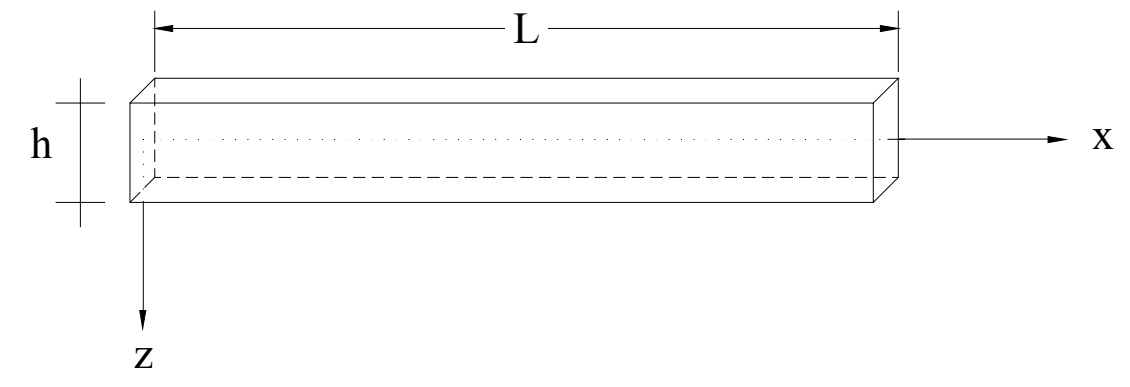

Figure A.2: Beam Geometry and Coordinate System. 


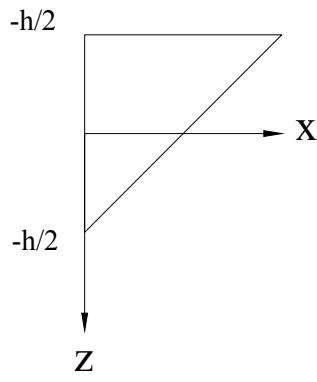

$\Delta T(z)$

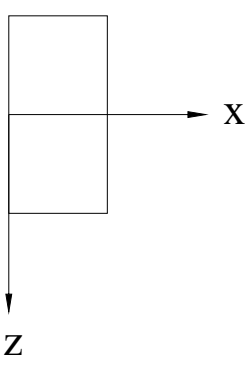

$T^{0}$

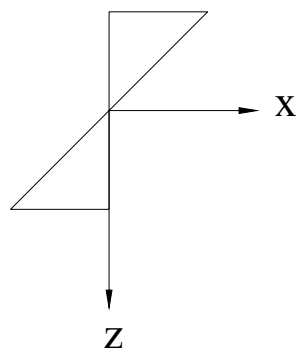

$z T^{1}$

Figure A.3: Temperature Change Profile along the Depth.

A linear function of temperature change can be defined as

$$
\Delta T(z)=T^{0}+z T^{1}
$$

where $T^{0}$ is a uniform temperature change along the depth $(z)$ and $z T^{1}$ is a gradient temperature change along the depth.

\section{$>$ Axial Forces}

$$
N_{x x}=\int \sigma_{x x} d A
$$

Combining Eqs. (A.7) and (A.9) and substituting into Eq. (A.10) we obtain

$$
N_{x x}=E \int_{\frac{-h}{2}}^{\frac{h}{2}}\left(\varepsilon_{x x}^{0}+z \varepsilon_{x x}^{1}-\alpha_{x x} T^{0}-z \alpha_{x x} T^{1}\right) b d z
$$

where $b$ is a beam width

$$
\begin{aligned}
& N_{x x}=E A\left(\varepsilon_{x x}^{0}-\alpha_{x x} T^{0}\right) \\
& N_{x x}=E A\left(\frac{d u_{0}}{d x}-N_{x x}^{T}\right)
\end{aligned}
$$

where $N_{x x}^{T}$ is an axial force resultant and defined as 


$$
N_{x x}^{T}=E A \alpha_{x x} T^{0}
$$

\section{Bending Moment}

$$
M_{x x}=\int \sigma_{x x} z d A
$$

Combining Eqs. (A.7) and (A.9) and substituting into Eq. (A.15) we obtain

$$
\begin{gathered}
M_{x x}=E \int_{-\frac{h}{2}}^{\frac{h}{2}}\left(\varepsilon_{x x}^{0}+z \varepsilon_{x x}^{1}-\alpha_{x x} T^{0}-z \alpha_{x x} T^{1}\right) z b d z \\
M_{x x}=E\left(\varepsilon_{x x}^{1}-\alpha_{x x} T^{1}\right) \int z^{2} d A \\
M_{x x}=E I\left(\varepsilon_{x x}^{1}-\alpha_{x x} T^{1}\right) \\
M_{x x}=E I\left(-\frac{d^{2} w}{d x^{2}}-M_{x x}^{T}\right)
\end{gathered}
$$

where $M_{x x}^{T}$ is a thermal moment resultant and defined as

$$
M_{x x}^{T}=E I \alpha_{x x} T^{1}
$$




\section{A.1.5 Design Example for a beam under a linear gradient temperature}

A rectangular beam has dimensions of 0.5 in. width $\mathrm{x} 0.8$ in. depth $\mathrm{x} 8 \mathrm{in}$. length. The beam is subjected to a linear temperature change $\left(\Delta T=0\right.$ to $80^{\circ} \mathrm{F}$ ) from bottom to top surface. Given properties : Young's Modulus $(E)=1.2 \times 10^{6} \mathrm{psi}$ and Coefficient of thermal expansion $(\alpha)=8 \times 10^{-6}$ psi. Calculate the maximum deflection, strain and stress on top and bottom surface based on simply supported and fixed boundary.

$\underline{\text { Solution }}$

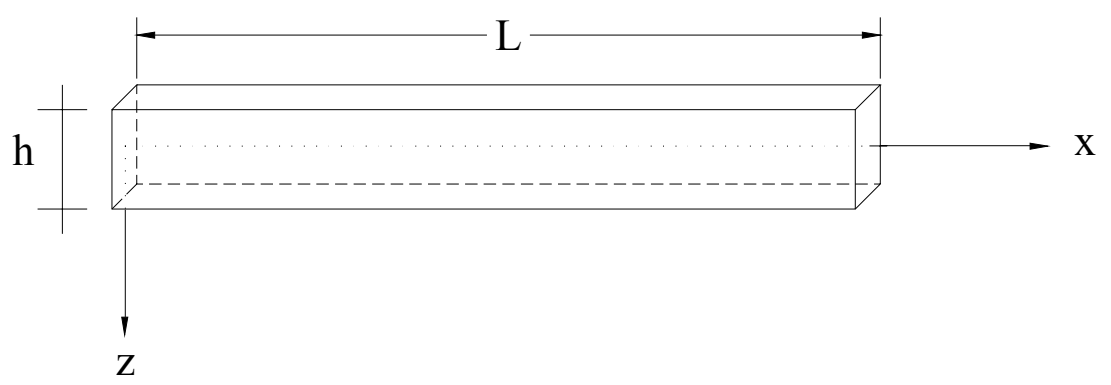

Temperature increment diagram along depth is shown below

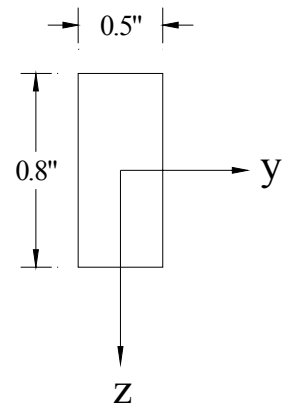

Cross Section

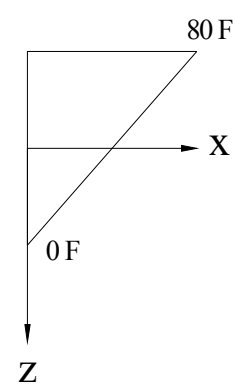

$\Delta T=T^{0}+z T^{1}$

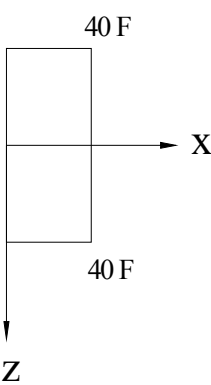

$T^{0}$

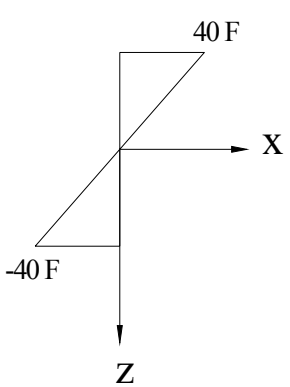

$z T^{1}$

(Membrane Effect)

(Bending Effect)

From the above diagram, the temperature increment can be divided into two parts such as an uniform temperature increment $\left(T^{0}\right)$ and a temperature gradient $\left(z T^{1}\right)$. A uniform temperature increment $\left(T^{0}\right)$ results in membrane effect (axial effect) while the temperature 
gradient $\left(z T^{1}\right)$ results in bending effect. A function of temperature change $(\Delta T)$ can be defined as

$$
\Delta T=T^{0}+z T^{1}=40-100 z \quad\left(\text { where } T^{0}=40, T^{1}=-100\right)
$$




\section{Case 1: Beam with Fixed Ends}

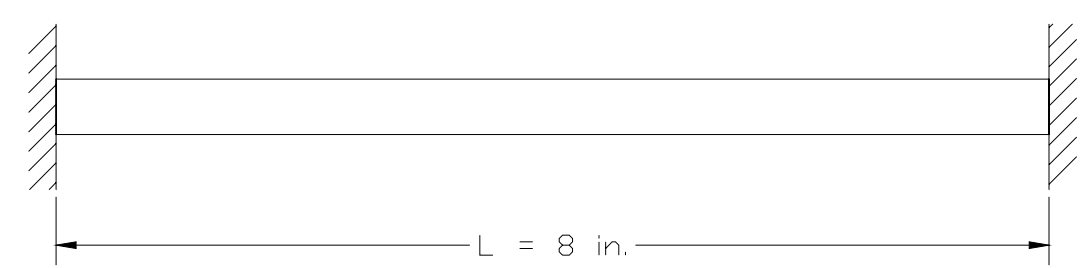

$>$ Calculating Stresses $\left(\sigma_{x x_{-} \text {top surface }}, \sigma_{x x_{-} \text {bottom surface }}\right)$

To calculate stress, either the stress-strain or stress-displacement relation from Eq. (A.6) and (A.8), respectively, can be used in calculation. In case of fixed ends, the beam is fully restrained and the measured strain is zero under temperature gradient. Since the measured strain is known (i.e. $\varepsilon_{x x}=0$ ), the stress will be calculated using the stress-strain relation in Eq. (A.6) as shown

$$
\sigma_{x x}=E_{x x}\left(\varepsilon_{x x}-\alpha_{x x} \Delta T\right)
$$

Substituting $\varepsilon_{x x}=0$ and $\Delta T=40-100 z$ into the above equation, we obtain

$\sigma_{x x}=\left(1.2 \times 10^{6}\right)\left[0-\left(8 x 10^{-6}\right)(40-100 z)\right]=-384+960 z$

$\therefore \sigma_{x x_{-} \text {top surface }}=-384+960(-0.4)=-768$ psi. (Note $z=-0.4$ in. at top surface.)

$\therefore \sigma_{x x_{-} \text {bottom surface }}=-384+960(0.4)=0$ psi. (Note $z=0.4$ in. at bottom surface.)

The above stresses results are the same results analyzed by finite element analysis (Ansys, solid 45 element) as shown in Table A.2. 


\section{Calculating Deflection and Strain}

Since the beam is fully restrained at the ends, deflection $\left(w_{0}\right)$ and $\operatorname{strain}\left(\varepsilon_{x x}\right)$ are zero. Deflection and strain results from finite element analysis are also zero.

\section{$>$ Comparison between theoretical and FEM results}

\begin{tabular}{|l|c|c|}
\hline @ Center of a Beam & Beam Theory & FEM \\
\hline$w_{0}$ (in.) & 0 & 0 \\
\hline$\sigma_{x x_{-} \text {Top Surface }}$ (psi.) & -768 & -768 \\
\hline$\sigma_{x x_{-} \text {Bottom Surface }}(\mathrm{psi})$. & 0 & 0 \\
\hline$\varepsilon_{x_{-} \text {Top Surface }}(\mu \varepsilon)$ & 0 & 0 \\
\hline$\varepsilon_{x x_{-} \text {Bottom Surface }}(\mu \varepsilon)$ & 0 & 0 \\
\hline
\end{tabular}

Table A.2: Comparison Results of Beam Theory and FEM for Case 1. 
Case 2: Beam Bending with simply supported ends (Note : $\left.u_{0}(0)=u_{0}(L)=0\right)$.

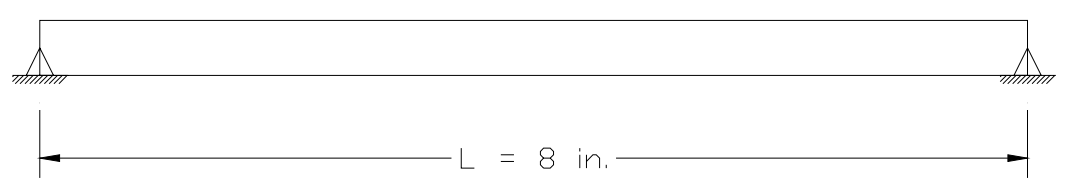

Governing Equation of the beam under thermoelastic effect.
Bending Effect
$E I \frac{d^{4} w_{0}}{d x^{4}}=-\frac{d^{2} M_{x x}^{T}}{d x^{2}}$

where $M_{x x}^{T}=E I \alpha_{x x} T^{1} \quad$ (Eq. (A.20)) and $\Delta T=T^{0}+z T^{1}=40-100 z\left(T^{0}=40, T^{1}=-100\right)$
Membrane Effect

$$
E A \frac{d^{2} u_{0}}{d x^{2}}=\frac{d N_{x x}^{T}}{d x}
$$

where $N_{x x}^{T}=E A \alpha_{x x} T^{0}$ (Eq. (A.14)) and $\Delta T=T^{0}+z T^{1}=40-100 z\left(T^{0}=40, T^{1}=-100\right)$

\section{Boundary Condition : at $x=0$ and $L$}

$u_{0}=w_{0}=0$ and $M_{x x}=-E I \frac{d^{2} w_{0}}{d x^{2}}-M_{x x}^{T}=0 \quad($ Refer to Eq. (A.19) )

$w_{0}$ and $u_{0}$ in Eq. (A.21) and (A.22) are solved by integration.

$$
\begin{gathered}
E I \frac{d^{2} w_{0}}{d x^{2}}=-M_{x x}^{T}+c_{1} x+c_{2} \\
E I \frac{d w_{0}}{d x}=-\int M_{x x}^{T} d x+c_{1} \frac{x^{2}}{2}+c_{2} x+c_{3}
\end{gathered}
$$

Substituting $M_{x x}^{T}=E I \alpha_{x x} T^{1}$ into the above equation

$$
\begin{gathered}
E I \frac{d w_{0}}{d x}=-E I \alpha_{x x} T^{1} x+c_{1} \frac{x^{2}}{2}+c_{2} x+c_{3} \\
E I w_{0}(x)=-\int\left(E I \alpha_{x x} T^{1} x\right) d x+c_{1} \frac{x^{3}}{6}+c_{2} \frac{x^{2}}{2}+c_{3} x+c_{4}
\end{gathered}
$$




$$
E I w_{0}(x)=-E I \alpha_{x x} T^{1} \frac{x^{2}}{2}+c_{1} \frac{x^{3}}{6}+c_{2} \frac{x^{2}}{2}+c_{3} x+c_{4}
$$

Using the boundary condition $w_{0}(0)=w_{0}(L)=0$ and $M_{x x}(0)=M_{x x}(L)=0$ where

$$
\begin{gathered}
M_{x x}=-E I \frac{d^{2} w_{0}}{d x^{2}}-M_{x x}^{T}=0, \text { we obtain } c_{1}=c_{2}=c_{4}=0 \text { and } c_{3}=\frac{E I \alpha_{x x} T^{1} L}{2} \\
\therefore w_{0}(x)=-\frac{\alpha_{x x} T^{1} L^{2}}{2}\left(\frac{x^{2}}{L^{2}}-\frac{x}{L}\right)
\end{gathered}
$$

\section{Determining $u_{0}(x)$}

Integrating Eq. (A.22), we obtain

$$
E A \frac{d u_{0}}{d x}=N_{x x}^{T}+c_{1}
$$

Substituting $N_{x x}^{T}=E A \alpha_{x x} T^{0}$

$$
E A u_{0}(x)=E A \alpha_{x x} T^{0} x+c_{1} x+c_{2}
$$

Using boundary condition $u_{0}(0)=u_{0}(L)=0$ we obtain $c_{2}=0$ and $c_{1}=-E A \alpha_{x x} T^{0}$

$$
\therefore u_{0}(x)=0
$$

\section{$>$ Calculating Maximum Deflection (at center)}

Maximum deflection occurs at the center of beam ( i.e. $x=\frac{L}{2}=4$ in.)

$\therefore w_{0}\left(\frac{L}{2}\right)=-\frac{\left(8 \times 10^{-6}\right)(-100)\left(8^{2}\right)}{2}\left(\frac{4^{2}}{8^{2}}-\frac{4}{8}\right)=-0.0064$ in. (upward direction)

Note : Above deflection is same as the deflection from the finite element analysis. 
Calculating Stresses $\left(\sigma_{x x_{-} \text {top surface }}, \sigma_{x x_{-} \text {bottom surface }}\right)$

To calculate stresses, stress-strain and stress-displacement relation shown in Eq. (A.6)and (A.8) can be used. Since the displacement functions (i.e. $u_{0}, w_{0}$ ) are determined in previous section, it is convenient to calculate stresses using the stress-displacement relation in Eq. (A.8).

$$
\sigma_{x x}=E_{x x}\left(\frac{d u_{0}}{d x}-z \frac{d^{2} w_{0}}{d x^{2}}-\alpha_{x x} \Delta T\right)
$$

Substituting $\Delta T=T^{0}+z T^{1}$

$$
\sigma_{x x}=E_{x x}\left(\frac{d u_{0}}{d x}-z \frac{d^{2} w_{0}}{d x^{2}}-\alpha_{x x} T^{0}-z \alpha_{x x} T^{1}\right)
$$

$\frac{d u_{0}}{d x}=0$ because the displacement $\left(u_{0}\right)$ is zero (simply supported boundary). Substituting $w_{0}(x)=-\frac{\alpha_{x x} T^{1} L}{2}\left(\frac{x^{2}}{L^{2}}-\frac{x}{L}\right)$ from Eq. (A.23) into $z \frac{d^{2} w_{0}}{d x}$, we have $z \frac{d^{2} w_{0}}{d x}=-z \alpha_{x x} T^{1}$. Substituting $\frac{d u_{0}}{d x}=0, z \frac{d^{2} w_{0}}{d x}=-z \alpha_{x x} T^{1}$ into the above equation, we obtain

$$
\begin{aligned}
\sigma_{x x} & =E_{x x}\left[0+z \alpha_{x x} T^{1}-\alpha_{x x} T^{0}-z \alpha_{x x} T^{1}\right] \\
& =-E_{x x} \alpha_{x x} T^{0} \\
& =-\left(1.2 \times 10^{6}\right)\left(8 \times 10^{-6}\right)(40) \\
& =-384 \mathrm{psi} .
\end{aligned}
$$

Note that the top stress is equal to bottom stress because bending effect disappears in the stress function but axial effect still appears in the stress function (i.e. $\sigma_{x x}=-E \alpha_{x x} T^{0}$ ) which only created uniform stress along the depth. 


\section{Calculating Strain}

The strain-displacement relation in Eq. (A.2) will be used to compute strain.

$$
\begin{aligned}
\varepsilon_{x x} & =\frac{\partial u_{0}}{\partial x}-z \frac{\partial^{2} w_{0}}{\partial x^{2}} \\
& =0+z \alpha_{x x} T^{1} \quad\left(\text { Note } u_{0}=0\right) \\
& =\left(8 \times 10^{-6}\right)(-100) z \\
& =-8 \times 10^{-4} z \\
\therefore \varepsilon_{x x_{-} \text {top surface }}=-8 \times 10^{-4}(-0.4)=320 \mu \varepsilon & \\
\therefore \varepsilon_{x x_{-} \text {bottom surface }}=-8 \times 10^{-4}(0.4)=-320 \mu \varepsilon &
\end{aligned}
$$

\section{$>$ Comparison between analytical (beam theory) and FEM results}

\begin{tabular}{|l|c|l|}
\hline @ Center of a Beam & Beam Theory & FEM \\
\hline$w_{0}($ in. $)$ & -0.0064 & -0.0064 \\
\hline$\sigma_{x x_{-} \text {Top Surface }}$ (psi.) & -384 & -325 \\
\hline$\sigma_{x x_{-} \text {Bottom Surface }}(\mathrm{psi})$. & -384 & -325 \\
\hline$\varepsilon_{x x_{-} \text {Top Surface }}(\mu \varepsilon)$ & 320 & 370 \\
\hline$\varepsilon_{x x_{-} \text {Bottom Surface }}(\mu \varepsilon)$ & -320 & -270 \\
\hline
\end{tabular}

Table A.3: Comparison Results of Beam Theory and FEM for Case 2.

Note : Difference between analytical (beam theory) and FEM results occurred since simply supported boundary for FEM solid element and beam theory are not identical (Rotational degree of freedom is not exist in FEM solid element.). 
Case 3 Beam with simply supported ends (Note : $u_{0}(0)=0$ and $u_{0}(L) \neq 0$, a roller).

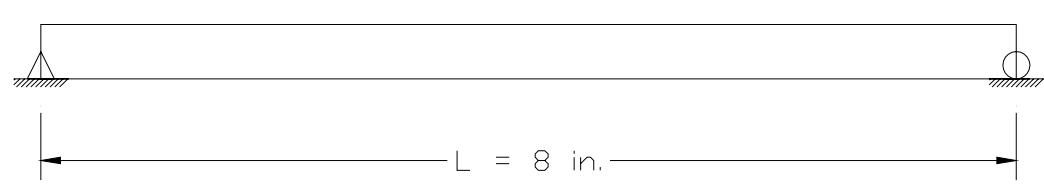

\section{Maximum Deflection ( at center)}

Deflection in this case is the same as that in case 2 because required boundary conditions (i.e. $w_{0}=0$ and $M_{x x}=0$ at $x=0$ and $\mathrm{L}$ ) for deflection analysis are identical. Axial displacement $\left(u_{0}\right)$ is not zero because a roller support allows a beam to expand freely in horizontal direction (i.e. Boundary condition $u_{0}(0)=0$ and $\left.u_{0}(L)=\alpha_{x x} T^{0} L\right)$.

Using boundary conditions $u_{0}(0)=0$ and $u_{0}(L)=\alpha_{x x} T^{0} L$, we obtain $c_{2}=0$ and $c_{1}=\alpha_{x x} T^{0}(1-E A)$ from Eq. (A.24)

$$
\therefore u_{0}(x)=\alpha_{x x} T^{0} x
$$

\section{$>$ Calculating Stresses $\left(\sigma_{x x_{-} \text {top surface }}, \sigma_{x x_{-} \text {bottom surface }}\right)$}

The stress-displacement relation of a beam can be defined as ( Refer to Eq. (A.26))

$$
\sigma_{x x}=E_{x x}\left(\frac{d u_{0}}{d x}-z \frac{d^{2} w_{0}}{d x^{2}}-\alpha_{x x} T^{0}-z \alpha_{x x} T^{1}\right)
$$

Substituting $u_{0}(x)=\alpha_{x x} T^{0} x$ into $\frac{d u_{0}(x)}{d x}$ we obtain $\frac{d u_{0}(x)}{d x}=\alpha_{x x} T^{0}$ and Substituting $w_{0}(x)=-\frac{\alpha_{x x} T^{1} L}{2}\left(\frac{x^{2}}{L^{2}}-\frac{x}{L}\right) \quad$ from Eq. (A.23) into $z \frac{d^{2} w_{0}}{d x}$, we have $z \frac{d^{2} w_{0}}{d x}=-z \alpha_{x x} T^{1}$ Substituting $\frac{d u_{0}(x)}{d x}=\alpha_{x x} T^{0}, z \frac{d^{2} w_{0}}{d x}=-z \alpha_{x x} T^{1}$ into the above equation, we obtain 


$$
\begin{aligned}
\sigma_{x x} & =E_{x x}\left(\alpha_{x x} T^{0}+z \alpha_{x x} T^{1}-\alpha_{x x} T^{0}-z \alpha_{x x} T^{1}\right) \\
& =0
\end{aligned}
$$

\section{Calculating Strain}

The strain-displacement relation in Eq. (A.2) will be used for the strain calculation.

$$
\begin{aligned}
\varepsilon_{x x} & =\frac{\partial u_{0}}{\partial x}-z \frac{\partial^{2} w_{0}}{\partial x^{2}} \\
& =\alpha_{x x} T^{0}+z \alpha_{x x} T^{1} \\
& =\alpha_{x x}\left(T^{0}+z T^{1}\right) \\
& =\left(8 x 10^{-6}\right)(40-100 z) \\
\therefore \varepsilon_{x x_{-} \text {top surface }}=-8 \times 10^{-6}(40-100(-0.4)) & =640 \mu \varepsilon \\
\therefore \varepsilon_{x x_{-} \text {bottom surface }}=-8 \times 10^{-6}(40-100(0.4)) & =0 \mu \varepsilon
\end{aligned}
$$

\section{Comparison between analytical (beam theory) and FEM results}

\begin{tabular}{|l|c|c|}
\hline @ Center of a Beam & Beam Theory & FEM \\
\hline$w_{0}$ (in.) & -0.0064 & -0.0064 \\
\hline$\sigma_{x x_{-} \text {Top Surface }}$ (psi.) & 0 & 0 \\
\hline$\sigma_{x x_{-} \text {Bottom Surface }}(\mathrm{psi})$. & 0 & 0 \\
\hline$\varepsilon_{x x_{-} \text {Top Surface }}(\mu \varepsilon)$ & 640 & 640 \\
\hline$\varepsilon_{x x_{-} \text {Bottom Surface }}(\mu \varepsilon)$ & 0 & 0 \\
\hline
\end{tabular}

Table A.4: Comparison Results of Beam Theory and FEM for Case 3. 


\section{A.2 Basic thermal analysis for Orthotropic Plate}

The basic mechanical relation with temperature effect for orthotropic plate is presented in this section.

\section{A.2.1 Strain-displacement relation (Kinematic)}

Kinematics is a study of the geometric changes or deformation in a body without considering forces causing such deformation. Kinematic shows a relationship of strain and displacement of elastic body as in Eq. (A.27) in Cartesian component form

$$
\varepsilon_{i j}=\frac{1}{2}\left(\frac{\partial u_{i}}{\partial x_{j}}+\frac{\partial u_{j}}{\partial x_{i}}\right)
$$

Using notation $x_{1}=x, x_{2}=y$ and $x_{3}=z$ and let $\left(u_{1}, u_{2}, u_{3}\right)=(u, v, w)$ as displacements along $(x, y, z)$, strain components in Eq. (A.27) become

$$
\left.\begin{array}{c}
\varepsilon_{x x}=\frac{\partial u}{\partial x}, \quad \varepsilon_{y y}=\frac{\partial v}{\partial y}, \quad \varepsilon_{z z}=\frac{\partial w}{\partial z} \\
\varepsilon_{x y}=\frac{1}{2}\left(\frac{\partial u}{\partial y}+\frac{\partial v}{\partial x}\right) \\
\varepsilon_{x z}=\frac{1}{2}\left(\frac{\partial u}{\partial z}+\frac{\partial w}{\partial x}\right) \\
\varepsilon_{y z}=\frac{1}{2}\left(\frac{\partial v}{\partial z}+\frac{\partial w}{\partial y}\right)
\end{array}\right\}
$$

Kenematic relations in Eq. (A.28) and (A.29) are used in three dimensional solid problem. In this section, we focus on 2-D orthotropic element (i.e. plate). The displacement and strain of an orthotropic plate as mentioned in Eqs. (A.28) and (A.29) can be modified or eliminated based on Kirchhoff hypothesis. Kirchhoff hypothesis (See Figure A.4) has the following assumptions. 

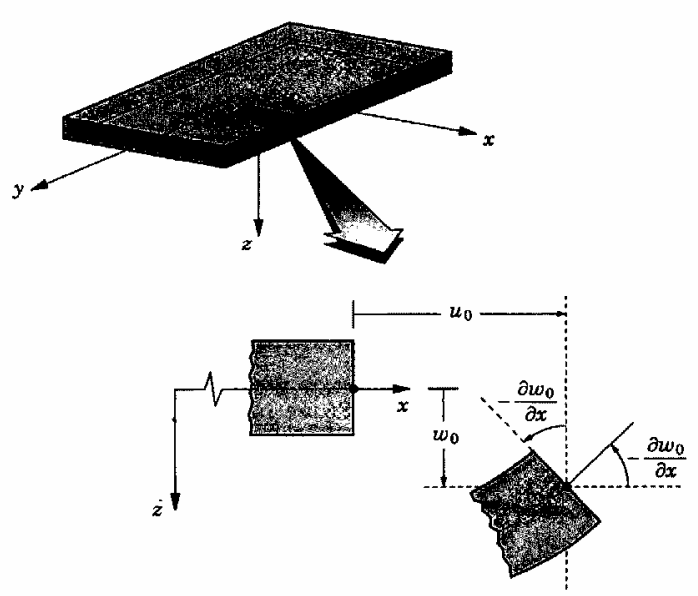

Figure A.4: Undeformed and Deformed Geometries of a Plate (Reddy 1999).

1. The transverse normals along thickness do not experience elongation. This implies that thickness normal strain is zero $\left(\varepsilon_{z z}=\frac{\partial w}{\partial z}=0\right)$. This also implies that $w$ is independent of $z$.

2. Straight lines perpendicular to the mid-surface remain straight and perpendicular to the mid-surface after deformation. This results in zero transverse shear strains $\left(\varepsilon_{x z}=\varepsilon_{y z}=0\right)$.

$$
\varepsilon_{x z}=\frac{1}{2}\left(\frac{\partial u}{\partial z}+\frac{\partial w}{\partial x}\right)=0 \text { and } \varepsilon_{y z}=\frac{1}{2}\left(\frac{\partial v}{\partial z}+\frac{\partial w}{\partial y}\right)=0
$$

The Kirchhoff hypothesis implies the following form of displacement field

$$
\begin{aligned}
& u(x, y, z)=u_{0}(x, y)-z \frac{\partial w_{0}(x, y)}{\partial x} \\
& v(x, y, z)=v_{0}(x, y)-z \frac{\partial w_{0}(x, y)}{\partial y} \\
& w(x, y, z)=w_{0}(x, y)
\end{aligned}
$$


where $\left(u_{0}, v_{0}, w_{0}\right)$ denote displacements of mid-surface of a plate in $(x, y, z)$ coordinate directions. Note that $\left(u_{0}, v_{0}\right)$ are associated with extensional deformation of the plate while $w_{0}$ denotes the bending deflection.

Substituting Eq.(A.30) into Eqs. (A.28) and (A.29), we obtain the linear strain-displacement relation as (Ref. Reddy, 1999)

$$
\begin{aligned}
\varepsilon_{x x} & =\frac{\partial u_{0}}{\partial x}-z \frac{\partial^{2} w_{0}}{\partial x^{2}} \\
\varepsilon_{y y} & =\frac{\partial v_{0}}{\partial y}-z \frac{\partial^{2} w_{0}}{\partial y^{2}} \\
\varepsilon_{x y} & =\frac{1}{2}\left(\frac{\partial u_{0}}{\partial y}+\frac{\partial v_{0}}{\partial x}-2 z \frac{\partial^{2} w_{0}}{\partial x \partial y}\right) \\
\varepsilon_{x z} & =\varepsilon_{y z}=\varepsilon_{z z}=0
\end{aligned}
$$

Note : Engineering shear strain $\left(\gamma_{x y}\right)$ is equal to $2 \varepsilon_{x y}$ (i.e. $\left.\sigma_{x y}=G_{x y} \gamma_{x y}\right)$.

Since the transverse strains $\left(\varepsilon_{x z}, \varepsilon_{y z}\right.$ and $\left.\varepsilon_{z z}\right)$ are identical to zero in the classical plate theory, linear strains in Eq.(A.31) can be reduced as

$$
\left\{\begin{array}{l}
\varepsilon_{x x} \\
\varepsilon_{y y} \\
\gamma_{x y}
\end{array}\right\}=\left\{\begin{array}{c}
\varepsilon_{x x}^{0} \\
\varepsilon_{y y}^{0} \\
\gamma_{x y}^{0}
\end{array}\right\}+z\left\{\begin{array}{c}
\varepsilon_{x x}^{1} \\
\varepsilon_{y y}^{1} \\
\gamma_{x y}^{1}
\end{array}\right\}
$$

where $\left(\varepsilon_{x x}^{0}, \varepsilon_{y y}^{0}, \gamma_{x y}^{0}\right)$ are the membrane strains, and $\left(\varepsilon_{x x}^{1}, \varepsilon_{y y}^{1}, \gamma_{x y}^{1}\right)$ are bending strains (or curvatures). Both membrane and bending strains are defined as (Reddy, 1999)

$$
\left\{\begin{array}{c}
\varepsilon_{x x}^{0} \\
\varepsilon_{y y}^{0} \\
\gamma_{x y}^{0}
\end{array}\right\}=\left\{\begin{array}{c}
\frac{\partial u_{0}}{\partial x} \\
\frac{\partial v_{0}}{\partial y} \\
\frac{\partial u_{0}}{\partial y}+\frac{\partial v_{0}}{\partial x}
\end{array}\right\} \quad \text { and } \quad\left\{\begin{array}{c}
\varepsilon_{x x}^{1} \\
\varepsilon_{y y}^{1} \\
\gamma_{x y}^{1}
\end{array}\right\}=\left\{\begin{array}{c}
-\frac{\partial^{2} w_{0}}{\partial x^{2}} \\
-\frac{\partial^{2} w_{0}}{\partial y^{2}} \\
-2 \frac{\partial^{2} w_{0}}{\partial x \partial y}
\end{array}\right\}
$$




\section{A.2.2 Stress-strain relation in orthotropic plate (Constitutive Equation)}

The generalized Hooke's law is defined as

$$
\left\{\begin{array}{c}
\sigma_{x x} \\
\sigma_{y y} \\
\sigma_{z z} \\
\sigma_{y z} \\
\sigma_{x z} \\
\sigma_{x y}
\end{array}\right\}=\left[\begin{array}{llllll}
C_{11} & C_{12} & C_{13} & C_{14} & C_{15} & C_{16} \\
C_{21} & C_{22} & C_{23} & C_{24} & C_{25} & C_{26} \\
C_{31} & C_{32} & C_{33} & C_{34} & C_{35} & C_{36} \\
C_{41} & C_{42} & C_{43} & C_{44} & C_{45} & C_{46} \\
C_{51} & C_{52} & C_{53} & C_{54} & C_{55} & C_{56} \\
C_{61} & C_{62} & C_{63} & C_{64} & C_{65} & C_{66}
\end{array}\right]\left\{\begin{array}{l}
\varepsilon_{x x} \\
\varepsilon_{y y} \\
\varepsilon_{z z} \\
\gamma_{y z} \\
\gamma_{x z} \\
\gamma_{x y}
\end{array}\right\}
$$

where $[C]$ is the stiffness matrix

Note $\left(\gamma_{y z}, \gamma_{x z}, \gamma_{x y}\right)$ are the engineering shear strain where $\left\{\begin{array}{l}\gamma_{y z} \\ \gamma_{x z} \\ \gamma_{x y}\end{array}\right\}=\left\{\begin{array}{l}2 \varepsilon_{y z} \\ 2 \varepsilon_{x z} \\ 2 \varepsilon_{x y}\end{array}\right\}$

\section{Stress-strain relation for orthotropic material}

An orthotropic material has three planes of symmetry that coincide with the coordinate planes. Fiber-reinforced composite may be considered to be orthotropic material. When three mutually orthogonal planes of material symmetry exist, the number of stiffness coefficient $\left(C_{i j}\right)$ is reduced to 9 (out of 36 ). The stress-strain relation for orthotropic material can be defined as

$$
\left\{\begin{array}{l}
\sigma_{x x} \\
\sigma_{y y} \\
\sigma_{z z} \\
\sigma_{y z} \\
\sigma_{x z} \\
\sigma_{x y}
\end{array}\right\}=\left[\begin{array}{cccccc}
C_{11} & C_{12} & C_{13} & 0 & 0 & 0 \\
C_{12} & C_{22} & C_{23} & 0 & 0 & 0 \\
C_{13} & C_{23} & C_{33} & 0 & 0 & 0 \\
0 & 0 & 0 & C_{44} & 0 & 0 \\
0 & 0 & 0 & 0 & C_{55} & 0 \\
0 & 0 & 0 & 0 & 0 & C_{66}
\end{array}\right]\left\{\begin{array}{c}
\varepsilon_{x x} \\
\varepsilon_{y y} \\
\varepsilon_{z z} \\
\gamma_{y z} \\
\gamma_{x z} \\
\gamma_{x y}
\end{array}\right\}
$$

The strain-stress relation can be defined by inversing Eq. (A.35) 


$$
\left\{\begin{array}{l}
\varepsilon_{x x} \\
\varepsilon_{y y} \\
\varepsilon_{z z} \\
\gamma_{y z} \\
\gamma_{x z} \\
\gamma_{x y}
\end{array}\right\}=\left[\begin{array}{cccccc}
S_{11} & S_{12} & S_{13} & 0 & 0 & 0 \\
S_{12} & S_{22} & S_{23} & 0 & 0 & 0 \\
S_{13} & S_{23} & S_{33} & 0 & 0 & 0 \\
0 & 0 & 0 & S_{44} & 0 & 0 \\
0 & 0 & 0 & 0 & S_{55} & 0 \\
0 & 0 & 0 & 0 & 0 & S_{66}
\end{array}\right]\left\{\begin{array}{c}
\sigma_{x x} \\
\sigma_{y y} \\
\sigma_{z z} \\
\sigma_{y z} \\
\sigma_{x z} \\
\sigma_{x y}
\end{array}\right\}
$$

where $[S]$ is the compliance matrix and symmetric.

$$
\left\{\begin{array}{l}
\varepsilon_{x x} \\
\varepsilon_{y y} \\
\varepsilon_{z z} \\
\gamma_{y z} \\
\gamma_{x z} \\
\gamma_{x y}
\end{array}\right\}=\left[\begin{array}{cccccc}
\frac{1}{E_{x}} & \frac{-v_{y x}}{E_{y}} & \frac{-v_{z x}}{E_{z}} & 0 & 0 & 0 \\
\frac{-v_{x y}}{E_{x}} & \frac{1}{E_{y}} & \frac{-v_{z y}}{E_{z}} & 0 & 0 & 0 \\
\frac{-v_{x z}}{E_{x}} & \frac{-v_{y z}}{E_{y}} & \frac{1}{E_{z}} & 0 & 0 & 0 \\
0 & 0 & 0 & \frac{1}{G_{y z}} & 0 & 0 \\
0 & 0 & 0 & 0 & \frac{1}{G_{x z}} & 0 \\
0 & 0 & 0 & 0 & 0 & \frac{1}{G_{x y}}
\end{array}\right]\left\{\begin{array}{l}
\sigma_{x x} \\
\sigma_{y y} \\
\sigma_{z z} \\
\sigma_{y z} \\
\sigma_{x z} \\
\sigma_{x y}
\end{array}\right\}
$$

where $E_{x}, E_{y}, E_{z}$ are Young's moduli in $x, y$ and $z$ material directions, respectively.

$v_{i j}$ is Poisson's ratio, defined as the ratio of transverse strain in the $\mathrm{j}^{\text {th }}$ direction to the axial strain in the $\mathrm{i}^{\text {th }}$ direction when stressed in the $\mathrm{i}^{\text {th }}$ direction. $G_{x y}, G_{x z}$ and $G_{y z}$ are shear moduli in the $x-y, x-z$ and $y-z$ planes. Since the compliance matrix $[S]$ is a symmetric matrix, it implies that

$$
\frac{v_{x y}}{E_{x}}=\frac{v_{y x}}{E_{y}}, \frac{v_{x z}}{E_{x}}=\frac{v_{z x}}{E_{z}} \text { and } \frac{v_{y z}}{E_{y}}=\frac{v_{z y}}{E_{z}}
$$




\section{Stress-strain relation for orthotropic plate}

Through Kirchhoff hypothesis (plate theory), all three transverse strain components $\left(\varepsilon_{z z}, \gamma_{y z}, \gamma_{x z}\right)$ in Eq. (A.35) are identically zero or negligible. When all three transverse strains are identically zero, a problem can be defined as a plane strain of state. If all three transverse strain components $\left(\varepsilon_{z z}=\gamma_{y z}=\gamma_{x z}=0\right)$ are substituted into Eq. (A.35), we notice that $\sigma_{x z}=\sigma_{y z}=0$ but $\sigma_{x x}, \sigma_{y y}, \sigma_{x y}$ and $\sigma_{z z}$ are not zero. Since the stress $\sigma_{z z}$ does not appear in the virtual work statement and in the equation of motion for plate theory, the stress $\sigma_{z z}$ can be negligible. When all three stress components $\left(\sigma_{y z}, \sigma_{x z}, \sigma_{z z}\right)$ are neglected, a problem can be defined as a plane stress of state. Therefore, both plane strain and plane stress can be considered in the plate theory. As described above the stress-strain relation in Eq. (A.35) can be reduced as

$$
\left\{\begin{array}{l}
\sigma_{x x} \\
\sigma_{y y} \\
\sigma_{x y}
\end{array}\right\}=\left[\begin{array}{ccc}
Q_{11} & Q_{12} & 0 \\
Q_{12} & Q_{22} & 0 \\
0 & 0 & Q_{66}
\end{array}\right]\left\{\begin{array}{l}
\varepsilon_{x x} \\
\varepsilon_{y y} \\
\gamma_{x y}
\end{array}\right\}
$$

where $[Q]$ is called the plane stress-reduced stiffness matrix

$$
Q_{11}=\frac{E_{x}}{1-v_{x y} v_{y x}}, \quad Q_{12}=\frac{v_{x y} E_{y}}{1-v_{x y} v_{y x}}, \quad Q_{22}=\frac{E_{y}}{1-v_{x y} v_{y x}} \text { and } Q_{66}=G_{x y}
$$

Inversing Eq. (A.39), we obtains

$$
\left\{\begin{array}{l}
\varepsilon_{x x} \\
\varepsilon_{y y} \\
\gamma_{x y}
\end{array}\right\}=\left[\begin{array}{ccc}
\frac{1}{E_{x}} & \frac{-v_{y x}}{E_{y}} & 0 \\
\frac{-v_{x y}}{E_{x}} & \frac{1}{E_{y}} & 0 \\
0 & 0 & \frac{1}{G_{x y}}
\end{array}\right]\left\{\begin{array}{c}
\sigma_{x x} \\
\sigma_{y y} \\
\sigma_{x y}
\end{array}\right\}
$$




\section{Stress-strain relation for orthotropic plate under thermoelastic effect}

The stress-strain relation in Eq. (A.39) does not include thermoelastic effect. In this section the thermoelastic effect is included in the stress-strain relation (Eq. (A.41)).

$$
\left\{\begin{array}{c}
\sigma_{x x} \\
\sigma_{y y} \\
\sigma_{x y}
\end{array}\right\}=\left[\begin{array}{ccc}
Q_{11} & Q_{12} & 0 \\
Q_{12} & Q_{22} & 0 \\
0 & 0 & Q_{66}
\end{array}\right]\left\{\begin{array}{c}
\varepsilon_{x x}-\alpha_{x x} \Delta T \\
\varepsilon_{y y}-\alpha_{y y} \Delta T \\
\gamma_{x y}
\end{array}\right\}
$$

where $\alpha_{x x}, \alpha_{y y}$ are the coefficients of thermal expansion in $x$ and $y$ direction, respectively.

$\Delta T$ is the temperature increment from a reference temperature, $\Delta T=T-T_{r e f}$.

Note that $\alpha_{x y}=0$ for orthotropic materials.

\section{A.2.3 Stress-displacement relation in orthotropic plate}

In this section, stress-displacement relation is formulated by combining the stressstrain and strain-displacement relations. The stress-strain and strain-displacement relations are expressed in Eq. (A.41) and (A.32), respectively. Substituting Eq. (A.32) into Eq. (A.41), we obtain

$$
\left\{\begin{array}{l}
\sigma_{x x} \\
\sigma_{y y} \\
\sigma_{x y}
\end{array}\right\}=\left[\begin{array}{ccc}
Q_{11} & Q_{12} & 0 \\
Q_{12} & Q_{22} & 0 \\
0 & 0 & Q_{66}
\end{array}\right]\left\{\begin{array}{c}
\varepsilon_{x x}^{0}+z \varepsilon_{x x}^{1}-\alpha_{x x} \Delta T \\
\varepsilon_{y y}^{0}+z \varepsilon_{y y}^{1}-\alpha_{y y} \Delta T \\
\gamma_{x y}^{0}+z \gamma_{x y}^{1}
\end{array}\right\}
$$

Substituting Eq. (A.33) into Eq. (A.42), we obtain the stress-displacement relation as

$$
\left\{\begin{array}{l}
\sigma_{x x} \\
\sigma_{y y} \\
\sigma_{x y}
\end{array}\right\}=\left[\begin{array}{ccc}
Q_{11} & Q_{12} & 0 \\
Q_{12} & Q_{22} & 0 \\
0 & 0 & Q_{66}
\end{array}\right]\left\{\begin{array}{l}
\frac{\partial u_{0}}{\partial x}-z \frac{\partial^{2} w_{0}}{\partial x^{2}}-\alpha_{x x} \Delta T \\
\frac{\partial v_{0}}{\partial y}-z \frac{\partial^{2} w_{0}}{\partial y^{2}}-\alpha_{y y} \Delta T \\
\frac{\partial u_{0}}{\partial y}+\frac{\partial v_{0}}{\partial y}-2 z \frac{\partial^{2} w_{0}}{\partial x \partial y}
\end{array}\right\}
$$


Stress components in Eq. (A.42) or (A.43) can be divided into three terms such as stresses due to membrane, bending and temperature changes.

\section{Stresses due to membrane strain}

According to Eq. (A.42), stresses due to membrane strain can be defined as

$$
\left\{\begin{array}{l}
\sigma_{x x_{-} \text {membrane }} \\
\sigma_{y y_{-} \text {membrane }} \\
\sigma_{x y_{-} \text {membrane }}
\end{array}\right\}=\left[\begin{array}{ccc}
Q_{11} & Q_{12} & 0 \\
Q_{21} & Q_{22} & 0 \\
0 & 0 & Q_{66}
\end{array}\right]\left\{\begin{array}{c}
\varepsilon_{x x}^{0} \\
\varepsilon_{y y}^{0} \\
\gamma_{x y}^{0}
\end{array}\right\}
$$

Applying the strain-displacement relation into Eq. (A.44) we obtain

$$
\left\{\begin{array}{c}
\sigma_{x x_{-} \text {membrane }} \\
\sigma_{y y_{-} \text {membrane }} \\
\sigma_{x y_{-} \text {membrane }}
\end{array}\right\}=\left[\begin{array}{ccc}
Q_{11} & Q_{12} & 0 \\
Q_{12} & Q_{22} & 0 \\
0 & 0 & Q_{66}
\end{array}\right]\left\{\begin{array}{c}
\frac{\partial u_{0}}{\partial x} \\
\frac{\partial v_{0}}{\partial y} \\
\frac{\partial u_{0}}{\partial y}+\frac{\partial v_{0}}{\partial y}
\end{array}\right\}
$$

\section{Stresses due to bending strain}

According to Eq. (A.42), stresses due to bending strain can be defined as

$$
\left\{\begin{array}{l}
\sigma_{x x_{-} \text {bending }} \\
\sigma_{y y_{-} \text {bending }} \\
\sigma_{x y_{-} \text {bending }}
\end{array}\right\}=\left[\begin{array}{ccc}
Q_{11} & Q_{12} & 0 \\
Q_{12} & Q_{22} & 0 \\
0 & 0 & Q_{66}
\end{array}\right]\left\{\begin{array}{c}
z \varepsilon_{x x}^{1} \\
z \varepsilon_{y y}^{1} \\
z \gamma_{x y}^{1}
\end{array}\right\}
$$

Applying the strain-displacement relation into Eq. (A.46) we obtains 


$$
\left\{\begin{array}{l}
\sigma_{x x_{\text {_bending }}} \\
\sigma_{y y \_ \text {bending }} \\
\sigma_{x y \_ \text {bending }}
\end{array}\right\}=\left[\begin{array}{ccc}
Q_{11} & Q_{12} & 0 \\
Q_{12} & Q_{22} & 0 \\
0 & 0 & Q_{66}
\end{array}\right]\left\{\begin{array}{l}
-z \frac{\partial^{2} w_{0}}{\partial x^{2}} \\
-z \frac{\partial^{2} w_{0}}{\partial y^{2}} \\
-2 z \frac{\partial^{2} w_{0}}{\partial x \partial y}
\end{array}\right\}
$$

\section{Stresses due to temperature change}

According to Eq. (A.42), stresses due to thermal strain can be defined as

$$
\left\{\begin{array}{l}
\sigma_{x x_{-} \text {thermal }} \\
\sigma_{y y_{\text {_thermal }}} \\
\sigma_{x y_{\text {_tthrmal }}}
\end{array}\right\}=\left[\begin{array}{ccc}
Q_{11} & Q_{12} & 0 \\
Q_{12} & Q_{22} & 0 \\
0 & 0 & Q_{66}
\end{array}\right]\left\{\begin{array}{c}
-\alpha_{x x} \Delta T \\
-\alpha_{y y} \Delta T \\
0
\end{array}\right\}
$$

Combining all three terms of stress resultant, we can rewrite the stress resultant in an alternative form as

$$
\left\{\begin{array}{c}
\sigma_{x x} \\
\sigma_{y y} \\
\sigma_{x y}
\end{array}\right\}=\left\{\begin{array}{c}
\sigma_{x x_{-} \text {membrane }}+\sigma_{x x_{-} \text {bending }}+\sigma_{x x_{-} \text {thermal }} \\
\sigma_{y y_{-} \text {membrane }}+\sigma_{y y_{-} \text {bending }}+\sigma_{y y_{-} \text {thermal }} \\
\sigma_{x y_{-} \text {membrane }}+\sigma_{x y_{-} \text {bending }}
\end{array}\right\}
$$

It is important to understand that in order to find the resultant stress, all three terms of stresses (i.e. stresses due to membrane, bending and thermal) must be considered together as shown in Eq. (A.42) or (A.43) or (A.49). In the previous section, the stress resultant in a rod is calculated based on the stress-strain relation. In this section, the stress resultant of a rod will be calculated based on the stress-displacement relation. Since a rod is treated as a 1-D isotropic element, the stress component $\left(\sigma_{x x}\right)$ in $x$ direction will be only considered. Therefore, the stress-displacement relation for 1-D isotropic material can be defined as (Refer to Eq. (A.43) and (A.49))

$$
\sigma_{x x}=\sigma_{x x_{-} \text {membrane }}+\sigma_{x x_{-} \text {bending }}+\sigma_{x x_{-} \text {thermal }}
$$




$$
=E_{x}\left(\frac{d u_{0}}{d x}-z \frac{d^{2} w_{0}}{d x^{2}}-\alpha_{x x} \Delta T\right)
$$

$\underline{\text { First Case }}$ : a rod subjected to uniform temperature increment $\left(T^{0}\right)$ with free ends

The transverse displacement $\left(w_{0}\right)$ is zero because there is no bending strain from temperature gradient ( i.e. $\sigma_{x x_{-} \text {bending }}=-E_{x} z \frac{d^{2} w_{0}}{d x^{2}}=0$ ). Therefore, Eq. (A.51) becomes

$$
\sigma_{x x}=E\left(\frac{d u_{0}}{d x}-\alpha_{x x} \Delta T\right)
$$

Since the rod can expand freely, the axial displacement $\left(u_{0}\right)$ is equal to $\alpha_{x x} T^{0} L$ where

$L$ is length of a rod ( i.e. $\frac{d u_{0}}{d x}=\frac{\Delta L}{L}=\frac{\alpha_{x x} T^{0} L}{L}=\alpha_{x x} T^{0}$ ). Substituting $\frac{d u_{0}}{d x}=\alpha_{x x} T^{0}$ and $\Delta T=T^{0}$ into Eq. (A.52) we obtain $\sigma_{x x}=E\left(\alpha_{x x} T^{0}-\alpha_{x x} T^{0}\right)=0$.

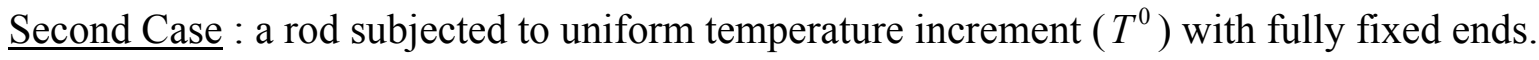

Since the rod is fully fixed and cannot expand, the axial and transverse displacement $\left(u_{0}\right.$ and $w_{0}$ ) is zero (i.e. $\left.\frac{d u_{0}}{d x}=\frac{d^{2} w_{0}}{d x^{2}}=0\right)$. Substituting $\frac{d u_{0}}{d x}=0$ into Eq. (A.52) we obtain $\sigma_{x x}=E\left(0-\alpha_{x x} T^{0}\right)=-E \alpha_{x x} T^{0}$

\section{A.2.4 Resultant forces and moments in othotropic plate}

The resultant forces and moments per unit width of orthotropic plate can be formulated by integrating stresses over the plate thickness $(h)$. Coordinate system is shown in Figure A.5. The free-body of axial forces and moment resultants is shown in Figure A.6. The 
resultant forces and moments in this section can be found in "Theory and Analysis of Elastic Plates", by Reddy 1999.

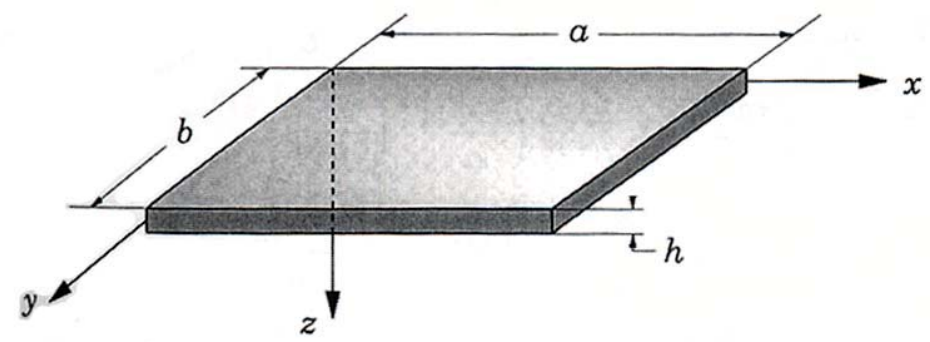

Figure A.5: Positive Directions of $\mathrm{x}, \mathrm{y}$ and $\mathrm{z}$ Axis (Ref. Reddy, 1999).

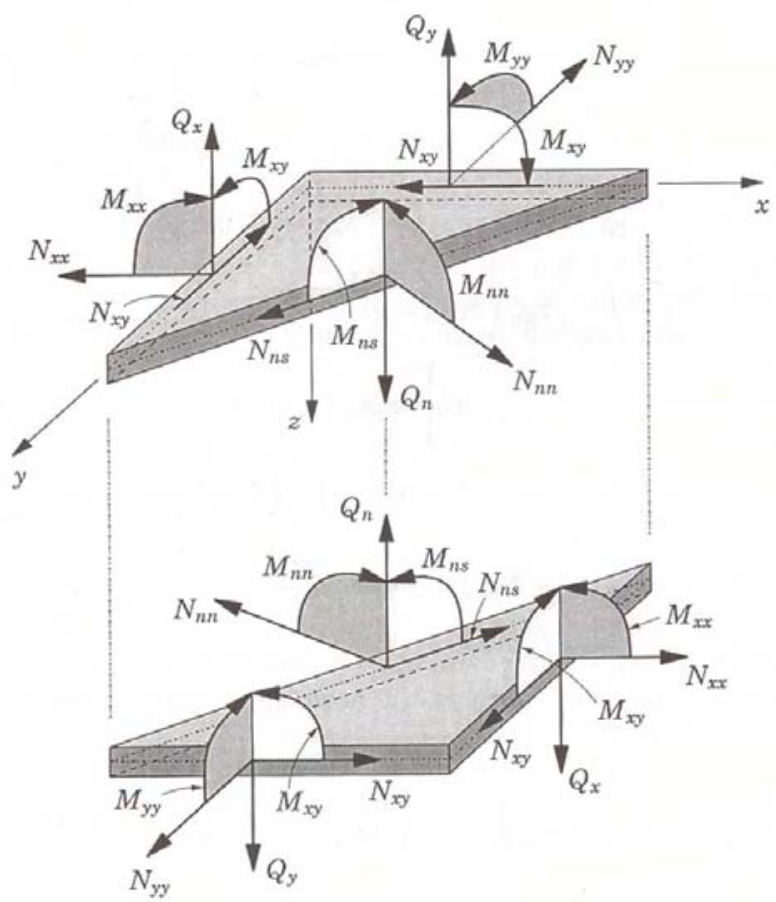

Figure A.6: Axial Forces and Moment Resultants on Plate (Ref. Reddy, 1999). 


\section{The axial forces per unit width}

$$
\left\{\begin{array}{c}
N_{x x} \\
N_{y y} \\
N_{x y}
\end{array}\right\}=\int_{-\frac{h}{2}}^{\frac{h}{2}}\left\{\begin{array}{c}
\sigma_{x x} \\
\sigma_{y y} \\
\sigma_{x y}
\end{array}\right\} d z
$$

Substituting Eq. (A.42) into Eq. (A.53)

$$
\begin{gathered}
\left\{\begin{array}{l}
N_{x x} \\
N_{y y} \\
N_{x y}
\end{array}\right\}=\int_{-\frac{h}{2}}^{\frac{h}{2}}\left[\begin{array}{ccc}
Q_{11} & Q_{12} & 0 \\
Q_{12} & Q_{22} & 0 \\
0 & 0 & Q_{66}
\end{array}\right]\left\{\begin{array}{c}
\varepsilon_{x x}^{0}+z \varepsilon_{x x}^{1}-\alpha_{x x} \Delta T \\
\left.\varepsilon_{y y}^{0}+z \varepsilon_{y y}^{1}-\alpha_{y y} \Delta T\right\} d z \\
\gamma_{x y}^{0}+z \gamma_{x y}^{1}
\end{array}\right\} \\
\left\{\begin{array}{c}
N_{x x} \\
N_{y y} \\
N_{x y}
\end{array}\right\}=\left[\begin{array}{ccc}
A_{11} & A_{12} & 0 \\
A_{12} & A_{22} & 0 \\
0 & 0 & A_{66}
\end{array}\right]\left\{\begin{array}{c}
\varepsilon_{x x}^{0} \\
\varepsilon_{y y}^{0} \\
\gamma_{x y}^{0}
\end{array}\right\}-\left\{\begin{array}{c}
N_{x x}^{T} \\
N_{y y}^{T} \\
0
\end{array}\right\}
\end{gathered}
$$

Substituting Eq. (A.33) into Eq. (A.55)

$$
\left\{\begin{array}{l}
N_{x x} \\
N_{y y} \\
N_{x y}
\end{array}\right\}=\left[\begin{array}{ccc}
A_{11} & A_{12} & 0 \\
A_{12} & A_{22} & 0 \\
0 & 0 & A_{66}
\end{array}\right]\left\{\begin{array}{c}
\frac{\partial u_{0}}{\partial x} \\
\frac{\partial v_{0}}{\partial y} \\
\frac{\partial u_{0}}{\partial y}+\frac{\partial v_{0}}{\partial x}
\end{array}\right\}-\left\{\begin{array}{c}
N_{x x}^{T} \\
N_{y y}^{T} \\
0
\end{array}\right\}
$$

where $A_{i j}=\int_{-\frac{h}{2}}^{\frac{h}{2}} Q_{i j} d z=Q_{i j} h$ are extensional stiffnesses and $\left(N_{x x}^{T}, N_{y y}^{T}\right)$ are thermal axial loads.

$$
\left\{\begin{array}{c}
N_{x x}^{T} \\
N_{y y}^{T}
\end{array}\right\}=\int_{-\frac{h}{2}}^{\frac{h}{2}}\left[\begin{array}{ll}
Q_{11} & Q_{12} \\
Q_{12} & Q_{22}
\end{array}\right]\left\{\begin{array}{l}
\alpha_{x x} \Delta T \\
\alpha_{y y} \Delta T
\end{array}\right\} d z
$$

Note that $N_{x y}^{T}$ is zero for orthotropic plate ( since $\alpha_{x y}=0$ ). 


\section{The moment resultants per unit width}

$$
\left\{\begin{array}{l}
M_{x x} \\
M_{y y} \\
M_{x y}
\end{array}\right\}=\int_{-\frac{h}{2}}^{\frac{h}{2}}\left\{\begin{array}{l}
\sigma_{x x} \\
\sigma_{y y} \\
\sigma_{x y}
\end{array}\right\} z d z
$$

Substituting Eq. (A.42) into Eq. (A.58)

$$
\begin{gathered}
\left\{\begin{array}{l}
M_{x x} \\
M_{y y} \\
M_{x y}
\end{array}\right\}=\int_{-\frac{h}{2}}^{\frac{h}{2}}\left[\begin{array}{ccc}
Q_{11} & Q_{12} & 0 \\
Q_{12} & Q_{22} & 0 \\
0 & 0 & Q_{66}
\end{array}\right]\left\{\begin{array}{c}
\varepsilon_{x x}^{0}+z \varepsilon_{x x}^{1}-\alpha_{x x} \Delta T \\
\varepsilon_{y y}^{0}+z \varepsilon_{y y}^{1}-\alpha_{y y} \Delta T \\
\gamma_{x y}^{0}+z \gamma_{x y}^{1}
\end{array}\right\} z d z \\
\left\{\begin{array}{l}
M_{x x} \\
M_{y y} \\
M_{x y}
\end{array}\right\}=\left[\begin{array}{ccc}
D_{11} & D_{12} & 0 \\
D_{12} & D_{22} & 0 \\
0 & 0 & D_{66}
\end{array}\right]\left\{\begin{array}{c}
\varepsilon_{x x}^{1} \\
\varepsilon_{y y}^{1} \\
\gamma_{x y}^{1}
\end{array}\right\}-\left\{\begin{array}{c}
M_{x x}^{T} \\
M_{y y}^{T} \\
0
\end{array}\right\}
\end{gathered}
$$

Substituting Eq. (A.33) into Eq. (A.60)

$$
\left\{\begin{array}{l}
M_{x x} \\
M_{y y} \\
M_{x y}
\end{array}\right\}=-\left[\begin{array}{ccc}
D_{11} & D_{12} & 0 \\
D_{12} & D_{22} & 0 \\
0 & 0 & D_{66}
\end{array}\right]\left\{\begin{array}{l}
\frac{\partial^{2} w_{0}}{\partial x^{2}} \\
\frac{\partial^{2} w_{0}}{\partial y^{2}} \\
2 \frac{\partial^{2} w_{0}}{\partial x \partial y}
\end{array}\right\}-\left\{\begin{array}{c}
M_{x x}^{T} \\
M_{y y}^{T} \\
0
\end{array}\right\}
$$

where $D_{i j}=\int_{-\frac{h}{2}}^{\frac{h}{2}} Q_{i j} z^{2} d z=Q_{i j} \frac{h^{3}}{12}$ are bending stiffnesses, and $\left(M_{x x}^{T}, M_{y y}^{T}\right)$ are thermal moment load.

$$
\left\{\begin{array}{l}
M_{x x}^{T} \\
M_{y y}^{T}
\end{array}\right\}=\int_{-\frac{h}{2}}^{\frac{h}{2}}\left[\begin{array}{ll}
Q_{11} & Q_{12} \\
Q_{12} & Q_{22}
\end{array}\right]\left\{\begin{array}{l}
\alpha_{x x} \Delta T \\
\alpha_{y y} \Delta T
\end{array}\right\} z d z
$$

Note that $M_{x y}^{T}$ is zero for orthotropic plate (since $\alpha_{x y}=0$ ). 


\section{A.2.5 Temperature Increment $(\Delta T(z))$ along the Depth}

Assuming that the temperature increment is uniform over the horizontal plane of a plate, temperature increment $(\Delta T(\mathrm{z}))$ along the depth $(z)$ can be defined as

$$
\Delta T(z)=T(z)-T_{r e f}
$$

where $T(z) \quad$ is the temperature function of $\mathrm{z} . T_{\text {ref }}$ is a reference temperature of FRP deck plate and $h$ is the depth of FRP deck plate.

Since temperature change $(\Delta T(z))$ is assumed to be linear along the depth $(z)$, Eq. (A.63) can be written in the form of linear function (i.e $y=a x+b)$ as :

$$
\Delta T(z)=T^{0}+T^{1} z
$$

where $T^{0}=\frac{\Delta T_{\text {top }}+\Delta T_{\text {bottom }}}{2} \quad($ A.65)

$$
T^{1}=-\left(\frac{\Delta T_{\text {top }}-\Delta T_{\text {bottom }}}{h}\right)
$$

Note : $\Delta T_{\text {top }}$ and $\Delta T_{\text {bottom }}$ are temperature changes on top and bottom surface of FRP deck, respectively. $\mathrm{z}$ is positive in downward direction. Therefore, $\mathrm{z}=\frac{h}{2}$ at the bottom surface of deck plate and $\mathrm{z}=-\frac{h}{2}$ at the top surface, while $\mathrm{z}=0$ at the middle of FRP deck plate. The profile of the temperature increment along the depth can be drawn as : 


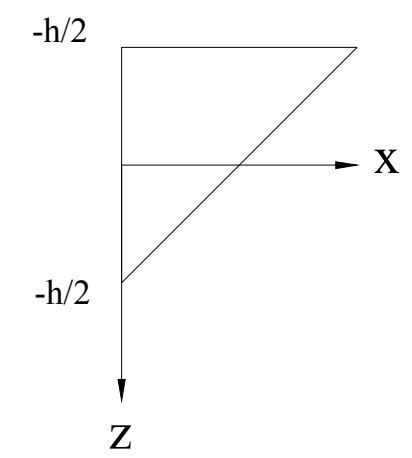

$\Delta T(z)$

$$
=
$$

(Axial Effect)

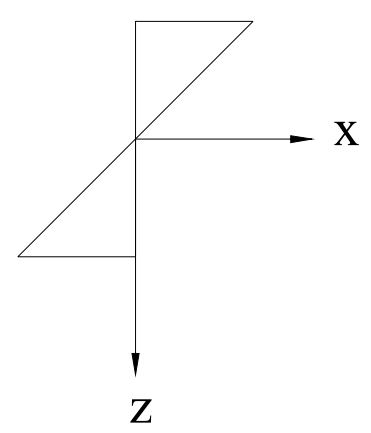

$T^{1} z$

According to Eq. (A.64), the temperature increment $(\Delta T(z))$ is divided into two terms (i.e. $T^{0}$ and $T^{1} z$ ). The first term, $T^{0}$, is a uniform temperature increment. The $T^{0}$ term creates only the thermal axial forces $\left(N_{x x}^{T}, N_{y y}^{T}\right)$. The second term, $T^{1} z$, is a gradient temperature increment and is zero at mid-plane $(z=0)$. The $T^{1} z$ term creates only the thermal bending moments $\left(M_{x x}^{T}, M_{y y}^{T}\right)$. 


\section{Appendix B}

\section{Derivation of Coefficients $M_{n}^{T_{x x}}(x)$ and $M_{n}^{T_{y y}}(x)$ for thermal load moment}

The objective of this appendix is to present the derivation of coefficients in fourier series which used in thermal load.

The thermal load, $M_{n}^{T_{x x}}(x)$, can be expanded to sine series as shown in (B.1) (Ref. Szilard, 1974)

$$
M_{x x}^{T}(x, y)=\sum_{n=1}^{\infty} M_{n}^{T_{x x}}(x) \sin \beta_{n} y
$$

Multiplying $\sin \frac{j \pi y}{b}$ and integrating from 0 to $\mathrm{b}$ on both sides of (B.1)

$$
\int_{0}^{b} M_{x x}^{T}(x, y) \sin \frac{j \pi y}{b} d y=\sum_{n=1}^{\infty} \int_{0}^{b} M_{n}^{T_{x x}} \sin \frac{n \pi y}{b} \sin \frac{j \pi y}{b} d y
$$

Note

$$
\int_{0}^{b} \sin \frac{n \pi y}{b} \sin \frac{j \pi y}{b} d y= \begin{cases}0 & \text { when } \mathrm{n} \neq \mathrm{j} \\ \frac{\mathrm{b}}{2} & \text { when } \mathrm{n}=\mathrm{j}\end{cases}
$$

From equations (B.2) and (B.3)

$$
M_{n}^{T_{x x}}(x)=\frac{2}{b} \int_{0}^{b} M_{x x}^{T}(x, y) \sin \frac{j \pi y}{b} d y
$$

For uniform thermal load (ie. uniform temperature on top and bottom of deck plate), we have a uniform thermal load as

where

$$
\begin{gathered}
M_{x x}^{T}(x, y)=M_{0}^{T_{x x}} \\
M_{0}^{T_{x x}}=-\left(D_{x x} \alpha_{x x}+D_{x y} \alpha_{y y}\right)\left(\frac{\Delta T_{\max }}{h}\right)
\end{gathered}
$$


Substituting (B.5) into (B.4), we obtain

$$
\begin{aligned}
M_{n}^{T_{x x}} & =\frac{2 M_{0}^{T_{x x}}}{b} \int_{0}^{b} \sin \frac{j \pi y}{b} d y \\
& =\frac{2 M_{0}^{T_{x x}}}{b} \frac{b}{j \pi}\left(-\cos \frac{j \pi y}{b}\right)_{0}^{b} \\
& =\frac{2 M_{0}^{T_{x x}}}{j \pi}(-\cos j \pi+1) \\
& =\frac{4 M_{0}^{T_{x x}}}{j \pi} \quad \text { for } j=1,3,5, \ldots
\end{aligned}
$$

Therefore

$$
\begin{aligned}
M_{n}^{T_{x x}} & =\frac{4 M_{0}^{T_{x x}}}{n \pi} \quad \text { for } n=1,3,5, \ldots \\
& =\frac{4\left(D_{x x} \alpha_{x x}+D_{x y} \alpha_{y y}\right)\left(\frac{\Delta T_{\max }}{h}\right)}{n \pi}
\end{aligned}
$$

Similarly,

$$
\begin{aligned}
M_{n}^{T_{y y}} & =\frac{4 M_{0}^{T_{y y}}}{n \pi} \quad \text { for } n=1,3,5, \ldots \\
& =-\frac{4\left(D_{x y} \alpha_{x x}+D_{y y} \alpha_{y y}\right)\left(\frac{\Delta T_{\max }}{h}\right)}{n \pi}
\end{aligned}
$$

\section{$\underline{\text { Reference: }}$}

- Szilard, R., Theory and Analysis of Plates. Classical and Numerical Methods, Prentice-Hall, Englewood Cliffs, NJ, 1974. 


\section{Appendix C}

\section{Laboratory Test Results for 8 in. FRP Bridge Deck}

Experimental data for 8 in. deep FRP bridge deck are presented in this appendix. Strain gage, TG sensor and LVDT location can be found in Figures 4.8 and 4.9.

\section{Test Case 8HS (Heating Test + SSFF Boundary )}

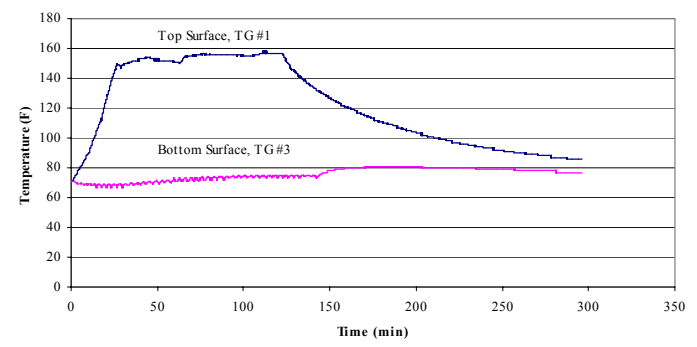

Figure C.1

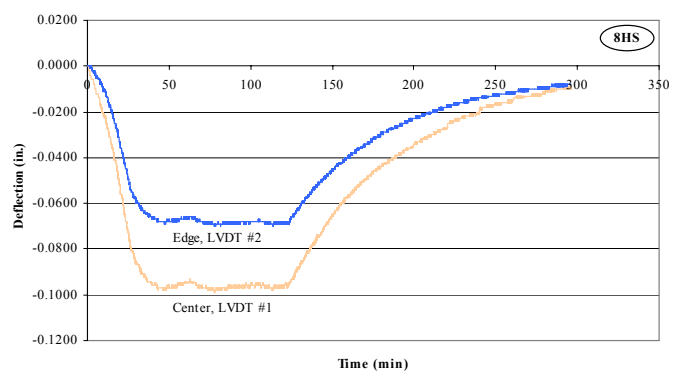

Figure C.3

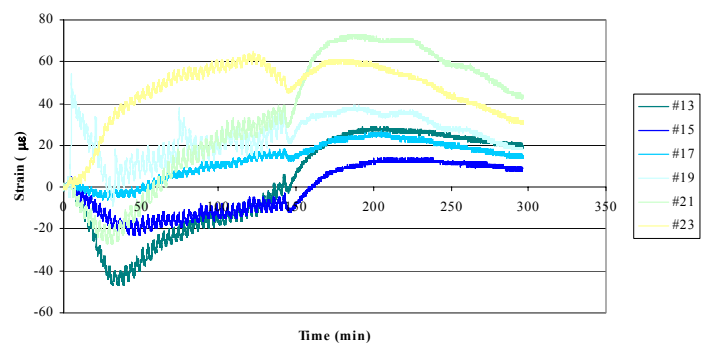

Figure C.5

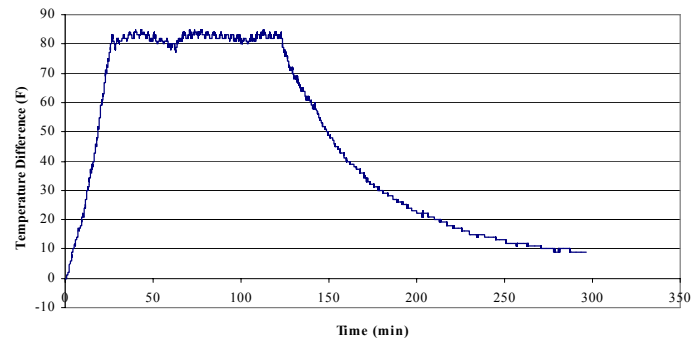

Figure C.2

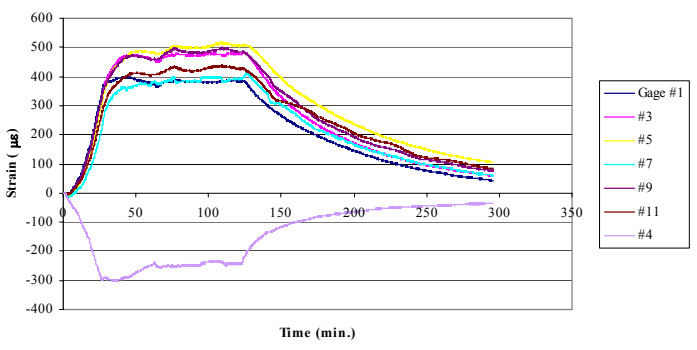

Figure C.4

The following were titles of above Figures.

Figure C.1 Temperature on Top/Bottom Surface for Test Case 8HS

Figure C.2 Temperature Difference ( $\Delta T=T_{\text {top }}-T_{\text {bottom }}$ ) for Test Case 8HS 
Figure C.3 Center/Edge Deflections for Test Case 8HS

Figure C.4 Strain in $y$ direction @ Top Surface for Test Case 8HS

Figure C.5 Strain in $y$ direction @ Bottom Surface for Test Case 8HS

\section{Test Case 8HF (Heating Test + FFFF Boundary)}

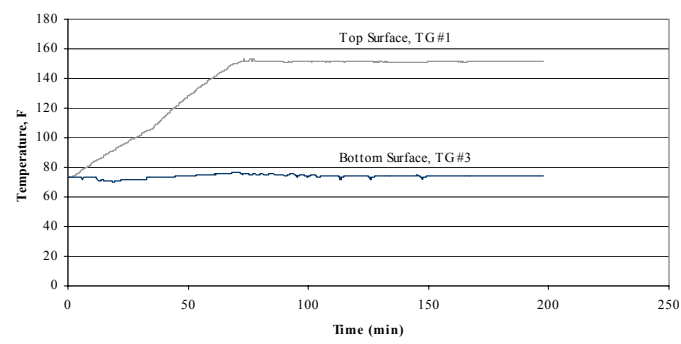

Figure C.6

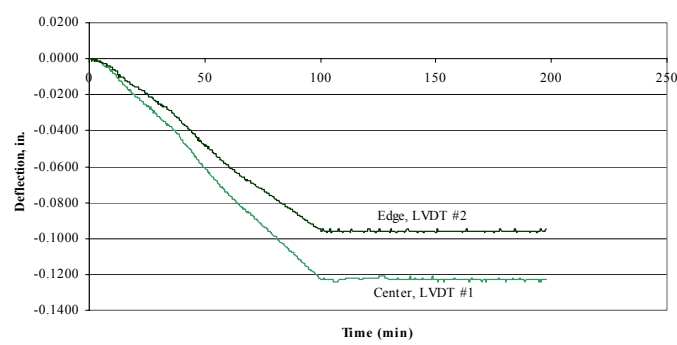

Figure C.8

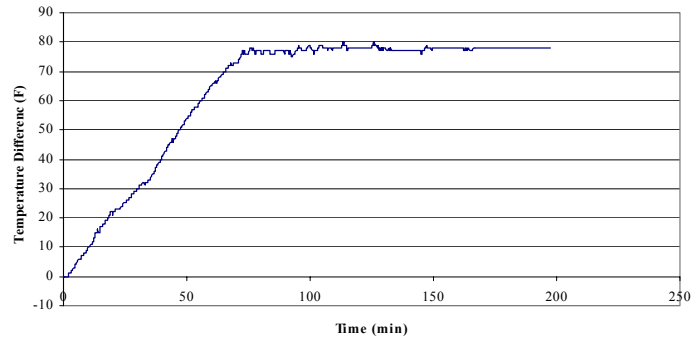

Figure C.7

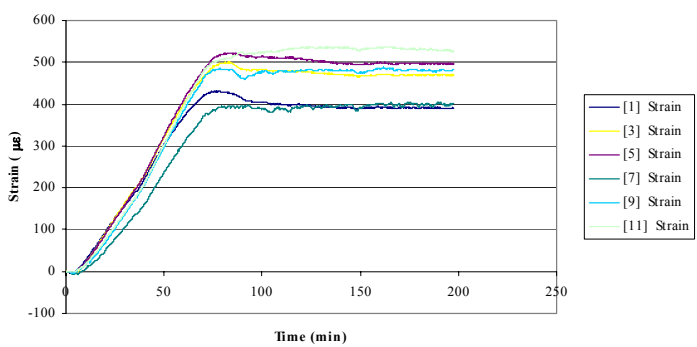

Figure C.9

The following were titles of above Figures.

Figure C.6 Temperature on Top/Bottom Surface for Test Case 8HF

Figure C.7 Temperature Difference ( $\Delta T=T_{\text {top }}-T_{\text {bottom }}$ ) for Test Case 8HF

Figure C.8 Center/Edge Deflections for Test Case 8HF

Figure C.9 Strain in $y$ Direction @ Top Surface for Test Case 8HF 


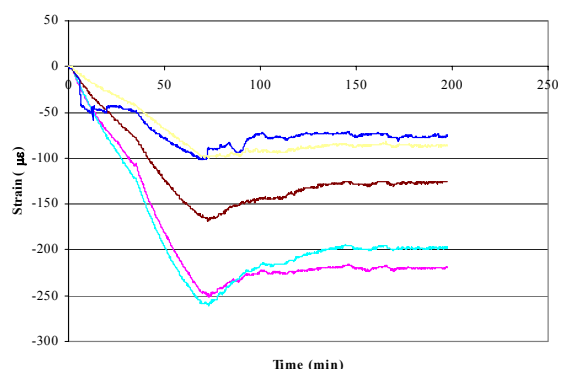

Figure C.10

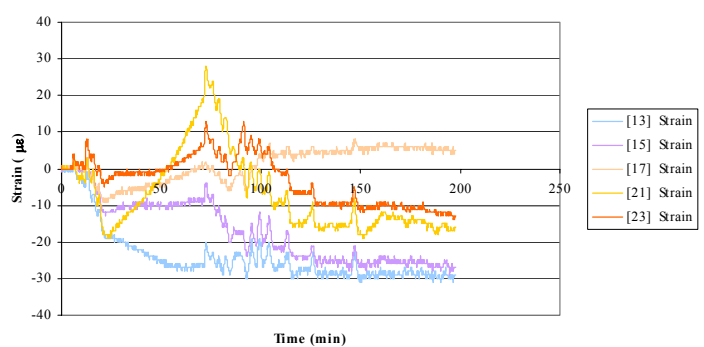

Figure C.11

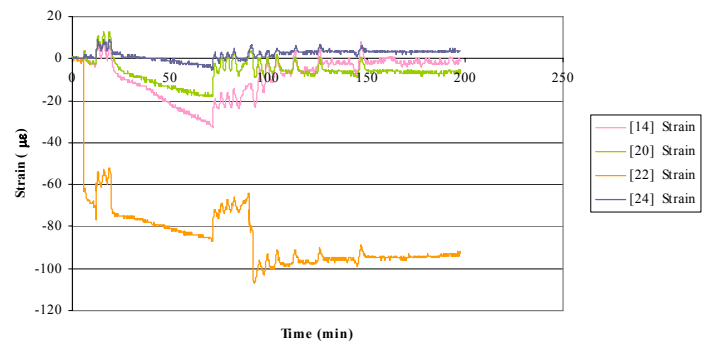

Figure C.12

The following were titles of above Figures.

Figure C.10 Strain in $x$ Direction @ Top Surface for Test Case 8HF

Figure C.11 Strain in $y$ Direction @ Bottom Surface for Test Case 8HF

Figure C.12 Strain in $x$ Direction @ Bottom Surface for Test Case 8HF 


\section{Test Case 8CS (Cooling Test + SSFF Boundary)}

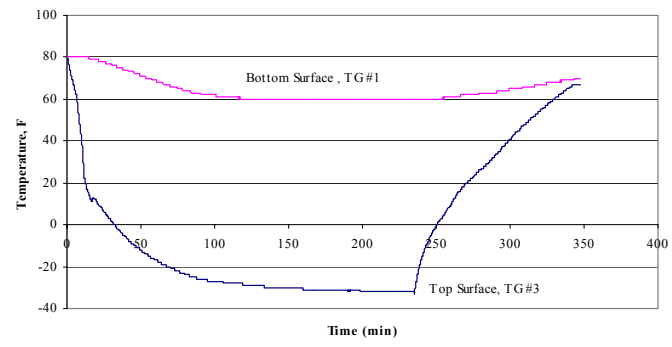

Figure C.13

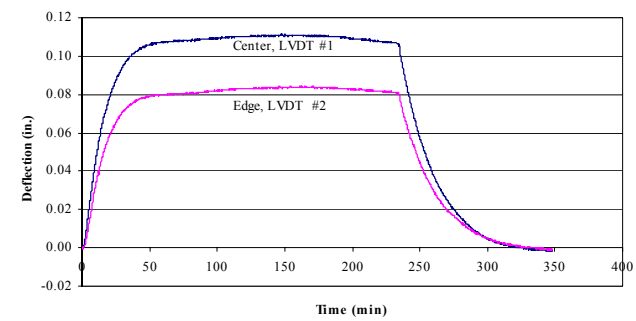

Figure C.15

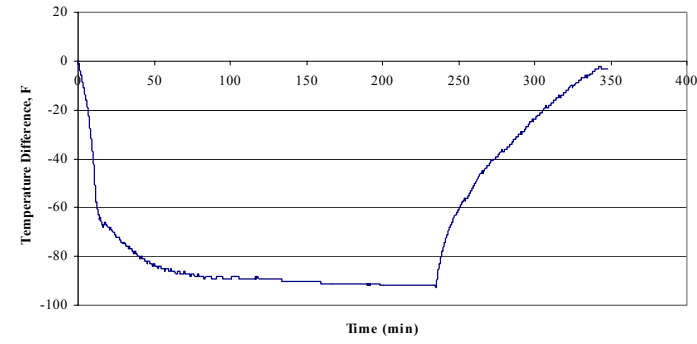

Figure C.14

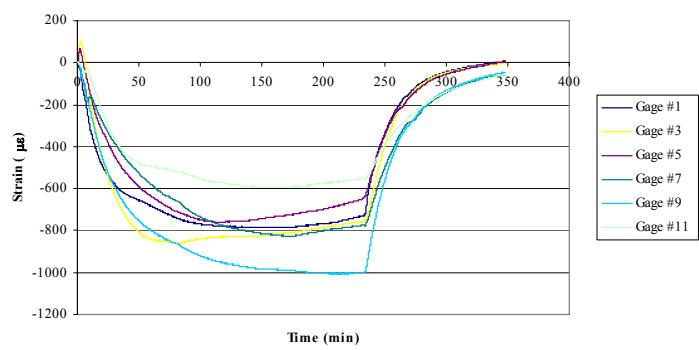

Figure C.16

The following were titles of above Figures.

Figure C.13 Temperature on Top/Bottom Surface for Test Case 8CS

Figure C.14 Temperature Difference ( $\Delta T=T_{\text {top }}-T_{\text {bottom }}$ ) for Test Case 8CS

Figure C.15 Center/Edge Deflections for Test Case 8CS

Figure C.16 Strain in $y$ Direction @ Top Surface for Test Case 8CS 


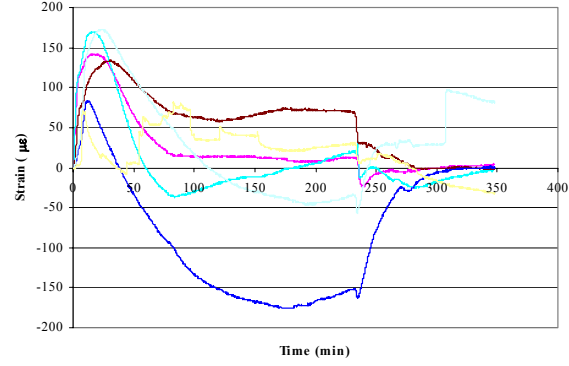

Figure C.17
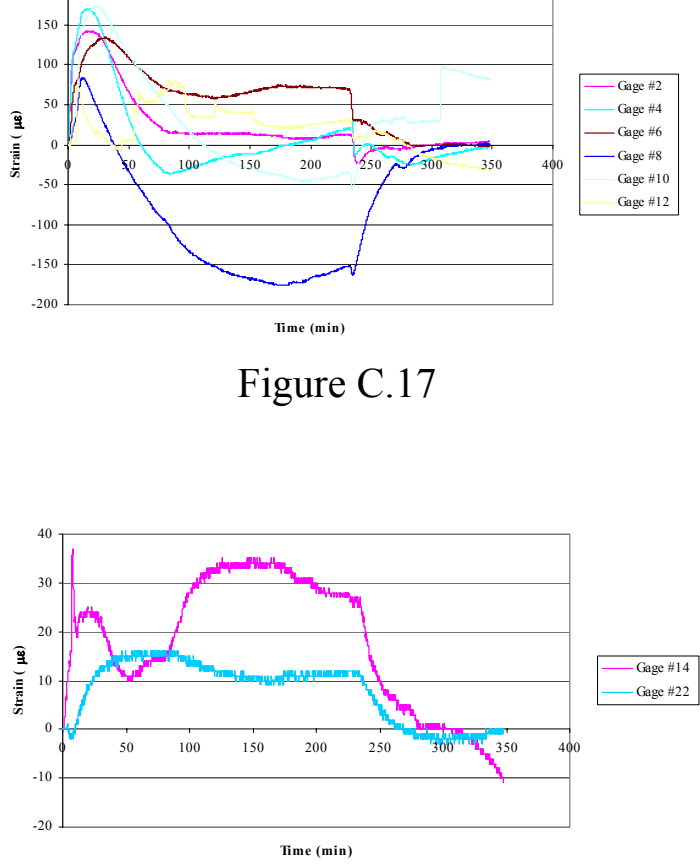

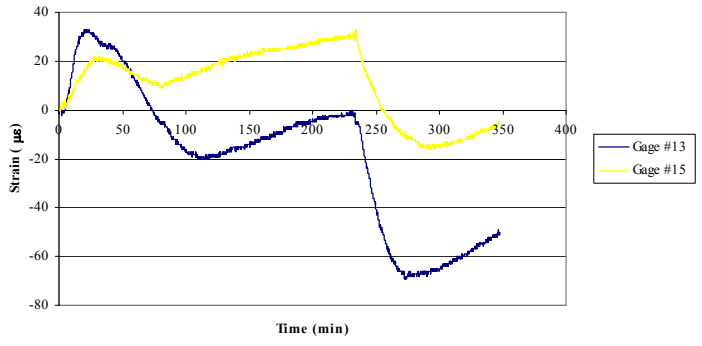

Figure C.18

Figure C.19

The following were titles of above Figures.

Figure C.17 Strain in $x$ Direction @ Top Surface for Test Case 8CS

Figure C.18 Strain in $y$ Direction @ Bottom Surface for Test Case 8CS

Figure C.19 Strain in $x$ Direction @ Bottom Surface for Test Case 8CS 


\section{Test Case 8CF (Cooling Test + FFFF Boundary)}

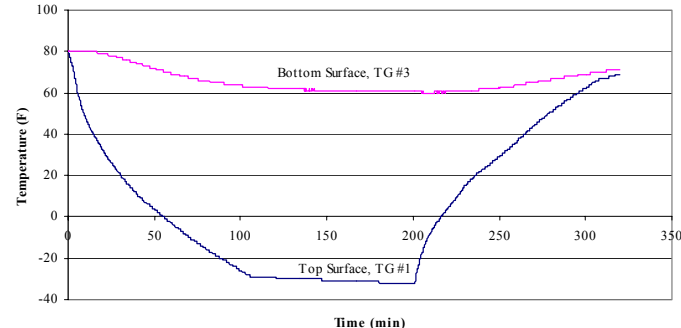

Figure C.20

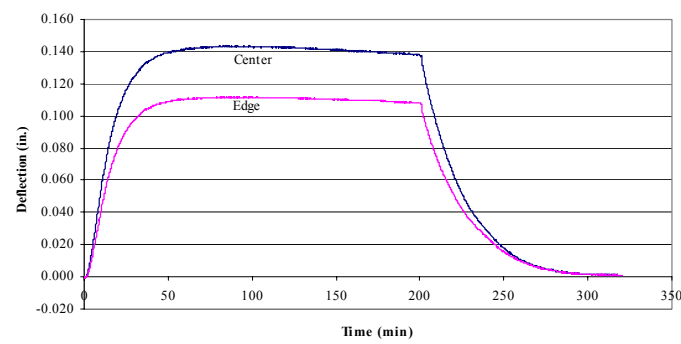

Figure C.22

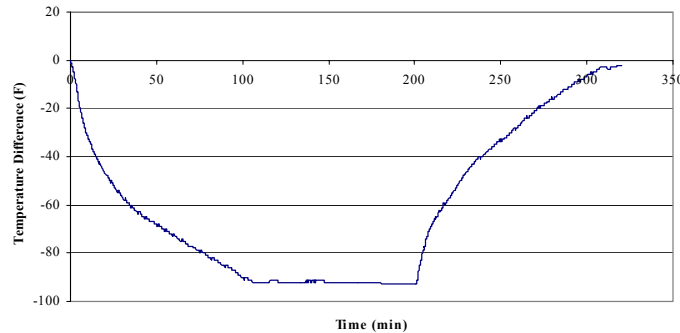

Figure C.21

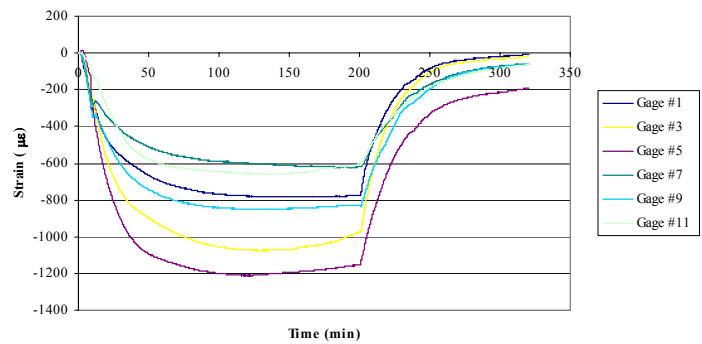

Figure C.23

The following were titles of above Figures.

Figure C.20 Temperature on Top/Bottom Surface for Test Case 8CF

Figure C.21 Temperature Difference $\left(\Delta T=T_{\text {top }}-T_{\text {bottom }}\right)$ for Test Case 8CF

Figure C.22 Center/Edge Deflections for Test Case 8CF

Figure C.23 Strain in y Direction @ Top Surface for Test Case 8CF 


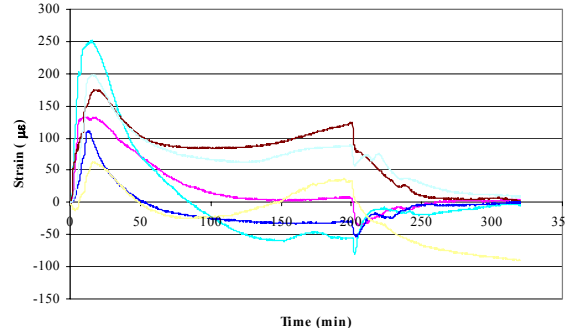

Figure C.24

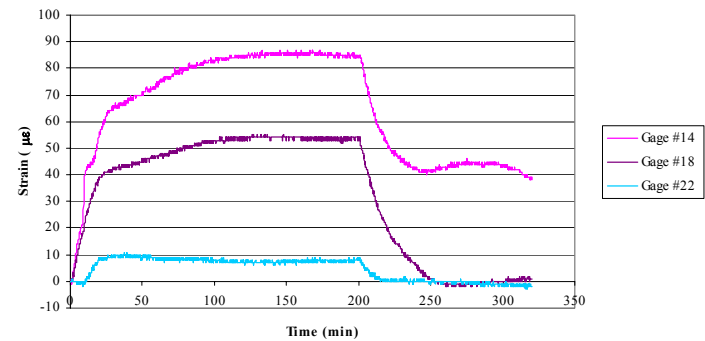

Figure C.26

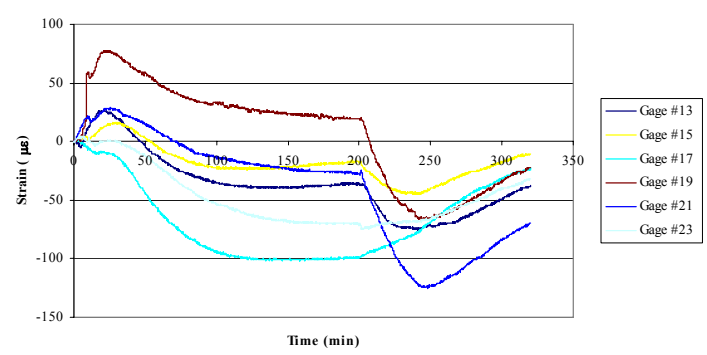

Figure C.25

The following were titles of above Figures.

Figure C.24 Strain in $x$ Direction @ Top Surface for Test Case 8CF

Figure C.25 Strain in $y$ Direction @ Bottom Surface for Test Case 8CF

Figure C.26 Strain in $x$ Direction @ Bottom Surface for Test Case 8CF 


\section{Appendix D}

\section{Laboratory Test Results for 4 in. FRP Bridge Deck}

Experimental data for 4 in. deep FRP bridge deck are presented in this appendix.

Strain gage, TG sensor and LVDT location can be found in Figures 4.10 and 4.11.

\section{Test Case 4HS (Heating Test + SSFF Boundary)}

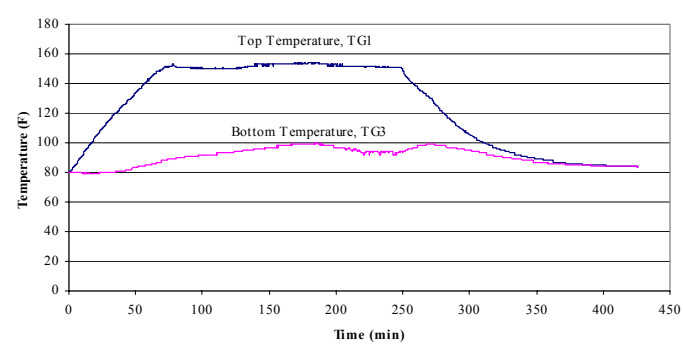

Figure D.1

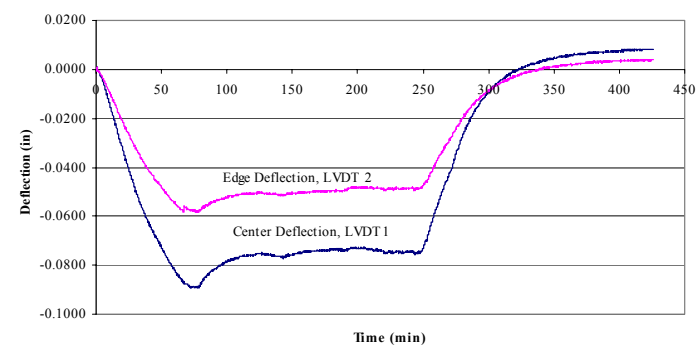

Figure D.3

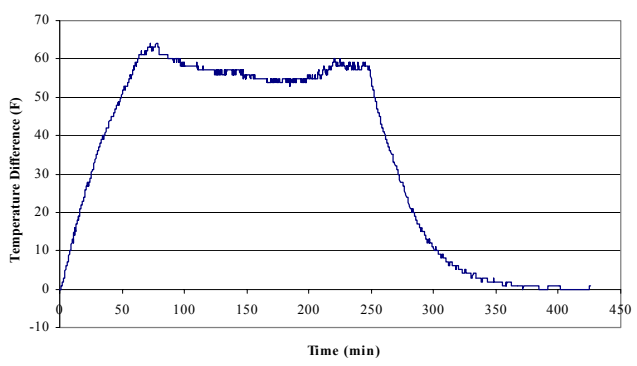

Figure D.2

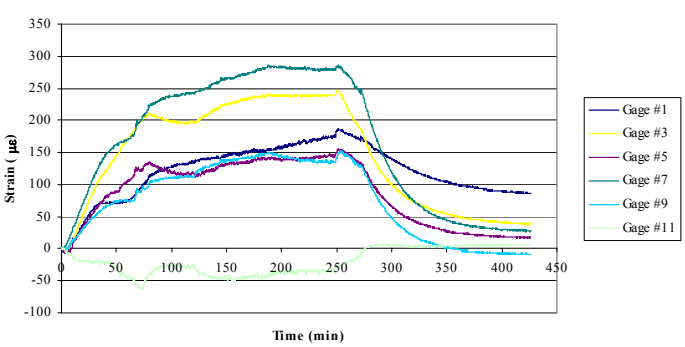

Figure D.4

The following were titles of above Figures

Figure D.1 Temperature on Top/Bottom Surface for Test Case 4HS

Figure D.2 Temperature Difference ( $\Delta T=T_{\text {top }}-T_{\text {bottom }}$ ) for Test Case 4HS

Figure D.3 Center/Edge Deflections for Test Case 4HS

Figure D.4 Strain in $y$ direction @ Top Surface for Test Case 4HS 


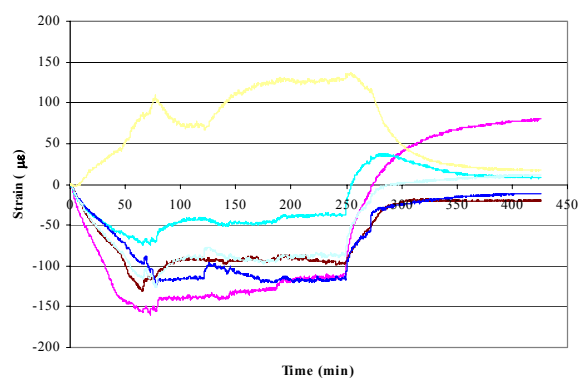

Figure D.5

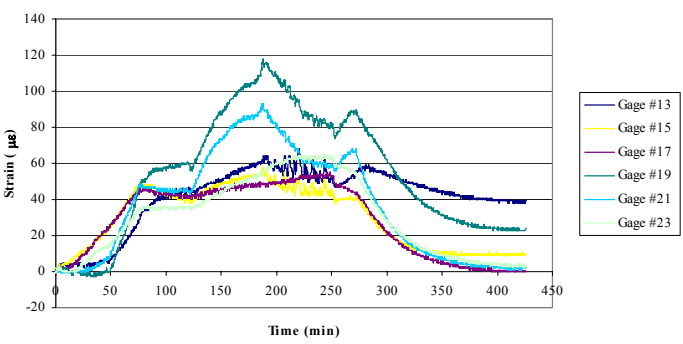

Figure D.6

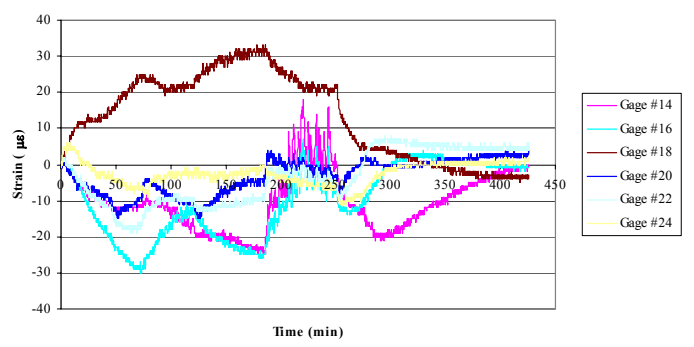

Figure D.7

The following were titles of above Figures

Figure D.5 Strain in $x$ direction @ Top Surface for Test Case 4HS

Figure D.6 Strain in $y$ direction @ Bottom Surface for Test Case 4HS

Figure D.7 Strain in $x$ direction @ Bottom Surface for Test Case 4HS 


\section{Test Case 4HF (Heating Test + FFFF Boundary)}

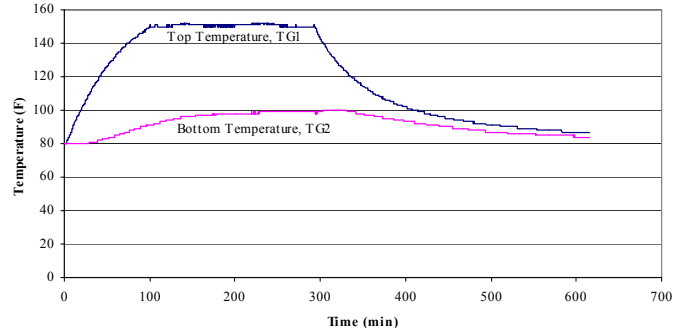

Figure D.8

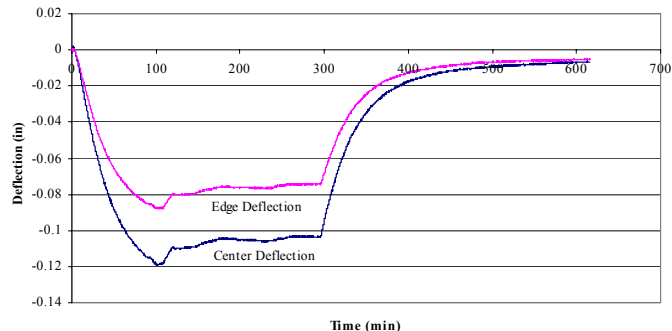

Figure D.10

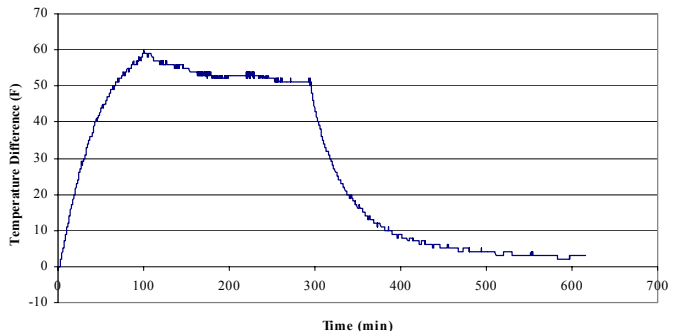

Figure D.9

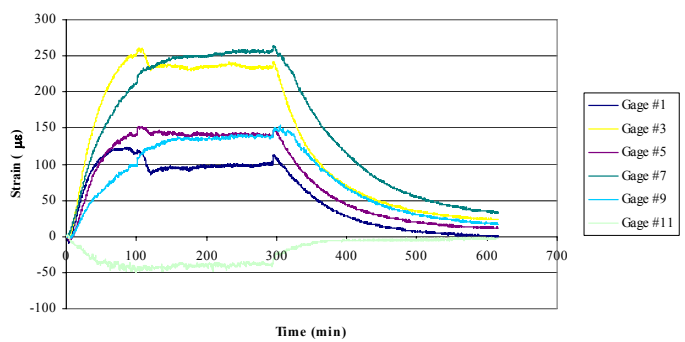

Figure D.11

The following were titles of above Figures

Figure D. 8 Temperature on Top/Bottom Surface for Test Case 4HF

Figure D.9 Temperature Difference ( $\Delta T=T_{\text {top }}-T_{\text {bottom }}$ ) for Test Case 4HF

Figure D.10 Center/Edge Deflections for Test Case 4HF

Figure D.11 Strain in $y$ direction @ Top Surface for Test Case 4HF 


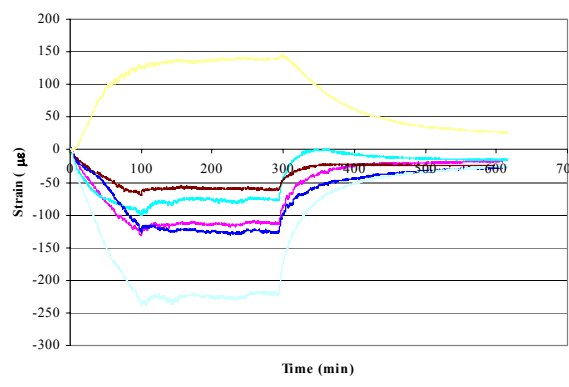

Figure D.12

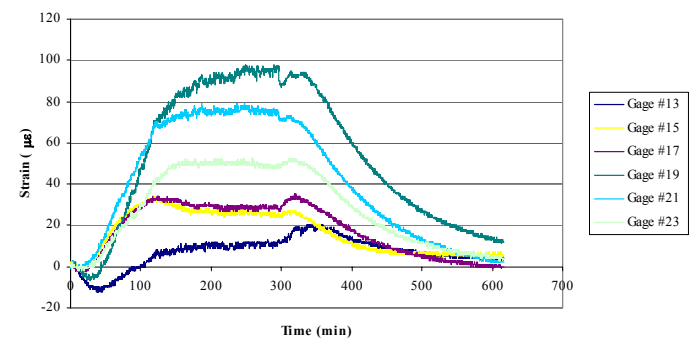

Figure D.13

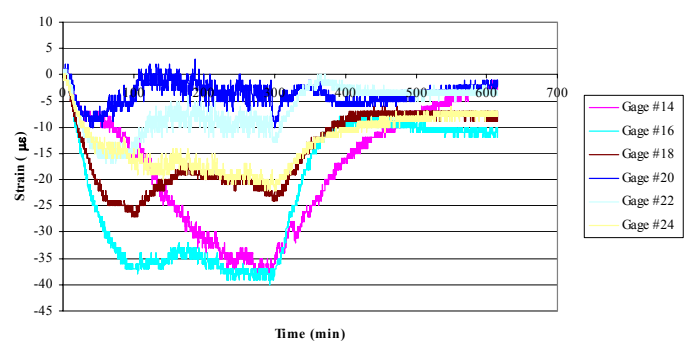

Figure D.14

The following were titles of above Figures

Figure D.12 Strain in $x$ direction @ Top Surface for Test Case 4HF

Figure D.13 Strain in $y$ direction @ Bottom Surface for Test Case 4HF

Figure D.14 Strain in $x$ direction @ Bottom Surface for Test Case 4HF 


\section{Test Case 4CS (Cooling Test + SSFF Boundary)}

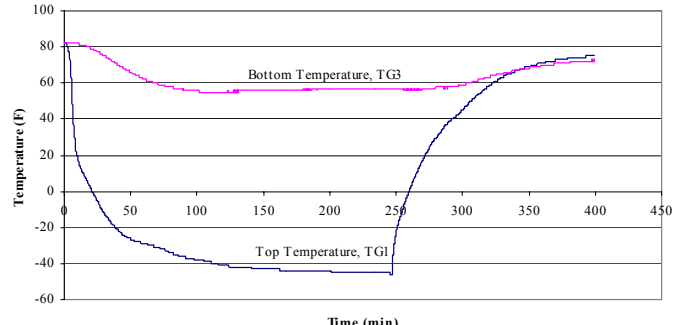

Figure D.15

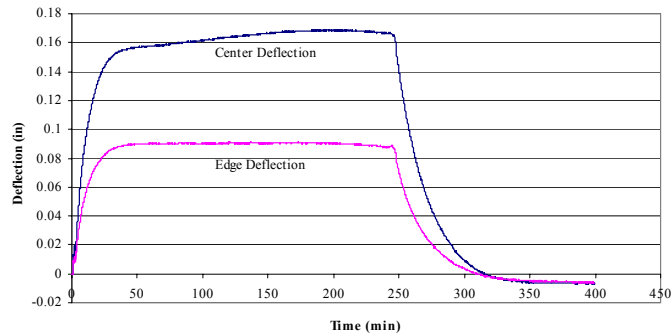

Figure D.17

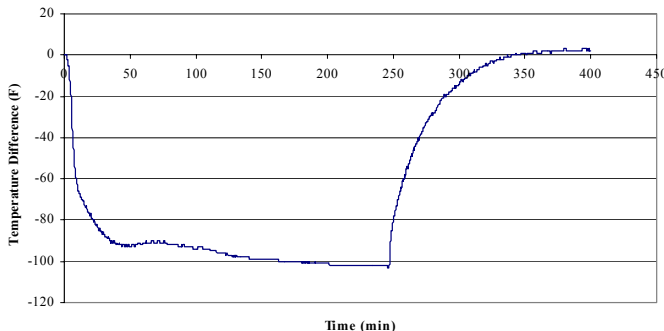

Figure D.16

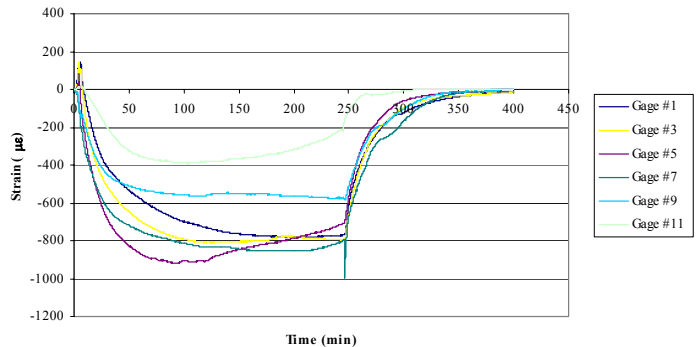

Figure D.18

The following were titles of above Figures.

Figure D.15 Temperature on Top/Bottom Surface for Test Case 4CS

Figure D.16 Temperature Difference ( $\left.\Delta T=T_{\text {top }}-T_{\text {bottom }}\right)$ for Test Case 4CS

Figure D.17 Center/Edge Deflections for Test Case 4CS

Figure D.18 Strain in $y$ direction @ Top Surface for Test Case 4CS 


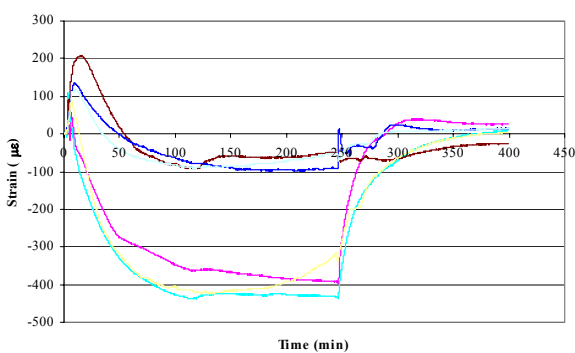

Figure D.19

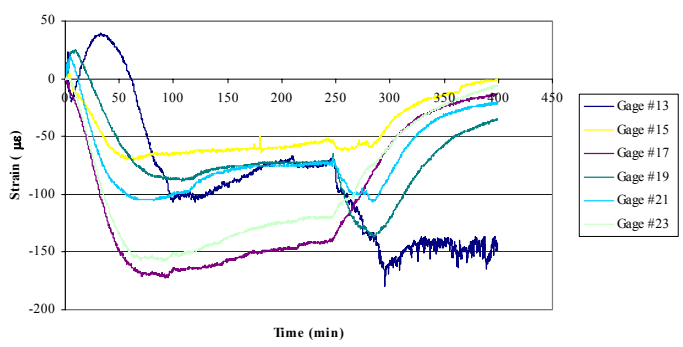

Figure D.20

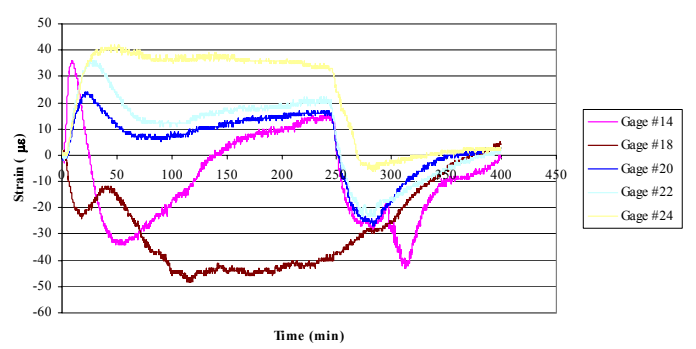

Figure D.21

The following were titles of above Figures

Figure D.19 Strain in $x$ direction @ Top Surface for Test Case 4CS

Figure D.20 Strain in $y$ direction @ Bottom Surface for Test Case 4CS

Figure D.21 Strain in $x$ direction @ Bottom Surface for Test Case 4CS 


\section{Test Case 4CF (Cooling Test + FFFF Boundary)}

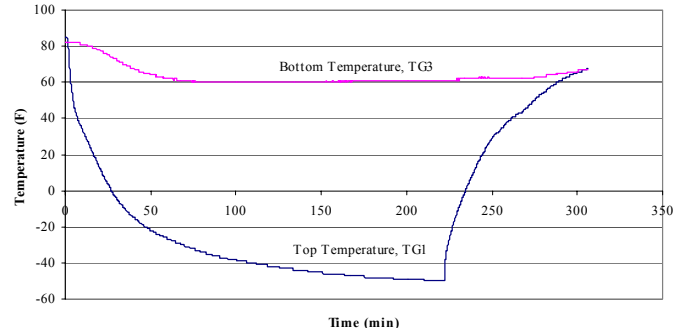

Figure D.22

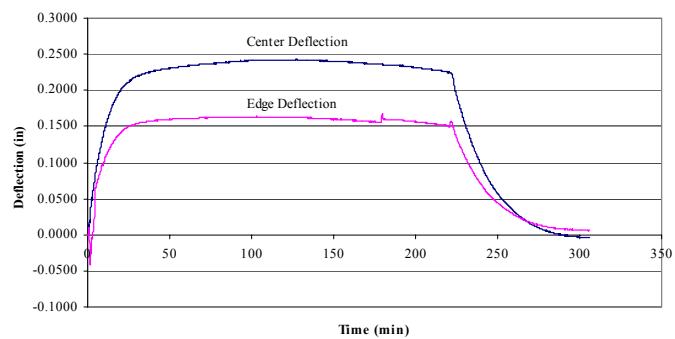

Figure D.24

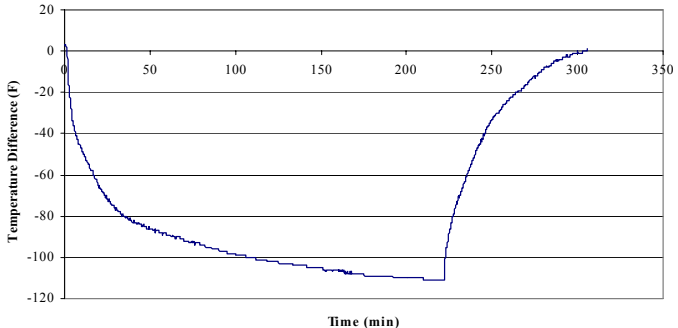

Figure D.23

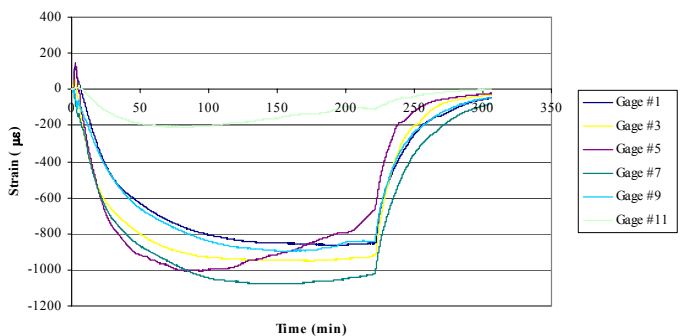

Figure D.25

The following were titles of above Figures

Figure D.22 Temperature on Top/Bottom Surface for Test Case 4CF

Figure D.23 Temperature Difference ( $\left.\Delta T=T_{\text {top }}-T_{\text {bottom }}\right)$ for Test Case 4CF

Figure D.24 Center/Edge Deflections for Test Case 4CF

Figure D.25 Strain in $y$ direction @ Top Surface for Test Case 4CF 


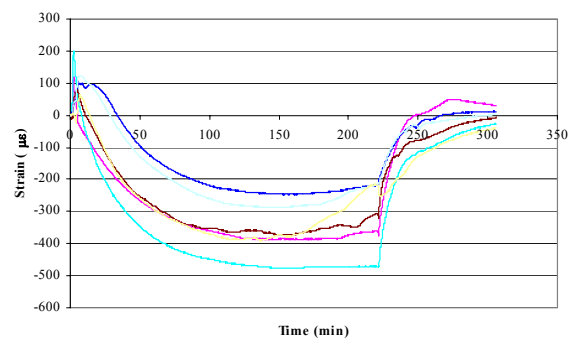

Figure D.26

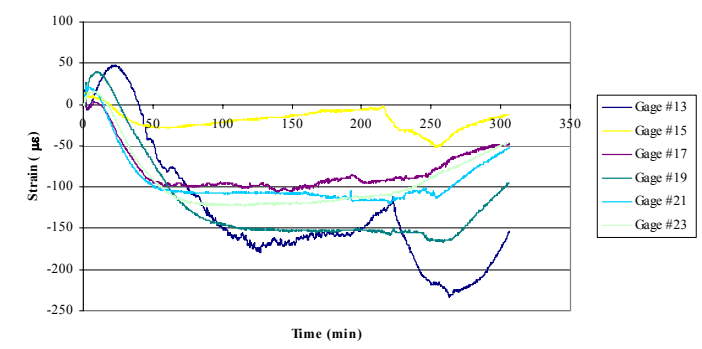

Figure D.27

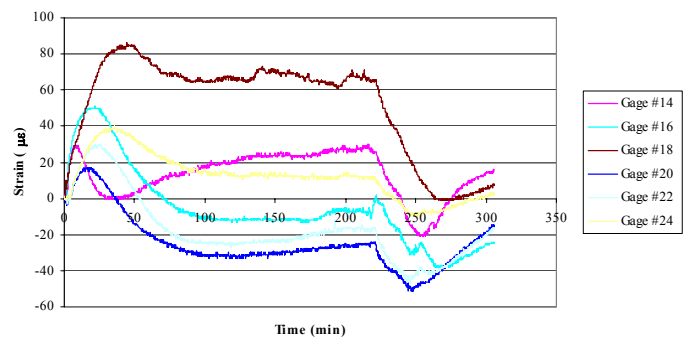

Figure D.28

The following were titles of above Figures

Figure D.26 Strain in $x$ direction @ Top Surface for Test Case 4CF

Figure D.27 Strain in $y$ direction @ Bottom Surface for Test Case 4CF

Figure D.28 Strain in $x$ direction @ Bottom Surface for Test Case 4CF 


\section{Appendix E}

\section{Theoretical Results From Navier-Levy and Macro Approach}

In this appendix, the theoretical deflection plot and Matlab program code for computation of Navier-Levy method were shown in section E.1 and E.2, respectively. And the theoretical deflection plot and Matlab program code for computation of Macro approach were shown in section E.3 and E.4, respectively.

\section{E.1 Deflection Plot based on Navier-Levy Method}

The deflection contour plots were presented for all test cases of simply supported edges. Center and edge deflection based on approximation terms of $n=1$ to 15 were plotted and compared to deflection results of the $1^{\text {st }}$ term approximation.

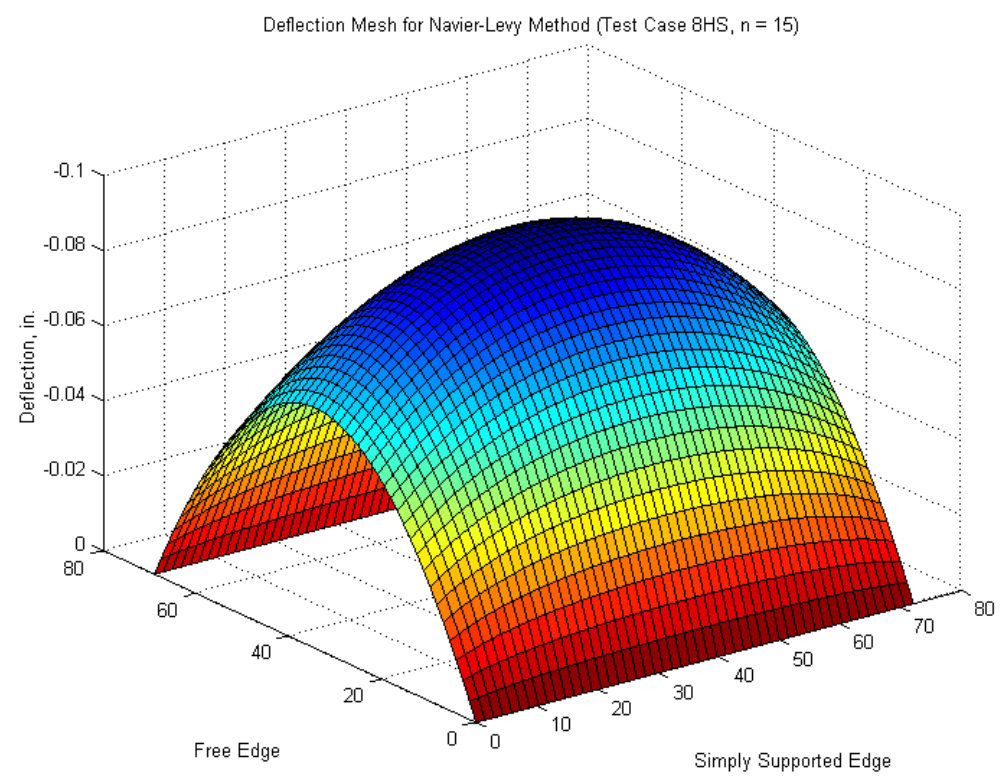

Figure E.1: Deflection Mesh for Test Case 8HS (Navier-Levy). 

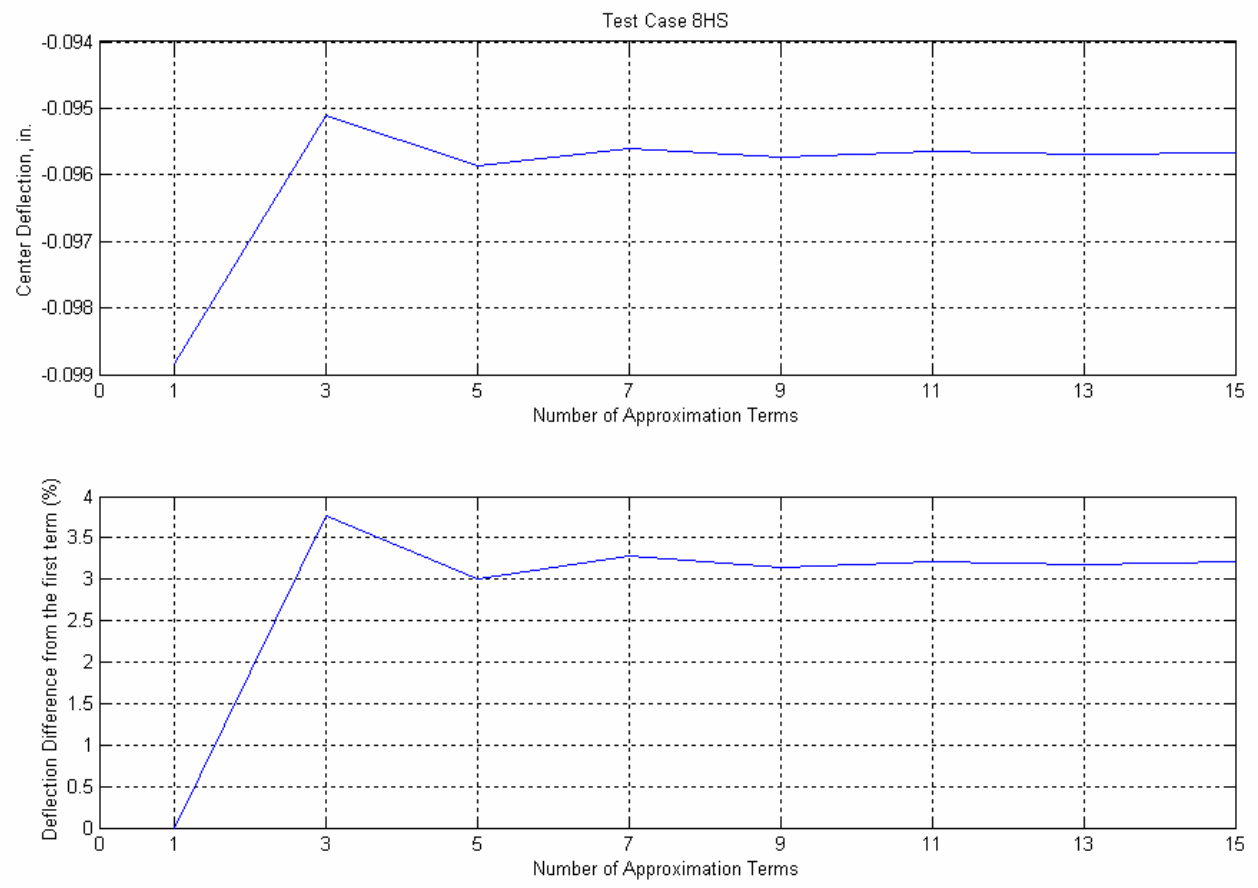

Figure E.2: Center Deflection and Deflection Difference for Test Case 8HS (Navier-Levy).
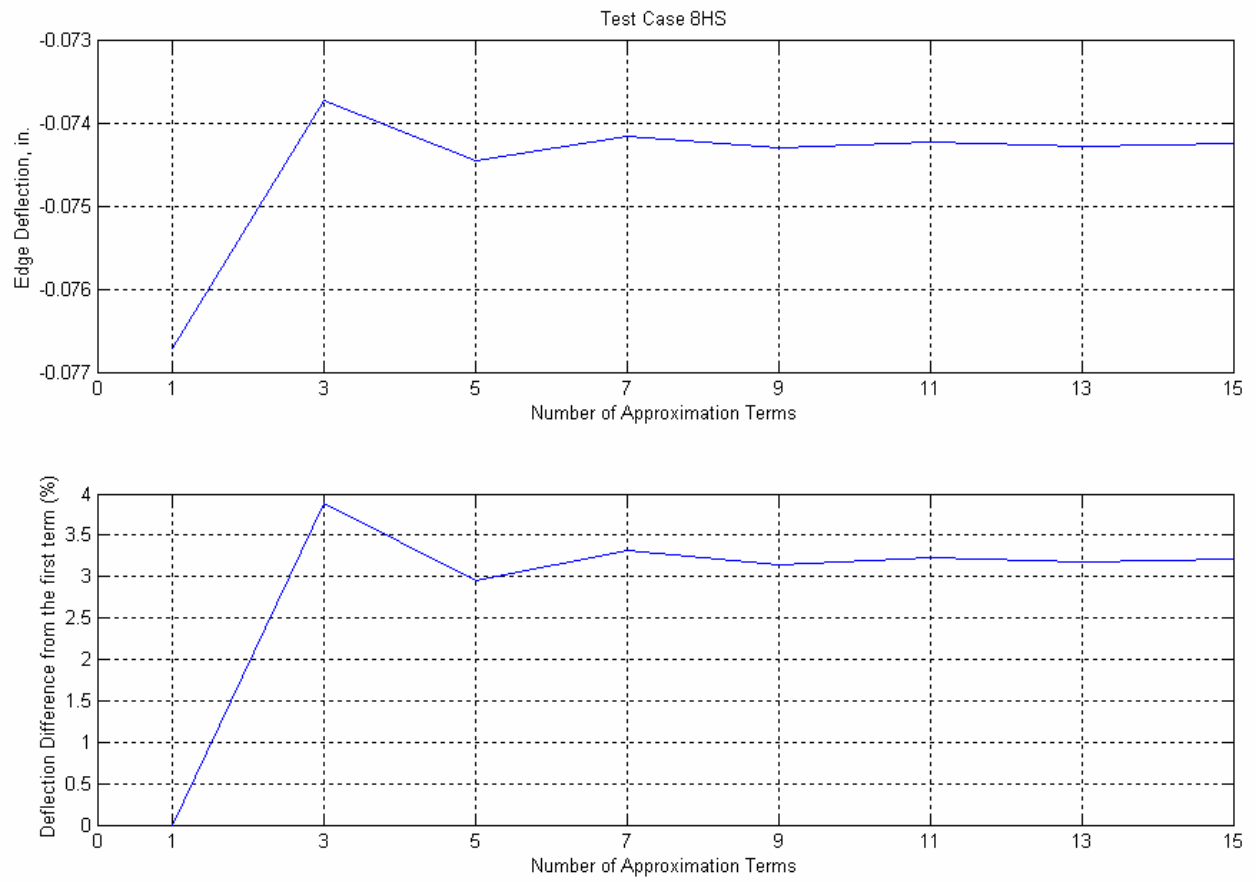

Figure E.3: Edge Deflection and Deflection Difference for Test Case 8HS (Navier-Levy). 


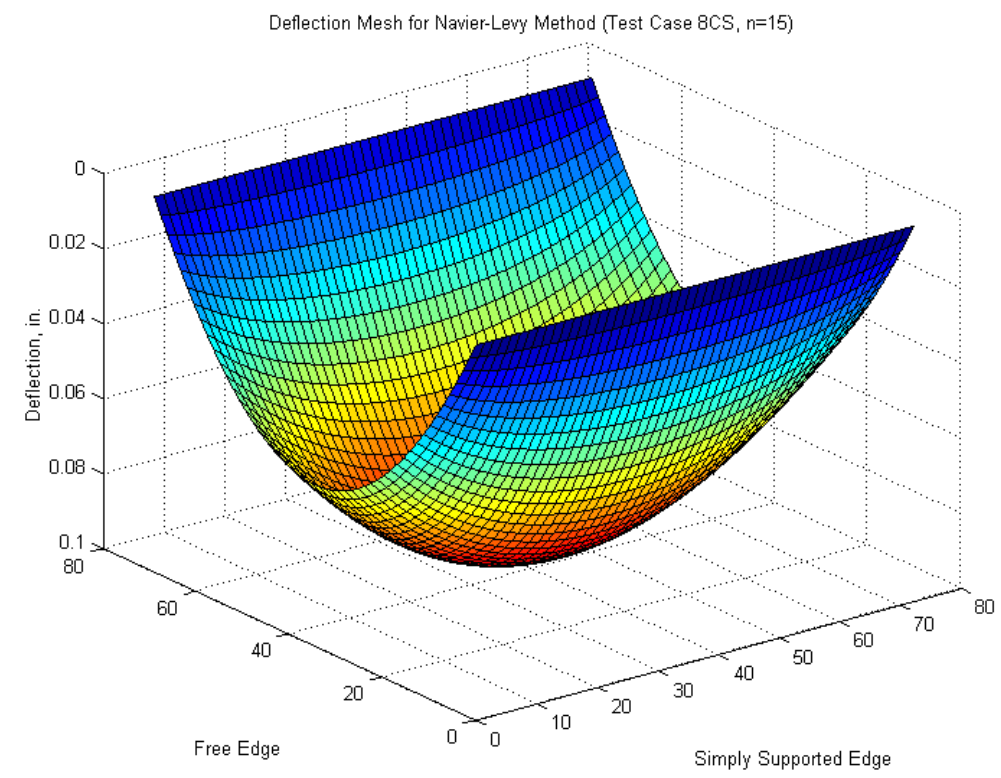

Figure E.4: Deflection Mesh for Test Case 8CS (Navier-Levy).
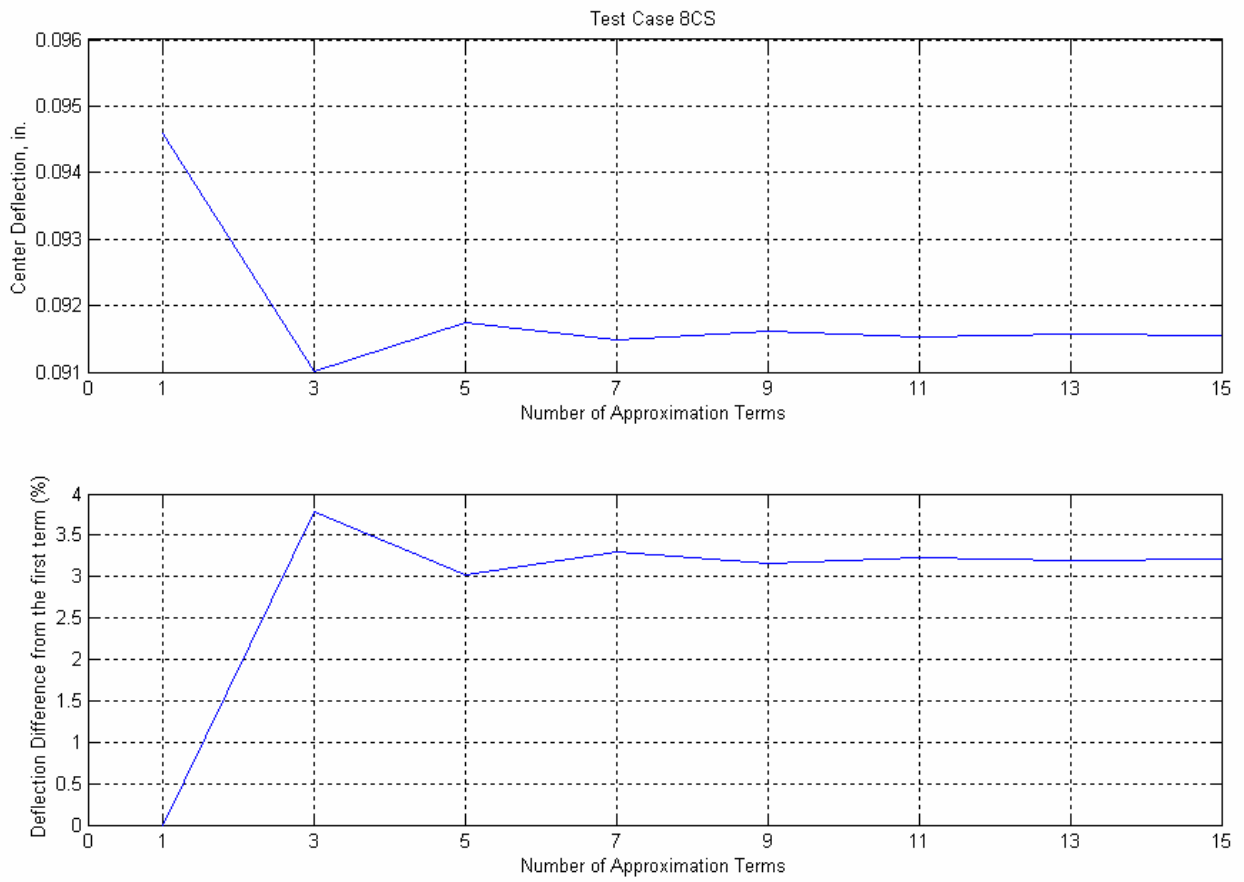

Figure E.5: Center Deflection and Deflection Difference for Test Case 8CS (Navier-Levy). 

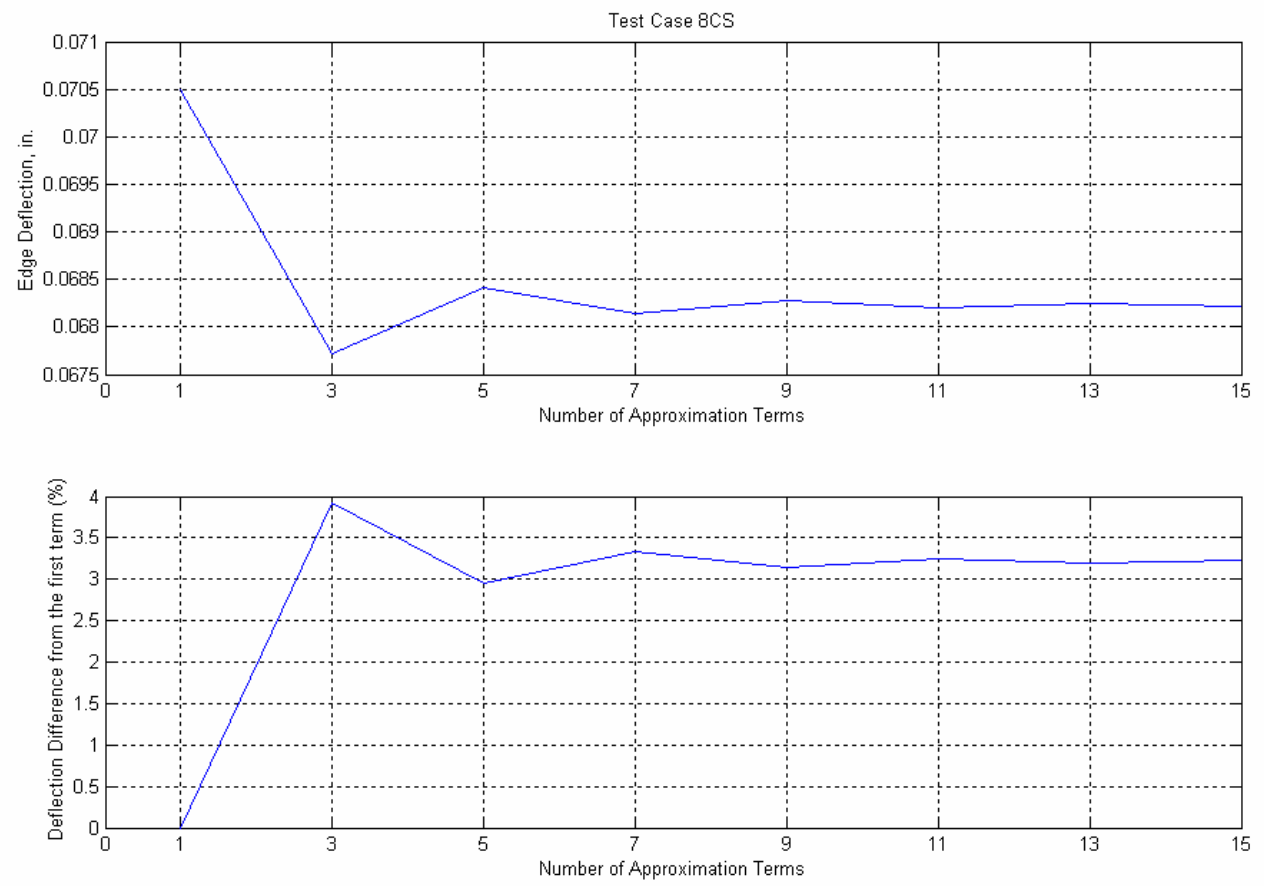

Figure E.6: Edge Deflection and Deflection Difference for Test Case 8CS (Navier-Levy).

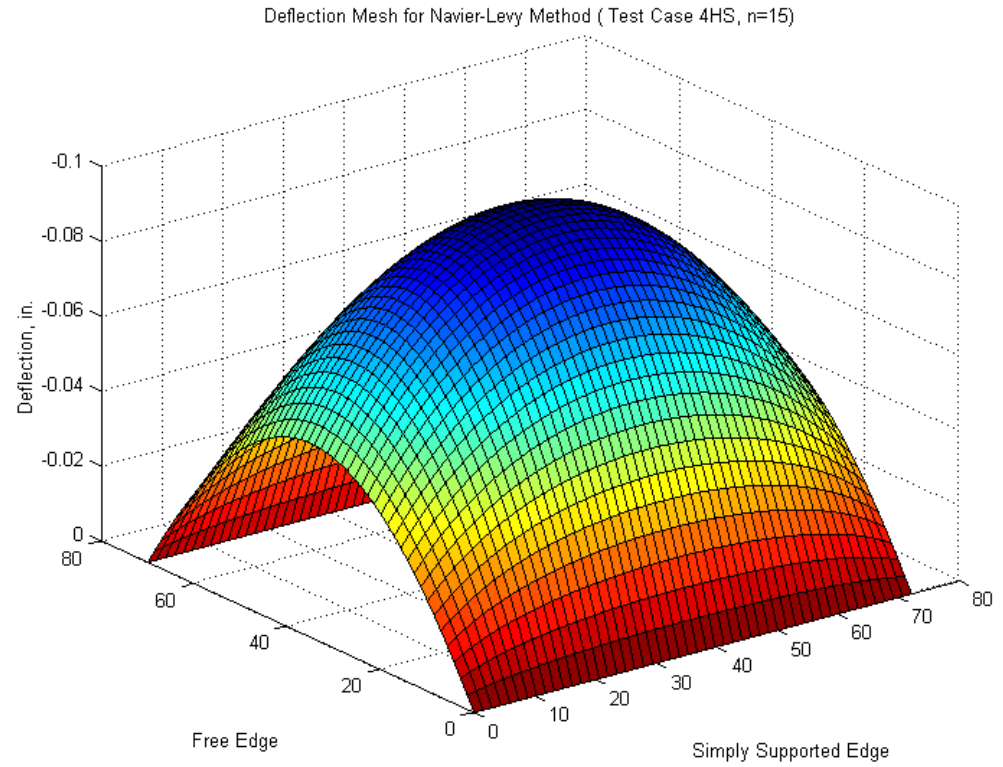

Figure E.7: Deflection Mesh for Test Case 4HS (Navier-Levy). 

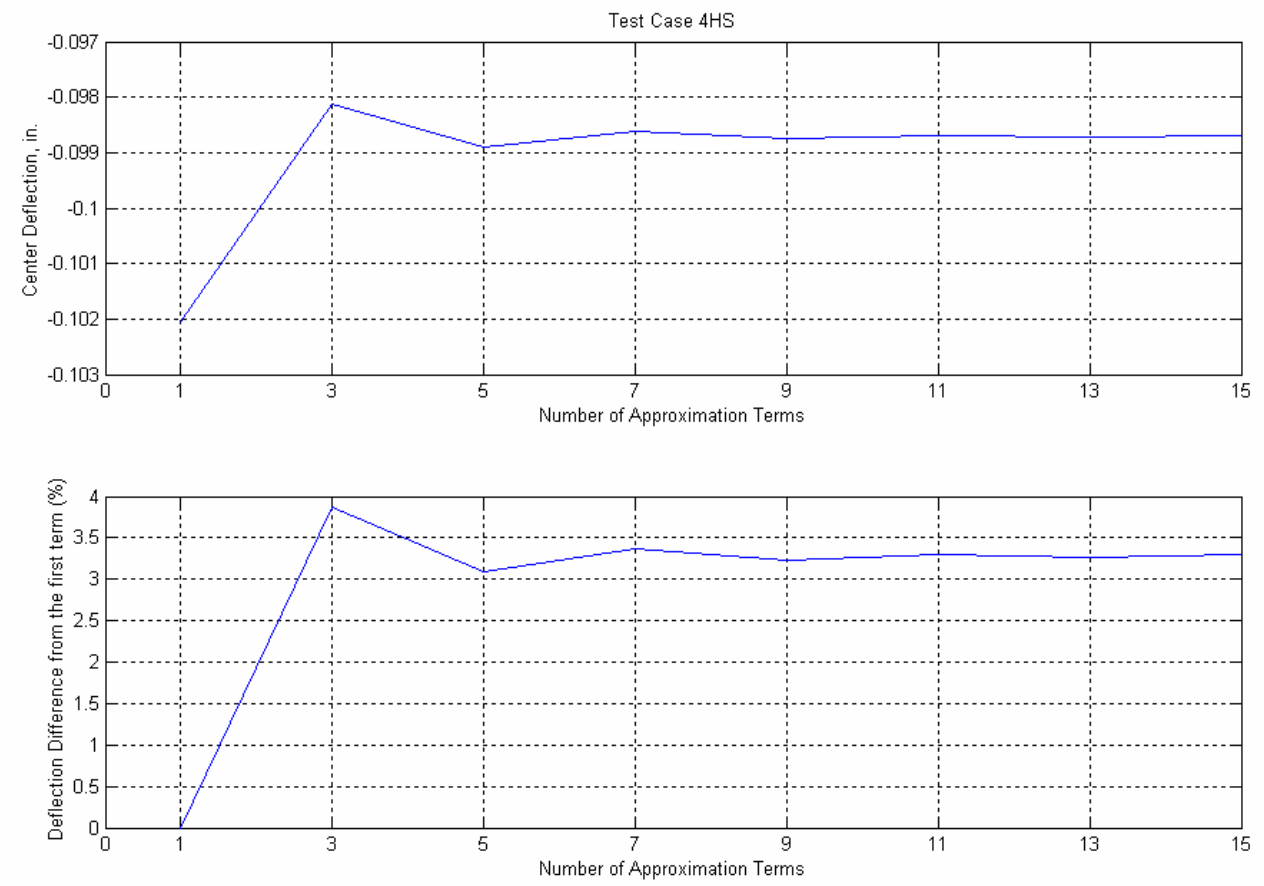

Figure E.8: Center Deflection and Deflection Difference for Test Case 4HS (Navier-Levy).
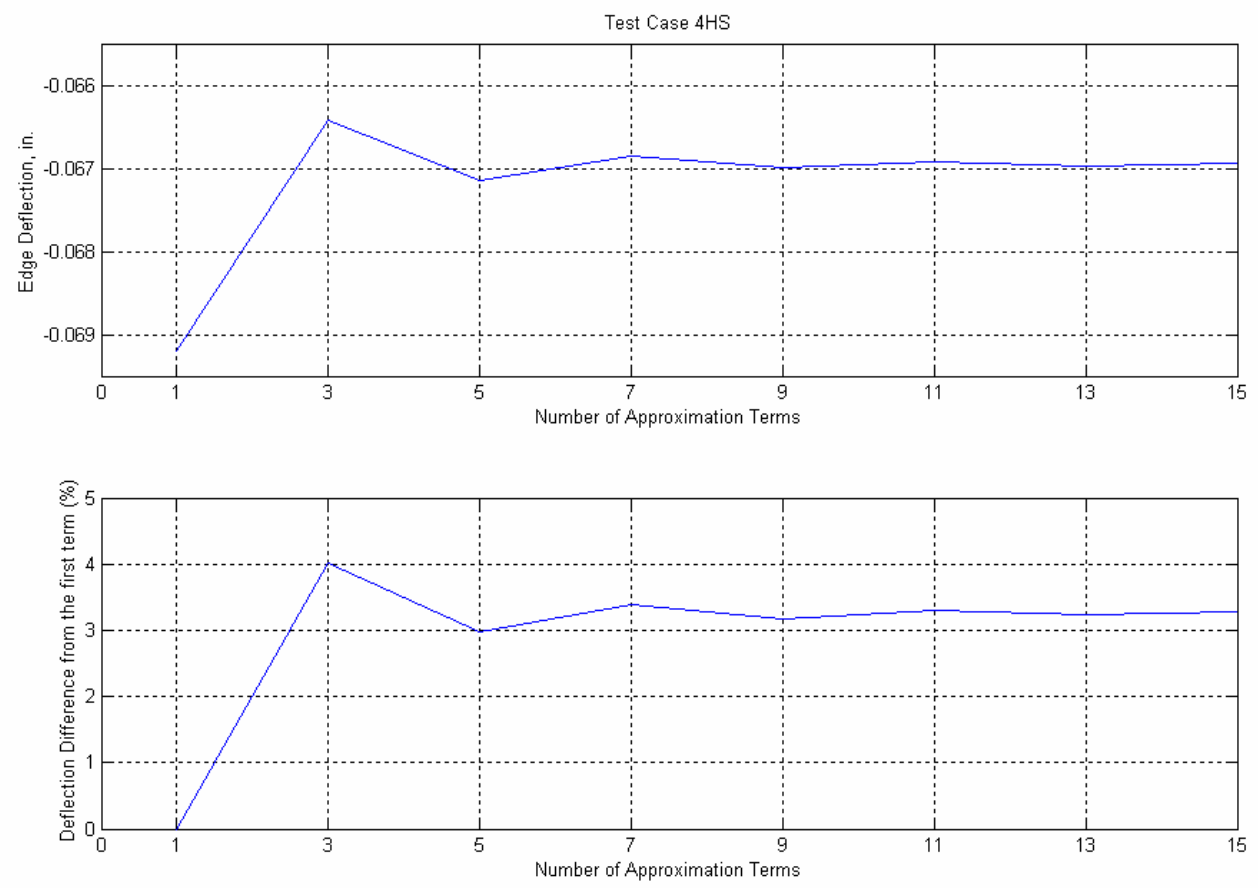

Figure E.9: Edge Deflection and Deflection Difference for Test Case 4HS (Navier-Levy). 


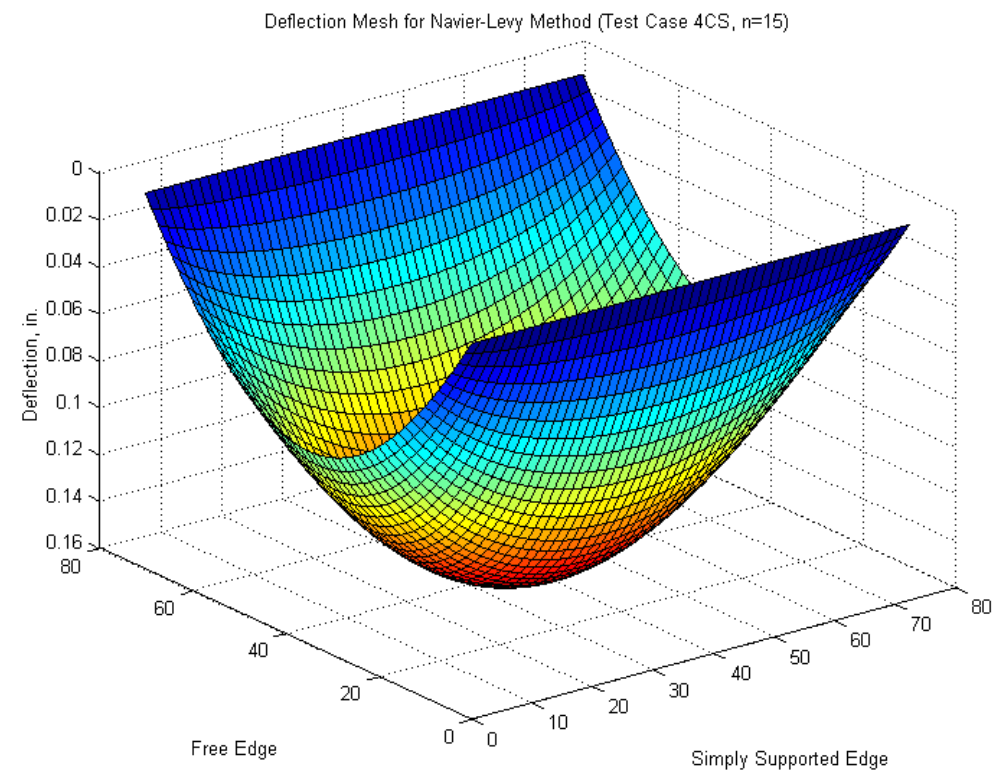

Figure E.10: Deflection Mesh for Test Case 4CS (Navier-Levy).
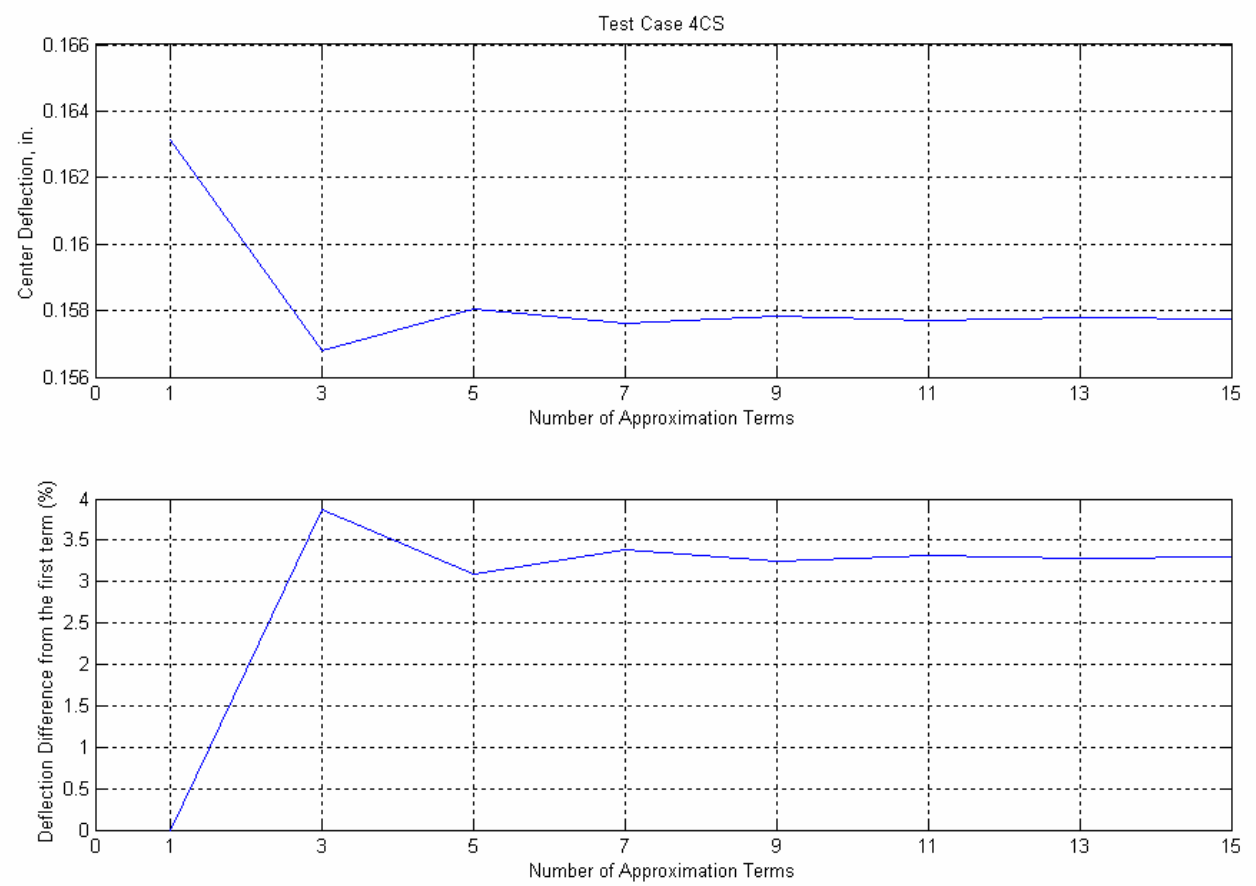

Figure E.11: Center Deflection and Deflection Difference for Test Case 4CS (Navier-Levy). 

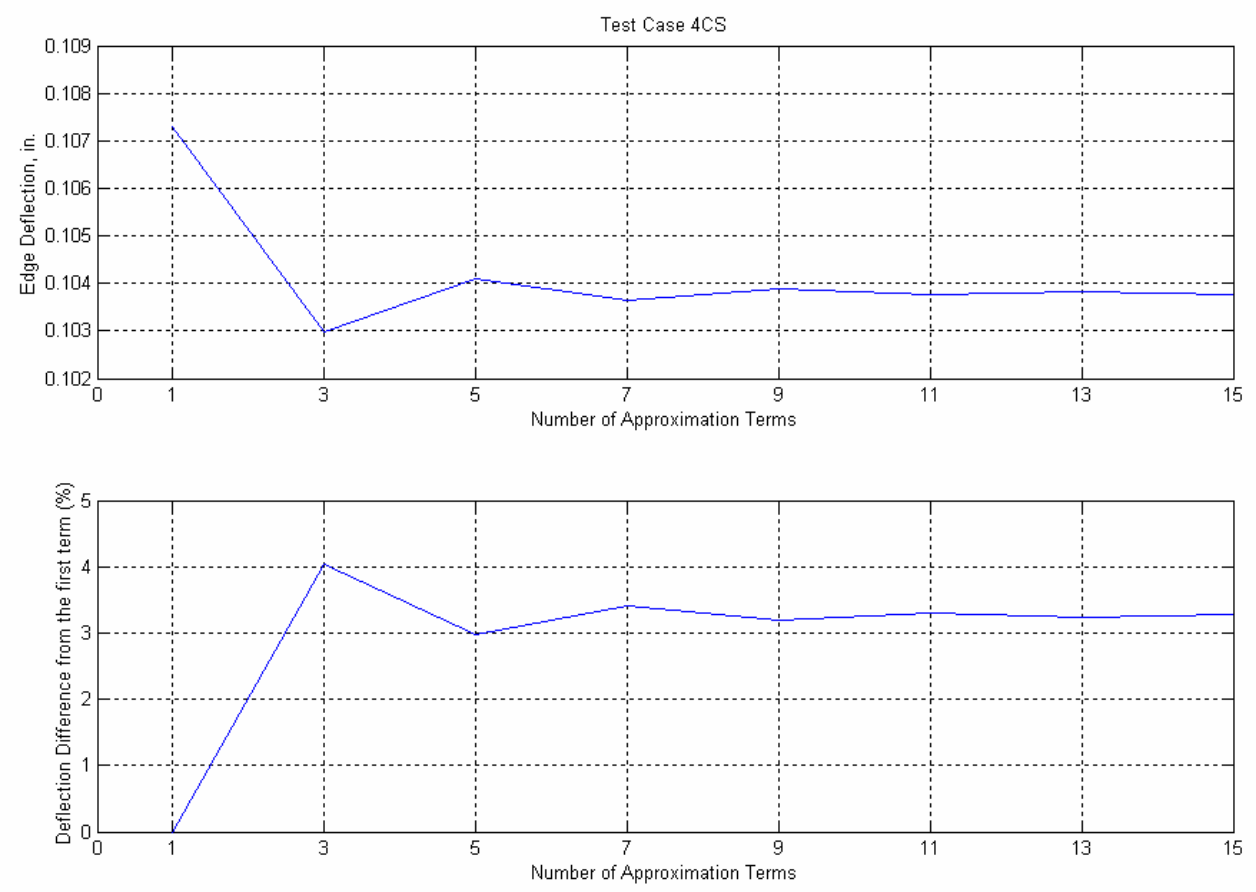

Figure E.12: Edge Deflection and Deflection Difference for Test Case 4CS (Navier-Levy). 


\section{E.2 Matlab program code for computation based on Navier-Levy Method}

\section{E.2.1 Deflection Mesh of Test Case 8HS (Navier-Levy)}

clc

clear

$\%$ Calculation of deflection at $\mathrm{x}, \mathrm{y}$ with SSFF condition

$\%$

$\%$ FRP Deck Properties

$\%$

$\mathrm{D} 11=7 \mathrm{e} 7$

$\mathrm{D} 22=1.81 \mathrm{e} 7$

$\mathrm{D} 12=4.11 \mathrm{e} 6$

$\mathrm{D} 66=9.3 \mathrm{e} 6$

$\mathrm{h}=8 \quad \%$ Height of FRP Deck

$\mathrm{a}=72 \quad \%$ Dimemsion in $\mathrm{x}$ direction (SS Edge)

$\mathrm{b}=69 \quad \%$ Dimemsion in y direction (Free Edge)

alpha $1=4.85 \mathrm{e}-6 \%$ Thermal Coefficient in $\mathrm{x}$ direction

alpha $2=14.14 \mathrm{e}-6 \%$ Thermal Coefficient in y direction

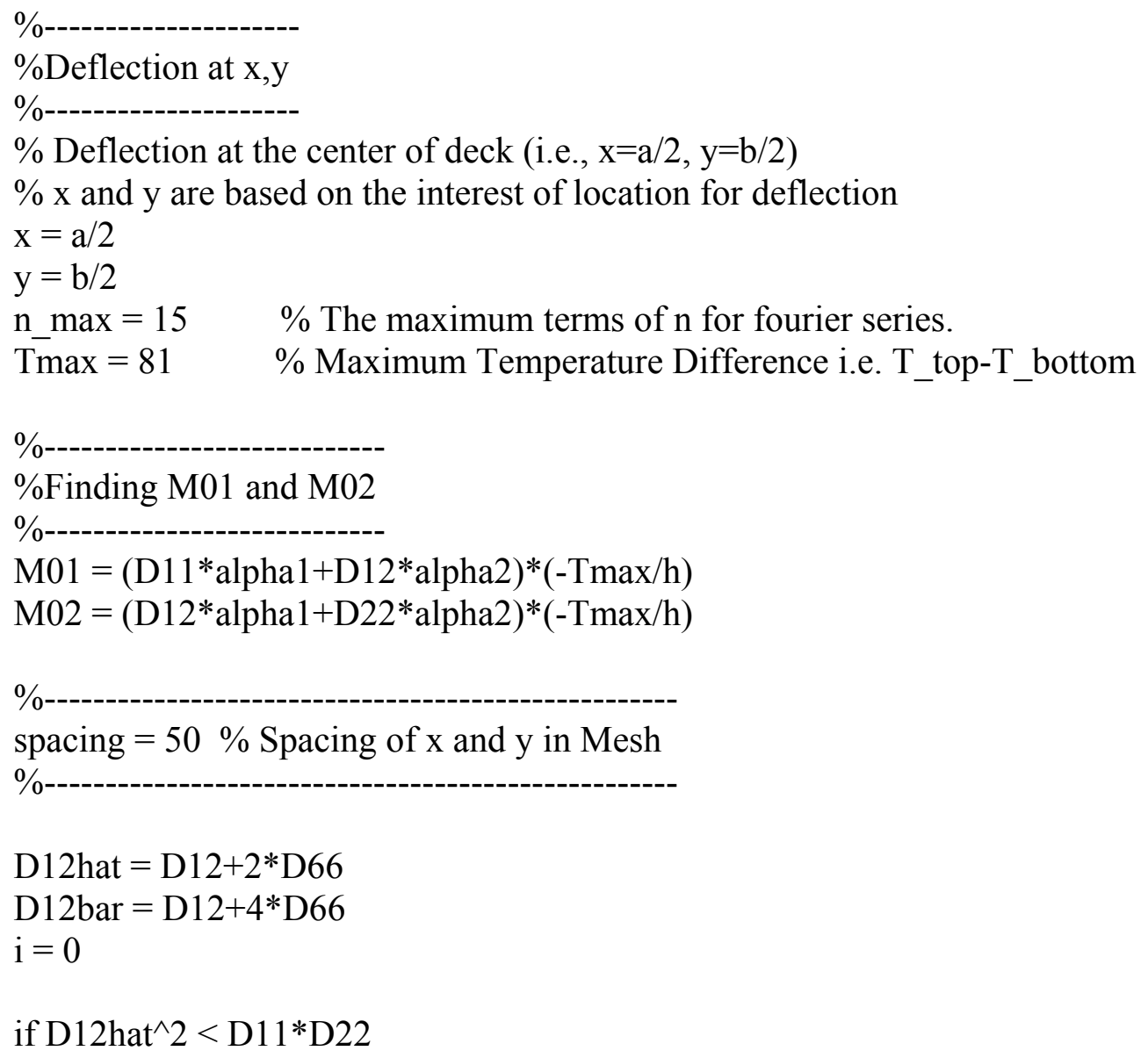

if D12hat ${ }^{\wedge} 2<$ D11*D22 


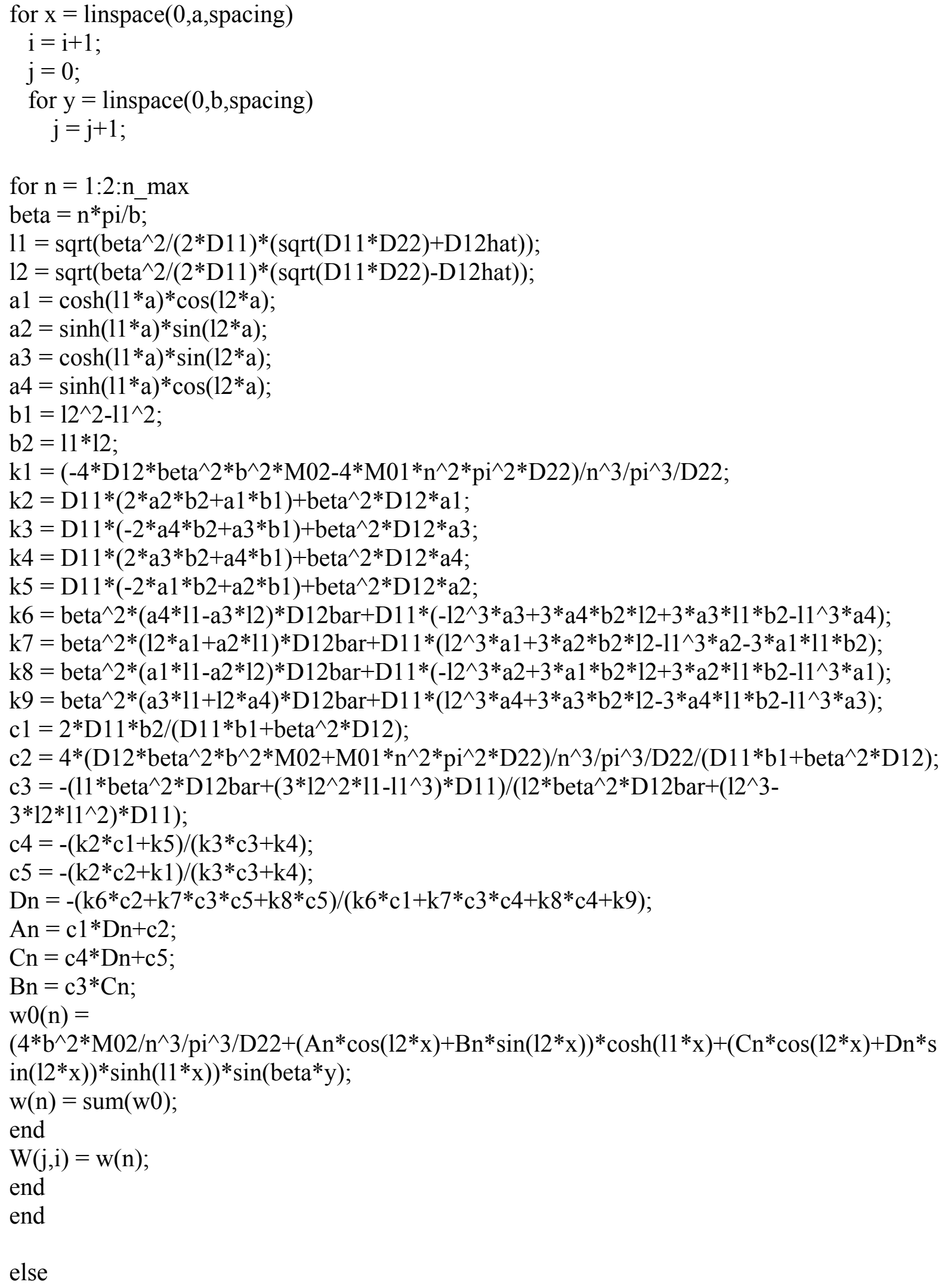


display('ERROR : Wnh is not in case 3. (see P 311)') end

$\mathrm{x}=$ linspace $(0, \mathrm{a}$, spacing $)$;

$\mathrm{y}=$ linspace $(0, \mathrm{~b}$, spacing $)$;

$\operatorname{mesh}(\mathrm{x}, \mathrm{y}, \mathrm{W})$

$\operatorname{surf}(\mathrm{x}, \mathrm{y}, \mathrm{W})$

title('Deflection Shape for Navier-Levy Method $\left.(n=15)^{\prime}\right)$

ylabel('Free Edge')

xlabel('Simply Supported Edge')

zlabel('Deflection, in.') 


\section{E.2.2 Center Deflection of Test Case 8HS (Navier-Levy)}

clc

clear

\%Calculation of deflection at $\mathrm{x}, \mathrm{y}$ with SSFF condition

$\%$

$\%$ FRP Deck Properties

$\%$

$\mathrm{D} 11=7 \mathrm{e} 7$

$\mathrm{D} 22=1.81 \mathrm{e} 7$

$\mathrm{D} 12=4.11 \mathrm{e} 6$

$\mathrm{D} 66=9.3 \mathrm{e} 6$

$\mathrm{h}=8$

$\%$ Height of FRP Deck

$\mathrm{a}=72$

$\%$ Dimemsion in $\mathrm{x}$ direction (SS Edge)

$\mathrm{b}=69 \quad \%$ Dimemsion in y direction (Free Edge)

alpha1 $=4.85 \mathrm{e}-6 \quad \%$ Thermal Coefficient in $\mathrm{x}$ direction

alpha $2=14.14 \mathrm{e}-6 \%$ Thermal Coefficient in y direction

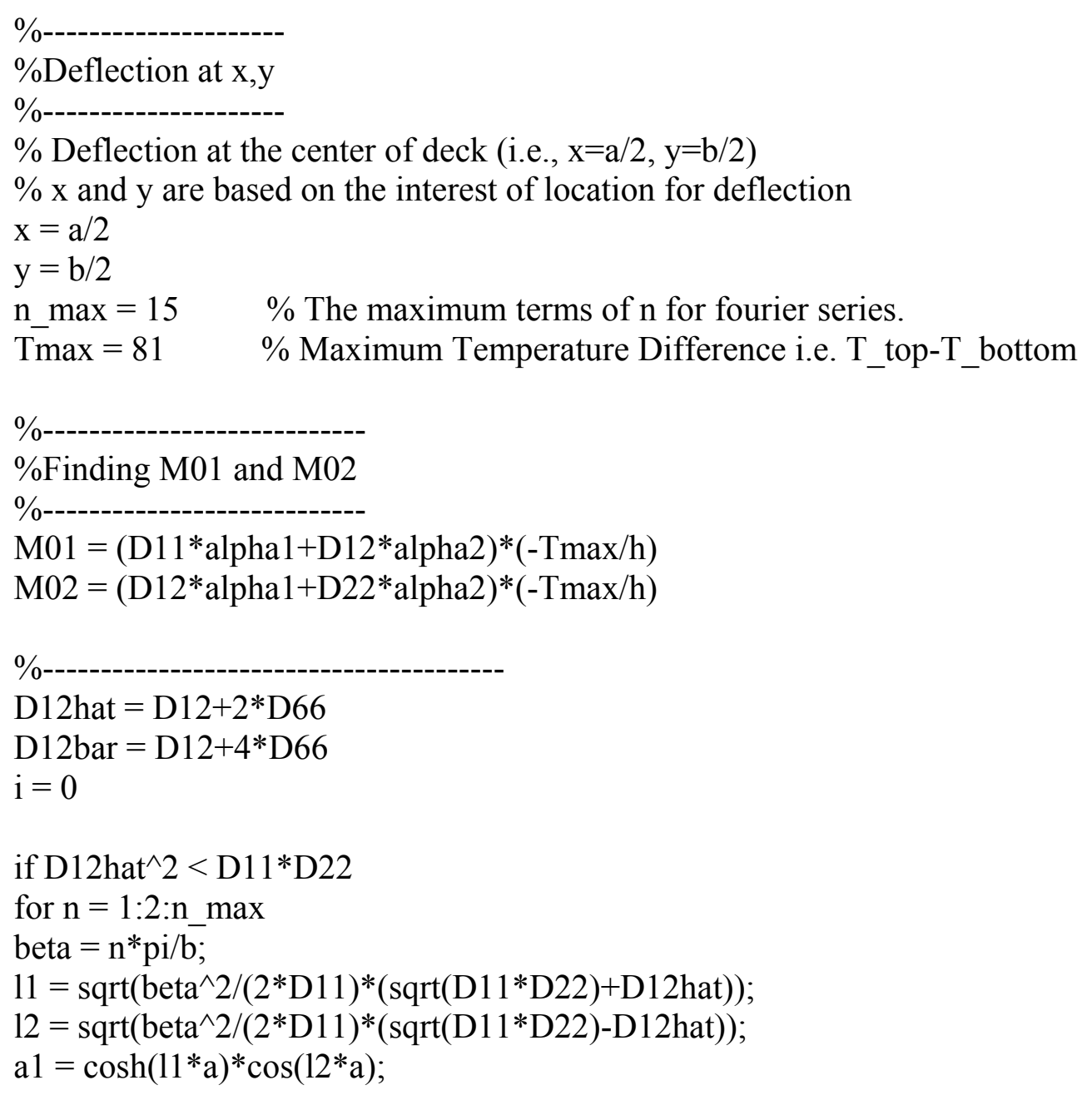




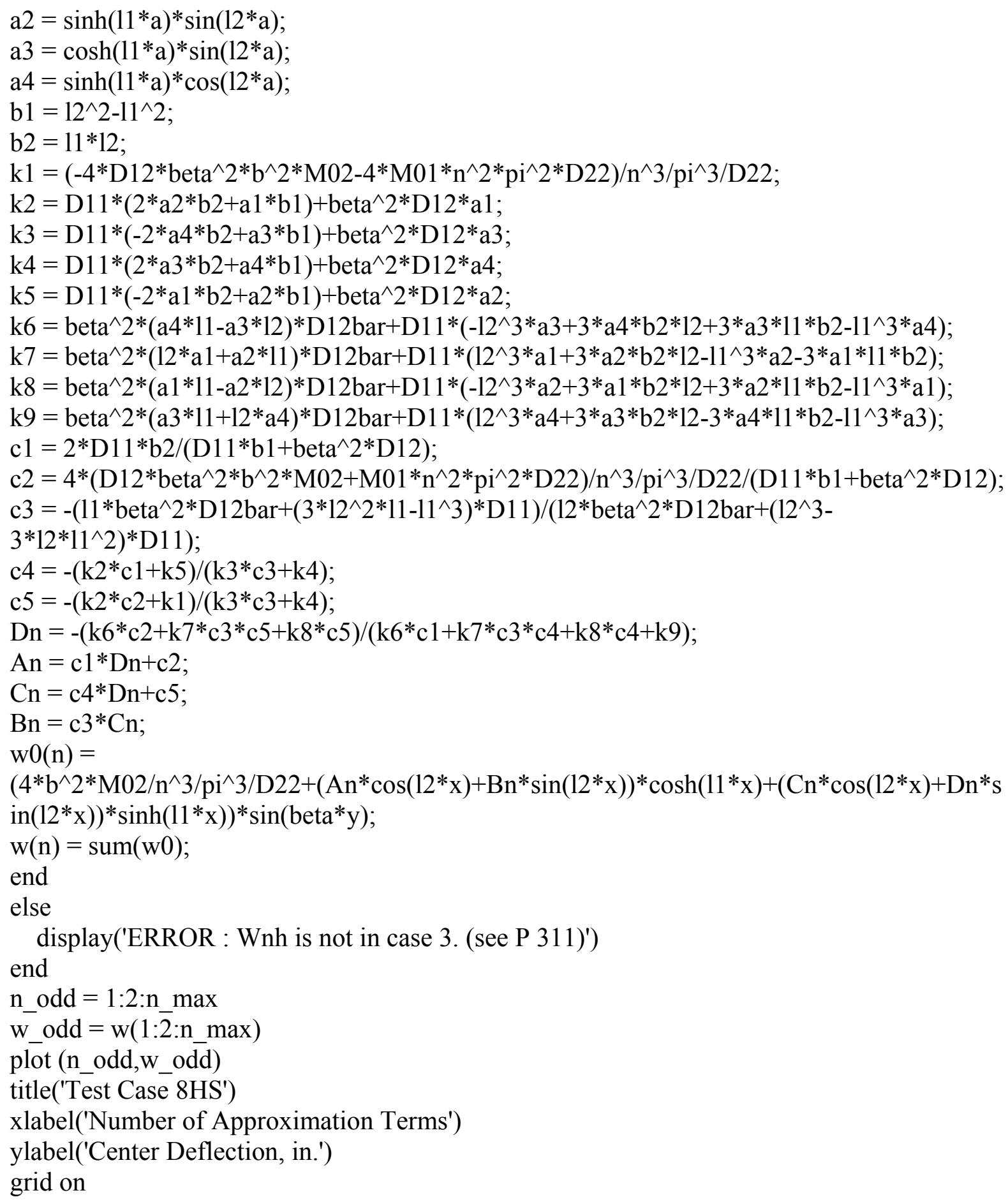




\section{E.2.3 Edge Deflection of Test Case 8HS (Navier-Levy)}

clc

clear

$\%$ Calculation of deflection at $\mathrm{x}, \mathrm{y}$ with SSFF condition

\%----------------------

$\%$ FRP Deck Properties

$\%$--------------------

$\mathrm{D} 11=7 \mathrm{e} 7$

$\mathrm{D} 22=1.81 \mathrm{e} 7$

$\mathrm{D} 12=4.11 \mathrm{e} 6$

$\mathrm{D} 66=9.3 \mathrm{e} 6$

$\mathrm{h}=8$

$\%$ Height of FRP Deck

$\mathrm{a}=72 \quad \%$ Dimemsion in $\mathrm{x}$ direction (SS Edge)

$\mathrm{b}=69 \quad \%$ Dimemsion in y direction (Free Edge)

alpha1 $=4.85 \mathrm{e}-6 \quad \%$ Thermal Coefficient in $\mathrm{x}$ direction

alpha $2=14.14 \mathrm{e}-6 \%$ Thermal Coefficient in y direction

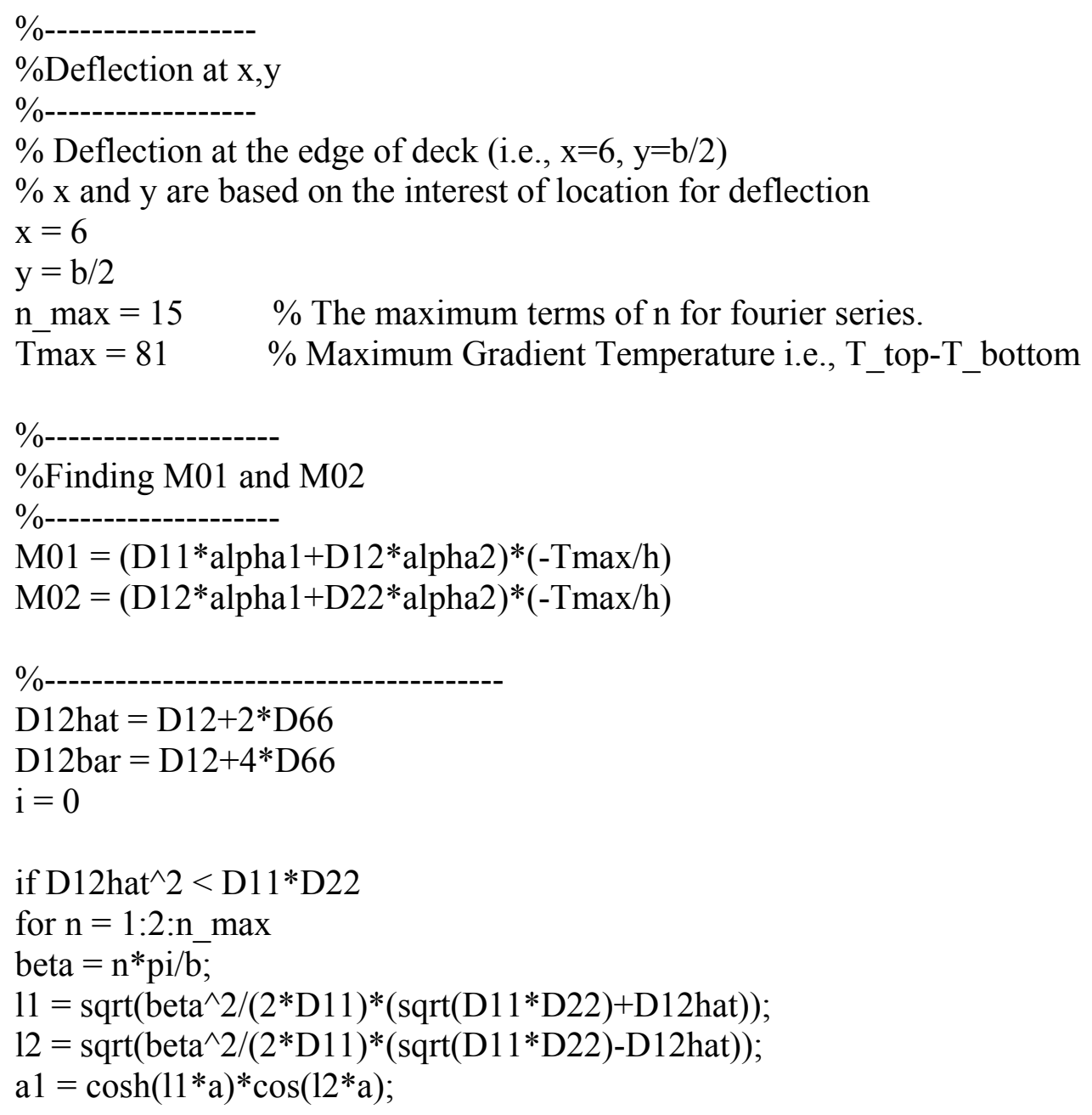




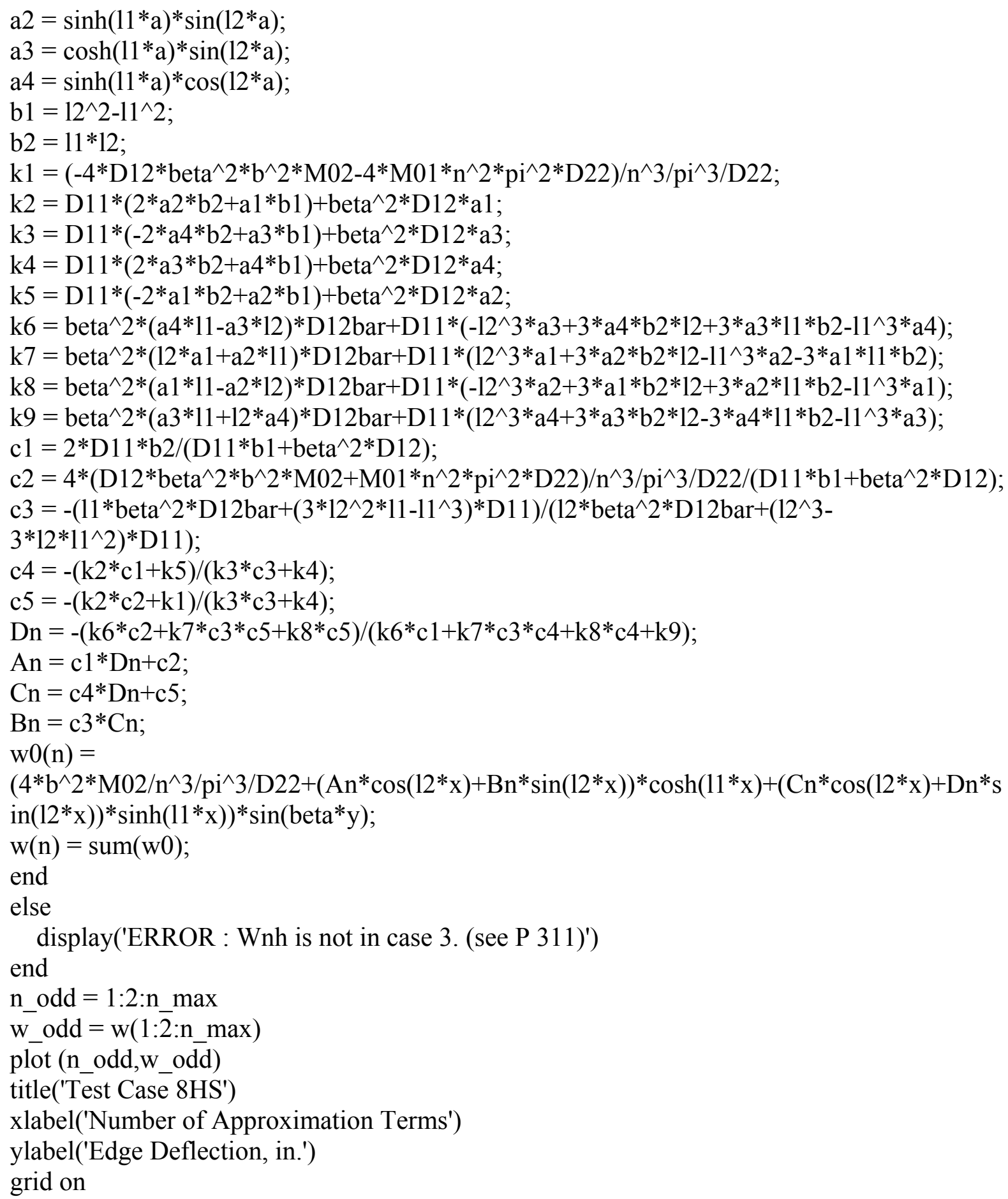




\section{E.2.4 Deflection Mesh of Test Case 8CS (Navier-Levy)}

The matlab code of deflection mesh for test case $8 \mathrm{CS}$ is similar to that for test case 8HS except the thermal coefficient and Tmax were changed as following.

alpha1 $=4.98 \mathrm{e}-6 \quad \%$ Thermal Coefficient in $\mathrm{x}$ direction alpha $2=11.92 \mathrm{e}-6 \%$ Thermal Coefficient in y direction Tmax $=-90 \quad \%$ Maximum Temperature Difference i.e., T_top-T_bottom

\section{E.2.5 Center Deflection of Test Case 8CS (Navier-Levy)}

The matlab code of center deflection for test case $8 \mathrm{CS}$ is similar to that for test case 8HS except the thermal coefficient and Tmax were changed as following.

alpha $1=4.98 \mathrm{e}-6 \quad \%$ Thermal Coefficient in $\mathrm{x}$ direction alpha $2=11.92 \mathrm{e}-6 \%$ Thermal Coefficient in y direction

Tmax $=-90 \quad \%$ Maximum Temperature Difference i.e., T_top-T_bottom

\section{E.2.6 Edge Deflection of Test Case 8CS (Navier-Levy)}

The matlab code of edge deflection for test case 8CS is similar to that for test case 8HS except the thermal coefficient and Tmax were changed as following.

alpha1 $=4.98 \mathrm{e}-6 \quad \%$ Thermal Coefficient in $\mathrm{x}$ direction alpha $2=11.92 \mathrm{e}-6 \%$ Thermal Coefficient in y direction

Tmax $=-90 \quad \%$ Maximum Temperature Difference i.e., T_top-T_bottom

\section{E.2.7 Deflection Mesh of Test Case 4HS (Navier-Levy)}

The matlab code of deflection mesh for test case 4HS is similar to that for test case $8 \mathrm{HS}$ except FRP deck properties, thermal coefficient and Tmax were changed as following.

$\mathrm{D} 11=11 \mathrm{e} 6$

$\mathrm{D} 22=2.75 \mathrm{e} 6$

$\mathrm{D} 12=.69 \mathrm{e} 6$

$\mathrm{D} 66=1.5 \mathrm{e} 6$

$\mathrm{h}=4 \quad \%$ Height of FRP Deck

$\mathrm{a}=72 \quad \%$ Dimemsion in $\mathrm{x}$ direction (SS Edge)

$\mathrm{b}=70 \quad \%$ Dimemsion in y direction (Free Edge) 
alpha1 $=5.73 \mathrm{e}-6 \quad \%$ Thermal Coefficient in $\mathrm{x}$ direction

alpha $2=9.56 \mathrm{e}-6 \%$ Thermal Coefficient in y direction

$\operatorname{Tmax}=56 \quad \%$ Maximum Temperature Difference i.e., T_top-T_bottom

\section{E.2.8 Center Deflection of Test Case 4HS (Navier-Levy)}

The matlab code of center deflection for test case 4HS is similar to that for test case 8HS except FRP deck properties, thermal coefficient and Tmax were changed as following.

$\mathrm{D} 11=11 \mathrm{e} 6$

$\mathrm{D} 22=2.75 \mathrm{e} 6$

$\mathrm{D} 12=.69 \mathrm{e} 6$

$\mathrm{D} 66=1.5 \mathrm{e} 6$

$\mathrm{h}=4 \quad \%$ Height of FRP Deck

$\mathrm{a}=72 \quad \%$ Dimemsion in $\mathrm{x}$ direction (SS Edge)

$\mathrm{b}=70 \quad \%$ Dimemsion in y direction (Free Edge)

alpha1 $=5.73 \mathrm{e}-6 \quad \%$ Thermal Coefficient in $\mathrm{x}$ direction

alpha $2=9.56 \mathrm{e}-6 \%$ Thermal Coefficient in y direction

Tmax $=56 \quad \%$ Maximum Temperature Difference i.e., T_top-T_bottom

\section{E.2.9 Edge Deflection of Test Case 4HS (Navier-Levy)}

The matlab code of edge deflection for test case 4HS is similar to that for test case

8HS except FRP deck properties, thermal coefficient and Tmax were changed as following.
$\mathrm{D} 11=11 \mathrm{e} 6$
$\mathrm{D} 22=2.75 \mathrm{e} 6$
$\mathrm{D} 12=.69 \mathrm{e} 6$
$\mathrm{D} 66=1.5 \mathrm{e} 6$
$\mathrm{h}=4 \quad \%$ Height of FRP Deck
$\mathrm{a}=72 \quad \%$ Dimemsion in $\mathrm{x}$ direction (SS Edge)
$\mathrm{b}=70 \quad \%$ Dimemsion in y direction (Free Edge)
alpha1 $=5.73 \mathrm{e}-6 \quad \%$ Thermal Coefficient in $\mathrm{x}$ direction
alpha $2=9.56 \mathrm{e}-6 \%$ Thermal Coefficient in y direction
Tmax $=56 \quad \%$ Maximum Temperature Difference i.e., T_top-T_bottom 


\section{E.2.10 Deflection Mesh of Test Case 4CS (Navier-Levy)}

The matlab code of deflection mesh for test case 4CS is similar to that for test case 8HS except FRP deck properties, thermal coefficient and Tmax were changed as following.

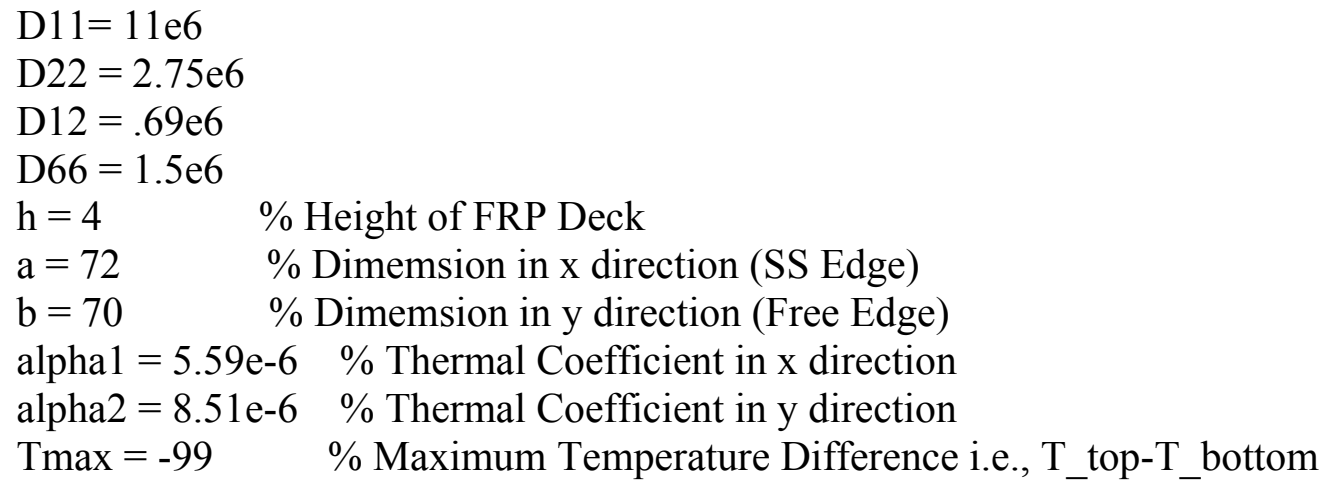

\section{E.2.11 Center Deflection of Test Case 4CS (Navier-Levy)}

The matlab code of center deflection for test case 4CS is similar to that for test case $8 \mathrm{HS}$ except FRP deck properties, thermal coefficient and Tmax were changed as following.

$\mathrm{D} 11=11 \mathrm{e} 6$

$\mathrm{D} 22=2.75 \mathrm{e} 6$

$\mathrm{D} 12=.69 \mathrm{e} 6$

$\mathrm{D} 66=1.5 \mathrm{e} 6$

$\mathrm{h}=4$

$\mathrm{a}=72$

$\%$ Height of FRP Deck

$\mathrm{b}=70$

$\%$ Dimemsion in $\mathrm{x}$ direction (SS Edge)

alpha1 $=5.59 \mathrm{e}-6$

alpha $2=8.51 \mathrm{e}-6 \quad \%$ Thermal Coefficient in y direction

Tmax $=-99 \quad \%$ Maximum Temperature Difference i.e., T_top-T_bottom

\section{E.2.12 Edge Deflection of Test Case 4CS (Navier-Levy)}

The matlab code of edge deflection for test case 4CS is similar to that for test case 8HS except FRP deck properties, thermal coefficient and Tmax were changed as following.

$\mathrm{D} 11=11 \mathrm{e} 6$

$\mathrm{D} 22=2.75 \mathrm{e} 6$ 


$$
\begin{aligned}
& \mathrm{D} 12=0.69 \mathrm{e} 6 \\
& \mathrm{D} 66=1.5 \mathrm{e} 6 \\
& \mathrm{~h}=4 \quad \% \text { Height of FRP Deck } \\
& \mathrm{a}=72 \quad \text { \% Dimemsion in x direction (SS Edge) } \\
& \mathrm{b}=70 \quad \% \text { Dimemsion in y direction (Free Edge) } \\
& \text { alpha1 }=5.59 \mathrm{e}-6 \quad \% \text { Thermal Coefficient in x direction } \\
& \text { alpha2 }=8.51 \mathrm{e}-6 \quad \% \text { Thermal Coefficient in y direction } \\
& \text { Tmax }=-99 \quad \text { \% Maximum Temperature Difference i.e., T_top-T_bottom }
\end{aligned}
$$




\section{E.3 Deflection Plot based on Macro Approach}

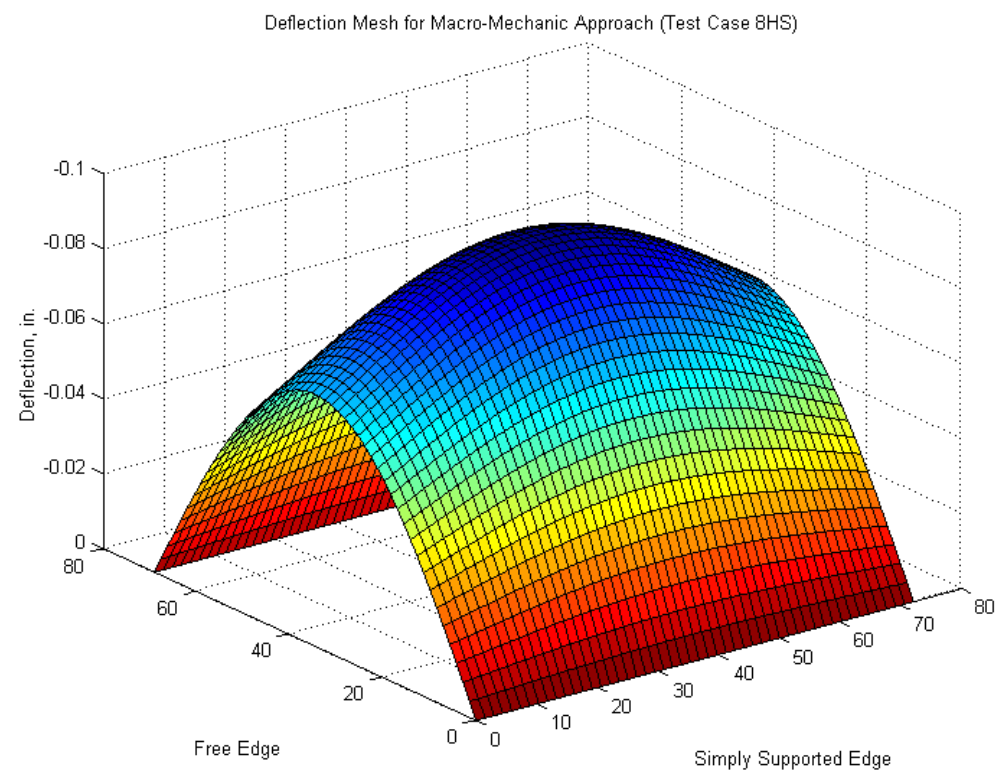

Figure E.13: Deflection Mesh for Test Case 8HS (Macro Approach).

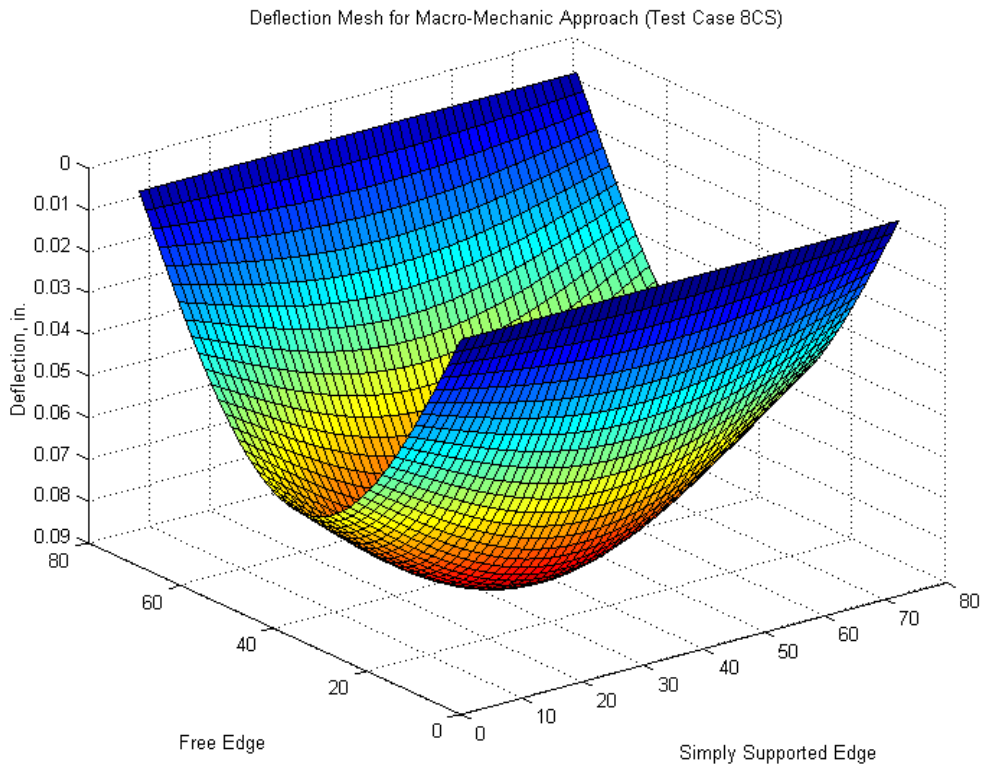

Figure E.14: Deflection Mesh for Test Case 8CS (Macro Approach). 


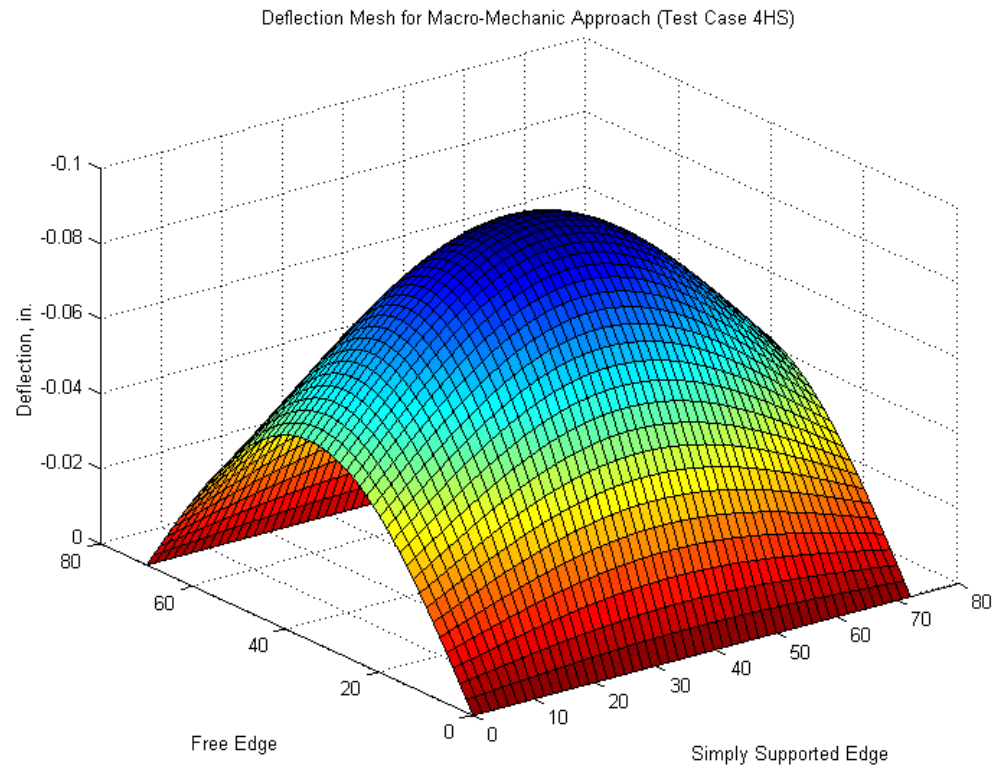

Figure E.15: Deflection Mesh for Test Case 4HS (Macro Approach).

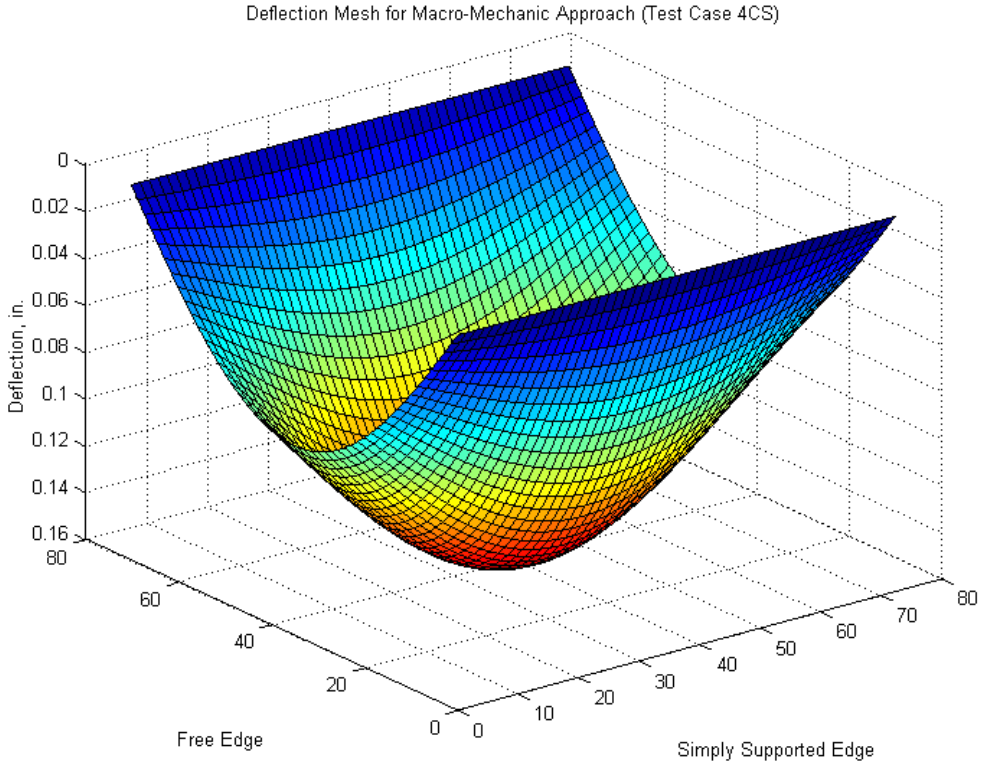

Figure E.16: Deflection Mesh for Test Case 4CS (Macro Approach). 


\section{E.4 Matlab program code for computation based on Macro Approach}

\section{E.4.1 Deflection Mesh of Test Case 8HS (Macro Approach)}

clc

clear

$\%$ Calculation of deflection at $\mathrm{x}, \mathrm{y}$ with SSFF condition

$\%$ Macro Approach

display('Test Case 8HS')

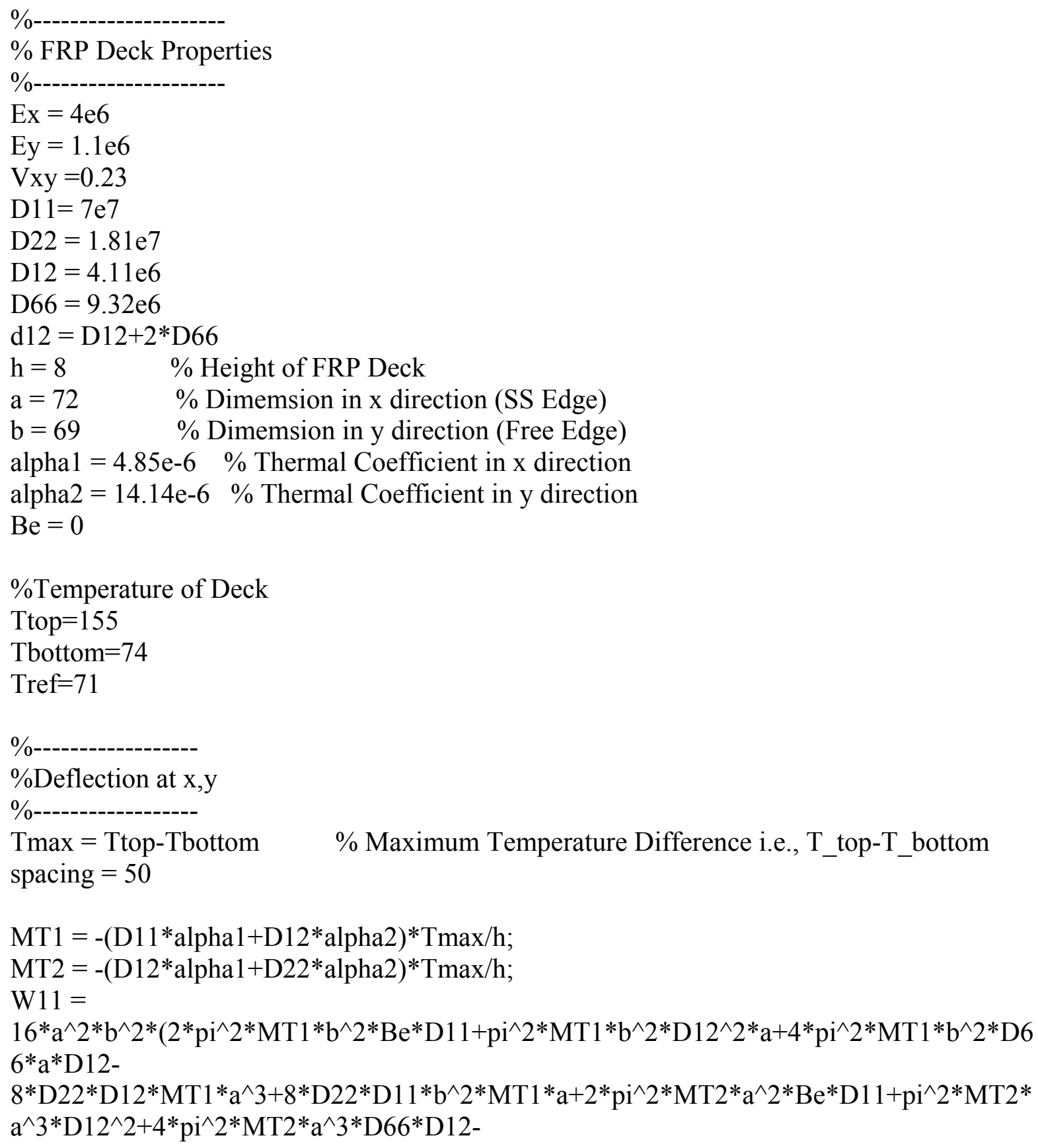


$\left.16 * \mathrm{~d} 12 * \mathrm{D} 12 * \mathrm{MT} 1{ }^{*} \mathrm{~b}^{\wedge} 2 * \mathrm{a}\right) / \mathrm{pi}^{\wedge} 4 /\left(2 * \mathrm{pi}^{\wedge} 2 * \mathrm{D} 11^{\wedge} 2 * \mathrm{~b}^{\wedge} 4 * \mathrm{Be}+\mathrm{pi}^{\wedge} 2 * \mathrm{D} 11^{*} \mathrm{~b}^{\wedge} 4 * \mathrm{D} 12{ }^{\wedge}{ }^{*} \mathrm{a}+4 * \mathrm{pi}^{\wedge} 2\right.$ *D11*b^4*D66*a*D12-8*D22*D12^2*a^5-

$32 * \mathrm{D} 22 * \mathrm{D} 12 * \mathrm{a}^{\wedge} 5 * \mathrm{D} 66+4 * \mathrm{pi}^{\wedge} 2 * \mathrm{~d} 12 * \mathrm{a}^{\wedge} 2 * \mathrm{~b}^{\wedge} 2 * \mathrm{Be} * \mathrm{D} 11+2 * \mathrm{pi}^{\wedge} 2 * \mathrm{~d} 12 * \mathrm{a}^{\wedge} 3 * \mathrm{~b}^{\wedge} 2 * \mathrm{D} 12^{\wedge} 2+8 * \mathrm{pi}$ ${ }^{\wedge} 2 * \mathrm{~d} 12 * \mathrm{a}^{\wedge} 3 * \mathrm{~b}^{\wedge} 2 * \mathrm{D} 66 * \mathrm{D} 12+8 * \mathrm{D} 22 * \mathrm{D} 11 \wedge 2 * \mathrm{~b}^{\wedge} 4 * \mathrm{a}+32 * \mathrm{D} 22 * \mathrm{D} 11 * \mathrm{~b}^{\wedge} 2 * \mathrm{a}^{\wedge} 3 * \mathrm{D} 66+2 * \mathrm{pi}^{\wedge} 2 * \mathrm{D}$ $22 * \mathrm{a}^{\wedge} 4 * \mathrm{Be} * \mathrm{D} 11+\mathrm{pi}^{\wedge} 2 * \mathrm{D} 22 * \mathrm{a}^{\wedge} 5 * \mathrm{D} 12 \wedge 2+4 * \mathrm{pi}^{\wedge} 2 * \mathrm{D} 22 * \mathrm{a}^{\wedge} 5 * \mathrm{D} 66 * \mathrm{D} 12-$

$\left.16 * \mathrm{~d} 12 * \mathrm{D} 12 * \mathrm{~b}^{\wedge} 4 * \mathrm{a}^{*} \mathrm{D} 11-16^{*} \mathrm{~d} 12 * \mathrm{D} 12^{\wedge} 2 * \mathrm{~b}^{\wedge} 2^{*} \mathrm{a}^{\wedge} 3-64 * \mathrm{~d} 12 * \mathrm{D} 12 * \mathrm{~b}^{\wedge} 2 \mathrm{a}^{*} \mathrm{a}^{\wedge} 3 * \mathrm{D} 66\right)$;

c2 $=2 * \mathrm{D} 11 * \mathrm{~b}^{\wedge} 2 *\left(\mathrm{D} 11 * \mathrm{~W} 11 * \mathrm{pi}^{\wedge} 4 * \mathrm{~b}^{\wedge} 2+\mathrm{D} 12 * \mathrm{~W} 11 * \mathrm{pi}^{\wedge} 4 * \mathrm{a}^{\wedge} 2-\right.$

$\left.16 * \mathrm{MT} 1 * \mathrm{~b}^{\wedge} 2 * \mathrm{a}^{\wedge} 2+4 * \mathrm{D} 66 * \mathrm{~W} 11 * \mathrm{pi}^{\wedge}{ }^{\wedge}{ }^{*} \mathrm{a}^{\wedge} 2\right) / \mathrm{W} 11 / \mathrm{pi}^{\wedge} 5 / \mathrm{a}^{\wedge} 3 /(2 *$ Be*D11+D12^2*a+4*D66*a*

D12);

$\mathrm{c} 1=1 / 2 * \mathrm{D} 12 * \mathrm{c} 2 * \mathrm{pi}^{\wedge} 2 / \mathrm{D} 11 / \mathrm{b}^{\wedge} 2$;

$\%$ Meshing deflection

$\mathrm{i}=0$

for $\mathrm{x}=$ linspace $(0, \mathrm{a}, \mathrm{spacing})$

$\mathrm{i}=\mathrm{i}+1$;

$\mathrm{j}=0$;

for $\mathrm{y}=$ linspace $(0, \mathrm{~b}$, spacing $)$

$\mathrm{j}=\mathrm{j}+1$;

$\mathrm{w}=\mathrm{W} 11 * \sin \left(\mathrm{pi}^{*} \mathrm{y} / \mathrm{b}\right) *\left(\sin \left(\mathrm{pi}^{*} \mathrm{x} / \mathrm{a}\right)+\mathrm{c} 1 * \mathrm{x} *(\mathrm{x}-\mathrm{a})+\mathrm{c} 2\right)$;

$\mathrm{W}(\mathrm{j}, \mathrm{i})=\mathrm{w}$;

end

end

$\mathrm{x}=$ linspace $(0, \mathrm{a}$, spacing $)$;

$\mathrm{y}=$ linspace $(0, \mathrm{~b}$, spacing $)$;

$\operatorname{mesh}(\mathrm{x}, \mathrm{y}, \mathrm{W})$

$\operatorname{surf}(\mathrm{x}, \mathrm{y}, \mathrm{W})$

title('Deflection Shape for Macro-Mechanic Approach')

ylabel('Free Edge')

xlabel('Simply Supported Edge')

zlabel('Deflection, in.') 


\section{E.4.2 Deflection Mesh of Test Case 8CS (Macro Approach)}

The matlab code of deflection mesh for test case $8 \mathrm{CS}$ is similar to that for test case 8HS in section E.4.1 except thermal coefficient and temperature data were changed as

following.

alpha1 $=4.98 \mathrm{e}-6 \quad \%$ Thermal Coefficient in $\mathrm{x}$ direction alpha $2=11.92 \mathrm{e}-6 \%$ Thermal Coefficient in y direction Ttop $=-30$

Tbottom $=60$

Tref $=80$

\section{E.4.3 Deflection Mesh of Test Case 4HS (Macro Approach)}

The matlab code of deflection mesh for test case 4HS is similar to that for test case 8HS in section E.4.1 except FRP deck properties, thermal coefficient and temperature data were changed as following.

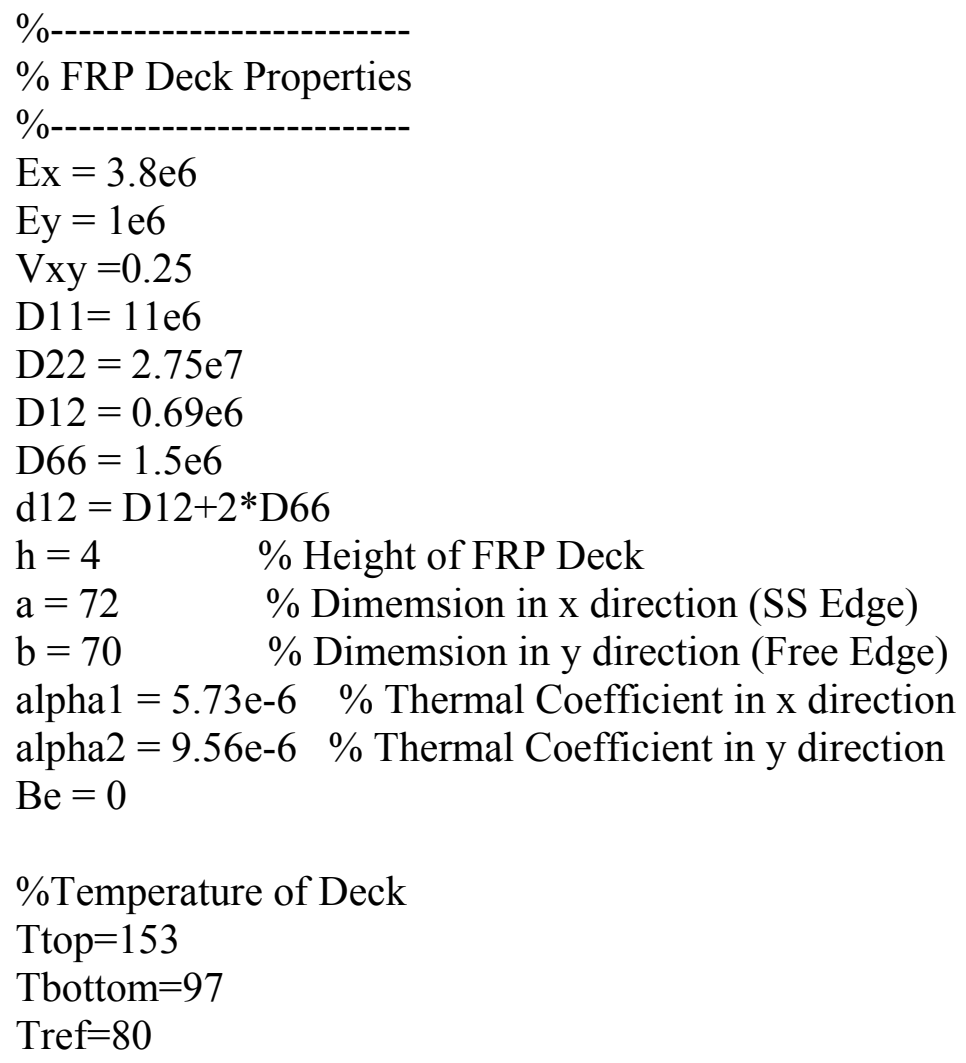




\section{E.4.4. Deflection Mesh of Test Case 4CS (Macro Approach)}

The matlab code of deflection mesh for test case 4CS is similar to that for test case 8HS in section E.4.1 except FRP deck properties, thermal coefficient and temperature data were changed as following.

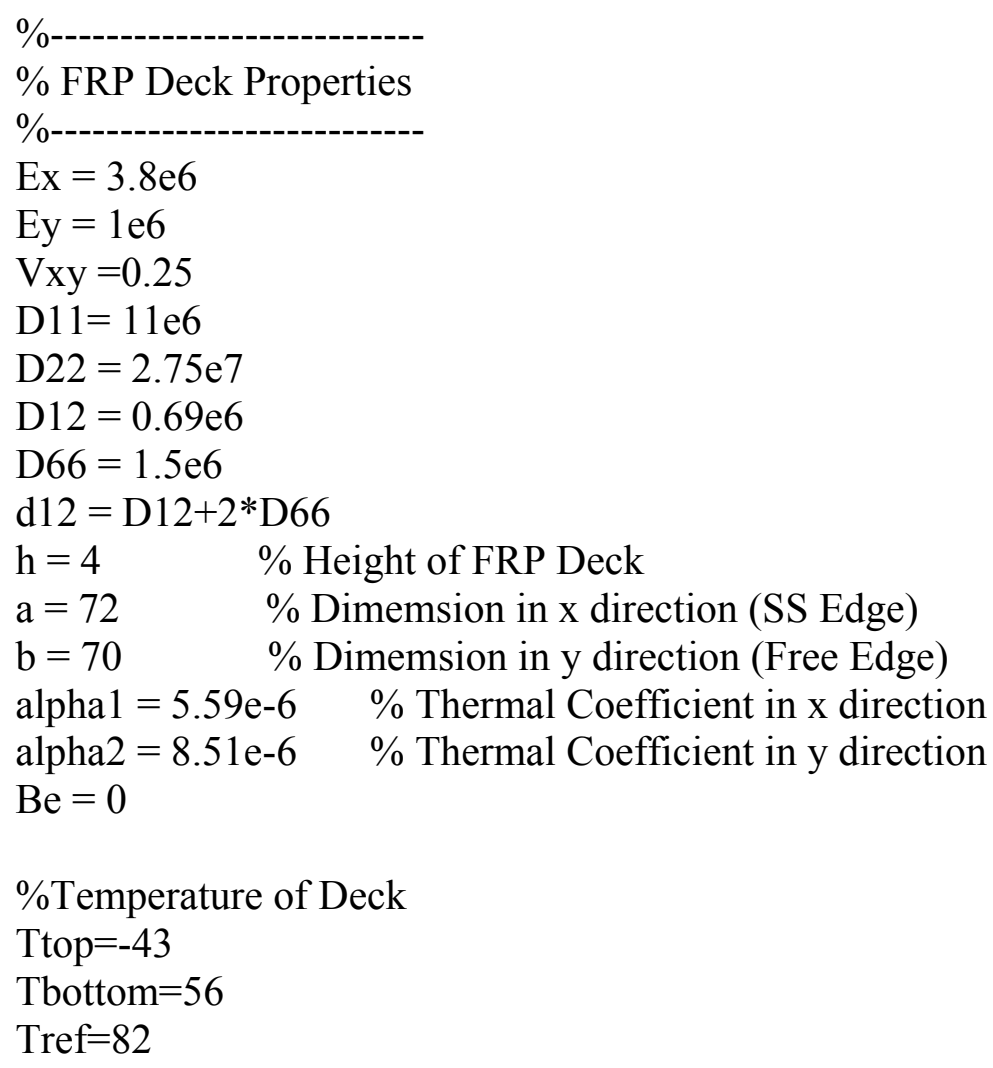




\section{Appendix F}

\section{Theoretical Results using FEM (ANSYS Version 7.1)}

Appendix F was divided into two section. Section 1 showed the contour plot of deflection, strain and stress for all test cases. Section 2 showed the input text command of ANSYS V7.1 for all test cases.

\section{Contour plot results of deflection, strain and stress}

\section{Notes for Test Case 8HS, 8CS, 4HS and 4CS (SSFF Boundary)}

- Simply Supported Edge @ $Y=0, \mathrm{~b}$ and Free Edge @ $X=0$, a ( $X$ is Cell Direction)

- Top Surface @ $Z=0$ and Bottom Surface @ $Z=4$ and 8 in. for 4 and 8 in. FRP deck specimens, respectively.

- The above contour was only shown a quarter model of specimens (i.e. Dimensions in $X$ and $Y$ direction were a/2 to $\mathrm{b} / 2$, respectively).

- Applied Temperature and elastic properties of FRP deck can be found in Table 6.1 to

6.4

in Chapter 6

\section{Notes for Test Cases 8HF, 8CF, 4HF and 4CF (FFFF Boundary)}

- Free Edge $@ X=0$, a and $Y=0, \mathrm{~b}(X$ is Cell Direction. $)$

- Top Surface @ $Z=0$ and Bottom Surface @ $Z=4$ and 8 in. for 4 and 8 in. FRP deck specimens, respectively.

- The above contour was only shown a quarter model of specimens (i.e. Dimensions in $X$ and $Y$ direction were a/2 to $\mathrm{b} / 2$, respectively).

- Applied temperature and elastic properties of FRP deck can be found in Table 6.1 to 6.4 in Chapter 6 


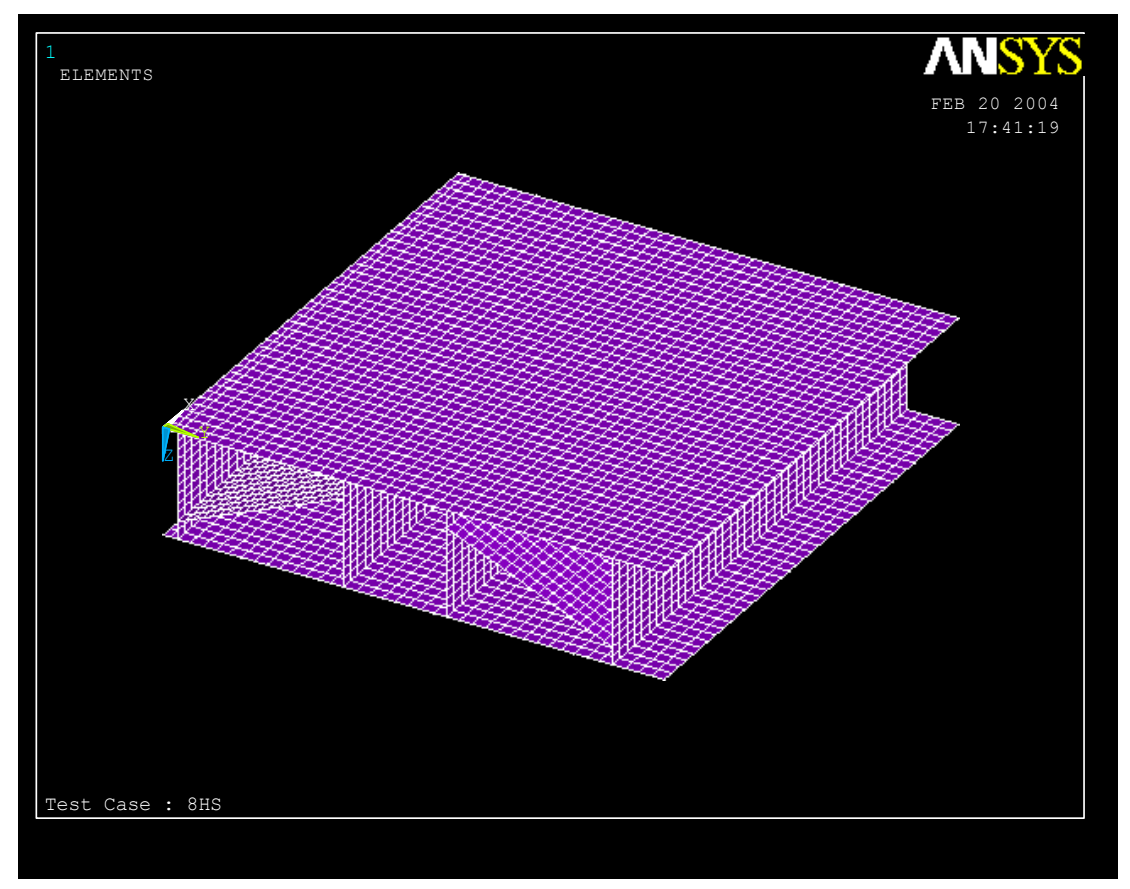

Figure F.1: A Quarter Model of 8 in. FRP Deck Specimens.

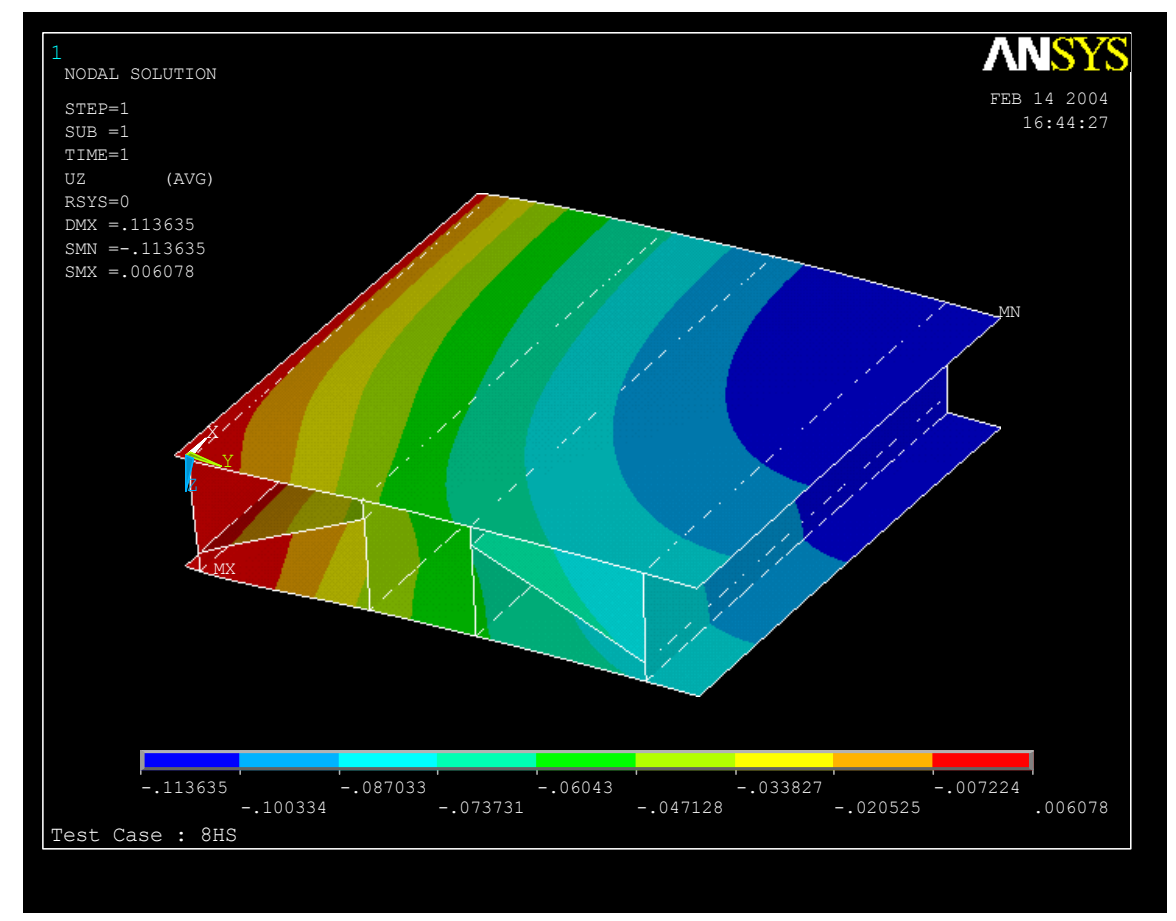

Figure F.2: Displacement Contour Plot in Z Direction (Test Case 8HS). 


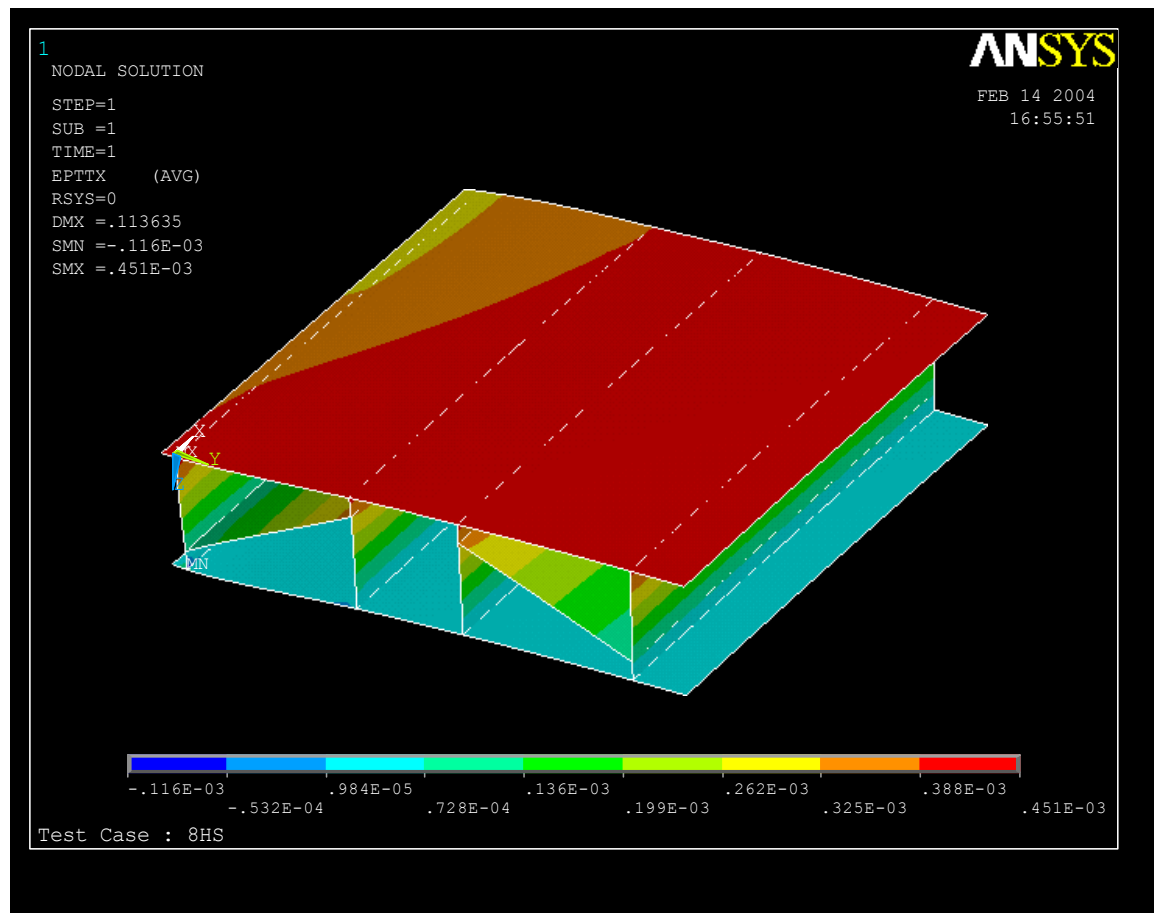

Figure F.3: Strain Contour Plot in X Direction (Test Case 8HS).

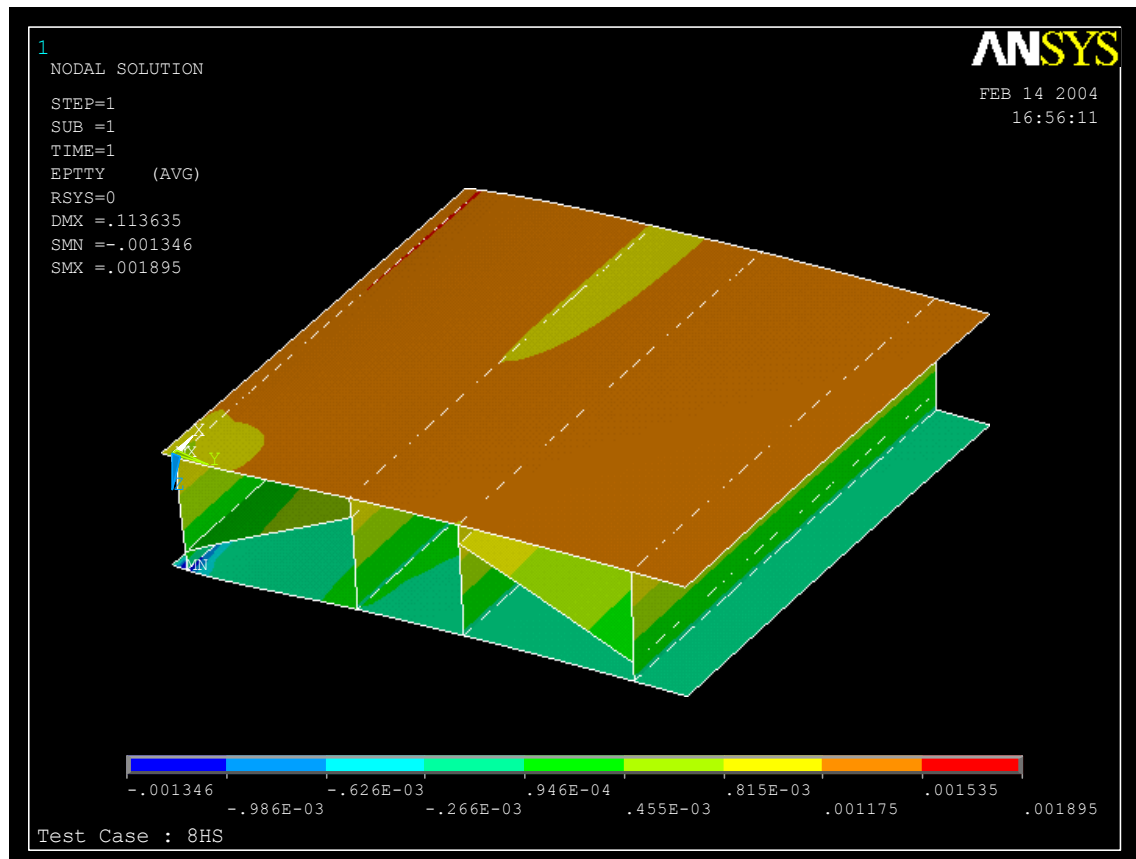

Figure F.4: Strain Contour Plot in Y Direction (Test Case 8HS). 


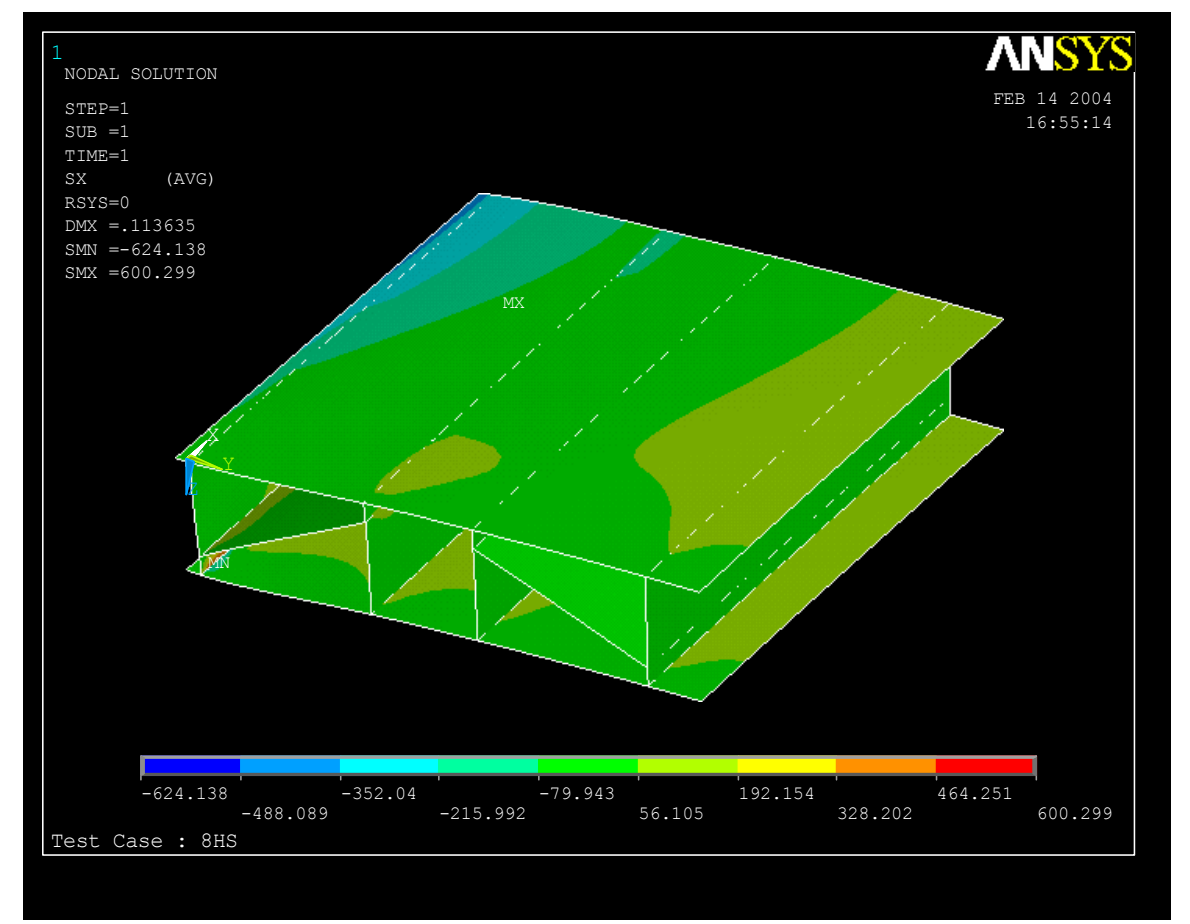

Figure F.5: Stress Contour Plot in X Direction (Test Case 8HS).

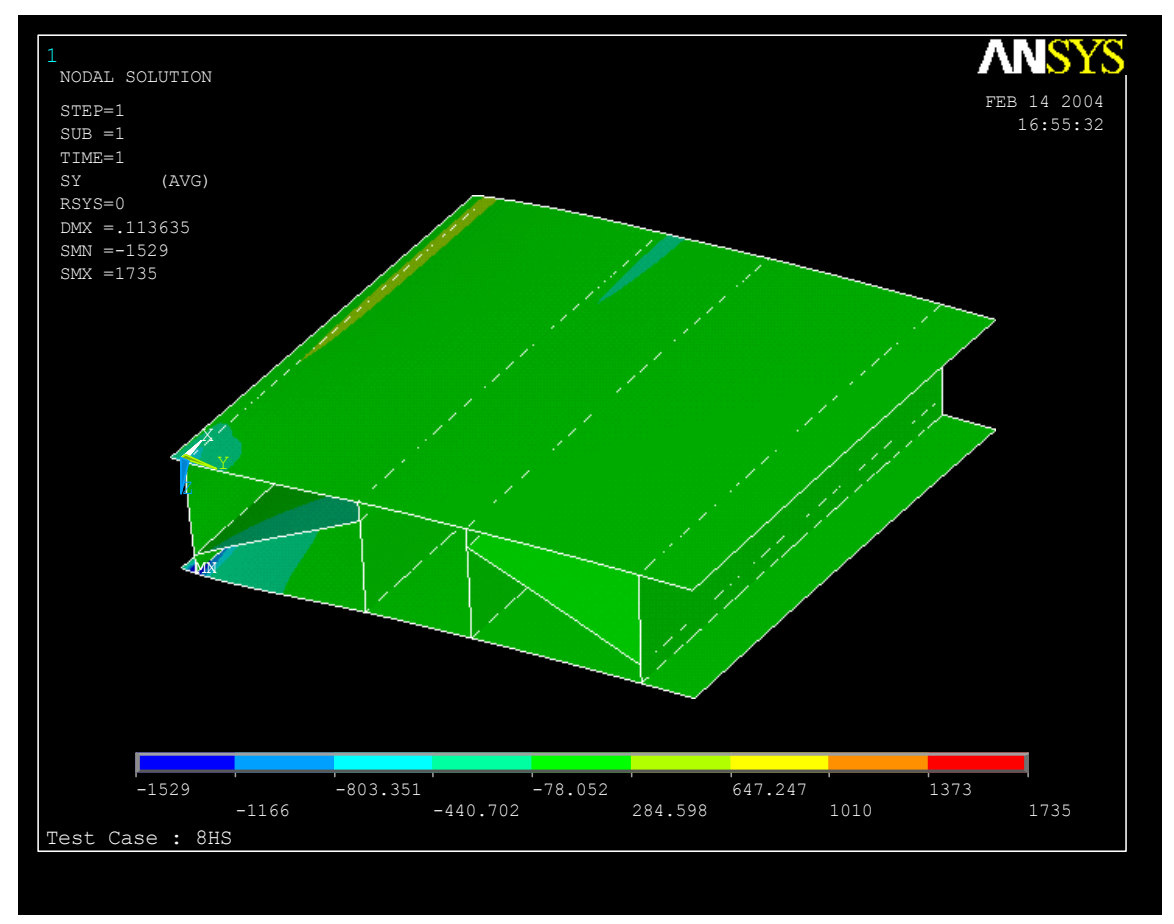

Figure F.6: Stress Contour Plot in Y Direction (Test Case 8HS). 


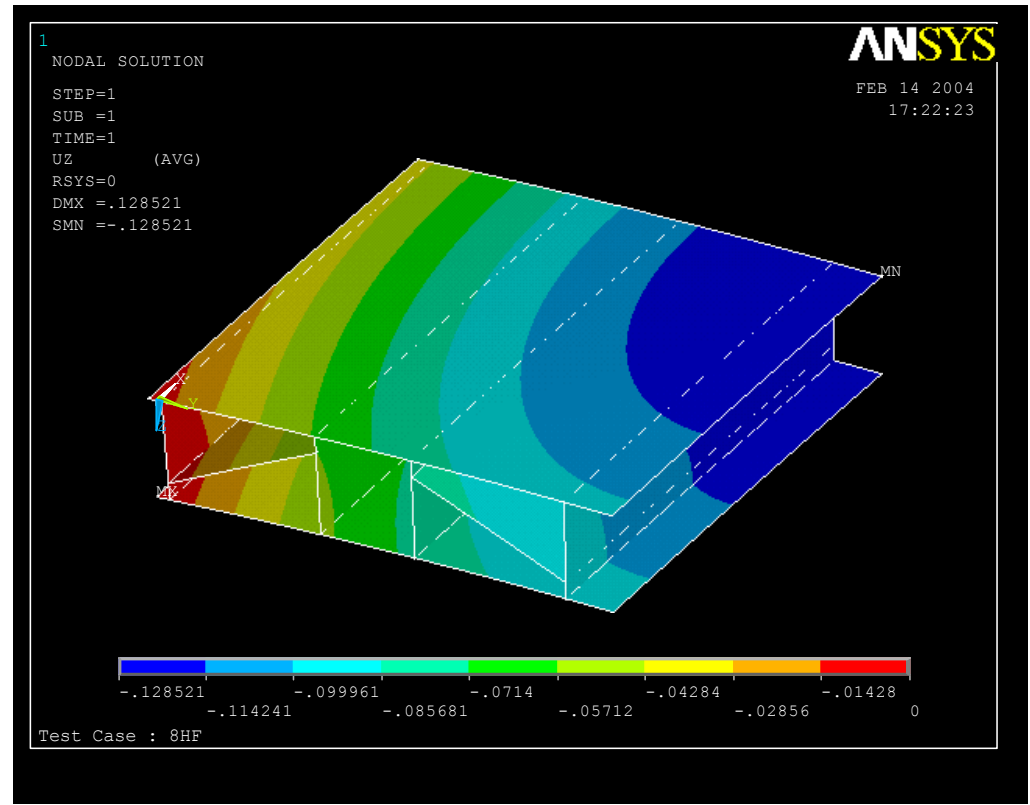

Figure F.7: Displacement Contour Plot in Z Direction (Test Case 8HF).

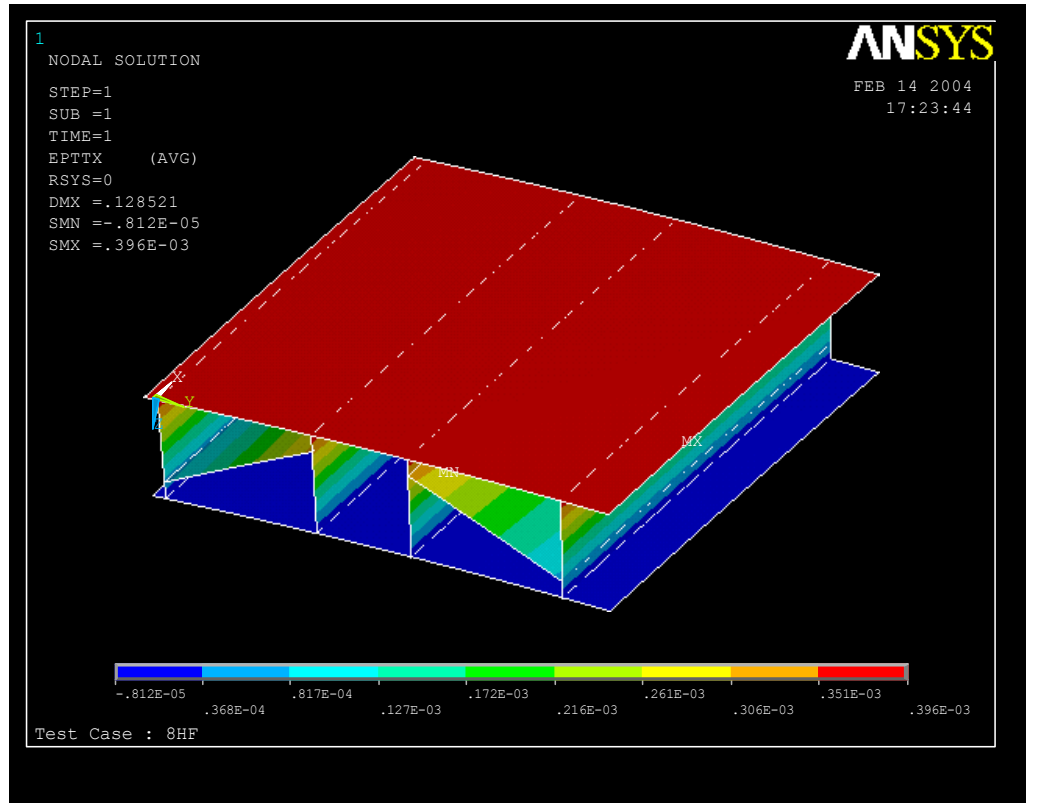

Figure F.8: Strain Contour Plot in X Direction (Test Case 8HF). 


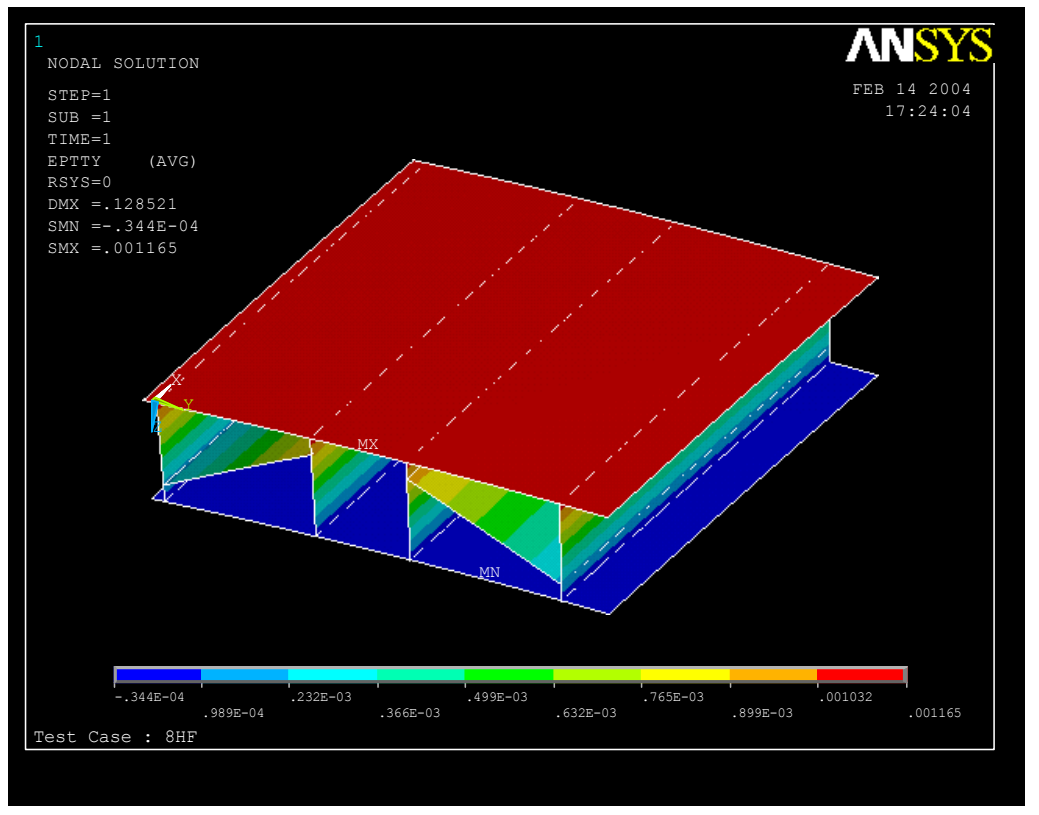

Figure F.9: Strain Contour Plot in Y Direction (Test Case 8HF).

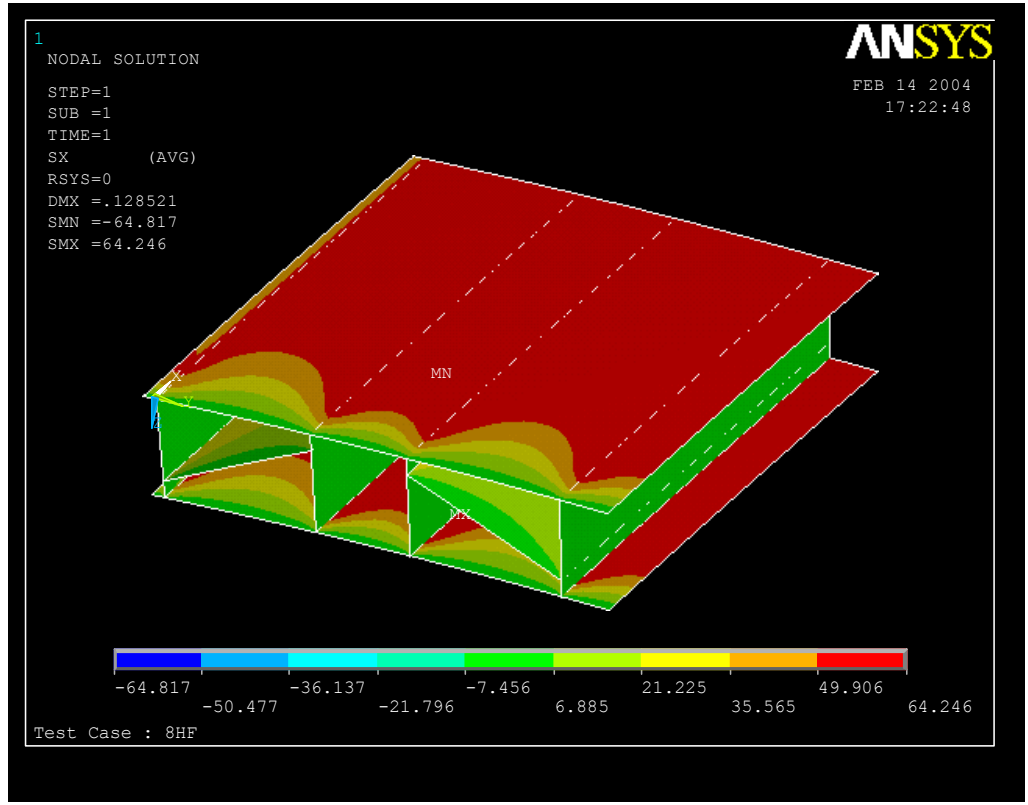

Figure F.10: Stress Contour Plot in X Direction (Test Case 8HF). 


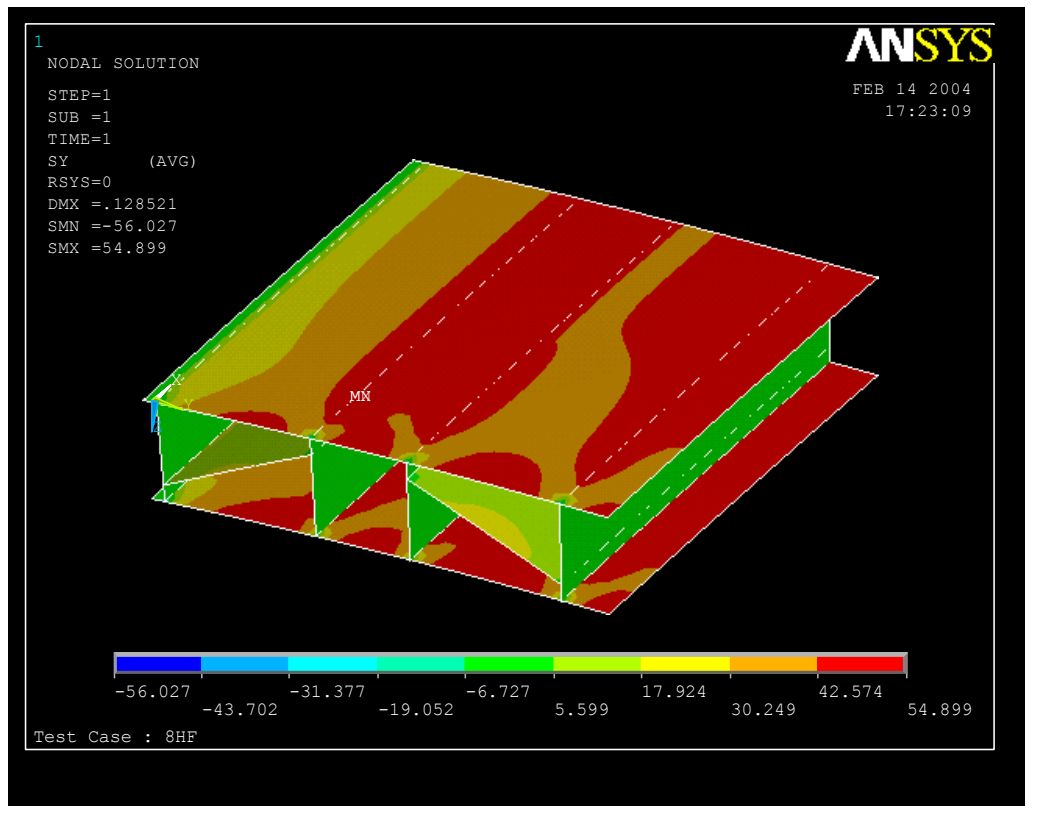

Figure F.11: Stress Contour Plot in Y Direction (Test Case 8HF).

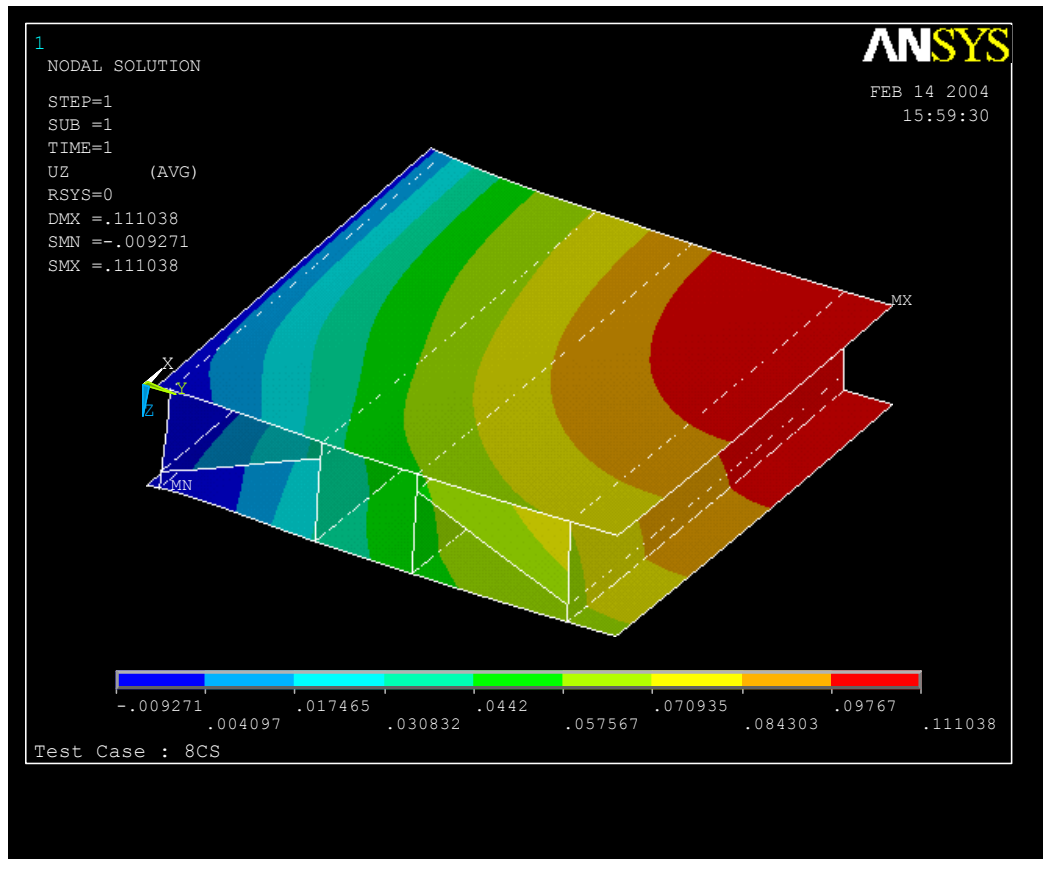

Figure F.12: Displacement Contour Plot in Z Direction (Test Case 8CS). 


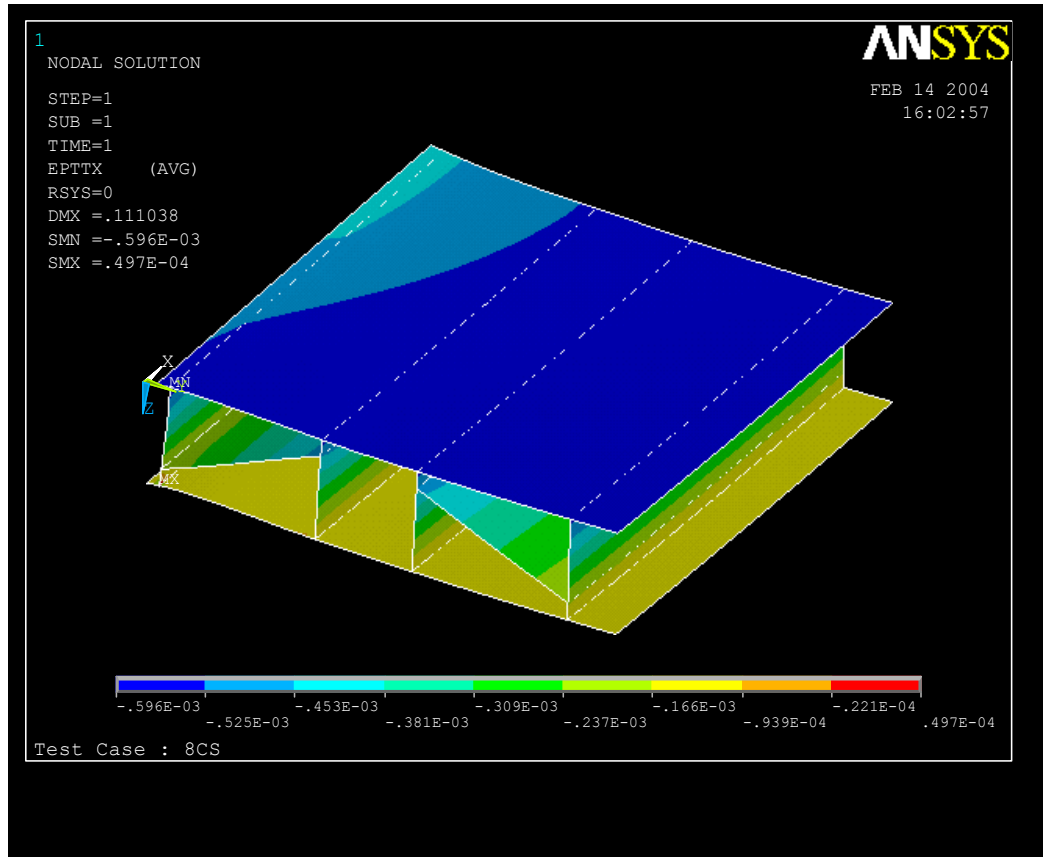

Figure F.13: Strain Contour Plot in X Direction (Test Case 8CS).

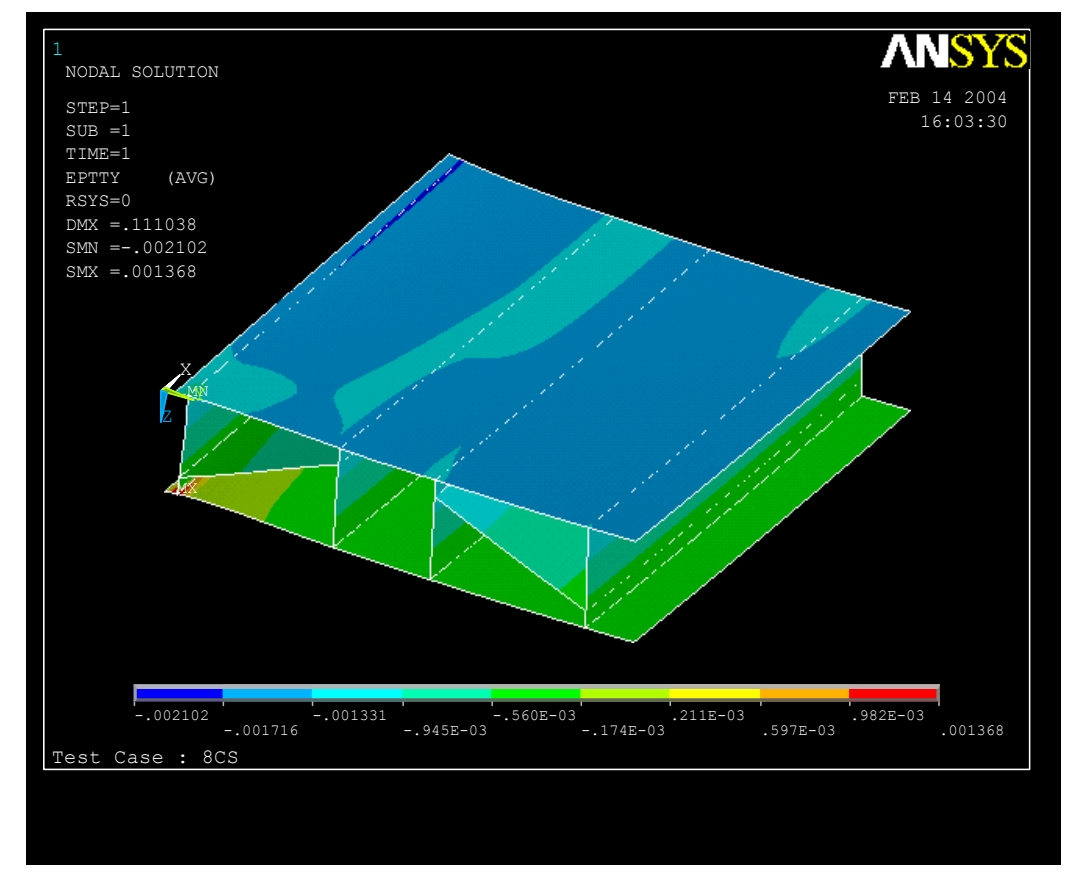

Figure F.14: Strain Contour Plot in Y Direction (Test Case 8CS). 


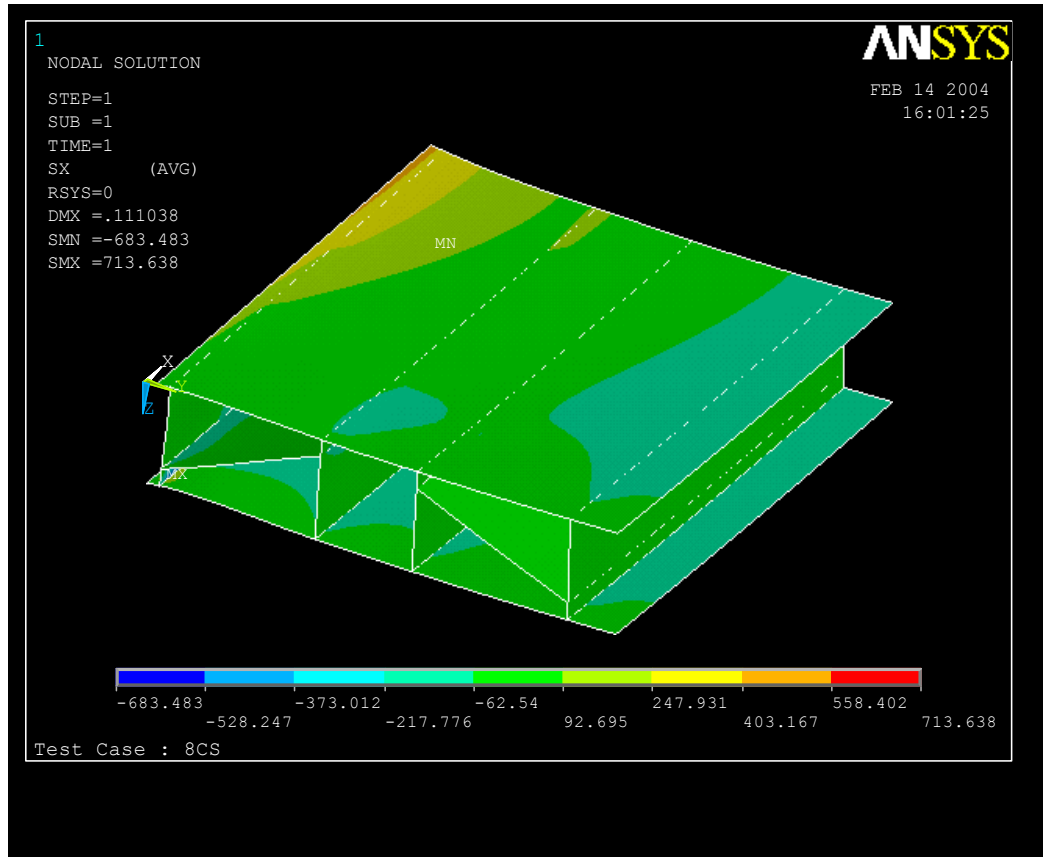

Figure F.15: Stress Contour Plot in X Direction (Test Case 8CS).

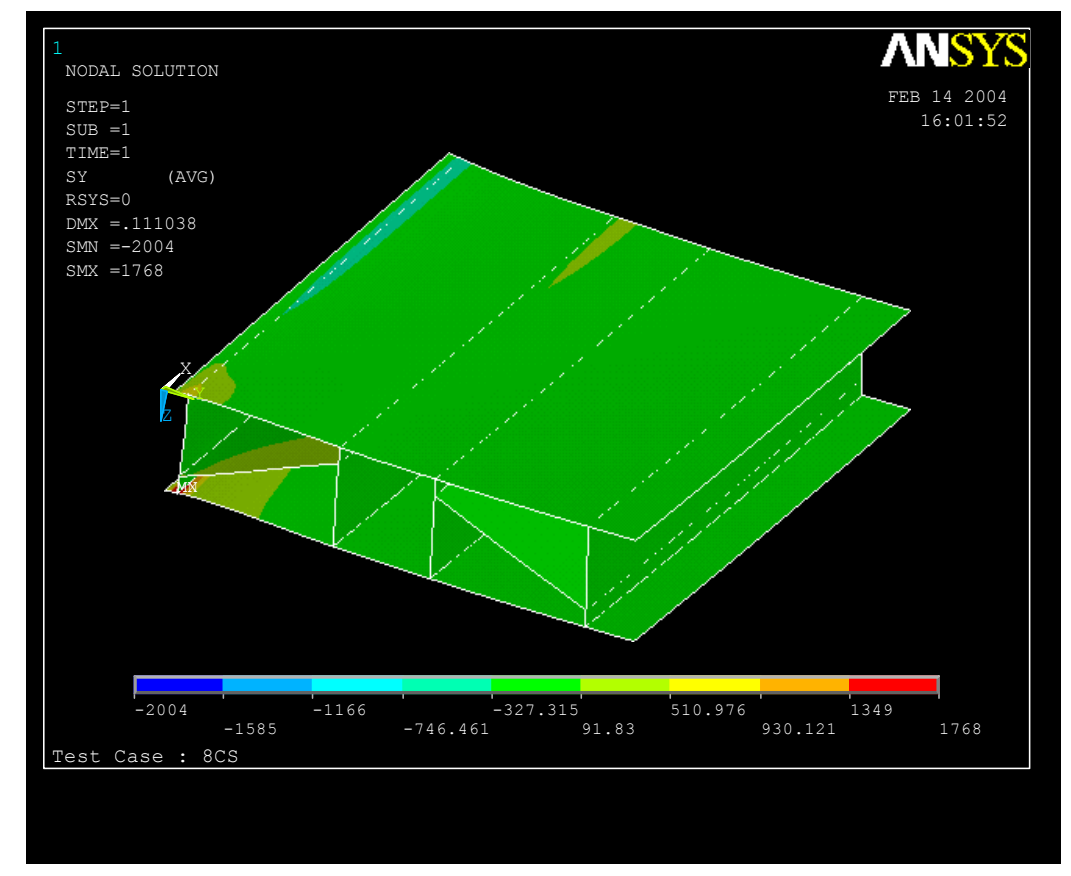

Figure F.16: Stress Contour Plot in Y Direction (Test Case 8CS). 


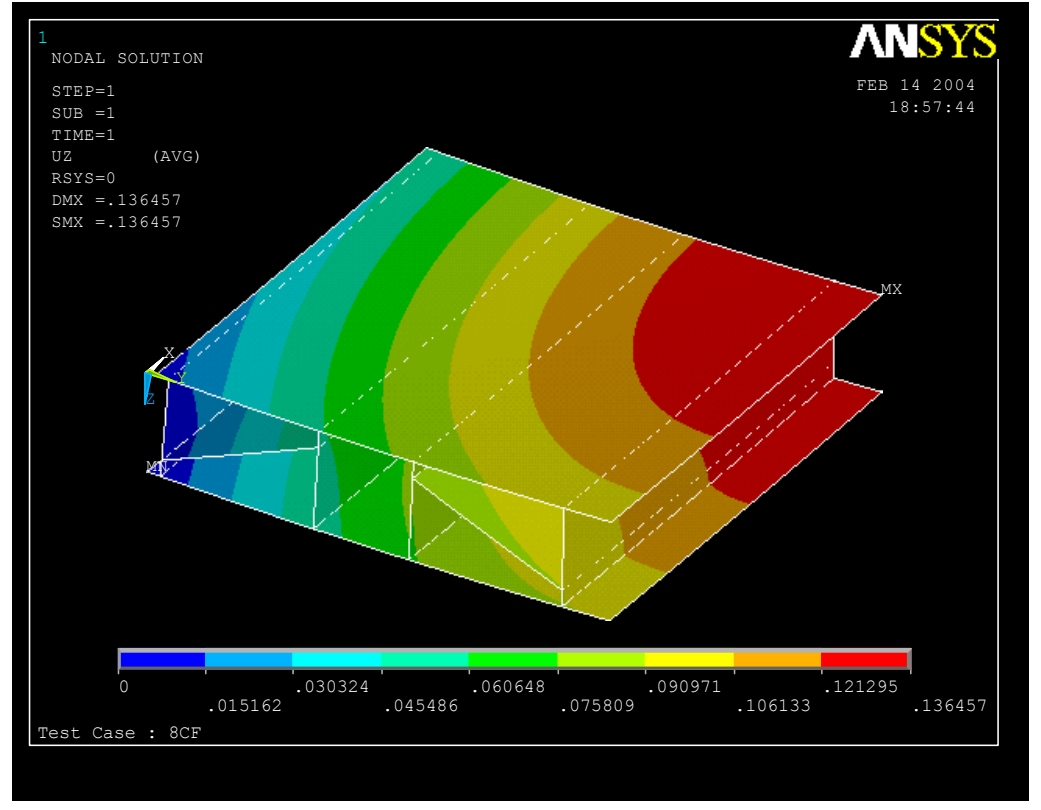

Figure F.17: Displacement Contour Plot in Z Direction (Test Case 8CF).

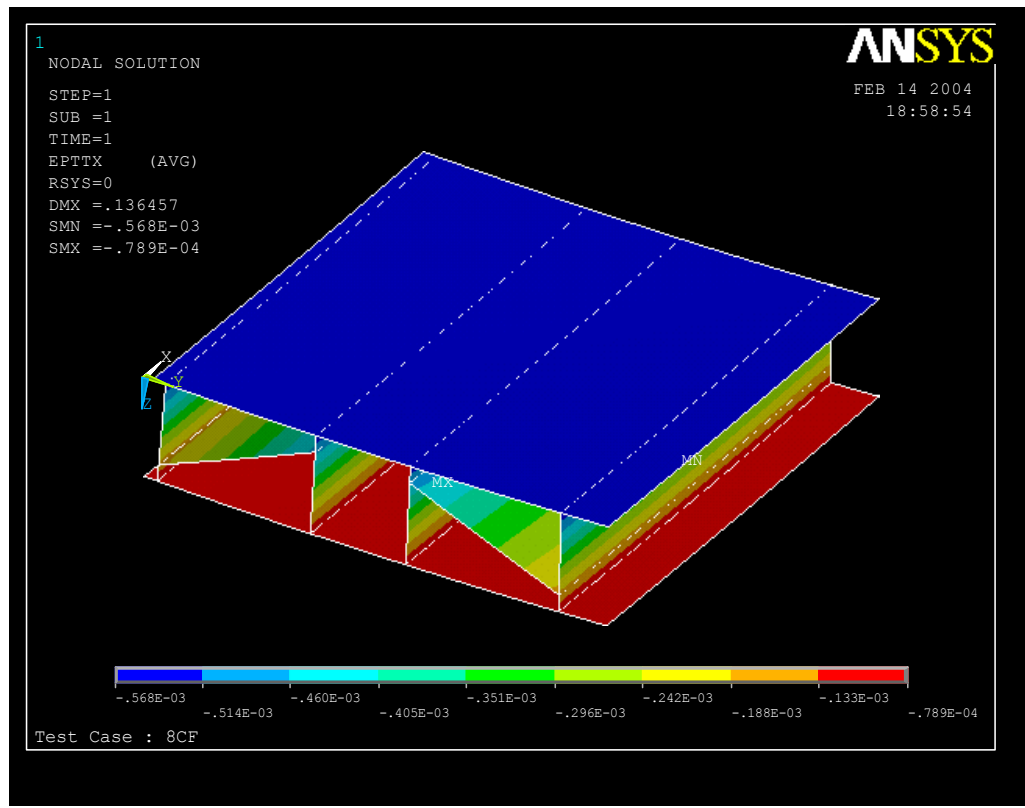

Figure F.18: Strain Contour Plot in X Direction (Test Case 8CF). 


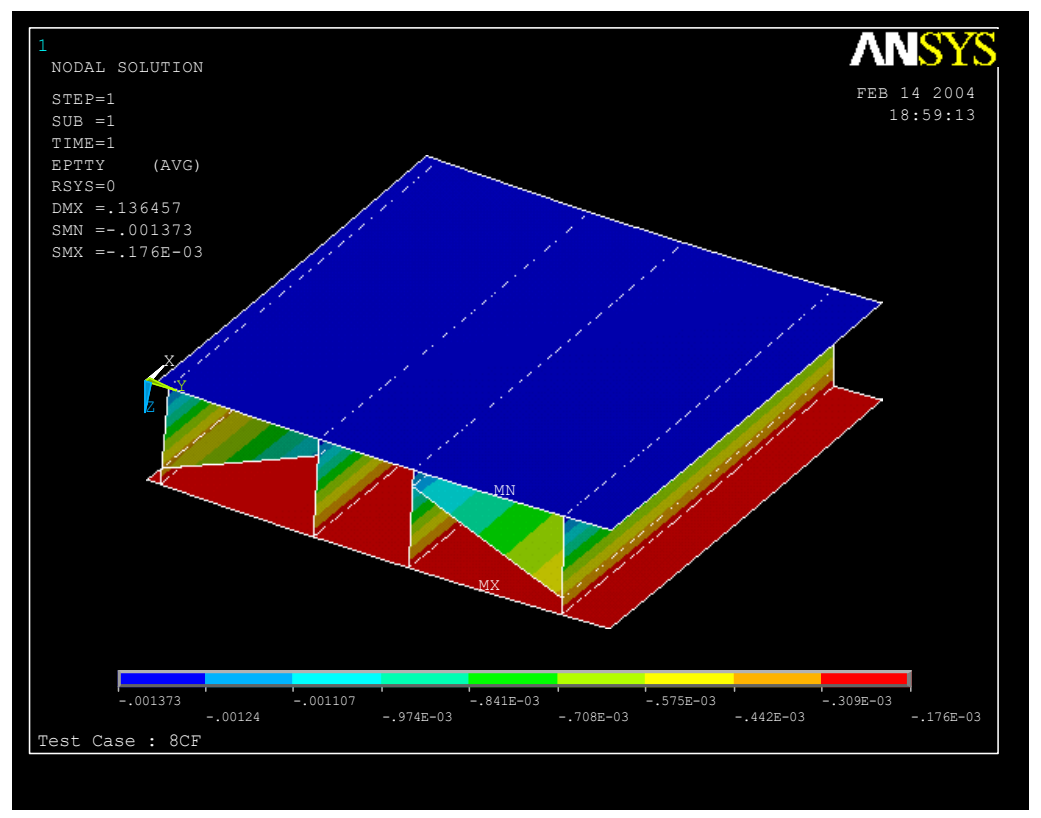

Figure F.19: Strain Contour Plot in Y Direction (Test Case 8CF).

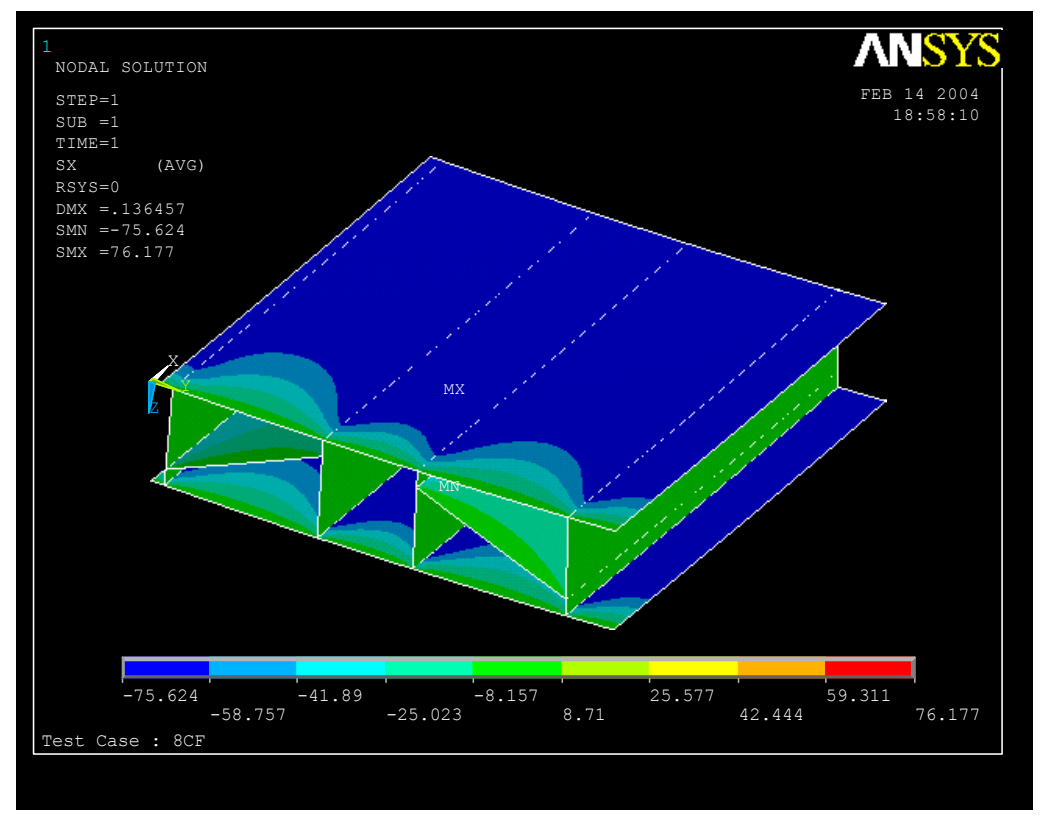

Figure F.20: Stress Contour Plot in X Direction (Test Case 8CF). 


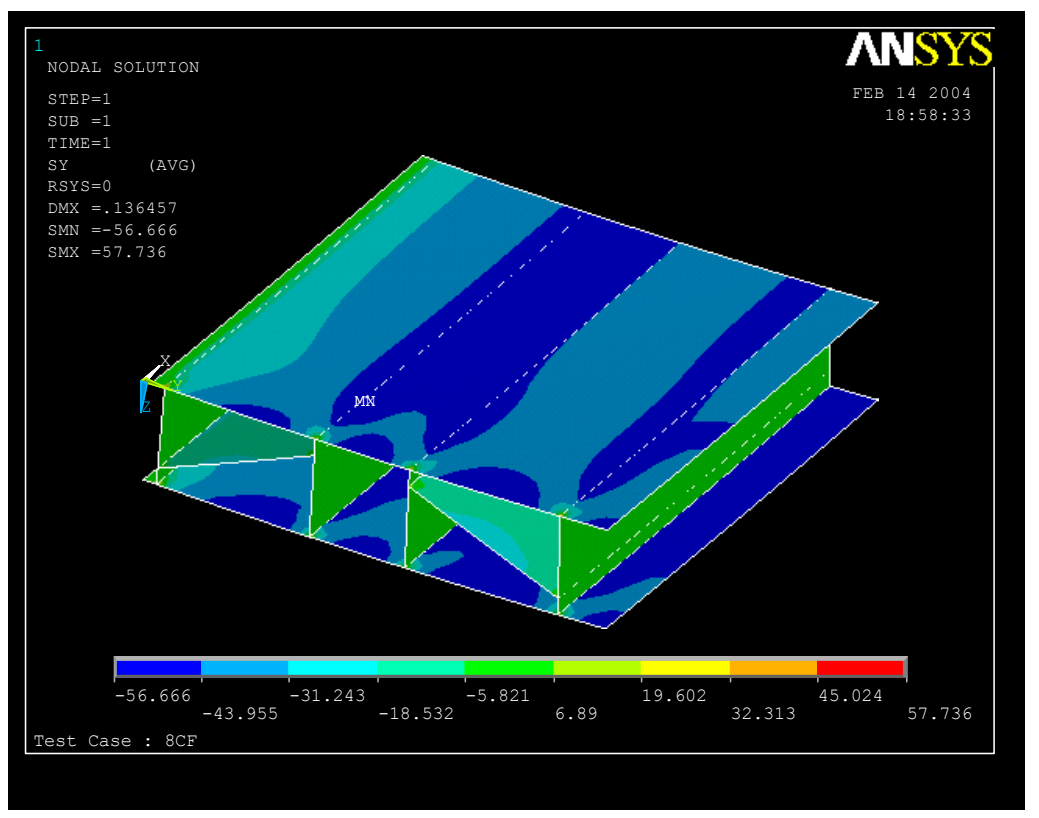

Figure F.21: Stress Contour Plot in Y Direction (8CF).

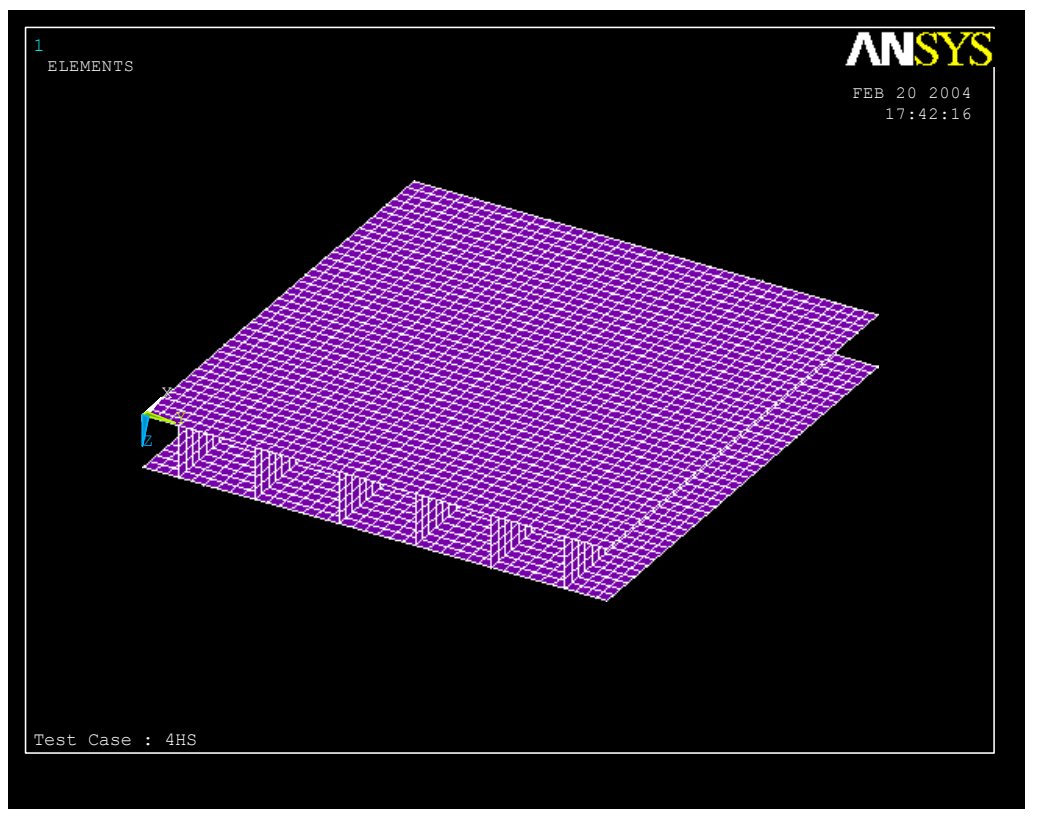

Figure F.22: A Quarter Model of 4 in. FRP Deck Specimens. 


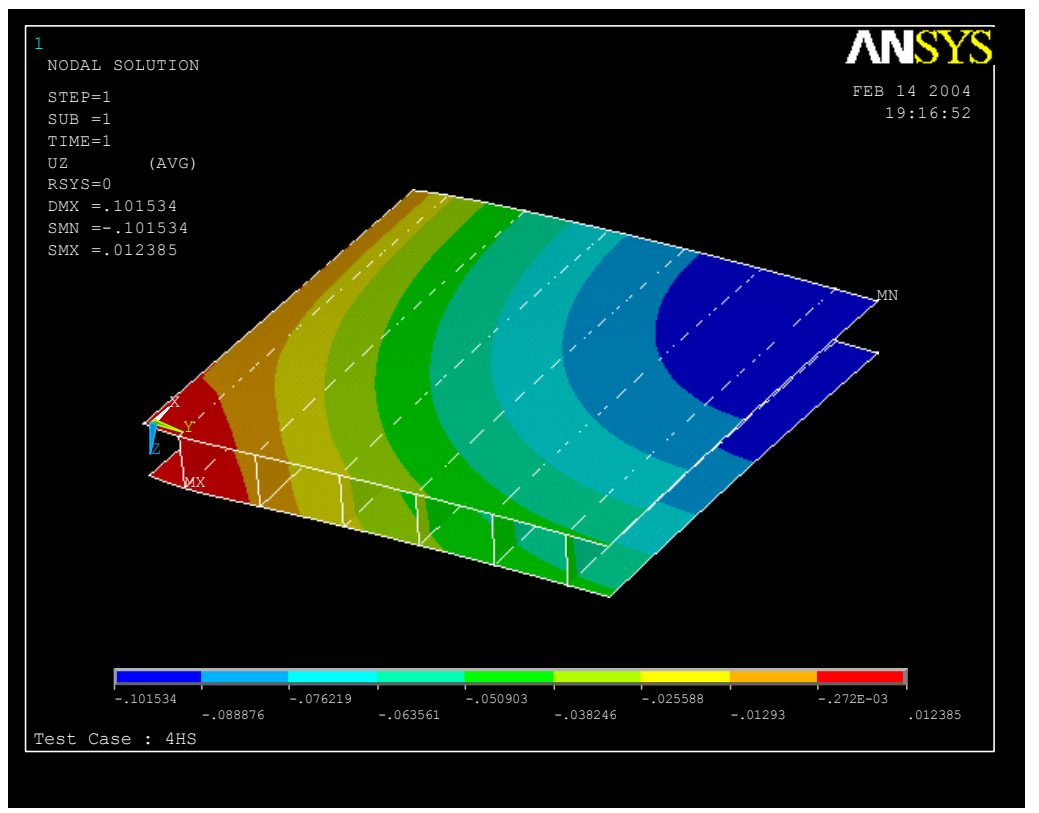

Figure F.23: Displacement Contour Plot in Z Direction (Test Case 4HS).

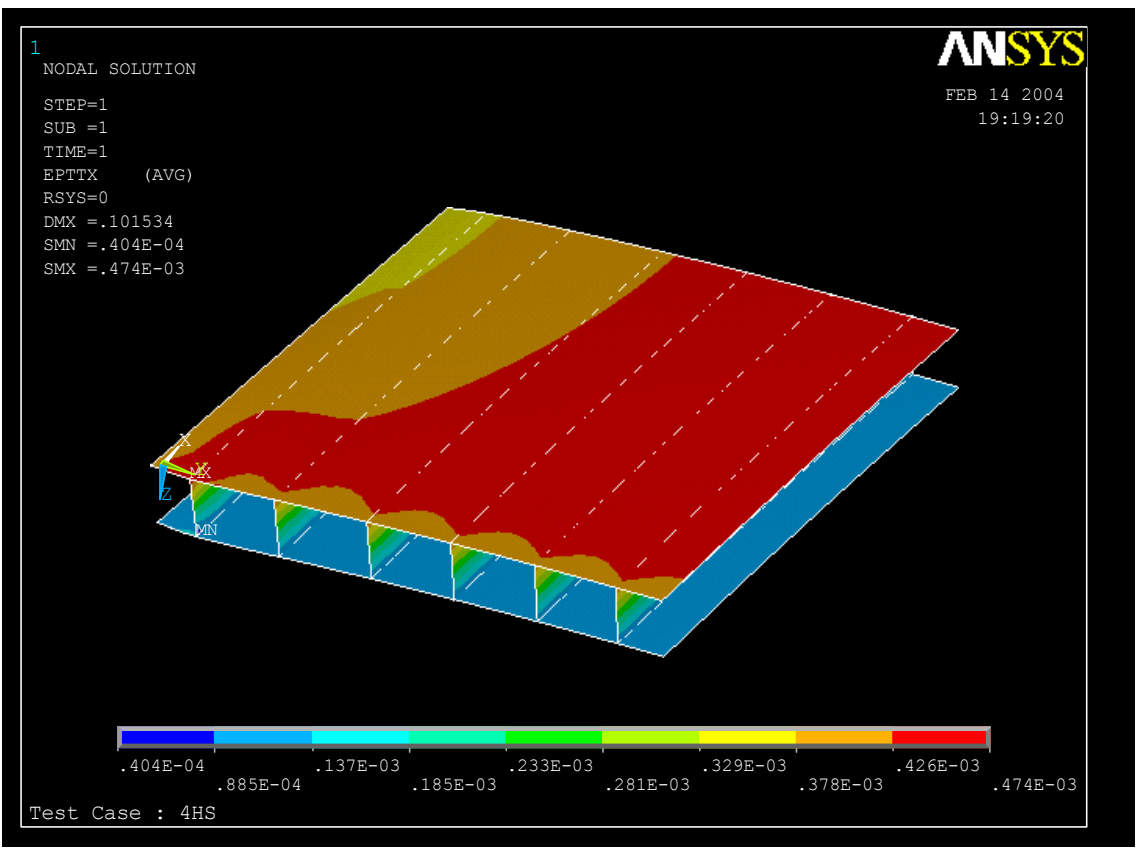

Figure F.24: Strain Contour Plot in X Direction (Test Case 4HS). 


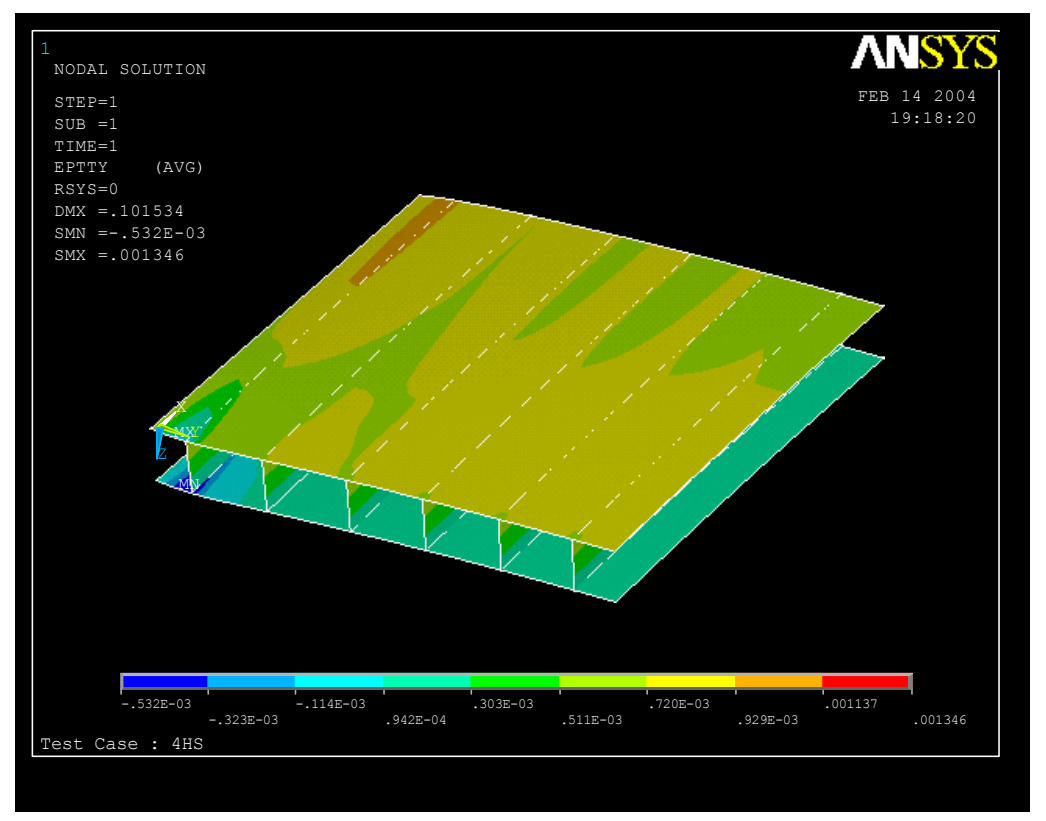

Figure F.25: Strain Contour Plot in Y Direction (Test Case 4HS).

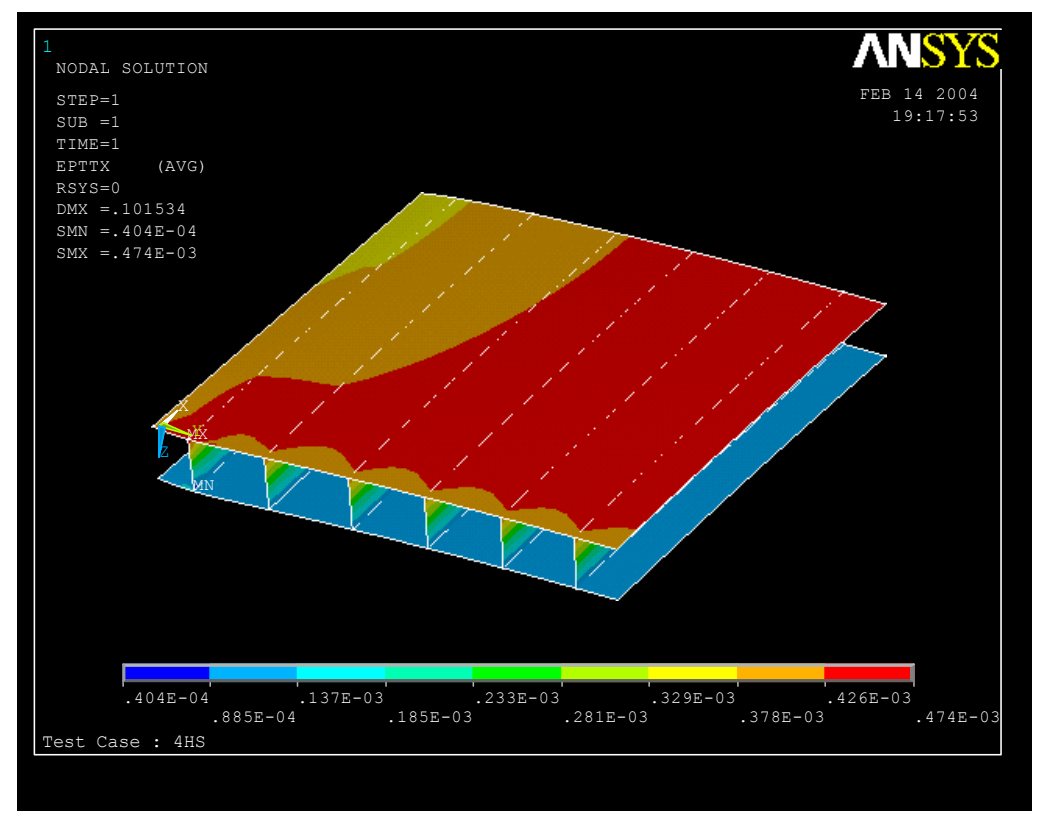

Figure F.26: Stress Contour Plot in X Direction (Test Case 4HS). 


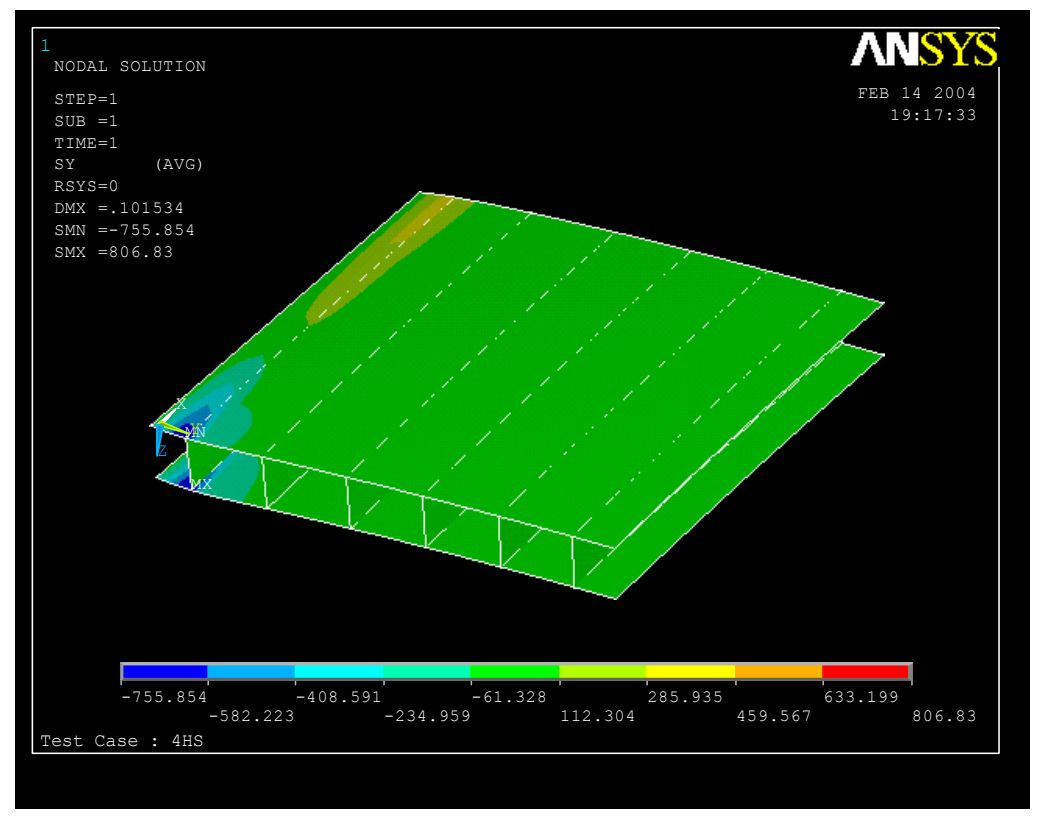

Figure F.27: Stress Contour Plot in Y Direction (Test Case 4HS).

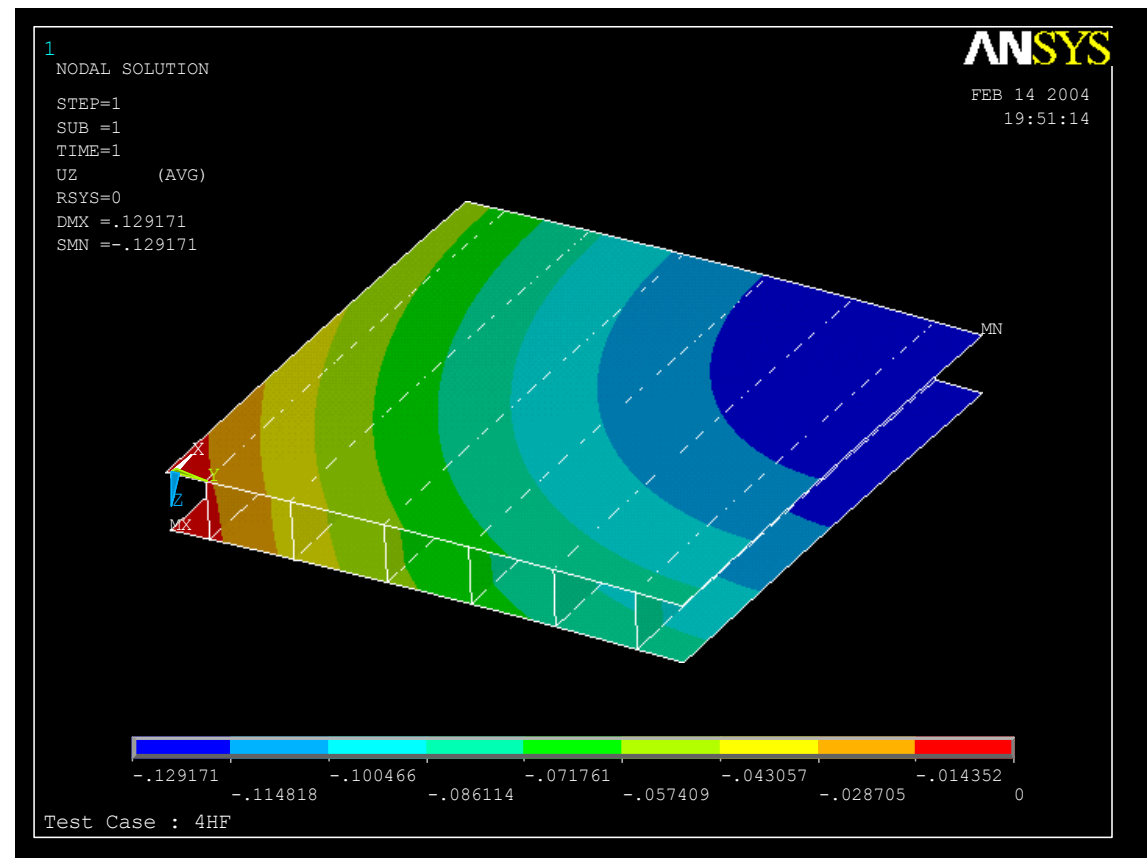

Figure F.28: Displacement Contour Plot in Z Direction (Test Case 4HF). 


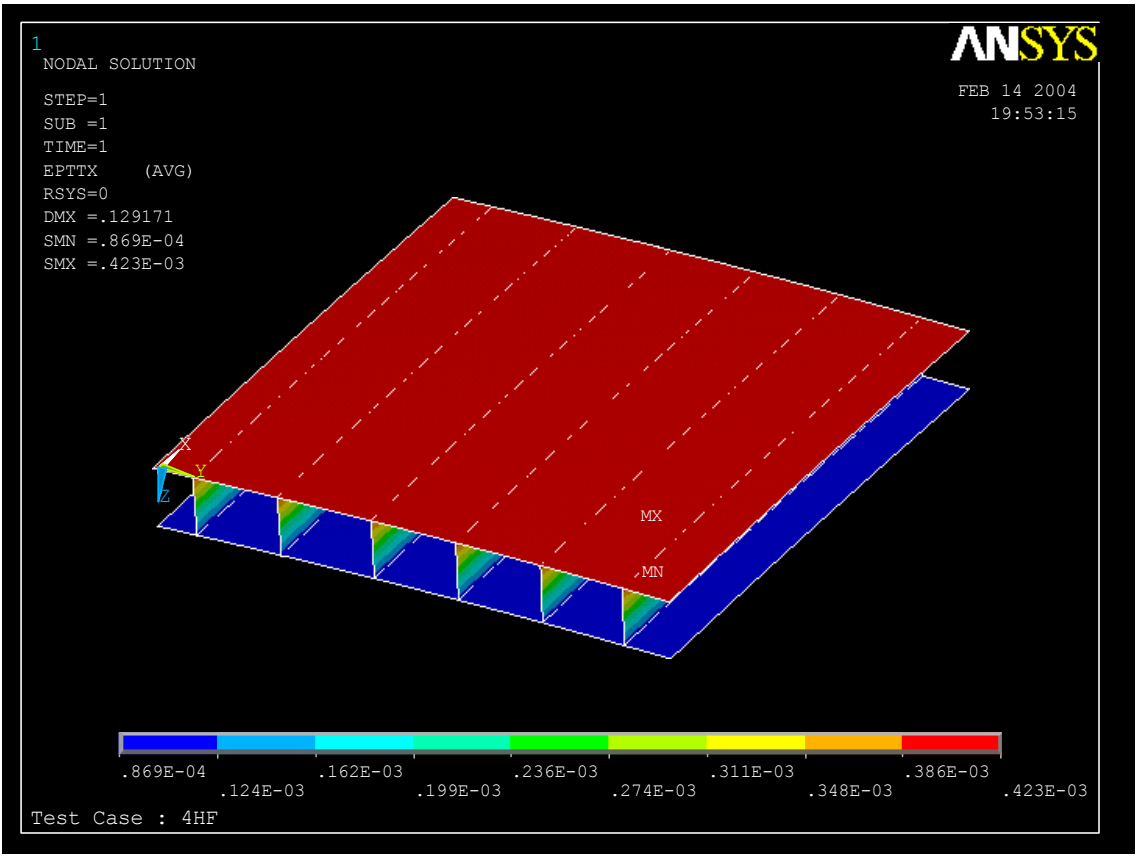

Figure F.29: Strain Contour Plot in X Direction (Test Case 4HF).

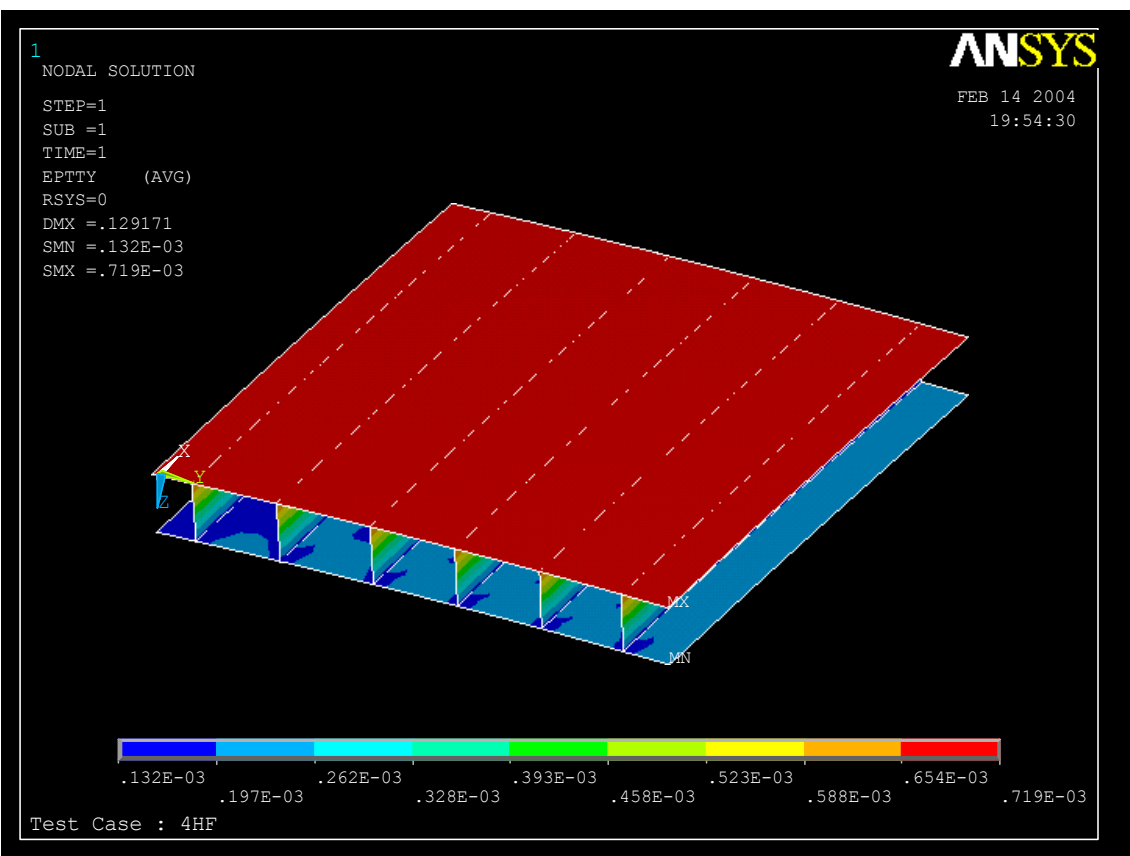

Figure F.30: Strain Contour Plot in Y Direction (Test Case 4HF). 


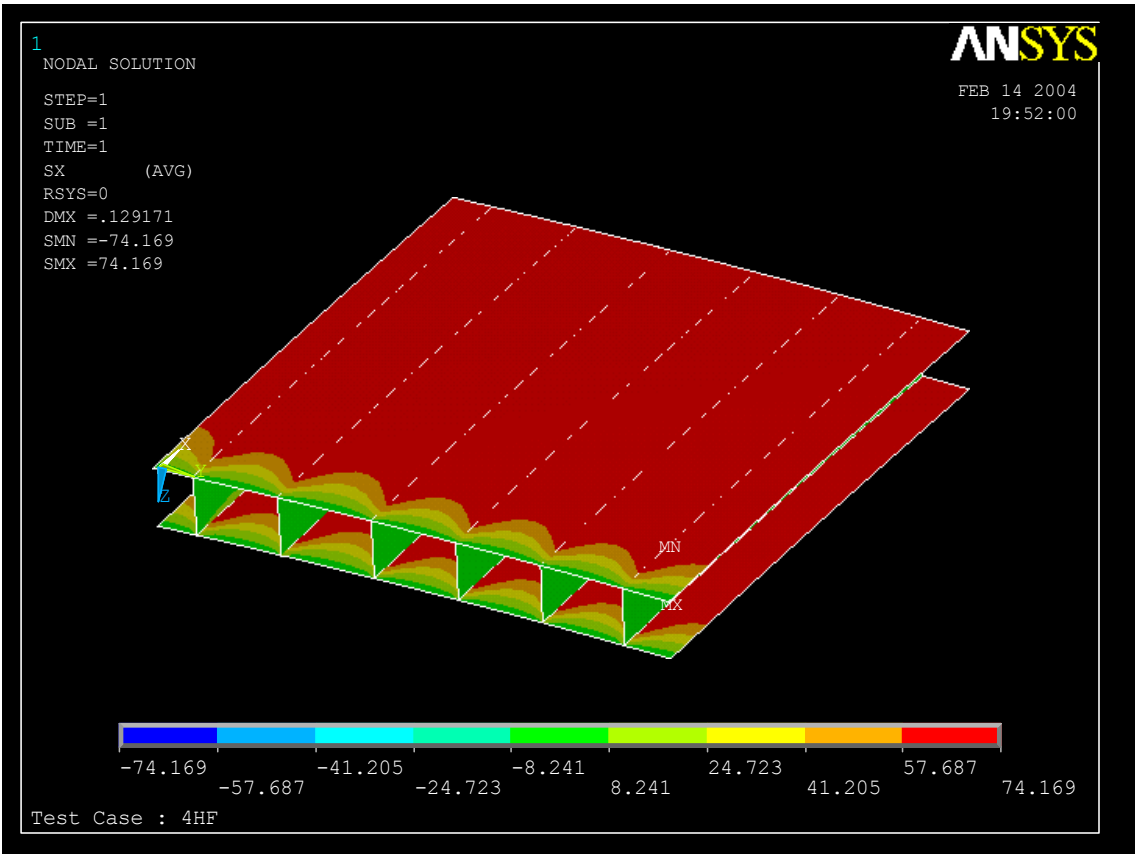

Figure F.31: Stress Contour Plot in X Direction (Test Case 4HF).

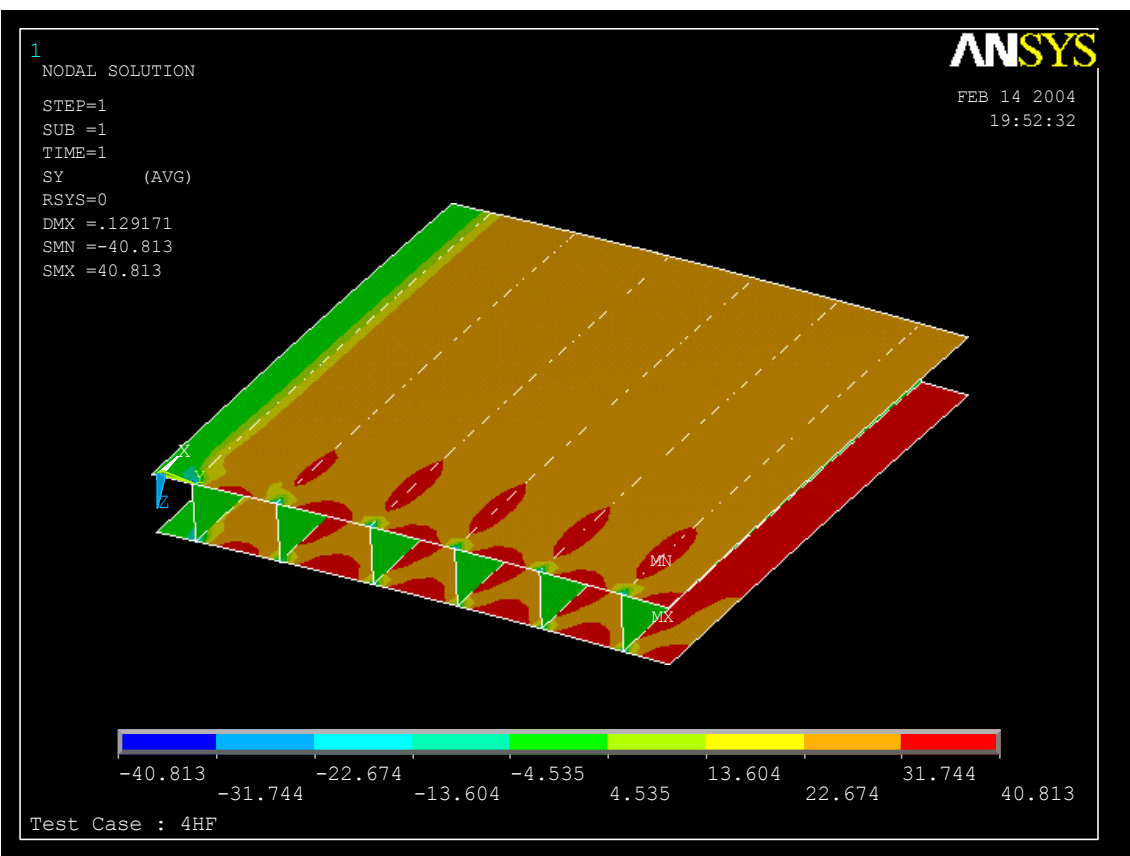

Figure F.32: Stress Contour Plot in Y Direction (Test Case 4HF). 


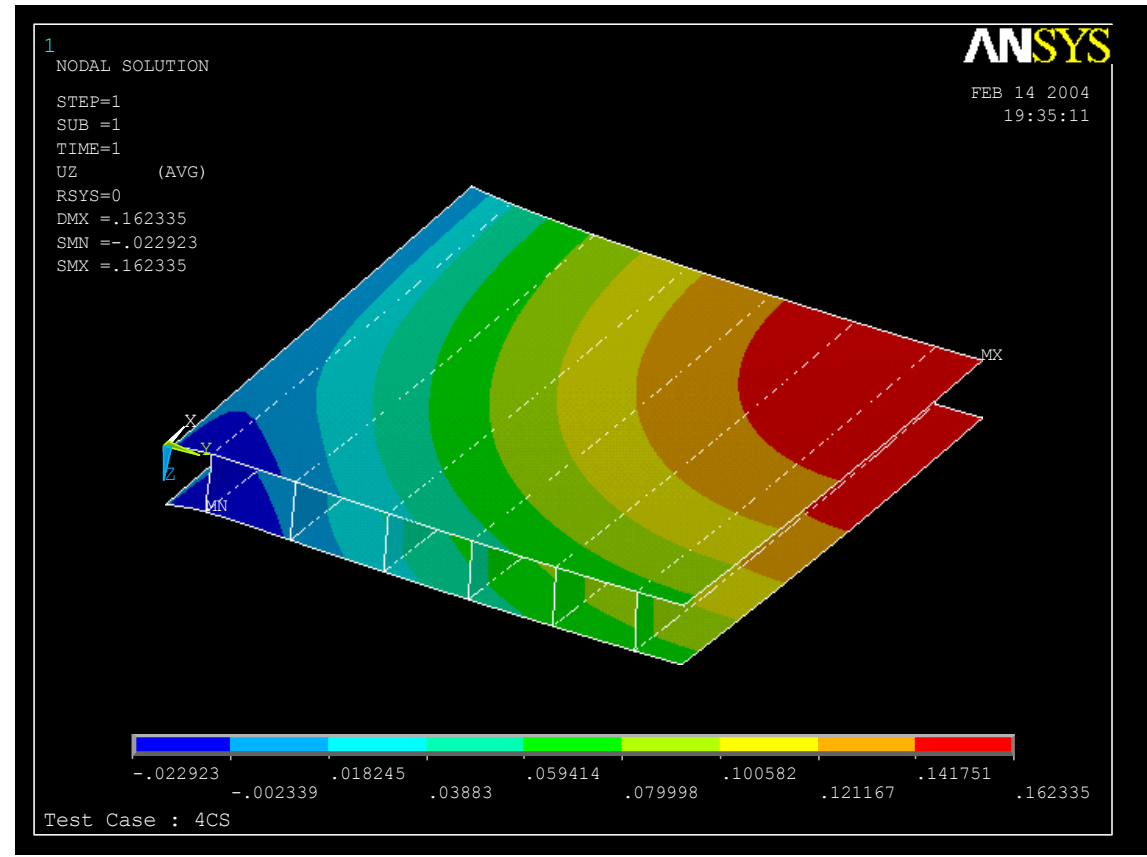

Figure F.33: Displacement Contour Plot in Z Direction (Test Case 4CS).

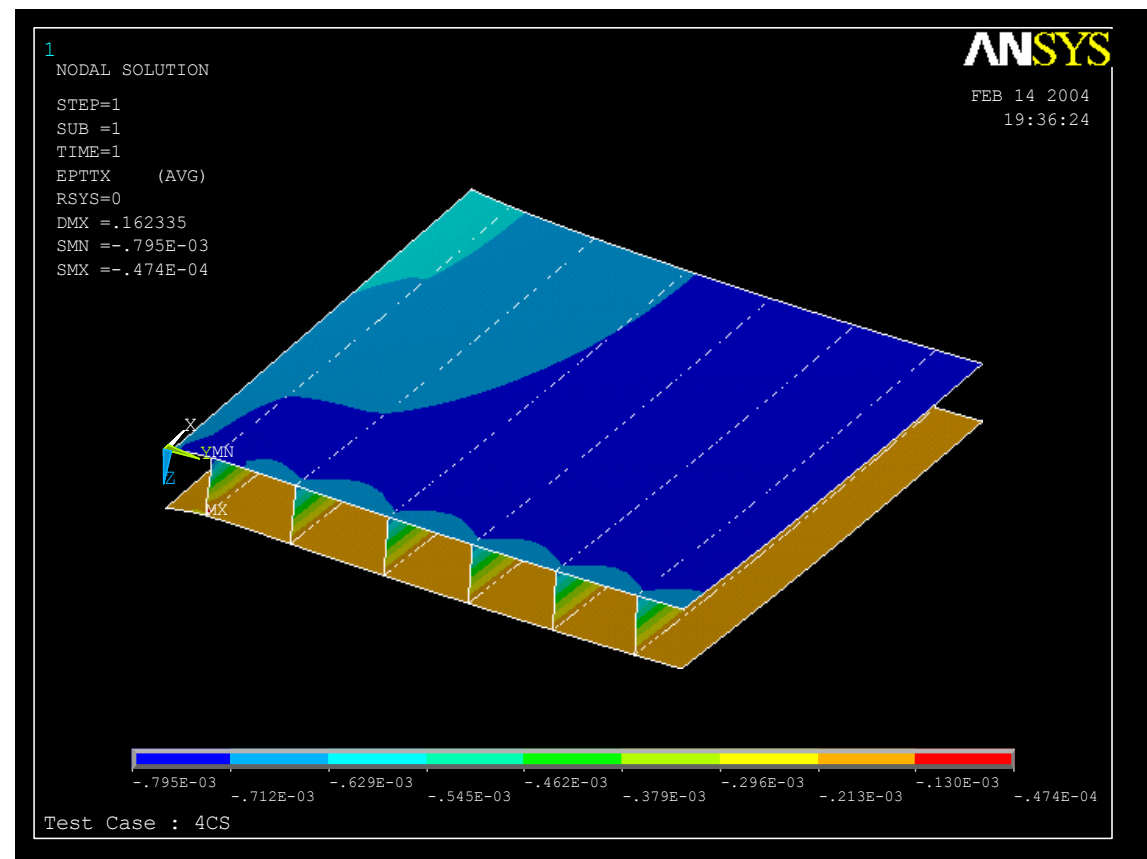

Figure F.34: Strain Contour Plot in X Direction (Test Case 4CS). 


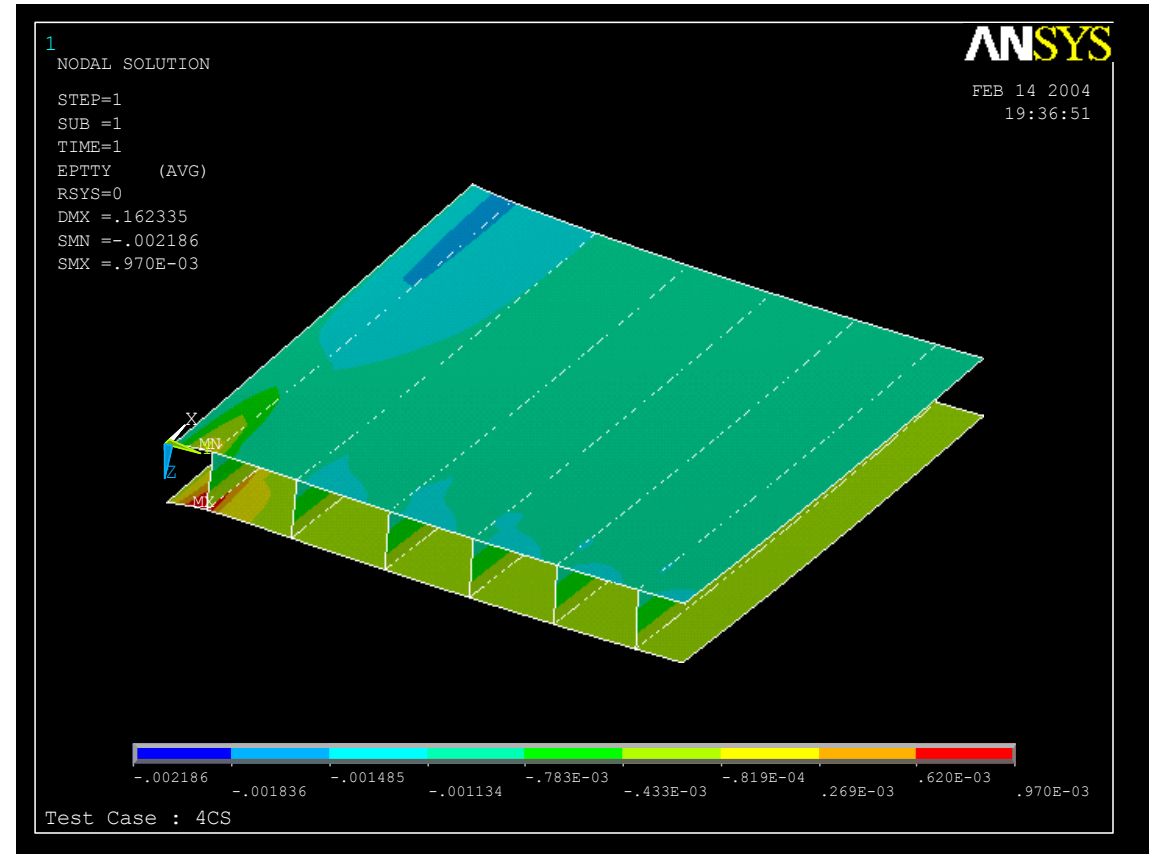

Figure F.35: Strain Contour Plot in Y Direction (Test Case 4CS).

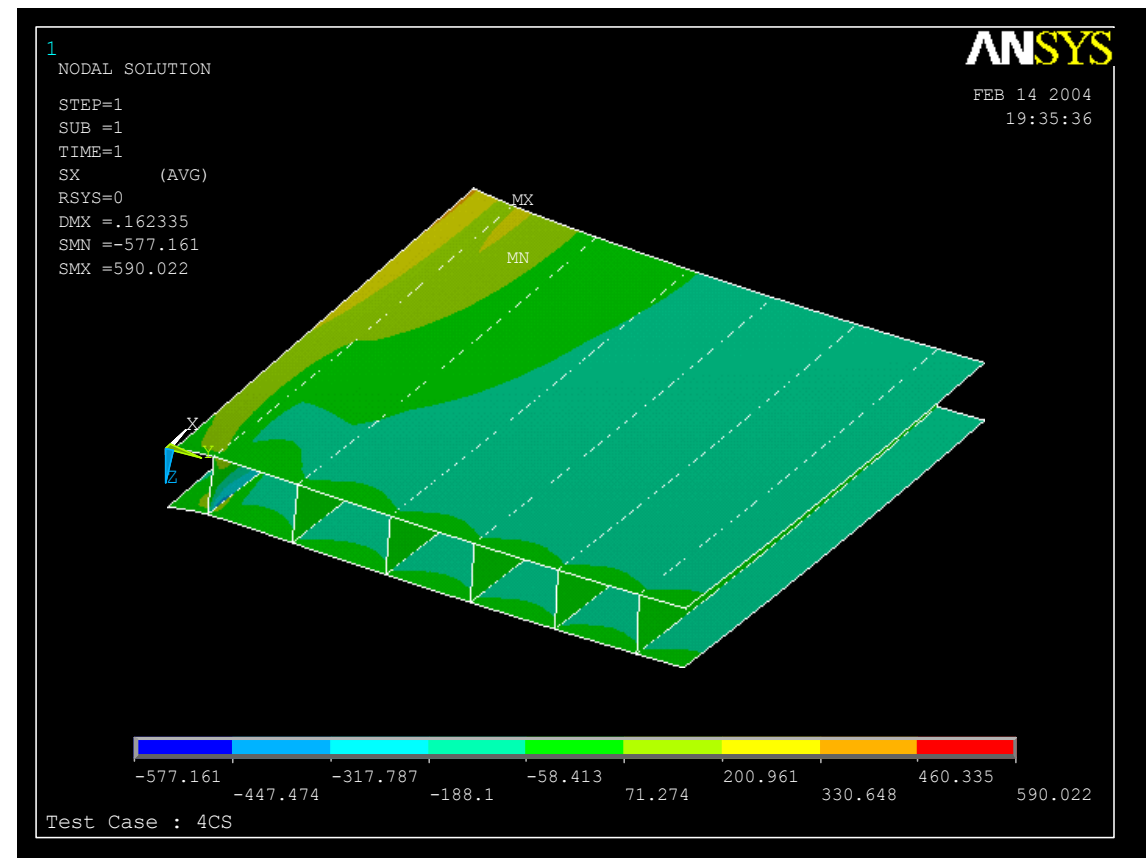

Figure F.36: Stress Contour Plot in X Direction (Test Case 4CS). 


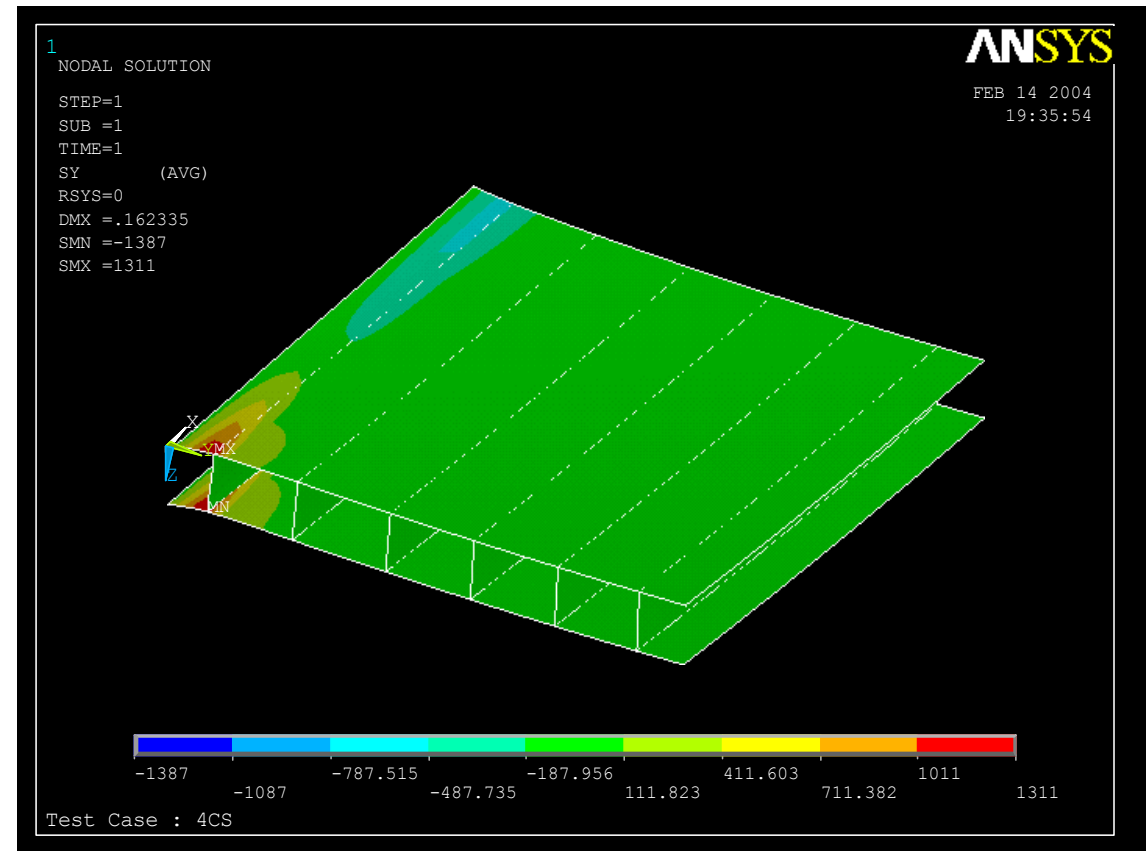

Figure F.37: Stress Contour Plot in Y Direction (Test Case 4CS).

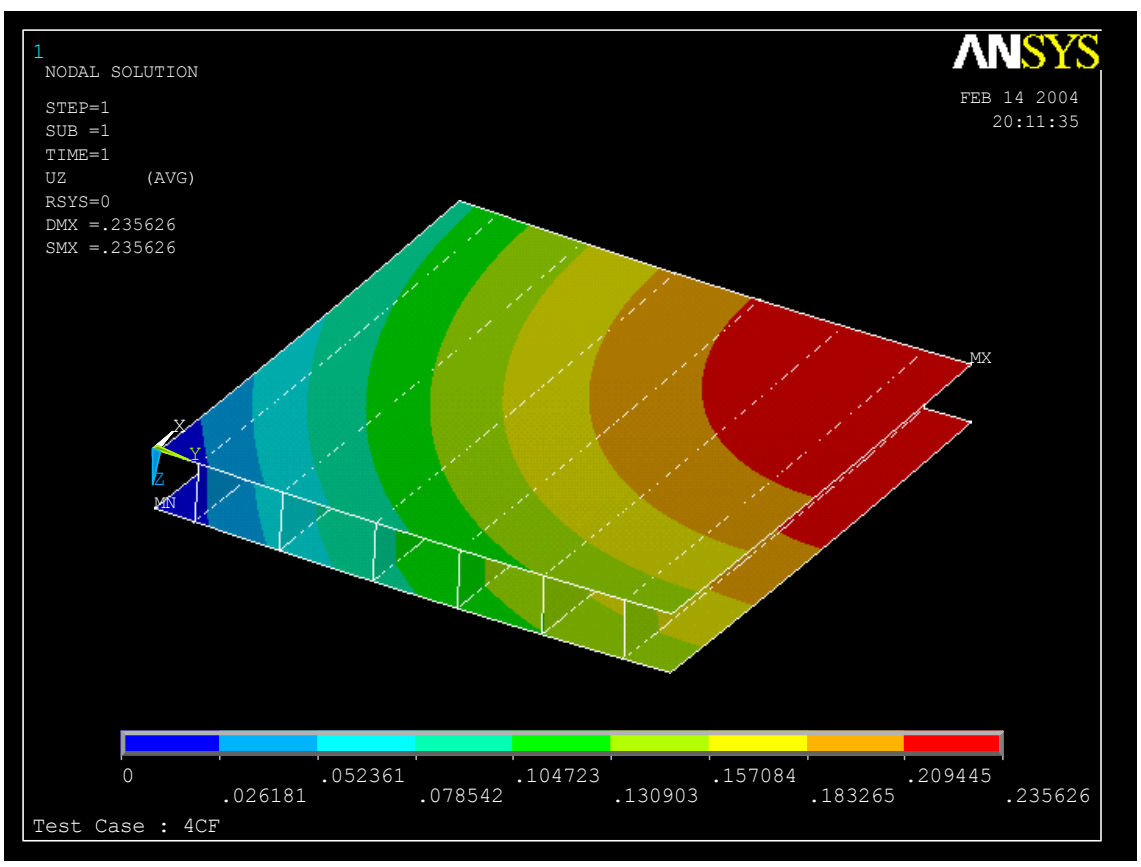

Figure F.38: Displacement Contour Plot in Z Direction (Test Case 4CF). 


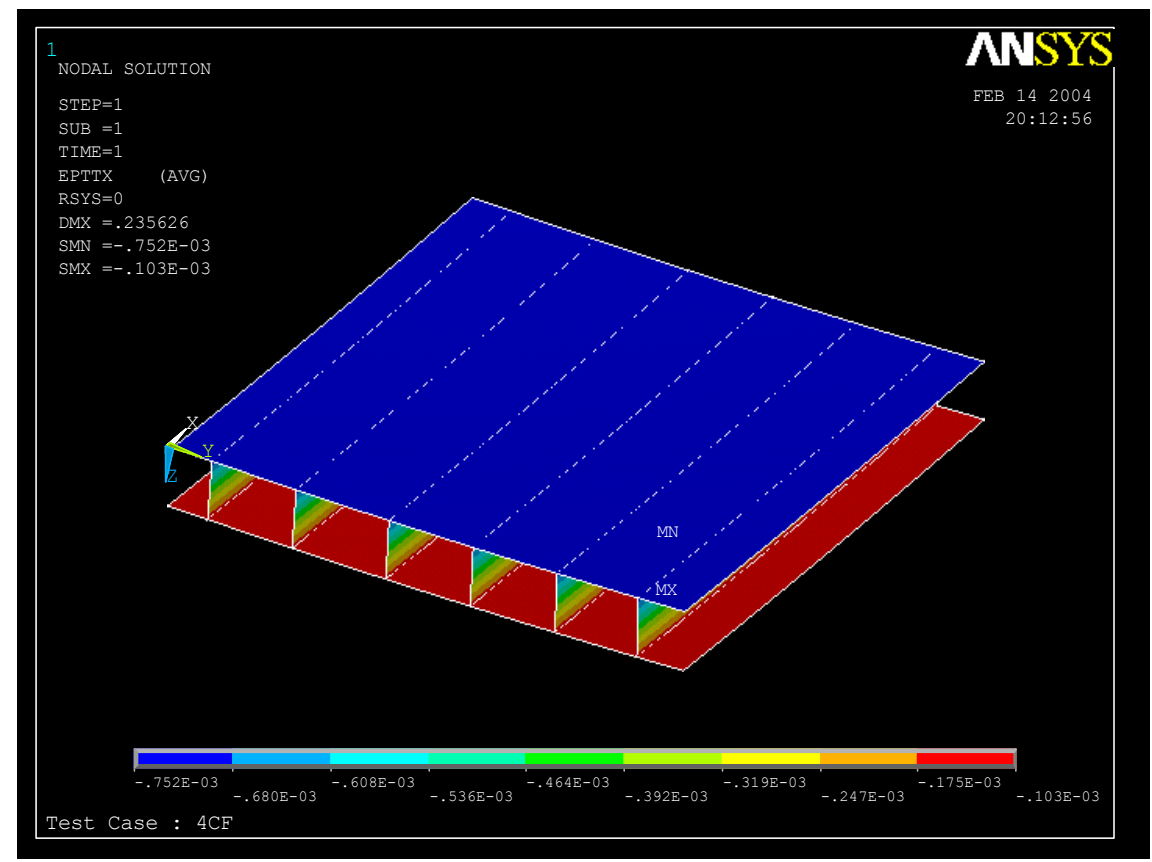

Figure F.39: Strain Contour Plot in X Direction (Test Case 4CF).

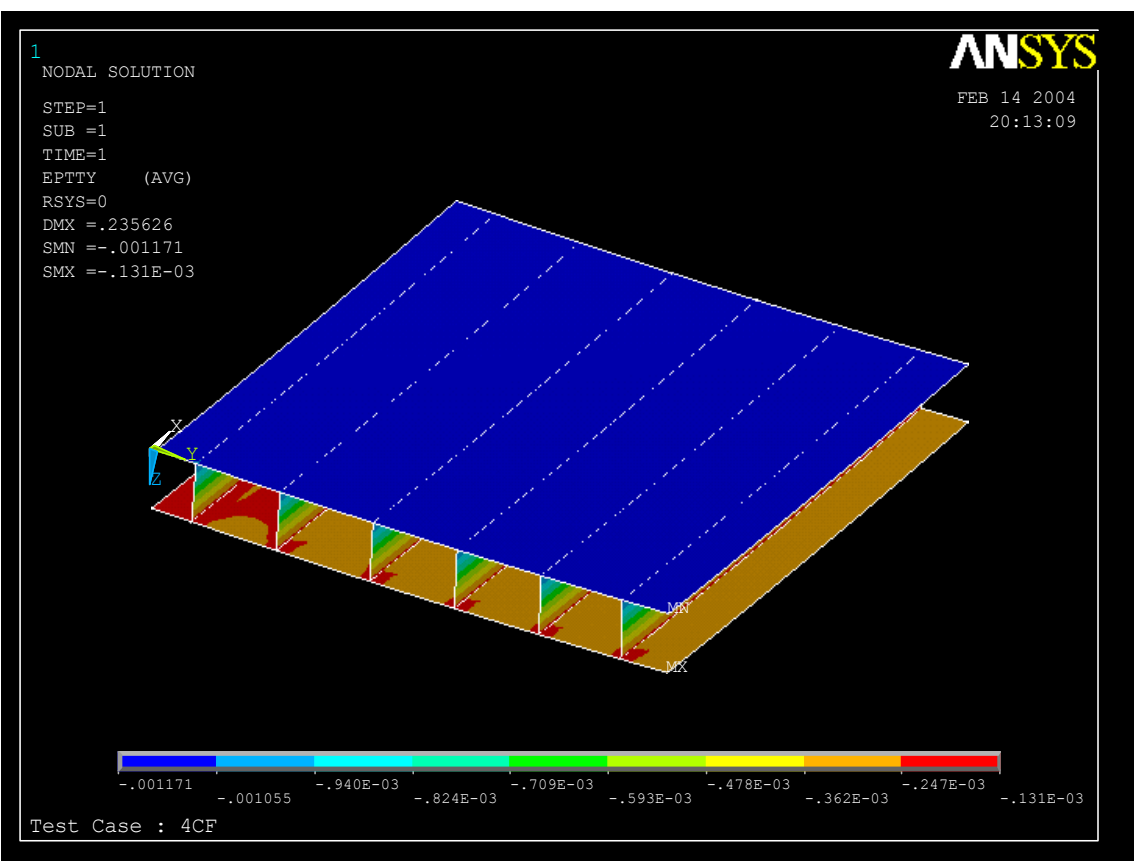

Figure F.40: Strain Contour Plot in Y Direction (Test Case 4CF). 


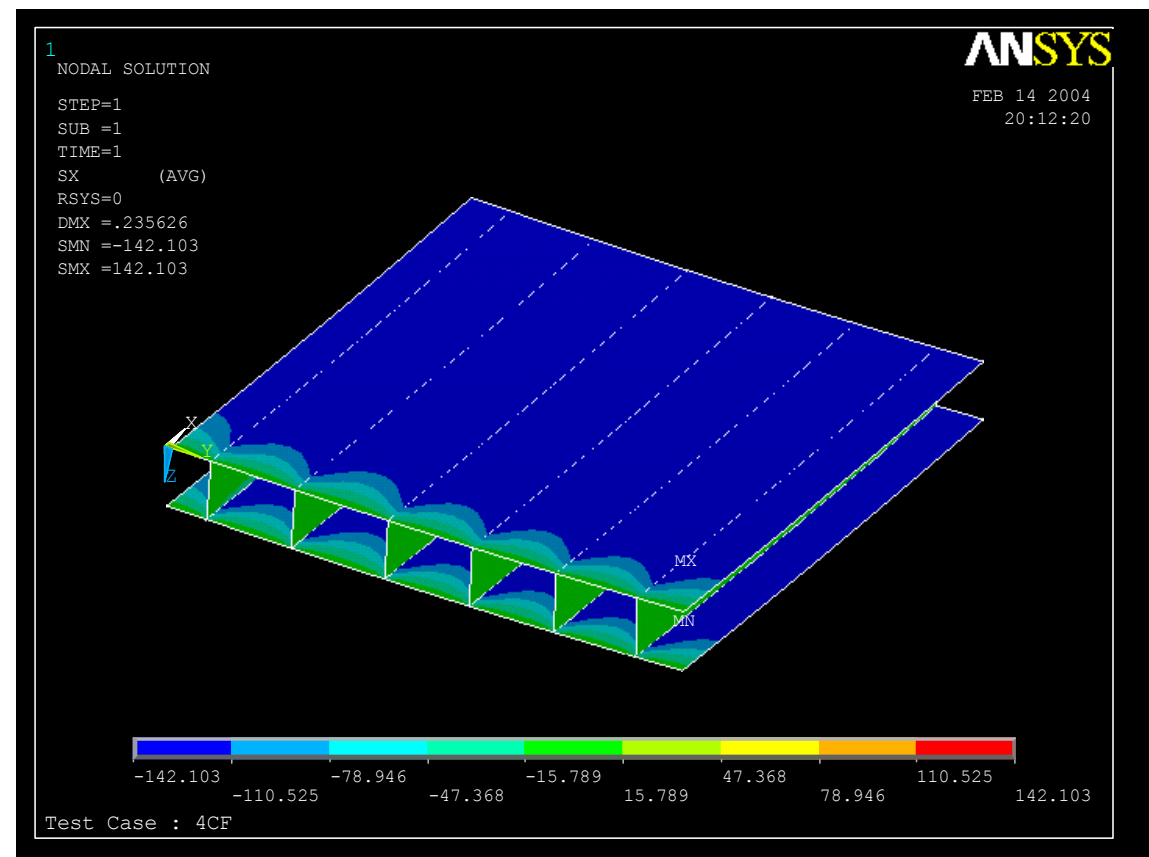

Figure F.41: Stress Contour Plot in X Direction (Test Case 4CF).

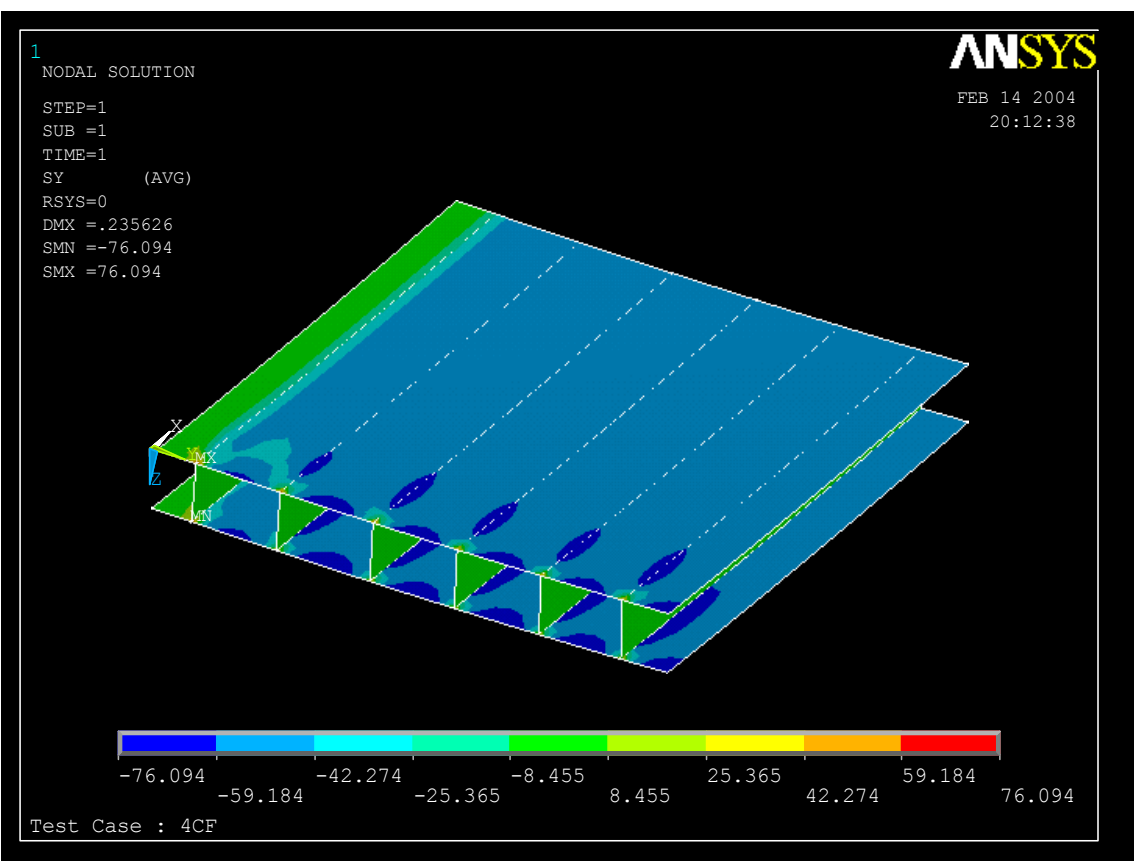

Figure F.42: Stress Contour Plot in Y Direction (Test Case 4CF). 


\section{Text Command for ANSYS (V 7.1)}

\subsection{Test Case 8HS (ANSYS Text Command)}

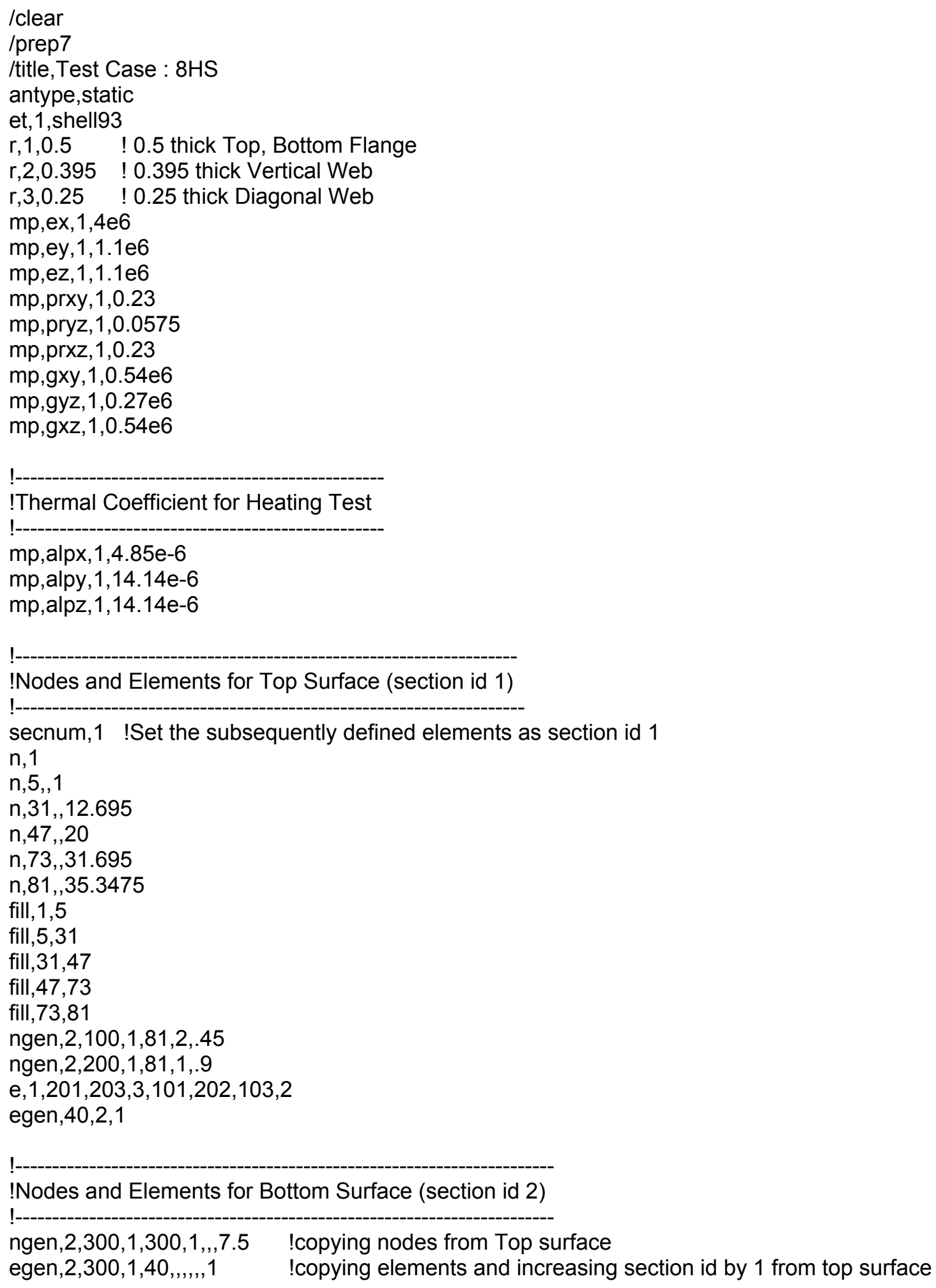




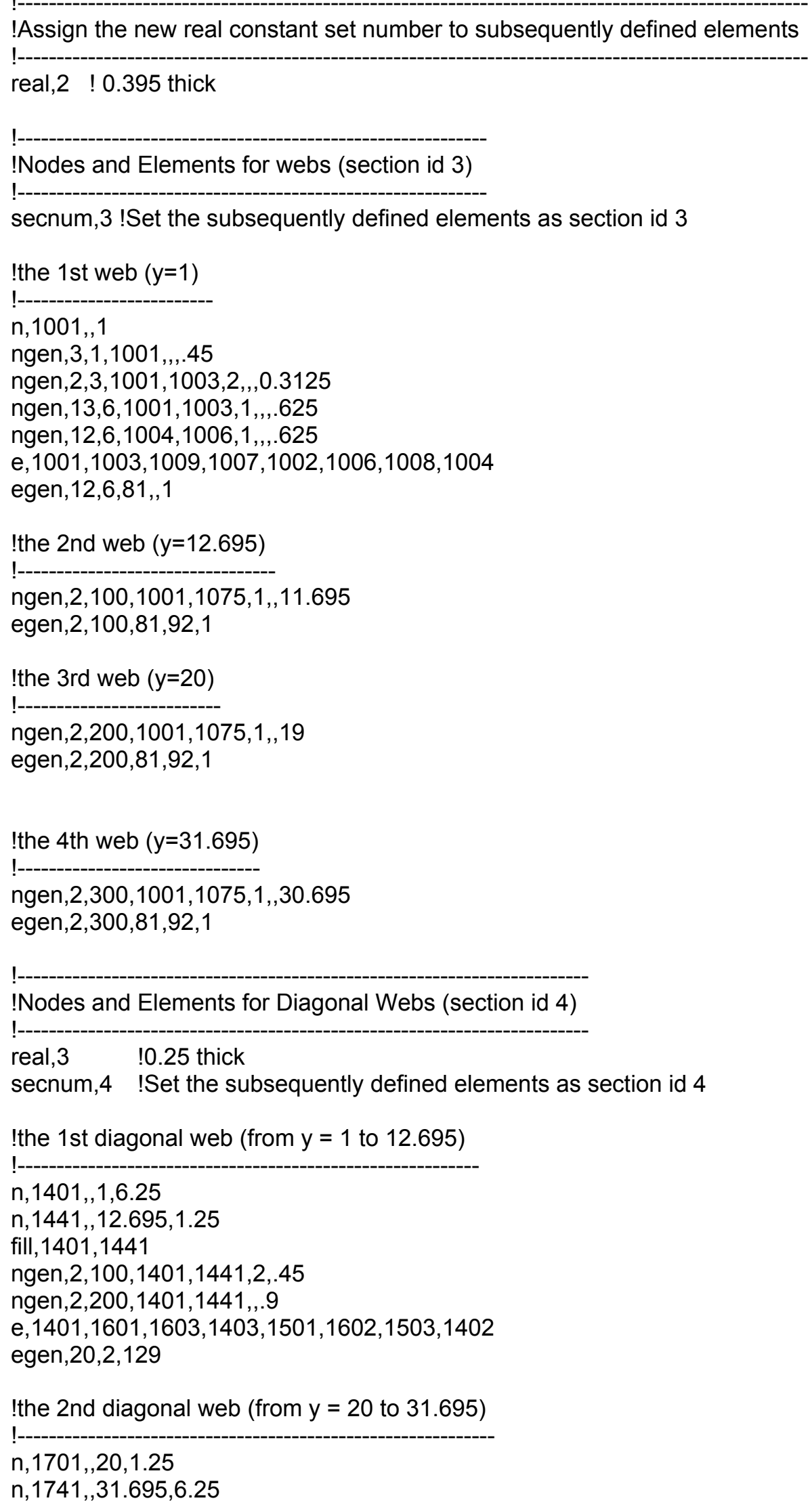




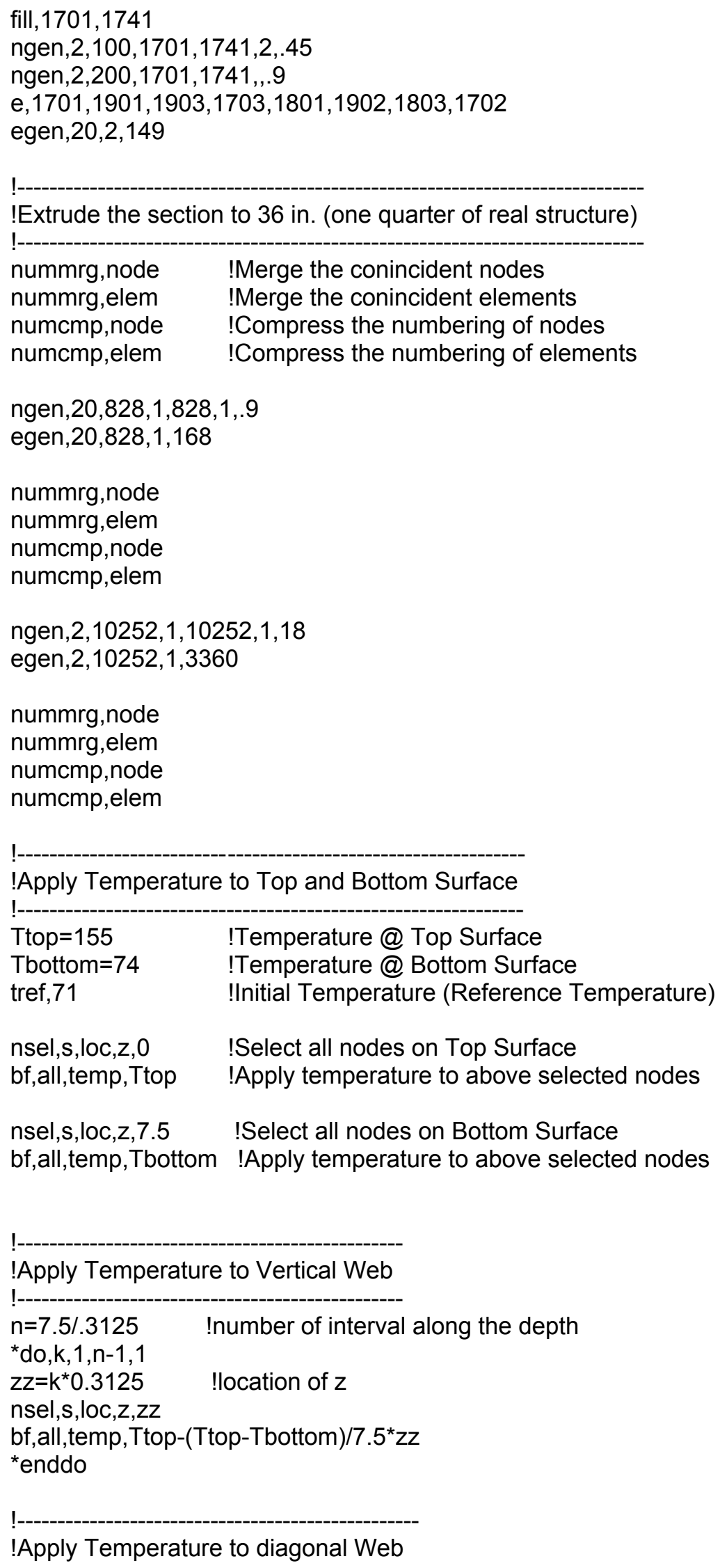




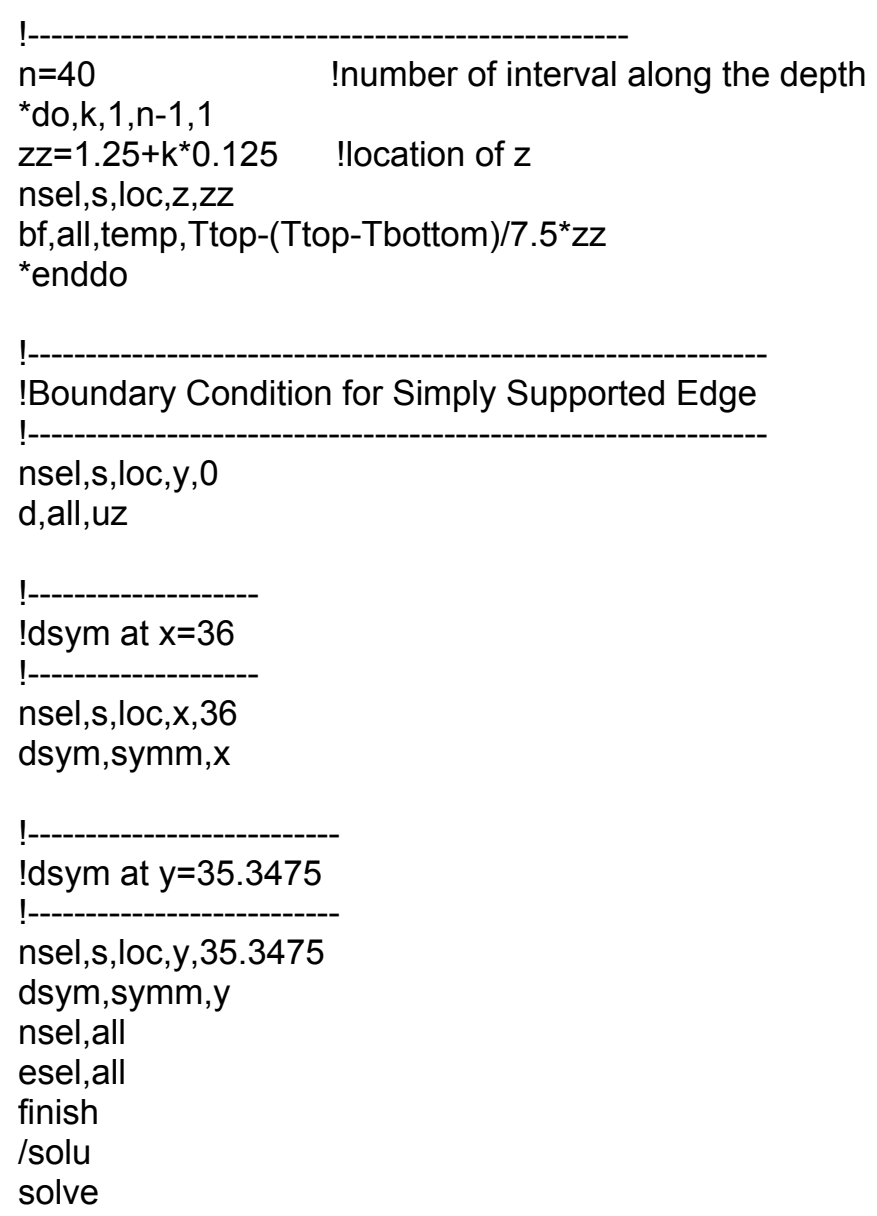




\subsection{Test Case 8HF (ANSYS Text Command)}

ANSYS text command for test case $8 \mathrm{HF}$ was similar to that for test case $8 \mathrm{HS}$ except applied temperature and boundary condition were changed as following

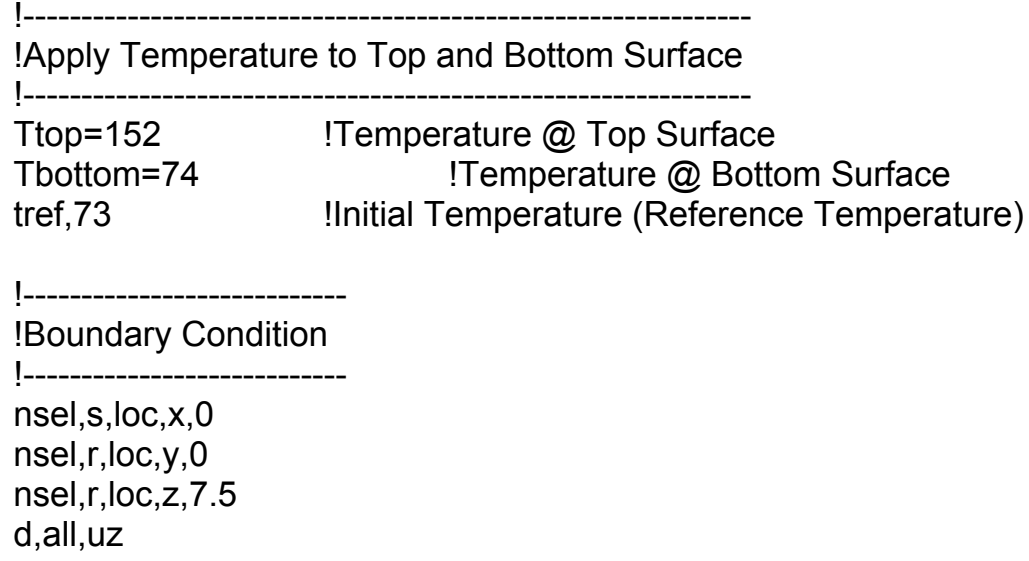

\subsection{Test Case 8CS (ANSYS Text Command)}

ANSYS text command for test case $8 \mathrm{CS}$ was similar to that for test case 8HS except applied temperature was changed as following

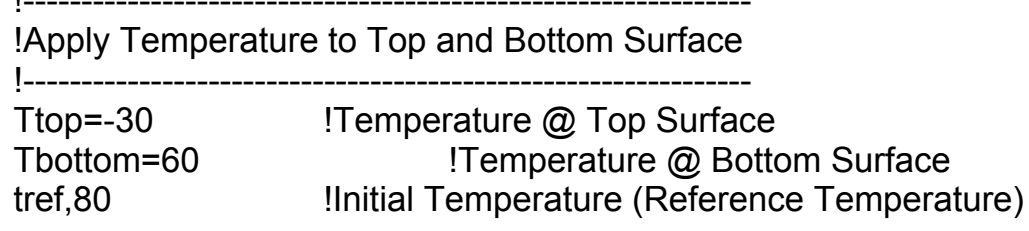

\subsection{Test Case 8CF (ANSYS Text Command)}

ANSYS text command for test case $8 \mathrm{CF}$ was similar to that for test case $8 \mathrm{HS}$ except applied temperature and boundary condition were changed as following

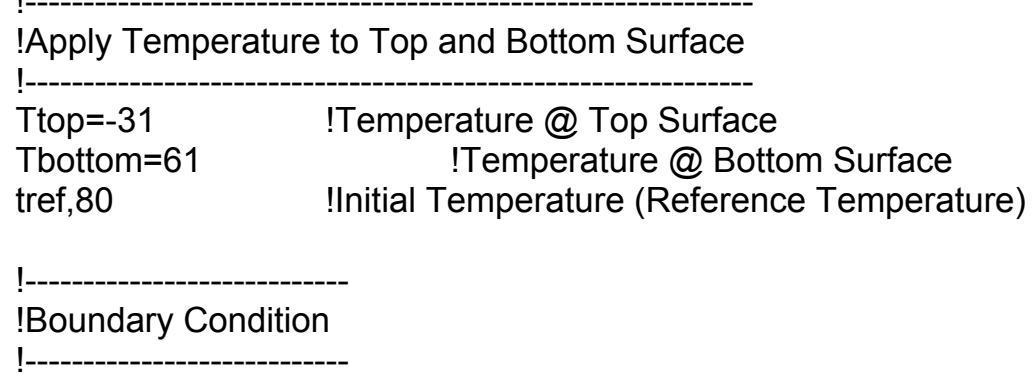


nsel,s,loc, $x, 0$

nsel, r,loc, $y, 0$

nsel,, ,loc,z, 7.5

d,all,uz

\subsection{Test Case 4HS (ANSYS Text Command)}

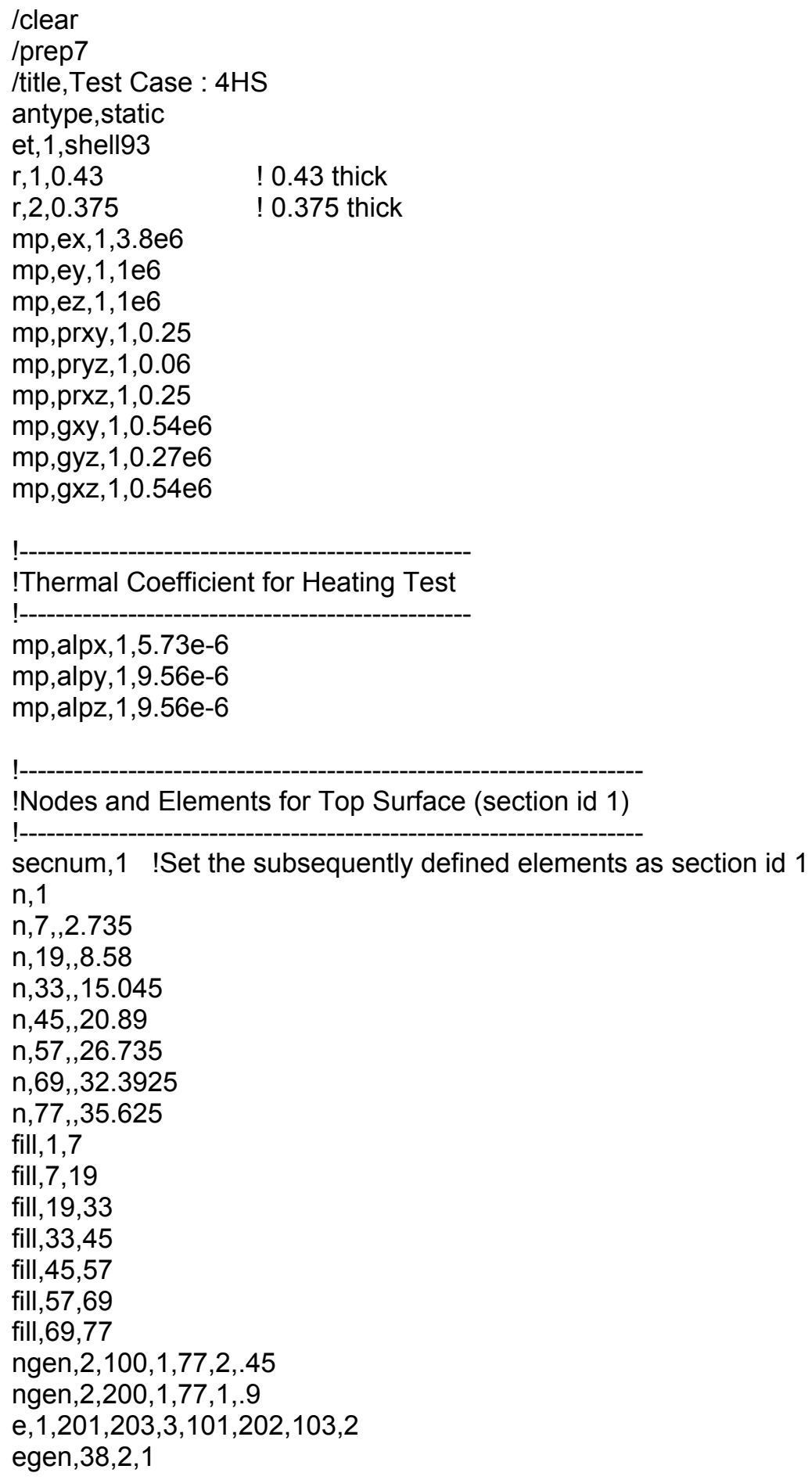




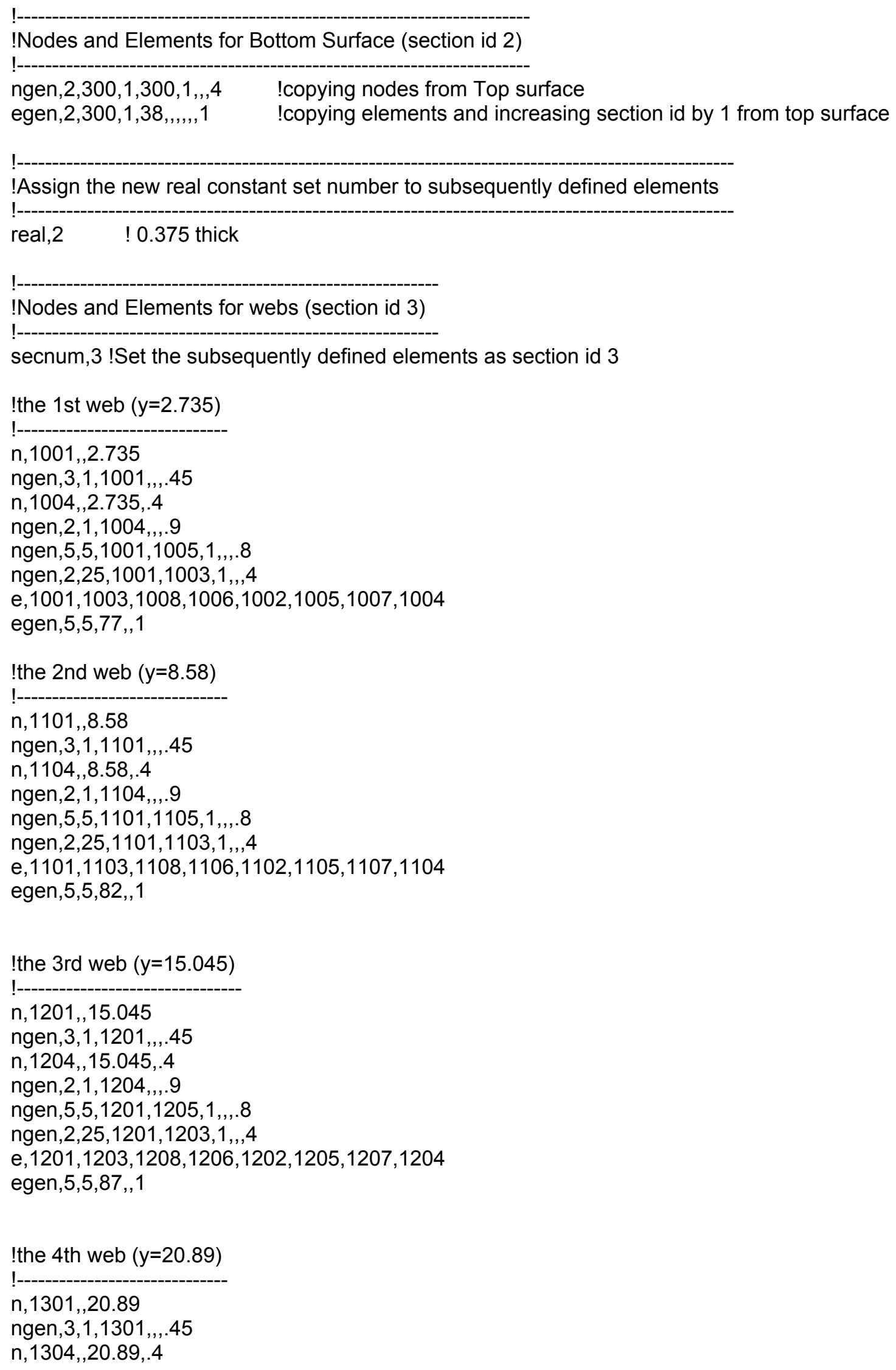




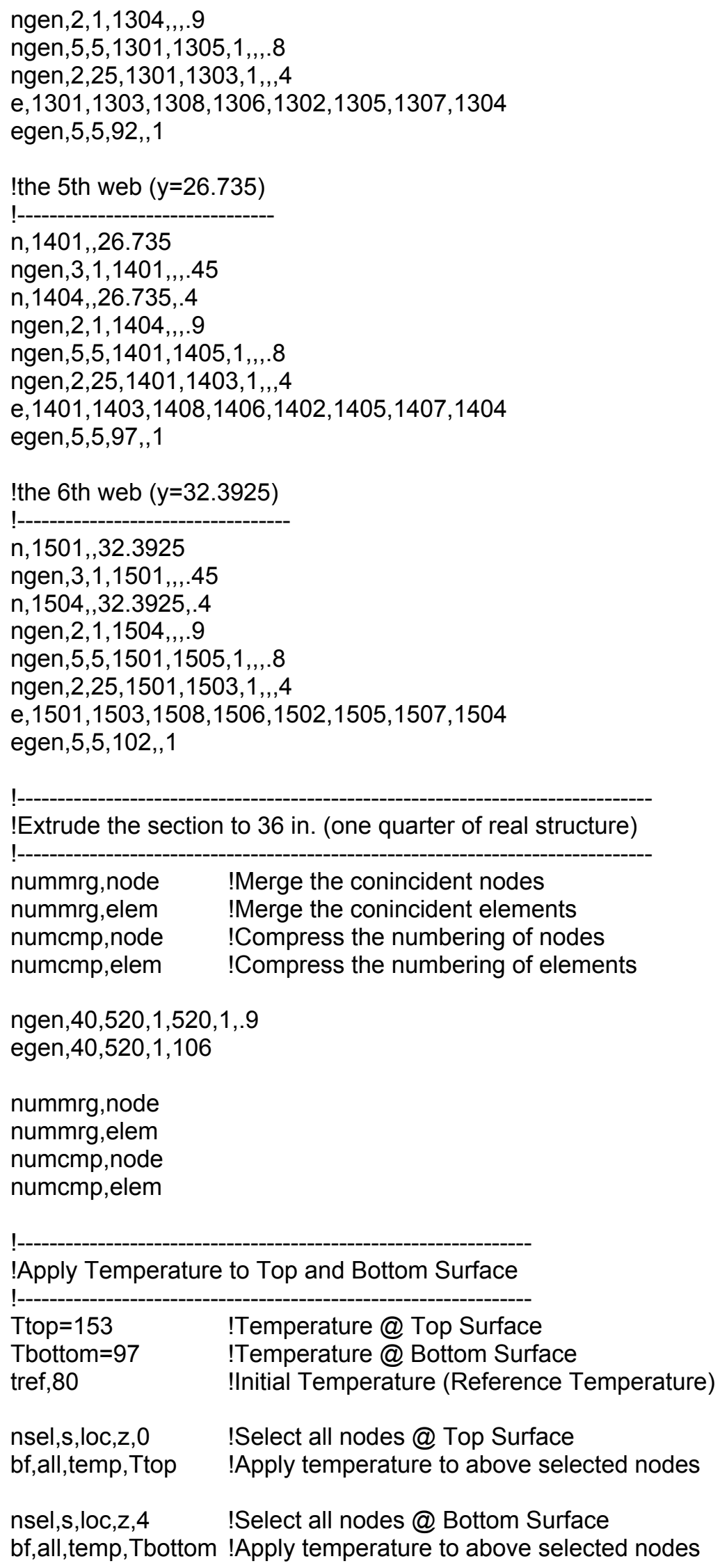




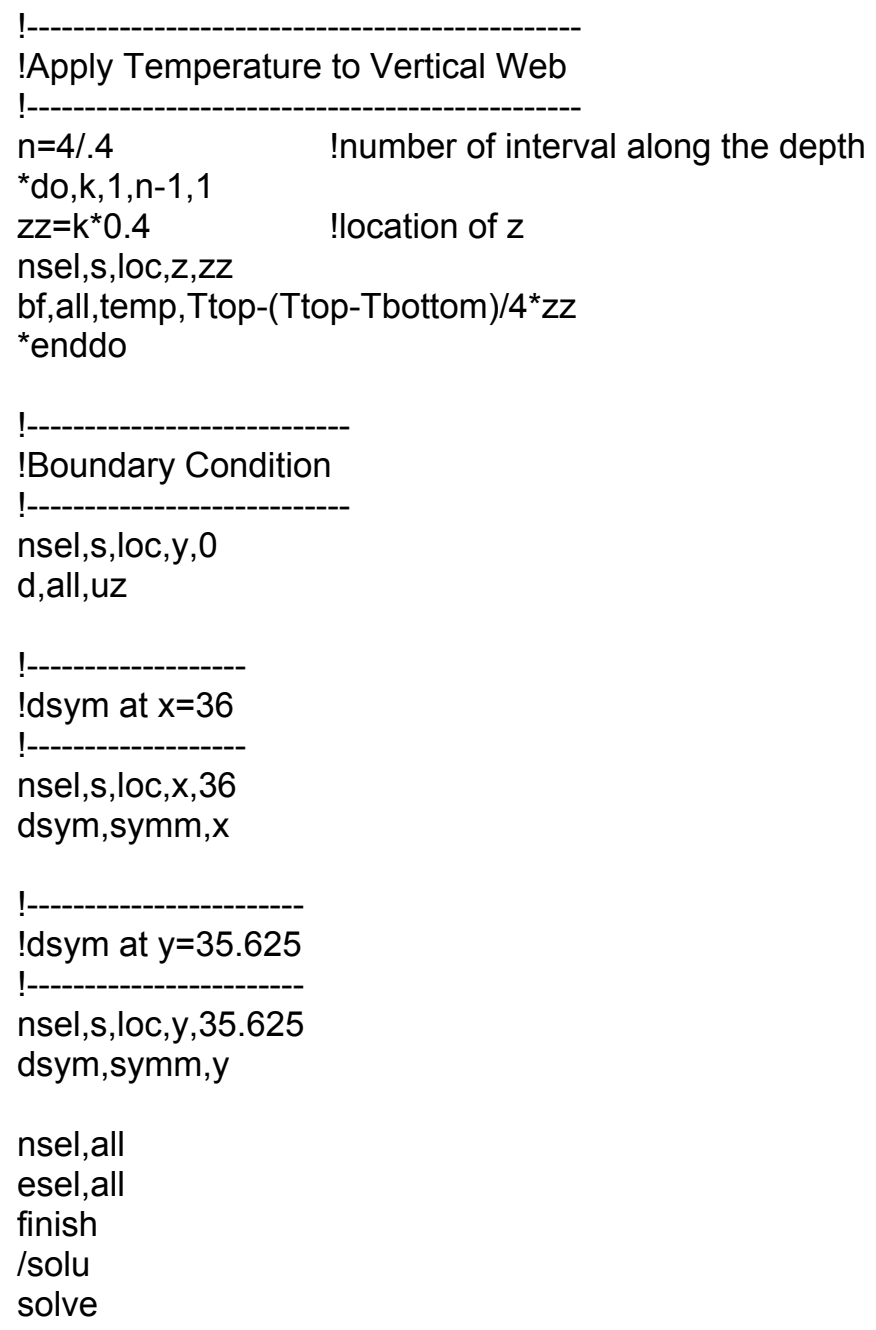

\subsection{Test Case 4HF (ANSYS Text Command)}

ANSYS text command for test case 4HF was similar to that for test case $4 \mathrm{HS}$ except applied temperature and boundary condition were changed as following

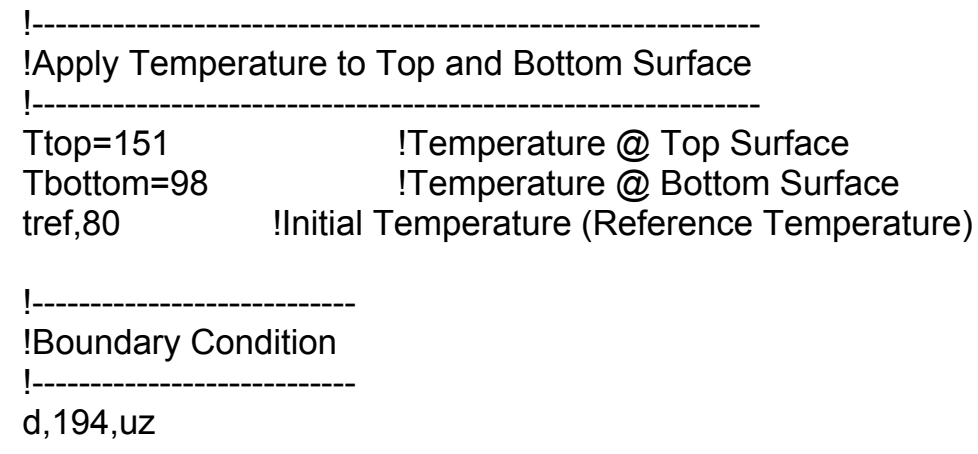




\subsection{Test Case 4CS (ANSYS Text Command)}

ANSYS text command for test case 4CS was similar to that for test case 4HS except applied temperature were changed as following

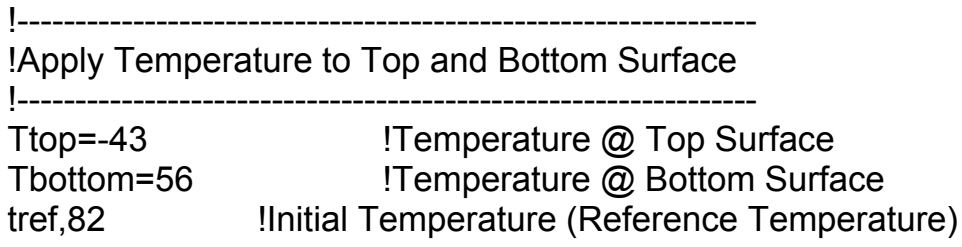

\subsection{Test Case 4CF (ANSYS Text Command)}

ANSYS text command for test case 4CF was similar to that for test case 4HS except applied temperature and boundary condition were changed as following

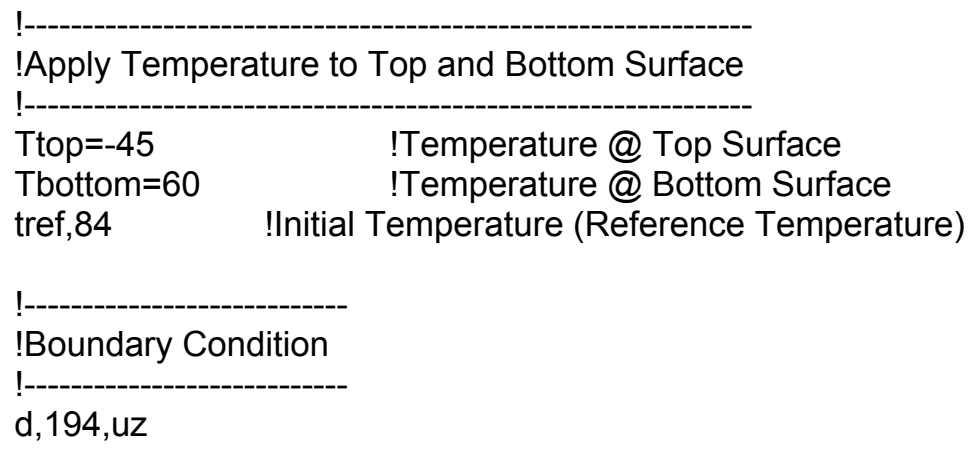




\section{Appendix G}

\section{Thermal Analysis of FRP Decks as Orthotropic Panels}

$\mathrm{n}$ this appendix, the overall behavior of an orthotropic rectangular plate subjected to a linear gradient temperature along the depth was analyzed using Navier-Levy method and Macro approach. The FRP deck is treated as a single equivalent layer of an orthotropic plate. In section G.1, thermal analysis of a rectangular plate under Free-Free-Simple-Simple (FFSS) boundary condition is derived by using Navier-Levy method (Using $1^{\text {st }}$ term approximation). In section G.2, the deflection equation for a rectangular plate with two elastic beams and two simply supported edges is derived based on Macro-mechanic approach.

\section{G.1 Navier and Levy's Method}

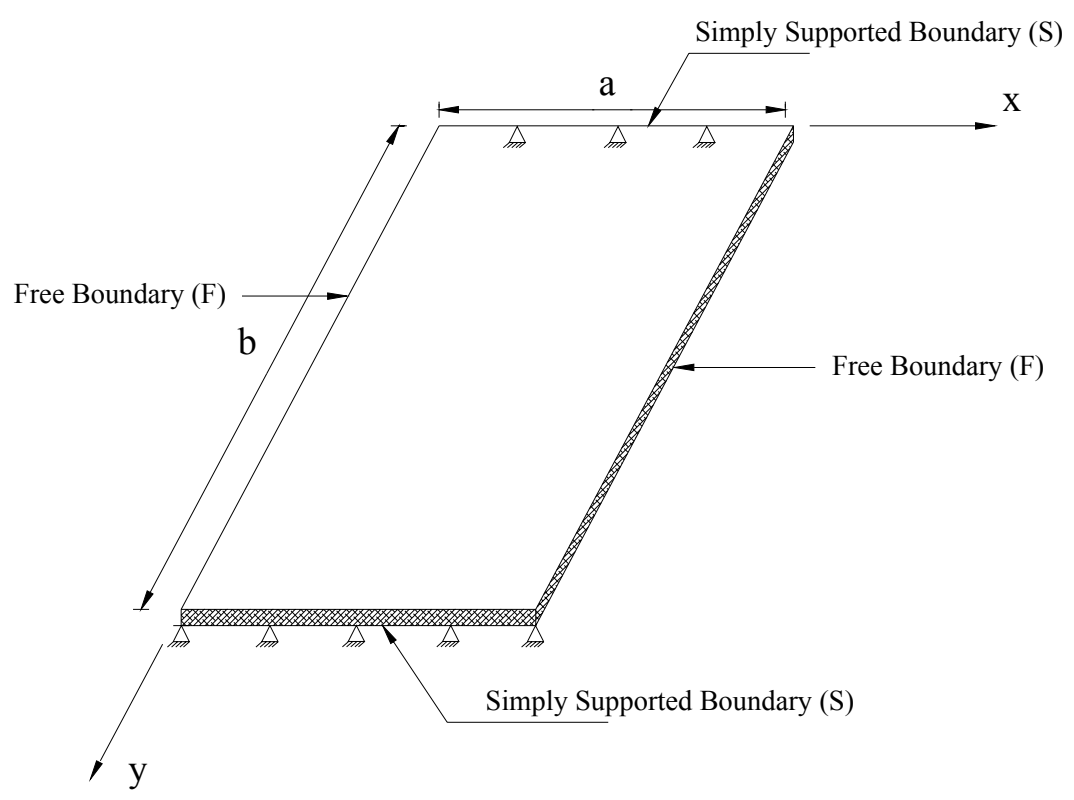

Figure G.1: Plate with FFSS Boundary Condition.

Consider a rectangular plate with simply supported edges along $\mathrm{y}=0, \mathrm{~b}$ (see Figure

3.1). The other two edges at $\mathrm{x}=0$, a can be either free, or simply supported, or clamped 
edges. In this section, we consider a rectangular plate with the other two edges at $\mathrm{x}=0$ and a, as free edges. Theory of thin plates with small deflection criterion $(<t / 10$, where $t=$ plate thickness) has been used in the analysis. The plate theory is valid under assumptions that the transverse normals along thickness do not experience elongation. Straight lines perpendicular to the mid-surface remain straight and perpendicular to the mid-surface after deformation. For the linear analysis of plate, the governing equation of bending effect is uncoupled from that of axial effect. The governing equation of an orthotropic plate for linear case is represented as:

$D_{x x} \frac{\partial^{4} w(x, y)}{\partial x^{4}}+2 \hat{D}_{x y} \frac{\partial^{4} w(x, y)}{\partial x^{2} \partial y^{2}}+D_{y y} \frac{\partial^{4} w(x, y)}{\partial y^{4}}+k w(x, y)=q-\left(\frac{\partial^{2} M_{x x}^{T}(x, y)}{\partial x^{2}}+2 \frac{\partial^{2} M_{x y}^{T}}{\partial x \partial y}+\frac{\partial^{2} M_{y y}^{T}(x, y)}{\partial y^{2}}\right)$

where $w(x, y)$ is deflection function of plate, $k$ is modulus of the elastic foundation, and $q$ is distributed traverse load. $M_{x x}^{T}(x, y)$ and $M_{y y}^{T}(x, y)$ are thermal moment load in $\mathrm{x}$ and $\mathrm{y}$ direction respectively. $D_{x x}$ and $D_{y y}$ are flexural rigidities per unit length in x and y direction respectively. $D_{s s}$ is torsional rigidity per unit length. $Q_{x x}$ and $Q_{y y}$ in Eq.(G.2) are the elastic stiffness. $E_{x}, E_{y}$ are Young's moduli in x, y direction respectively. $G_{x y}$ is the shear modulus in the x-y plane. $v_{x y}$ is Poisson's ratio, defined as the ratio of transverse strain in the $\mathrm{y}$ direction to the axial strain in the $\mathrm{x}$ direction when stressed in the $\mathrm{x}$ direction. Similar rule is applied to $v_{y x}$.

$$
\left\{\begin{array}{l}
D_{x x} \\
D_{y y} \\
D_{x y} \\
D_{s s}
\end{array}\right\}=\int_{-\frac{h}{2}}^{\frac{h}{2}} z^{2} d z\left\{\begin{array}{l}
Q_{x x} \\
Q_{y y} \\
Q_{x y} \\
Q_{s s}
\end{array}\right\}
$$




$$
\begin{gathered}
\left\{\begin{array}{l}
Q_{x x} \\
Q_{y y} \\
Q_{x y} \\
Q_{s s}
\end{array}\right\}=\left\{\begin{array}{c}
E_{x x} /\left(1-v_{x y} v_{y x}\right) \\
E_{y y} /\left(1-v_{x y} v_{y x}\right) \\
v_{x y} E_{y y} /\left(1-v_{x y} v_{y x}\right) \text { or } v_{y x} E_{x x} /\left(1-v_{x y} v_{y x}\right) \\
G_{x y}
\end{array}\right\} \\
D_{x y}=v_{x y} D_{y y}=v_{y x} D_{x x} \\
\hat{D}_{x y}=D_{x y}+2 D_{s s}
\end{gathered}
$$

In this analysis we consider the plate subjected to thermal loads only (ie. $\mathrm{k}=0$, and $\mathrm{q}$ =0). The thermal loads, $M_{x x}^{T}$ and $M_{y y}^{T}$, are provided by linear gradient temperature. $M_{x y}^{T}$ is identically zero for isotropic or orthotropic plates. Therefore the governing equation of an orthotropic plate under thermal load is reduced to (Reddy, 1999 and Szilard, 1974)

$$
D_{x x} \frac{\partial^{4} w(x, y)}{\partial x^{4}}+2 \hat{D}_{x y} \frac{\partial^{4} w(x, y)}{\partial x^{2} \partial y^{2}}+D_{y y} \frac{\partial^{4} w(x, y)}{\partial y^{4}}=-\frac{\partial^{2} M_{x x}^{T}(x, y)}{\partial x^{2}}-\frac{\partial^{2} M_{y y}^{T}(x, y)}{\partial y^{2}}
$$

In Navier's method or Levy's method the deflection functions, $w(x, y)$ and thermal loads $M_{x x}^{T}$ and $M_{y y}^{T}$ are expanded in trigonometric series. The trigonometric function used for deflection and thermal moments is restricted to those that satisfy the boundary conditions. Using Levy method, the deflection function, $w(x, y)$ for equation $(\mathrm{G} .7)$ is represented as 


$$
\begin{gathered}
w(x, y)=\sum_{n=1}^{\infty} W_{n}(x) \sin \frac{n \pi y}{b} \\
w(x, y)=\sum_{n=1}^{\infty}\left(W_{n}^{h}(x)+W_{n}^{p}(x)\right) \sin \beta_{n} y
\end{gathered}
$$

where $\beta_{n}=\frac{n \pi}{b}, W_{n}(x)$ is coefficient to be determined such that equation (G.7) is satisfied everywhere in the plate $(0<x<a, 0<y<b) . W_{n}^{h}(x)$ and $W_{n}^{p}(x)$ are the homogenous and particular solution of equation (G.7) respectively.

The right-hand side of equation (G.7) also is expanded in sine series. Therefore, thermal load $\left(M_{x x}^{T}, M_{y y}^{T}\right)$ can be expressed in Fourier Series as

$$
\begin{aligned}
& M_{x x}^{T}(x, y)=\sum_{n=1}^{\infty} M_{n}^{T_{x x}}(x) \sin \beta_{n} y \\
& M_{y y}^{T}(x, y)=\sum_{n=1}^{\infty} M_{n}^{T_{y y}}(x) \sin \beta_{n} y
\end{aligned}
$$

Assuming the temperature of top and bottom surfaces of an FRP deck are different in magnitude but are uniform over the top and bottom plate surfaces in the horizontal plane of the deck. Also assuming the orthotropic plate is subjected to a linear gradient temperature, temperature increment $(\Delta T(\mathrm{z}))$ along the depth $(z)$ can be defined as

$$
\Delta T(z)=T(z)-T_{r e f}
$$

where $T(z)$ the temperature function of $\mathrm{z} . T_{\text {ref }}$ is a reference temperature of FRP deck plate. $h$ is the depth of FRP deck plate.

Since temperature change $(\Delta T(z))$ is assumed to be linear along the depth $(z)$, Eq. (G.12) can be written in the form of linear function (i.e $y=a x+b)$ as following 


$$
\Delta T(z)=T^{0}+T^{1} z
$$

where

$$
T^{0}=\frac{\Delta T_{\text {top }}+\Delta T_{\text {bottom }}}{2}
$$

$$
T^{1}=-\left(\frac{\Delta T_{\text {top }}-\Delta T_{\text {bottom }}}{h}\right)
$$

Note : $\Delta T_{\text {top }}$ and $\Delta T_{\text {bottom }}$ are temperature changes on top and bottom surface of FRP deck, respectively. $\mathrm{z}$ is positive in downward direction as shown in Figure 3.2. Therefore, $\mathrm{z}=\frac{h}{2}$ at the bottom surface of deck plate and $\mathrm{z}=-\frac{h}{2}$ at the top surface while $\mathrm{z}=0$ at the middle of FRP deck plate.

The thermal moment load can be defined as ( Refer to Eq. (A.62) in Appendix A )

$$
\left\{\begin{array}{l}
M_{x x}^{T} \\
M_{y y}^{T}
\end{array}\right\}=\int_{-\frac{h}{2}}^{\frac{h}{2}}\left[\begin{array}{ll}
Q_{11} & Q_{12} \\
Q_{12} & Q_{22}
\end{array}\right]\left\{\begin{array}{l}
\alpha_{x x} \Delta T \\
\alpha_{y y} \Delta T
\end{array}\right\} z d z
$$

Substituting $\Delta T$ from Eq. (3.13) into the above equation, we obtain

$$
\begin{aligned}
\left\{\begin{array}{c}
M_{x x}^{T} \\
M_{y y}^{T}
\end{array}\right\}= & {\left[\begin{array}{ll}
Q_{x x} \alpha_{x x} & Q_{x y} \alpha_{y y} \\
Q_{x y} \alpha_{x x} & Q_{y y} \alpha_{y y}
\end{array}\right]_{-\frac{h}{2}}^{\frac{h}{2}}\left\{\begin{array}{l}
T^{0}+T^{1} z \\
T^{0}+T^{1} z
\end{array}\right\} z d z } \\
& =\left[\begin{array}{ll}
Q_{x x} \alpha_{x x} & Q_{x y} \alpha_{y y} \\
Q_{x y} \alpha_{x x} & Q_{y y} \alpha_{y y}
\end{array}\right]_{-\frac{h}{2}}^{\frac{h}{2}}\left\{\begin{array}{l}
\int^{0} z+T^{1} z^{2} \\
T^{0} z+T^{1} z^{2}
\end{array}\right\} d z \\
& =\left\{\begin{array}{l}
\left(D_{x x} \alpha_{x x}+D_{x y} \alpha_{y y}\right)\left(T^{1}\right) \\
\left(D_{x y} \alpha_{x x}+D_{y y} \alpha_{y y}\right)\left(T^{1}\right)
\end{array}\right\}
\end{aligned}
$$




$$
=\left\{\begin{array}{l}
-\left(D_{x x} \alpha_{x x}+D_{x y} \alpha_{y y}\right)\left(\frac{\Delta T_{\max }}{h}\right) \\
-\left(D_{x y} \alpha_{x x}+D_{y y} \alpha_{y y}\right)\left(\frac{\Delta T_{\max }}{h}\right)
\end{array}\right\}
$$

Note that $\Delta T_{\max }=\Delta T_{\text {top }}-\Delta T_{\text {bottom }}$

Based on the above equation, we notice that the thermal load moments $\left(M_{x x}^{T}, M_{y y}^{T}\right)$ are constant because we assume that the temperature over plate surface in the horizontal plane ( $x y$ plane) of the deck is uniform (i.e. $\Delta T$ is a function of $z$.). The coefficients, $M_{n}^{T_{x x}}$ and $M_{n}^{T_{y y}}$, of $\sin \beta_{n} y$ in equation (G.10) and (G.11) are defined as

$$
\begin{gathered}
M_{n}^{T_{x x}}(x)=\frac{4 M_{0}^{T_{x x}}}{n \pi} \quad \text { where } \quad M_{0}^{T_{x x}}=-\left(D_{x x} \alpha_{x x}+D_{x y} \alpha_{y y}\right)\left(\frac{\Delta T_{\max }}{h}\right) \\
M_{n}^{T_{y y}}(x)=\frac{4 M_{0}^{T_{y y}}}{n \pi} \quad \text { where } \quad M_{0}^{T_{y y}}=-\left(D_{x y} \alpha_{x x}+D_{y y} \alpha_{y y}\right)\left(\frac{\Delta T_{\max }}{h}\right)
\end{gathered}
$$

See Appendix B for derivation of $M_{n}^{T_{x x}}(x)$ and $M_{n}^{T_{y y}}(x)$ in equations (G.17) and (G.18)

The constant thermal load moments $\left(M_{x x}^{T}, M_{y y}^{T}\right)$ will be expanded in sine series ( Eq. (G.10) and (G.11) ) before substituting them into the governing equation (Eq. (G.1)) in order to solve equation conveniently (i.e. Left and right side of Eq. (G.1) are sine series.) Substituting (G.8), (G.10) and (G.11) into (G.7)

$$
\begin{gathered}
\sum_{n=1}^{\infty}\left[D_{x x} \frac{d^{4} W_{n}(x)}{d x^{4}}-2 \beta_{n}^{2} \hat{D}_{x y} \frac{d^{2} W_{n}(x)}{d x^{2}}+\beta_{n}^{4} D_{y y} W_{n}(x)\right] \sin \beta_{n} y=\sum_{n=1}^{\infty}\left[-\frac{d^{2} M_{n}^{T_{x x}}(x)}{d x^{2}}+\beta_{n}^{2} M_{n}^{T_{y y}}(x)\right] \sin \beta_{n} y \\
\sum_{n=1}^{\infty}\left[D_{x x} \frac{d^{4} W_{n}(x)}{d x^{4}}-2 \beta_{n}^{2} \hat{D}_{x y} \frac{d^{2} W_{n}(x)}{d x^{2}}+\beta_{n}^{4} D_{y y} W_{n}(x)+\frac{d^{2} M_{n}^{T_{x x}}(x)}{d x^{2}}-\beta_{n}^{2} M_{n}^{T_{y y}}(x)\right] \sin \beta_{n} y=0
\end{gathered}
$$


Since equation (G.20) must be true for all points (x, y) in the domain $0<\mathrm{x}<\mathrm{a}$ and $0<$ $\mathrm{y}<\mathrm{b}$, the coefficient of $\sin \beta_{n} y$ must be zero for any $\mathrm{n}$. This leads to the following equation.

$$
\begin{aligned}
& D_{x x} \frac{d^{4} W_{n}(x)}{d x^{4}}-2 \beta_{n}^{2} \hat{D}_{x y} \frac{d^{2} W_{n}(x)}{d x^{2}}+\beta_{n}^{4} D_{y y} W_{n}(x)+\frac{d^{2} M_{n}^{T_{x x}}(x)}{d x^{2}}-\beta_{n}^{2} M_{n}^{T_{y y}}(x)=0 \\
& D_{x x} \frac{d^{4} W_{n}(x)}{d x^{4}}-2 \beta_{n}^{2} \hat{D}_{x y} \frac{d^{2} W_{n}(x)}{d x^{2}}+\beta_{n}^{4} D_{y y} W_{n}(x)=-\frac{d^{2} M_{n}^{T_{x x}}(x)}{d x^{2}}+\beta_{n}^{2} M_{n}^{T_{y y}}(x)
\end{aligned}
$$

\section{Determining $W_{n}^{h}(x)$, the homogenous solution}

From equation (G.22), the form of the homogenous solution depends on the nature of the roots $\lambda$ of the following equation.

$$
D_{x x} \lambda^{4}-2 \beta_{n}^{4} \hat{D}_{x y} \lambda^{2}+\beta_{n}^{4} D_{y y}=0
$$

The following three cases are the solution for $\lambda$.

$\underline{\text { Case } 1} \hat{D}_{x y}^{2}>D_{x x} D_{y y}$

$$
\begin{gathered}
W_{n}^{h}=A_{n} \cosh \lambda_{1} x+B_{n} \sinh \lambda_{1} x+C_{n} \cosh \lambda_{2} x+D_{n} \sinh \lambda_{2} x \\
\lambda_{1}^{2}=\beta_{n}^{2}\left(\frac{\hat{D}_{x y}}{D_{x x}}\right)-\beta_{n}^{2}\left[\left(\frac{\hat{D}_{x y}}{D_{x x}}\right)^{2}-\frac{D_{y y}}{D_{x x}}\right]^{\frac{1}{2}} \\
\lambda_{2}^{2}=\beta_{n}^{2}\left(\frac{\hat{D}_{x y}}{D_{x x}}\right)+\beta_{n}^{2}\left[\left(\frac{\hat{D}_{x y}}{D_{x x}}\right)^{2}-\frac{D_{y y}}{D_{x x}}\right]^{\frac{1}{2}}
\end{gathered}
$$

$\underline{\text { Case } 2} \hat{D}_{x y}^{2}=D_{x x} D_{y y}$

$$
W_{n}^{h}=\left(A_{n}+B_{n} x\right) \cosh \lambda x+\left(C_{n}+D_{n} x\right) \sinh \lambda x
$$




$$
\lambda^{2}=\beta_{n}^{2}\left(\frac{\hat{D}_{x y}}{D_{x x}}\right)
$$

$\underline{\text { Case } 3} \hat{D}_{x y}^{2}<D_{x x} D_{y y}$

$$
\begin{gathered}
W_{n}^{h}=A_{n} \cosh \lambda_{1} x+B_{n} \sinh \lambda_{1} x+C_{n} \cosh \lambda_{2} x+D_{n} \sinh \lambda_{2} x \\
\lambda_{1}^{2}=\frac{\beta_{n}^{2}}{2 D_{x x}}\left(\sqrt{D_{x x} D_{y y}}+\hat{D}_{x y}\right) \\
\lambda_{2}^{2}=\frac{\beta_{n}^{2}}{2 D_{x x}}\left(\sqrt{D_{x x} D_{y y}}-\hat{D}_{x y}\right)
\end{gathered}
$$

The four constants, $A_{n}, B_{n}, C_{n}$ and $D_{n}$ are determined by using the boundary conditions on edges $\mathrm{x}=0$, a.

\section{Determining $W_{n}^{p}(x)$, the particular solution}

The particular solution, $W_{n}^{p}(x)$, can be determined by substituting

$$
\begin{aligned}
& w(x, y)=\sum_{n=1}^{\infty} W_{n}^{p}(x) \sin \beta_{n} y \text { into equation (G.22). We obtain } \\
& D_{x x} \frac{d^{4} W_{n}^{p}(x)}{d x^{4}}-2 \beta_{n}^{2} \hat{D}_{x y} \frac{d^{2} W_{n}^{p}(x)}{d x^{2}}+\beta_{n}^{4} D_{y y} W_{n}^{p}(x)=-\frac{d^{2} M_{n}^{T_{x x}}(x)}{d x^{2}}+\beta_{n}^{2} M_{n}^{T_{y y}}(x)
\end{aligned}
$$

Substituting $M_{n}^{T_{x x}}$ and $M_{n}^{T_{y y}}$ from equations (G.17) and (G.18) into the right-hand side of equation (G.32), we found that the right hand side of equation (G.32) become a constant. If the right-hand side of equation (G.32) are constant or linear functions of $\mathrm{x}$, the particular solution, $W_{n}^{p}(x)$, is also a constant or a linear function of $\mathrm{x}$ resulting in $\frac{d^{4} W_{n}^{p}(x)}{d x^{4}}$ and $\frac{d^{2} W_{n}^{p}(x)}{d x^{2}}$ being zero. The particular solution, $W_{n}^{p}(x)$, is given by solving equation (G.32) 


$$
W_{n}^{p}(x)=\frac{-\frac{d^{2} M_{n}^{T_{x x}}(x)}{d x^{2}}+\beta_{n}^{2} M_{n}^{T_{y y}}(x)}{\beta_{n}^{4} D_{y y}}
$$

Substituting equations (G.17) and (G.18) into (G.33), we obtain

$$
W_{n}^{p}(x)=\frac{4 b^{2}}{n^{3} \pi^{3} D_{y y}} M_{0}^{T_{y y}}
$$

Substituting equations (G.29) for case 3 and (G.34) into (G.9), we obtain the deflection function as $w(x, y)=\sum_{n=1}^{\infty}\left(\frac{4 b^{2}}{n^{3} \pi^{3} D_{y y}} M_{0}^{T_{y y}}+A_{n} \cosh \lambda_{1} x+B_{n} \sinh \lambda_{1} x+C_{n} \cosh \lambda_{2} x+D_{n} \sinh \lambda_{2} x\right) \sin \beta_{n} y$

Equation (G.35) is valid for case 3 when $\hat{D}_{x y}^{2}<D_{x x} D_{y y}$. We consider case 3 since the properties of FRP deck, given in Chapter 6, meet the criteria for case $3\left(\hat{D}_{x y}^{2}<D_{x x} D_{y y}\right)$. From equation (G.35), four unknown coefficients have to be determined. $A_{n}, B_{n}, C_{n}$ and $D_{n}$ are determined by applying the boundary conditions on edges $\mathrm{x}=0$ and a, giving 4 equations to solve for 4 unknowns.

Determining $A_{n}, B_{n}, C_{n}$ and $D_{n}$

Free Boundary Condition on Edges $\mathrm{x}=0, \mathrm{a}$

The free boundary conditions on edges $\mathrm{x}=0$, a are $M_{x x}=0$ and $V_{x}=0$. We expand it into four equations as $M_{x x}(0, y)=0, M_{x x}(a, y)=0, V_{x}(0, y)=0$, and $V_{x}(a, y)=0$. This provides four equations to solve for four unknowns, $A_{n}, B_{n}, C_{n}$ and $D_{n}$.

For $M_{x x}=0$

Substituting $M_{x x}$ from equation (G.6) into $M_{x x}=0$ for free boundary condition, we obtain 


$$
-D_{x x} \frac{\partial^{2} w(x, y)}{\partial x^{2}}-D_{x y} \frac{\partial^{2} w(x, y)}{\partial y^{2}}-M_{x x}^{T}(x, y)=0
$$

Substituting $M_{x x}^{T}(x, y)$ from a combination of equations (G.10) and (G.17) into above equation, we obtain

$$
D_{x x} \frac{\partial^{2} w(x, y)}{\partial x^{2}}+D_{x y} \frac{\partial^{2} w(x, y)}{\partial y^{2}}+\sum_{n=1}^{\infty} \frac{4 M_{0}^{T x x}}{n \pi} \sin \beta_{n} y=0
$$

For $V_{x}=0$

Substituting $V_{x}=\frac{\partial M_{x x}(x, y)}{\partial x}+2 \frac{\partial M_{x y}(x, y)}{\partial y}$ into the equation of $V_{x}=0$ for free boundary condition, we obtain

$$
\frac{\partial M_{x x}(x, y)}{\partial x}+2 \frac{\partial M_{x y}(x, y)}{\partial y}=0
$$

Substituting $M_{x x}(x, y), M_{y y}(x, y)$ from equation (G.6) into the above equation

$$
\begin{gathered}
-D_{x x} \frac{\partial^{3} w(x, y)}{\partial x^{3}}-D_{x y} \frac{\partial^{3} w(x, y)}{\partial x \partial y^{2}}-4 D_{s s} \frac{\partial^{3} w(x, y)}{\partial x \partial y^{2}}=0 \\
D_{x x} \frac{\partial^{3} w(x, y)}{\partial x^{3}}+\bar{D}_{x y} \frac{\partial^{3} w(x, y)}{\partial x \partial y^{2}}=0
\end{gathered}
$$

where

$$
\bar{D}_{x y}=D_{x y}+4 D_{s s}
$$

Now we have equations (G.37) and (G.40) for $M_{x x}=0$ and $V_{x}=0$ corresponding to free boundary conditions. Substituting $w(x, y)$ from equation (G.35) into equations (G.37) and (G.40) and expanding derivative. Applying $w(0, y)$ and $w(a, y)$ into the expanded equation then solving for $A_{n}, B_{n}, C_{n}$ and $D_{n}$. Maple software is conducted for solving and simplifying the solution. These following are formula for coefficients $A_{n}, B_{n}, C_{n}$ and $D_{n}$. 


$$
\begin{aligned}
& A_{n}=c_{1} D_{n}+c_{2} \\
& B_{n}=c_{3} C_{n} \\
& C_{n}=c_{4} D_{n}+c_{5} \\
& D_{n}=-\frac{k_{6} c_{2}+k_{7} c_{3} c_{5}+k_{8} c_{5}}{k_{6} c_{1}+k_{7} c_{3} c_{4}+k_{8} c_{4}+k_{9}} \\
& k_{1}=\frac{-4 D_{x y} \beta_{n}^{2} b^{2} M_{0}^{T_{y y}}-4 n^{2} \pi^{2} D_{y y} M_{0}^{T_{x x}}}{n^{3} \pi^{3} D_{y y}} \\
& k_{2}=\left(a_{1} b_{1}+2 a_{2} b_{2}\right) D_{x x}+\beta_{n}^{2} a_{1} D_{x y} \\
& k_{3}=\left(a_{3} b_{1}-2 a_{4} b_{2}\right) D_{x x}+\beta_{n}^{2} a_{3} D_{x y} \\
& k_{4}=\left(2 a_{3} b_{2}+a_{4} b_{1}\right) D_{x x}+\beta_{n}^{2} a_{4} D_{x y} \\
& k_{5}=\left(-2 a_{1} b_{2}+a_{2} b_{1}\right) D_{x x}+\beta_{n}^{2} a_{2} D_{x y} \\
& k_{6}=\left(-a_{3} \lambda_{2}^{3}+3 a_{4} b_{2} \lambda_{2}+3 a_{3} b_{2} \lambda_{1}-a_{4} \lambda_{1}^{3}\right) D_{x x}+\beta_{n}^{2}\left(a_{4} \lambda_{1}-a_{3} \lambda_{2}\right) \bar{D}_{x y} \\
& k_{7}=\left(a_{1} \lambda_{2}^{3}+3 a_{2} b_{2} \lambda_{2}-3 a_{1} b_{2} \lambda_{1}-a_{2} \lambda_{1}^{3}\right) D_{x x}+\beta_{n}^{2}\left(a_{1} \lambda_{2}-a_{2} \lambda_{1}\right) \bar{D}_{x y} \\
& k_{8}=\left(-a_{2} \lambda_{2}^{3}+3 a_{1} b_{2} \lambda_{2}+3 a_{2} b_{2} \lambda_{1}-a_{1} \lambda_{1}^{3}\right) D_{x x}+\beta_{n}^{2}\left(a_{1} \lambda_{1}-a_{2} \lambda_{2}\right) \bar{D}_{x y} \\
& k_{9}=\left(a_{4} \lambda_{2}^{3}+3 a_{3} b_{2} \lambda_{2}-3 a_{4} b_{2} \lambda_{1}-a_{3} \lambda_{1}^{3}\right) D_{x x}+\beta_{n}^{2}\left(a_{3} \lambda_{1}+a_{4} \lambda_{2}\right) \bar{D}_{x y} \\
& a_{1}=\cosh \left(a \lambda_{1}\right) \cos \left(a \lambda_{2}\right) \\
& a_{2}=\sinh \left(a \lambda_{1}\right) \sin \left(a \lambda_{2}\right) \\
& a_{3}=\cosh \left(a \lambda_{1}\right) \sin \left(a \lambda_{2}\right) \\
& a_{4}=\sinh \left(a \lambda_{1}\right) \cos \left(a \lambda_{2}\right) \\
& b_{1}=\lambda_{2}^{2}-\lambda_{1}^{2} \\
& b_{2}=\lambda_{1} \lambda_{2} \\
& c_{1}=\frac{2 b_{2} D_{x x}}{b_{1} D_{x x}+\beta_{n}^{2} D_{x y}} \\
& c_{2}=\frac{4\left(\beta_{n}^{2} b^{2} D_{x y} M_{0}^{T_{y y}}+n^{2} \pi^{2} D_{x x} M_{0}^{T_{x x}}\right)}{n^{3} \pi^{3} D_{y y}\left(b_{1} D_{x x}+\beta_{n}^{2} D_{x y}\right)}
\end{aligned}
$$




$$
\begin{gathered}
c_{3}=-\frac{\lambda_{1} \beta_{n}^{2} \bar{D}_{x y}+\left(3 \lambda_{1} \lambda_{2}^{2}-\lambda_{1}^{3}\right) D_{x x}}{\lambda_{2} \beta_{n}^{2} \bar{D}_{x y}+\left(\lambda_{2}^{3}-3 \lambda_{1}^{2} \lambda_{2}\right) D_{x x}} \\
c_{4}=-\frac{k_{2} c_{1}+k_{5}}{k_{3} c_{3}+k_{4}} \\
c_{5}=-\frac{k_{2} c_{2}+k_{1}}{k_{3} c_{3}+k_{4}}
\end{gathered}
$$




\section{G.2 Macro Approach}

Theory of plates and shells was used in the following analysis based on Macro approach. The following were some additional assumptions and criteria for the analysis excluding assumptions of theory of plates and shells. Temperature was uniformly distributed along horizontal plane (surface plane). The exterior beams do not resist torsion but do resist bending in vertical plane. The exterior beam properties are identical to each other. Neglect axial forces induced from thermal expansions.

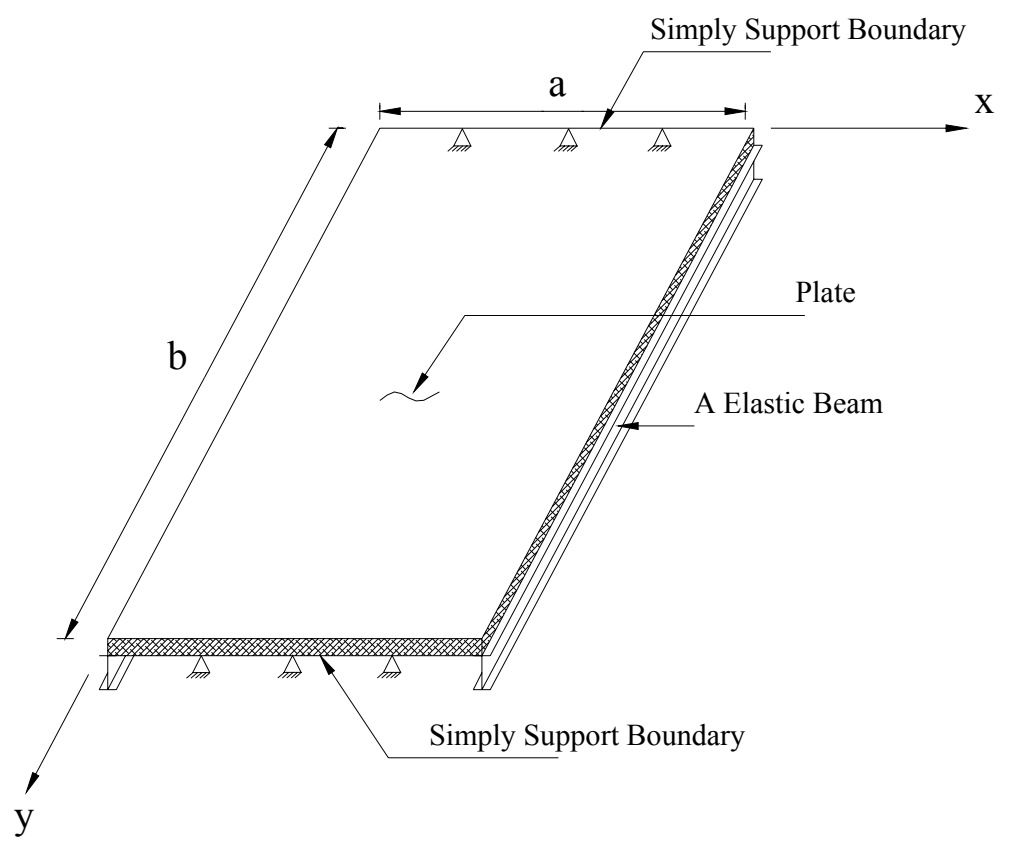

Figure G.2: Plate with Elastic Beams.

According Eq. (G.7), the governing equation of an orthotropic plate under thermal loads is defined as

$$
D_{x x} \frac{\partial^{4} w(x, y)}{\partial x^{4}}+2 \hat{D}_{x y} \frac{\partial^{4} w(x, y)}{\partial x^{2} \partial y^{2}}+D_{y y} \frac{\partial^{4} w(x, y)}{\partial y^{4}}=-\frac{\partial^{2} M_{x x}^{T}(x, y)}{\partial x^{2}}-\frac{\partial^{2} M_{y y}^{T}(x, y)}{\partial y^{2}}
$$

In the previous section, the generalized deflection function $(w(x, y))$ based on Navier and Levy's method is in the form of sine series only. In this section, the polynomial function 
can be added into the generalized deflection function in order to have faster convergence of solution which will improve the accuracy of the first term approximation. The generalized deflection function $w(x, y)$ of a plate is defined as

$$
w(x, y)=\sum_{i=1}^{\infty} \sum_{j=1}^{\infty} W_{i j}\left(\sin \left(\frac{i \pi x}{a}\right)+c_{1}+c_{2} x+c_{3} x^{2}+c_{4} x^{3}\right)\left(\sin \left(\frac{j \pi y}{b}\right)+d_{1}+d_{2} y+d_{3} y^{2}+d_{4} y^{3}\right)
$$

Since boundaries are symmetric and the temperature was uniformly distributed over horizontal plane, i.e. top and bottom surface, the deflection function of $w(x, y)$ can be reduced to a symmetric function (i.e. $c_{4}$ and $d_{4}=0$ ) as following

$$
w(x, y)=\sum_{i=1}^{\infty} \sum_{j=1}^{\infty} W_{i j}\left(\sin \left(\frac{i \pi x}{a}\right)+c_{1}+c_{2} x+c_{3} x^{2}\right)\left(\sin \left(\frac{j \pi y}{b}\right)+d_{1}+d_{2} y+d_{3} y^{2}\right)
$$

where $c_{1}$ to $c_{3}$ and $d_{1}$ to $d_{3}$ are the constants coefficients. $W_{i j}$ are the coefficients of series. The deflections along edges ( $y=0$ and $b$ ) are zero because simply supported boundaries are applied on both edges (i.e. $w(x, 0)=w(x, b)=0)$. This implies that the generalized deflection function $(w(x, y))$ in Eq. (G.67) can be reduced to

$$
w(x, y)=\sum_{i=1}^{\infty} \sum_{j=1}^{\infty} W_{i j} \sin \left(\frac{j \pi y}{b}\right)\left(\sin \left(\frac{i \pi x}{a}\right)+c_{1}+c_{2} x+c_{3} x^{2}\right)
$$

The thermal load moments $\left(M_{x x}^{T}(x, y), M_{y y}^{T}(x, y)\right)$ are expanded in term of sine series as

$$
\begin{aligned}
& M_{x x}^{T}(x, y)=\sum_{i=1}^{\infty} \sum_{j=1}^{\infty} M_{i j}^{T_{x x}} \sin \left(\frac{i \pi x}{a}\right) \sin \left(\frac{j \pi y}{b}\right) \\
& M_{y y}^{T}(x, y)=\sum_{i=1}^{\infty} \sum_{j=1}^{\infty} M_{i j}^{T_{y y}} \sin \left(\frac{i \pi x}{a}\right) \sin \left(\frac{j \pi y}{b}\right)
\end{aligned}
$$

where $M_{i j}^{T_{x x}}, M_{i j}^{T_{y y}}$ are the coefficients of sine series. 
Since the temperatures are uniform over plate surfaces in the horizontal plane, thermal load induced moments are uniform (Refer to Eq. (G.16)). In case of uniform thermal load induced moment, we can define $M_{i j}^{T_{x x}}, M_{i j}^{T_{y y}}$ as

$$
\begin{gathered}
M_{i j}^{T_{x x}}=\frac{16 M_{0}^{T_{x x}}}{\pi^{2} i j} \quad \text { where } M_{0}^{T_{x x}}=-\left(D_{x x} \alpha_{x x}+D_{x y} \alpha_{y y}\right)\left(\frac{\Delta T_{\max }}{h}\right) \\
M_{i j}^{T_{y y}}=\frac{16 M_{0}^{T_{y y}}}{\pi^{2} i j} \quad \text { where } M_{0}^{T_{y y}}=-\left(D_{x y} \alpha_{x x}+D_{y y} \alpha_{y y}\right)\left(\frac{\Delta T_{\max }}{h}\right)
\end{gathered}
$$

In order to have a simple solution for practicing design, only the first term of sine series will be used in the analysis. Therefore, generalized deflection function $(w(x, y))$ in Eq. (G.67) and thermal load moments ( $M_{x x}^{T}$ and $M_{y y}^{T}$ ) in Eqs. (G.69) and (G.70) become

$$
\begin{gathered}
w(x, y)=W_{11} \sin \left(\frac{\pi y}{b}\right)\left(\sin \left(\frac{\pi x}{a}\right)+c_{1}+c_{2} x+c_{3} x^{2}\right) \\
M_{x x}^{T}(x, y)=M_{11}^{T_{x x}} \sin \left(\frac{\pi x}{a}\right) \sin \left(\frac{\pi y}{b}\right)=\frac{16 M_{0}^{T_{x x}}}{\pi^{2}} \sin \left(\frac{\pi x}{a}\right) \sin \left(\frac{\pi y}{b}\right) \\
M_{y y}^{T}(x, y)=M_{11}^{T_{y y}} \sin \left(\frac{\pi x}{a}\right) \sin \left(\frac{\pi y}{b}\right)=\frac{16 M_{0}^{T_{y y}}}{\pi^{2}} \sin \left(\frac{\pi x}{a}\right) \sin \left(\frac{\pi y}{b}\right)
\end{gathered}
$$

where $M_{11}^{T_{\text {xx }}}$ and $\mathrm{M}_{11}^{\mathrm{T}_{\mathrm{yy}}}$ are defined in Eqs (G.71) and (G.72) by letting $i=j=1$.

Boundary Conditions for simply supported and elastic beam supported boundary are : $\underline{\text { At } y=0 \text { and b (Simply Supported Boundaries) }}$

$$
\begin{gathered}
w(x, 0)=w(x, b)=0 \\
M_{y y}(x, 0)=M_{y y}(x, b)=0
\end{gathered}
$$

$\underline{\text { At } x}=0$ and a (Elastic Beam Boundaries)

$$
M_{x x}(0, y)=M_{x x}(a, y)=0
$$




$$
\begin{gathered}
E I \frac{\partial^{4} w(0, y)}{\partial y^{4}}=\frac{\partial M_{x x}(0, y)}{\partial x}+2 \frac{\partial M_{x y}(0, y)}{\partial y} \quad\left(=V_{x}(0, y)\right) \\
E I \frac{\partial^{4} w(a, y)}{\partial y^{4}}=-\frac{\partial M_{x x}(a, y)}{\partial x}-2 \frac{\partial M_{x y}(a, y)}{\partial y} \quad\left(=V_{x}(a, y)\right)
\end{gathered}
$$

where $E I$ is flexural rigidity of a elastic beam. The right hand side of Eq. (G.79) and (G.80) is the shear force per unit length of plate along the edge $(x=0$ and $a)$.

The generalized deflection function $(w(x, y))$ must be satisfied on all above boundary conditions and governing equation in Eq. (G.65). Suppose that origin (i.e. $x=y=0$ ) is maintained at a corner of plate (not at the center of a plate), generalized deflection function in Eq. (G.73) can be written in an alternative form as :

$$
w(x, y)=W_{11} \sin \left(\frac{\pi y}{b}\right)\left(\sin \left(\frac{\pi x}{a}\right)+c_{1} x(x-a)+c_{2}\right)
$$

We need to check if the generalized deflection $(w(x, y))$ in Eq. (G.81) satisfies the boundary conditions in Eqs. (G.76) to (G.80) or not.

\section{$\underline{\text { At boundary } \mathrm{y}=0 \text { and } \mathrm{b} \text { (Simply Supported Boundaries) }}$}

Check if the generalized deflection $(w(x, y))$ is satisfied the boundary condition in Eq.

$$
\left\{\begin{array}{l}
w(x, 0)=0 \\
w(x, b)=0
\end{array}\right\} \stackrel{\text { satisfied }}{\longrightarrow}\left\{\begin{array}{l}
w(x, 0)=W_{11} \sin \left(\frac{\pi(0)}{b}\right)\left(\sin \left(\frac{\pi(x)}{a}\right)+c_{1}(x)(x-a)+c_{2}\right)=0 \\
w(x, a)=W_{11} \sin \left(\frac{\pi(b)}{b}\right)\left(\sin \left(\frac{\pi(x)}{a}\right)+c_{1}(x)(x-a)+c_{2}\right)=0
\end{array}\right\}
$$


Check if the generalized deflection $(w(x, y))$ is satisfied the boundary condition in Eq.

(G.77) (i.e. $\left.M_{y y}(x, 0)=M_{y y}(x, b)=0\right)$. Moment resultants are defined as (Refer to Eq. (A.61) in Appendix A)

$$
M_{y y}(x, y)=-D_{x y} \frac{\partial^{2} w(x, y)}{\partial x^{2}}-D_{y y} \frac{\partial^{2} w(x, y)}{\partial y^{2}}-M_{y y}^{T}(x, y)
$$

Substituting the generalized deflection $(w(x, y))$ from Eq. (G.81) and thermal load moment $\left(M_{y y}^{T}\right)$ from Eq. (G.75) to the above equation .

$$
\begin{aligned}
M_{y y}(x, y)= & -D_{x y} W_{11} \sin \left(\frac{\pi y}{b}\right)\left(-\frac{\pi^{2}}{a^{2}} \sin \left(\frac{\pi x}{a}\right)+2 c_{1}\right)+\frac{\pi^{2}}{b^{2}} D_{y y} W_{11} \sin \left(\frac{\pi y}{b}\right)\left(\sin \left(\frac{\pi x}{a}\right)+c_{1} x(x-a)+c_{2}\right) \\
& -\frac{16 M_{0}^{T_{y y}}}{\pi^{2}} \sin \left(\frac{\pi x}{a}\right) \sin \left(\frac{\pi y}{b}\right)
\end{aligned}
$$

Substituting $y=0$ and $b$ to the above equation, we obtain $M_{y y}(x, 0)=M_{y y}(x, b)=0$. This implies that the generalized deflection $(w(x, y))$ in Eq. (G.81) is satisfied the boundary condition in Eq. (G.77).

\section{At boundary $\mathrm{x}=0$ and a (Elastic Beam Boundaries)}

The boundary condition in Eq. (G.78) is $M_{x x}(0, y)=M_{x x}(a, y)=0$. The relation of $c_{1}$ and $c_{2}$ will be determined by this boundary condition. The moment resultant $\left(M_{x x}(x, y)\right)$ is defined as (Refer to Eq. (A.61) in Appendix A))

$$
M_{x x}(x, y)=-D_{x x} \frac{\partial^{2} w(x, y)}{\partial x^{2}}-D_{x y} \frac{\partial^{2} w(x, y)}{\partial y^{2}}-M_{x x}^{T}(x, y)
$$


Substituting the generalized deflection $(w(x, y))$ from Eq. (G.81) and thermal load moment $\left(M_{x x}^{T}\right)$ from Eq. (G.74) to the above equation.

$$
\begin{aligned}
M_{x x}(x, y)= & -D_{x x} W_{11} \sin \left(\frac{\pi y}{b}\right)\left(-\frac{\pi^{2}}{a^{2}} \sin \left(\frac{\pi x}{a}\right)+2 c_{1}\right)+\frac{\pi^{2}}{b^{2}} D_{y y} W_{11} \sin \left(\frac{\pi y}{b}\right)\left(\sin \left(\frac{\pi x}{a}\right)+c_{1} x(x-a)+c_{2}\right) \\
& -\frac{16 M_{0}^{T_{x x}}}{\pi^{2}} \sin \left(\frac{\pi x}{a}\right) \sin \left(\frac{\pi y}{b}\right)
\end{aligned}
$$

Substituting $x=0$ into the above equation and using boundary condition in Eq. (G.78) (i.e. $\left.M_{x x}(0, y)=0\right)$ to solve for the relation $c_{1}$ and $c_{2}$,

$$
M_{x x}(0, y)=\left[-2 D_{x x} W_{11} c_{1}+\frac{\pi^{2}}{b^{2}} D_{y y} W_{11} c_{2}\right] \sin \left(\frac{\pi y}{b}\right)=0
$$

The above equation implies that the coefficient of $\sin \left(\frac{\pi y}{b}\right)$ must be zero for all $y$.

Therefore, the relation of $c_{1}$ and $c_{2}$ can be express as

$$
c_{1}=\frac{\pi^{2} D_{x y}}{2 b^{2} D_{x x}} c_{2}
$$

The coefficient $\left(c_{2}\right)$ in the above equation will be determined by using the boundary condition in Eq. (G.79) expressed as

$$
E I \frac{\partial^{4} w(0, y)}{\partial y^{4}}=\frac{\partial M_{x x}(0, y)}{\partial x}+2 \frac{\partial M_{x y}(0, y)}{\partial y}
$$

The above equation can be written in the general form as

$$
E I \frac{\partial^{4} w(x, y)}{\partial y^{4}}=\frac{\partial M_{x x}(x, y)}{\partial x}+2 \frac{\partial M_{x y}(x, y)}{\partial y}
$$

Expand the above equation by substituting $w(x, y)$ from Eq. (G.81), $M_{x x}(x, y)$ from Eq. (G.85)and $M_{x y}(x, y)$ from Eq. (G.6), we have 


$$
\begin{aligned}
& \frac{\pi^{4}}{b^{4}} E I W_{11} \sin \left(\frac{\pi y}{b}\right)\left(\sin \left(\frac{\pi x}{a}\right)+c_{1} x(x-a)+c_{2}\right)-\frac{\pi^{3}}{a^{3}} D_{x x} W_{11} \sin \left(\frac{\pi y}{b}\right) \cos \left(\frac{\pi x}{a}\right) \\
& -\frac{\pi^{2}}{b^{2}} D_{x y} W_{11} \sin \left(\frac{\pi y}{b}\right)\left(\frac{\pi}{a} \cos \left(\frac{\pi x}{a}\right)+c_{1}(x-a)+c_{1} x\right)+\frac{16 M_{0}^{T_{x x}}}{\pi a} \sin \left(\frac{\pi y}{b}\right) \cos \left(\frac{\pi x}{b}\right) \\
& -4 \frac{\pi^{2}}{b^{2}} D_{s s} W_{11} \sin \left(\frac{\pi y}{b}\right)\left(\frac{\pi}{a} \cos \left(\frac{\pi x}{a}\right)+c_{1}(x-a)+c_{1} x\right)=0
\end{aligned}
$$

Substituting $x=0$ (for the boundary condition) and $\quad c_{1}=\frac{\pi^{2} D_{x y}}{2 b^{2} D_{x x}} c_{2}$ from (G.87) into the above equation, we have

$$
\begin{aligned}
& \frac{\pi^{4}}{b^{4}} B_{e} W_{11} \sin \left(\frac{\pi y}{b}\right) c_{2}-\frac{\pi^{3}}{a^{3}} D_{x x} W_{11} \sin \left(\frac{\pi y}{b}\right)-\frac{\pi^{2}}{b^{2}} D_{x y} W_{11} \sin \left(\frac{\pi y}{b}\right)\left(\frac{\pi}{a}-\frac{\pi^{2} D_{x y}}{2 b^{2} D_{x x}} c_{2}\right) \\
& +\frac{16 M_{0}^{T_{x x}}}{\pi a} \sin \left(\frac{\pi y}{b}\right)-4 \frac{\pi^{2}}{b^{2}} D_{s s} W_{11} \sin \left(\frac{\pi y}{b}\right)\left(\frac{\pi}{a}-\frac{\pi^{2} D_{x y}}{2 b^{2} D_{x x}} c_{2}\right)=0
\end{aligned}
$$

Solve the above equation for $c_{2}$

$$
c_{2}=k_{1}+\frac{k_{2} M_{0}^{T_{x x}}}{W_{11}}
$$

where $k_{1}=\frac{2\left(b^{4} D_{x x}^{2}+a^{2} b^{2} D_{x x} D_{x y}+4 a^{2} b^{2} D_{x x} D_{s s}\right)}{\pi a^{3}\left(2 B_{e} D_{x x}+a D_{x y}^{2}+4 a D_{x y} D_{s s}\right)}$

$$
\begin{aligned}
& k_{2}=\frac{-32 b^{4} D_{x x}}{\pi^{5} a\left(2 B_{e} D_{x x}+a D_{x y}^{2}+4 a D_{x y} D_{s s}\right)} \\
& B_{e}=E I \text { is flexural rigidity of a elastic beam. }
\end{aligned}
$$

Now $W_{11}$ is the only unknown in deflection function $(w(x, y))$ that we need to determine. Substituting thermal moment load $\left(M_{x x}^{T}, M_{y y}^{T}\right)$ and the deflection function $(w(x, y))$ from Eqs (G.74), (G.75) and (G.81), respectively into the governing equation in Eq. (G.65), we have 


$$
\begin{aligned}
& \frac{\pi^{4}}{a^{4}} D_{x x} W_{11} \sin \left(\frac{\pi x}{a}\right) \sin \left(\frac{\pi y}{b}\right)+2 \frac{\pi^{2}}{b^{2}} \hat{D}_{x y} W_{11} \sin \left(\frac{\pi y}{b}\right)\left(\frac{\pi^{2}}{a^{2}} \sin \left(\frac{\pi x}{a}\right)-2 c_{1}\right) \\
& +\frac{\pi^{4}}{a^{4}} D_{y y} W_{11} \sin \left(\frac{\pi y}{b}\right)\left(\sin \left(\frac{\pi x}{a}\right)+c_{1} x(x-a)+c_{2}\right)=16 \sin \left(\frac{\pi x}{a}\right) \sin \left(\frac{\pi y}{b}\right)\left(\frac{M_{0}^{T_{x x}}}{a^{2}}+\frac{M_{0}^{T_{y y}}}{b^{2}}\right)
\end{aligned}
$$

Dividing both sides of the above equation by $\sin \left(\frac{\pi y}{b}\right)$

$$
\begin{aligned}
& \frac{\pi^{4}}{a^{4}} D_{x x} W_{11} \sin \left(\frac{\pi x}{a}\right)+2 \frac{\pi^{2}}{b^{2}} \hat{D}_{x y} W_{11}\left(\frac{\pi^{2}}{a^{2}} \sin \left(\frac{\pi x}{a}\right)-2 c_{1}\right)+\frac{\pi^{4}}{a^{4}} D_{y y} W_{11}\left(\sin \left(\frac{\pi x}{a}\right)+c_{1} x(x-a)+c_{2}\right) \\
& =16 \sin \left(\frac{\pi x}{a}\right)\left(\frac{M_{0}^{T_{x x}}}{a^{2}}+\frac{M_{0}^{T_{y y}}}{b^{2}}\right)
\end{aligned}
$$

Multiplying both sides of the above equation by $\sin \left(\frac{\pi x}{a}\right)$ and integrating with respect to $\mathrm{x}$ from 0 to a, applying orthogonality conditions of trigonometric function and substituting $c_{1}$ and $c_{2}$ from Eqs (G.87) and (G.90), respectively, we obtain

$$
W_{11}=\frac{k_{3} M_{0}^{T_{x x}}+k_{4} M_{0}^{T_{y y}}}{k_{5}}
$$

where

$$
\begin{aligned}
& k_{3}=\left(4 \pi^{3} a^{6} D_{x y} D_{y y}+8 \pi^{3} a^{4} b^{2} \hat{D}_{x y} D_{x y}-4 \pi^{3} a^{4} b^{2} D_{x x} D_{y y}\right) k_{2}+16 a^{2} b^{6} D_{x x} \\
& k_{4}=16 a^{4} b^{4} D_{x x} \\
& k_{5}=\pi^{3}\left(4 a^{4} b^{2} D_{x x} D_{y y}-4 a^{6} D_{x y} D_{y y}-8 a^{4} b^{2} \hat{D}_{x y} D_{x y}\right) k_{1}+\pi^{4}\left(a^{4} b^{2} D_{x x} D_{y y}+2 a^{2} b^{4} \hat{D}_{x y} D_{x x}+b^{6} D_{x x}^{2}\right)
\end{aligned}
$$

Finally we obtain the deflection function $(w(x, y))$ of plate with two opposite edges simply supported an the other two edges supported elastically by beams as following 


$$
\begin{gathered}
w(x, y)=W_{11} \sin \left(\frac{\pi y}{b}\right)\left[\sin \left(\frac{\pi x}{a}\right)+c_{1} x(x-a)+c_{2}\right] \\
W_{11}=\frac{k_{3} M_{0}^{T_{x x}}+k_{4} M_{0}^{T_{y y}}}{k_{5}} \\
c_{1}=\frac{\pi^{2} D_{x y}}{2 b^{2} D_{x x}} c_{2} \\
c_{2}=k_{1}+\frac{k_{2} M_{0}^{T_{x x}}}{W_{11}} \\
k_{1}=\frac{2\left(b^{4} D_{x x}^{2}+a^{2} b^{2} D_{x x} D_{x y}+4 a^{2} b^{2} D_{x x} D_{s s}\right)}{\pi a^{3}\left(2 B_{e} D_{x x}+a D_{x y}^{2}+4 a D_{x y} D_{s s}\right)} \\
k_{5}=\pi_{3}^{3}\left(\begin{array}{c}
\left.a^{4} b^{2} D_{x x} D_{y y}-4 a^{6} D_{x y} D_{y y}-8 a^{4} b^{2} \hat{D}_{x y} D_{x y}\right) k_{1}+\pi^{4}\left(a^{4} b^{2} D_{x x} D_{y y}+2 a^{2} b^{4} \hat{D}_{x y} D_{x x}+b^{6} D_{x x}^{2}\right. \\
\pi^{5} a\left(2 B_{e} D_{x x}+a D_{x y}^{2}+4 a D_{x y} D_{s s}\right) \\
\left(4 \pi^{3} a^{6} D_{x y} D_{y y}+8 \pi^{3} a^{4} b^{2} \hat{D}_{x y} D_{x y}-4 \pi^{3} a^{4} b^{2} D_{x x} D_{y y}\right) k_{2}+16 a^{2} b^{6} D_{x x}
\end{array}\right.
\end{gathered}
$$

\section{Linear Elastic Strain of Plate under a Linear Gradient Temperature}

The strain-displacement relation of plate can be defined as (Refer to Eq. A.32 in Appendix A)

$$
\left.\begin{array}{c}
\varepsilon_{x x}=\varepsilon_{x x_{-} a x i a l}+\varepsilon_{x x_{-} \text {bending }}=\varepsilon_{x x}^{0}+z \varepsilon_{x x}^{1}=\frac{\partial u_{0}}{\partial x}-z \frac{\partial^{2} w_{0}}{\partial x^{2}} \\
\varepsilon_{y y}=\varepsilon_{y y_{-} \text {axial }}+\varepsilon_{y y_{-} \text {bending }}=\varepsilon_{y y}^{0}+z \varepsilon_{y y}^{1}=\frac{\partial v_{0}}{\partial y}-z \frac{\partial^{2} w_{0}}{\partial y^{2}}
\end{array}\right\}
$$


The first and second terms of the above equation are the strains due to axial and bending effect, respectively.

For pure bending case, Eq. (G.101) reduced to

$$
\left.\begin{array}{l}
\varepsilon_{x x_{-} \text {bending }}=z \varepsilon_{x x}^{1}=-z \frac{\partial^{2} w_{0}}{\partial x^{2}} \\
\varepsilon_{y y_{-} \text {bending }}=z \varepsilon_{y y}^{1}=-z \frac{\partial^{2} w_{0}}{\partial y^{2}}
\end{array}\right\}
$$

Substituting $w_{0}(x, y)=W_{11} \sin \left(\frac{\pi y}{b}\right)\left[\sin \left(\frac{\pi x}{a}\right)+c_{1} x(x-a)+c_{2}\right]$ from Eq. (G.93) into the above equation, we obtain

$$
\begin{aligned}
& \varepsilon_{x x_{-} \text {bending }}=-W_{11} \sin \left(\frac{\pi y}{b}\right)\left[-\frac{\pi^{2}}{a^{2}} \sin \left(\frac{\pi x}{a}\right)+2 c_{1}\right] z \\
& \varepsilon_{y y_{-} \text {bending }}=\frac{\pi^{2}}{b^{2}} W_{11} \sin \left(\frac{\pi y}{b}\right)\left(\sin \left(\frac{\pi x}{a}\right)+c_{1} x(x-a)+c_{2}\right) z
\end{aligned}
$$

\section{Linear Elastic Stress of a Plate under a Linear Gradient Temperature}

A linear gradient temperature of a plate can be defined as (Refer to Eq. (A.66) in Appendix A)

$$
\Delta T(z)=T^{0}+T^{1} z
$$

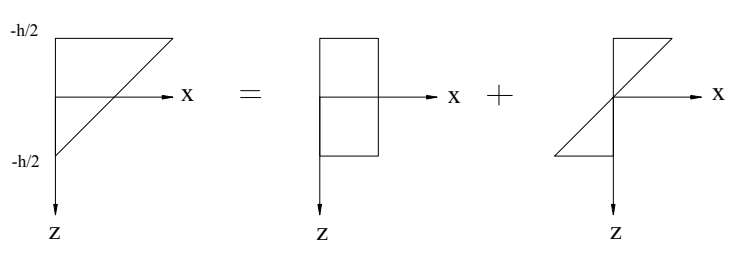


The first term $\left(T^{0}\right)$ of the above equation is a uniform temperature increment (axial effect). The second term $\left(T^{1} z\right)$ is the a linear gradient temperature increment which is zero at ${ }^{\text {mid- }}$ plane of a plate, $z=0$ (bending effect).

Stress components of a plate can be defined by displacement function or strain. The stress-displacement relation can be expressed as (Refer to Eq. (A.42) in Appendix A)

$$
\left\{\begin{array}{c}
\sigma_{x x} \\
\sigma_{y y}
\end{array}\right\}=\left[\begin{array}{ll}
Q_{11} & Q_{12} \\
Q_{12} & Q_{22}
\end{array}\right]\left\{\begin{array}{c}
\varepsilon_{x x}^{0}+z \varepsilon_{x x}^{1}-\alpha_{x x} \Delta T \\
\varepsilon_{y y}^{0}+z \varepsilon_{y y}^{1}-\alpha_{y y} \Delta T
\end{array}\right\}
$$

Substituting $\Delta T(z)=T^{0}+T^{1} z$ into the above equation, we obtain

$$
\left\{\begin{array}{l}
\sigma_{x x} \\
\sigma_{y y}
\end{array}\right\}=\left[\begin{array}{ll}
Q_{11} & Q_{12} \\
Q_{12} & Q_{22}
\end{array}\right]\left\{\begin{array}{l}
\left(\varepsilon_{x x}^{0}-\alpha_{x x} T^{0}\right)+z\left(\varepsilon_{x x}^{1}-\alpha_{x x} T^{1}\right) \\
\left(\varepsilon_{y y}^{0}-\alpha_{y y} T^{0}\right)+z\left(\varepsilon_{y y}^{1}-\alpha_{y y} T^{1}\right)
\end{array}\right\}
$$

The stress components in the above equation are divided into stresses due to axial and bending effects. The first term (i.e. $\varepsilon_{x x}^{0}-\alpha_{x x} T^{0}$ and $\varepsilon_{y y}^{0}-\alpha_{y y} T^{0}$ ) results in the axial effect.

The second term ( i.e. $z\left(\varepsilon_{x x}^{1}-\alpha_{x x} T^{1}\right)$ and $\left.z\left(\varepsilon_{y y}^{1}-\alpha_{y y} T^{1}\right)\right)$ results in the bending effect.

Substituting $\left\{\begin{array}{c}\varepsilon_{x x}^{0} \\ \varepsilon_{y y}^{0}\end{array}\right\}=\left\{\begin{array}{c}\frac{\partial u_{0}}{\partial x} \\ \frac{\partial v_{0}}{\partial y}\end{array}\right\}$ and $\left\{\begin{array}{c}\varepsilon_{x x}^{1} \\ \varepsilon_{y y}^{1}\end{array}\right\}=\left\{\begin{array}{c}-\frac{\partial^{2} w_{0}}{\partial x^{2}} \\ -\frac{\partial^{2} w_{0}}{\partial y^{2}}\end{array}\right\}$ into the above equation, we obtain the stress and displacement relation as

$$
\left\{\begin{array}{l}
\sigma_{x x} \\
\sigma_{y y}
\end{array}\right\}=\left[\begin{array}{ll}
Q_{11} & Q_{12} \\
Q_{12} & Q_{22}
\end{array}\right]\left\{\begin{array}{l}
\left(\frac{\partial u_{0}}{\partial x}-\alpha_{x x} T^{0}\right)-z\left(\frac{\partial^{2} w_{0}}{\partial x^{2}}+\alpha_{x x} T^{1}\right) \\
\left(\frac{\partial v_{0}}{\partial y}-\alpha_{y y} T^{0}\right)-z\left(\frac{\partial^{2} w_{0}}{\partial y^{2}}+\alpha_{y y} T^{1}\right)
\end{array}\right\}
$$

Note : The $\left(\frac{\partial u_{0}}{\partial x}-\alpha_{x x} T^{0}\right)$ and $\left(\frac{\partial v_{0}}{\partial y}-\alpha_{y y} T^{0}\right)$ terms result in axial effect. 
The $-z\left(\frac{\partial^{2} w_{0}}{\partial x^{2}}+\alpha_{x x} T^{1}\right)$ and $-z\left(\frac{\partial^{2} w_{0}}{\partial y^{2}}+\alpha_{y y} T^{1}\right)$ terms result in bending effect.

For pure bending case, the stress components in Eqs. (G.105) and (G.106) reduced to

$$
\begin{aligned}
\left\{\begin{array}{l}
\sigma_{x x} \\
\sigma_{y y}
\end{array}\right\} & =\left[\begin{array}{ll}
Q_{11} & Q_{12} \\
Q_{12} & Q_{22}
\end{array}\right]\left\{\begin{array}{l}
z\left(\varepsilon_{x x}^{1}-\alpha_{x x} T^{1}\right) \\
z\left(\varepsilon_{y y}^{1}-\alpha_{y y} T^{1}\right)
\end{array}\right\} \\
& =\left[\begin{array}{ll}
Q_{11} & Q_{12} \\
Q_{12} & Q_{22}
\end{array}\right]\left\{\begin{array}{l}
-z\left(\frac{\partial^{2} w_{0}}{\partial x^{2}}+\alpha_{x x} T^{1}\right) \\
-z\left(\frac{\partial^{2} w_{0}}{\partial y^{2}}+\alpha_{y y} T^{1}\right)
\end{array}\right\}
\end{aligned}
$$

Substituting $w_{0}(x, y)=W_{11} \sin \left(\frac{\pi y}{b}\right)\left[\sin \left(\frac{\pi x}{a}\right)+c_{1} x(x-a)+c_{2}\right]$ for Eq.(G.93) into the above equation, we obtain stress components for pure bending case as

$$
\left\{\begin{array}{l}
\sigma_{x x} \\
\sigma_{y y}
\end{array}\right\}=\left[\begin{array}{ll}
Q_{11} & Q_{12} \\
Q_{12} & Q_{22}
\end{array}\right]\left\{\begin{array}{c}
-W_{11} \sin \left(\frac{\pi y}{b}\right)\left[-\frac{\pi^{2}}{a^{2}} \sin \left(\frac{\pi x}{a}\right)+2 c_{1}\right] z-\alpha_{x x} T^{1} z \\
\frac{\pi^{2}}{b^{2}} W_{11} \sin \left(\frac{\pi y}{b}\right)\left(\sin \left(\frac{\pi x}{a}\right)+c_{1} x(x-a)+c_{2}\right) z-\alpha_{y y} T^{1} z
\end{array}\right\}
$$

Design examples for Navier-Levy and Macro approaches can be found in section 5.1 and 5.2 of chapter 5 . 